\title{
Schuck, Albert
}

Beitrage zur Meerskunde 



\section{Hambury 1905 thai 18.

\section{ZWEI MAGNETISCHE BEOBACHTUNGEN}

VOR DER WESTKÜSTE NORWEGENS IM JAHRE 1902. *

\section{BEITRÄGE ZUR MEERESKUNDE.}

I. Ältere Mitteilungen und Kärtchen über Ergebnisse des Fischfanges in der Nordsee.

(Mit 2 Tafeln und Tabellen).

II. Beobachtungen von Wärme, Salzgehalt und spezifischem Gewicht des Meerwassers westindischer Gewässer.

(Mit 4 Tafeln, 3 Abbildungen im Druck und einem Journal-Auszug).

III. Zur Kenntnis der Wirbelstürme.

Häufigkeit. Bahnen, einige Richtungswinkel und Barometerkurven in Taifunen.

(Mit 15 Tafeln, 2 Abbildungen im Druck und Journal-Auszügen).

vON

* A. SCHÜCK, hambURG.

SELBSTVERLAG DES VERFASSERS.

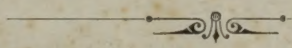

HAMBURG 1905. 





\section{ZWEI MAGNETISCHE BEOBACHTUNGEN}

VOR DER WESTKÜSTE NORWEGENS IM JAHRE 1902.

\section{BEITRÄGE ZUR MEERESKUNDE.}

I. Ältere Mitteilungen und Kärtchen über Ergebnisse des Fischfanges in der Nordsee.

(Mit 2 Tafeln und Tabellen).

II. Beobachtungen von Wärme, Salzgehalt und spezifischem Gewicht des Meerwassers westindischer Gewässer.

(Mit 4 Tafeln, 3 Abbildungen im Druck und einem Journal-Auszug).

III. Zur Kenntnis der Wirbelstürme.

Häufigkeit. Bahnen, einige Richtungswinkel und Barometerkurven in Taifunen.

(Mit 15 Tafeln, 2 Abbildungen im Druck und Journal-Auszügen).

VON

A. SCHÜCK, hambURG.

SELBSTVERLAG DES VERFASSERS.

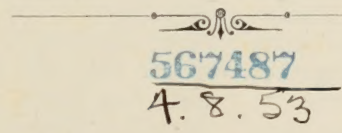

HAMBURG 1905. 


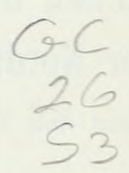

Digitized by the Internet Archive in 2011 with funding from University of Toronto 


\section{ZWEI MAGNETISCHE BEOBACHTUNGEN VOR DER WESTKÜSTE NORWEGENS.}

$\mathrm{F}$ olgende Dampfschiffahrts-Gesellschaften, Rheder, Vereine und Versicherer ermöglichten mir die Weiterführung meiner Arbeiten, auch dieser Veröffentlichung:

Hamburg-Amerika Linie (Wolff), Hamburg-Südamerikanische Dampfschiffahrts-Gesellschaft (Th. Amsinck), Deutsche Dschf.-Ges. Kosmos (Pepper, Overweg, Vorwerk), Dentsche Ost-Afrika Linie (Hertz, Woermann), West-Afrikanische Dschf.-Ges., Woermann-Linie (A. Amsinck), Deutsch-Amerikanische Petroleum - Ges. (Riedemann), Deutsch-Australische Dschf.-Ges. (Harms, Schmidt), Deutsche Levante-Linie und Dschf.-Rhed. v. 1889 (Kote, Petersen), Hanseat. Dpf. - Comp. (Menzell), Carl Hirschberg (Carl Hirschberg, Detleffsen), A.-(t. Alster (Loesener-Sloman), Aug. Bolten (Binder, Eckhusen sr. und jr.), C. Gustav Gabel, Knöhr \& Burchard Nfl. (Elvers, Zimmer), F. Laeisz (Ganssange, Reisse, Struck) A. H. Wappäus, Kapt. Hooge, Norddentsche Versichermugs-Ges. (Duncker, Schulzc), Verein Hamburger Assecuradeure (Baunbeck, Duncker), V. f. Verbesserungen im Hamburger Hafen (Ganssauge, Eckhusen, Heldmann, Liitgens, Möring, Clemens Wiiller, Schliuter), Verein Hamburger Spediteure (Berger, Dchls, Lampcke), Vereinigte Bugsirund Frachtschiffahrts-Ges. (Böger).

Diesmal, wie in früheren Jahren habe ich hierfür, sowie bei Vorbereitung zu Reisen u. dgl. viel zu danken der gutigen Fürsprache und freundlichem Entgegenkommen der Herren $M$. G. Amsinck, Liaunbeck, Duncker, Elvers, G. Kolberg, O. Schulze, Letze, Knudsen.

Mein Wunsch war, i. J. I9O2 auf den norwegischen Außenschären nordwärts ugf. von da aus zu beobachten, wo ich 1900 aufgehört hatte, d. h. an ein Paar Stellen vor dem Bömmelen Fjord, dann von Husö nordwärts um das Nordkap herum bis zur Murmannischen Grenze; die kgl. norwegische Regierung Excc. Minister Steen und 16 sen erteilten bereitwilligst guitige Ausweise dazu, ebenso die $\mathrm{kgl}$. norwegische Zollverwaltung, Staatsrat Herr Arstad, betr. ungehinderten Landens meiner nötigen Ausrüstung und evt. Ein- Auspassierens der Zollgrenze, wobei Herr Aksel S. Steen, $2^{\text {ter }}$ Direktor des kgl. norw.
Meteorologischen Instituts, für baldmöglichste Zustellung gütigst sich bemühte, — auch für Bossekop den sehr entgegenkommenden Herrn Kaufm. Diedr. Nielsen mir angab; ebenso war Herr Prof. Dr. Birkeland so freundlich, Rat und Auskunft btr. Vergleichs-Beobachtungen mir zu erteilen, - ferner ließ Herr Oberst Nissen, Chef der $\mathrm{kgl}$. norwegischen Landes-Aufnahme gütigst mir zukommen das Verzeichnis der sts. Beamter dieses Instituts angestellten Mißweisungs-Beobachtungen und die damals neu erschienene Sonder-Karte eines Teiles des nördlichen Norwegen. Herr Prof. Dr. Geelmuyden, Direktor der Sternwarte, sagte ebenso bereitwillig seine Unterstützung $\mathrm{zu}$, falls ich nach Kristiania käme, Vergleichs-Beobachtungen anzustellen, schickte mir auch später die Ergebnisse dort angestellter Beobachtungen für die von mir gewünschten Tage. -

Es galt also noch Miete eines passenden Fahrzeuges mit guter williger Besatzung; von den Direktoren der Norddeutschen Versicherungs-Gesellschaft hier, Herren Duncker und Schulze erhielt ich gütige Erlaubnis an deren Agenten in Norwegen mich wenden zu dürfen, später auch Empfehlungsschreiben an dieselben. Die Antworten wiesen alle auf Bergen, als den Ort, an welchem allein solch Fahrzeug mietbar sein dürfte; der Fischerei-Direktor, Herr Buvig in Haugesund wies mich auch auf die norwegische Gesellschaft zur Rettung Schiffbrïchiger, Hauptsitz in Kristiania. Herr Konsul Krohn in Bergen nahm Rücksprache mit Herrn Kpt. Wille, rühmlich bekannt von der norwegischen Eismeer-Expedition unter Leitung von Herrn Prof. Dr. Mohn; er veranlaßte den Expert Hr. Kpt. Larsen sich zu bemühen, der ihm mitteilte, augenblicklich sei ein Fahrzeug für solche Miete erhältlich; da $\mathrm{Hr}$. Kpt. Wille naturgemäß ohne eine Ermächtigung nichts abschließen mochte und man eine Woche rechnen muß, ehe Antwort aus Hamburg in Bergen eintraf, der Führer des Fahrzeugs solange nicht warten konnte, nahm dieser ihm gebotene Fracht an. - Ins Ungewisse hinein mußte ich also nach Bergen reisen; im Begriff das Haus zu verlassen, erhielt ich Depesche von Hr. Kpt. Bille, Direktor der norweg. Ges. z. Rettung Schiff brüchiger, welcher den Preis für Miete eines Bootes derselben zu 
680 Kronen monatlich bestimmte, ohne Beköstigung für mich selbst, so daß ich wenigstens 24 Kronen $=27$ Mark täglich rechnen mußte. - Auf der Fahrt nach Bergen erhielt ich auf dem norweg. Dampfschiff "Neptun " von $\mathrm{Hr}$. Kapt. Fentoft und dem Obersteuermann Hr. Blehl in entgegenkommendster Weise jede, genannten Herren mögliche Erleichterung, sowohl in Bezug auf Reisekosten als Unterbringen der Chronometer und Instrumente, Gepäckbeförderung u. dgl.; auch auf der Rückreise an Bord des norweg. Dschfs. „Olaf Kyrre«, wies man mir in der Postkammer an, den bestmöglichsten Platz für die Chronometer und Instrumente, - verhinderte hier in Hamburg arge Anmaßung seitens Gepäckträger.

Vor meiner Abreise erhielt ich von $\mathrm{Hr}$. Admiralitätsrat, Prof. Dr. Börgen, Vorstand des Kais. Marine-Observatorium in Wilhelmshaven, bereitwilligst guitige Erlaubnis für dort vorzunehmende Vergleichs-Beobachtungen, die wieder mit Hilfe von Hr. Lehrer Tiedemann ich anstellte, wobei sts, des Assistenten des Observatorium Hr. E. Stiick und Hr. E. Sperling, Obersteuermann a. D. Kais. Marine, jede mögliche Unterstuitzung und Mitteilung guitigst mir gewährt ist; letzterer hat unverdrossen den Gang meiner Beobachtungsuhren ein paarmal geprifft.

In Bergen zeigten sich $\mathrm{Hr}$. Kpt. Wille (der damals aus dem Staatsdienst schied), Hr. Konsul Krohn und der Versicherungsdirektor Hr. Th. Ameln, sowie dessen Bureau-Chef Hr. Olaf Böckmann und der Schiffsmakler Hr. Bolmann, sehr entgegenkommend. Der Direktor der Navigationsschule, Marine-Kapitän Hr. Bergersen, und Hr. Ltnt. O. S. Giertsen, Lehrer an genannter Schule, waren sogleich gern bereit, meine Instrumente und Chronometer in Verwahrung zu nehmen, letztere zu vergleichen, fuir erstere einen Platz anzuweisen, wo sie ohne Erschütterung stehen konnten, um die Kokonfäden ausdrehen zu lassen. - Es traf sich, daß bereits erwähnter $\mathrm{Hr}$. Kpt. Larsen auch für $\mathrm{Hr}$. Dir. Ameln Expert war, leider war jener verreist, so konnte dieser mich nur an einen ihm bekannten Makler, $\mathrm{Hr}$. Andr. Höyem verweisen. - Den Vertreter der norweg. Ges. z. Rettung Schiffbrichiger in Bergen traf ich erst nach wiederholt vergeblichem Aufsuchen, um von ihm zu erfahren, daß außer vorhin erwähntem, schon sehr hohen Preise für ein Fahrzeug, ich auch noch einen zuverlässigen Lootsen in Bergen annehmen sollte, was doch wenigstens I $50-200$ Kronen monatlich mehr gekostet hätte!

Selbst für die Teile der norwegischen Küste, für welche neuere Einzel-Aufnahme nicht vorliegt, sind die vorhandenen Karten besser, als für manche, von großen Schiffen ohne Lootsen, oder - was noch schlimmer ist - nur mit unzuverlässigen Lootsen befahrene Gegenden. - Wie manches mal mußte man nicht und müssen Schiffsfuhrer, selbst mit schlecht zu lenkenden Schiffen, Flüsse auf und niederfahren, ohne oder nur mit oberflächlichen Karten; ebenso durch schwierige Passe segeln, - bei gutem Wetter, mit günstigem Wind gelangt man hinein, an den schlimmsten Stellen, wird es dick, Gegenwind, auch noch steife Brise, Ankergrund ist nicht, also: ist man drin, muß man durch! - Hier, für Gegenden, wo die Felsen zum überwiegend größten
Teil vom Grunde steil aufsteigen, - nachdem ich vielfach gesehen, wie man beim Kreuzen so dicht an sie heransegelte, um wendend das Fahrzeug durch Absetzen mittelst eines starken Bootshakens rascher drehen $\mathrm{zu}$ machen, - blinde Klippen bezeichnet sind, wenigstens in den Karten vor ihnen gewarnt wird, - zu einer Jahreszeit, in der es keine eigentliche Nacht giebt bezw. um Mitternacht die Sonne noch über dem Gesichtskreis ist, - für solche Nußschale, die, wie man sagt, sich auf dem Teller dreht, wo wir schon, außer dem Mann am Ruder, mit 4 Mann waren, um zwei kleine Schraatsegel zu handhaben, sollte ich noch einen Lootsen mitschleppen, ohne Gewißheit wirklich dahin zu gelangen, wohin ich eigentlich wollte! Darauf einzugehen, betrachtete ich für ausgeschlossen.

Der Schiffsmakler Herr Andreas Höyem, war es also, von dessen Verständnis für die Sache, Kenntnis von Fahrzeugen und deren Führern ich abhing; wie wenig von ersterem vorhanden war, zeigte seine Frage, was ich an Schleppnetzen und dgl. so wie Mitteln sie einzuziehen habe, - daß man fur andere Zwecke als Jagd- oder Fischerei-Beobachtungen ein Fahrzeug miete, schien ihm unbekannt, - wenn nicht unbegreiflich. Beim Einfahren in den Hafen von Bergen hatte ich einen, offenbar in Yarmouth zur Fischerei gebauten Kutter gesehen, von der für meine Zwecke passenden Größe, - auch gut gehalten, sodaß ich sogleich frug, ob ich ihn würde mieten können; es lag noch ein zweiter erheblich größerer da, der jedoch schon lange außer Gebrauch gewesen sein mußte und vernachlässigt schien, sodaß kein Vertrauen auf ihn hatte. - Herr Höyem sagte mir, daß er den Besitzer und Führer des kleineren Fahrzeuges kenne, zu bestimmter Stunde sei er am Kontor su sprechen; in ihm fand ich einen zuverlässig aussehenden Mann mittleren Alters, einen Fischer der genügend Englisch verstand, um einzusehen was ich wollte und verlangte, auch offenbar Lust zu dergleichen hatte, — als ich ihm aber auf den Karten zeigte, wie weit die Reise sich erstrecken solle, trat er sogleich zurück, da sei er nicht bekannt; offenbar verstand er nicht, sich in anderen Karten zurecht zu finden, als in denjenigen, die für verhältnismäßig geringe Entfernung von Bergen gefertigt waren. - Hr. Höyem hatte als Ersatz ein anderes Fahrzeug, in einem anderen Hafen (Sunde) liegend, das er aber als besonders geeignet empfahl, noch kein Jahr alt, 300 Faß Heringe ladend, der Führer kein junger, aber sehr rüstiger durchaus zuverlässiger Mann, der früher Schiffe auf großer Fahrt geführt, dann Lootse im nördlichen Norwegen gewesen, - was recht guten Schein für sich hatte; in Bergen selbst versicherte er mir, sei z. Z. keine auch nur annähernd so gute Gelegenheit. Er telephonierte sogleich an den Eigner und Führer der Sköit, der antwortete, er würde mit dem nächsten Dampfschiff (nach zwei Tagen) kommen; tägliche Verbindung dorthin war nicht, ich wäre selbst auch nicht eher dorthin gelangt. - Im Hafen und auf der Rhede von Bergen sah ich auch tatsächlich kein Fahrzeug, was ich geneigt gewesen wäre zu mieten; entweder große Schlupen, oder ausgefahrene Sköiten, nur für "schön Wetter « tuichtig, Segel und Ankergeschirr abgenutzt. - Das mir angestellte Fahrzeug hieß Svanen, 
der Eigner und Führer $A$. T. Sunde; als er nach Bergen kam, machte er keinen guten Eindruck, bestätigte, daß cr Seeschiffer auf großer Fahrt gewesen, die Zeit nach Chronometer gut anschreiben könne und werde, im Norden Lootse gewesen, mit den Ankerplätzen der Außenschären gut bekannt sei, eigne Karten jener Gegrenden sowie den besten Willen habe, mir dienlich und behiflich zu sein. Es wurde ausbedungen, daß das Fahrzeug bis »leicht beladen " geballastet sei, um beim Kreuzen gut Segel zu tragen, außer dem Schiffer mit sogen. Bestmann ein befahrener Junge angenommen werden solle, der steuern könne und zuverlässig genug sei, ihn, während wir segelten, eine Wache allein an Deck zu lassen, damit dic beiden Männer jederzeit dienstbereit sein könnten; meine Beköstigung eingeschlossen betrug der Mietpreis 16 Kronen $=18$ Atäglich, falls ich auf der Rückreise das Schiff in Vadso entließ sollte ich 24 Tage Abstandsgeld für die Rückfahrt bis Bergen zahlen, - entließ ich es in Bossekop 20 Tage. - Sowohl der Mietpreis als diese Abschlagsumme erschienen mir erheblich zu hoch; Herr Höycm versicherte mir, sie entsprächen durchaus den Frachtraten, - da ich wußte, daß augenblicklich keine passenden Fahrzeuge im Ort waren, -- von allen anderen Gegenden man mich auf Bergen verwiesen hatte, - so blieb mir nichts übrig, als darauf einzugehen; - i. J. 1900 hatte ich 12 Kronen $=13^{1} / 2 \mathbb{N}$ täglich für einen größeren ebenso bemannten, in Yarmouth gebauten Kutter bezahlt, - doch war auch damals schon bis 18 Kronen $=20^{1} / 4 \mathrm{~N}$ gefordert worden.

Auf dem für ein Küstendampfschiff gut eingerichteten und mit guter Küche versehenen »Lyderhorn " erwies sich Kpt. Rasmussen sehr entgegenkommend; für Chronometer und Instrumente gab er mir den bestmöglichsten Platz im Brückenhause. - In Sunde fand ich "Svanen " allerdings als neues, in Bezug auf Segel, Takelung, Ankergeschirr gut eingerichtetes Fahrzeug, doch schien mir der Ballast nicht genügend; indes Sunde versicherte, es sei im besten Segeltrim, er selbst und sein Sohn als Bestmann, erwiesen sich sogleich als saumselig. - Es war verabredet, Alles solle bei meiner Ankunft (gegen I Uhr nachmittags) segelbereit sein, doch waren die Landtaue noch aus, er wunderte sich, daß ich nicht an Land gehen wollte Mittag zu essen, und verlangte selbst hinzufahren, um von dem Vorschuß ( 100 Kronen) Proviant zu bezahlen. Letzteres erst zu tun, als ich an Bord war, mag ihm nicht zu verdenken sein, doch wären dazu nicht Stunden nötig gewesen; auch fuhr sein Sohn mit ihm. Der Junge war ziemlich groß, kräftig aussehend. - Irgendwelche Bequemlichkeit in der Kajute konnte ich nicht erwarten obgleich $S$. gesagt, sie sei nett und verhältnismäßig groß, - dann möchte ich die kleinen nicht sehen, doch war Platz für Chronometer und Instrumente, selbst in der äußerst kleinen Koje, in welcher die Füße höher lagen als der Kopf (ihn nach hinten gerichtet zu liegen, war nicht möglich) fand ich Raum, die Uhren aufzuhängen ohne an sie zu stoßen wenn ich hinein-oder herauskroch und mich umdrehte; meine beiden Reisekoffer konnte ich jedoch nicht bei mir haben, sie mußten vorn im Raum untergebracht, so oft ich etwas aus ihnen gebrauchte, heraufgelangt werden. Vom Raum aus drang entsetzlicher Geruch in die Kajuite, meine Hoffunng zu nicht machend, falls die Koje zu klein sei, dort eine mir aufschlagen zu lassen; die mehr als 20 Jahr alten Fischerewer, auf denen ich $1893,94,95$ segelte, konnten nicht angenehm riechen, aber was in dieser nur Io Monate alten Sköit in den Enden, unter und zwischen dem Ballast verderben mochte, um derartigen den Atem benehmenden Gestank zu verbreiten ist mir nicht erklärlich; Schiffer Sundz, Sohn \& Co. spürten davon nichts. Die Beköstigung erwies sich auch sehr schlecht, mir nicht begreiflich, wie Leute, die arbeiten, davon die nötige Kraft erhalten können, - nur eine Art Roggenbrot und Hafergrütz-Suppe waren schmackhaft, — schlechteste Margarine, Makrelen oder Speck halb verbrannt, schlechteste Kartoffeln, woraus Kaffee und Thee eigentlich bestand nicht erklärlich. - Dies hätte ich uiberwunden, wenn der Zweck, für den ich das Schiff gemietet, Förderung erfahren; indes zeigte sich sehr bald, daß kein Gedanke daran sei, im Gegenteil für Schiffer Sunde \& Co. nur der eigne Vorteil und die eigne Bequemlichkeit maßgebend.

Als ich meine Koje gepackt, Chronometer, Instrumente gehörig gesichert hatte, waren Sunde \& Solnn noch nicht zurück; nach einigem Warten ließ ich den Jungen die Landtaue losmachen, holte sie mit ihm ein, und wartete; - dann wand ich mit ihm die Ankerkette ein soweit rätlich, - wartete; setzte mit ihm das Großsegel, - wartete; endlich erschienen Schiffer und Bestmann. anscheinend erstaunt iber meine Eile die Reise $\mathrm{zu}$ beginnen. - Wir hatten zu kreuzen; als der Junge ans Ruder kam, sah ich sofort, daß er beim Winde schlecht steure, - am nächsten Morgen nach Rövaer segelnd, wurde er seekrank, darüber ob er je aus den Binnenfjorden gewesen, erhielt ich keine Auskunft. Zwischen Rövaer, wohin ich zuerst segelte, wurde nicht der äußere Ankerplatz gewählt, den ich wünschte, das Wetter sehe für ihn nicht ruhig genug aus; auf der Fahrt dorthin stellte ich Probe an, wie Sunde die Zeit nach Chronometer anschriebe, - er zeigte sich ganz unbrauchbar, nicht einmal die Minuten konnte er sicher überblicken, sondern addierte sie zur vorhergehenden lateinischen Ziffer; scin Sohn erwies sich anstellig, doch war es ihm bei wirklichem Gebrauch schon das zweite mal zu ermiidend.

Von Rövaer nach Espevaer segelnd, sollte der Junge Kurs steuern, da gierte das Sköit hin und her, als ich Schiffer Sunde darauf aufmerksam machte, erwiderte er, ein wenig steuern könne er ja; wenn ich in der Koje lag, saß der Junge über meinem Kopf auf dem Rande der Kajüte und trommelte mit seinen Holzpantoffeln gegen das Schott, von dort weggeschickt, trampelte er hinten auf dem Deck herum; am dritten Morgen hörte ich ihn sich gegen den Bestmann wundern, daß er mein Trinkgeschirr reinigen solle! als die Sachen zum Beobachten an und von Land gebracht wurden, wollte er mit so gut wie nichts abkommen, sodaß ich ihm sehr einfach das Kistchen umhing, was ihm außerdem zukam. - Während ich in Espevaer bei etwas feuchtem Winde in leichtem Anzuge ohne Beschwerden beobachte, fror Sunde jr. in dickem Zeuge, großer 
Pijacke mit hochgeschlagenem Kragen, - half aber nicht einmal, das Boot zum Fahrzeug zu rudern! - In Bergen hatte Sunde sr. es ganz in der Ordnung gefunden, daß ich verlange, sobald ich vom Beobachten zurückläme, müßten wir unter Segel gehen, um möglichst rasch zum nächsten Ort zu gelangen, - or hatte mir auch versichert, er sei für rasches Vorwärtskommen, war aber das unter Segel kommen in Sunde schon nicht eilig, so war es am nächsten Tage in Rövaer dies noch weniger und an dritten in Espevaer schien es auffallend, daß ich es verlangte, doch war wirklich keine Ausrede, es zu verweigern, - dagegen wollte der Schiffer durchaus nicht den Seeweg nach Husö nehmen, sondern nur ganz innerhalb der Schären segeln.

Der WVind war bis dahin nur leicht gewesen, sobald er etwas auffrischte zeigte es sich, dal3 die Sköit keine Segel tragen konnte; als erheblich kleinere, nur halbgedecktc Fahrzeuge, ohne zu pressen ", Gafftopsegel führten, mußten wir es einnehmen, selbst den Klüver auf halben Baum holen. Beim Kreuzen im cngen Fahrwasser zeigte sich Sunde sr. durchaus nicht auf rasches Vorwärtskommen bedacht; wir hätten bei jedem Gange noch $1^{1 / 2}$ bis 2 der Fahrzeugs-Länge den Felsen näher kommen können, ohne am IVenden gehindert zu werden, - als ich darauf aufmerksam machte, hörte Sunde sr. nicht. - In der Nacht rom 4. zum 5. Tage, wahe dem nördlichen Ausgang des Fjelte Fjord, wurde die Brise steif, der große Klüver mußte gegen den kleinen vertauscht, dieser auf halben Baum gesetzt werden, es kam günstiger, starker Strom, - da der Wind ihm entgegen wehte, natürlich kurze See, in welcher das Sköit den Kopf nieder segelte; nach meiner Meinung war der Kluiver mehr schädlich als nuitzlich, „wem er eingenommen wird, wendet das fahrzeug nicht sicher! P'ötzlich hält Sunde sr. ab, segelt ein Paar Seemeilen (à $1,85 \mathrm{Km}$.) zurück um einen, ihm zusagenden Ankerplatz aufzusuchen! anfangs Juni, bei ganz klarem Wetter, günstigem Strom! - Bald nach 6 Uhr morgens wurde der Wind mäßiger, aber Sunde schlief, ließ3 sich auch nicht erwecken; als er aufkam und ich verlangte unter Segel zu gehen, weigerte er sich, aufsen wehe es noch stark, sodaß kein Vorwärtskommen sci. Nach ein Paar Stunden bequemte er sich dazu, - da zeigte der Junge, daß er nicht einmal den gewöhnlichen Bootsdienst verstand, denn als er das Landtau losmachte, ließ er das Boot treiben; zum Glïck waren gutmutige Fischer in der Nähe, die es aufnahmen und ihm brachten, - das Aussegeln wurde dadurch verzögert. - Der Strom setzte jetzt südwärts, aber der Wind, wenn auch leicht, drelite ostwärts, sodaf3 wir Kurs steuern konnten; nachmittags drehte der Wind zuriick, der Strom begann nordwärts zu setzen, dic Brise wurde aufs neue steif, natiirlich kam wieder kurze Sec, in welche das Fahrzeug stampfte, - wir waren ugf. in der Mitte zwischen dem Nord-Ende von Saelö und Torsken, da hält Sunde sr. wieder ab, segelt an Sjelanger Feuer vorbei um bei Ringholm zu ankern! Der nordwärts setzende günstige Strom war so stark, dafi im Boot beide Riemen senkrecht aufgestellt werden mufiten, damit der Wind es vom Schiffe frei halten komnte. - Innerhalb 24 Stunden zwcimal ein Paar
Seemeilen zurück gesegelt und geankert, weil bei steifer Brise, ein wenig See gegen günstigen Strom stand!!

Morgens flaute es wieder ab, mehreremal weckte ich Sunde vergeblich, als er endlich aufstand, weigerte er sich wieder unter Segel zu gehen; während also i. J. 1900 der Norweger erklärt hatte, bei der für mich 7.4 leistenden Arbeit würde der Mensch zu faul, - war mir jetzt ein Mann als ganz besonders geeignet und zuverlässig empfohlen, der selbst fiir diese Arbeit zu faul, vor ein wenig IVind und See, bange war; - das gerihmte Fahrzeug, hatte nur für sich: neu, folglich dicht $7 u$ sein, -- ein Haupterfordernis: gutes Seeboot zu sein, mit dem man auch bei starkem WVind aufkreuzen kann, das fehlte ihm.

Mit meinem Zelt und anderen Sachen, wurde sehr unverständig umgegangen. Unter solchen Verhältnissen zeigte es sich wahrscheinlich, während der günstigen Jahreszeit höchstens bis Hammerfest zu kommen, wenn ich dort umkehren wollte der bisherigen Reise entsprechend bis zur russischen Grenze und zurück bezahlen zu müssen. Das wäre ivon Aerger und Verdruf abgesehen) nichts Anderes gewesen als Geld wegwerfen: um ausgelacht $\mathrm{zn}$ werden. - Am vorhergehenden Tage hatte Sunde sr. geäußert, wenn mit ihm ich unzufrieden wäre, könnten wir ja nach Bergen zurücksegeln und ich versuchen, ob ich besseren Mann und Fahrzeug fände; daran schloß ich an und es gelang, indem ich zu dem erhaltenen Vorschuß noch I 50 Kronen zuzahlte, seinen Verzicht auf die Miete zu erhalten, unter der Bedingung. daß er mich und meine Sachen, rasch und sicher nach Bergen an Land bringe.

Dort angelangt, suchte ich sogleich ein anderes Fahrzeug zu mieten; durch Hr. Böckmann's (Bureauchef Hr. Dir. Aneln's) Vermittlung suchte Hr. Kpt. Larsen mich auf und versprach, was er könne für mich zu tun: Hr. Bolmann. der keine kleinen Schiffe an der Hand hatte, empfahl mich dem Schiffsmakler Hr. H. $1 / . \mathrm{Mey}_{\mathrm{c}}$. (Mcyerhoff). der sich in der Tat auf freundlichste und entgegenkommendste Weise größtmögliche Mühe gab. mein Interesse zu fördern. Es war auch ein kleiner. netter Kutter mietfrei, dessen Eigner gut bekannt mit Hr. M.; fruiher Zollkutter, verkauft als größere sich zweckmäßiger zeigten, diente er in letzterer Zeit nur als Vergniugungsjacht in der Nähe Bergens; offenbar hatte der Eigner vom früheren Inventar alles hierfür ïberfluissige verkauft und hätte, wenn er das Fahrzeug jetzt mir vermietete, erhebliche Auslagen gehabt, es wieder zu beschaften. Möglicherweise wollte er sie durch diese eine Reise decken, denn er forderte 24 Kronen $=$ 27 Mark täglich, auch sollte ich, falls auf dem Rückwege Gelegenheit sei, den Kutter verkaufen, dic Besatzung mit ihren gesetzlichen Ansprïchen nach Bergen zuriickliefern. Hr. Meyer stellte ihm ror, dies seien zu weit gehende Forderungen, aber er war nicht von ihnen abzubringen. - Hr. Kpt. Larsen sagte mir, die Schiffer, mit denen er gesprochen, hätten ebenfalls 24 Kronen täglich gefordert, natiirlich ohne Sicherheit besser bedient zu werden, als von Sunde. Bei meinen Rundgängen durch die Häfen hatte ich, außser jenen Kutter, kein Fahrzeug gesehen, welches für mich mietwert war, - die von passender Grölie waren plump 
oder gänzlich ausgefahrene. - Sunde war dreist genug, seinen Sohn zu mir zu schicken, ob ich nicht "Svanen " für eine runde Summe zur beabsichtigten Reise mieten wolle; der staunte nicht wenig, als ich ihn auf den Karten zeigte, wohin ich fahren wollte, - sein Vater konnte ihm dies also nicht richtig mitgeteilt haben; ich konnte ihm nur antworten, sein Vater habe um das Vertrauen sich gebracht, also könne ich auch keines haben, er werde unter anderer form des Vertrages diesen besser erfüllen, - ich könne mich mit ihm nicht mehr einlassen. - Ich mußte also meinen Wunsch aufgeben und nach Hamburg zurückkehren.

Nebenbei bemerkt, wohnte ich in Bergen in Smeby's Hôtel, das nahe beim Zollhause liegt, wo ich bei gehöriger Sauberkeit gute Küche fand; der Inhaber, Hr. Schamann, und Portier ließen an Aufmerksamkeit und Entgegenkommen nichts zu wiinschen.
Auf dieser Reise wurde mir bestätigt, daß den Herren Kapitänen der Kgl. Norw. Post-Dampfschiffe bekannt ist und von ihnen beobachtet wird der ablenkende Einfluß gewisser Strecken der norw. SüdostKüste auf den Kompaß; gedruckt erwähnt fand ich ihn in $M . T h$. v. Henglin: Reisen nach dem Nordpolarmeer i. d. Jn. 1870 und I 87 I. ,Th. II. I 87 I. VII. 8 a $4^{\text {h }}$ fuhr »Germania « von Tönsberg ab und segelte längs der Südostküste von Norwegen. VII 9 und Io bemerkte man, daß der Kompaß eine Abweichung von I bis $I^{1 / 2}$ Strich $\left(I^{1 / 4}\right.$ bis $I 7^{0}$ ) von seinem gewöhnlichen Zustand hatte. Die Ursache wird den reichen Erz. massen in dem benachbarten Gestein zugeschrieben. Nachdem wir Oxø (westwärts) passiert hatten schien der Kompaß wieder normal zu sein".

Die Ergebnisse der beiden Beobachtungen sind:

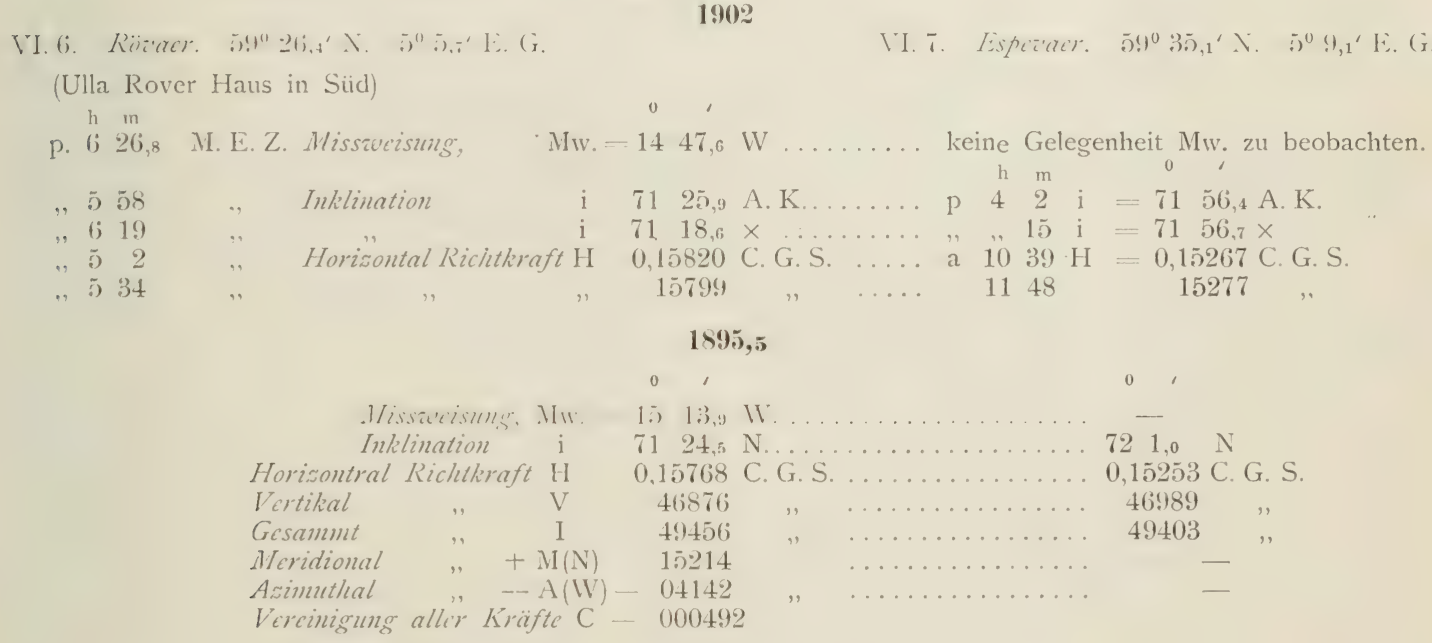

In den Jn. 1878 bis 1889 latte ich mich bemuiht, für die Kommission zur. Untersuchung der deutschen Meere (Kiel) Beobachtungen von Schiffen $2 \mathrm{u}$ verschaffen, die 1889 aufhören mußsten, weil mit Vergrößerung und Verlegung der Häfen es mir nicht länger möglich war, es unentgeltlich zu tun, (ausgenommen Ersatz für Jollenführer-, Straßenbahn-, Porto-Auslagen). Auf den meisten Schiffen war, soweit das Wetter es erlaubte, vierstüncllich auch das spez. Gewicht des Meerwassers gemessen; bei meinen Reisen zu magnetischen Beobachtungen i. d. Jn. I890, 9I hatte ich Wasser-'Temperatur und spez. Gew. (wenn möglich bei Tage noch öfter) beobachtet. Davon ist bisher nur wenig bekannt geworden; vgl.
Faluresbericht IV und $V, 1884-87$, geehrter Kommission; Annalen der Hydrographie etc. XI, 1883. Seite 429: Beobachtungen in der Nähe der La Plata-Mündung und Kap Horn, sowie i. a. Jgg.: Reihentemperaturen von Kpts. Kinge und Sicgmund, (Aräometer und TiefenThermometer teilweise von der Kommission, teilweise vom Hydrographischen Ant der Kais. Admiralität). Hansa XXIV 1887 No. 15: Beobachtungen i. d. Nähe von Eis im Nord-Atlantik; XXV I888 No. I9 und 2I: Ankerplätze, Winde und Strömungen im Golf von Californien; XXVI I889 No. 7. Beilage: Einige Beobtungen von Temperatur, Salzgehalt, spez. Geivicht des Nordseewassers. - Deshalb hielt ich es angebracht, 
wenigstens für die vier Monate: Juli, August, September, Oktober, in denen ich selbst beobachtet, die vorhandenen Beobachtungen von Temperatur der Luft, des Wassers und dessen spez. Gewicht zu sammeln, meines anzuschließen, um das Gesammte zu veröffentlichen.

Herr Geheimrat Prof. Dr. Hensen, Vorsitzender der Kommission, sandte mir durch deren Sekretair. Herrn Professor Dr. Lohmann mit größter Bereitwilligkeit die in jenen Monaten angestellten Schiffs- und Fischer-Beobachtungen, nebst guitiger Erlaubnis, aus anderem in Besitz der Kommission befindlichen Material, in ihren Räumen Abschrift mir machen zu dürfen. Bei Benutzung dieser Erlaubnis ist durch $\mathrm{Hr}$. Geh. R. Prof. Dr. Hensen und Hr. Prof. Dr. Lohmann jede mögliche Erleichterung freundlichst mir gewährt worden.

Da die Fischer ihren Standort nur kennen nach ugf. Abstandsrichtung und Lotung, so war es nötig, darnach geogr. Länge und Breite in den Karten zu suchen; hierbei ergab sich, daß in diesen, für die deutsche Bucht der Nordsee angegebene Lotungen den Ansprïchen des heutigen Verkehrs nicht mehr genügen; dies ist natürlich, da seit der letzten Auslotung längere Zeit vergangen ist, all' solche Arbeiten sich auch nach bewilligten Mitteln richten und die Küsten-Aufnahme mit Ausloten der unmittelbar an die Küsten grenzenden Meeresteile erhebliche Zeit und Mittel beansprucht. Der Nautischen Abteilung des Reichs-Marine-Amtes ist von mir Mitteilung gemacht worden, daß auf oder in der Nähe der NNW von Norderney gelegenen ovalen Stelle (ugf. $53^{0} 52^{1} / 2^{\prime} \mathrm{N}, 7^{0} 2^{\prime} \mathrm{E}$. G.) nur $17,2 \mathrm{~m}$. gelotet sind, NNE rom Ost-Ende Spiekeroog's und SW z. IV ron Weser Fsch. Stellen mit größerer IVassertiefe gelotet sind, als angegeben ist, es auch nicht unwahrscheinlich ist, daß die NW z. W $1 / 4$ W 18 - I9 Sm. von Helgoland angegebene Stelle mit $40 \mathrm{~m}$. W Wassertiefe, nur ein Teil ist einer größeren Gegend mit mehr als $40 \mathrm{~m}$. Wassertiefe. - Die Kompasse u. S. w. der Fischer sind sehr geringwertig, also genaue Angaben von ihnen nicht zu erwarten, immerhin halte ich derartiges beachtenswert. Zufallig strandete im vorigen Jahre ein Dampfschiff an einer Insel nördlich von Helgoland, dessen Führer nach den geloteten Wassertiefen glaubte, südlich von Helgoland $z . u$ sein.

Bei den Vorarbeiten beschäftigt, erschien eine Mitteilung uber außerordentlich große und rasche Abnahme des Barometerstandes im, ,de Witte" Taifun, bei der übersehen war, daß ich schon vor Jahren ähnliche, teils neu veröffentlicht, teils durch andre ergänzt hatte; dies und später zu erwähnendes veranlaßte mich, als Erholungsarbeit vorzunehmen Zusammenstellung gewisser Erscheinungen bei Taifunen. Die Erholung erwies sich allmählich als eine recht umfassende Arbeit, die es rätlich war, \%u ergänzen mit noch nicht veröffentlichten, bej auslän- dischen meteorologischen Instituten hefindlichen Mitteilungen; dieselbe Ergänzung war von mir beabsichtigt für die Nordsee-Arbeit. Die Herren Direktoren der britischen und niederländischen meteorologischen Institute ersuchte ich daher i. J. I903 um gütige Erlaubnis, aus dort befindlichen Material Auszüge machen zu dürfen, die mir auch bereitwilligst gewährt wurde, - von ersterem, dem Gebrauch entsprechend, mit gütiger Billigung des Meteorological Council. In London war ich 8 Wochen, in de Bilt bei Utrecht 4 Wochen beschäftigt, an letzterem Ort noch Hülfe annehmend, die besonders Hr. van Socst mit gutem Willen leistete. So wie an anderer Stelle ich getan, kann ich auch hier nur rühmen das grofe Entgegenkommen und die Freundlichkeit, die an beiden Instituten ich genoß; in London traf ich recht unpassende Zeit, da die Räumlichkeiten eine nach der andern aufgefrischt wurden und dieselben (seit ugf. jo Jahren nur Mieträume!) sowieso höchst beschränkt sind: aber immer wuiste man guten Platz mir zu verschaffen. - Den Anweisungen und dem Beispiel der Herren Haupt- und Abteilungs-Direktoren entsprechend (in England die Herren Dr. Shaw und Kpt. Camp. bell Hepworth, Korv. Kpt. Kgl. Gr.-Brit. Mar. Res., in den Niederlanden die Herren Dr. Wind, Sncllen und Dr. van der Stok) taten die Herren Unter-Direktoren, Haupt-Assistenten, Assistenten und Bibliothekare alles in ihren Kräften stehende, die Arbeit leicht und angenehm mir zu machen; dort waren es die Herren fames und Charles Harding, Wim. Allingham. Allcn, Fames. Bell. Tarrant. - hier die Herren Ltnt. z. See I. Kl. Kluit, van Eicrdingen, Monnc, - und Herren, mit denen ich nur voribergehend in Berührung kam, selbst die Hausdiener.

Ihre Majestät, die Königin-Mutter, Emma, bis vor wenigen Jahren Königin-Regentin der Niederlande, besichtigte während meiner Anwesenheit das Institut in de Bilt, selbstverständlich auch das Lese- und Versammlungszimmer, in dem damals Hr. Dr. san Rijcke. corssel (Rotterdam) und ich arbeiteten; mit dem großen Takt, vereint mit Huld, Güte und Wü̈rde, die Allerhöchstselben höchste Achtung, Herz und Gemüt Aller gewinnt, mit denen Ihre Majestät in Berührung kommen, richteten Allerhöchstdieselben auch einige freundliche Worte an uns Gäste, welcher hohen Ehre stets aufrichtig dankbar und freudig ich mich erinnern werde.

Allen Herren, die mir direkt und indirekt Unterstuitzung gewährten, mir irgendwie behilflich waren (Hrr. Eckardt \& Messtorf. Inh. Kipt. Messtorf. liehen wiederholt, vorubergehend nötige Bücher und Karten) erstatte ich hiermit offentlich aufrichtigen, verbindlichsten Dank.

Folgendes konnte ich bis jetzt fertigstellen. 


\section{Beiträge zur Meereskunde.}

a)

Die gcographische Länge ist stets gezähit von Greenwich

Die Angaben der Luft- und Wasserwärme sind stets nach dem hundertteiligen Naßstabe, d. i. ${ }^{0} \mathrm{C}$; wenn der Schiffsort angegeben ist nach Graden und Minuten, so ist dies in den mir vorliegenden Werken und Journalen so gegeben oder nach den den Schiffsjournalen entnommenen Kursen und zurückgelegten Seemeilen mit Berïcksichtigung der Versetzung von mir berechnet; Orte nach Graden und Zehntelgraden sind abgeleitet aus der Zeit entsprechender Verteilung des Unterschiedes der Mittagsorte.

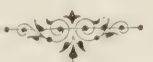





\title{
BEITRÄGE ZUR MEERESKUNDE.
}

\author{
I.
}

\section{Ältere Mitteilungen und Kärtehen über Ergebnisse des Fischfanges in der Nordsee.}

\author{
(Mit 2 Tafeln und Tabellen.)
}

Das Kgl. Ndld. Meteorologische Institut in de Bilt besitzt eine über Erwarten groß̉e Anzahl von Journalen, welche niederländische Heringsfischer auf ihren Reisen führten; der größte Teil stammt aus den Jahren I 856 63, dann sehr unregelmäßig, die letzten a. c. J. I878. 1856 beteiligten sich 45 Fahrzeuge, 1863 noch 21; aus späterer Zeit liegen keine Berichte vor und die für I $856-63$ veröffentlichten sind äußerst selten, sie waren weder im Buchhandel noch antiquarisch zu erhalten, weder die Königliche Bibliothek in Berlin. noch die Rijks Universiteits-Bibliothek in Leiden besitzen sie, das Institut selbst nur eine vollständige Reihe von Abzügen, - naturgemäß schätze ich es sehr hoch, daß mir dort gestattet und dic nötigen Sachen gegeben wurden, eine zugehörende Kartenskizze abzuzeichnen später die Direktion die Güte hatte, Duplikate mir zu leihen und den letzten Bericht fur mich abschreiben zu lassen. Das Schema der journale war s. Z. angefertigt nach Verabredung mit Sach- und Fachkundigen, unter dem Direktor der Abteilung Zeevaart Hr. wan Gogh, Ltnt. z. See I. Kl.; es umfaiste Jahr, Monat, Tag, Zcit der Beobachtung, des Aussetzens und des Einholens der Netze, Wassertiefe, Ortsangabe, Wind-Richtung und -Stärke, Temperatur der Luft, des Wassers an der Oberfläche und in der Tiefe (nebst Angabe letzterer), Wetter, Fang nach Art und Betrag, Farbe und Zustand des Meeres, Bemerkungen über Trift-Gegenstände u. dgl. Selbstverständlich kann man an die, solchem Betriebe Obliegenden derartige Ansprüche nicht stellen, wie an Führer von Seeschiffen, da letztere, wenn sie auch vielfach bis zum 14. oder 15. Jahre nur eine Volks-, selbst nur Dorfschule besuchten, doch durch dic Vorbereitung zu ihren Prüfungen erheblich mehr geistige Anregung erhielten als jene; jedoch: ich war erstaunt und bewundere, soviel verhältnismaßig gut gefuhrte Fischerjournale zu finden. Sehr zu bedauern ist, daß die Fischer ungenügende Anleitung hatten - wohl auch ungenügende Mittel - zur Ortsbestimmung; erhebliche Muihe, die sie sich gaben, verliert dadurch an Wert. Je nach Neigung und Verständnis für die Sache ist die Anzahl der Beobachtungen verschieden; manche lieferten täglich nur eine, andere drei, andere die beim Ausstecken und Einholen der Netze, noch andere diese und $1-3$ mehr; von den Temperatur-Beobachtungen erschienen mir die im Oktober und November (wenn das Wasser, wic man sagt, sich unangenehm naß anfühlt) häufig unzuverlässig, da dieselben Angaben auffallend oft sich wiederholten.
I. J. I 856 , auch noch später, scheint es zweifelhaft gewesen zu sein, ob der Hering ein Zugfisch ist, im selben Sinne wie mancher Vogel ein Zugvogel, d. h. daß er den Jahreszeiten entsprechend in weit von einander entfernten Gegenden sich aufhält und in zusammengedrängten Scharen von einer zur andern zieht, - oder ob ein Wanderfisch, der, gewöhnlich zerstreut lebenci, zur Laichzeit in bestimmten Gegenden sich zusammenfindet und sie durchwandert; gegenwärtig ist jene Ansicht wohl gänzlich aufgegeben - ob dies allein geschehen ist durch genaue Beobachtung der aus verschiedenen Gegenden stammenden Tiere und ihrer Unterschiede voneinander, oder ob und wieweit die Mitteilungen der Fischer dazu beigetragen haben, ist mir unbekannt; in Deutschland verfaßte wohl das eingehendste Werk uiber den Hering und seine Eigenheiten Hr. Prof. Dr. Heincke, Vorstand der biologischen Anstalt Helgoland, das herausgegeben ist von der Kommission zur Untersuchung der deutschen Mecre (Kiel) und genannter Anstalt.

[rraglich erscheint mir, ob schon aufgeklärt sind die vielfach in diesen Journalen der holländischen Fischer erwähnten Heringsbetten; von ihnen schrieb allerdings Fan Verweij, Führer der .. Vernicurude Hoop", aus Vlaardingen I86 I am 19. November: ,als Fischer habe ich 56 Jahre zur See gefahren, aber ich erinnere nicht, ein einziges Heringsbett gesehen $\mathrm{zu}$ haben." Das kann Zufall sein, dic von ihm erwähnten Quallen sahen auch Andere vielfach, aber nie in zusammengefügten Mengen. Der damalige Direktor der Abteilung Zievaart, Kgl. Ndld. Meteorol.-Inst., K. F. R. Andrau, Ltnt. z. See I. K1., schrieb I86I, Febr. I4, in seinem Bericht uiber die I 860 eingelieferten Journale der Heringsfischer: „Im Beginn des Frühjahrs (März und April) sehen die zum Kabljau-Fang fahrenden Fischer sogen. Heringsbetten treiben. Dies sind zusammengepackte Massen von Milch und Rogen, deren Ausdehnung häufig mehr als I Faden (also ugf. $2 \mathrm{~m}$ ) im Vierkant beträgt. Diese Heringsbetten haben ein filzartiges, zähes Aussehen und die Saat (befruchteter Rogen) zeigt sich von der Größe eines Stecknadelknopfes, in dem sich ein schwarzer Fleck (stipje) befindet, welches man als die erste Entstehung des Herings ansieht. Je älter diese Heringsbetten werden, umsomehr Leben ist in ihnen zu entdecken, endlich bemerkt man im Mai die jungen Heringe. Sie haben dann bereits die Länge großer Stinte. Manchmal erscheinen sie an der Meeresoberfläche in solcher Menge, daß das Auge nicht überblicken kann die Stelle, 
die sie zu ihrem Spielplatz erwählten. $\mathrm{Zu}$ diesem Vorkommen scheinen besonders beizutragen stilles Wetter und ruhige See; das geringste Kräuseln vertreibt sie rasch in die Tiefe". - In ..De Grootwisclucrij op de Nordzee" von $A$. Hoogendijk $\mathcal{F}_{z}$.. Haarlem I895, finde ich S. I8I folgendes Zitat der Angabe von Prof. Schlegel: „Der ausgestoßene Laich bedeckt zuweilen große Flächen am Mecresufer entlang und wird schon aus der Ferne als weißliche Masse kenntlich, derartige Stellen nennt man Heringslaichbetten. Auf diesen und naheliegenden Stellen bemerkt man auch Mengen junger Heringe." Es ist wohl wert, die bezügliche Mitteilung eines Fischers in seiner eigenen Sprachweise zu hören. Klaas den Adnirant, Schiffer auf .,Willem Barendsz", schreibt I $87 \mathrm{~S}$ in seinem Journal: ,VII. I5. schöpfte ich ein Heringsbett, das ich genau nachsah; Sie hätten auch sehen sollen, wie das zusammensitzt. Solch ein Heringsbett ist ein vierkantiger flacher Lappen, der fest ineinander gesponnen ist; es sitzt voll von kleinen schwarzen Stippen, die alle Heringe sind; es ist nicht möglich, anzugeben, welch unendlich große Anzahl in solchem Netz sitzen, es ist gräßlich. Ich will Ihnen sagen, wie solches Heringsbett cntsteht: Wienn der Hering reif, d. h. laichkrank ist, beginnt der Hering zu paaren, so ist es mit rogen- und milchkrankem Hering; solch' Heringbett entsteht nur durch Iilch und Rogen, die sich zusammenfügen: denn wenn die Rogener keine Milcher bei sich haben, können sie nicht paaren; wenn sic doch paaren kommt davon kein Hering. Ihr Herren, dic dies lest, könnt Euch wohl vorstellen, daß möglicherweise hunderttausend beieinander sind, so begreift Ihr, daß, sobald die Heringe Rogen und Milch auspressen, daß unnennbar viel Saatkörner beicinander sind und von jedem Saatkorn kommt ein Hering, vorausgesetzt, daß solchem Heringsbett nichts zustößt oder daß es auseinandergerissen wird, denn ist solches Heringsbett auseinander, dann stirbt alles was darin sitzt. Vereinzelt habe ich sie gesehen bis 3 Faden (ugf. $51 / 2 \mathrm{~m}$ ) im Vicrkant, aber oft sehen wir sie nicht, doch habe ich auch viel, sehr viele gesehen. WVir haben später noch einzelne Stiicke an Bord bekommen, die (nämlich die Heringe) waren etwas größer, ihre Augen und noch alles Zugehörende, das konnte ich deutlich sehn. Es ist wohl hübsch, so etwas zu sehen, als fhr das Alles einmal sehen solltet, dann möchtet Ihr wahrscheinlich wohl sagen, so Etwas hab' ich in meinem Leben noch nicht gesehen; es ist wohl wert, dies zu sehen. So Herren, jetzt wißt Ihr Alles, so wie ich wenigstens nicht besser weiß."

$\mathrm{Ob}$ in der Tat die sogen. "Milch" des Herings, wenn in überflüssiger Menge an derselben Stelle ausgepreßt (die Fischer sagen vom Auspressen des Rogens und der Milch "Schießen") in gallertartiger Masse die verhältnismäßig an Zahl nicht geringen Eier (Rogenkörner) derart umfassen kann, daß diese nicht an den Meeresgrund sinken um dort an Blättern und Steinen zu haften - sondern das Ganze wie ein zäher, filziger Faden an der Meeres-Oberfläche schwimmen bleibt und doch in ihm die Brut zur Entwichlung gelangt: darüber erlaube ich mir kein Urteil.

Der schon genannte fan $V_{e} r v e i j$ schreibt noch: "Wenn aber Heringsbetten sind oder treiben, sollen die dann für das ganze Neer maßgebend sein: Ich habe nie gehört, daß sie im Süden (d. i. im südlichen Teil der Nordsee) gesehen wurden, wohl im Norden und Osten (d. i. auf den nördlichen und östlichen Teilen der Herings-Grunden, soweit die Niederländer fischen) .

Ferner schreibt er: "Es ist vorgekommen, als ich auf $57^{\circ} 10^{\prime}$ bis $20^{\prime} N I^{\circ} 50^{\prime} \mathrm{E}$ fischte und beim Loten Talg auf das Lot geschmiert hatte, ich sehen konnte, wie am Talg eine Art Milch und Rogen am Lot hing, sodaß ich das Gefühl habe, daß die Saat (der befruchtete Rogen) dort still und beschützt liegt, bis zum Fruhjahr, wenn die Natur wieder zur Entwicklung schreitet und die Jungen dann hervorkommen, wie wir im Frihjahr, im Mai und Juni bei stillem VVetter morgens sie spielen sehen. Die Engländer, die unter VTick und anderwärts Heringe fischen, tun es so lange, als der Hering noch nicht ausgelaicht hat; sobald der Hering gelaicht oder gepaart hat, hören sie auf zu fischen, denn dann verziehen sich die leeren und nach meinem Gefuhl bleibt die Saat dort liegen, wie ich schon gesagt habe

In dem Bericht von 1863 finde ich folgende Mitteilungen und Tabellen, die mir auch gegenwartig noch mitteilenswert erscheinen, weil Angaben über Einholen der Netze mit Fang und ohne Fang sonst nicht nebeneinander gestellt sind, hier auch der Einfluß der IVasserwärme auf den Fang in Betracht gezogen ist:

\begin{tabular}{|c|c|c|c|c|c|c|c|c|}
\hline Im Jahr & $\begin{array}{c}\text { Eingelicferte } \\
\text { Journale }\end{array}$ & $\begin{array}{c}\text { Anzahl } \\
\text { des Einholens } \\
\text { der Netze }\end{array}$ & $\begin{array}{l}\text { Fang } \\
\text { in Tonnen }\end{array}$ & $\begin{array}{c}\text { Durchschnittl. } \\
\text { Fang } \\
\text { bei jeclem } \\
\text { Einholen }\end{array}$ & $\begin{array}{l}\text { Anzahl } \\
\text { ohne Fang }\end{array}$ & $\int_{\text {mit liang }}^{\text {Einholen }}$ & \begin{tabular}{|c|} 
Durchschnittl. \\
Fang \\
bei jedem \\
Einholen \\
mit Fang
\end{tabular} & Im Jahr \\
\hline 1856 & 45 & 3266 & 21623 & $(j, 66$ & $88 \%$ & 2384 & 9,1 & 15506 \\
\hline 18507 & 39 & $35 \check{64}$ & 10831 & 3,04 & 1506 & 2058 & $\overline{5}, 26$ & 1857 \\
\hline 1858 & 31 & 2299 & 5994 & 2,6 & 1050 & $12+9$ & +.8 & 1855 \\
\hline 1859 & 23 & $1666 ;$ & $6525^{1 / 2}$ & 3,9 & 817 & 849 & 7,7 & 1559 \\
\hline 1860 & 25 & $20+5$ & $8814^{1 / 2}$ & 4,3 & 627 & $1+1 \mathrm{~S}$ & 6,2 & 1860 \\
\hline 1861 & 26 & 2056 & 11239 & 5.5 & 569 & 1487 & 7,6 & 1861 \\
\hline 1862 & 22 & $147 t$ & $135200^{1 / 4}$ & 9,2 & $2+9$ & 12:25 & 11,0 & $1860^{\circ}$ \\
\hline $186: 3$ & 21. & 1500 & 9989 & $6, \bar{i}$ & 366 & 1132 & 8,8 & 1863 \\
\hline
\end{tabular}


Das Verhältnis des Einholens der Netze mit Fang zu dem ohne Fang war:

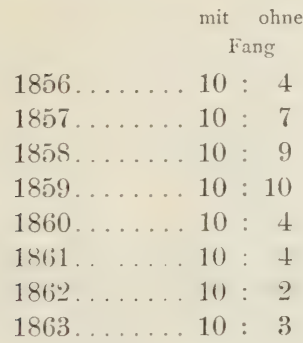

Für die Jahre I858, I862 und 1863 enthalten Tabellen III und IV hierüber Näheres, geordnet nach Streifen des Fischgebietes von $I^{0}$ geogr. Breite und den Monaten des Heringsfanges. "Aus den Journalen ist ersichtlich, daß während der Fangzeit, besonders in ihrem Beginn, eine ansehnliche Menge Haie auf den Fischgründen waren, während später die Fischer durch das sturmische Wetter mehrmals gehindert wurden, ihre Netze auszustecken (zu schießen). Sehr wahrscheinlich ist der Fang hierdurch weniger vorteilhaft geworden, als er hätte sein können «.

[Die im btr. Bericht für I 863 gegebene Tabelle der Einzelheiten des Fanges in diesem Jahre habe ich fortgelassen, in Tabelle I zog ich zusammen die beiden für I $856-60$ und 186 I -63 ; nach ihr erhielten die Heringsfischer, deren Journale vorliegen, den besten Fang

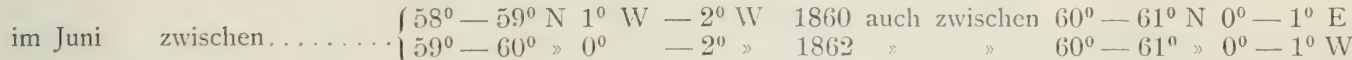

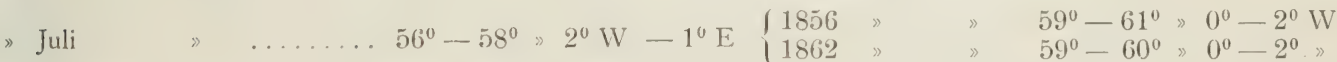

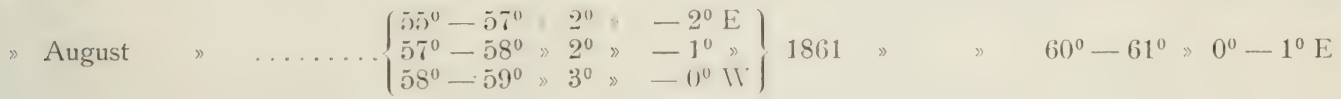

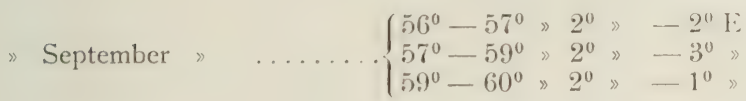

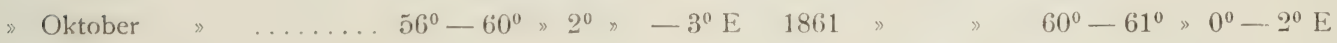

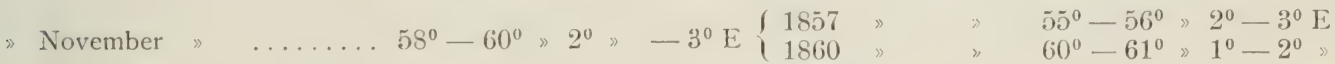

Vgl. Tafel I Fig. 1, wo wiedergegeben ist (verkleinert und mit Einfügung der Banken, sowie von Kustenorten) die vorhin erwähnte Karte aus dem Bericht für die Jahre $1856-6 \mathrm{r}$ von Dir. Andrau, Ltnt. z. S. I. K1.: selbstverständlich konnten zu ihr die Ortsbestimmungen genauer verwandt werden, als nach $\mathrm{Ta}$ belle I, auch die Einzelheiten besser in Betracht gezogen. Die Fischchen sollen andeuten, aus welcher Richtung (nach Angaben der Fischer) die Heringe in die Netze geschwommen waren; abgesehen davon, daß tatsächlich recht oft zu lesen war: "von beiden Seiten* halte ich dies für natülich, weil an allen Orten an denen ich mit dem Schiffe am Anker oder fest gemacht lag und das Wasser klar genug war, ich sah, wie die kleineren Fische mit dem Kopf gegen die Strömung schwammen bezw. trieben, um ihre Nahrung zu erhaschen; wenn also das Netz über die Zeit des StillWassers, ausgesteckt blieb, so schwammen die Heringe aus entgegengesetzter Richtung in dasselbe.]

"Außer der Tabelle über den Heringfang im Zeitraum der acht Jahre $1856-1863$ ist diesem Bericht noch beigefügt zunächst eine Tabelle (II) die enthält die durchschnittlichen Werte der Beobachtungen von
Wärme ${ }^{0} \mathrm{C}$ der Luft und des Wassers an der MeeresOberfläche für jedes Fach von I0 geogr. Breite und I0 geogr. Länge in jedem Monat der Zeit des HeringFanges während der Jahre I858, I862 und I863. In der Reihe 1856 - I863, zeigt sich in Bezug auf FangErgebnisse I 858 als das ungünstigste, während I862 das günstigste war, 1863 ungefähr die Mitte hält zwischen 1858 bis 1863 . Der durchschnittliche Fang für jedesmal Fischen war: $1858=2,6$ Ton, $1862=9,2 \mathrm{~T}$., $1863=6,7 \mathrm{~T} . \ll$

:Deshalb erschien es der Abteilung Zeevaart nicht unzulässig, diese drei Jahre auszuwählen, um nach den Beobachtungen der Wärme zu beurteilen ob diese etwa Einfluß haben könne, auf den größeren oder geringeren Fang jedes Jahres«.

"Tabelle II deutet an, daß 1858 in jedem Monat die Wärme der Luft sowohl als des Wassers an der Meeres-Oberfläche mehr ${ }^{0} \mathrm{C}$ angab, als die Wärme in den gleichen Monaten der Jahre 1862 und I863.

»In Betreff der Meeres-Oberfläche zeigt es deutlich folgende kleine Tabelle des durchschnittlichen $\mathrm{Be}$ trages : 


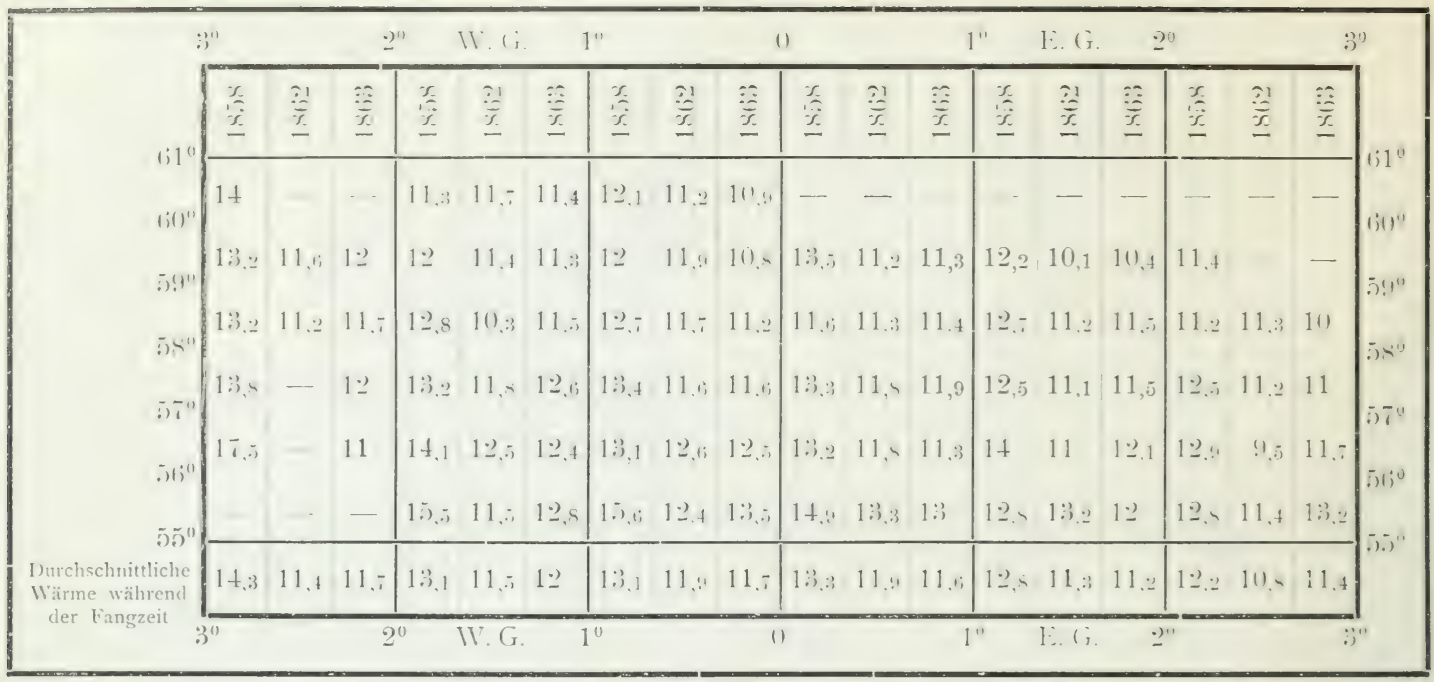

Im J. I 858 schwankt der durchschnittliche Betrag der Wärme des WVassers a. d. Meeres-Oberfläche größtenteils zwischen I I0 und I40 C; i. d. Jn. I862 und I863 zwischen 110 und I20; nach Tabelle II nimmt die Wärme der Jahreszeit entsprechend zu und ab. -- So kann es möglich sein, daß i. J. I 558 das etwas wärmere Wasser der Meeres-Oberfläche beigetragen hat, den Fang weniger vorteilhaft zu machen. Im J. I $\$ 58$ war das Verhältnis von Einholen der Netze mit Fang zu dem ohne Fang wie $10: 9$, i. d. Jn. IS62 und I 863 wie $10: 2$ und $10: 3$

Um besser beurteilen zu können den Einfluss der Wärme auf den Fang, wurde, wie Tabelle III angiebt, für diese drei Jahre soweit als möglich ein Auszug gemacht der Anzahl Einholens der Netze mit Fang und ohne Fang bei derselben Wärme der Meeres-Oberfäche. Zwischen je zwei Grad geogr. Breite findet man dort die Anzahl mit Fang und ohne Fang, welche bei gleicher Warme in demselben Monat der drei genannten Jahre man erhielt; eine bequeme Übersicht über das mehr oder minder günstige Verhältnis zwischen mit Fang oder ohne Fang giebt Tabelle IV, die beruht auf Tabelle III. In Tabelle IV sieht man unmittelbar wieviel mal ohne Fang die Netze einzuholen waren, gegen 10 mal mit Fang bei denselben Wärme-Graden im selben Monat jedes Jahres

"Obivohl in dieser Tabelle viele Liicken vorkommen, da die Schiffer fast stets zu gleicher Zcit auf einem bestimmten Gebiet der Nordsee sich bewegen und dann nicht uiberall beobachtet wird, außerdem nicht alle gleichmäßßig genau angeben die Beobachtungen der Wärme bei Einholen der Netze mit Fang und ohne Fang so zeigt sich doch recht deutlich, daß bei gleicher Warme clas Verhailtnis zwischen mit fang und ohne Fang in den verschiedenen Jahren sehr unregelmäBig ist, selbst wenn Gegend und Monat dieselben sind.
Im Monat September z. B. ist zwischen $57^{\circ}$ und $58^{0} \mathrm{~N}$ bei $13^{\circ} \mathrm{C}$ Wärme das Verhältnis von mit Fang zu ohne Fang i. J. I\$5S wie IO: 7 , i. J. IS62 wie $10: 0,6$, i. J. 1863 wie $10: \mathrm{I}$; im .Monat Oktober zwischen $58^{\circ}$ und $59^{\circ} \mathrm{N}$ bei $11^{\circ} \mathrm{W}$ ärme i. J. I 858 wie IO:4. i. J. IS62 wie $10: 0,9$, i. J. IS63 wie IO: I.3. Im Allgemeinen war i. J. I 858 für jedes lach, das genügend Beobachtungen enthält bei gleicher Wärme das Verhältnis zwischen mit Fang und ohne Fang am ungünstigsten, während i. Jn. 1862 und $186_{3}$, welche beide nahe genug gleich waren, das Verhältnis zwischen mit Fang und ohne Fang bei gleicher IVärme für $186_{3}$ etwas weniger günstig ausfiel.

Möchte nun auch ein außergewöhnlich warmes Jahr in ein oder anderer Weise auf den Fang nachteilig wirken so hat doch nach Tabelle IV die Wärme der Meeres-Oberfläche keinen Einfluß auf das mehr oder weniger günstige Verhältnis zwischen mit Fang und ohne Fang, - man kann in denselben Monaten, auf demselben Breitenstrich, bei derselben Wärme in einem Jahre mit Vorteil fischen, während man in einem anderen Jahr ungünstigen Fang hat. Aus diesem ungleichen Verhalten läßst sich ferner einigermalsen folgern, dafi die Wärme der Oberfläche des Meeres schwerlich als Führer dienen kann, den Fischern bei Ausübung ihres Berufes einige Sicherheit $z u$ geben, wo und wann sie auf einen guten Fang rechnen können. In Bezug auf den Einflufs der übrigen Umstände, verweisen wir auf die friiher ausgegebenen Berichte.

Der Direktor der Abteilung Zeevaart (gez.) A. . . $\tilde{\mathcal{f}}$. ז'an Asporin.

Utrecht, MÏ̈r. IS6.4. 
In den mir gütigst geliehenen Berichten über I 859 und 1860 finde ich folgende Ansichten ausgesprochen und Einzelheiten erwähnt:

"Man vermutete bereits früher, daß die Heringe, durch die Notwendigkeit ihren Rogen an Orte zu bringen, wo die Bedingungen zur Entwicklung ihrer Jungen vereinigt sind, gezwungen werden, die flacheren und untiefen Meere aufzusuchen. Aus den Beobachtungen können wir andeuten, daß diese Vermutung sich mehr und mehr befestigt.

Besonders im Beginn der Fischzeit hatte man den besten Fang gegen aufsteigenden Grund. -- Vor Allem scheint scharfer Sandgrund, gemengt mit gebrochenen Muschelschalen (Schülpen), vom Hering mit Vorliebe gewählt $\mathrm{zu}$ werden zur obenerwähnten Rogenablage.

»Da zu jeder Zeit gefangen werden Kabljauen mit lebenden oder unverzehrten Heringen im Magen und die Kabljauen in sehr tiefem Wasser leben müssen, so folgert man daraus, daß der Hering in seinem gewöhnlichen Zustand die tiefen Wasser zum Wohnort wählt; die tiefen Meere, in denen er zu Hause gehört, verläßt er nur, um seinen Samen auf flachere Ufergegenden $\mathrm{zu}$ bringen - $-\ldots$

"Man hat bemerkt, daß der volle Hering meistens in den oberen Netzen angetroffen wird, die leeren dagegen in die untersten kamen ". "Dafür, daß die nördlichen Heringe sich mit den süulichen vermengen und mit ihnen zusammen in die Nordsee kommen, liefern hinlänglichen Beweis die verschiedenen Arten, welche von Juni bis November gefangen werden.

" $Z u$ fernerer Aufklärung in dieser Sache werden die Fischer ersucht, ihre Erfahrung mitteilen zu wollen, betr. folgende noch unklare Punkte:

"Ist es wahr, daß die männlichen Heringe ihre Milch über den Rogen fließen lassen bei stillem Wetter, besonders gegen Sonnen-Aufgang?

-Kann man sagen, wie lange die Eier in See liegen, ehe sie sich zu jungen Heringen entwickeln?" (Vergl. Jahresberichte IV - VI, Kommission z. Untschg. dtsch. Meere und Dr. H. A. Meyer, Biolog. Beobchtgn. bei künstlicher Aufzucht des Herings der westlichen Ostsee, Mttlg. d. Kommiss. I.)

"Um welchen Zeitpunkt trifft man zuerst auf junge Heringe?

\section{Ursachen ungleichen Fanges.}

"Als hauptsächlichste Ursachen ungleichen Fanges geben wir folgende 4 Punkte:

I) Man hat bemerkt, daß der Hering gegen die Paarungszeit sehr ungleichmäßig schwimmt.

2) Nach Zeugnis einiger Fischer steigt der Hering bei stillem Wetter steil nach oben und nachdem einige Zeit an oder nahe der Meeres-Oberfläche er sich aufgehalten hat, taucht er wieder steil nieder. Ein Fischer, der gerade diese Stelle wählte, seine Netze auszuwerfen, kann einen guten Fang haben, während sein Nebenmann keinen Fang hat.

3) Während hellerer Nächte, besonders bei Mondschein schwimmt der Hering gewöhnlich tiefer, als während dunkler Nächte. Da die Tiefe, auf welcher gefischt werden soll, abhängig ist von der Ansicht des Fischers, dessen geringere oder erheblichere Erfahrung ihm allein hier als Leiter dient, wird auch das Fischen in sehr verschiedenen Tiefen stattfinden. Die an der Oberfläche Fischenden werden dann wenig oder keinen Fang haben, während die ihre Netze tiefer hängenden besseren Fang erwarten können.

4) Die Haie, Kabljaue, Störe, Nordkapers und andere große Fische, die auf die Heringe Jagd machen, treiben die Massen auseinander, zersplittern sie in kleine Abteilungen; um sich von diesen lästigen Nachbarn zu befreien, werden die Heringe in größter Eile von ihrem bevorzugten Sammelplatz sich entfernen und zwar nach verschiedenen, meistens unbestimmten Richtungen «

\section{Ursachen ron Einholen der Netze ohne Fang.}

Die Fischer geben an, folgende Umstände seien Ursache von vergeblichem Ausstecken der Netze (von leeren Netzen); eingehender Vergleich mit den Beobachtungen bestätigte hiervon nur die ersten vier:

I) Im Anfang der Fischzeit ist kaltes Wasser weniger vorteilhaft fuir den Fang.

2) IVenn vom IVasser unangcnehmer Gernch ausströmt.

3) Wenn der Horing an dor Oberfäche spielt oder spaddelt (zappelt).

4) Stilles Wetter, sowie hin und her drehender Wind, weil die Netze dann gestreckt nicht liegen können.

5) Seler heller Mondschein (wir haben jedoch gesehen, daß dies gänzlich abhängt von der Tiefe in der man fischt)

(3) Einige Fischer behaupten, bei Unwetter (Gewitter?) käme der Hering nicht in die Höhe, jedoch zeigt ein Vergleich der Beobachtungen, daß man dabei öfter guten Fang hatte.

-1 Wenn klcine Krabben in die Netze verwickelt werden; doch hat man auch dabei abwechselnd guten und schlechten Fang bemerkt.

S) Quallen werden von einigen Fischern gern gesehen, andere hingegen sagen, sie seien ein Vorzeichen von leeren Netzen, - Zusammenstellung der Beobachtungen ergab, daß der Fang dann äußerst gering war .

\section{Ursachen von Fang.}

"Als Vorzeichen guten Fanges, wird Folgendes angegeben, das auch durch dic Untersuchungen begründet sich erwies:

1) Wenn die Heringe an beiden Seiten an den Netzen hängen, kann man in den nächsten 2 bis 3 Tagen guten Fang erwarten.

2) Wenn viele Vögel auf das Wasser sich fallen lassen, um Futter aufzunehmen; ziemlich sichere Vorzeichen eines guten Fanges sind auch klcine Zucige Tang (besonders im Beginn der Fischzeit) und kleint Blasen auf dem Wasser, die entstehen vom Entweichen der Gase von den in der Tiefe lebenden Fischarten,

3) Einige Tage nach schlechtem Wettcr. 
4) Mit starkem Than.

5) In dunklen Nächten, in denen der Hering vielfach dichter an der Oberfläche schwimmt und die Netze dann nicht zu tief hängen.

6) Nach Ansicht einiger Fischer, soll die beste FangGelegenheit sein, abends gegen Sonnemuntergang (falls die Netze gestreckt hängen), dann kommt der Hering nach oben; je mehr Haie, je früher kommt er herauf.

7) Wenn Gewitterböen von schwerem Regen begleitet sind, soll der Hering erst gegen Beginn von Tagwerden (Anbrechen des Morgenrots) naci oben kommen».

》Mit großem Entgegenkommen haben einige Fischer dem Ersuchen entsprochen, ein.kleines $N e t z$ anzufertigen und zu gebrauchen, um zu sehen, ob die Anzahl Heringe, die mit ihm in größeren Tiefen gefangen wird, verhaltnismäßig größer oder geringer war als in der Fleet (d. i. der gesammten Netzstrecke); die darauf verwendete Mühe mußs als mißglückt bezeichnet werden. In 3 I mal Herablassen der Netze in die Tiefe, kamen nur 4 mal einige wenige Heringe in sie: während nur einmal das Verhältnis der darin gefangenen Anzahl Heringe die in der Fleet gefangenen um die Hälfte übertraf

Es soll noch zu entscheiden sein, ob die Ursache der zahlreichen Fälle, in denen in großer Tiefe das Netz leer blieb, eher zuzuschreiben ist dem nicht gestreckt hängen desselben (was scheinbar sehr beschwerlich zu erreichen ist), als der Abwesenheit des Herings. Deshalb wird man ersucht, diese Beobachtungen fortzusetzen, auch dabei aufmerksam gemacht, ob das Guthängen des Netzes befördert werden kann, inclem man eine eiserne Stange an dem ganzen Unterliek entlang befestigt, wodurch man wohl verhinclem mag das Zusammenfalten und sich zusammenwirren des kleinen Netzes

Ferner wird man ersucht, angeben zu wollen die Richtungen in welchen die Fleet und das kleine Netz hängen; sobald dieses mit der Fleet einen Winkel bildet, wird man ihn am besten erkennen, wenn man nach dem Kompaß angiebt die Richtung in der die Fleet streckt und die in welcher das kleine Netz liegt. Für die Fïscher selbst kann es vorteilhaft werden, wenn sie genau anmerken, von welcher Seite bei bestimmter Richtung der Fleet die grölte Anzahl Heringe hineinkam Andrau:

Im Bericht f. cl. J. I 860 schricb dann noch $\mathrm{Hr}$. Dir.

Noch eine Ursache fiir das Leerbleihen der Netze. Zu den im vor. Jahresbericht aufgezählten Angaben, kann noch diese als Ursache ungleichen lianges gefügt werden: Je nachdem in der Jahreszeit Wind weht, dessen Richtung mit dem IVeg des Herings (d. h. dieser als Zug-oder Wanderfisch angenommen) übereinstimmt oder mit ihm einen größeren oder kleineren Winkel bildet, kann der Fang besser oder schlechter sein "

Während des Jahres 1860 gebrauchten 10 lïscher cin kleine's $N_{c} t z$, um auf größeren Tiefen zu fischen, als mit der Flect geschieht; von ihnen haben 2, der eine I, der andere 2 Netze von ihrer Flect abgesondert und sich ihrer als kleines Netz bedient; zusammengerechnet ließen die Fischer das Netz I 5 mal in die Tiefe sinken, sie hatten 47 mal Fang, durchschnittlich jedesmal 30 Heringe, - während $68 \mathrm{mal}$ sie keinen Fang darin fanden:

"Als Ursache des geringen Fanges in der Tiefe geben einige Fischer an, daß die Heringe, wenn sie sich nahe am Meeresboden aufhalten und nach einer anderen Gegend wollen, steil nach oben steigend die beabsichtigte Richtung erst einhalten, sobald sie dichter an die Meeres-Oberfläche kommen. Hierdurch wird begreiflich, warum man im Allgemeinen im kleinen Netz auf großer Tiefe so wenig fängt und wir dürfen deswegen kaum anraten, damit noch Versuche anzustellen, bis der Scharfsinn der Fischer uns ein besseres Mittel an die Hand giebt, diese Untersuchung mit grölerer Sicherheit zu gutem Ende zu führen

Zunächst hat man große Anerkennung zu zollen Hr. N. M. F. Krocf, Ltnt. z. S. I. Kl. Kgl. Ndld. Nar., der scheint zuerst den Plan gefaßt zu haben, die Heringfischer zu Beobachtungen heranzuziehen und den ersten Entwurf zu dem Journal lieferte, - dann Herrn Prof. Dr. Buijs Ballot, dem Gründer und ersten HauptDirektor des Kigl. Ndld. Neteor. Inst., den Plan gebilligt und befurwortet, sowie dem Collegic der Groots Visscherij und den verschiedenen Reedern won FischerFaluraugen ihn liäftig unterstützt $z u$ haben; ferner kann man nur anerkennen die Bemühungen der Herren van Gogh, Andran, ran Asperen, Flur. W. W. Bowier. Cornclissen, Baron P. F. ran Heerdt (alle Ltnts. z. S. I. Kl. Kgl. Ndld. Mar.) und Herrn Ezjsbrock, welche die Sache unverdrossen weiter führten und den Inhalt der Journale bearbeiteten. Außerordentliches Lob verdienen die lïscher, welche Journale, hauptsächlich dic guten führten; gewils, es hatten stets mehr sich dabei beteiligen können, fragen wir jedoch in welchem Verhältnis stand die Anzahl der Beobachter zur Anzahl der Heringfischer-Fahrzeuge und in welchem Verhältnis steht die Anzahl der Beobachter auf, bei der Nordsee-Fahrt beschäftigten Schiffen zu der Anzahl dieser Schiffe: so müssen wir sagen, dic Fischer zcigten ron $1856-186_{3}$ ein überraschend günstiges Verhältnis. 45 Beobachter in 1856 selbst 21 in 1863 sind im Verluältnis zu den auf der Nordsce beobachtenden Schiffen außerordentlich viel zu nennen und dürften damals ron keinem anderen Volke, später und bis jetzt wohl nur von dänischen Schiffen übertroffen sein; mir fehlte es an Mitteln, auch konnte ich nur einen Teil meiner Zeit dazu verwenden, sonst wäre auch sts. deutscher Schiffe und Fischer s. Z. mehr geschehen, als der Fall war. - Ueber die Gründe, aus denen die niederländischen Fïscher zu beobachten aufhörten, kann man nur Vermutungen äußern; möglicherweise erwarteten sie raschere Ergebnisse als naturgemäl? geliefert werden konnten; - vielleicht glaubten sic, das eigne :Ich fände nicht genügende Inerkennung, - hauptsïchlich mag jedoch gewesen sein, dafi dic Agenten nicht genigendes Interesse zeigten oder nicht genuigende persönliche Berïhrung mit den Fischern hatten. Dies verbunden mit vorsichtiger freundlicher Kontrolle ist durchaus notwendig bei allen Beobachtern, ebenso notwendig ist rasche Bearbeitung der 
Beobachtungen nebst freigebige Verteilung der Veröffentlichungen; bei guten Vermittlern sowie Mitteilungen bin ich uiberzeugt, würden sich unter den Fischern und auf Nordsee nebst Ostsee befahrenden Schiffen aller Nationen eine gute Anzahl verläßlicher Beobachter finden.

In Bezug auf Versagen der Messungen der Wärme des Wassers an der Meeres-Oberfläche zur Auswahl eines guten Fangplatzes, so halte ich es für nicht zweckmäßig, nach ihnen allein solche Orte auszuwählen; die Wärme des Wassers in der Tiefe, Salzgehalt an der Oberfläche und in verschiedenen Tiefen, sowie Vorhandensein passender Nahrung haben darauf doch erheblichen Einfluß. Beim Durchsehen u. m. der FischerJournale, gelangte ich zur Ansicht, daß3 Beobachter der Wasserwärme in der Tiefe erheblichen Einfluß zuschrieben, deshalb diese recht oft maßen; leider war das damals dafür gebräuchliche Instrument (Röhre mit Klappe oben und unten) nicht genügend, sodaß 3 das heraufgeholte Tiefenwasser noch mit solchem der Oberfläche gemischt blieb, - dann sind aber auch die Messungen noch nicht zusammengestellt. - Die 3 Eindener Fischer, die ein paar Jahre für die Kommission zur Uniersuchung der deutsclicn Hecre Beobachtungen lieferten, hatten auch vorgenommen solche des spez. Gew. des Wassers, dessen Wärme sic gemessen; leider sind für viele Angaben nur ungenügende Ortsbestimmungen vorhanden.

Es ist doch nicht anzunehmen, daß dic Fortpflanzung des Herings stets gleichmäßig geschähe; ansteckende Krankheiten werden auch unter ihnen vorkommen, während denen die schwachen, leiclıtere Beute anderer Fische werden; endlich bringt Unregelmäßigkeit der Strömung und der Wellenbewegung sein Futter bald mehrere Secmeilen bezw. Kilometer nach einer oder andern Richtung. - Erleben kann man recht viel ohne daraus viel Lehren zu ziehen, d. h. Erfahrung zu sammeln, der Fischer, wie jeder Andre, hat bei seinem Betriebe Vorteil aus seiner Erfahrung, nicht aus seinen Erlebnissen; zweifellos hat auch cr Vorteil aus meteorologischen Beobachtungen, wenn or sie regelmäßig anstellt und lernt, sie miteinander zu vergleichen bzw. zu verbinden; maschinenmäßig kann das ebensowenig geschehen wie er überhaupt nicht maschinenmäßig fischen kann, sondern stets den einzelnen Umständen Rechnung $\mathrm{zu}$ tragen hat.

Nachdem ich die unter Hr. Dir. Andran's Leitung gefertigte Karte erhalten, wollte ich mich iberzeugen, $\mathrm{ob}$ und wie dieselbe sich eingliedere in älnnliche Veröffentlichungen; soweit die in hiesigen Bibliotheken vorhandenen Werke Aufschluß gaben, fand ich keinen Vorgänger. 2I Jahre später erschien: $O . T$. Olscu's The Piscatorial Atlas of the North-Sea, English und St. George's Channels. Grimsby and London 1883 . Nach der in diesem Atlas enthaltenen Karte iiber die Verbreitung des Herings in der Nordsee, kommt er in ihr überall vor, nur am häufigsten in der Nähe der britischen Küsten; sonst heißt es in Bezug auf ihn: "Laichzeit September bis November. Jede Örtlichkeit hat ihre besondere Zeit (für besten Fang). - - Der Hering ist ein Wander- (migratory) Fisch, der an verschiedenen Orten, $\mathrm{zu}$ verschiedenen Zeiten gefangen wird. Jedenfalls kurz und bündig, auch kein GeschäftsGeheimnis allgemein nutzbar machend.

Erheblich mehr ist mitgeteilt von $\mathrm{Hr}$. A. Hoogendijk Fz. in seinem Buch: "De Grootvischerij op de Nordzce." Haarlem. H. D. Tjenk, Willink I 895. Beknopte Uitgave. In ihm fand ich bei S. I 84 , Taf. XLV eine Karte von IS92 für die Gegenden, in denen die niederländischen Fischer von Juni bis November Heringsfang betreiben, die ich zum selben Maßstab verkleinerte, wie ich die des Kgl. Ndld. Meteorolog. Inst. verkleinert hatte und auf I Taf. 1, als Fig. 2 neben letztere brachte; Fig. 2 zeigt also die 30 Jahre später als nach Fig. I befischten Gründe, nur daß diese die Plätze angiebt, an denen damals die besten Fänge geschahen. In genanntem Buch ist die Karte farbig ausgeführt; der Kosten wegen unterließ ich es und behielt von Fig. I die Schraffierung der einzelnen Monate.

Hr. Hoogendijk's Mitteilungen betr. der Fischgründe in den einzelnen Monaten stimmen nicht genau mit der Karte, er schreibt S. $200-204$;

"Von den letzten Tagen des April bis Mitte Funi trifft man den Hering von $58^{\circ}-57^{\circ} \mathrm{N} 4^{0}-6^{0} \mathrm{E}$. In den letzten Jahren fährt man dorthin um Hering- mit Hand- und Grundangel-Fischen zu verbinden. Anfänglich fängt man nur Matjes-Heringe, zuletzt einzelne volle. In genannten Monaten d. Js. 1892 fingen dort 3 Fahrzeuge der Maatschapij voor Zeevischerijen in Maassluis viel Hering und kamen bereits Mitte Juni mit gutem Fang an. Im Frühjahr von I\$93 erprobten dies Fahrzeuge mehrerer Reedereien.

"Die eigcntliche Heringsfahrt begann in den letzten Jahren auf $60^{\circ} 30^{\prime}-60^{\circ} \mathrm{N} 1^{0} \mathrm{E}-1^{0} \mathrm{~W}$. Im Fuli wird gefischt auf $58^{\circ} \mathrm{N}$ und ugf. derselben geogr. Länge. In den ersten Tagen des August fischt man auf $56^{\circ} \mathrm{N}$ $1^{0} \mathrm{E}-2^{\circ} \mathrm{W}$. Hauptsächlich fängt man dann vollen Hering, mehr westlich auch laichkranken (d. h. der so reichlich Milch und Rogen hat, daß diese ihm olne Druck entströmen).

Der Fischer begiebt sich stets südlicher, so daß am Ende von September bereits zwischen $56^{\circ}$ und $54^{\circ} \mathrm{N}$ $1^{\circ} \mathrm{W}$ und $2^{\circ} \mathrm{E}$ die Netze ausgeworfen werden. Unter der englischen Küste fängt man dann nahezu ausschließlich volle und leere, in der sogenannten »Steile " schöne volle und auf der Doggerbank laichkranke Heringe."

"Bis Mitte Oktober trifft man auf $54^{0}-53^{0} \mathrm{~N} 10-$ $40 \mathrm{E}$ (die Wellen wohl nach den Well-Banken) viel laichkranke, auch wohl leere Heringe. Bis Mitte November wird gefischt zwischen $53^{\circ}$ und $52020^{\prime} \mathrm{N} 20-$ $40 \mathrm{E}$.

»Abhängig vom Winde fängt man dann an vom Osten oder vom Westen zu fischen, am liebsten von IVesten. In Westen fängt man um diese Zeit den sogenannten englischen Wall- (Land-) Hering, im Osten feste, volle Heringe, an der holländischen Küste kleine volle Heringe, zuletzt auch wohl laichkranke.

Während des Zeitraums von Mitte Oktober bis Mitte November fahren einzelne Fischer wieder nach dem "Sand « auf $56^{\circ} \mathrm{N}$.

"Im Allgemeinen kann man feststellen, daß der Hering größer ist, im Verhältnis je näher man der englischen Küste fischt und kleiner im Verhältnis in dem 
man sich östlicher begiebt. Der Heringfang beginnt also sehr nördlich bei den Shetland In. und verzieht sich stetig in südlicher Richtung bis zur Höhe von L. owest of t. «

"Der Hering, der am Ende Oktober und Anfang November gefangen wird, ist nicht mehr von solcher Güte, daß er dem holländischen Ruhm entsprechen kann. Besonders der englische WVall- (Land-) Hering ist vielfach für das Auge sehr gut, verrät sich jedoch durch geringere Feinheit im Geschmack.

Einzelne Reedereien von Schiffen. die während des Winters zum Stilliegen verurteilt sind, senden diese schon im April auf den Fang mit Handangeln (Kabljau, Schellfisch u. dgl.). Diese Fahrzeuge haben das Gerät an Bord, Hering zu fischen und machen davon Gebrauch, sobald die ersten Anzeichen von Hering erscheinen; einen Teil des so gefangenen Herings benutzen sie als Fischköder.

" - - Bei dem Fischen mit Handangeln muß das Fahrzeug still liegen; wälhrend letzteres an der Fleet (den ausgesteckten Heringsnetzen) liegt, kann also jenes sehr gut ebenfalls betrieben werden.

Wenn der Heringfang in der Nordsee beendet 1st, versucht man noch, ihn auszudehnen durch Fischen an den Küsten Frankreichs, was bisher wenig ergab, weil die Güte des dort gefangenen Herings nicht gerühmt werden kann; obenein ist das Fischen dort gefährlich für das kostbare Fischer-Gerät.

" - - Daß bei der Hering-Fahrt das Salz eine unentbehrliche Sache ist, bedarf wohl keiner besonderen Betonung.

- - Jetzt wird das dazu nötige $\mathrm{Salz}$ ausschließlich aus Portugal bezogen, davon schwankt der Salzgehalt in engen Grenzen ( $85-90 \%$ Kochsalz).

"Kleine Abweichungen finden auch hierbei statt, doch scheinen sie zu gering, um. besonders erwähnt zu werden. - - - I7 Kantjes = I4 Tonnen Hering; auf je 40 Kantjes werden IO Tonnen Salz verbraucht.

"Wenn jetzt ausschließlich portugiesisches, spanisches, auch wohl Mittelmeer-Salz gebraucht wird, so war dies doch nicht immer der Fall. In dem Werk des Prof. Beanjon findet man als Frucht seiner Nachforschungen, daß in 1519 kein andres Salz gebraucht werden durfte als das waus Salz (wohl Salzsohle) gesotten " oder "Salz von gutem grauem, ,zelle".

Der Gebrauch von lissabonsch Salz war verboten, während später unter der Republik als die ,neeringhe ian den zell" (wohl die Zunft der Salzsieder) ausgestorben war, kein anderes gebraucht werden durfte wie spanisches oder portugiesisclues ruw (grobes) Salz. Nach Prof. Beanjon soll Zirikzee der Ort gewesen scin, an dem man ersterwähntes Salz gewann. Auf den Sandbanken und flachen Stellen einiger unserer Flußmündungen war früher ein torfähnlicher Stoff »darink genannt, durchzogen von Salzwasser. Man verbrannte diesen "darink «, dessen mit Scewasser besprengte Asche scheint ein besonders feines graues Salz geliefert zu haben. - Eine Abbildung im Teil IV von Wagcnaar's Vadcrlandsche Historie veranschaulicht oben beschriebenes Verfahren. «
Die Ursache des gänzlichen Aufgebens oder seltenen Aufsuchens der nördlichen Hering-Grunden während des Herbstes, ist wohl zu suchen in dem seltenen Gewinn wenn nicht in Verlust, welcher durch Fangreisen dorthin erzielt wurde. Liest man, wie oft die Netze bald nach dem Ausstecken wieder eingeholt werden mußten, wie oft sie vom Seegang durcheinander und um das Halttau geworfen waren (was doch außer vergeblichem Ausstecken noch Scheuern und größere Beschädigung der Netze mit sich brachte), so kann man sich vorstellen, daß, trotz einiger guten Fänge, die Fahrt nach dem Norden in später Jahreszeit - in der schwere Stürme und höherer mächtigerer Seegang Schiff, Segel und Takelung noch mehr mitnahmen als das Herbstwetter der suidlichen Nordsee - für Reeder und Besatzung sich weniger bezahlt machte, als der Fang in letztgenannter Gegend.

Hier füge ich noch an ein Paar Zusammenstellungen über die Anfuhr von Hering der Hochsee- oder GroßFischerei in den einzelnen Monaten und nach ihrer Beschaffenheit in den Jahren I892 bis 1902, auch den Salzverbrauch in den Heringsplätzen, — sowie die Ausfuhr von gesalzenem Hering, Buickling nach Deutschland und im Ganzen, ferner den Salzverbrauch für sämtlichen Fischereibedarf von Nord- uud Süd-Holland. Die betreffenden Zahlen habe ich ausgezogen, bezw. abgeschrieben aus dem ,Verslag wan den Staat der Nederlandsche Zeevischerijen", d. i. den amtlichen Berichten der Niederlandischen Fischerei-Kommission.

Die Ausfuhr nach Deutschland zeigt, dal3 wir unseren eigenen Heringsfang noch erheblich vergröliern können ohne unsere guten Nachbarn zu schädigen; deren eigene Schuld wäre es wenn die Rheingegenden nicht ihre Abnehmer blieben und die stetig wachsende Kundschaft Amerika's bietet reichlichen Ersatz fiir die durch Vergrößerung des deutschen Heringsfanges $\mathrm{zu}$ erwartende Abnahme der Kundschaft Mittel- und OstDeutschlands. (Tabelle s. S. I7.)

Hr. A. Hoogcndijk gibt in seinem bereits genannten "De Grootvisscherij op de Noordzec" nach S. I 84 eine Karte der Nordsee mit Bezeichnung der Grunden auf denen damals (ugf. I893) - besonders während des sogen. IVinterfanges mit Grundangeln nach Kabljau, Lengen, Schelfisch, Rochen, Steinbutt, gefischt wurde, von ihrem hierfur in Betracht kommenden Teil ist I Taf. 2 Fig. I eine verkleinerte Nachzeichnung im selben Maßstabe wie der zu den Kärtchen btr. Heringsfang, d. i. I Taf. I benutzte; zur Unterscheidung der einzelnen Fang-Grunden verwendete ich wieder statt Farben: Schraffierung. S. $140-144$ seines Buches enthalten Erklärungen zur Karte und Bemerkungen; erstere stimmen auch nicht genau zu den Abgrenzungen der Karten, doch wiederhole ich sie hier, dem Wortlaut gemäß; vielleicht ist so die beste Fanggegend angedentet.

Vorher sei noch erwähnt, daß das Fischen mit Angein betrieben wird sowohl mit am Grunde verankerten, durch Bojen gekennzeichneten, als auch mit Handangeln; ferner unterscheidet man dabei Frischfahrt und Salzfahrt; bei ersterer wird der Fisch im Bimn lebend angebracht, oder sorgsam in Kisten in Eis verpackt, - 


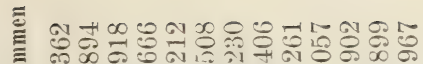

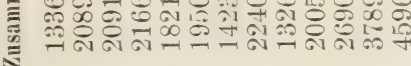

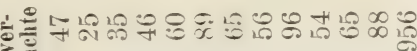

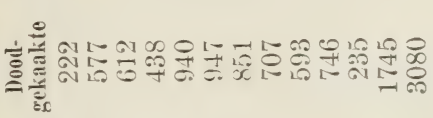

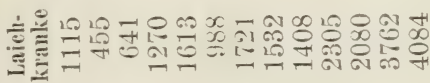

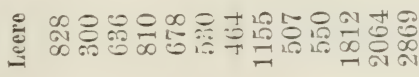

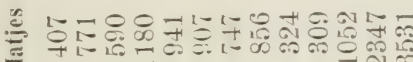
产旁 此

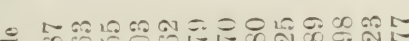

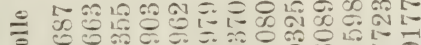

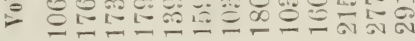

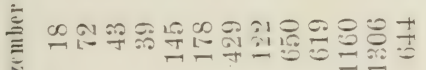

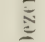

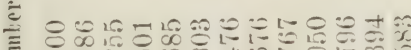
ดो

I

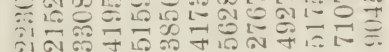

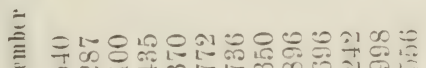

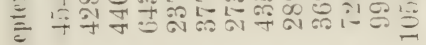

平

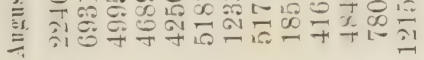

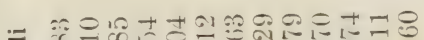

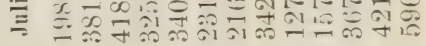

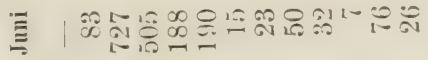

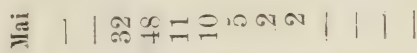

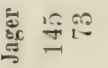

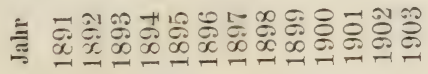

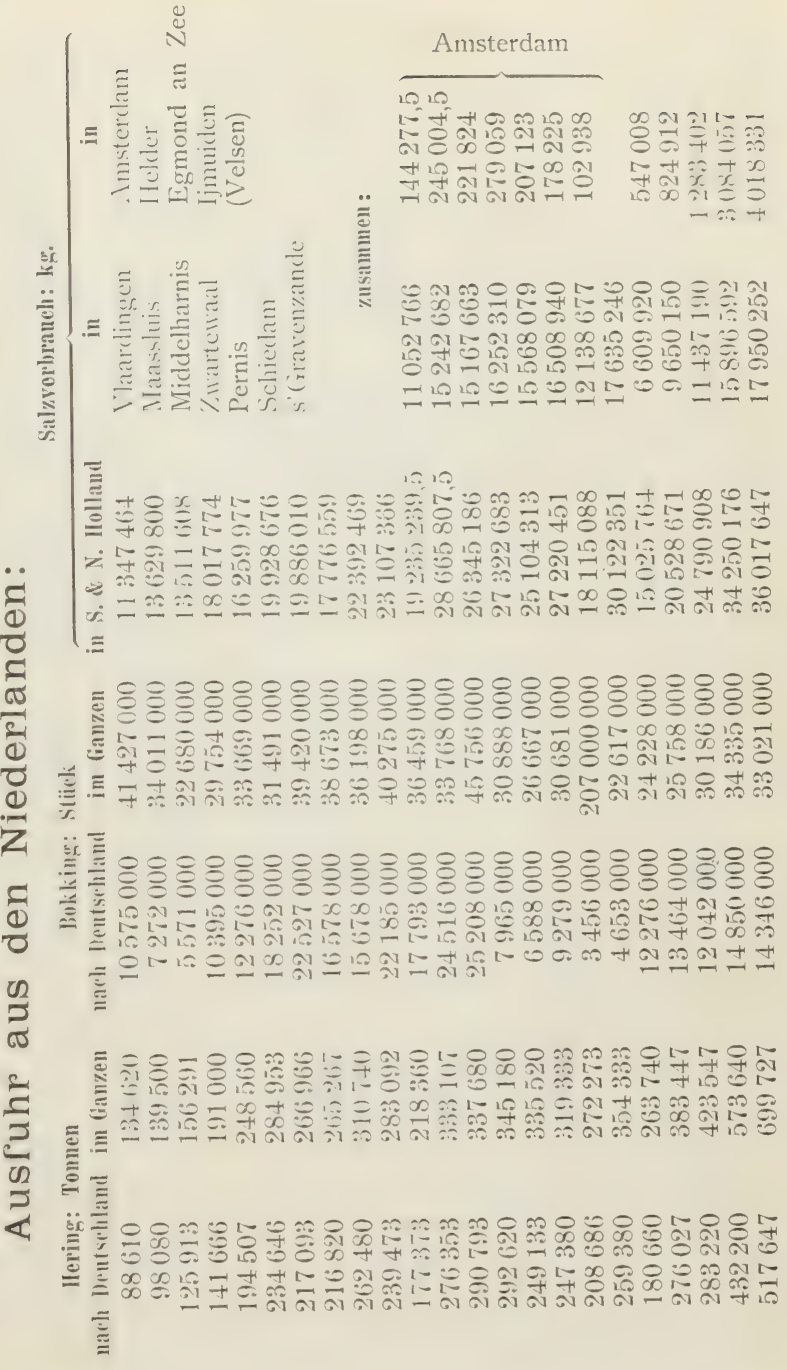

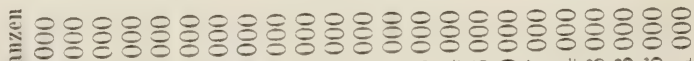

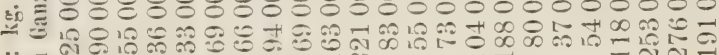

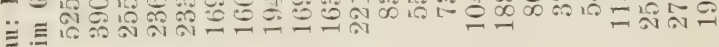
离

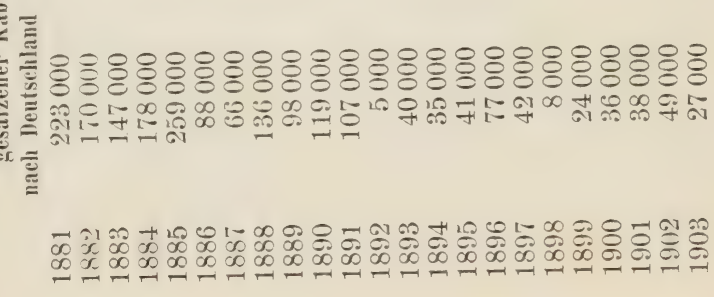


bei letzterer gesalzen in Fässern. Man glaubte, großen Nutzen $z u$ erzielen, wenn man die vom Heringsfange zurïickkehrenden Fahrzeuge baldmöglichst aussandte auf den Fang mit Grundangeln; dieser Nutzen scheint sich nicht ergeben zu haben, denn die Anfuhr im Winter ist gering, - auch scheinen unsere Hochseefischer dem Fischen mit Angeln nicht zugeneigt, indes ist es doch angebracht von Herrn Hoosendijk's Mitteilungen am meisten beachtenswert mir Erscheinendes, wiederzugeben. Zur Frischfahrt auf lebende Fische ist selbstverständlich nur geeignet ein mit Bünn versehenes Fahrzeug; in betreff des Bünn heißt es S. 86: "es ist in 3 Abteilungen zerlegt, jedoch nicht willkürlich, sondern sowohl von einem technischen Standpunkt aus, als auch weil die während einer Reise gefangenen Fische nicht von derselben Art sind. Es kann nützlich sein, die einzelnen Arten von cinander getrennt zu halten, _ - wo es tunlich ist, den $\mathrm{Kabljau}$ stets abgeschieden vom Schelfisch. Denn sobald ein Kabljau dem Verenden nahe ist, sperrt er den Rachen auf und nun ist es eine eigenartige Erscheinung, daß stets der Schelfisch in jenes Rachen schwimmt und dadurch ebenfalls den Tod findet

"Im Frühjahr, wenn der Rochen- und HeilbuttFang beginnt, ist die Teilung des Bünn von großem Wert. Heilbutt vor allem ist ein riesiger Fisch, sodaß mit einer gewissen Anzahl von ihm der Raum, auch eines gut bemessenen Bünn, rasch gefuillt ist, deshalb ist es wichtig, einen Teil frei zu behalten für Schelfisch und Kabljau. - Hat man bedacht, die letzteren beiden Arten so viel als möglich frei herumschwimmen zu lassen, so kann man Heilbutt im Gegenteil am besten lebend halten, indem man sie lebend im Bünn am Schwanz aufhängt; hierfür an den Seiten des Bünnkasten befestigte Klampen sind nicht zweckmäßig, weil dann der Fisch zu viel leidet durch Scheuern an den Wandungen des Bünn. Leinen quer über die Bünn zu spannen dürfte am ziveckmäßigsten sein, um an ihnen den Fisch so viel als möglich in der Mitte zu befestigen "

Für die Salzfahrt galten und gelten vielleicht noch, F luß-Neunaugen (Petromyzon fluviatillus) als bester Köder; das ist jedoch ein kostspieliger, empfindlicher und mit nicht angenehmer Verrichtung verbundener Fiscl. Bis er gebraucht wird hat man ihn aufzubewahren in besonders abgeteilten Kästen (Bakken), die nicht aus beliebigem Holz gefertigt sein können, sondern nur aus solchem das frei von Harz ist, also Tannenoder Föhrenholz. Das Fluß-Neunauge soll lebend gehalten werden bis man es gebraucht; sobald dies geschieht, beißt ihm der Junge den Kopf ab und ein Mann schneidet es in Stuicke, die nicht zu groß und nicht zu klein sein diurfen. - Das Aufbewahren in den mit $W$ asser gefüllten und mehrfach geteilten Kästen ist nicht einfaches Einsetzen der Tiere in jene, sondern es mul3 clen Umständen entsprechend dafür gesorgt werden, dal3 das W Wasser sich nicht zu stark und nicht zu wenig bewegt, - durch vorsichtiges, zweckentsprechendes Klopfen und Rühren mit Reisern muß verhütet werden, daf3 die Tiere in den Ecken und Wandungen sich festsaugen.
Bei der Frischfalurt dienen als Ködır: Sardinen, Rindsleber, frischer Hering, Hornfisch (gemeiner Hornhecht, belone vulgaris).

S. 9I. "Die Sardine und Rindsleber bei der Frischfahrt als Köder gebraucht, werden, (wenn im Februar die Schelfischfahrt beendet ist) als solcher abgelöst von frischem Hering, der während der Monate Februar, März nnd April in Nieuwediep und an den Häfen der Zuiderzce auf den Markt gebracht wird. Im Vergleich mit Neunaugen-Köder ist der frische Hering nicht kostspielig, obwohl die Preise bedeutenden Unterschied zeigen mit dem Köder für Schelfisch .

"Der Hornfisch ugf. $70 \mathrm{~cm}$. lang, ist im Frühjahr besonders geeignet als Köder, wenn das Fischen mit den schon erwähnten Fischarten kein Ergebnis mehr hat, besonders wegen seiner glitzernden und zähen Haut, welche scheint die Fische anzulocken und in der die Angelhaken gut befestigt werden können. - _ Zum Köder schneidet man den Hornfisch auf, und reinigt die Gräte mittelst Hornfisch-Bürstchen gänzlich von Fett. - Versuche, den Hornfisch von Portugal zu beziehen, sind mißglückt, dort gefangener schien zu fett zu sein .

In der Salzfahrt beschäftigte Fahrzeuge können natürlich länger in See bleiben als in der Frischfahrt beschäftigte; für diese ist auch von großem Einfluß der Salzgehalt des Wassers bis zu und in dem Hafen, in dem der gefangene Fisch an den Markt gebracht wird.

S. I 40. "Die Frischfahrt steht auch in engem Verband mit der Fastenzeit (d. h. in den Niederlanden), die gewöhnlich im April endet; deshalb dauert sie ugf. vom November bis April. - Dieser Zeitraum ist noch geteilt in die Schelfischfahrt bis Ende Januar und Beginn Februar, die Fahrt für Keulenrochen und Glattrochen bis Ostern - und der Fang von Heilbutt, der auch gegen Ostern mit Vorteil unternommen wird"

Das Kärtchen für den Fang mit Grundangeln zeigt. wo die erwähnten Fische hauptsächlich gefangen werden. Keulenrochen, Glattrochen und Heilbutt müssen besonders aufgesucht werden, daher spricht man von Butt-, Keulenrochen- und Glattrochen-Reisen. Den $\mathrm{Kabljau}$ findet man während des ganzen Jahres auf allen diesen Fischgrunden, so auch den Schelfisch, obwohl nicht überall in gleich großer Anzahl; wo daher die Kabljau- und Schelfisch-Grunden in der Karte bezeichnet sind, bedeutet es, daß diese Fischarten dort hauptsächlich gesucht werden. - Man sicht, daß in bezug auf lischen mit Grundangeln, die Nordsee in 4 Teile geteilt werden kann :

I) "Die Kabljau-Grunden, zwischen 56 und $56^{\circ} \mathrm{N}$ $\mathrm{I}^{\circ}$ und $5^{\circ} \mathrm{E}$ (Buchstabe C). Dies Gebiet umfaßt die große Fischerbank, das tiefe Loch, Fischersgat, die Westkante der großen Fischerbank, die Killen, die SIV-Spitze und das Nord-Ende der großen Fischerbank. Die Tiefe auf diesen Grunden schwankt von 54 bis 86 Meter, sie nimmt zu von Ost nach West. In den Killen (Gruben?) zeigt das große Lot nicht selten 90 bis 108 m., ostwärts ist der Grund reiner Sand mit Bank(see)gras; westwärts, weicher Grund besiit mit Hornschnecken (Tritonshörnern :). 
2) „Die Scluelfisch.Grunden, zw. $53^{\circ} 30^{\prime}$ bis $54^{\circ}$ I $3^{\prime} \mathrm{N}$ $3^{\circ}$ bis $5^{\circ} \mathrm{E}$ für die größere (Buchstabe B) - und zwischen $54^{\circ}$ bis $55^{\circ} 30^{\prime} \mathrm{N} \quad \mathrm{I}^{\circ}$ bis $3^{\circ} \mathrm{E}$ für die kleinere Art (Bchstb. A). Das Gebiet der kleinen Schelfische umfaßt die westliche Hälfte der Doggerbank und das große Silbertief, westlich der Doggerbank das "Scharfe" und an der NW-Spitze das "Steile«. Bei 16 bis $27 \mathrm{~m}$. Wassertiefe ist reiner Sandgrund mit Muscheln (Schelpen); im Silbertief bei ugf. $68 \mathrm{~m}$. Tiefe weicher Grund, bei $45 \mathrm{~m}$. Steingrund und bei $85 \mathrm{~m}$., im "Steilen ", weicher Grund. - Großer Schelfisch wird nordwärts gefangen (Bchstb. B), aber hauptsächlich ostwärts »am Wasser" wie die Seeleute es nennen, tatsächlich das Amelandsche Platt, (ebenfalls Bchstb. B); bei Wassertiefe von 36 bis $45 \mathrm{~m}$. ist der Grund dort muddig «

3) "Die Keulenrochen- und Glattrochen-Gmunden liegen zwischen $54^{\circ}$ und $56^{\circ} \mathrm{N} 6^{\circ}$ bis $8^{\circ} \mathrm{E}$. (Buchstb. D); sic umfassen den NElichen Teil von Horn's-Riff (Sandgrund), das Amelandsche Flach. Bei 27 bis $36 \mathrm{~m}$. Tiefe findet man reinen Sand, bei 36 bis $45 \mathrm{~m}$. Tiefe ist der Grund weich und muddig «.

4) Die Butt-Grunden zw. $56^{\circ}$ und $57^{\circ} \mathrm{N} 6^{\circ}$ bis $8^{\circ} \mathrm{E}$ (Buchstabe E); diese umfassen die NW-Ecke der kleinen Fischerbank (steiniger Grund) ferner den östlichen Teil der Jütland-Bank, ebenfalls steinig. Die Wassertiefe beträgt 30 bis $32 \mathrm{~m}$., bei $4 \mathrm{I}$ bis $45 \mathrm{~m}$. trifft man auf weichen Grund und reinen Sand

"Nach den mit Buchstabe C angedeuteten Grunden begeben sich unsere Fischer vorzugsweise, wenn sie bestimmt Kabljau fangen wollen; übrigens reicht seinc Verbreitung über die ganze Nordsee, Ostsee, selbst an die Küsten von Island und Nord-Amerika. Die sich in der Nähe der Doggerbank aufhaltenden sind auf den niederländischen Marktplätzen am meisten bekannt und in Allgemeinen größer auch heller als die, welche nördlicher und östlicher man fängt. - Die schwersten Kabljauen trifft man in den "Killen " (Prielen?); um vollen Handelswert zu haben, müssen sie $86 \mathrm{~cm}$. (33 Zoll theinl.) lang sein. Der Kabljau (Gadus morrhua) ist der bedeutendste von der Familie der Dorsche. Dezember und Januar sind die besten Monate, diesen Fisch zu salzen und frisch zu gebrauchen, im Februar und März während der Laichzeit ist er mager und nicht so fein von Geschmack«.

Der Schelfisch (Gadus aeglefinus) - - obwoh! von geringerer Größc ist er von feinerem Geschmack und wird vorzugsiveise benutzt in den Monaten November, Dezember und Januar, besonders die SchelfischLeber ist feiner als die des Kabljau.

"Keulenroche (Raja clavata) wird in allen Meeren angetroffen, ïberdies in der Ostsee; während der Monate März und April suchen ihn unsre Fischer hauptsächlich NEwärts von Texel, fangen ihn dort auch öfter in sroßer Anzahl. Man bringt ihn frisch auf den Markt und verkauft ihn in »Puntje« d. i. ein Korb der I 4 Stück enthält. Die Länge beträgt mit dem Schwanz ugf. $42 \mathrm{~cm}$. In den Niederlanden ist Keulenroche wenig geschätzt, in Belgien findet man dafür regelmäßigen Absatz .
"Glattroche (Raja batis) ist in den Niederlanden als Nahrungsmittel wenig bekannt; gekocht und kalt mit Essig und Oel, ist es ein sehr schmackhaiter Fisch, an Alose (Maifisch) erinnernd; es ist. zu bedauern, daß3 so wenige diesen Leckerbissen kennen. Der Glattroche lebt ebenfalls auf den genannten Grunden, durch niederländische Fischer an den Markt gebracht, wird er nach ben (Körben) verkauft; I ben (Korb) $=$ I I-I 2 Stuick

"Nordlich von diesen Grunden liegt das Jütsche Riff ( $\mathrm{Jutl}$ and $\mathrm{Bank}$ ); auf diesem steinigen Grund ist das Fischen nicht bequem und hierfür hat man recht starkes Fischgerät nötig, da die Fischleinen sehr oft hinter die auf dem Grunde liegenden Steinbrocken geraten und Gefahr laufen $z, 1$ brechen durch das Ziehen des sich stetig fortbewegenden Schiffes, auch wohl durch die scharfen Kanten der Steine. Damit man dann wieder in Verbindung kommt mit dem Fischgerät, muß man die folgende Boje (joon) aufsuchen

"Auf diesen Steingrunden fängt man Heilbutt (Hippoglossus vulgaris), es ist einer der größten Plattfische, der selbst $\mathrm{I}^{3 / 4} \mathrm{~m}$. lang wird; gewöhnlich lebt er auf Thon (Klai) selbst mudartigem Grund, bis an die Küsten von Island und Neu-Fundland, doch im. April sucht er die bereits genannten Grunden auf um zu laichen; - - gekocht ist es ein schmackhafter Fisch, obwohl nicht so fein wie Steinbutt; gebraten ist er etwas trocken. Des Heilbutts Futter sind Weichtiere und Krebse (selbst kleine Seevögel)«.

"Leng (Gadus molva) wird auf derselben geogr. Breite und Länge hauptsächlich angetroffen, doch von niederländischen Fischern nur in geringer Anzahl gefangen; wenn gesalzen ist sein Wert ugf. $2 / 3$ von dem des gesalzenen Kabljau, - frisch an den Markt gebracht ist sein Wert merklich höher. In viel größerer Anzahl findet man Leng längs den Küsten Norwegens, wo man ihn als Stockfisch auf den Markt bringt .

"Wo ich Näheres angab über den Meeresgrund, stimmen meine Mitteilungen nicht immer genau mit den 'Liffern der Karte, obwohl große Abweichungen wohl nicht gefunden werden. Die kleinen Unterschiede kommen davon, daß die in der Karte amtlich festgestellten Tiefen bis in die kleinsten Besonderheiten nicht übereinstimmen können mit den Erfahrungen der Fischer «.

(Die in amtliche Karten eingetragenen Wassertiefen, sind $\mathrm{zu}$ bestimmten Zeiten erhaltene Lotungen die auf den sogen. mittleren Niedrig-Wasserstand übertragen sind; die Fischer berichten von dem, den sie, nach ihrer Erinnerung, gewöhnlich finden, aber nur auf besonderen Wunsch regelmäßig anschreiben; manchmal mögen ihre Lotleinen nicht so sorgfältig abgemessen sein, wie die amtlichen).

Sehr richtig sagt Hr. A. Hoogendijk Jz.: „En grand seigneur ist keine Fischerei-Gesellschaft zur Bliite zu bringen .

Die folgende Zusammenstellung enthält die Anfuhr an niederländische Märkte von auf hoher See nicht mit der Kurre d. h. dem Grund-Schleppnetz, sondern fast ausschließlich mit Grundangeln gefangenen Seefischen (Hering ausgeschlossen) in den einzelnen Monaten der Jahre I89I, I893- I902 (leider fehlt hier der "Verslag u. S. IV. " für I 892) auch die jährliche Anfuhr in genanntem 


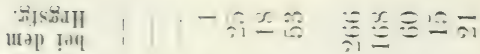

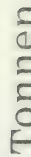

$\frac{5}{0}$
$\frac{0}{0}$
$\frac{\pi}{0}$
$\frac{0}{0}$
$\frac{0}{2}$
$\frac{0}{0}$
$\frac{0}{2}$

$\cong$

(1)

仓

๘)

$\frac{2}{3}$

$10 \mathrm{Y}$

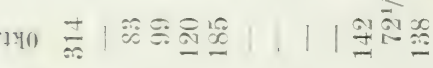

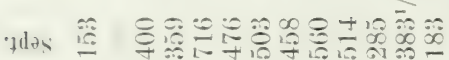

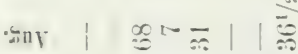

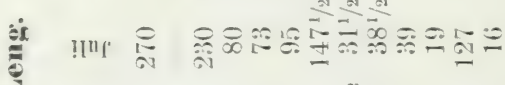

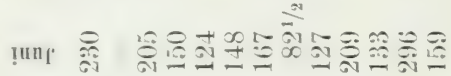

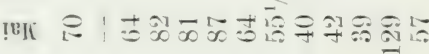

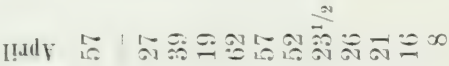

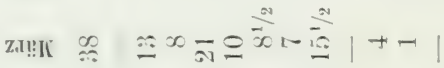

याम4

U⿺辶

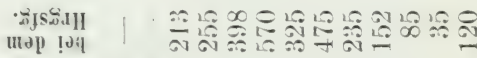

"Zo(I) g]

$\because 104$

1. 140

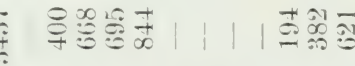

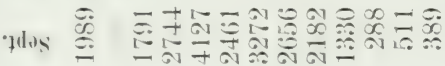

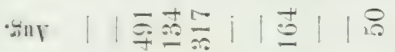

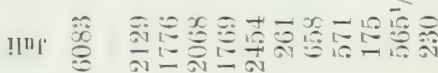

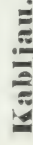

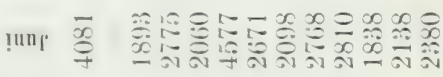

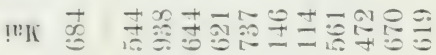

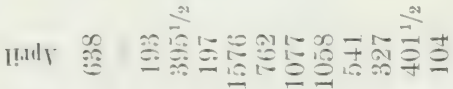

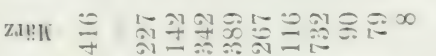

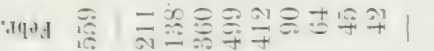

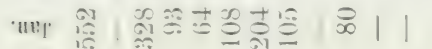

씹.

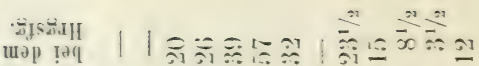

$\mathrm{Z \partial}(\mathrm{I}=1$

$.10 \mathrm{~N}$

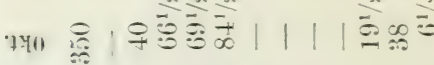

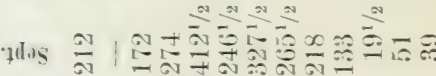

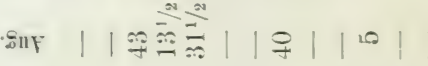
! In

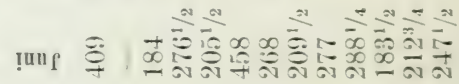
In I!aly

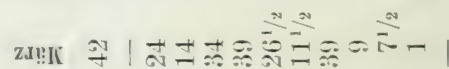

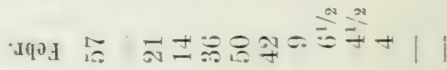

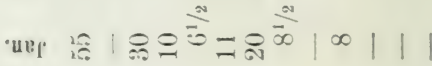

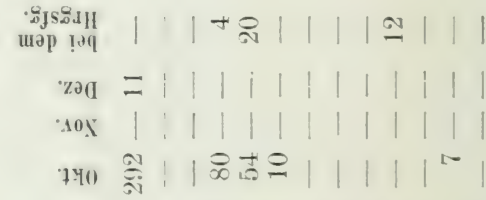

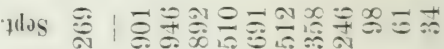

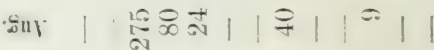

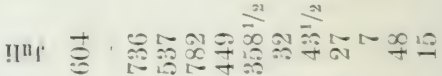

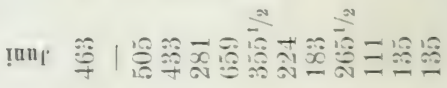

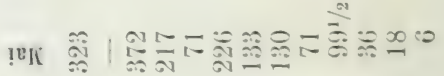

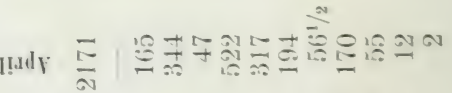

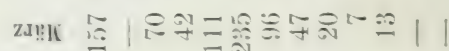

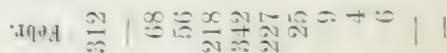

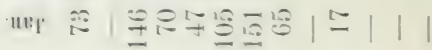

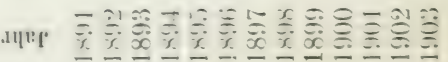




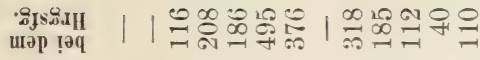

'za $|1| 1|1| 1|1| 1$ $\cdot 10 \mathrm{~N}|1|+||||||||$

140 ิㅡㄴ

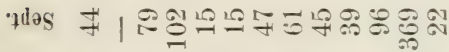

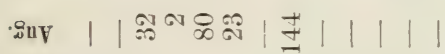

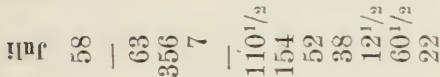
!un

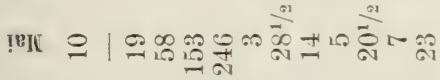

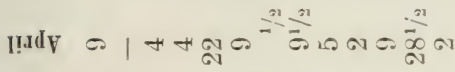

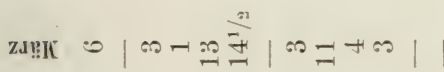

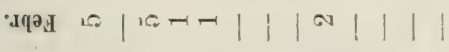

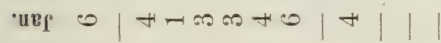

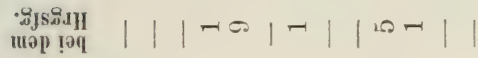
$\operatorname{zad}|1| 1|1| 1|1|$ $\cdot \operatorname{son}|1| 1|1| 1|1| 1$ 140 인 Hlas ค sny $\left|1010110110 \frac{\pi}{\frac{\pi}{2}}\right|$

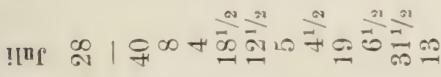

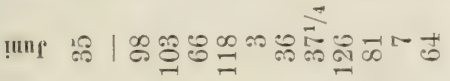
!ा สำ

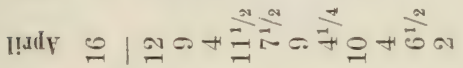

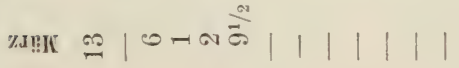

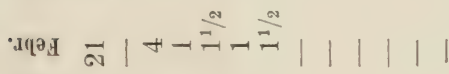
urp $\mid$ m $1|1| 1|1|$

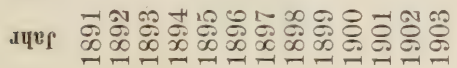

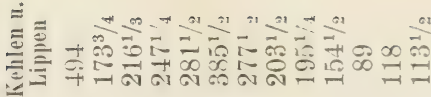

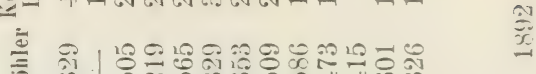

心1

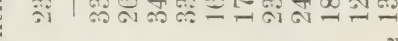

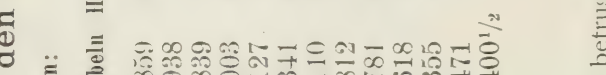

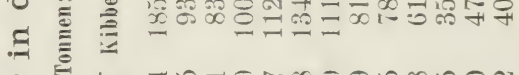

当

है

产

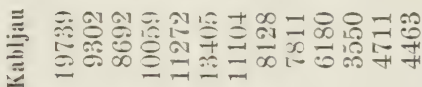

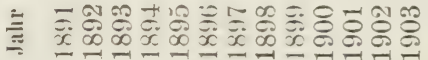

焉离

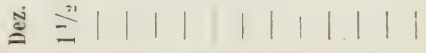

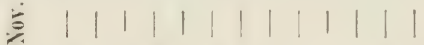

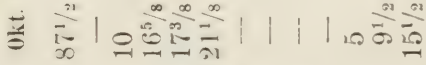
苛交|

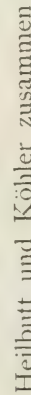

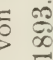

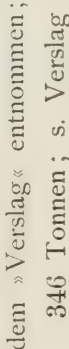

를

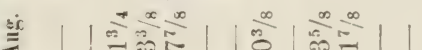

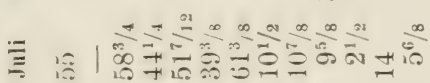

$\stackrel{\cong}{\Xi}$

$\frac{1}{9}$

主等

冚

E

다일

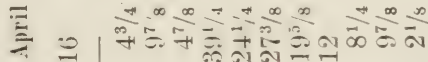

至苛|

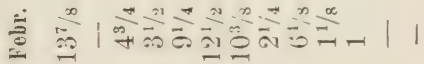

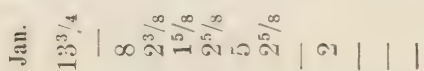

$=$

जี

当

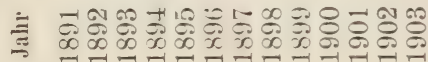


Zeitraum. -- Ich weise gleichzeitig darauf hin, daß in den "Mitteilungen des deutschen Seefischerei-Vereins erscheinen jährlich Uebersetzungen sämtlicher Tabellen aus dem "Verslag u. s. w. ", welche die niederländische Seefischerei betreffen, einschließlich der Kurr- (GrundSchleppnetz)fischerei, des Fanges in der Zuiderzee und der Flußmündungen.

Man sieht sogleich, wie die Anfuhr von Oktober bis März sehr zurückbleibt hinter der von April bis September; genau wie für unsere Segelfischer erweist sich für die niederländischen die Winterfahrt nicht vorteilhaft. Sobald man bei uns Fang mit Angeln betreiben will, werden die Erfahrungen der Niederländer auch uns zu Nutz kommen; nicht allein Schollen sondern auch diesc Fische lebend an den Markt zu bringen könnte vorteilhaft sein.

Unrecht und unrichtig würde es mir scheinen, wenn ich nicht anschlösse die Uebersicht über die Fanggrunden deutscher Fischdampfer, welche von Seiten des dentschen Scefischerei-Vereins gegeben wurde i. J. I90 I im I7. Bande seiner Mitteilungen (s. I Tafel 2 Fig. 2); sie gehört zum Aufsatz von $\mathrm{Hr}$. Prof. Dr. Henking: $\gg$ Die Befischung der Nordsee durch deutsche Fischdampfer" und beruht auf einer Statistik, geführt von Hr. Kpt. Duge, Kgl. Hafenmeister in Geestemünde. Man sieht, in wie enger Verbindung mit einander stehen, Arbeitsfeld, Fangweise und Beschaffenheit des Grundes; wo letzterer für das Gerät d. i. für die Fangweise nicht geeignet ist, da kann man das Feld zur Arbeit nicht benutzen; ob man aber für andere Grunden auch andere Fangweise wahlen soll, hängt von verschiedenen Um- ständen $a b$, - nicht zum wenigsten davon, ob die Anzahl derer, die geneigt sind für bessere IVare höhere Preise zu zahlen, groß genug ist, um höheren Unkosten entsprechende höhere Einnahme zu sichern. - Naturgemäß ist Steingrund für Fischen mit Grundnetzen durchaus ungeeignet.

Zusammenfassung von Schiffsbeobachtungen und Anschluß an die auf Feuerschiffen nebst Landstationen betr. Wärme nebst spez. Gew. des Nordseewassers sowie kleine Kärtchen mit den Abstufungen der Wasserwärme in den einzelnen Monaten: ist zuletzt gegeben i. J. 1884 von der Kommission zur Untersuchung der deutschen Meeve in Kiel in deren IV. Jahresbericht, durch den verstorbenen Geh. Reg.-Rat Hr. Prof. Dr. G. Karsten. Dort und im V. Jahresbericht I887, ist auch genannt der größte Teil der Schiffe und Fischerfahrzeuge, auf denen man beobachtete. Auf Schiffen Angestellte und Fischer, welche durch regelmäßige Beobachtungen und Mitteilungen über WVind und Wetter, Luftdruck, Wärme der Luft sowie des Wassers, des letzteren spez. Gew. mit Wärme z. Z. der Messung, Wassertiefe, Grund, Treibgegenstände, Strömung, Fang mit Nebenumständen u. dgl. bei bestmöglicher Ortsbestimmung: beitragen um genauere Zusammenstellungen zu ermöglichen, btr. gleichzeitige auch aufeinander folgende Wind und Wetter, Strömung, aus denen man kennen lernt Lebensbedingungen, Eigenart nebst Eigenschaften der Fische - werden sich, ihrem Beruf, ihren Reedern nützen, keinesfalls weder sich schaden, noch irgend Jemandem der Gutes will.

(Tabelle I-III siche hinter Tabelle IV.) 
Tabelle IV.

Bei gleicher Wärme ${ }^{\circ} \mathrm{C}$ des Wassers an der Meeres-Oberfläche in den Jahren 1858, 1862 und 1863

verhielt sich die Anzahl des Einholens der Netze mit Fang (m) zu der ohne Fang (o) wie 10: den Zahlen der Tabelle.

$\mathrm{m}: 0=10:$ Tabellen-Zahlen.

\begin{tabular}{|c|c|c|c|c|c|c|c|c|c|c|c|c|c|c|c|c|c|c|c|c|c|}
\hline \multirow{4}{*}{$61^{0}$} & \multirow{3}{*}{ 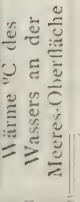 } & \multicolumn{3}{|c|}{ Juni } & \multicolumn{3}{|c|}{ Juli } & \multicolumn{3}{|c|}{ August } & \multicolumn{3}{|c|}{ September } & \multicolumn{3}{|c|}{ Oktober } & \multicolumn{3}{|c|}{ November } & \multirow{3}{*}{ 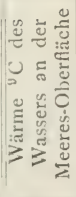 } & \multirow{4}{*}{$61^{0}$} \\
\hline & & $155 ็ 8$ & 1562 & 1863 & 1858 & 1862 & 1563 & 18.5 & 1562 & 1863 & 1858 & 1862 & 1863 & 1SอัS & 1862 & 1863 & 1858 & 1862 & 1863 & & \\
\hline & & 0 & (1) & () & () & 0 & () & (1) & () & () & () & () & () & () & (1) & () & () & () & () & & \\
\hline & $\begin{array}{l}13 \\
12 \\
11 \\
11\end{array}$ & 40 & 17 & $\begin{array}{c}\cdots \\
12.2 \\
116\end{array}$ & $\begin{array}{l}7.5 \\
20 \\
20 \\
2 \%\end{array}$ & $\begin{array}{l}123 \\
24 \\
3011\end{array}$ & $\begin{array}{l}2 \\
2(i \\
21) \\
\because: ;\end{array}$ & - & $\begin{array}{l}- \\
- \\
-\end{array}$ & $\begin{array}{l}- \\
- \\
-\end{array}$ & $\frac{-}{-}$ & $\frac{-}{-}$ & $\frac{-}{-}$ & $\begin{array}{l}- \\
- \\
-\end{array}$ & 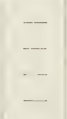 & - & - & $\frac{-}{-}$ & $\frac{-}{-}$ & $\begin{array}{l}1: 3 \\
12 \\
11 \\
10\end{array}$ & \\
\hline & $\begin{array}{l}14 \\
13 \\
12 \\
11 \\
10\end{array}$ & $\frac{-2}{20}$ & . & $\begin{array}{c}- \\
.0 \\
.0\end{array}$ & $\begin{array}{l}-12 \\
24 \\
30 \\
70\end{array}$ & $\begin{array}{l}- \\
\overline{5 i} \\
12 \\
12\end{array}$ & $\begin{array}{l}- \\
- \\
\overline{36} \\
2.2\end{array}$ & $\begin{array}{l}- \\
- \\
-\end{array}$ & $\begin{array}{l}- \\
- \\
-\end{array}$ & $\begin{array}{l}- \\
- \\
- \\
-\end{array}$ & $\begin{array}{l}- \\
- \\
- \\
-\end{array}$ & $\begin{array}{l}- \\
- \\
-\end{array}$ & $\begin{array}{l}- \\
- \\
- \\
-\end{array}$ & $\begin{array}{l}- \\
- \\
-\end{array}$ & $\begin{array}{l}- \\
- \\
-\end{array}$ & $\begin{array}{l}- \\
- \\
-\end{array}$ & $\begin{array}{l}- \\
- \\
-\end{array}$ & $\begin{array}{l}- \\
- \\
-\end{array}$ & $\begin{array}{l}- \\
- \\
- \\
-\end{array}$ & $\begin{array}{l}14 \\
13 \\
12 \\
11 \\
10\end{array}$ & \\
\hline I & $\begin{array}{l}14 \\
13 \\
12 \\
11 \\
11 \\
!\end{array}$ & - & $\begin{array}{l}- \\
- \\
- \\
-\end{array}$ & $\begin{array}{l}- \\
- \\
- \\
- \\
- \\
-\end{array}$ & $\begin{array}{l}- \\
25 \\
7(1) \\
- \\
- \\
-\end{array}$ & $\begin{array}{l}- \\
-3: 3 \\
12 \\
-\end{array}$ & $\begin{array}{l}- \\
- \\
- \\
- \\
-\end{array}$ & $\begin{array}{l}14 \\
- \\
- \\
-\end{array}$ & $\begin{array}{l}- \\
- \\
- \\
-\end{array}$ & $\begin{array}{l}- \\
- \\
- \\
- \\
-\end{array}$ & $\begin{array}{r}5 \\
13 \\
- \\
- \\
-\end{array}$ & $\begin{array}{l}- \\
- \\
- \\
-\end{array}$ & $\begin{array}{c}- \\
- \\
1,5 \\
1,2 \\
- \\
-\end{array}$ & - & $\begin{array}{l}- \\
- \\
0,3 \\
0,9 \\
0,8 \\
-\end{array}$ & $\begin{array}{l}-- \\
4 \\
2,7 \\
1,3 \\
1 \\
2\end{array}$ & $\begin{array}{l}- \\
- \\
- \\
-\end{array}$ & $\begin{array}{l}- \\
- \\
- \\
-\end{array}$ & $\begin{array}{l}- \\
- \\
- \\
- \\
-\end{array}$ & $\begin{array}{r}14 \\
13 \\
12 \\
11 \\
10 \\
9\end{array}$ & $\mathrm{~N}$ \\
\hline & $\begin{array}{l}16 \\
15 \\
14 \\
13 \\
12 \\
11 \\
10\end{array}$ & $\begin{array}{l}- \\
- \\
- \\
-\end{array}$ & $\begin{array}{l}- \\
- \\
- \\
- \\
-\end{array}$ & $\begin{array}{l}- \\
- \\
- \\
- \\
- \\
-\end{array}$ & $\begin{array}{l}- \\
- \\
8 \\
20 \\
-- \\
--\end{array}$ & $\begin{array}{l}- \\
- \\
\overline{1} \\
3,5 \\
6\end{array}$ & $\begin{array}{c}- \\
- \\
- \\
8 \\
3 \\
1 ! \\
10\end{array}$ & $\begin{array}{r}17 \\
6 \\
! \\
11 \\
5 \\
- \\
-\end{array}$ & $\begin{array}{l}- \\
- \\
\overline{10,27} \\
1,4 \\
-\end{array}$ & $\begin{array}{l}-1 \\
-5 \\
1,5 \\
1,3 \\
2 \\
-2\end{array}$ & $\begin{array}{c}- \\
9 \\
7 \\
8 \\
-\end{array}$ & $\begin{array}{l}- \\
- \\
\overrightarrow{0,6} \\
0,3 \\
0,9 \\
-\end{array}$ & $\begin{array}{l}- \\
- \\
1 \\
1,2 \\
0,7 \\
-\end{array}$ & $\begin{array}{l}- \\
- \\
- \\
- \\
\overline{10} \\
\bar{z}\end{array}$ & $\begin{array}{l}- \\
- \\
- \\
\frac{1,3}{-}\end{array}$ & $\begin{array}{l}- \\
- \\
- \\
- \\
2 \\
2,1\end{array}$ & $\begin{array}{l}- \\
- \\
- \\
\ddot{7}\end{array}$ & $\begin{array}{l}- \\
- \\
- \\
- \\
-\end{array}$ & $\begin{array}{l}- \\
- \\
- \\
- \\
-\end{array}$ & $\begin{array}{l}16 \\
15 \\
14 \\
13 \\
12 \\
11 \\
11\end{array}$ & \\
\hline & $\begin{array}{l}17 \\
16 \\
15 \\
1.4 \\
1.3 \\
12 \\
11 \\
10\end{array}$ & $\begin{array}{l}- \\
- \\
- \\
- \\
-\end{array}$ & $\begin{array}{l}- \\
- \\
- \\
- \\
- \\
-\end{array}$ & $\begin{array}{l}- \\
- \\
- \\
- \\
- \\
-\end{array}$ & $\begin{array}{l}- \\
- \\
- \\
4(x) \\
- \\
-\end{array}$ & $\begin{array}{l}- \\
- \\
- \\
3,3 \\
0,1 \\
(1,3 \\
-\end{array}$ & $\begin{array}{l}- \\
- \\
- \\
- \\
- \\
13 \\
13 \\
17\end{array}$ & $\begin{array}{l}30 \\
90 \\
- \\
- \\
- \\
- \\
-\end{array}$ & $\begin{array}{l}- \\
- \\
- \\
1,3 \\
1,2 \\
0,7 \\
--\end{array}$ & $\begin{array}{l}- \\
- \\
- \\
6 \\
\overline{5} \\
-\end{array}$ & $\begin{array}{l}- \\
- \\
- \\
- \\
- \\
-\end{array}$ & $\begin{array}{l}- \\
- \\
\frac{4}{27} \\
- \\
-\end{array}$ & $\begin{array}{l}- \\
- \\
- \\
- \\
- \\
- \\
-\end{array}$ & $\begin{array}{l}- \\
- \\
- \\
- \\
- \\
-\end{array}$ & $\begin{array}{l}- \\
- \\
- \\
- \\
- \\
-\end{array}$ & $\begin{array}{l}- \\
- \\
- \\
- \\
-\end{array}$ & $\begin{array}{l}- \\
- \\
- \\
- \\
- \\
-\end{array}$ & $\begin{array}{l}- \\
- \\
- \\
- \\
- \\
-\end{array}$ & $\begin{array}{l}- \\
- \\
- \\
- \\
-\end{array}$ & $\begin{array}{l}17 \\
16 \\
15 \\
14 \\
1: 3 \\
12 \\
11 \\
10\end{array}$ & \\
\hline
\end{tabular}


Tabelle I.

Heringfang in dem Zeitraum

Durchschnitt der gefischten Heringe

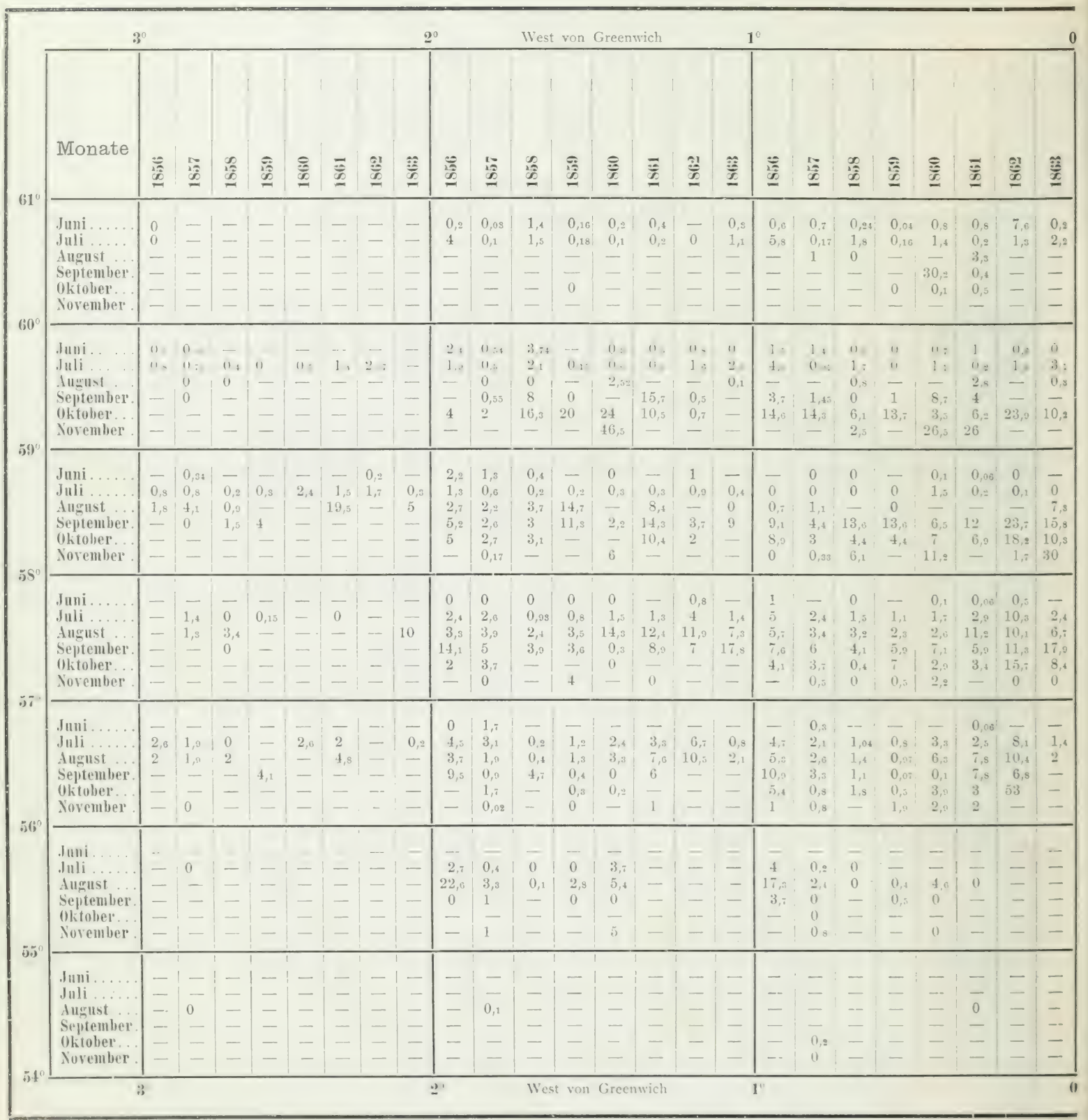


der acht Jahre 1856 - 1863.

Tabelle I.

in Tonnen bei jedesmaligem Fischen.

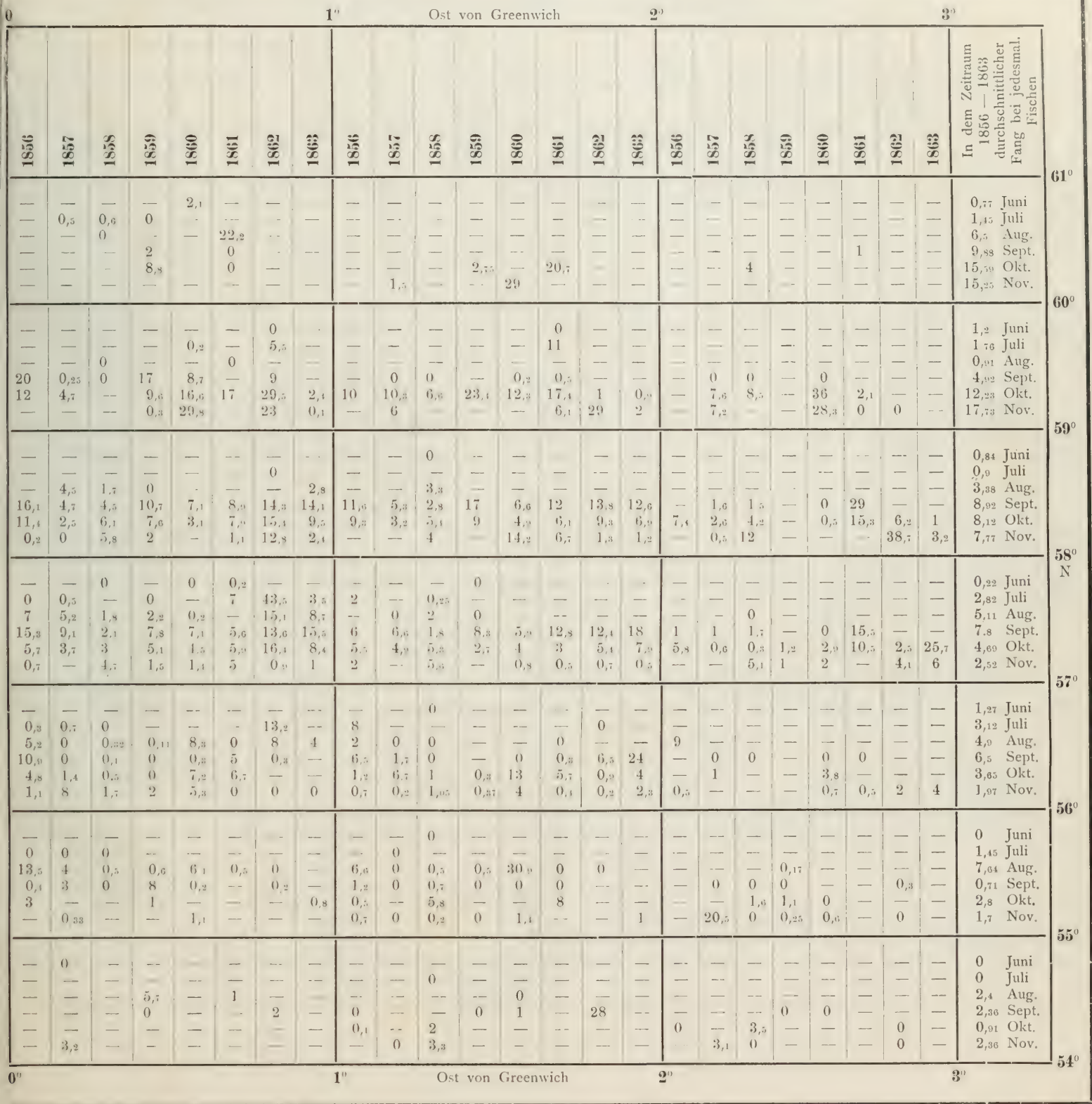


Tabelle II.

\section{Wärme ${ }^{0} \mathrm{C}$ der Luft und Meeres-Oberfläche}

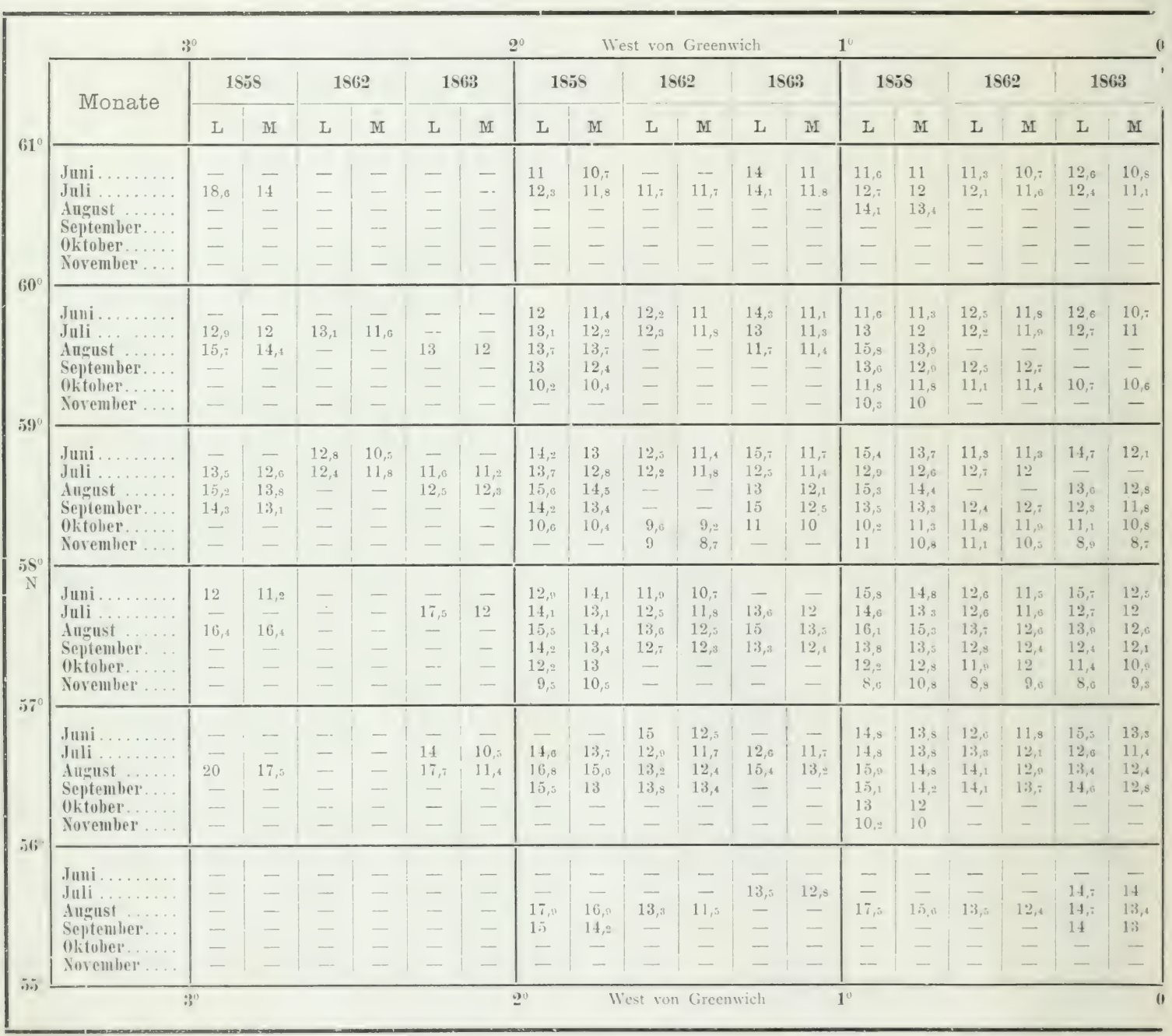




\section{z. Z. des Herings-Fanges i. d. Jn. 1858. 1862, 1863.}

\section{$\mathrm{M}=\mathrm{Wärme} \mathrm{der} \mathrm{Meeres-Oberfläche.}$}

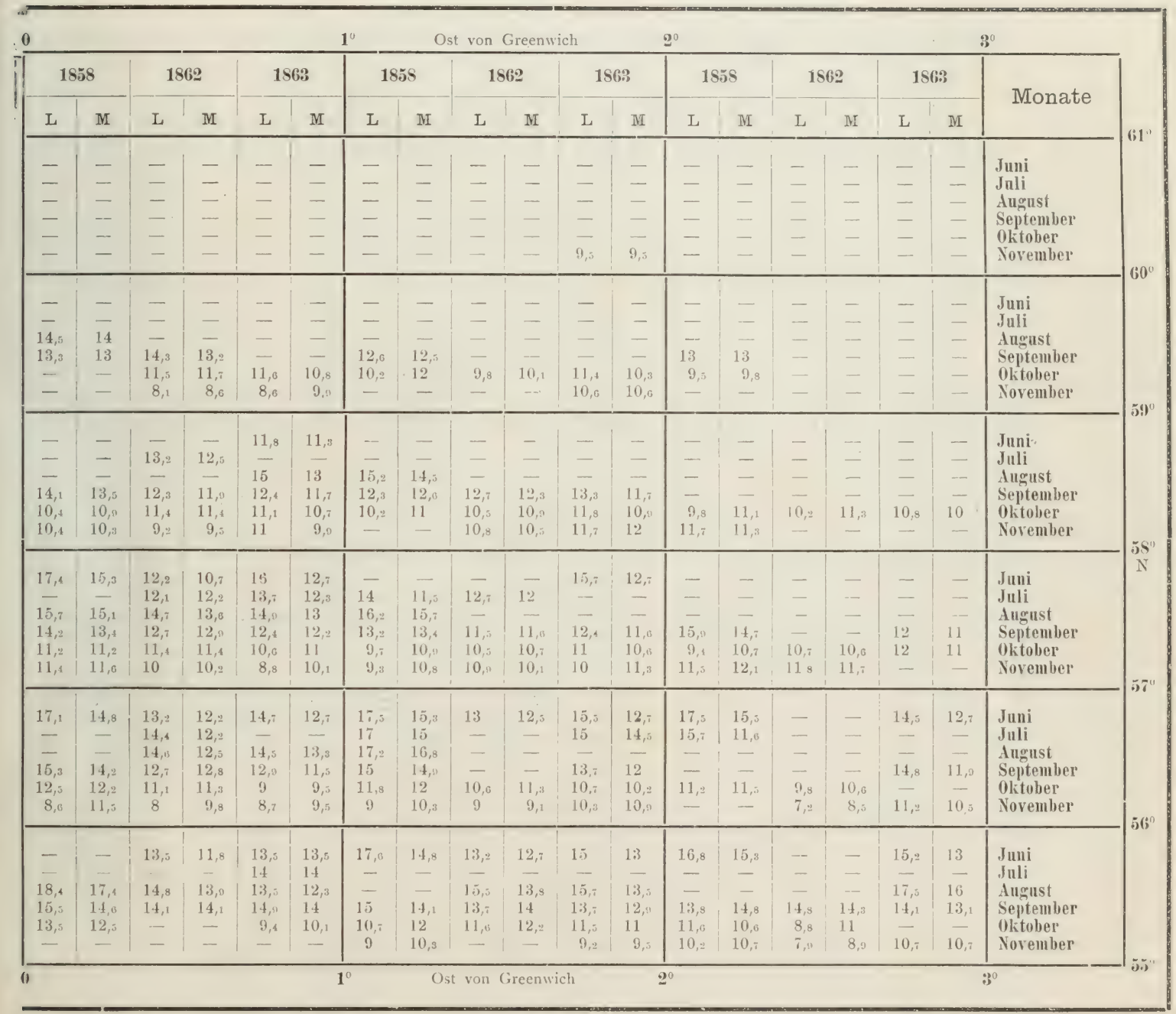


Tabelle III.

In den Jahren 1858, 1862, 1863 wurden in den Monaten der Fangzeit bei folgender

\begin{tabular}{|c|c|c|c|c|c|c|c|c|c|c|c|c|c|c|c|c|c|c|c|}
\hline \multirow{4}{*}{$61^{\circ}$} & \multirow{3}{*}{ 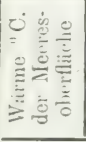 } & \multicolumn{6}{|c|}{ Juni } & \multicolumn{6}{|c|}{ Juli } & \multicolumn{6}{|c|}{ Angust } \\
\hline & & \multicolumn{2}{|c|}{1858} & \multicolumn{2}{|c|}{1862} & \multicolumn{2}{|c|}{1863} & \multicolumn{2}{|c|}{1555} & \multicolumn{2}{|c|}{1862} & \multicolumn{2}{|c|}{1563} & \multicolumn{2}{|c|}{$15 \tilde{s}$} & \multicolumn{2}{|c|}{1562} & \multicolumn{2}{|c|}{1563} \\
\hline & & M & 0 & M & 0 & $\mathrm{MI}$ & 0 & M & 0 & M & 0 & M & 0 & M & 0 & MI & 0 & MI & 0 \\
\hline & $\begin{array}{l}14 \\
13 \\
12 \\
11 \\
10\end{array}$ & $\begin{array}{c}- \\
\overline{-} \\
\overline{5} \\
5\end{array}$ & $\begin{array}{r}- \\
1 \\
21 \\
21 \\
9\end{array}$ & $\begin{array}{l}- \\
- \\
- \\
4 \\
3\end{array}$ & $\begin{array}{l}- \\
1 \\
2 \\
6 \\
4\end{array}$ & $\begin{array}{c}- \\
\overline{-} \\
4 \\
3\end{array}$ & $\begin{array}{l}- \\
\overline{2} \\
49 \\
35\end{array}$ & $\begin{array}{r}- \\
2 \\
19 \\
23 \\
3\end{array}$ & $\begin{array}{r}4 \\
15 \\
37 \\
52 \\
8\end{array}$ & $\begin{array}{r}- \\
- \\
3 \\
10 \\
3\end{array}$ & $\begin{array}{r}- \\
\overline{37} \\
24 \\
9\end{array}$ & $\begin{array}{r}- \\
- \\
5 \\
27 \\
4\end{array}$ & $\begin{array}{r}- \\
2 \\
13 \\
54 \\
13\end{array}$ & $\begin{array}{l}- \\
\bar{z} \\
-\end{array}$ & $\begin{array}{l}\overline{-} \\
\overline{5} \\
-\end{array}$ & $\begin{array}{l}z \\
z \\
-\end{array}$ & $\begin{array}{l}- \\
z \\
z\end{array}$ & $\begin{array}{l}\bar{z} \\
\bar{z}\end{array}$ & $\begin{array}{l}\bar{z} \\
\bar{z} \\
-\end{array}$ \\
\hline & $\begin{array}{r}14 \\
13 \\
12 \\
11 \\
10 \\
9 \\
8\end{array}$ & $\begin{array}{c}- \\
\overline{1} \\
5 \\
1 \\
-\end{array}$ & $\begin{array}{r}1 \\
3 \\
4 \\
11 \\
8 \\
-\end{array}$ & $\begin{array}{l}- \\
\overline{4} \\
\overline{-} \\
-1\end{array}$ & $\begin{array}{r}- \\
3 \\
4 \\
2 \\
2 \\
- \\
-\end{array}$ & $\begin{array}{l}- \\
\overline{-} \\
\overline{1} \\
\frac{-}{-}\end{array}$ & $\begin{array}{c}- \\
\overline{-} \\
7 \\
5 \\
-\end{array}$ & $\begin{array}{r}- \\
4 \\
15 \\
13 \\
1 \\
-\end{array}$ & $\begin{array}{r}1 \\
17 \\
36 \\
40 \\
7 \\
- \\
-\end{array}$ & $\begin{array}{r}- \\
- \\
3 \\
22 \\
5 \\
- \\
-\end{array}$ & $\begin{array}{r}-4 \\
16 \\
26 \\
6 \\
- \\
-\end{array}$ & $\begin{array}{l}- \\
2 \\
1 \\
5 \\
5 \\
- \\
-\end{array}$ & $\begin{array}{r}1 \\
1 \\
18 \\
11 \\
-\end{array}$ & $\begin{array}{l}\bar{z} \\
\bar{z} \\
\bar{z} \\
\overline{-}\end{array}$ & $\begin{array}{l}7 \\
5 \\
- \\
= \\
= \\
-\end{array}$ & $\begin{array}{l}\bar{z} \\
\bar{z} \\
\bar{z} \\
\overline{-}\end{array}$ & $\begin{array}{l}I \\
\bar{I} \\
\bar{E} \\
\overline{-}\end{array}$ & $\begin{array}{l}\bar{z} \\
\overline{1} \\
\overline{-}\end{array}$ & $\begin{array}{l}- \\
- \\
2 \\
3 \\
- \\
-\end{array}$ \\
\hline & $\begin{array}{r}16 \\
15 \\
14 \\
13 \\
12 \\
11 \\
10 \\
9 \\
8\end{array}$ & $\begin{array}{l}= \\
= \\
= \\
= \\
=\end{array}$ & $\begin{array}{l}- \\
4 \\
1 \\
- \\
= \\
= \\
-\end{array}$ & $\begin{array}{l}= \\
= \\
= \\
= \\
= \\
=\end{array}$ & $\begin{array}{l}- \\
- \\
- \\
-1 \\
1 \\
3 \\
-\end{array}$ & $\begin{array}{l}-- \\
= \\
= \\
= \\
= \\
=\end{array}$ & $\begin{array}{l}= \\
= \\
= \\
= \\
= \\
=\end{array}$ & $\begin{array}{l}- \\
\overline{1} \\
4 \\
2 \\
- \\
= \\
-\end{array}$ & $\begin{array}{r}- \\
-1 \\
10 \\
14 \\
1 \\
- \\
-\end{array}$ & $\begin{array}{c}- \\
\overline{-} \\
2 \\
6 \\
5 \\
1 \\
- \\
-\end{array}$ & $\begin{array}{r}- \\
\overline{-} \\
1 \\
20 \\
6 \\
1 \\
- \\
-\end{array}$ & $\begin{array}{l}\overline{-} \\
\overline{-} \\
\overline{3} \\
\overline{3} \\
\overline{-}\end{array}$ & $\begin{array}{c}- \\
\overline{1} \\
\overline{3} \\
9 \\
1 \\
-\end{array}$ & $\begin{array}{l}\overline{2} \\
5 \\
\overline{-} \\
\overline{-} \\
\overline{-}\end{array}$ & $\begin{array}{l}- \\
3 \\
7 \\
4 \\
1 \\
- \\
- \\
-\end{array}$ & $\begin{array}{l}\bar{z} \\
\overline{1} \\
\overline{-} \\
\bar{z} \\
\overline{-}\end{array}$ & $\begin{array}{l}\overline{-} \\
\overline{-} \\
\overline{-} \\
\overline{-} \\
\overline{-}\end{array}$ & $\begin{array}{c}- \\
\overline{1} \\
1 \\
5 \\
1 \\
- \\
- \\
-\end{array}$ & $\begin{array}{l}\overline{-} \\
\overline{2} \\
2 \\
- \\
\overline{-} \\
-\end{array}$ \\
\hline & $\begin{array}{c}17 \\
16 \\
15 \\
14 \\
13 \\
12 \\
11 \\
10 \\
5 \\
4\end{array}$ & $\begin{array}{l}= \\
= \\
= \\
= \\
= \\
=\end{array}$ & $\begin{array}{l}\bar{z} \\
\overline{1} \\
\bar{z} \\
\overline{-} \\
\bar{z}\end{array}$ & $\begin{array}{l}- \\
\overline{-} \\
\overline{-} \\
\overline{2} \\
- \\
-\end{array}$ & $\begin{array}{l}- \\
- \\
- \\
- \\
-1 \\
3 \\
1 \\
-\end{array}$ & $\begin{array}{l}\overline{-} \\
= \\
= \\
= \\
= \\
= \\
-\end{array}$ & $\begin{array}{l}= \\
= \\
= \\
= \\
= \\
=\end{array}$ & $\begin{array}{l}\overline{-} \\
= \\
\overline{18} \\
6 \\
\overline{-} \\
= \\
-\end{array}$ & $\begin{array}{l}- \\
\overline{-} \\
-3 \\
15 \\
12 \\
- \\
- \\
=\end{array}$ & $\begin{array}{r}- \\
= \\
- \\
2 \\
32 \\
23 \\
5 \\
-\end{array}$ & $\begin{array}{l}- \\
- \\
- \\
- \\
1 \\
3 \\
8 \\
3 \\
- \\
-\end{array}$ & $\begin{array}{r}- \\
-1 \\
1 \\
3 \\
9 \\
38 \\
14 \\
6 \\
- \\
-\end{array}$ & $\begin{array}{r}- \\
- \\
- \\
2 \\
7 \\
11 \\
27 \\
7 \\
3 \\
\end{array}$ & $\begin{array}{r}1 \\
4 \\
41 \\
32 \\
32 \\
22 \\
1 \\
- \\
-\end{array}$ & $\begin{array}{r}7 \\
25 \\
29 \\
32 \\
11 \\
4 \\
- \\
=\end{array}$ & $\begin{array}{r}- \\
\overline{-} \\
6 \\
37 \\
29 \\
6 \\
= \\
-\end{array}$ & $\begin{array}{l}- \\
= \\
- \\
1 \\
1 \\
- \\
-\end{array}$ & $\begin{array}{c}- \\
20 \\
19 \\
110 \\
7 \\
31 \\
10 \\
- \\
-\end{array}$ & $\begin{array}{r}- \\
-2 \\
9 \\
17 \\
10 \\
6 \\
= \\
=\end{array}$ \\
\hline & $\begin{array}{c}17 \\
16 \\
15 \\
14 \\
1: 3 \\
112 \\
11 \\
10 \\
9\end{array}$ & $\begin{array}{l}= \\
= \\
z \\
= \\
=\end{array}$ & $\begin{array}{l}1 \\
- \\
= \\
=\end{array}$ & $\begin{array}{l}= \\
= \\
= \\
= \\
= \\
-\end{array}$ & $\begin{array}{l}\bar{z} \\
z \\
z \\
z \\
z\end{array}$ & $\begin{array}{l}I \\
I \\
z \\
- \\
- \\
-\end{array}$ & $\begin{array}{l}= \\
= \\
= \\
=\end{array}$ & $\begin{array}{l}- \\
= \\
1 \\
3 \\
- \\
= \\
=\end{array}$ & $\begin{array}{r}\ldots \\
2 \\
2 \\
9 \\
14 \\
6 \\
= \\
= \\
-\end{array}$ & $\begin{array}{r}- \\
- \\
- \\
\overline{9} \\
23 \\
34 \\
1 \\
-\end{array}$ & $\begin{array}{l}- \\
- \\
- \\
3 \\
1 \\
1 \\
3 \\
-\end{array}$ & $\begin{array}{c}- \\
-1 \\
3 \\
\vdots \\
\vdots \\
1 \\
-\end{array}$ & $\begin{array}{r}- \\
- \\
\overline{4} \\
4 \\
4 \\
12 \\
10 \\
-10\end{array}$ & $\begin{array}{l}3 \\
1 \\
2 \\
- \\
\overline{1} \\
- \\
-\end{array}$ & $\begin{array}{r}9 \\
3 \\
5 \\
10 \\
2 \\
2 \\
- \\
- \\
-\end{array}$ & $\begin{array}{r}- \\
4 \\
9 \\
62 \\
92 \\
14 \\
1\end{array}$ & $\begin{array}{r}- \\
\overline{1} \\
\overline{8} \\
11 \\
1 \\
-\end{array}$ & $\begin{array}{l}- \\
- \\
- \\
5 \\
2 \\
4 \\
-\end{array}$ & $\begin{array}{l}- \\
- \\
4 \\
3 \\
1 \\
2 \\
-\end{array}$ \\
\hline
\end{tabular}


Tabelle III.

die Herings-Netze eingeholt $\left\{\begin{array}{l}\frac{M}{1}=-\frac{m i t}{0} \text { Fang } \\ 0\end{array}\right.$

gleicher Wärme ${ }^{\circ} \mathrm{C}$. der Meeresoberfläche.

\begin{tabular}{|c|c|c|c|c|c|c|c|c|c|c|c|c|c|c|c|c|c|c|c|}
\hline \multicolumn{6}{|c|}{ September } & \multicolumn{6}{|c|}{ Okitober } & \multicolumn{6}{|c|}{ Norember } & \multirow{3}{*}{ 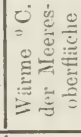 } & \\
\hline \multicolumn{2}{|c|}{1855} & \multicolumn{2}{|c|}{1862} & \multicolumn{2}{|c|}{1563} & \multicolumn{2}{|c|}{1858} & \multicolumn{2}{|c|}{1862} & \multicolumn{2}{|c|}{1863} & \multicolumn{2}{|c|}{1858} & \multicolumn{2}{|c|}{1862} & \multicolumn{2}{|c|}{1863} & & \\
\hline M & 0 & M & 0 & MI & 0 & M & 0 & $\mathrm{MI}$ & 0 & MI & 0 & MI & 0 & M & 0 & M & 0 & & $30^{\circ}$ \\
\hline $\begin{array}{l}\overline{-} \\
\overline{-}\end{array}$ & $\begin{array}{l}= \\
\overline{-} \\
=\end{array}$ & $\begin{array}{l}= \\
= \\
=\end{array}$ & $\begin{array}{l}\overline{-} \\
\overline{-} \\
\overline{-}\end{array}$ & $\begin{array}{l}\overline{-} \\
\overline{-} \\
\overline{-}\end{array}$ & $\begin{array}{l}- \\
- \\
- \\
-\end{array}$ & $\begin{array}{l}E \\
E \\
=\end{array}$ & $\begin{array}{l}\overline{-} \\
\overline{-} \\
=\end{array}$ & $\begin{array}{l}\overline{-} \\
\overline{-} \\
-\end{array}$ & $\begin{array}{l}- \\
\overline{-} \\
-\end{array}$ & $\begin{array}{l}- \\
= \\
=\end{array}$ & $\begin{array}{l}- \\
- \\
-\end{array}$ & $\begin{array}{l}- \\
\overline{-} \\
-\end{array}$ & $\begin{array}{l}- \\
= \\
=\end{array}$ & $\begin{array}{l}- \\
\bar{z} \\
\overline{-}\end{array}$ & $\begin{array}{l}= \\
= \\
=\end{array}$ & $\begin{array}{l}\bar{z} \\
\bar{z} \\
\overline{-}\end{array}$ & $\begin{array}{l}E \\
- \\
-\end{array}$ & $\begin{array}{l}14 \\
13 \\
12 \\
11 \\
10\end{array}$ & \\
\hline $\begin{array}{l}3 \\
1 \\
- \\
- \\
- \\
-\end{array}$ & $\begin{array}{l}\overline{5} \\
2 \\
- \\
- \\
-\end{array}$ & $\begin{array}{l}- \\
= \\
= \\
= \\
=\end{array}$ & $\begin{array}{l}- \\
= \\
- \\
-\end{array}$ & $\begin{array}{l}\overline{-} \\
= \\
= \\
-\end{array}$ & $\begin{array}{l}\overline{-} \\
\overline{-} \\
\overline{-} \\
-\end{array}$ & $\begin{array}{r}\overline{-} \\
\frac{2}{4} \\
- \\
2 \\
-\end{array}$ & $\begin{array}{c}- \\
\overline{1} \\
1 \\
2 \\
-\end{array}$ & $\begin{array}{l} \pm \\
\pm \\
- \\
-\end{array}$ & $\begin{array}{l}\overline{-} \\
\overline{-} \\
\overline{-} \\
-\end{array}$ & $\begin{array}{r}- \\
2 \\
4 \\
11 \\
-\end{array}$ & $\begin{array}{c}\text { ב } \\
\overline{-} \\
3 \\
9 \\
1 \\
-\end{array}$ & $\begin{array}{l}\overline{-} \\
\overline{-} \\
\frac{2}{-}\end{array}$ & $\begin{array}{l}- \\
- \\
- \\
- \\
-\end{array}$ & $\begin{array}{l}\overline{-} \\
\overline{-} \\
\overline{-} \\
-\end{array}$ & $\begin{array}{l}\bar{z} \\
\bar{z} \\
\bar{z} \\
\overline{-}\end{array}$ & $\begin{array}{l}\bar{z} \\
\bar{z} \\
\overline{1} \\
\overline{1}\end{array}$ & $\begin{array}{l}\bar{E} \\
\bar{E} \\
\bar{E} \\
\overline{-}\end{array}$ & $\begin{array}{r}14 \\
13 \\
12 \\
11 \\
10 \\
9 \\
8\end{array}$ & \\
\hline $\begin{array}{r}- \\
6 \\
13 \\
3 \\
- \\
- \\
-\end{array}$ & $\begin{array}{r}-1 \\
3 \\
17 \\
1 \\
- \\
= \\
-\end{array}$ & $\begin{array}{l}- \\
- \\
10 \\
14 \\
1 \\
2 \\
- \\
-\end{array}$ & $\begin{array}{l}E \\
E \\
\overline{-} \\
\overline{-} \\
-\end{array}$ & $\begin{array}{r}-- \\
- \\
2 \\
4 \\
19 \\
17 \\
2 \\
-\end{array}$ & $\begin{array}{c}- \\
1 \\
-1 \\
3 \\
2 \\
1 \\
- \\
-\end{array}$ & $\begin{array}{r}- \\
1 \\
1 \\
35 \\
46 \\
8 \\
-\end{array}$ & $\begin{array}{r}- \\
- \\
4 \\
6 \\
14 \\
12 \\
1 \\
-\end{array}$ & $\begin{array}{l}- \\
\overline{-} \\
22 \\
36\end{array}$ & $\begin{array}{l}- \\
\text { - } \\
\text { - } \\
1 \\
2 \\
1 \\
2 \\
-\end{array}$ & $\begin{array}{r}- \\
- \\
\overline{11} \\
15 \\
52 \\
70 \\
9 \\
3\end{array}$ & $\begin{array}{c}- \\
- \\
4 \\
4 \\
7 \\
7 \\
2 \\
-\end{array}$ & $\begin{array}{l}- \\
- \\
- \\
- \\
2 \\
2 \\
7 \\
1 \\
-\end{array}$ & $\begin{array}{l}- \\
- \\
- \\
- \\
2 \\
- \\
-\end{array}$ & $\begin{array}{l}- \\
\overline{-} \\
\overline{2} \\
\overline{-} \\
\overline{5} \\
-\end{array}$ & $\begin{array}{c}- \\
\overline{-} \\
- \\
-3 \\
-3 \\
2 \\
1\end{array}$ & $\begin{array}{c}- \\
- \\
\overline{1} \\
1 \\
3 \\
-2 \\
1\end{array}$ & $\begin{array}{c}\overline{-} \\
\overline{-} \\
\overline{1} \\
\overline{1} \\
\overline{2} \\
-\end{array}$ & $\begin{array}{r}16 \\
15 \\
14 \\
13 \\
12 \\
11 \\
10 \\
9 \\
8\end{array}$ & \\
\hline $\begin{array}{r}- \\
\overline{5} \\
48 \\
92 \\
11 \\
1 \\
- \\
-\end{array}$ & $\begin{array}{r}- \\
-2 \\
45 \\
68 \\
9 \\
1 \\
- \\
-\end{array}$ & $\begin{array}{r}- \\
- \\
3 \\
21 \\
83 \\
116 \\
37 \\
- \\
-\end{array}$ & $\begin{array}{c}- \\
- \\
- \\
5 \\
5 \\
3 \\
3 \\
- \\
- \\
-\end{array}$ & $\begin{array}{r}- \\
3 \\
3 \\
29 \\
60 \\
45 \\
9 \\
-\end{array}$ & $\begin{array}{c}- \\
- \\
- \\
- \\
3 \\
7 \\
3 \\
= \\
-\end{array}$ & $\begin{array}{r}- \\
- \\
- \\
2 \\
1 \\
4 \\
10 \\
20 \\
3 \\
1\end{array}$ & $\begin{array}{r}- \\
\overline{-} \\
\overline{1} \\
4 \\
10 \\
9 \\
= \\
=\end{array}$ & $\begin{array}{r}- \\
- \\
6 \\
4 \\
19 \\
8 \\
- \\
-\end{array}$ & $\begin{array}{c}- \\
\overline{-} \\
2 \\
2 \\
1 \\
\frac{1}{1} \\
-\end{array}$ & $\begin{array}{r}- \\
- \\
- \\
-3 \\
15 \\
21 \\
1 \\
-\end{array}$ & $\begin{array}{l}- \\
= \\
= \\
= \\
- \\
3 \\
5 \\
- \\
-\end{array}$ & $\begin{array}{l}- \\
- \\
- \\
2 \\
-10 \\
6 \\
1 \\
-\end{array}$ & $\begin{array}{l}- \\
= \\
= \\
- \\
- \\
3 \\
4 \\
1 \\
-\end{array}$ & $\begin{array}{l}= \\
= \\
- \\
1 \\
-1 \\
1 \\
2 \\
-\end{array}$ & $\begin{array}{l}\overline{-} \\
= \\
\overline{-} \\
\frac{2}{2} \\
\overline{2} \\
-\end{array}$ & $\begin{array}{l}= \\
= \\
= \\
= \\
= \\
-1\end{array}$ & $\begin{array}{l}\overline{-} \\
\overline{-} \\
\overline{-} \\
1 \\
\overline{1} \\
\overline{1} \\
-\end{array}$ & $\begin{array}{r}17 \\
16 \\
15 \\
14 \\
13 \\
12 \\
11 \\
10 \\
9 \\
8\end{array}$ & \\
\hline $\begin{array}{l}\overline{-} \\
\overline{1} \\
1 \\
- \\
\overline{-} \\
-\end{array}$ & $\begin{array}{l}\overline{1} \\
2 \\
3 \\
3 \\
- \\
- \\
-\end{array}$ & $\begin{array}{c}- \\
4 \\
9 \\
3 \\
4 \\
1 \\
-\end{array}$ & $\begin{array}{l}- \\
- \\
\overline{4} \\
8 \\
- \\
- \\
-\end{array}$ & $\begin{array}{l}- \\
\overline{-} \\
- \\
- \\
1 \\
1 \\
-\end{array}$ & $\begin{array}{l}- \\
\overline{-} \\
-\end{array}$ & $\begin{array}{l}- \\
- \\
- \\
-1 \\
1 \\
1 \\
2 \\
-\end{array}$ & $\begin{array}{l}- \\
= \\
\overline{5} \\
3 \\
= \\
-\end{array}$ & $\begin{array}{l}= \\
= \\
= \\
= \\
=\end{array}$ & $\begin{array}{l}\bar{z} \\
\bar{z} \\
\overline{-} \\
=\end{array}$ & $\begin{array}{l}- \\
= \\
- \\
- \\
- \\
-\end{array}$ & $\begin{array}{l}= \\
= \\
= \\
= \\
=\end{array}$ & $\begin{array}{l}\bar{E} \\
= \\
- \\
- \\
\overline{-} \\
\overline{1}\end{array}$ & $\begin{array}{l}- \\
- \\
- \\
- \\
- \\
- \\
1 \\
2\end{array}$ & $\begin{array}{l}\bar{z} \\
\bar{z} \\
\bar{z} \\
\bar{z} \\
=\end{array}$ & $\begin{array}{l}\bar{z} \\
= \\
= \\
= \\
= \\
=\end{array}$ & $\begin{array}{l}= \\
= \\
= \\
- \\
-4 \\
1 \\
1\end{array}$ & $\begin{array}{l}\overline{-} \\
\overline{-} \\
- \\
- \\
5 \\
1 \\
-\end{array}$ & $\begin{array}{r}17 \\
16 \\
15 \\
14 \\
13 \\
12 \\
11 \\
10 \\
9\end{array}$ & \\
\hline
\end{tabular}





\title{
BEITRÄGE ZUR MEERESKUNDE.
}

II.

\author{
Beobachtungen von Wärme, Salzgehalt
}

und

\section{spezifischem Gewicht des Meerwassers westindischer Gewässer.}

\author{
(Mit 4 Tafeln, 3 Abbildungen und einem Journalauszug).
}

Die Verwertung der in $"$ Rand-und Binnemmecren "s: angestellten Beobachtungen kann auf dieselbe WVeise wie der für den offenen Ozean gesammelten, - wohl nur dann geschehen, wenn sie als ein Teil der letzteren, mit ihnen, gewissermaßen zu ihnen gehörig betrachtet und veröffentlicht werden; sobald man Beobachtungen in Rand- und Binnenmeeren allein verwendet, sind, sowohl der Anzahl als der Oertlichkeit entsprechend verschiedene Zusammenstellungen vorzunehmen, - welcher Art: dürfte in den meisten Fällen erst bei den Arbeiten selbst sich bestimmen lassen. Eh' den reichhaltigen Stoff für die Nordsee ich zusammenfaßte, schien es mir angebracht, an weniger zahlreichen Beobachtungen gewissermaßen zu üben; ich wählte die westindischen Gewässer oder den Raum zwischen $8^{1} 2^{0}$ bis $30^{\prime \prime} \mathrm{N}-13 \mathrm{r}$. $60^{0}$ bis $98^{0} \mathrm{~W}$; in der Hauptsache mich beschränkend auf Wärme, Salzgelialt und spezifisches Gezvicht des Meerwassers: nach den, mir leicht zugänglichen Einzelbeobachtungen.

Ueber die Wärme des Mecruasse'rs besitzen meteorologische Anstalten reichhaltige Angaben, die jedoch, soweit mir bekannt, in einer Sonderarbeit noch nicht vereint sind; das britische Institut hat nicht wenige des spez. Gew., indes ist das benutzte Instrument zu klein für genaue, -- auch ist nicht ersichtlich, die Wasserwärme während der Messung (Temperatur im Glase); ferner mag diese meistens geschehen sein, wenn das Aräometer (Hydrometer) im Schöpfeimer sich befand, was nur sehr unsichere Ablesung gestattet; für Salzgchalt und spez. Gerw. hoffe ich, mehr Stoff zu bieten, als sonst erreichbar wäre. -- Das spez. Gcre. (4 St.) gilt für die Wärme des mit dem Schöpfeimer aufgeholten

*) Von Hr. Prof. Dr. K'rümmel, Kiel, eingeführte Bezcichnungen.
Wassers (für die der Meeresoberfläche, wenn die des frischen Wassers bei $+4^{0} \mathrm{C}=1,000 \ldots$. ist).

Von Beobachtungen der genannten drei Eigenschaften des Meerwassers jener Gegend waren folgende mir zugänglich:

V.J. I873. März I2-I5, 25-3I. April I, 2. I. B. M. S. Challenger (Kommdt. Cpt. [Sir] George Nares) Beobachter: 1. Navigations-Offizier Ober-Ltnt. $\mathrm{Hr}$. Thomas H. Tizard und 2. Navigations-Offizier Ltnt. Hr. Arthur Havergal; spez. Gew. einmal, Temperatur u. m. zwölfmal täglich, Wasserwärme zuletzt stündlich; alle Beobachtungen letzterer fanden leider nicht Platz in der Skizze; Tenerifa-St. Thomas - Bermudas. In dem großen Challenger Werk (Reports; Physics and Chemistry Vol. I London I 883 ) sind nur veröffentlicht die Beobachtungen des spez. Gew. mit der Wasserwärme Z. Z. der Tiefseelotungen sowie Mittags; das Meteorological-Office in London sandte mir gütigst und in überraschend kurzer Zeit, auf mein Ersuchen, Abschrift des während jener Tage geführten meteorologischen Journals. - 1875 Mai Io. 1876 Mai 10 - I2, I5 - I8. I877 Fanuar 25, 28, 30; April 15; Mai 10, 17, 20, 24; Funi 2, 10. $\quad 1878$ Mai I I, 12, 22, 23, 30, 31. 1879 März 21, 23, 24, 30, 31; April 27; Mai II. 1880 Februar II, I5, 22; April 30; Mai I 4, 29, 30; Funi. U. S. N. A. C. G. S. S. Blake. Beobachter Commdrs. Hrr. Sigsbec, Bartlett und Offiziere. Golf von Mexico, Karaibische See, Florida-Straße, Atlantic; entnommen aus: Alexander Agassiz: Three Cruizes of the United States (Nd. Amer.) Coast-and Geodetic Survey Steamer Blake. London I 888 und Annalen der Hydrograplice 1882. - 1884. Dezember 25-29. I885. Fanuar 2-5, I I, I 5, 29, 30. D. D. 
Holsatia (H. A. L. Kpt. Böcke). Bcoliachter nicht genannt; diese Beobachtungen sind unregelmäßig; auf Strecken fehlt Wasserwärme. März 13-17, 20--22; April I-5, 10-12, I7, I8; Havre-Port au Prince-Colon-Puerto Cabello-La GuayraNayaguez, St. Thomas-Hâvre. Funi II-I4, Fuli 20, 2I; Hâvre-Hayti, St. Thomas-Hàvre. D. D. Holsatia (H. A. L. Kpt. Böcke); Beobachter $\mathrm{Hr}$. Paschen; wenn Gelegenhcit war, vierstündliche Beobachtungen, vereinzelt fehlt Wasserwärme. November 12-30; Dezember; in westindischen Gewässern. S. Kön. Kais. Östr. Ung. M. S. Zrinyi (Kommdt. Fregattenkapitän Hr. Vincenz Edler v. Rosenzwcig). Beobachter: Kön. Kais. Linienschiffsltnt. [jetzt Fregatten-Kapitän Hr. Adolf Sobiecaky, mit Hilfe der Seekadetten: Hrr. Erwin Raisp v. Caliga, A. Willanick, Welschan, Graubner, Moncilovic und Nital; vierstündliche Beobachtungen (I, 5, 9, I, 5, $\left.9^{\text {h}}\right)$; sts. Kön. Kais. Östr. Ung. Hydro. graphischen Antes in Pola giitigst und umgehend auf mein Ersuchen mir mitgeteilt, spez. Gew. nicht beobachtet. November 25, 26. Hàvre-St. Thomas. D. D. Holsatia (H. A. L. Kpt. Bücke) Beobachter Hr. Lassen, vierstündliche Beobachtungen. I886. Famuar und Fcbruar; in westindischen Gewässern. S. Kön. Kais. Öster. Ung. M. S. Zrinyi; wie vorhin. Februar I-4. Santos-New-York. D. D. Paranagua (H. S. A. D. G. Kpt. Belumann). Beobachter Hr. Nieschulz; vierstündlich; regelmäßig und eingehend; Mai 9, 10. Funi I 5, 16. Hàvre-St. Thomas, St. Thomas-Hâvre. D. D. Holsatia. (H. A. L. Kpt. Böcke). Beobachter Hr. Mïller; vierstiindlich; Temperatur im Glase nicht angegeben. I887. Funi i 8.-25. Hâvre-Vera Cruz. Fuli 4, 5. Tampico-Pro. greso; Fuli 8-Io. Progreso-Hayti. Fuli 24. St. Thomas-Havre. September 9. HamburgSt. Thomas. D. D. Hungaria (H. A. L. Kpt. Leithäuser). Beobachter Hrr. Beck und Heydorn; meistens zwischen $8^{\mathrm{h}}$ mgs, und $\mathrm{S}^{\mathrm{h}}$ abds. 1902. April 23-Mai 26 an 19 Tagen 24 Beobachtungen auf der Fahrt ron Hâve - St. Thomas - Haiti-Hamburg. D. D. Croatia (H. A. L. Kpt. Brunswigig). Beobachter Hr. Dr. G. Schott; entnommen aus Annalin der Hydrograplic XXX. 1902. H. IX. S. 43 I - 432. Die Schiffs-Inspelition des Sicherheitsdienstes der Hamburg-Amerika Linie Hrr. Kpt. Serveloh, i. V. Kpt. Rüidiger und Witt. hatte die Guite, zur Ergänzung das Schiffsjournal auf mein Ersuchen mir zu leihen bzw. durch $\mathrm{Hr}$. Madsen bereitwilligst mir leihen zu lassen.

Die Betrachtung der Wärme der Wasser-Oberfläche sollte verbunden sein mit der der Luftwärme; dies ist im vorliegenden Falle nur teilweise möglich, wcil für letztere nur von Challenger, Zriilyi und Paranagua brauchbare Beobachtungen vorhanden sind; Holsatia erhielt von mir nicht nur gute Thermometer sondern auch cin weiss angestrichenes Thermometer-Häuschen, ganz aus Jalousien, olme Boden, dic beiden Thermometer und das keine Wassergefass nur in Messingdrat hängend, jene $10 \mathrm{~cm}$. von einander und vom nachsten Holzwerk befestigt; als das Schiff zuriickkam fand ich die vordere Seite des Häuschens mit dunnem Brettchen verschlossen, dic Thermometer rom Zimmermann in Ilolzfitssung ge- bracht und an jene Brettchen genagelt; "So sind wir es gewöhnt. "Dasselbe wiederholte sich die folgende Reise. - Im Beobachtungsheft (wie in manchem anderen) durchstrich ich also diese Beobachtungen und schrieb vorn: Lufttemperatur durchaus unbrauchbar; später nahm ich die Thermometer nebst Häuschen zurick.

Zur Beobachtung der Wasserwärme erhielten Holsatia, Hunsaria und Paranagua von der Kommission zur. Untersuchung der deutsiluen Mecre auf mein Ersuchen und durch mich Thermometer in Kpt. Krabbo's Fassung, die ich schon mehrfach erwähnte. 3 dünne quadratische Messingbleche (das untere 5-6 cm. Seite; die Seite des nächsten $\mathrm{I} 1 / 2-2 \mathrm{~mm}$, die des oberen $3-4 \mathrm{~mm}$ kïrzer als die des untersten) sind an ihren Ecken durchbohrt,

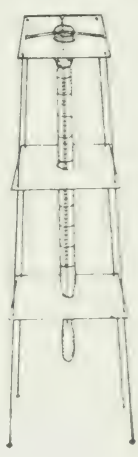
um 4 Messingstäbe aufzunehmen von ugf. $2-2^{1 / 2} \mathrm{~mm}$. Dicke und $3-4 \mathrm{~cm}$. länger als das Thermometer. Diese Stäbe werden an das obere Blech geschraubt oder an dasselbe genietet; die beiden anderen sind an ihnen verschiebbar; die drei Bleche sind auch in der Mitte durchbohrt, das unterste nur soviel, um die Kugel oder den Sack des Thermometers durchizulassen, die beiden oberen der Stärke des Thermometer-Körpers entsprechend. Das unterste Blech wird so eingestellt, daß wenn das Thermometer gebrauchsfertig ist, sein unteres Ende ugf. $2 \mathrm{~cm}$. über dem unteren Ende der Messingstangen, das obere ugf. I $\mathrm{cm}$. unter dem obersten Blech ist, das mittlere Blech stellt man ugf. auf die Mitte, so daß es die Ablesung nicht hindert; sobald das Thermometer in diese Fassung geschoben ist, führt man in die Öfinung des oberen Blechs einen sie verschließenden, bis auf das Thermometer reichenden Kork-Pfropfen ein, der dieses fest auf das unterste Blech drückt, sollte letzteres Neigung zum Verschieben haben, so wird es leicht festgebunden, ebenso wird der Kork-Pfropfen durch über ihn und um das oberste Blech gefuihrtes Garn gehindert, sich zu lockern oder herauszufallen. In dieser Fassung erhält das Thermometer die Wärme des Wassers viel rascher als in anderen aus Blech und in der gewöhnlichen Holzfassung; es ist auch sehr leicht die Kugel oder den Sack rein zu halten; wenn die Schiffe hier waren und ich es möglich machen konnte, sah ich die Thermometer nach und wenn ich den geringsten Salzansatz bemerkte, schabte ich ihn ab, dann noch die Kugel oder den Sack mit warmem WVasser vkfls. durch Bürsten reinigend; zerbrochen ist in dieser Fassung ein Thermometer sehr selten. Neben autiallige Angaben setzte ich in den Skizzen cin Ausrufungszeichen.

Es war nicht möglich, für jeden Monat eine besondere Tafel zu zeichnen, dadurch sind die vorliegenden Skizzen stellenweise sehr geniillt, sodals die nur an fluichtige Übersicht Gewöhnten, den Einzelheiten ungewohnte Aufmerksamkeit widmen müssen; wenn auch Arbeiten wie die vorliegende streng genommen nur sein können, der Anfang zu eingehenderen für das betrefiende Gebiet, so ist doch bei ihnen gröliere Aufmerksamkeit stets unvermeidlich; ich hoffe, dals es nicht zu grobe Mühe kostet den hier gegebenen Einzelheiten z.u folgen. 


\section{'Tafel I. Wärme des Meerwassers.}

Januar. Für den Golf von Mexico liegen nur vor 4 Beobachtungen aus dem Jahre 1877. I. 25, 28 und 30 angestellt an Bord des U. S. N. A. S. Blake bei $95^{\circ} \mathrm{W}$. zwischen $26^{\circ}$ und $28^{\circ} \mathrm{N}$-Br.; sie gehören zu 13 Tiefsee-Lotungen verbunden mit Reihen-Messung der Wärme des Meerwassers. Diese sind ausgeführt zwischen der Küste Mexico's sudlich von Vera Cruz bis Galveston I., - leider nicht eine nach der anderen, sondern I877 Januar 25, 28, 30, April I5, Mai IO, 17,20 und 24, Juni 2 und Io. - Bei $95^{\circ} \mathrm{W}$. zwischen $26^{\circ}$ und $27^{\circ} \mathrm{N}-\mathrm{Br}$. betrug 1877 Ende Januar die Wasserwärme $21,1^{\circ}$ und $20,0^{\circ}$, bei $28^{\circ} \mathrm{N}$. nur $19,7^{\circ}$, wegen Mangel der Angabe der Tageszeit, Luftwärme und Salzgehalt ist jede Vermutung ausgeschlossen, ob diese oder Unterschied der geogr. Breite Einfluß hatten. - Weiter ostwärts sind hier zur Benutzung Beobachtungen zwischen K. S. Antonio und Havana von S. O. U. M. S. Zrinyi I 886 I, 23-25; die Wasserwärme schwankte zwischen $26,0^{\circ}$ und $24,8^{\circ}$ wobei Einfluß der Tageszeit und Luftwärme unverkennbar. (Nebenbei bemerkt war das Wasser an der Oberfläche des Hafens von Havana erheblich kälter; vom 25. Januar bis 10. Februar etwas an Wärme abnehmend, im allgemeinen sich haltend zwischen $23^{1 / z^{0}}$ und $2 \mathrm{I}^{1} / 4^{0}$ vereinzelt reichen die höchsten und niedrigsten Angaben bis $24,4^{\circ}$ und $\mathrm{I} 8,6^{\circ}$ wobei Tageszeit und Luftwärme ihren Einfluß zeigen. Das Wasser ist fast stets wärmer als die Luft, der Unterschied mgs. und abds. natürlich am bedeutendsten, bis $61 / 2^{0}$ betragend vereinzelt $-0,5^{0}$; größte Luftwärme $23,7^{\circ}$ geringste $14,9^{\circ}$.) - Im östlichen Teil des alten $\mathrm{Bahama-Kanal}$ giebt Commdr. Bartlett Januar I880 die Wasserwärme zu $24,4^{\circ}$. - Südlich von Cuba, zwischen K. San Antonio-Kingston, JamaicaPort au Prince, Haït, I886 23-I8, Io-S. Januar, liegen ebenfalls vor Beobachtungen von Zrinyi. Der Einfluß von Tageszeit und Luftwärme ist unverkennbar, ebenso der Unterschied in geogr. Breite. Zwischen K. S. Antonio und $20^{\circ} 26^{\prime}$ N. $8 I^{\circ} 22^{\prime} \mathrm{WV}$. schwankt die Wasserwärme zwischen $25,3^{\circ}$ und $25,6^{\circ}$ (I 23--2I Luft $23,1-27,1^{\circ}$ ), zwischen $20^{\circ} 20^{\prime} \mathrm{N}$. $81^{0} 8^{\prime} \mathrm{W}$. und $18^{0} 23^{\prime} \mathrm{N} .79^{\circ} 5^{\prime} \mathrm{WV} .26,0-26,6^{\circ}$ (I $2 \mathrm{I}-\mathrm{I} 9$; L $\left.23,5-25,3^{\circ}\right)$; zwischen $18^{\circ} 23^{\prime} \mathrm{N} .79^{\circ} 5^{\prime} \mathrm{W}$. und dem nächstvorhergehenden $18^{\circ} \mathrm{I} 2^{\prime} \mathrm{N} .78^{\circ} 5 \mathrm{O}^{\prime} \mathrm{W}$. ist ein größerer Unterschied als durch den der Luftwärme bedingt mir scheint $(25,2$ gegen 28,1$): 26,4$ gegen 27,6 ; dicht vor Kingston in $17^{\circ} 53^{\prime} \mathrm{N} .76^{\circ} 52^{\prime} \mathrm{W}$. war dic Wasserwärme $26,4^{\circ}$, dann in $17^{\circ} 35^{\prime} \mathrm{N} .77^{\circ} \mathrm{I} 2^{\prime} \mathrm{W}$. $27,0^{\circ}$ (L26,0 und $28,9^{\circ}$ ), blieb dann bis zur obengenannten Stelle zwischen 26,8 und $27,6^{\circ}\left(\mathrm{L} 28,9-25,1^{\circ}\right)$. - Zwischen Kingston und Caymas, genauer $17^{0} 49^{\prime}$ N. $76^{\circ} 20^{\prime} \mathrm{W}$. - $18^{\circ} 48^{\prime} \mathrm{N} .73^{\circ} 46^{\prime} \mathrm{W}$. beobachtete man $27,6^{\circ}$ $-27,0^{\circ}\left(\mathrm{L} 27,7^{\circ}-24,7^{\circ}\right)$ bis dort von $18^{\circ} 38^{\prime} \mathrm{N} .72^{\circ} 43^{\prime} \mathrm{W}$. $28,1^{\circ}-27,6^{\circ}$ (L $\left.29,3^{\circ}-24,9^{\circ}\right)$. In dem Hafen von Jamaica betrug die Wärme der Wasseroberfläche $25,6^{\circ}-27,3^{\circ}$, mit Ausnahme von nchmttgs. $I^{h}$, ein paarmal auch nachmittags $5^{\text {h }}$ stets mehr als die der Luft

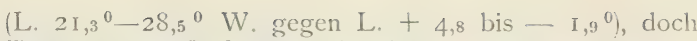
Tageszeit und Luftwärme die des Wassers beeinflußend. Im Hafen von Port au Prince I I- 8 beobachtete man die Wasserwärme $26,4^{0}-27,8^{0} ;$ P. I ${ }^{\text {h }}$ stets, p. $5^{\text {h }}$ fast immer geringer zu anderen Zeiten größer als die der Luft $\left(\mathrm{L} .2 \mathrm{I}, 2^{\circ}-3 \mathrm{I}, 2^{0}\right.$. IV. gegen L. $+6,3^{\circ}$ bis $\left.-3,5^{\circ}\right)$. - Im Windward-Pa $\beta$ fand Commdr. Bartlett I880 Januar nur $24,4^{\circ}$; also erheblich $\left(3^{\circ}\right)$ weniger als 6 Jahre später $1^{1 / 4^{0}}$ geogr. Breite südlicher gemessen ist; was hiervon über weite Strecken, anhaltend stürmisch wehendem Passat man zuzuschreiben hat, kann nur entschieden werden durch eingehende Vergleiche: falls genügend Stoff für sie vorhanden ist. - Aus der Karaibischen See liegen für diesen Monat jetzt mir nur vor 7 Beobachtungen, die angestellt sind im südlichsten Teil zwischen Savanilla Pünte und mittwegs nach Colon I885 I. 4 und 5 sowie II auf D. D. Holsatia; sie zeigten damals dic Wasserwärme $25^{\circ}-25,6^{\circ}$, dies ist auffallend gering, gegen die Beobachtungen von I 880 und I 886 im nördlichen Teil. Am 29. und 30. I. I88; lieferte dasselbe Schiff auf dem Wege St. Thomas-Hâvre zwischen $19^{\circ} 45^{\prime} \mathrm{N} .64^{\circ} 2^{\prime} \mathrm{IV}$. und $23^{\circ} 6^{\prime} \mathrm{N} .60^{\circ} 29^{\prime} \mathrm{W} .5$ Beobachtungen die liegen zwischen $24,5^{\circ}$ und $23,5^{\circ} \mathrm{C}$. Die Farbe des Mecres ist nur angegeben nahe der Küste des südlichen Festlandes: bei $10,9^{0}$ N. $67,8^{0}$ W. G. schwarzblau; zwischen den Monks In. und Gallinas Pünte $\left(12,4^{0} \mathrm{~N} .7 \mathrm{I}, 2^{0} \mathrm{WV}\right.$.) blau, ugf. $23 \mathrm{Sm}$. NNE. von Savanilla Pünte $\left(\right.$ I $1,4^{\circ}$ N. $74,9^{\circ}$ IV.) dunkelblau, weiter auf dem WVege nach Colon ugf. quer von Galera de Zamba $\left(\operatorname{II}, 1^{\circ}\right.$ N. $75,0^{\circ} \mathrm{WV}$.) griinblau; ugf: quer von Cartagena Bay oder Rosario I. (II, $0^{\circ}$ N. $75,9^{\circ} \mathrm{W}$.) dunkelblau ebenso bei $10,5^{\circ} \mathrm{N}$. $76,9^{\circ} \mathrm{W}$. - Auf der Heimreise ist im vorliegenden Gebiet bei $22,2^{0} \mathrm{~N}$. $6 \mathrm{I}, 4^{0} \mathrm{~W}$. auch dunkelblau mitgeteilt. - Es ist bekannt, daf3 die schembare Farbe des Wassers abluängt von Bewölkung, Klarheit der Luft, über dem WVasser schwebendem Dunst und Staubteilen, im Wasser schwimmenden oder aufgelösten tierischen und Pflanzen-Stoffen, Wassertiefe, Beschaffenheit des Mecresgrundes. Die erwähnten Stoffe gelangen nicht selten in bald größeren, bald kleineren Mengen bis in erhebliche Entfernung vom Herkunftsort.

Februar. Für diesen Monat besitze ich nur Beobachtungen: I886. S. Ö. U. M. S. Zrinyi II. IO.-I3. von Havana nach Nassau im Providence Kanal, von dort II $15-26$, nach $29^{\circ} \mathrm{N} .75^{\circ} \mathrm{IV}$. und $30^{1 / 2} 2^{\prime \prime} \mathrm{N}$. $64^{\circ} \mathrm{IV}$; in ugf. $30^{\circ} \mathrm{N} .69^{\circ} \mathrm{W}$, schneidet dieser $\mathrm{Weg}$ den des D. D. Paranagua II 4, welches Schiff von Santos nach New York am I. dslb. Js. bei $23^{\prime \prime} \mathrm{N}$. $60^{\circ} \mathrm{IV}$. in das vorliegende Gebiet gelangte; außerdem I8S0 2 Tiefsee-Reihenmessungen des U. S. N. A. S. Blake; cine im IV indward Pass von Guanos P'ünte, (uba, nach lortugas I. bei Ilä̈t, Il I I und 15; eine II 22 von $\mathrm{San} J$ ago, Cuba uber Formigas Bank nach Morant Pünte, Jamaical. - Zrinyis Fahrt Havana-Nassau hat zwei Teile, Havana durch Florida Straße - West-Eingang der Südseite des Providence Kanals, von hier bis Nassau; auf beiden ist das Wasser stets wärmer als die Luft, Linfluß der Tageszeit jedoch bemerkbar; auf dem ersten Teil d. i. von $23^{\circ}$ I $^{\prime} \mathrm{N} .82^{0}$ I $5^{\prime} \mathrm{W}$. $-25^{\circ} 33^{\prime} \mathrm{N} \cdot 79^{0} 37^{\prime} \mathrm{W}$ 
bleibt die Wasserwärme trotz Änderung geogr. Breite um $2,6^{\circ}$ zwwischen $24,4^{\circ}$ und $25,1^{\circ} \mathrm{C}$. da letztere höchste Mittagswärme ist, so kann man auch sagen zwischen

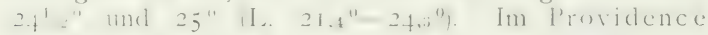
Kanal sind Luft und Wasser kälter, trotz Einfluß der Tageszeit (L. a. $9^{\mathrm{h}} 2 \mathrm{I}, 9^{0}$ p. $\mathrm{I}^{\mathrm{h}} 24,2^{0}$ ) ist das Wasser am I2. p. $I^{\mathrm{h}}: 0,1^{0}$ kälter als a $9^{\mathrm{h}}: 24,4^{0}$ gegen $24,5^{0}$, crstere in $26^{\circ} 6^{\prime} \mathrm{N} .79^{\circ} 6^{\prime} \mathrm{W}$. Die nächste Nessung in $26^{\circ} 7^{\prime} \mathrm{N} .78^{0} 42^{\prime} \mathrm{W}$. ist nur $23,2^{0}$; der Unterschied von $\mathrm{I}_{2}{ }^{0}$ ist kaum dem der Luftwärme allein zuzuschreiben, $\left(24,2^{\circ}\right.$ und $\left.2 \mathrm{I}, 7^{\circ}\right)$ auch bleiben von den nächsten $5 \mathrm{An}$ gaben 4 unter $23^{\circ}$; die geringste ist $22,3^{\circ}$; eine, quer von der Nordspitze der Berry In. zeigte am I 3. a. I ${ }^{\text {h }}$ auffallend warmes Wasser $=24,9^{\circ} \mathrm{C}$. trotz Abnahme der Luftwärme um ${\mathrm{I}, 4^{0}}^{0}\left(2 \mathrm{I}, 5^{\circ}\right.$ und $\left.20,1^{\circ}\right)$ eine Zunahme von $2,7^{0}$. - Während des zweitägigen Aufenthalts war das Wasser an der Oberfläche des Hafens von Nassau stets wärmer als die Luft. (L. $18,8^{0}-22,5^{\circ}$, W. 22,4 $4^{0}-23,0^{\circ}$ ) - Die beiden (nachmittags) Beobachtungen im NElichen Teil des Providence Kanals zeigen II I5 größere Wasser- und Luftwärme als man im allgemeinen im NWlichen Teil fand: W. $24,2^{0}$ und $24,0^{\circ}$, I. $24,5^{\prime \prime}$ und $23,2^{\circ}$. Von $26,1^{\circ}$ N. $76,9^{\circ} \mathrm{W}$. erreicht die Wasserwärme nicht mehr $24^{\circ} \mathrm{C}$; bis II I9 bei $29^{\circ} 5^{\prime} \mathrm{N} .76^{0} \mathrm{II}^{\prime} \mathrm{W}$. schwankt sic zwischen $22,0^{\circ}-23,6^{\circ}$. (L. $20,3^{0}-24,7^{\circ}$ ); nicht verkennen lassend, daß das Schiff nahe der Grenze der Warmwasserströmung sich befand; bis II 26 abds. bei $30^{0} 43^{\prime} \mathrm{N}$. $64^{0} 23^{\prime} \mathrm{W}$. sind Wasser und Luft wieder kälter, ersteres zeigt nur viermal $2 \mathrm{I}, \mathrm{t}^{0}-2 \mathrm{I}^{0} \mathrm{C}$. Sonst zwischen $19,2^{0}-20,6^{0}$ (L. $\left.13,5^{0}-2 \mathrm{I}, 3^{0}\right)$; die geringste Wärme L. $13,5^{\circ} \mathrm{W} .19,2^{\circ}$ beobachtete man II $2 \mathrm{I}$. a. $5^{\mathrm{h}}$ bei $29^{\circ} 27^{\prime}$ N. $71^{0} 6^{\prime}$ W. nach IVind NNW 8 bei NNW 5. D. D. Paranagua befand sich I 886 II I p. $4^{\text {h }}$ bei $23,1^{0} \mathrm{~N}$. 59,9 $\mathrm{W}$., dort beobachtete man $23,8^{\circ} \mathrm{C}$; (L. $26,7^{\circ}$ ) bei abnehmender Luftwärme, ergaben bis $23,8^{\circ}$ N. $60,9^{\circ}$ W. die beiden nächsten Wassermessungen $26,0^{\circ}-26,2^{\circ} \mathrm{C}$; $\left(\mathrm{L} \cdot 24,6^{0}-24,3^{\circ} \mathrm{C}\right.$.), dies ist auffällig, da selbst vor Havana I 25 nur $25^{1} \%^{\circ} \mathrm{C}$. beobachtet war. Ausnahmefälle nach mehr sowohl als nach weniger findet man wahrscheinlich in allen Gegenden, der Zusammensteller hat jedoch auf sie aufmerksam zu machen. Bei den weiteren Angaben des NWwärts fahrenden Schiffes erkennt man deutlich die Abnahme der Wasscrwärme bei Zunahme der geogr. Breite; II 4 M. $29^{0} \quad 5^{\prime} \mathrm{N} .68^{0} 30^{\prime} \mathrm{W}$. beträgt jene nur noch $20,5^{0}$, doch ist ersichtlich, daß von hier an, die bei Wlichen Winden erheblich kälter werdende Luft auch Einfluß hat auf die Wasserwärme, bis das Schiff tatsächlich in den kalten Küstenstrom gelangt. Auf der hier in Betracht kommenden Strecke $23,1^{\circ} \mathrm{N}$. 59,9 $\mathrm{W}$. bis $29^{\circ} 58^{\prime} \mathrm{N}$. $68^{\prime \prime} 30^{\prime} \mathrm{W}$. ist das Wasser gröl3tenteils wärmer als dic Luft (jene beiden Ausnahmestellen und eine Mittagsbeobachtung $=24,0^{\circ}$ weglassend IV. 23,9" bis $20,5^{\circ}$ L. $24,6^{\circ}-20,3^{\circ}$ ). In der Gegend, bei der die Wege von Zrinyi und Paranagua sich kreuzen beobachtete:

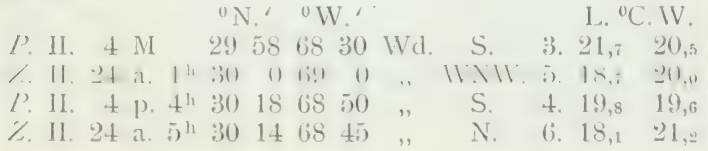

wobei zu beachten, daß letzterer Ort von Zrinj'i einer der 4 oben erwähnten ist, an denen nach Verlassen von $29^{\circ} \mathrm{N}$. die Wasserwärme $2 \mathrm{I}^{0}$ und mehr betrug. - Weiter südlich quer über den nördlichen Teil des WVindward Paß beobachtete I 880 II II und I 5 U. S. N. A. S. Blake an 9 Stellen zwischen Guanos Pünte, Cuba und Tortuga I., da Tageszeit und Luftwärme nicht angegeben, so ist fraglich, ob diese Einflul3 hatten und wie groß er war; II I I die geringste Wärme $24,4^{\circ}$ ist angegeben in $1 / 4$ der Entfernung von der $\mathrm{Cuba}$ Küste, die größte $27,2^{0}$ in $1 / 3$ der Entfernung von derselben, in ugf. $1 / 8$ war sie $25,0^{\circ} \mathrm{C}$; ; die erste Messung war verbunden mit einer Tiefseelotung bis 1000 Faden $=$ ugf. I\$oo Meter bei der die Wasserwärme einschließlich der Oberfläche senkrecht an I5 Stellen man maaß; falls man damit mgs. begann, kann die zweite Angabe sehr wohl stammen aus der heißesten Zeit, die dritte nach einiger Abkühlung. Die Verhältniße weiter ostwärts liegen ähnlich; II I 5 ugf. mittwegs nahm man wieder eine Tiefseelotung bei 800 Faden - ugf. 1450 Meter mit Reihe von I3 Wärmemessungen, dabei Oberflächc $=25,4^{0} ;$ ugf. $1 / 10$ der ganzen Strecke westlicher sind angegeben $25,8^{\circ}$, ebensoviel östlicher $25,3^{\circ}$; von hier bis ugf. $1 / 10$ von Tortuga entfernt nimmt die Oberflächenwärme wieder zu bis $26,4^{0}$; ob $25,5^{\circ}$ am II . oder 15 . man beobachtete, ist nicht ersichtlich; so wie die Sache liegt, kann man nur sagen, es ist nicht unmöglich, daß damals die Meeresoberfläche an der Haïti Seite etwas wärmer war als an der $\mathrm{Cuba}$ Seite, ferner zwei kalte Stellen vorhanden waren, die kälteste in 1/s, die nächstkalte $1 / 2$ der Entfernung von $\mathrm{Cuba}$, dagegen eine sehr warme in $1 / 3$ derselben. - Wie erwähnt vollführte dasselbe Schiff I880 II 22 eine Reihe von I4 Tiefseelotungen zwischen San Ja go, Cuba-F'ormigas Bk. - Morant l't., Jamaica; bei 12 von ihnen mas man die Wärme an der Oberfläche und am Grunde, hiervon bei einer eine senkrechte Reihe mit im Ganzen 9 Beobachtungsstellen. An letzterer, - die liegt etwas näher an Formigas Bk. als an Cuba, - ist angegeben die geringste Oberflächenwärme $24, \mathrm{~s}^{\prime \prime}$; sowohl nach Cuba als nach Jamaica zu, sind Angaben von größerer Wärme bis $25,6^{\circ}$, an der $\mathrm{Cuba}$ Seite beginnt diese erst in $1 / 1$ der Entfernung bis Formigas, während an der Jamaica Seite $25,6^{\circ}$ möglicherweise schon über Formigas Bk. waren, jedenfalls bis $2 / 3$ der Strecke zwischen ihr und Jamaica angegeben sind, nur an einer Stelle durch 25,30 unterbrochen; Einflu13 der Tageszeit kann nicht beurteilt werden. - Masserfarbe:

Iïr\%. In diesem Nonate liegen mir vor Beobachtungen auf 4 Linien im Elichen bzw. SElichen Teil dieses Gebietes, alle angestellt zwischen dem 12. und 31 . 1873 I. B. MI. S. Challenger III $12-\mathrm{I}_{5}$ von $\mathrm{IS}^{\prime \prime} 5^{\prime} \mathrm{C}^{\prime} \mathrm{N}$. $59^{\circ} 36^{\prime} \mathrm{W}$. bis St. Thomas; III $25-3$ I nahe bei $65^{\circ} \mathrm{W}$. von $\mathrm{St}$. Thomas bis ugf. $28,4^{\circ}$ N.; is79 U.S. N.A.S. Blake III 3o, 3 I von Virgin Gorda bis ostwärts Sombrero; III 2I, 23, 24 von St. Vincent über $\mathrm{St}$. Lucia und Martinique bis Dominica; ISS; D. D. Holsatia III I $3-16$ von $26^{\circ} \mathrm{N}$. $60^{\prime \prime} \mathrm{IV}$. durch Turks I. Paß nach Haiti; III $20-22$ von Port au Prince nach Colon - Charllinser näherte sich den Antillen auf geringer Anderung in geogr. Breite; dabei 
ist zunächst auffällig die von I $8,9^{\circ} \mathrm{N}, 59,6^{\circ} \mathrm{W}$. bis I $8,6^{\circ} \mathrm{N}$. $63,8^{\circ} \mathrm{W}$. reichende Zunahme der Wasserwärme von $23,9^{\circ}$ bis $25,0^{\circ}$, von dort bis $\mathrm{St}$. Thomas wieder abnehmend $\mathrm{zu} 24,4^{\circ}$; der Einfluß der Tageszeit ist nur dann kenntlich, wenn abds. oder nachts nicht mehr als $23,9^{\circ}$ beobachtet sind; ferner fällt auf eine warme Gegend bei $18,6^{\circ} \mathrm{N}$. $63^{\circ} \mathrm{W}$. da dort die Angaben von $24,4^{\circ}$ auf $26,1^{\circ}$ steigen; dies ist allerdings von Mittag bis p. $2^{\mathrm{h}}$, - die Luftwärme änderte jedoch nur von $25,0^{\circ}$ zu $25,6^{\circ}$, ich scheue mich also nicht, anzunehmen, daß auch hier eine Ausnahmestelle lag; selbstverständlich finden sich ebenfalls solche mit kälterem Wasser. (Die Luftwärme betrug $\left.23,3^{\circ}-26,1^{\circ}\right)$. I 879 III. 30 erhielt V. S. N. A. S. Blake von Virgin Gorda bis Sombrero 3 Tiefseelotungen mit Wärmemessungen in nicht ganz $1 / 4$, etwas mehr als $1 / 3$ und etwas mehr als $3 / 5$ der Entfernung von $\mathrm{V}$. G. die mittelste war verbunden mit einer Reihe von I4 Messungen der Wasserwärme, hier wieder die geringste an der Oberfläche $26,1^{\circ}$, bei den beiden anderen $26,7^{\circ}$ also erheblich mehr als 6 Jahre früher Challenger; III 3 I erfolgte eine zweite ReiheMessung ugf. $1 / 3$ jencr Entfernung $(20 \mathrm{Sm}$.) ostwärts von Sombrero auf 2558 Faden $=$ ugf. $4600 \mathrm{~m}$. IVassertiefe mit I5 Angaben der Wärme; an der Oberfläche $25,0^{\circ}$ entsprechend der von Challenger in Bezug auf Jahreszeit ugf. $1 / 2$ Monat früher gefundenen von $24,7^{\circ}$ und $25,0^{\circ}$. I 879 im März sind von Blake auch angegeben 3 Beobachtungen von Grand Cayman bis halbwegs nach $\mathrm{K}$. Cruz, Cuba, d. i. ugf. $19^{1 / 2}{ }^{0} \mathrm{~N}$. $80^{1} / 2^{0}-79^{1} / 2^{0} \mathrm{~W}$. oder ugf. I ${ }^{0}$ nördlicher aber $14^{0}$ westlicher, als letzterwähnte; sic lauten $26,7^{\circ}-26,1^{\circ}-25,6^{\circ}$ also ugf. gleich den östlichen. - IIf 2 I geschahen mit demselben Schiff 6 Lotungen mit Wärmemessungen zwischen Tarratce Pt., St. Vincent und K. Moule à Chique, St. Lucia; das wärmste Oberflächenwassc1 war nahe St. V. $27,2^{0}$ auf der größten Tiefe wo man in senkrechter Linie im Ganzen I 5 Wärmemessungen vornahm, von dort bis St. L. $26,7^{\circ}, 26,4^{\circ}, 26,7^{\circ}, 26,1^{\circ}$, $26,9^{\circ}$, letztere auf flachem Wasser. III. 23 von Pt. Hardy, St. Lucia-Salines Pt. Martinique 5 Lotungen bei $26,7^{\circ}-26,4^{\circ}-26,1^{\circ}-25,8^{\circ}-25,8^{\circ}$ Oberflächenwärme, die erste auf geringer Tiefe, die dritte verbunden mit Reihe-Messung von I I Angaben. III 24 von Pt. du Diable, Martinique - Pt. Rosalie, Dominica Io Lotungen, 27,2 ${ }^{\circ}[26,9] \quad 26,7^{\circ} \quad\left[26,9^{\circ}-26,9^{\circ}-27,2^{\circ}-26,7^{\circ}\right]$ $26,7^{\circ}-25,8^{\circ}$ Oberflächenwärme, die in [] stehenden lagen auf flachem IVasser. Die in geogr. Breite $3^{1 / 2} 2^{0}-5^{1 / 2} 2^{0}$ siidlicher liegenden Beobachtungen zeigten also kaum wärmeres Wasser; Einfluß3 der Tageszeit nicht bestimmbar. - 1873 in den letzten 6 Tagen des März steuerte Cluallenger von St. Thomas nahe Nord nach den Bermudas. Bis $2 \mathrm{I}, 8^{\circ} \mathrm{N} .65,2^{\circ} \mathrm{W}$. blieb die IVärme der Meeresoberfäche $24,4^{0}$, nur einmal mittags vor St. Thomas zu $25,0^{\circ}$ zunehmend sonst mgs. bis $1 / 2{ }^{\circ}$ weniger (bis $23,9^{\circ}$ ) abnehmend. (Die Luftwärme hatte ebenfalls wenig geändert, nur $23,3^{\circ}-25,6^{\circ}$ Mindest- und Meistbetrag, jener auffallender Weise auch mttgs. III 27). - Von 21,80 N. 65,2 ${ }^{\circ} \mathrm{W}$. bis $28,5^{\circ} \mathrm{N}$. $65^{\circ} \mathrm{W}$. nehmen Wasser- und Luftwärme schwankend ab; $24,4^{\circ}-2 \mathrm{I}, 1^{\circ}$. Von $25,8^{\circ} \mathrm{N}$. $65,3^{\circ} \mathrm{W}$. geschahen die Wärmemessungen stuindlich; da es vorkam, daß trotz zunchmender und gleicher Luftwärme, mittags etwas kälteres Wasser, auch nachts etwas wärmeres beobachtet wurde, so liegt die Vermutung nahe, daß auch auf dieser Strecke Stellen oder Streifen von in suidlicheren Gegenden erhitztem, in nördlicheren erkältetem Wasser hierher gelangten. (Die Luftwärme schwankte auf diesem Teil des Weges zwischen $25,6^{\circ}-2 \mathrm{I}, 7^{0}$; nach Norden zu abnehmend.) - I 2 Jahre nach Challenger, $7^{0}$ in geogr. Breite nördlicher I885 III I 3 gelangt D. D. Holsatia bei $25,9^{\circ} \mathrm{N}$. $60^{\circ} \mathrm{IV}$. in west indische Gewässer, auf Turks I. Paß zusteuernd; Oberflächenwärme $23^{\circ}$ und $22^{\circ} \mathrm{zu} 25^{\circ}$ zunehmend, mit mit tags bis $26^{\circ} ; 25^{\circ}$ wird auch beobachtet bis III. I6 querab Perle Pt. Vom III $20-22$ IS" $4 \mathrm{O}^{\prime} \mathrm{N} .73^{\circ} 2 \mathrm{O}^{\prime} 1 \mathrm{II}^{\circ}$ bis III $22=10,3^{\circ} \mathrm{N} \cdot 79,3^{\circ} \mathrm{W}$. nimmt die Wärme des Wassers zu bis $26^{\circ}$; mittags größer als zu anderen Zeiten. - Wasserfarbe nur angegeben querab Turks I. = dunkelblau, dann zwischen Caymites und K. Dame Marie = blau.

April. I 873 IV. I, 2 beobachtet Challenger zwischen $28,5^{\circ} \mathrm{N} \cdot 6_{5}{ }^{\circ} \mathrm{W} \cdot-29,8^{\circ} \mathrm{N} \cdot 65,1^{\circ} \mathrm{WV}$. Oberflächenwärme schwankend, von $2{\mathrm{I}, 7^{\circ}}^{\circ}$ zunehmend $\mathrm{zu} 22,2^{\circ}$ und abnehmend zu 20,8 ${ }^{\circ}$ (L. zwischen $\left.2 \mathrm{I}, 7^{\circ}-24,7^{\circ}\right)$ - I 877 IV 15 giebt Blake auf der Lotungsreihe Vera CruzGalveston zwischen ugf. $28,6^{\circ} \mathrm{N} .95,1^{\circ} \mathrm{W},-27,4^{0} \mathrm{~N}$ $94,5^{\circ} \mathrm{W} .3$ Beobachtungen von $19,4^{0}-20,0^{\circ}-2 \mathrm{I}, 7^{\circ}$ Unterschiede die kaum von geogr. Breite allein stammen, bei denen wohl Landabwässerung auch Einfluß zeigt. I880 IV 30 hatte Blake angestellt eine Reihe (I I) Tiefseelotungen zwischen $\mathrm{K}$. Cruz, Cuba und Westende Jamaicas, möglicherwcise kurz vorher oder nachher auch zwischen diesem und Pedro Bk. (7); die Wärme des Oberflächenwassers betrug auf der nördlichen Reihe (7) $26,9^{\circ}-26,4^{\circ}$, auf der südlichen (5) $26,8^{\circ}-26,1^{\circ}$. I879 IV 27 lotete Blake quer über den Mona Paß von Pt. Espada, S. Domingo-Disecheo I.-Jiguero Pt., Portorico (6 und 3); die 4 und I Angabe der Oberflächenwärme sind $26,9^{\circ}-26,7^{\circ}-26,7^{\circ}-26,9^{\circ}, 26,9^{\circ}$ also nahe gleich den im nächsten Jahr 3 Tage später weiter westlich angestellten. - Ungefähr auf derselben geographischen Breite wie dic letzterwähnten beiden Beobachtungsreihen des Blake, liegen 5 auf D. D. Croatia von Hr. Dr. G. Schott I902 IV 24, 27, 30 angestellten die fallen zwischen $19^{0} \sigma^{\prime} \mathrm{N} .63^{0} \mathrm{~S}^{\prime} \mathrm{W}$. $-18^{\circ} 9^{\prime}$ N. $69^{\circ} 45^{\prime}$ W. (nach Schiffsjournal berechnet); die Wasserwärme betrug allmählich zunehmend $25,6^{\circ}{ }^{\circ}$ $26,3^{\circ}$, da Luftwärme auch hier nicht angegeben, so ist kein Anhalt ob diese alleín Einfluß hatte, oder möglicherweise auch bezw. noch mehr die Anderung in geogr. Länge. Im Mona Paß beobachtete Hr. Dr. Scliott 26,6 ${ }^{\circ}$, am selben Monatstage IV 27 durchaus ïbereinstimmend mit s. Z. Blake. Wer mehrfach Einzelangaben zusammenstellte oder verglich, wird dies als Zufall betrachten - wer mit geistiger Teilnahme an der Sache selbst beobachtete, freut sich, daß der Zufall stattfand; wenn D. D. Holsatia I 885 IV I2 im südlichsten Teil des Paßes zwischen Mona I. und der SW Pünte Portoricos nur $25^{\circ}$ angab, so beweist dies nicht fehlerhaftes Beobachten, sondern weist nur darauf hin, daß in verschiedenen Jahren die Oberflächenwärme ein Paar ${ }^{0} \mathrm{C}$. verschieden sein kann - man darf wohl sagen je nach Luftıärme, Windrichtung und -stärke auch Dauer der 
letzteren verschieden sein wird. - I885 IV. I- 5 fuhr D. D. Holsatia von Colon nach. Porto Cabello, wobei auffallig kaltes Wasser beobachtet ist; nur vor Colon, querab Manzanillas Pt. und ugf. recht $\mathrm{N}$. vom Golf von Darien fand man $26^{\circ} \mathrm{C}$, gleich den Beobachtungen Ende März und wenig wärmer als die im Januar; alle anderen Angaben sind jedoch niedriger, teilweise unter denen letztgenannten Monats, die geringsten $22^{\circ}$, Nord vom Golf v. S. B las bei $9,9^{\circ}$ N. $78,7^{\circ} \mathrm{W} . ; 20,5^{\circ}$ Nord von K. de la Vela bei $12,2^{\circ} \mathrm{N} .72^{\circ} \mathrm{W}$., und $22,5^{\circ}$ zwischen Monks oder Seven North In. und Aruba In. im NNW der Paraguana Halbinsel; als kälteste Gegend zeigt sich diesmal die zwischen Savanilla Pt. und K. de la Vela $24^{\circ}-23^{\circ}-20,5^{\circ} \mathrm{C}$., aber auch zwischen Aruba I. und querab Tucacas Pt. sind $25^{\circ}$ und $24^{\circ}$ (diese sogar mittags) als gering zu betrachten - wenn auch nicht $\mathrm{zu}$ gering gegen die weit nordwärts bei $60^{0}-66^{0} \mathrm{~W}$. G. gemeßenen $=23-23^{1 / 2^{0}}$, die übereinstimmten mit den s. Z. auf Challenger (vgl. betr. Bemerkung im Mona Paß) nahe da, wo die Wege beider Schiffe sich kreuzten. - Auf dem Wege von $2 \mathrm{O}, 2^{\circ} \mathrm{N}$. $6_{3,5^{\circ}} \mathrm{W}$. ist beobachtet $24,5^{\circ}-25,5^{\circ}$, letzteres mittags. 1902 IV 23, in Bezug auf den Monat 6 Tage später als Holsatia, beobachtete Hr. D. G. Schott bei $20^{\circ} 53^{\prime} \mathrm{N}$. $60^{\circ} 22^{\prime} \mathrm{W}$ (Schiffsjournal) $25,3^{\circ}$; I 885 IV. I7 H. bei $20^{0} 40^{\prime} \mathrm{N} .63^{\circ} 8^{\prime} \mathrm{W} .25,5$, bei $2 \mathrm{I}, 1^{\circ} \mathrm{N} \cdot 62,7^{\circ} \mathrm{W} \cdot 25,2^{\circ}$; der Unterschied in geogr. Länge zwischen beiden Beobachtern beträgt $3^{\circ}$, es ist wohl nicht anzunehmen, dal3 dieser den Unterschied in der Wasserwärme veranlassen würde; die zufällige Übereinstimmung kann, wie schon erwähnt, jeden der selbst gern beobachtet nur freuen. - Die Wasserfarbe ist auf Holsatia wenige Mal angegeben; bei II,1 ${ }^{0}$ N. $75,3^{\circ} \mathrm{W}$. und $11.4^{11} \backslash 74,3^{11} \mathrm{IV}$ grun; (querab) von Tucacas l't. grinblau (etwas ENE. von diesem Schiffsort, war sie im Januar schwarzblau; dies hängt in solcher Gegend vielfach davon ab, wieviel und wieweit färbende Stoffe vom Lande ins Meer getrieben werden), I I , ${ }^{\circ} \mathrm{N}, 67,1^{\circ} \mathrm{W}$. dunkelblau, $\mathrm{I} 3,8^{\circ} \mathrm{N} .67,4^{\circ} \mathrm{W}$. schwarzblau, $2 \mathrm{I}, 1^{\circ} \mathrm{N} .62,7^{\circ} \mathrm{W}$. blau. Hr. Dr. G. Schott berichtet über die Wasserfarbe in Worten nur an einigen Stellen, durchgehend mit Zahlen nach dem Maßstabe von Forel $=\%$; auf den im April durchfahrenen Strecken beobachtete er $\mathrm{O}-2$. - I ï Herren die auf Hochschulen oder durch andauernden Selbstunterricht studieren lernen sollten bezw. gelernt haben, ist es selbstverständlich, daß sie sich den Gebrauch solcher hundertteiliger Maßstäbe geläufig machten; wenn dieselben dann auf Reisen lernen Buchwissen zu gebrauchen, dem Gebrauch und den Umständen anzupaßen, so kömnen sie durch Benutzung solcher Maßstäbe über Einzelheiten erheblich genauere Auskunft geben, als es durch Worte geschehen kann. Für den Scemann ist das in solche cingehende Maßstäbe "sich Hineindenken " recht nutzlich, weil es sowohl Überblick als Unterscheidungsvermögen schärft, aber es ist für den Beruf selbst zu nebensächlich, als daß3 die größte Anzahl es in Betracht zichen wird; mir scheint. man wird Angabe der Wasserfarbe auch in Einzelheiten mehren und erleichtern wenn man dic Farben blau, grin, gelb als Grundlage von $\mathrm{O}-\mathrm{I}$ o höchstens $\mathrm{O}-\mathrm{I} 2$ reichender Maf3stibe nimmt, diese in larben ausgefuhrt sowohl an
Beobachter als an Navigationsschulen und nautische Buchhändler zur Verteilung giebt. - In Büchern und Zeitschriften, die in erster Linie bestimmt sind, Seefahrern zum Gebrauch und Nutzen in ihrem Beruf zu dienen, sollten auch für solche Bezeichnungen außer dem Zahlenmaßstabe gemeinverständliche Worte benutzt werden.

Mai. Unter den mir für diesen Monat vorliegenden Mitteilungen überwiegen die, angestellt auf U.S. N. A. S. „Blake" aus den Jahren I876-I88I; der Örtlichkeit entsprechend beginnen sie nahe $95^{\circ} \mathrm{W}$. auf der Lotungslinie Vera Cruz-Galveston, 4 Angabenv. J. I877 $\mathrm{V}$ IO, $17,20,24$ zwischen $25,7^{\circ} \mathrm{N}$. und $20,8^{\circ} \mathrm{N}$. Oberflächenwärme $25,4^{\circ}-25,6^{\circ}-26,7^{\circ}-28,1^{\circ}$ (Einfluß der Luftwärme nicht bekannt). Dies ist mehr als im vorhergehenden Jahre auf ugf. paralleler Reihe zwischen Yucatan Bk. und dem SE. $P a ß$ des Missisippi Delta's beobachtet ist, stimmt im Süden aber überein mit den Ergebnissen der im vorhergehenden und folgenden Jahr ausgeführten Lotungsreihen von jener Bank ostwärts. Die Reihe Tiefseclotungen vom SEPaß zur Y ucatan oder Campeche Bk. ist durchgefuhrt $1876 \mathrm{~V} 10-12$, sie zeigt etwas unregelmäßige Zunahme der Oberflächenwärme von $2 \mathrm{I}, 1^{\circ}$ am nördlichsten bis $25,6^{\circ}$ am südlichsten Ort mit einer Ausnahmestelle von $26,7^{\circ}$ bei $25^{\circ} \mathrm{N}$. $89^{\circ} \mathrm{W}$.; sie liegt nicht auf der damals geloteten größten Tiefe von $2010 \mathrm{Fd}$. $=3620 \mathrm{~m}$., wo nur $23,9^{\circ}$ (wie die Tageszeit beeinflußte ist nicht ersichtlich). I $876 \mathrm{~V}$ 15- Is nahm Blake eine Lotungsreihe von jener Bank nach dem Loggerhead Key Feuer der Dry Tortugas; hier liegen die Angaben zwischen $26,1^{\circ}-26,7^{\circ}-26,1^{\circ}-27,2{ }^{\circ}$. $26,1^{0}-26,7^{0}-26,1^{0}-26,7^{0}-27,2^{0}-26,1^{\circ}$, da Tageszeiten nicht angegeben, so ist nicht $z u$ entscheiden, ob diese oder wärmere Streifen, auch kälteres Wasser auf flacherem Grunde die Ursache der, nicht großen Unterschiede sind. - Zunächst in diesen Breiten bleibend, ist bekannt eine Reihe des Blake von Garden Key Feuer, Dry Tortugas nach l't. Muriel, Cuba 1878 V II-12; auf geringen Tiefen ist das WVasser am kältesten $=25,0^{\circ}-25,6^{\circ}$, wird in noch nicht $1 / 4$ der Entfernung rasch 26,7 nimmt etwas zu bis noch weniger als dies vom Steilufer Cuba's $=27,2^{\circ}$ und ist unweit dieses noch $26,9^{\circ}$. Im selben Jahre $1878 \mathrm{~V} 30,3 \mathrm{I}$ ist von Blake gelotet von K. Florida Feuer nach Gun Key F., Gr. Bahama Bk., südlich der Bemini In., also schräg über den, Bemini Straße genannten Teil der Florida Straße. Nach den Angaben war das kälteste Wasser auf den geringen Tiefen an der Florida Seite $=27,8^{\circ}$, nahm bis nahe der Mitte $z u=28,3^{\circ}$, dann in ugf. $2 / 3$ der Entfernung wieder $27,8^{\circ}$ in der Nähe von Gun Key 29,20 und $28,3^{\circ}$. I 88 I V 30 folgte eine Reihe von Memory Klippe auf der kl. Bahama Bk. quer über die Strake nach Jupiter Inlet, Florida. Am Ankerplatz nahe Memory Klippe betrug die Oberflächenwärme $25,6{ }^{\circ} \mathrm{C}$; nur $5 \mathrm{Sm}$. westlicher schon $27,5^{\circ}$, nahm zu bis 24 und $29 \mathrm{Sm}$. von M. Kl. $28,3^{\circ}$ dann ab bis $39^{3 / 4}$ Sm. 26,7" und blieb so bis $50 \mathrm{Sm}$. von M. Ki. $26,7^{\prime \prime}$; das kältere Wasser also auch hier über geringerer Wassertiefe. - Weiter südlich fand biluk $1878 \mathrm{~V} 22-23$ auf einer Lotungsreihe von K. San Antonio, Cuba nach Yucatan (Campeche) Bank etwas wärmeres Wasser als 10 Tage früher zwischen 
den Dry Tortugas und Muriel Pünte. Bei K. S. A. maß man $27,3^{\circ}$, der Betrag nahm zu bis er in ugf. $4 / 5$ der Strecke nach der Bank zu $28,9^{\circ}$ betrug, auf dem Beginn der Bank wieder nur 27, I $880 \mathrm{~V}$ I4 folgte eine Lotungsreihe von Isle of Pines nach Grand Cayman, V 29 von hier nach Pedro Bk; auf ersterer fand man die Meeres-Oberfläche wärmer als auf letzterer; dort von I. of P. an: schwankend zwischen $27,5^{\circ}$ bis $26,9^{\circ}$ und $27,2^{\circ}$, hier allmählich zunehmend von $G$. C. an: $25,3^{\circ}$ bis $26,7^{\circ}$ unweit von und an der Bank. Dahingestellt muß in dieser Übersicht bleiben ob dies vereinzelter Zufall war oder tatsächlich SE. von Gr. Cayman im Mai etwas kälteres Wasser ist als NWlich davon. - I879 am I I. Mai lotete Blake von Morant Pt., J a ma ica, nach K. T iburon, S. Domingo; in einiger Entfernung von ersterem Ort war dabei die Oberflächenwärme $25,6{ }^{\circ}$ blieb so bis $3 / 8$ der ganzen Strecke, wo man sic $25,3^{\circ}$ maß, von dort aus sehr schwankend $27,8^{0}-27,5^{0}-28,9^{0}-28,1^{0}-3 \mathrm{I}, 4^{0}(!)-27,8^{\circ}$; unbestimmt ist ob bei $3 \mathrm{I}, 4^{\circ}$ ein Schreibfehler vorliegt oder ob es ausnahmsweise heiß und windstill war. - Im östlichen Teil des Gebietes, im Norden beginnend folgen zunächst einige Beobachtungen die Hr. Dr. G. Schott (D. D. Croatia) anstellte: $1902 \mathrm{~V} I 7,19^{\circ} 2 \mathrm{I}^{\prime} \mathrm{N} .68^{\circ} \mathrm{I} 4^{\prime} \mathrm{W} . \mathrm{G} .=28,2^{0}$, $\mathrm{V}$ I $8 \mathrm{NNE}$. $20 \mathrm{Sm}$. von $\mathrm{K}$. Monte Christi $=27,1^{\circ}$ und 5 Mitteilungen von $20^{\circ} 4 I^{\prime} \mathrm{N}$. $7 \mathrm{I}^{\prime} 2^{\prime} 6^{\prime} \mathrm{W}$. bis $30^{\circ} 22^{\prime} \mathrm{N}$. 6 I $^{\prime \prime} 4^{\prime} \mathrm{IV} .=27,2^{\circ}$ abnehmend $\mathrm{zu} 22,6^{\circ}-$ wobei die Abnahme rom 24. an $\left(25^{\circ} 32^{\prime} \mathrm{N} .66^{\circ} \mathrm{I} 7^{\prime} \mathrm{IV}\right.$. $\left.=25,0^{\circ}\right)$ erhebiich stärker war als vorher. - 1886 $\mathrm{V}$ 9, 10 fand man auf D. D. Holsatia zwischen $2 \mathrm{I}, 2^{\circ} \mathrm{N} .60,6^{\circ} \mathrm{W}$. und St. Thomas bei 6 Beobachtungen dic Wasscrwärme stetig zunehmend von $26,0^{\circ}$ bis $27,4^{\circ}$. - Im Elichen Teil der karaibischen See stellte Hr. Dr. G. Schott (D. D. Croatia) noch an 9 Beobachtungen: $1902 \mathrm{~V} I$ bis $\mathrm{V} I 2$ von $15^{\circ} \mathrm{II}^{\prime} \mathrm{N} .69^{\circ} 6^{\prime} \mathrm{IV}=26,4^{\prime \prime}$ I I " $23^{\prime} \mathrm{N} .67^{\circ} 29^{\prime} \mathrm{W} .=26,6^{\circ}$, I I ${ }^{\circ} 22^{\prime} \mathrm{N} .64^{\circ} 33^{\prime} \mathrm{W} . \mathrm{G}$. $=24,1^{\circ}, 10^{\circ} 54^{\prime} \mathrm{N} .63^{\circ} 37^{\prime} \mathrm{IV} .=24,1^{\circ}$, halbivegs zwischen Carupano und Trin idad $24,6^{\circ}$ dann V $14-I_{5}$ I $2^{\prime \prime} \mathrm{I}^{\prime} \mathrm{N} .62^{\circ} 26^{\prime} \mathrm{W}$. bis halbwegs zwischen St. Croix und St. Thomas $=27,2^{\circ}-27,8^{\circ}$. Hr. Dr. G. Schott macht mit Recht aufmerksam auf das kalte IVasser hier ostwärts von $6_{5}{ }^{\prime \prime} \mathrm{W} .$, - dabei sei erinnert, daß Holsatia I7 Jahre fruher I 885 IV I -5 es auch fand, selbst noch schroffer bemerkbar, zwischen Colon und Porto Cabello. - Dic Wasscrfarbe ist nur angegeben von Hr. Dr. G. Scliott, nach dem Forel'schen Maßstabe: im Süden 30-20, im Norden 3-I; außerdem wieder einigemal in $\mathrm{W}$ orten, wobei besonders beachtenswert: zwischen $18,2^{\circ}$ N. $69,8^{\circ}$ W. - $I_{1,4}{ }^{\circ}$ N. 67,50 W. (S. Domingo-La Guayra) „Überall hier im Karaibischen Meer Wasserfarbe schwarzgrau bis schwarzgrün, ohne jede Spur von Blau; Durchsichtigkeit offenbar gering. "Selbst wenn dies vereinzeltes Vorkommen sein sollte, lenkt es die Aufmerksamkeit auf die Frage, »welche Ursache bewirken es « dann aber wird mancher Beobachter dadurch veranlaßt werden, seltene Erscheinungen mitzuteilen, auch wenn er keine, gewissermaßen als Beleg dienende Begleit-Umstände angeben kann. Viele Beobachter erwähnen ihnen geläufige Dinge nicht, weil sie glauben, was ihnen gut bekannt ist, müßte Zusammen- stellern erst recht vertraut sein, _- dadurch gelangt es manchmal als Seltenheit an die Öfrentlichkeit. - Andere verschweigen sehr beachtenswerte Seltenheiten, weil diese gewissermaßen in der Luft schweben, im Glauben: man denkt, ich habe mich geirt, oder: der erzählt Latein; finden sic, daß andere ungescheut scheinbar durch nichts unterstützte Ausnahmefälle berichten, so fühlen sie sich ermutigt, gutem Beispiel zu folgen. - Im Schiffsjournal ist auf jener Strecke nur V I vormittags Regen angegeben, sonst leicht bewölkt und bewölkt bei bewegter See, dabei könnte das Meer in jener Gegend und auf so großer IVassertiefe doch blaue Farbe bewahren.

Juni. Zur Vervollständigung der Reihe Vera Cruz-Galveston lotete Blake an 2 Stellen 1877 VI 2, IO; dabei fand man Oberflächenwärme bei $19,2^{\circ} \mathrm{N} \cdot 95,7^{\circ} \mathrm{W} .=28,3^{\circ}$, bei $24,6^{\circ} \mathrm{N} \cdot 95,1^{\circ} \mathrm{W} .=26,1^{\circ}$ Luftwärme unbekannt; ein Teil des Unterschiedes wird wohl zuzuschreiben sein der geogr. Breite. - Von den quer über den Golfstrom fuhrenden Lotungsreihen amerikanischer Aufnahmeschiffe fallen in dieses Gebiet 4 i. J. I88I VI vom Blake ausgefuhrte; auf ihnen fand man $27^{\circ} 57^{\prime} \mathrm{N} .-27^{\circ} 5 \mathrm{I}^{\prime} \mathrm{N} .77^{\circ} 33^{\prime} \mathrm{W}$. bei Abstand von der Küste $34-\mathrm{I} 60 \mathrm{Sm} .=26,7^{\circ}-27,8^{\circ}(65$ und $75 \mathrm{Sm})-25,6^{\circ}$, letzteres von I I $6 \mathrm{Sm}$. an; $28^{\circ} 4 \mathrm{O}^{\prime} \mathrm{N}$. $28^{\circ} 44^{\prime}$ N. $78^{\circ} 22^{\prime} \mathrm{W} .(38-130 \mathrm{Sm}$. v. d. Küste) = $26,7^{\circ}-27,8^{\circ}$ (80 Sm.) - 26,10 (von $100 \mathrm{Sm}$. an) mit Unterbrechung durch $25,5^{\circ}$ ( $84 \mathrm{Sm}$.) und $25,8^{\circ}$ (1 $20 \mathrm{Sm}$.); $29^{\circ} 25^{\prime}$ N. $-29^{\circ} 3 I^{\prime}$ N. $7^{\circ} 38^{\prime} \mathrm{W} . \quad(38-236 \mathrm{Sm}$ v. d. Küste) $=26,7^{\circ}-3{\mathrm{I}, 5^{\circ}}^{\circ}\left(65 \mathrm{Sm}\right.$.) $-26,9^{\circ}$ (1 2 I und I $39 \mathrm{Sm}.)-27,8^{0}$ (198 Sm. $-27,4^{\circ}$ und $27,5^{\circ}(216-236 \mathrm{Sm}$.); von St. John Flup, Florida, $30^{\circ} 24^{\prime} \mathrm{N}$. 8 I $^{\circ} 26^{\prime} \mathrm{W}$. - $30^{\circ} 30^{\prime} \mathrm{N} .76^{\circ} 44^{\prime} \mathrm{W} .(66-242 \mathrm{Sm}$. v. d. Kiiste)

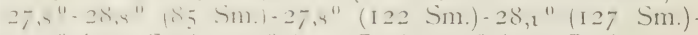
$27,8^{\circ}$ (I $37 \mathrm{Sm}$.) -29,90 (I92 Sm.)-27,10 (242 Sm.). Agassiz gicbt von Blake's Lotungen noch Clichés mit Zahlen von 2 Reihen, eine von den Bahama's nacl den Bermudas, eine von Santo Domingo bis 275 Sm. NEwärts; doch sah ich nicht Jahr und Monat; in Tafel I sind cingetragen die Angaben der Oberflächenwärme; möglicherıveise sind die Beobachtungen angestellt im Frühjahr; von den $\mathrm{B}$ ahamas aus ist kenntlich bis $30^{1 / 2}$ " N. stetige Abnahme mit geographischer Breite $25^{\circ}-21^{1} / 2^{0}$; unter $S$. Dom ingo kaltes Küstenwasser: $25^{3}+1 "$ gencen $25^{\prime \prime}=$ ".

D. D. Hungaria beobachtete I 887 VI I $8-2$ I von $30^{\prime \prime} 20^{\prime} \mathrm{N}$. bis zum Elichen Ende des Providence Kanals, VI $22-25$ von dessen westlichem Ende bis $20^{\prime \prime} 50^{\prime} \mathrm{N} .94^{\circ} 38^{\prime} \mathrm{W}$. (vor Vera Cruz); die Oberflächenwärme nahm (von der Tageszeit beeinflußt) unrcgelmäßig zu und ab von $24,4^{\circ}$ bis $26,8^{\circ}$ bis $25,8^{\circ}$ dann $27,1^{\circ}$ und $28,0^{\circ}$ (mttgs.). Am W.-Ende des Providence Kanals $27,8^{\circ}$ querab Florida Lt. nur $27,0^{\circ}$. dann $28,0^{\circ}-28,8^{\circ}$ bis zuletzt: ausgenommen auf der N. Ecke der Yucatan Bk. bei $23^{\circ} 34^{\prime} \mathrm{N} .88^{\circ} 2^{\prime} \mathrm{W}$. wo man nur $26,4^{\circ}$ fand. - I 885 VI I I beobachtete D. D. Holsatia von $30,4^{\circ}$ N. $59,8^{\circ} \mathrm{W} .=23^{\circ}$ bis VI i 2 bei $25,5^{\circ} \mathrm{N} \cdot 65_{5,9^{\circ}} \mathrm{W} .=28^{\circ}\left(\mathrm{p} .4^{\mathrm{h}}\right)$, dann zwischen $26^{\circ}$ und $27,5^{\circ}$ bis $20,3^{\circ}$ N. $72,3^{\circ} \mathrm{W}$. (vor K. Haïtien). I 886 VI I 5 und I 6 von St. Thomas nach Hâvre $20^{\circ} 55^{\prime} \mathrm{N}$. $62^{\circ} 47^{\prime} \mathrm{W}$. bis $24,1^{\circ} \mathrm{N}$. $59,6^{\circ} \mathrm{W}$ : : zwischen $27,5^{\circ}$ und $26,9^{\circ}$. - Die Wasserfarbe ist angegeben 
1887 bci $30^{\circ} 38^{\prime} \mathrm{N} .63^{\circ} 5 \mathrm{I}^{\prime} \mathrm{W}$. und $29^{\circ} 39^{\prime} \mathrm{N}$. $66^{\circ} 30^{\prime} \mathrm{W}$. = blau; $26^{\circ} 9^{\prime} \mathrm{N} \cdot 7^{\circ} 34^{\prime} \mathrm{W}$. (vor dem Providence Kanal) = blau mit schwarzen Flecken; östlich vom Süd-Ende Florida's: $25^{\circ} 7^{\prime} \mathrm{N}$. $80^{\circ} \mathrm{I} 2^{\prime} \mathrm{W}$. = hell; $23^{\circ} 58^{\prime} \mathrm{N} .84^{\circ} 20^{\prime} \mathrm{W}$. = tiefblau; auf der Yucatan Bank und westlich davon bei $23^{\circ} 34^{\prime} \mathrm{N}$.

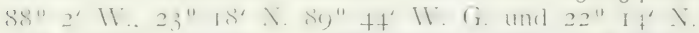

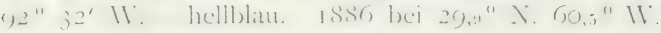
dunkelblau, bei $2 \mathrm{I}, 0^{\circ} \mathrm{N} \cdot 7 \mathrm{I}, 2^{\circ} \mathrm{W}$. = blau. I $88_{5}$ bei $20^{\circ} 55^{\prime} \mathrm{N} .62^{\circ} 47^{\prime} \mathrm{W}=$ blau.

Juli. Im Westen beginnend: D. D. Hungaria fuhr 1887 VII I von Vera Cruz nach Tampico; bald nach Verlassen ersteren Platzes beobachtete man mttgs. die recht hohe Oberflächenwärme $29,{ }^{\circ}{ }^{\circ} \mathrm{C}$., möglicherwveise verursacht durch Überhitzung auf flacherem Wasser infolge der Tageszeit. Während der Reise von Tampico nach Progreso I 887 VII 4, 5 (4 Beobchtgn.) schwankt die Wasserwärme zwischen $28,2^{\circ}-27,8^{\circ}-28,8^{\circ}$, cloch ist fraslich, ob die niedrigste veranlaßt ist durch Auf stauen von kälterem Wasser auf geringerer Wassertiefe. Von Progreso nach Haïti (VII $8-10$, bis südlich von Damas (ay 7 Messungen) sind die Angaben nur wenig höher als die aus westlicherer Gegend $=28,2^{\circ}-29^{\circ}$. VII $2 \mathrm{I}$ a. $8^{\mathrm{h}} \mathrm{im}$ Norden des Mona Paß bei $19^{0} 7^{\prime} \mathrm{N}$. $68^{\circ} 4^{\prime} \mathrm{W}$. fand man $27,4^{\circ}$, verhältnismäßig wenig gegen 1902 Mitte Mai etwas NWlicher bei $19^{\circ} 2 \mathrm{I}^{\circ} \mathrm{N} .68^{\circ} 14^{\circ} \mathrm{WV}$. von $\mathrm{Hr}$. Dr. G. Schott gefundenen $2 S_{, 2}{ }^{\circ}$ - Von St. Thomas heimwärts beginnen die Bbchtgn. auf $\mathrm{D}$. D. Holsatia 1885 VII. 20 p. $4^{\text {h }}$ bei $21,4^{0}$ N. $62,5^{\circ}$ IV. G.

$28^{\circ}$; bei $24,3^{\circ} \mathrm{N}, 59,6^{\circ} \mathrm{W}$. ist die Wasserwärme noch $27^{\circ}$, auf den Slichen Teil dieser Strecke ist sie vielleicht $1 / 2^{0}$ geringer — im Nlichen ebensoviel höher als im vorhergehenden Monat. I887 D. D. Hungaria übergab mir nur j Beobachtungen VII. 23, 24 zwischen $21,7^{\circ} \mathrm{N}$. $6 \mathrm{r}_{, 7}{ }^{\circ} \mathrm{W}$. bis $23^{\circ} 46^{\prime} \mathrm{N}$. $59^{\circ} 47^{\prime} \mathrm{W} .=26,9^{\circ}$ $26,2^{0}-27.8^{0}$ (mttgs.); abgesehen von möglichem Einfluß des Unterschiedes in geogr. Breite, sind die ersten beiden Angaben $1 / 2^{0}-3^{0} 4^{0}$ niedriger als die 2 Jahre früher, aus der Nähe, von D. D. Holsatia übermittelten. - Die Wasserfarbe ist gegeben I887 VII I Nlich von Vera Cruz, nahe an Land: hell; von Tampico-Progreso auf tiefem Wasser blau, auf der Bank hellblau bis hellgriin, nahe der Ostkante der Yucatan Bk: dunkel, bei K. San Antonio blau, bei K. Cruz tiefblau, im $N$. von Mona Paß und bei der letzten, hier zu benutzenden Beobachtung der Heimreise ebenso wie s. Zt. auf Holsatia = blau. nicht vor.

Angust. Gegenwärtig liegen mir Beobachtungen

September. Nur v. J. ISS7 IX 9 besitze ich 2 Angaben von D. D. Hungaria von $20^{\circ}$ I $3^{\prime} \mathrm{N}$. $6 \mathrm{I}^{\circ} 5^{\prime} \mathrm{WV}$.

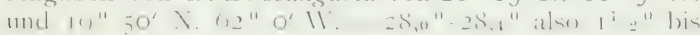
$1^{3 / 4^{0}}$ mehr als im Nai 1886 etwas Nlicher berichtet.

Olitober I4, I887. Hungaria bei $22^{\circ} 27^{\prime} \mathrm{N}$. $59^{\circ} 53^{\prime} \mathrm{W}$. beobachtete $27,2^{0}$ ugf. $1^{1 / t^{0}}$ weniger als einen Monat früher ugf. I ${ }^{0}$ geogr. Br. SEwärts jener Gegend.

November. 1885 XI 25, 26 zwischen $22^{\circ} 13^{\prime} \mathrm{N}$.

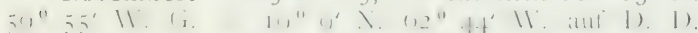
Holsatia; nach 7 libchtgn. wechselt die Wasserwärme zwischen $27,5^{\circ}-27^{0}-28^{\circ}$, ist also $1 / 2^{\circ}$ bis $1^{3 /} / 4^{\prime \prime}$ höher, als unweit dieser Strecke im Mai desselben Jahres, auf demselben Schiff man sie maß. - Viel weiter Slich XI I 2 desselben Jahres I 885 kam S. Östr. Ung. M. S. Zrinyi in das hier betrachtete Gebiet bei I I $^{0} 37^{\prime} \mathrm{N}$. $59^{\circ} 20^{\prime} \mathrm{W}$.; Nlich von Tobago I. bleibend gelangte das Schiff am I3. vmttgs. in Dragons Mouth vor Port of Spain, Trinidad und beobachtete $28,2^{\circ}$ $28,4^{\circ}-27,6^{\circ}$ also nur wenig höhere Wasserwärme als I 3 Tage später Holsatia auf dem Io Breitengrade nördlicheren IVeg nach St. Thomas (Luft 26, ${ }^{\circ}-29,0^{\circ}-$ $\left.26,3^{\circ}-28,0^{\circ}\right)$. Auf der Rhede von Port of Spain XI I3-I 8 betrug die geringste Wasserwärme $27,6^{\circ}$ die höchste $29,0^{\circ}$ (L. $\left.24,7^{\circ}-31,5^{\circ}\right)$. Auf dem Wege von Port of Spain nach Bridgetown, Barbados $\mathrm{IO}^{\circ} 43^{\prime} \mathrm{N}$. 6I $\mathrm{I}^{\circ} 4 \mathrm{I}^{\prime} \mathrm{IV}$. bis $\mathrm{I}^{\circ}{ }^{\circ} 46^{\prime} \mathrm{N}$. $59^{\circ} 44^{\prime} \mathrm{IV}$. maß man IV. $28,0^{\circ}-29,2^{\circ}-28,2^{\circ}-28,6^{\circ}$ (L. $30,4-27,7$ ); in letztgenanntem Hafen XI $19,20=28,6^{\circ}-28,0^{\circ}$ (L. $29,9^{\circ}-25,9^{\circ}$ ); weiter bis Kingstown, St. Vincent XI 2 I a. $I^{\text {h }}-$ p. $5^{\text {h }} 28,2^{0}-28,4^{0}-27,60^{0}$, p. $9^{\text {h }}$ aber $28,4^{0}$ im Hafen $27,1^{\circ}-28,4^{\circ}$ (L. $26,0-28,2$ bzw. $24,5^{\circ}-29,7^{\circ}$ ); $\mathrm{XI} 24$ weiter nach Port Castries, St. Lucia: $28,0^{\circ}$ $27,8^{0}-28,4^{0}$ (L. $\left.25,3^{0}-29,9^{0}\right)$; dort selbst zwischen $27,6^{\circ}$ und $28,1^{\circ}$ (L. 25,2 ${ }^{\circ}-29,2^{\circ}$ ) [1879 III 2 I Blake W. $=26,9^{\circ}-26,7^{\circ}$. XI 26 bis Fort de France. Martinique 2 bbchtgn. a. $y^{\mathrm{h}}$ und p. $\mathrm{I}^{\mathrm{h}}=28,2^{0}-28,4^{0}$ (L. $28,6^{\circ}{ }^{\circ}-29,7^{\circ}$ ) hier blieb Zrinyi bis XI 30 nchmttgs.; um diese Zeit änderte man den Liegeplatz nach St. Pierre, Martinique; auf Ft. de France Rhede maß man WV. zwischen $28,4^{\circ}$ und $27,4^{\circ}$ (L. 24,1-30,1). - Wasserfarbe: lieine Angaben.

Dezember. S. Östr. Ungar. MI S. Zrinyi teilt mit weitere Beobachtungen zwischen den westindischen Inseln von Martinique bis Haïti. ISS 5 XII I auf der Rhede von St. Pierre ersterer Insel schwankt die Wasserwärme zwischen $27,9^{\circ}-29,0^{\circ}$ (L. $26,4^{\circ}-29,9^{\circ}$ ) XII I p. $9^{\mathrm{h}}$ bis 2 a. $5^{\mathrm{h}}$ vor Roseau road, Dominica, ist beobachtet $28,1^{\circ}$ zweimal $27,8^{\circ}$ (L. $26,9^{\circ}-27,3^{\circ}$ ), im Hafen $28,0^{\circ}-27,6^{\circ}$ (L. $\left.29.5^{\circ}-25,5^{\circ}\right)$; XII 3 vimttgs. bis Pointe à Pitre, Guadeloupe : $28,0^{\circ}-27,3^{\circ}-27,8^{\circ}$ (L. $\left.27,4^{\circ}-24,8^{\circ}\right)$; im Hafen zivischen $27,0^{\circ}$ und $28,2^{\circ}$ (L. $24,9^{\prime \prime}-29,8^{\circ}$; ; XII 6 nchmttgs. und 7 vmttgs. nach St. Johns Hafen, Antigua 6 Bbchtgn. $27,7^{0}-27,3^{11}-27,6^{0}$ (L. $\left.24,7^{\circ}-27,5^{\circ}\right)$, dort $27,6^{0}-26,9^{\circ}-27,3^{\circ}-27,2$ (L. $26,3^{\circ}$ $\left.-28,9^{\circ}\right)$; XII 8 abds. -9 mgs. bis Basscterre, St. Kitts, $27.2^{\circ}-27,6^{0}-27,4^{\circ}$ (L. $\left.26,9^{\circ}-26,7^{\circ}\right)$; im Hafen $27,7^{\circ}-26,9^{\circ}-27,8^{\circ}-27,7^{\circ}$ (L. $\left.24,1^{\circ}-28,9^{\circ}\right)$; ron da bis St. Thomas XII II, 12: 7 Beobchtgn. von ihnen 5 zwischen $27,6^{\circ}$ und $27,4^{\circ}$ XII I2 a. I th bei $17^{\circ} 59^{\prime} \mathrm{N}$. 1.4" I $4^{\prime}$ IV. I" weniger $=26,4^{\circ}$ ohne bedeutende Minderung $\left(0,6^{\circ}\right)$ der Luftwärme, a. $5^{\text {h }}$ bei $I^{\circ}{ }^{\prime \prime} \sigma^{\prime} \mathrm{N}$. $64^{\circ} 3 \mathrm{I}^{\prime} \mathrm{IV}$. wieder $27,0^{\circ}$ trotz weiterer $0,3^{\circ}$ Abnahme der Luftwärme (L. $23,7^{\circ}-27,5^{\circ}-25,8$ ) jenes scheint also eine kalte Stelle gewesen zu sein; im Hafen von St. Thomas XII I2-I5 schwankte die Wasserwärme zwischen $26,1^{\prime \prime}-27,0^{\circ}$ (L. $\left.24,7^{\circ}-28,7^{\circ}\right)$; XII 16 vmttgs. bis Sa $n \mathrm{Juan}$, Portorico 3 Bbchtgn, : $26,5^{\circ}-26,4^{\circ}-25,6^{\circ} \mathrm{C}$. (L. $26,5^{\circ 1}-25,7^{\circ}$ ) hier bis 21 . mgs. IV. : $25,7^{\circ}-27,6^{\circ}$ (L. $\left.21,9-29,1^{\circ}\right)$. Auf dem Wege nach San Domingo Rhede XII 2 I-23 scheint an der Nordkiuste Portorico's

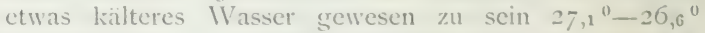
(L. $27,1^{\circ}-25,1^{\circ}$ ), im Mona Pals bis SSIV von Saona I. 
wieder $26,9^{\circ}-27,2^{\circ}$ (L. $25,3^{\circ}-29,0^{\circ}$ ), dann bei erheblich geringerer Luftwärme $\left(241^{0}--24,9^{\circ}\right)$ XII 23 vmttgs. $\mathrm{W}$. $=26,1^{0}-26,8^{\circ}$, auf der Rhede von S. D. IV. zwischen $25, \mathrm{~s}^{\circ}$ und $27,2^{\circ}$ (L. $21,9^{0}-28,1^{\circ}$ ). Während der Fahrt nach Port au Prince, Haïti XII 25 nachmittags - 3I vmttgs. blieb die Wasserwärme ziemlich gleich bis in kurze Entfernung vom Bestimmungsort wo sie $27,8^{\circ}$ war, sonst Meistbetrag 27,20, Mindestbetrag $26,0^{\circ} \mathrm{C}$.; die wärmste Gegend : $27,1^{\circ}-27,2^{0}-27,2^{\circ}-27,0^{\circ}$ lag zwischen $17^{0} 20^{\prime} \mathrm{N}$. $7 \mathrm{I}^{0} 4 \mathrm{O}^{\prime} \mathrm{W}$. bis $17^{0} \mathrm{I} 4^{\prime} \mathrm{N}$. $72^{0} 2^{\prime}$ W. SSW.-SW. der S.pünte Haiti's. (L. 23,7 $-27,3^{\circ}$ vor Pt. au Pr. $\left.29,9^{\circ}\right)$. - I 884 XII 28, 29 liegen vor 5 Bbchtgn. vom D. D. Holsatia zwischen $15,8^{\circ} \mathrm{N} .65,4^{\circ} \mathrm{W}$ $=25^{\circ}$ und $11,3^{\circ} \mathrm{N} .66,4^{\circ} \mathrm{W} .=26^{\circ}$; man fand Slich von $15^{\circ}$ N. 4 mal $26^{\circ}$. - Meeresfarbe nur angegeben Nwärts von Los Roques und Orchilla bei $12^{\circ} 14^{\prime} \mathrm{N}$. $66^{0} 20^{\prime} \mathrm{W}$. = dunkelblau.

Es erscheint mir beachtenswert, daß I $_{8} 85$ November S. Östr. Ung. M. S. Zrinyi zwischen Trinidad I. und Dominica I. trotz Unterschiedes in geogr. Breite von nahezu $5^{0}$ ugf. gleiche Wasserwärme fand (ebenso I879 März V. S. N. A. S. Blake von Dominica bis St. Vincent Br. Utschd. ugf. $2^{1} 4^{0}$ hier eher im Norden wärmer als im Süden). Von Dominica bis St. Thomas ist sie ebenfalls nahe gleich, nur ugf. $1 / 2-3 / 4^{0}$ geringer als vorher. Im Übrigen sind die Beobachtungen zu spärlich, um allgemeine Schlüsse zu ziehen, man kann sagen, nach ihnen ist es nicht unmöglich, daß i. J. I884-85 im Dezember, März und April im östlichen und mittleren Teil der Karaibischen See die Wasserwärme nahe gleich war; auf dem hier in Betracht genommenen Teil des Weges Hàvre-Sombrero I. betrug der Unterschied in Wasserwärme zwischen Mai und Oktober, November höchstens $1,8^{\circ}$ C. (Herbst wärmer als Frühjahr), - auf dem St. ThomasHavre zwischen Januar und Juli höchstens $4 \frac{1}{1} 2^{\circ} \mathrm{C}$.

\section{Tafel 2. Salzgehalt}

des Meerwassers wird bestimmt:

I) aus Beobachtungen des spez. Gew. des Meerwassers mittelst Glasinstrumente, Aräometer (von Briten Hydrometer, von Franzosen Densimeter) genannt;

2) durch chemische Untersuchung;

3) durch Bestimmung des Verhältnisses der Brechung von Lichtstrahlen, die ihren Weg nehmen durch chemisch reines Frischwasser, zu der Brechung von Lichtstrahlen, die ihren Weg nehmen durch die Meerwasser-Probe

$\mathrm{Zu}$ I) muß bekannt sein die Wasserwärme während der Messung, dic - weil letztere in einem Glasgefäß vorgenommen werden soll - gewöhnlich bezeichnet wird: Temperatur (des Wassers) im Glase. Das so bestimmte spez. Gew. überträgt man nach Tabellen auf einen gewissen Wärmegrad, dann steht der Salzgehalt in bekanntem Verhältnis zum spez. Gew.; auch für diese Umwandlung (spez. Gew. in Prozente bezw. Promille
Salz) sind Tabellen gefertigt. - Das Aräometer muß den Umständen angepaßt sein, - das Glas in dem die Messung vorgenommen wird, nur wenig tiefer und umfangreicher als das Aräometer, - Schöpfeimer, Messglas Aräometer und Thermometer peinlich rein, ganz besonders frei von Fett oder Ol gehalten (der geringste Ansatz von letzteren bringt erhebliche Fehler in die Einstellung cles Instrumentes, folglich in die Ergebnisse der Beobachtung) - die Instrumentfehler bekannt, - die Messung selbst möglichst genau.

$\mathrm{Zu}$ 2). Die chemische Untersuchung kann selbstverständlich bedeutend sichere Ergebnisse liefern als die Beobachtung mit Aräometern, indes ist erstere auf Schiffen nicht immer möglich, - sobald es sich um große Anzahl von Wasserproben handelt, wird sie auch an Land unmöglich.

$\mathrm{Zu}$ 3). Die Bestimmung der Brechung von Lichtstrahlen im Meerwasser (wozu ebenfalls nötig ist, genaue Kenntnis der Wärme desselben) erfordert Instrumente, die kostspieliger sind und mehr Platz einnehmen als Aräometer; es ist fraglich, ob jene so leicht und gut in Ordnung gehalten werden können, ferner erfordern sic mehr Anstrengung der Seh- und andrer Nerven.

Es scheint mir nicht, daß Vergleichsbeobachtungen nacli allen 3 Beobachtungsarten in genügender Anzahl vorhanden sind, um zu entscheiden, ob die größeren Ausgaben als für Aräiometer lohnen; durch diese würde jedenfalls vermindert die Anzahl der Beobachter folglich auch der Beobachtungen.

Für Schiffs- und Fischerei Zwecke, — zur. Herstellung von Übersichtskarten der Verteilung des Salzgehaltes im Meerwasser, sowie der Unterschiede des spez. Gew. von letzterem, genuigt die Beobachtung des spez. Gew. mittelst Aräometer. Wie schon 1893 von mir gesagt ist (Das Ausland No. 4I S. 648) haben sich die Aräometer des, von der Kommission zur Untersuchung der deutschen Neere zusammengestellten "Marine Besteck " in der Nordsee und den Oceanen als sehr zweckmäßig erwiesen. Die größeren sind eingerichtet für Gebrauch im Seewasser von 1,0220 bis 1,0200 spez. Gew., erheblich geringeres und größeres kann man messen mit den kleineren, nur ist die Genauigkeit geringer, weil die Einstellung unsichrer, die Ablesung beschränkt ist auf die dritte Dezimale.

Bei den größeren, am häufigsten benutzten Aräometern des "Marine Bestek" beträgt der Durchmesser des Schwimmkörpers $3^{3 / 4}$ bis $4^{1 / 5} \mathrm{~cm}$., die Länge des ganzen Instrumentes ugf. 2 I cm., das zylindrische Mess. glas hat einen Durchmesser von ugf. $5^{1 / 2} \mathrm{~cm}$. bei nahe $35 \mathrm{~cm}$. Höhe; das zur Bestimmung der Wasserwärme während des Messens benutzte Thermometer hat ugf. I cm. Durchmesser. - Durch diese Abmessungen hat das, in den mit Wasser bis ugf. drei Viertel seiner Höhe gefüllten Zylinder gestellte Aräometer, nach den Seiten und nach unten, nur soviel Spielraum, um beim Einsenken nicht auf den Boden zu stoßen und bei geringfügiger Neigung des Glases nicht dessen innere Wandung zu berühren. - Der in die Spindel oder den Stiel des Instrumentes eingeschlossene Maßstab ist von zwei zu zwei Einheiten der vierten Dezimale geteilt (der Raum zwischen je zwei Teilstrichen ist gleich zwei Einheiten der vierten Dezimale), der Zwischenraum zwischen zwei 
Teilstrichen beträgt $\mathrm{I}_{6}-\mathrm{I}, \tau \mathrm{mm}$; sodaß die vierte Dezimale man sicher schätzen kann. .- Das Thermometer ist geteilt in halbe Grade des hundertteiligen Wärmemaßstabes, der Raum zwischen je zwei Teilstrichen genügt, um $1 / 5$ des Z wischenraumes also ${ }^{1 / 10^{0}} \mathrm{zu}$ schätzen, sodaß die Ablesung auf $1 / 4^{0} \mathrm{C}$. sicher ist.

Zum Gebrauch wurde das Meßglas in eine starke, möglichst dünne Schnur geschlungen, - auf ähnliche Weise, wvie man offne, mit Flüßigkeit gefüllte Gefässe zur Auf- oder Niederbewegung schlingt, — und möglichst nahe mittschiffs an einen genügend starken, jedoch möglichst dünnen Haken, senkrecht aufgehangen. - Ein kardanisches Gehänge halte ich nicht nur für überflüssig sondern unter Umständen auch schädlich; entweder braucht man noch ein Paar Ständer auf festem Unter. satz in welche der Hängering gelegt wird, oder man hat ihn in einen Tauring zu legen der ebenso aufgehangen

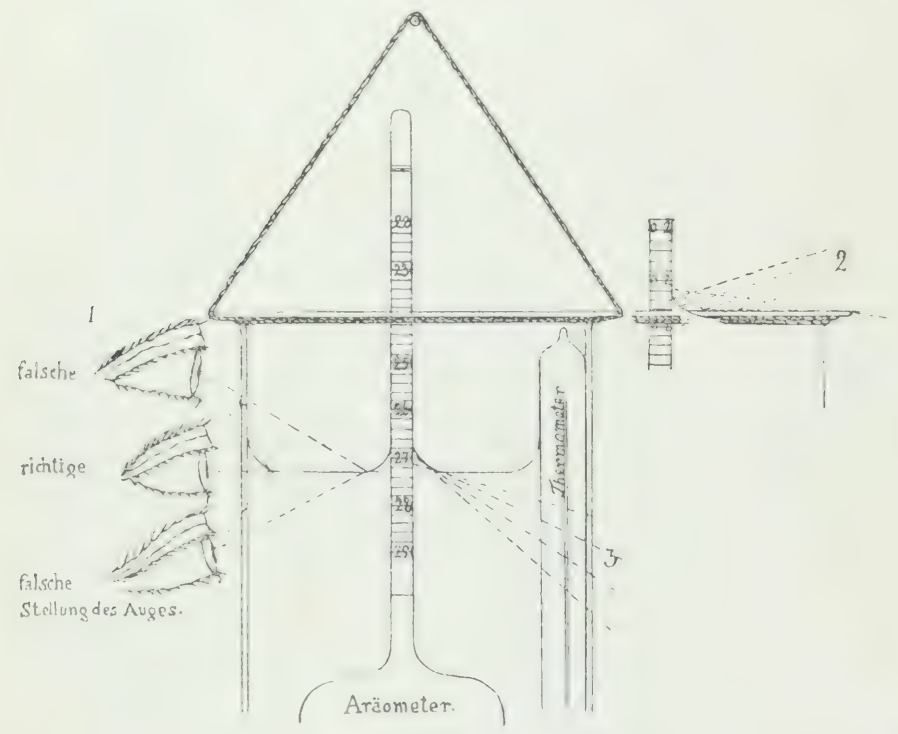

I 866-70 als die einzige, die unter gleichen Umständen stets dasselbe Ergebnis lieferte. Zur Bestimmung des spez. Gew. konnte ich IS66 hier nur Beaune's Salzspindeln erhalten, bei denen die Ablesung mit einer bestimmten Zahl multipliziert werden muß; dies bedingt sehr genaue Ablesung, die ich, soweit überhaupt möglich, nur erreichte, wenn ich das Auge genau auf der Linie des Wasserspiegels hatte, - sobald das Auge nur wenig zu hoch oder zu niedrig war, sah ich den WVasserspiegel als Fläche und die Peil(Visir-)linie bezw. -ebene fehlte, (vgl. I -3 nebenstehender Figur). I 868 hatte ich mehr Zeit, mich um solche Instrumente zu bemühen, aber anfangs konnte ich ebenfalls nur den Salzspindeln ähnliche. wenn auch erheblich größere erhalten; endlich verschafite mir Greiner, Berlin, ein Paar Aräometer den kleineren des "Marine Besteck" ähnlich, - doch nicht von so weitem Spielraum, deshalb etwas genauer. Die vielfachen Versuche, die ich damals anstellte, ergaben sämtlich, daß, je größer das Gefäß3 im Verhältnis zum Aräometer, - sei es in Bezug auf Weite oder Tiefe oder Beides, - je längere Zeit brauchte letzteres, zur Ruhe zu kommen, dabei hatte es stets Neigung, an den Rand des Gefäßses sich zu drängen; am raschesten stellte es sich ein, wenn - wie früher angegeben - dieses nur den nötigen Spielraum ließ, sodaß das Aräometer weder beim Einstellen in das Wasser, noch bei geringer Neigung des Glases den Boden oder die WVandung berührte. Als i. J. I872 $\mathrm{Hr}$. Dr. H. Aे. $\mathrm{Mej}_{\mathrm{C}} \mathrm{Cr}$ für seine Beobachtungen u. a. m. ein Seeschiff $z u$ beschaffen dachte. empfahlen $\mathrm{Hr}$. IV. v. Freedin und andere Herren die er befrug, mich als Führer und Mann von genügender fachlicher Kenntnis um in Bezug auf Takelung, Einrichtung u. dgl. Anhalt zu ugeben. Selbstverständlich wollte er sich ïberzeugen, wie ich die Beobachtungen. mit ihnen verbundene Rechnungen. Zeichnungen u. s. w. ausführen könne. so war für ihn ein halbes Jahr an wird wie vorhin die Schnur, die um das Glas geschlungen ist; in solchem Tauring haben die Zapfen jedoch zu großsc Reibung. Jederzeit kann es vorkommen, daß beim Eingiessen des IVassers, etwas davon auf die Zapfen fällt; sehr wenig kann statt Öls, Talg, Graffit schmierend d. h. Reibung mindernd wirken, das Geringste zuviel (genau wie von jedem andern Schmiermittel) vermehrt die Reibung; sobald dies statthat ist das Gehänge gegeniiber der einfachen Schnur schädlich. Diese fand ich zweckentsprechend auf I I Segelschiffen und 3 Dampfschiffen, - selbst bei Windstärke 10; da die Beobachter alles ihnen Auffällige mir mitteilten, würden sie mir es auch gesagt haben, wenn diese Aufhängung des Glases dic Beobachtung becinträchtigt hätte.

Bei der Ablesung sind drei verschiedene Arten im Gebrauch, die ich in beistehender Zeichnung veranschaulichte; I. die älteste mir bekannte, fand ich i. d. In. der Kieler Bucht mit den verschiedenen Beobachtungen, ihren Lbertragungen, Zusammenstellungen, Nappierungen u. s. w. ich beschäftigt. Dabei fand ich. daßs diese Art und Weise der Ablesung des spez. Gew. des Neerwassers am Aräometer seinen Beobachtern er ebenfalls angegeben hatte; da in solchen Sachen Hr. Geh. R. Prof. Dr. G. Karstin sein Ratgeber war, so mag uieser Herr sie veranlalit haben. Bei passender Gelegenheit kunnte ich damals zeigen, wie leicht, aber schwer bemerkbar, Luftblasen unter einem Aufstreif- oder Auflege-Plättchen bleiben, infolgedessen wurden die Glas-Aräometer nicht damit versehen, sondern für geringeres und größeres spez. (jew, als 1,0220 und 1,0290 sowie für feinere Beoachtungen besondere Aräometer angefertigt. - Ein Schiff von der Grölie, die Sicherheit der Beobachtungen mit genügender Bequemlichkeit verbindet, erwies sich Herm Dr. H. - I. I Ie $1 \mathrm{er}$ 
doch zu kostspielig]. - Allen Herren, die ich zu diesen Beobachtungen veranlaßte, zeigte ich diese Art der Ablesung, gab ihnen auch mit freier Hand ausgeführte, der beistehenden I. ähnliche Zeichnung. Ferner machte ich auf Folgendes aufmerksam: Wenn Luftblasen sich an den Rand des Glases gesetzt hatten, müssen sie mit dem Thermometer abgeschabt werden, damit sie sich nicht beim Messen loslösen und an das Aräometer setzen können, wodurch dieses gehoben, hiermit zur Angabe von zu großem spez. Gew. veranlaßt wird; an der Oberfläche des WVassers im Glase befindliche Luftblasen führt man an des letzteren Rand und zerdrückt sie dort. Luftblasen am Aräometer entfernt man, indem man es vorsichtig auf und nieder bewegt, oder indem man sie an der Wand des Glases zerdrückt, oder mit dem Thermometer abnimmt, schlimmstenfalls klopfe man schwach an den oberen Rand des Glases, um Wasser und Aräometer in zitternde Bewegung zu bringen, dadurch die Blasen abzulösen; dies ist häufig nötig bei Aräometern. die einen besonderen Beschwerungskörper, unten also eine Hohlkehle haben, da die Blasen sich leicht in diese setzen; man zögert, das Instrument herauszunehmen, - weil bei erneutem Einsenken noch mehr Luft an ihm haften bleiben kann: das Abklopfen dauert manchmal recht lange (vgl. Zeitschrift für Naturwissenschaften. Bd. 68. Herausg. Dr. G. Brandes. Verlag C. E. M. Pfeffer, Lcipzig: Bestimmung des spez. Gew. des Meerwassers mittelst Aräometer von A. Schiick. I 896). - Da, wenn Luftblasen aus dem Wasser bezw. vom Glase z.u entfernen waren, das Thermometer dazu ich benutzte, so kam dies in solchem Falle vor dem Aräometer in das Glas, sonst gleich nach ihm, damit beide die Temperatur des Wassers angenommen hatten, wenn ihre Angaben ich ablas. Soweit mir bekannt, taten dies auch die Herren, die zum Beobachten ich veranlasste; - weder sie noch ich hatten daher Gelegenheit zu bemerken, daß ein Aräometer, welches sich bereits eingestellt hatte, seine Einstellung änderte sobald man das Thermometer einsenkte. - Die meisten Beobachter füllten das geschöpfte Meerwasser in Standflaschen, die im oder am Kartenhause ihren Platz hatten, - und maßen das spez. Gew. zu bequemer Zeit; auf Holsatia und Hungaria scheint dies nicht immer tunlich gewesen zu sein. Die Herren waren von mir ersucht, die geleerten Flaschen bis zum Wiedergebrauch, umgekehrt hinzustellen, - auch Flaschen, Glas, Aräometer und Thermometer möglichst oft mit frischem Wasser auszuspülen und zu trocknen.

2) U.S. N. A. Coast Survey Report for 1874 . Appendix No. 16; wiederholt in U.S.N.A. Coast and Geodetic Survey'. Deep-Sea Sonnding and Dredging. By Charles D. Sigsbee. Washington 1880. S. $99-$ » Mit Rücksicht auf zweckmäßiges Anpassen an die Verhältnisse unter denen sie gebraucht wird, ist beistehende Einrichtung für die Küsten-Aufnahme (U. S. N. A.) entworfen vom Assistenten Hilgard. Das Instrument besteht aus einem einzelnen Schwimmer von ugf. 9 Zoll $(22,9 \mathrm{~cm}$.) Länge. Der Maßstab reicht von 1,020 bis I,O3 I um für Einfluß der Wärme genügenden Spielraum zu lassen. Jede Einheit der dritten Dezimale oder Tausendstel der Dichte von Frischwasser ist dargestellt durch eine Länge von 0,3 Zoll (7,62 mm.) die wiederum in 5 gleiche Teile geteilt ist; dies gestattet genaue Schätzung einer Einheit der vierten Dezimalstelle. Dem Schwimmer ist beigegeben eine Kupfer-Kanne, in deren, vorn durch Glas ersetzte Rundung ein Thermometer eingelassen ist. Beim Gebrauch wird die Kanne fast ganz mit Wasser gefuillt, sodaß dieses überfließt, wenn der Schwimmer (das Aräometer) hineingestellt wird; die Ablesung geschieht dann leicht an der Oberfläche des Wassers." - D Die Einrichtung des Aräometers ist

\section{Prof. Hilgard's Ocean-Salinometer abgezeichnet aus: \\ Cins. D. Sigsbee: Deep Sea Sounding and Dredging.}

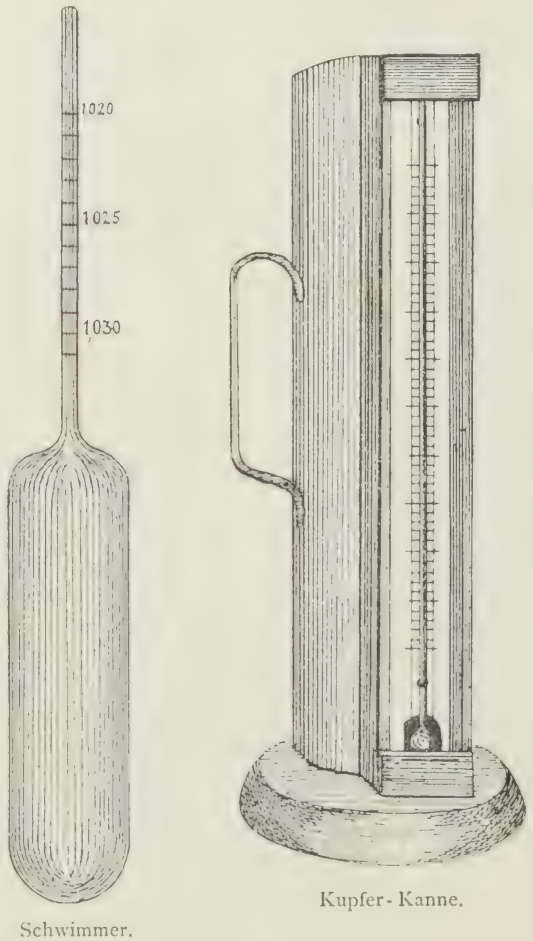

dieselbe wie die des "Marine-Besteck"; ob die Farbe des Glases und der Stoff aus dem die Bodenbeschwerung besteht dieselben sind, - muß dahingestellt bleiben. Diese Einrichtung kann aber keine sichren Ergebnisse liefern, denn es ist schwer, auf See sehr leicht unmöglich, Gewißheit zu erhalten, daß keine Luftblasen am Aräometer haften. Am Land, in einem vor Erschütterungen möglichst geschützten Laboratorium bzw. Studierund/oder Versuchszimmer, mag sich »die Oberfläche des Wassers oder der Wasserspiegel gleich halten mit dem Rande der Kupferkanne, bei den auf See am Bord eines Schiffes (auch wenn es grade liegen könnte) stets vorhandenen Erschütterungen ist dies jedoch nicht 
annehmbar, - nur dann möglich, wenn die Schwingung (kleine Wellenbewegung) des WVassers in der Kanne zur Erschütterung in solchem Verhältnis steht, daß beide sich ausgleichen. Die Kanne darf nicht schief stehen, sonst, selbst bei ruhiger Oberfläche cles in ihr befindlichen Wassers, ist es nicht immer möglich dic Ablesung vorzunehmen, weil man das Auge nicht in clie richtige Lage bringen kann oder die Beleuchtung des Instruments dort ungenügend ist; sollte der Glas-Einsatz durchsichtig sein, so wird doch scheinbar das in einem feststehenden Gefäß befindliche Wasser die Bewegungen des Schiffes mitmachen, die Ablesung also sehr unsicher sein. Selbst wenn die Beobachtung auf diese Weise in einem ruhig schwebenden Glase vorgenommen wird, ist die „Oberfläche des Wassers" - wie aus den punktirten Linien bei 2 der Figur Seite 10 ersichtlich - schwer d. h. nur unsicher zu bestimmen. - Die in I gezeigte richtige Stellung des Auges cinzunehmen fiel mir nie schwer.

Die Anzahl der Beobachtungen des spez. Gew. des Meerwassers aus denen des letzteren Salzgehalt abgeleitet wurde, ist erheblich geringer als die Anzahl der Beobachtungen von Wärme des Obenflächenwassers; nur auf Holsatia ist im Journal — wie bereits erwähnt besonders auf der ersten der hicr vorliegenden Reisen, manchmal spez. Gew. eingetragen, während Oberflächenwärme fehlt. - Zur Umwandlung des spez. Gew. in Salzgehalt benutzte ich die Tabellen von $\mathrm{Hr}$. Martin Knudsen, Kopenhagen [Hydrograpliische Tabellen nach den Messungen von Carl Forch, 7. P. Facobsen, Martin Knudsen und S. P. L. Serensen und unter Beihülfe von Biön-Anderscn, H. F. Hansen, F. N. Niclsen, B. Trolle, Alfred Wölk u. a., herausgegeben von Martin Knudscn. Die Messungen und die Berechnungen erfolgten nach den Vorschlägen und unter der Kontrolle einer internationalen Kommission bestehend aus: H. N. Dickson. Martin Knndscn, O. Krimmel. S. Makaroff, Sir Fohn Murray, Fridtjof Nansen und Otto Pettersson. Kopenluagen: G. E. C. Gad. Hamburg: L. Friederichsen \& Co. I901. Nebenbei sei erwähnt, daß3 für die nötigen Untersuchungen, aus schr verschiedenen Meeresteilen Wasserproben entnommen und nach dem, in Kopenhagen hierfür besonders eingerichteten und ausgestatteten Raum geschafft wurden. Eigenartig erscheint es, daß von deutscher Seite nur von einem unserer Kriegsschiffe eine Probe eingesandt ist; entweder hat man sich nicht an die Rhedercien gewandt, oder man hat die Ersuchen auf eine Weise gestellt, dâ3 die Liffillung untunlich wurde 7. B. cine größere Anzahl Proben auf ciner Reise zu nchmen, wenn 2-3 hinter cinander fahrende Schiffe, jedes ein Paar noch rechtzeitig bringen konnte. Soweit ich die Hamburgischen Rhedereien, Schiffsführer, Steuerleute und Mannschaften kennen gelernt, hätten sie gern den nötigen Raum bewilligt und die geringe Arbeit übernommen, um sic am gewünschten Orte pünktlich auszufuhren; so hätte noch von mehr Gegenden Proben man erhalten können, deren Untersuchung als nutzlos nicht zu betrachten wäre. - Die Beobachtungen der Ausclehnung des Meerwassers bei verschiedener IVärme sind angestellt von Hr. Dr. Cirl Forch, damals P'rivatdocent a. d. Technischen Hochschule in Darmstadt.
Da der hier angegebene Salzgehalt stets größer ist als $3 \%$ so bleibt in Folgendem (ebenso wie in der Tafel) das 3 , fort; die Zahlen bedeuten also die Zehntel und Hundertel um welche der Salzgehalt mehr betrug als $3 \%$.

Jantar. I 885 I $2-5$ bei der Reise von la Guayra nach Colon beobachtete D. D. Holsatia zweimal bis Curaçao, sechsmal von Gallinas Pt. bis Colon. Bei allen, in der Nähe von Kuisten angestellten Beobachtungen hat man sich gefaßt zu machen auf recht verschiedene Angaben. Bald kann frisches Wasser in ungewöhnlicher Menge sich längere Zeit mit dem Meerwasser mischen, bald kann salzärmeres, bald salzreicheres IVasser aus der Tiefe aufsteigen - ohne daß inmer seine Wärme Anhalt dafür giebt. $\mathrm{W}$ cnn und wie weit das eine oder andre dient, Annäherung an Land, Erscheinen oder Fortbleiben von Fischen und Mollusken, Fern- bezw. Nachwirken anderer Erscheinungen (Erdbeben, Stürme u. m.) anzudeuten und zu erklären, können nur zuverläßige, vielfache Beobachtungen lehren. Wer immer mit Hingebung an die Sache solche anregt, sowie ihre $\mathrm{Zu}$ sammenstellung vornimmt, der hofft auch, daß letztere zur Vermehrung jener anregen, die Abweichungen größtmögliche Aufmerksamkeit erhalten, bezw. herbeiführen werden. - - Bei der oben erwähnten Fahrt fand Holsatia vor dem Golf von Triste nahe querab Tucacas Pt. ugf. $30 \mathrm{Sm}$. von Land salzärmeres Vasscr $=55$ als 4 Std. später d. i. $40 \mathrm{Sm}$. nach Curaçao zu $=62$; so gut wie derselbe Salzgehalt $=6 \mathrm{I}$ ist gemessen bei Pt. Gallinas, salzreiches $=70$ bei $\mathrm{K}$. de Vela beidemal nur ugf. IO $\mathrm{Sm}$. von Land; von den nächsten 4 Bbchtgn. zwischen Savanilla Pt. bis ugf. quer vom Golf von Morosquillo zeigen die ersten beiden 56 und $59 \mathrm{~d}$. i. zwischen 55 und 60 ; die letzten zwei (vor dem Golf von Darien) nur 53. Am I II, auf der Rückreise von Colon, ebenfalls vor dem Golf von Darien und etwas SWlich der vorigen ergaben zwei Bbchtgn. $=56 \mathrm{~d}$. i. etwas mehr als eine Woche vorher. - Von St. Thomas heimwärts liegen von demselben Schiffe vor I 29,30: 5 Bbchtgn., die ersten beiden in der Nähe von $20^{0} \mathrm{~N} .64-63^{1 / 2^{0}} \mathrm{IV}$. verhältnismäßig salzarm $=52$, die nächste bei $22,2^{0} \mathrm{~N}$. $6 \mathrm{I}_{1,4}{ }^{\circ} \mathrm{IV}$. soviel salzreicher $=75$, dann bis $23,1^{\circ} \mathrm{N}$. $60,5^{\circ} \mathrm{IV}=6 \mathrm{I}$.

Februar. D. D. Paranagua fand zwischen $23,1^{\circ} \mathrm{N}$ $59,9^{\circ} \mathrm{WV}$. bis $30,3^{\circ} \mathrm{N} .68,8^{\circ} \mathrm{IV} .72-68-71-66-72-69-73$ und 66; also meistens ugf. 70 ; das salzärmste war bei $26,1^{\circ} \mathrm{N} .64^{\circ} \mathrm{W} .-26,5^{\circ} \mathrm{N} .64,5^{\circ} \mathrm{WV}$. und $30,3^{\circ} \mathrm{N} .68,8^{\circ} \mathrm{WV}$; das salzreichste $=73 \mathrm{lag}$ nicht bei der ausnahmsweise hohen Wasserwärme im Süden, sondern bei $30^{\prime \prime} \mathrm{N} .68_{1,5} \mathrm{II}^{\circ}$ - Sargasso, und zwar viel traf man am 2. bei $26,50 \mathrm{~N}$. $64,5^{\circ} \mathrm{W} ., 26,9^{\circ} \mathrm{N} \cdot 65^{\circ} \mathrm{W}$. und $27^{\circ}$ I $8^{\prime} \mathrm{N} \cdot 65^{\circ} 35^{\prime} \mathrm{W}$

Miïz. Die ältesten mir vorliegenden Beobachtungen sind die I. 13. M. S. Challenger is 33 III $12-15$ und 25-3I; auf ihm fand man von I $S^{\prime \prime} 5 \sigma^{\prime} \mathrm{X} .59^{\circ} 35^{\prime} \mathrm{WV}$. bis I $8^{\circ} 28^{\prime} \mathrm{N} \cdot 63^{\circ} 35^{\prime} \mathrm{W}$. bei 4 Wasserproben zuerst 3,64 dann 3,61 \%, also mit Annahherung an die Antillen abnehmenden Salzgehalt; ron St. Thomas nach den Bermudas nahe $\mathrm{N}$. steuernd sind 9 Untersuchungen angestellt, von denen die ersten $3=\sigma_{5}$ und $\sigma_{4}$ bis $21^{\circ} 26^{\prime} \mathrm{N} .65^{\circ}{ }^{\prime} \sigma^{\prime} \mathrm{W}$. als gleich $z u$ betrachten sind und ebenso wie auf der Hinreise in verhältnismälsiger Nähe der Karaibischen Inseln etwas salzämeres 
Wasser ergeben, da der Gehalt von letztgenannter Gegend bis $27^{\circ} 49^{\prime}$ N. $64^{\circ} 59^{\prime} \mathrm{WW}$. am 31. zu $70 \mathrm{zu}-$ nimmt. - I885 III 13 abds. gelangt Holsatia in vorliegendes Gebiet bei $25,9^{\circ} \mathrm{N}$. $60^{0} \mathrm{~W}$. nach Turks I. Paß steuernd, wohin III I 6 man kommt. Bis $24,9^{\circ} \mathrm{N}$. $62,1^{\circ} \mathrm{W}$ beobachtete man 68 und 67 , von dort aber nimmt der Salzgehalt ab bis $24^{\circ} \mathrm{N} .64,1^{\circ} \mathrm{W}$. zu 64 und $58 \mathrm{um}$ dann stark zu schwanken zunächst zu 68 zuzunehmen (volle 10 Einheiten der letzten Dezimalstelle) dann wieder 63,70 u. s. w.; bei Annäherung an die Riffe nur 64, nicht weit von ihnen 66 im $P a ß 67$, jenseits desselben bis Perle Pt., der NWpünte Haïti's 65. - Auf dem Wege von Port au Prince nach Colon sind die Angaben im Ganzen verhältnismäßig niedrig, nur zweimal 65 (zwischen Caymites und K. Dame Marie, dann bei $17,9^{\circ} \mathrm{N} .75^{\circ} \mathrm{W}$.), bei $14,7^{\circ} \mathrm{N} \cdot 77,1^{\circ} \mathrm{W}$. sogar nur 52 von hier bis $10,3^{\circ} \mathrm{N} .79,3^{\circ} \mathrm{WV}$. wieder ansteigend $\mathrm{zu}$ 63. - Sargasso meldet Challenger in kleinen Mengen III 29 bei $24,2^{\circ} \mathrm{N} \cdot 65,4^{\circ} \mathrm{W}$, in bedeutenden zufällig da, wo sein Weg den der Paranagua kreuzt bei $26,9^{\circ} \mathrm{N} \cdot 65,2 \mathrm{~W} \cdot-$ p. $10^{\mathrm{h}}$ bei $27^{\circ} \mathrm{N} \cdot 65,1^{\circ} \mathrm{W}, \mathrm{G}$. auch leichtes Meerlenchten.

April. I. B. M. S. Challenger I873 IV I, 2 fand bei $29^{\circ} 5^{\prime} \mathrm{N} .65^{\circ} \mathrm{I}^{\prime} \mathrm{IV}$. und $29^{\circ} 5 \mathrm{I}^{\prime} \mathrm{N} .65^{\circ} 8^{\prime} \mathrm{IV}, \mathrm{G}$. 3,70 bezw. $3,69 \%$ also kenntlich mehr als vor St. Thomas. - Im Süden auf der Fahrt von Colon nach Puerto Cabello bemerkte Holsatia I885. IV I-5 ungemein abweichenden Salzgehalt (vgl. IVärme); vor ersterem Ort, dann ugf. $N$. von Manzanillo Pt. 62 und 66 , bei $9,9^{\circ} \mathrm{N} .78,7^{\circ} \mathrm{WV}$. (ugf. N. vom G. v. St. Blas) den ausserordentlich hohen von $3.94 \%$, an derselben Stelle war auch die Wasserwärme gering $\left(22^{\circ}\right.$ gegen vorher $26^{\circ}$ nachher $25^{1} / 2^{0}$ C.), doch ist dies kein regelmäßiges $\mathrm{Zu}$ sammentreffen, wie die späteren Beobachtungen zeigen. Vor dem G. v. Darien nahe derselben Gegend in der man im Januar 56, 53, 59 angab, findet man jetzt 67-6I-69-6I-68; bei Savanilla Pt. 66 und 62, bei K. A guja 64, gleich darauf zweimal nur 52; SWl. und NEl. von $\mathrm{K}$. de Vela wierer 62 letzteres sogar bei nur $20^{1} /{ }^{\circ} \mathrm{C}$; ; im Januar lag ugf. in der Mitte beider Stellen eine mit 70. An der NE. Seite der Halbinsel mit Bahia Honda, sind jetzt 67 und $\sigma_{4}$ (Januar 61 ); zwischen Aruba I. und Paraguana Halbinsel 65--65; ugf. querab Curaçao I. 73, dann 62-61-65. Von La Guayra nach Mayaguez bestimmt, I 885 IV IO-I2 hat das wärmste auf dieser Strecke gemessene Wasser $3,69 \%$ Salz, bis $13,1^{\circ}$ N. $67,3^{\circ}$ IV. G. nimmt dies ab zu 60 , dann bis $14,5^{\circ} \mathrm{N}$. $67,5^{\circ} \mathrm{WW}$. zu bis 67 (3, 6.69$)$; nahe dasselbe auf gleicher geogr. $\mathrm{Lg}$. bei $15,2^{\circ} \mathrm{N}$. $(3,678)$, bei $16^{0} \mathrm{~N}$. wieder nur 60 , weiter bis zur SW. Ecke Portorico's 70-65-70; im Ganzen zeigte es sich Slich von $15^{\circ} \mathrm{N}$. eher leichter als Nlich davon, ähnlich wie Ende März ugf. $8^{0}$ geogr. Lg. westlicher. Von St. Thomas heimwärts liegen vor 10 Beobachtungen IV I 7, I 8 zwischen $20,2{ }^{\circ} \mathrm{N} .63,5^{\circ} \mathrm{W} .-24,4^{\circ} \mathrm{N} .59,6^{\circ} \mathrm{W}$.; sie ergaben $7 \mathrm{I}-65-72-68-67$. (Die Mitteilungen vom Januar zeigen besonders bei $20^{\circ} \mathrm{N}$. erheblich geringeren Salzgehalt, bei $22,3^{\circ} \mathrm{N}$. $61,6^{\circ} \mathrm{W}$. größeren [vgl. Juli], nordwärts hiervon wieder weniger). 1902 IV 23,24 von $20^{\circ} 53^{\prime} \mathrm{N}$. $60^{\circ} 22^{\prime} \mathrm{W}$. bis $18^{\circ} 2 \mathrm{I}^{\prime} \mathrm{N}$. $64^{\circ} 26^{\prime} \mathrm{W}$. stellte 3 Beobachtungen an Hr. Dr. G. Schott auf D. D. Croatic: 66-66-62; erivägt man, daß an vorhergehenden Tagen $68-69$ bemerkt ist, so erkennt man auch hier etwas Abnahme bei Annäherung an die Antillen, die größte zwischen ihnen. IV. 27 und 30, bei der NIVEcke Portorico's, im Mona Paß und Slich der Stadt San Domingo fand derselbe Herr 60-58-59. Sargasso sah Challenger in großen Haufen 1873 IV I bei $29^{\circ}$ N. $65^{\circ}$ IV.; D. D. Holsatia I 885 IV 17 bei $2 \mathrm{I}, 1^{\circ} \mathrm{N} \cdot 62,7^{\circ} \mathrm{W}$. in kleinen Feldern; Hr. Dr. Schott I 902 IV 24 bei $19^{\circ} 6^{\prime} \mathrm{N} .63^{\circ} 8^{\prime} \mathrm{W}$. einzelne Bündel.

Mai. Im Anschluß an die letzten, die Beobachtungen von $\mathrm{Hr}$. Dr. G. Schott zuerst wiedergebend, so fand er auf dem Wege von San Domingo nach la Guayra $1902 \mathrm{~V}$ I, 2 bei $15^{\circ} \mathrm{II}^{\prime} \mathrm{N}$. $69^{\circ} 6^{\prime} \mathrm{W}$. und II ${ }^{\circ} 23^{\prime} \mathrm{N}$. $67^{\prime \prime} 29^{\prime}$ IV. 59 bzw. 57 also verhältnismäßig geringen Salzgehalt, verhältnismäßig hohen (bei erheblich geringerer Wärme) auf dem Wege nach Carúpano V i I bei II ${ }^{\circ} 22^{\prime} \mathrm{N} .64^{\circ} 33^{\prime} \mathrm{W}$. und $10^{\circ} 54^{\prime} \mathrm{N}$. $63^{\circ} 37^{\prime} \mathrm{W}=65$ bzw. 6r. (Bei ersterem setzte Hr. Dr. Schott ein Fragezeichen, offenbar in Bezug auf die nur zu vermutende Herkunft des Wassers; die Beobachtungen der Holsatia, von denen genannter Herr keine Kenntnis hatte, zeigen, daß in jenen Gegenden nicht geringe Unterschiede vorkommen können [wie erwähnt an Küsten überhaupt] wenn nicht beständige, breite und tiefe Strömungen vorhanden sind). V I2, halbwegs zwischen Carúpano und Trinidas moch immer bei seringer Wtarme 58 . Der geringe Salzgehalt 3,30 \% in Hafen von Port of Spain ist erklärlich durch die Landabwässerung, doch kann er dort gewiß auch erheblich höher beobachtet werden. $\mathrm{V}$ I4, I5 von Port of Spain nach $\mathrm{St}$. Thomas fand Hr. Dr. Schott Wwärts Grenada's von ihm sogleich als auffallend gering bezeichneten Salzgehalt $=3,500 / 0$, auch bei $13^{\circ} 53^{\prime} \mathrm{N} .63^{\circ} 10^{\prime} \mathrm{W}$. ist er noch niedrig 54 , erst bei $15^{\circ} 58^{\prime} \mathrm{N}$. $63^{\circ} 58^{\prime} \mathrm{W}$. wird er wieder 59 , zwischen St. Croix und St. Thomas 6o. Mit Ausnahme der erwähnten Stellen, ist auch hier Slich von $15^{\circ} \mathrm{N}$. weniger Salzgehalt als nördlich davon (selbstverständlich ist $15^{\circ} \mathrm{N}$. nicht zu betrachten als die Linie mathematischer Geographie, sondern nur als ungefähre Gegend). V I7, I8 von St. Thomas nach der Nküste $\mathrm{Haïtis,} \mathrm{berichtet}$ Hr. Dr. Schott bei $19^{\circ} 2 \mathrm{I}^{\prime} \mathrm{N}$. $68^{\circ} \mathrm{I} 4^{\prime} \mathrm{W} .=6 \mathrm{I}$, etwas Nlich der Nkante der Monte Christi BK. 62; in der Lagune von liort Liberté 58, kann hier wohl höher und niedriger gefunden werden. Auf der Heimreise HaitiHàvre V 22-26 von $20^{\circ} 4 \mathrm{I}^{\prime} \mathrm{N}$. $7 \mathrm{I}^{\circ} 26^{\prime} \mathrm{W}$. bis $30^{\circ} 22^{\prime} \mathrm{N}$. 6r " ${ }^{\prime \prime} \mathrm{W}$. beobachtete Hr. Dr. Schott $6_{3}$ bis 68 , d. i. in größerer Entfernung von den Inseln zunehmenden Salzgehalt. - Von D. D. Holsatia liegen noch vor $1886 \mathrm{~V}$ 9, 10: 6 Beobachtungen zwischen $2 \mathrm{I}, 2^{\circ} \mathrm{N}$. $60,6^{\circ} \mathrm{W}$. bis St. Thomas; wie schon erwähnt ist bei ihnen nicht angegeben die Wärme des Wassers im Glase bei der Messung, - das allein macht sie unsicher, in der Karte und hier werden sie nur wiederholt um deutlich zu zeigen, wie unangenehm dicses Fehlen wirkt, wäre die Wärme nur $\mathrm{I}^{0}$ anders gewesen, so ergäbe dies schon 3-4 Einheiten der letzten Dezimale; gemeldet sind 73-75 abnehmend zu 7I, hier also dieselbe Erscheinung der Abnahme mit Annäherung an die Inseln, aber fortlaufend sehr hoher Salzgehalt, wie er sonst eher ausnahmsweise gefunden wird. - - 
Sarcasso sah Hr. Dr. G. Schott: nordwärts von Mona Paß in großen Feldern, bei der Monte Christi Bk. in kleinen Büscheln; bei $23^{\circ} 3^{\prime} \mathrm{N}$. $69^{\circ} 4^{\prime} \mathrm{W}$. vereinzelte ganz lileine Büschel; $25^{\circ} 32^{\prime} \mathrm{N}$. $66^{\circ} 17^{\prime} \mathrm{IV}$. schr viele aber kleine Stücke, $28^{\circ} 2^{\prime}$ N. $63^{\circ} 38^{\prime} \mathrm{W}$. sehr viel; $30^{0} 22^{\prime}$ N. 6I ${ }^{\circ} 4^{\prime}$ W. wenig.

Juıi. Die nördlichsten und westlichsten Beobachtungen werden mitgeteilt vom D. D. Hungaria bei der Rcise Hâve-Vera Cruz 1887 VI I8-25, von $30^{\circ} 20^{\prime} \mathrm{N} .64^{\circ} 37^{\prime} \mathrm{W}$. bis $20^{\circ} 5 \mathrm{O}^{\prime} \mathrm{N} .94^{\circ} 38^{\prime} \mathrm{W}$. Im nördlichsten 'Teil bis $29^{\circ} 25^{\prime} \mathrm{N}$. $67^{0} 37^{\prime} \mathrm{W}$. ist verhältnismäßig geringer Salzgnlaalt: 6I-59-60-55-59 (i886 II 4 beobachtete Paranagua nahe bei: 7I). Von

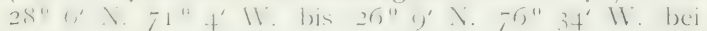
rasch zunchmender Wasserwärme nimmt er stark schwankend zu: 64-74, 63-73. In der Florida Straße ist er ebenfalls sehr veränderlich: wenig südlich vom NWEnde des Providence Kanal und SElich von K. Fiorida 60, Swlich von dieser Stelle 68, bis Sombrero Cay abnehmend 2457 , dann wieder wachsend bis $24^{\circ} 10^{\prime} \mathrm{N} .83^{\circ} 25^{\prime} \mathrm{W}$. $\mathrm{zu}$ 72. (Im ersten Augenblick erscheint dies befremdend, weil in stärksten Teil des sogen. Golfstroms - ; man wird sich jedoch sogleich sagen, daß - abgesehen von möglicher Einwirkung des kalten, nordamerikanischen Küstenstromes - die hier gerviß starke Landabwässerung bald an dieser bald an jener Stelle sich kenntlich macht. Da sie im Juni, besonders in seiner letzten Hälfte dort schon ebenso warm sein kann wie das Meerwasser, so kann der, nur an Wärmemessungen Gewöhnte glauben, man befinde sich im vollen Golfstrom - ohne es an der betreffenden Stelle $z$ sein. Strömungen sind keine regelmäßigen Linien, sondern unregelmäßig wellenförmig sowohl in der Richtung der Wasserfläche als in der senkrechten). Bis zur Yucatan Bk. nimmt der Salzgehalt wieder ab bis 60 , an der Westseite derselben $z u$ und $\mathrm{ab}=-66-63$; im Golf von Campeche ist er hoch: 72-68-73. I 885 VI II von Hâvre nach K. Haïti bestimmt gelangt D. D. Holsatia nach $30,4^{\circ} \mathrm{N} .59,8^{\circ} \mathrm{WV}$; ; dort Salzgehalt $3,68 \%$ abnehmend $z u, 59$ bei $29,5{ }^{\circ} \mathrm{N}$. $61.2{ }^{\circ} \mathrm{IV}$. dann wieder zunehmend zu 66 selbst 72 bei $26,5^{\circ} \mathrm{N}$. $64 .{ }^{\circ} \mathrm{IV}$.; es folgt $67-7 \mathrm{I}-64-65-6 \mathrm{I}$ bei $24^{\circ} \mathrm{N}$. $67,6{ }^{\circ} \mathrm{W}$.; weiter $68-68-67$ bis $22,6{ }^{\circ} \mathrm{N}$. $69,3^{\circ} \mathrm{W}$. von hier $\mathrm{zu}$ $20,3^{\circ} \mathrm{N} \cdot 72,3^{\circ} \mathrm{W} .=63$ und 64 . Der geringste ist also im nördlichsten Teil, aber nicht ausgesprochen bei der geringsten Wärme, da dort bei gleicher $\left(23^{\circ} \mathrm{C}\right.$.) auch 68 man fand. - I886 VI 15, 16 war auf Holsatio beobachtet bei der Fahrt St. Thomas-Havre von

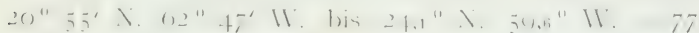
schwankend abnehmend $z u 72$, jedoch gilt hierfü das bei den Mitteilungen vom selben Schiff i $886 \mathrm{~V}$ Gesagte: dic Warme des W'assers bei der Beobachtung ist nicht angegeben; sonst wäre hier auffallig. daß mit Entfernung von den Inseln der Salzgehalt nicht zu- Sondern abnimmt. - Sargasso ist geschen: von Hungaria in Strichen bei $29^{\prime \prime} 25^{\prime} \mathrm{N} .67^{\circ} 37^{\prime} \mathrm{W}$., in großen Maßsen bei $27^{\prime \prime} 4^{8^{\prime}} \mathrm{N} .7 \mathrm{I}^{\circ} 5 \mathrm{O}^{\prime} \mathrm{W}$,; hier auch viele fliegende Fische; nach Zeichen im Berichtsbuch gilt letzteres Beides vielleicht bis $27^{\prime \prime} \mathrm{I} 4^{\prime} \mathrm{N} .73^{\circ} 12^{\prime} \mathrm{IV}$. Außserdem ist angegeben in der filorida Straße: viele buntgefleckte Springer (Cetaceen), Landvögel und Schmetterlinge; starke
Strömung mit Kabbelungen, Wasserwärme gleichmäßig $28-29^{\circ} \mathrm{C}$; von $24^{\circ} \mathrm{IO} 0^{\circ} \mathrm{N} .83^{\circ} 25^{\prime} \mathrm{IV}$. bis $23^{\circ} 48^{\prime} \mathrm{N}$. $85^{\circ} 49^{\prime}$ IV.: Stromscheeren. -

Juli. D. D. Hungaria von Vera $\mathrm{Cruz}$ nach Tampico, beobachtet 1887 VII I unweit der Mündung eines kleinen Flußes bei $19^{\circ} 27^{\prime}$ N. $96^{\circ}$ I $3^{\prime} \mathrm{WV}$. 59: von Tampico nach Progreso VII 4,5 von $2 I^{\circ} 56^{\circ} \mathrm{N}$. $95^{\circ} \mathrm{I} 8^{\prime} \mathrm{WW}$. bis $21^{\prime \prime} \mathrm{I}^{\prime} \mathrm{N}$. $90^{\circ} \mathrm{I} 9^{\prime} \mathrm{IV}, 6 \mathrm{I}-58-62-5 \mathrm{I}$ letzteres unweit der NiVEcke der Yucatan Halbinsel (Sisal). Von P'rogreso nach Haiti (20-30 Sm. von Land) VII 8-IO NElich von K. Catoche nahe dem Rande der Yucatan Bank 55, SSE von K. S. Antonio 67 . Slich von I. of Pines 66 bei $21^{\circ} 8^{\prime} \mathrm{N}$. $82^{\circ} 45^{\prime} \mathrm{IV}$. 70, im E. von K. Cruz bis Süd von Damas Cay: 76-69-72. - Von Haiti nach St. Thomas VII 2I NNEwärts von K. Engano (Nl. der Wseite des Mona Paß) 76 ; St. Thomas-Hâvre zwischen $21,7^{\circ} \mathrm{N}$. $6 \mathrm{I}, 7^{\circ} \mathrm{W}$. bis $23^{\circ} 46^{\prime}$ I. $59^{\circ} 47^{\prime} \mathrm{IV}:$ : 64-58-63. 一 1885 fand D. D. Holsatia, St. Thomas-Hâvre

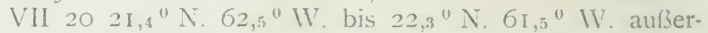
gewöhnlich hohen Salzgehalt: $82-84-83$; dann bis 24.3 ${ }^{\circ}$ N. 59,6 $\mathrm{IV}$. 70-70-64-62. - Hungaria sah 1887 VII I grofse Stücke bewachsenes Treiblholz: am EEnde der Yucatan Bank VII 8: viel Sectang. Sargasso vereinzelt bei $23^{\prime \prime} 46^{\prime}$ N. $59^{\prime \prime} 47^{\prime} . \mathrm{IV}$.

August. Keine Beobachtungzn.

September. D. D. Hungaria Hâvre-St. Thomas I 887 IX 9 zwei Beobachtungen bei $20^{\circ} \mathrm{I} 3^{\prime} \mathrm{N}$. $6 \mathrm{I}^{\circ} 5^{\prime} \mathrm{IV}$. $-73,19^{\circ} 50^{\circ} \mathrm{N} .62^{\circ} \mathrm{O}^{\prime} \mathrm{WV}=68$. Sargasso vereinzelt bei der letzten.

Oktoher. D. D. Hungaria. St. Thomas-Hàvre I $887 \mathrm{X}$ i4 cine Beobachtung $22^{\circ} 27^{\prime}$ N. $59^{\prime \prime} 53^{\prime} \mathrm{W}$. $=64$, auch Sargasso.

Norember. D. 1). Holsatia: Hâve-St. Thomas I $885 \mathrm{XI} 25,26$ zwischen $22^{\prime \prime} \mathrm{I} 3^{\prime} \mathrm{N} .59^{\prime \prime} 55^{\prime} \mathrm{IV}$. bis $21,2^{\circ}$ N. 60, ${ }^{\circ}$ IV. nimmt der Salzgehalt ab: 66-66-62; von $20,7^{\circ} \mathrm{N} \cdot 61,3^{\circ} \mathrm{WV}$. nimmt er wieder $z u: 62-67-69-69$.

Dezember. D. D. Holsatia; Hàre-St. Thomas. I 884 XII 25, 26. Von 22,6 $0^{\circ}$ N. 59,6 ${ }^{\circ}$ II. G. bis $18^{\circ} 49^{\prime} \mathrm{N} .63^{\circ} 3^{\prime} \mathrm{WV}$. G. nahm der Salzgehalt ab von $63 \mathrm{zu}$ 53. - St. Thomas-La Guayra XII 28, 29; I $6,8^{\prime \prime} \mathrm{N}$. $64,9^{\prime \prime} \mathrm{W}$. und in $16^{\circ} 27^{\prime} \mathrm{N}$. $65^{\prime \prime} 10^{\prime} \mathrm{W}$. beobachtete man 46 , bei $15,8^{\circ} N .65,4^{\prime \prime} \mathrm{IV} .57$, dann Slich von $15^{\circ} \mathrm{N}$. bis $12^{\prime \prime} \mathrm{I} 4^{\prime} \mathrm{N}$. $66^{\prime \prime} 20^{\prime} \mathrm{IV} .55$ Während die ersten beiden Angaben recht niedries sind, schließen dic anderen an die $17^{1 / 2}$ Jahr später von $\mathrm{Hr}$. Dr. G. Sihott weiter östlich und westlich beobachteten. sind aber erheblich geringer als die von demselben Schiffe $3^{1 / 2}$ Monate später zwischen La Guayra und Portorico gemachten. - Sargasso: keine Mitteilungen.

Die Herren, die (ich kamn es nicht anders nennen) in der Zwangslage sind, die wenigen vorhandenen Beobachtungen betr. Salzgehalt der Meere zusammenzustellen und zu mappieren, die sind vielleicht betroften von den vielen, manchmal nicht unbedeutenden Abweichungen: bedenkt man jedoch, dals auch Wärmebeobachtungen durchaus nicht genau übereinstimmen, das In- und Durcheinandergreifen der Mceresströmungen nur ausnahmsweise erkannt werden kann, - so, darf man sich sagen, je mehr Beobachtungen man erhält, je mehr Abweichungen werden sich finden. Zur Feststellung, 
wie weit diese abhängen von Jahreszeiten, - wie weit von Ausnahmefällen in deren Eigenheiten, Stürmen, besonders Wirbelstürmen, würde man bestrebt sein müßen, die Anzahl der Beobachter erheblich zu vermehren, sie mit besseren Instrumenten und Anleitungen zu versehen, als in den meisten Fällen bisher geschehen ist.

In Bezug auf Zuverlässigkeit der hier vorliegenden Beobachtungen von Handelsschiffen so leben noch Herren die sagen können, ob die nötige Mühe ich mir gab, sie herbeizuführen; den Beobachtern selbst stand keinerlei persönlicher Nutzen, Belohnung, Auszeichnung, Dankschreiben u. dgl. in Aussicht; sie wußten, daß sie keinem Schaden, Vorwurf, selbst nur einer bösen oder verdrossenen Miene ausgesetzt waren, wenn sie ablehnten, die Beobachtungen vorzunehmen oder sagten, sie hätten die Neigung dazu verloren. - Stets wurden sie ersucht, die Zehntel der Thermometer-Grade zu schätzen, fand ich, daß es nicht geschehen war und sprach dariber, so erhielt ich die Antwort: Andre sind nicht so peinlich, warum sind Sie es? Da es sich dabei um höchstens $1 / 2{ }^{\circ} \mathrm{C}$. handelt, so ist der Meistbetrag hierdurch möglichen Fehlers $=2$ Einheiten der letzten Stelle oder $2 / 100$ Procent des spez. Gew. - Der Einfluß der Oberflächen-Spannung des Wassers war s. Z. mir unbekannt; wenn, bei der geringen Fläche, er die Ausdehnung der Wassermenge, mit ihr das spez. Gew. ändern kann, -wird (soweit Beobachtungen der Schiffsbesatzung in Betracht kommen) er sehr selten abzuwenden sein. Zur vorgeschlagenen Beseitigung nötige Stoffe erfordern Platz, sie selbst Zeit. Für jede Messung des spez. Gew. (aus dem der Salzgehalt abgeleitet wird) rechne ich jetzt $3-5$ Minuten; das ergiebt für 6 hintereinander: $18-30$ Minuten; noch mehr Zeit werden sehr Wenige daran wenden können.

Nochmals zurückkommend auf die in örtlichen Verhältnissen liegenden Abweichungen, so ist für gewisse Nebenumstände in Betracht zu ziehen, daß verschiedene Menschen auch je nach ihrer Veranlagung zu deren Beachtung bezw. Erkennen verschiedenartig geeignet sind. Es bemerken nicht alle Beobachter, daß selbst in den Passaten das Gewölk derselben Schicht nicht gleichmäßig zieht, sondern teilweise eine Zeitlang zu stocken scheint, wo dies geschieht sich zusammenschiebt, das Meer beschattet und im beschatteten Teil dic Verdunstung geringer wird; das dafür geeignete Auge erkennt dies daran, daß dort der vom Wasser aufsteigende Dunst nicht allein deutlicher ist, sondern auch die schnecken- oder flockenförmigem Gebilde die in geringer Höhe über dem Wasser vom Dunst sich ablösen, nicht so dicht beieinander sich befinden, auch die Höhe des Dunstes geringer ist als an den nicht beschatteten Gegenden. Wer bei starkem Sonnenschein an ihm ausgesetzten Stellen des Decks oder in der Takelung sich aufzuhalten hatte, der kann auch bemerkt haben, daß die Sonne nicht gleichmäß3ig »brennt«, - dann sind wohl in größerer Höhe Anhäufungen des Dunstes vorhanden, die nicht dicht genug, um als Wolken erkannt zu werden doch Wärme beanspruchen um sich zu verteilen, diese also tieferen Schichten entziehen, in der obersten Schicht des Meeres-Verdunstung, mit ihr den Betrag des sonst vorhandenen Salzgehaltes mindern.
Ferner ist in Betracht zu ziehen die ungleiche Bewegung der untersten Luftschichten d. i. die ungleiche Windstärke, die bald strichweise bald, sozusagen, fleckenweise sich kenntlich macht, dementsprechend Verdunstung fördert oder mindert. -

Kleinigkeiten vereinzelt, mögen unmeßbar oder nur als kleine Underschiede in der Messung bleiben, ihr Zusammentreffen kann befremdende Unterschiede veranlassen. - Die Erwähnten sind nur ein Paar der möglichen; bei starker Wellenbewegung sind sie vielleicht nie bemerkbar, - da der Seegang in den Passaten meist nur mäßig ist, so mögen sie Einem oder Anderem auffallen ohne daß diese im Allgemeinen bessere Beobachter sind als Diejenigen, die sie nicht bemerken; letztere sind wieder für Dinge empfänglich, die an jenen spurlos vorübergehen. Es ist nicht alles Einbildung Anderer was selbst zu bemerken man nicht im Stande ist.

\section{Tafel 3.}

\section{Spezifisches Gewicht ihrer Oberfläche $=4$ St.} Westindischer Gewässer bei der Wärme

Auf dieser Tafel und im Folgenden ist, wie jetzt allgemein gebräuchlich, als Grundlage für spez. Gew. (d. i. $=$ I) angenommen: das Gewicht des destillierten (frischen) Wassers bei $4^{0} \mathrm{C}$; abgekürzt geschrieben: hier ist das spez. Gew. = 4 St. Da es stets größer ist als $\mathrm{I}, 02$, so sind diese drei Ziffern fortgeblieben, die gegebenen Zahlen sind also Tausendstel und Zehntausendstel des spez. Gew. (dessen dritte und vierte Dezimale).

Das spez. Gew. des Meerwassers hat gewissen Einfluß auf die Meeres-Strömung̉en; die Größe festzustellen dürfte kaum möglich sein wegen geringer Anzahl sowie ungleicher Verteilung der Beobachtungen. Abhängig ist hier das spez. Gew. von dem Betrage der mit dem Wasser verbundenen oder von ihm aufgenommenen, sonst festen Stoffe (unter denen Salz weit überwiegt) sowie der Wärme desselben, die wieder abhängt von Jahres- und Tageszeit, dann kommen in Betracht Zufälle, wie sie bei ,Salzgehalt" angedeutet sind. Neben den vom Winde hauptsächlich veranlaßten Drift-, Abflußund Ersatz-Strömungen muß vorhanden sein eine, wenn auch geringe, die bei gleichem Salzgehalt an der MeeresOberfläche vom wärmeren nach dem kälteren Wasser gerichtet ist, also dem Sonnenstande entspricht; sie ist nach Norden und Süden als beständig anzusehen; indes je nach der Jahreszeit sowohl ungleich, als ihre Grenzen ändernd; außerdem folgt sie der Sonne während des Tages nach Westen und Osten; mit anderen Worten: wenn die Gegenden über denen das wärmende Gestirn bis dahin stand abgekühlt sind, muß das Wasser derer über denen es steht, also der wärmsten ebenso nach jenen abfließen, wie nach denen, die noch erwärmt werden sollen: weil das Wasser durch Erwärmung an Umfang zunimmt wobei dieselbe Maß-Menge an Gewicht 
verliert, sodaß seinc Oberfläche höher zu stehen kommt als die der kälteren Umgebung. Das liältere, bei gleichem Maße also schwerere Wasser drängt sich unter das leichtere, hebt dies gewissermaßen, verstärkt dadurch jenes Abfließen. Wie erwähnt mag der Betrag nur gering sein, der Vorgang ist aber beständig (Gegensätze gebrauchend): die Natur arbeitet nicht nur mit einer oder mehreren großen Kraftmassen, sondern auch mit unendlich kleinen Kräften und ihren Summen.

Januar. Aus der Karaibischen See selbst liegen nur vor Beobachtungen vom D. D. Holsatia 188514,5

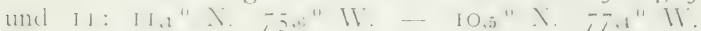
zwischen a. $8^{\mathrm{h}}$ und $\mathrm{p} .4^{\mathrm{h}}$; da IVärme und Salzgehalt sich ausgleichen, schwankt das spez. Gew. nur zwischen $(\mathrm{I}, 02) 38$ und 36 . I 29,30 bei $19,8^{\circ} \mathrm{N} \cdot 64^{\circ} \mathrm{IV}$. und $20^{\circ} \mathrm{IO}^{\prime} \mathrm{N} .63^{\circ} 36^{\prime} \mathrm{WV}=37$, es folgt eine Stelle mit hohem Salzgehalt $(75)$ a. $8^{\text {hl }}$ also zu kälterer Tageszeit bei $22,2^{\circ} \mathrm{N}$. $61,4^{\circ} \mathrm{W}$. $=57$, dann bei $22^{\circ} 40^{\prime} \mathrm{N}$. $60^{0} 55^{\prime} \mathrm{W}$. $=45$, bei $23,1^{\circ} \mathrm{N} \cdot 60,5^{\circ} \mathrm{W} .=46$. Die Zeiten dieser 5 Beobachtungen sind ebenfalls a. $8^{\mathrm{h}}$, mttgs., und p. $4^{\text {h }}$

Februar. D. D. Paranagua I 886 II I-4 berichtete von größeren Schwankungen der Wasserwärme, auch des Salzgehaltes, daher hat man zu erwarten größere des spez. Gew. Die beiden ausnahmsweise warmen Stellen bei $23,5^{\circ} \mathrm{N}$. $60,4^{\circ} \mathrm{W}$. und $23,8^{\circ} \mathrm{N}$. $60,9^{\circ} \mathrm{IV}$. (p. $8^{\mathrm{h}}=26,0^{\circ}$ M. N. $26,2^{\circ}$ C.) zeigen $44-43$ sonst zwischen $23,1^{\circ} \mathrm{N}$. $59,9^{\circ} \mathrm{W}$. bis $26,5^{\circ} \mathrm{N}$. $64,5^{\circ} \mathrm{W}$. $54-52$ und $5 \mathrm{I}$, die beiden geringsten Werte mttgs. und a. $4^{\text {h }}$ bei verhältnismäßig grölßter Wasserwärme. Bis $29,5^{\circ} \mathrm{N}$. $68^{\circ} \mathrm{W}$. nimmt das spez. Gew. schwankend zu 62, dann zeigt sich bei $29^{\circ} 58^{\prime} \mathrm{N}$. $68^{\circ} 30^{\prime} \mathrm{WV}$. entsprechend dem größten Salzgehalt jener Gegend (73) 65, bis $30,6{ }^{\circ} \mathrm{N}$. $69,2^{\circ} \mathrm{W}$. folgen wieder $6 \mathrm{I}$ und 62 .

März. I. B. M. S. Challenger's Beobachtungen I 873 III I2-I 5 ergeben wegen des höheren Salzgehaltes und etwas geringerer Wärme bei $I^{\circ} 56^{\prime} \mathrm{N} .59^{\circ} 35^{\prime} \mathrm{W}$. spez. Gew. $=5 \mathrm{I}$, dann bis $18^{\circ} 28^{\prime} \mathrm{N}$. $63^{\circ} 35^{\prime} \mathrm{W}$. : 45-46-46. III $25-3 \mathrm{I}$ von $18^{\circ} 43^{\prime} \mathrm{N}$. $65^{\circ} 5^{\prime} \mathrm{W}$. bei ziemlich gleicher Wärme und Salzgehalt bis $2 \mathrm{I}^{\circ} 26^{\prime} \mathrm{N}$. $65^{\circ} 16^{\prime} \mathrm{IV}=46$ und 47 ; dann bis $27^{\circ} 49^{\prime} \mathrm{N}$. $64^{\circ} 59^{\prime} \mathrm{IV}$. bei etwas zunehmendem Salzgehalt und abnelimender Wärme 48-57.-- D. D. Holsatia I885 III I3, I4 $25,9^{\circ} \mathrm{N} .60^{\circ} \mathrm{W}-24,9^{\circ} \mathrm{N} .62,1^{\circ} \mathrm{W}$, findet bei ziemlich gleichem Salzgehalt und der Tageszeit entsprechender Wärme-Änderung 53-56; weiter bis $24^{\circ} \mathrm{N}$. $64,1^{\circ} \mathrm{W}$. ist ersterer geringer letztere schon zunehmend, daher 50 und 46; dann bis in Turks I. Paß schwankt der Gchalt an Salz bei Steigen der Wärme, daher zeigt sich spez. Gew. auch schwankend (beim wärmsten Wasser am geringsten) zwischen 53-44-49; jenseits des Paßes bis Perle. P't., Hä̈t bei noch größerer Wärme 43 und dreimal 42. - Von Port au Prince nach Colon. I885 III 20-22 ist der Salzgehalt schwankend, die Wärme nimmt abgesehen vom Einflu\} der Tageszeit nach Suiden etwas zu, so finden wir im Norden von Caymites bis $17,9^{\circ} \mathrm{N}$. $75^{\circ} \mathrm{WV}$ - - 45-41-45; damn bei $17^{\prime \prime} 14^{\prime} \mathrm{N} .75^{\prime \prime} 22^{\prime} \mathrm{W}$. Weil Salzgehalt geringer, Wärme die größte die angegeben ist, nur 33, - zunehmend bis $16^{\circ}$ N. $76,2^{\prime \prime}$ IV. bis 41 , - wieder mit Salzgehalt und Warme abnehmend bei $14,7^{\circ} \mathrm{N} .77,1^{\circ}$ WV. $z$. 35 ,
- weiter bis $10,3^{\circ} \mathrm{N} .79,3^{\circ} \mathrm{W}$. bei Zunahme jener beiden Größen auch schwankend zunehmend bis $4 \mathrm{I}$.

April. I. B. MI. S. Challenger fand I873 IV I, 2 bei $29^{\circ} 5^{\prime} \mathrm{N} .65^{\circ} \mathrm{I}^{\prime} \mathrm{IV}$. und $29^{\circ} 5 \mathrm{I}^{\prime} \mathrm{N} .65^{\circ} 8^{\prime} \mathrm{IW}$. nahe gleichen Salzgehalt und einige Abnahme der Wasserwärme daher $4 \mathrm{St}$. $=57$ und $58 \mathrm{~d}$. i., anschließend an die letzten Beobachtungen im MIärz, nordwärts hin einige Zunahme. -- D. D. Holsatia I 885 IV I-5, ColonPuer to Cabello beobachtete schwankenden Salzgehalt, nach ostwärts etwas abnehmende IVärme aber drei ausnahmsweise kalte Stellen, an denen man auch den größten Salzgehalt fand; dadurch wird bei $9,9^{\circ} \mathrm{N} .78,7^{\circ} \mathrm{IV}$. (querab Golf S. Blas $22^{\circ} \mathrm{C}$. und 84 ) 4 St. $=68$; bei $12,2^{\circ} \mathrm{N} \cdot 7 \mathrm{I}, 8^{\circ} \mathrm{WV}$. (zwischen $\mathrm{K}$. de Vela und Gallinlas Pt. $20,5^{\circ}$ C. und $62 j=56$; bei $12^{\circ} \mathrm{N}$. $70,5 \mathrm{WV}$. (SIV. von Aruba I. $22,5^{\circ} \mathrm{C}$. und 66 ) $=54$. An zwei der wärmsten Stellen ist verhältnismäßig geringer Salzgehalt, daher dort auch $4 \mathrm{St}$. am niedrigsten: bei $9,4^{\circ} \mathrm{N}$. $79,8^{\circ} \mathrm{W}$. (unweit Colon $26^{\circ} \mathrm{C}$. und 62 ) $=40$; bei ${ }_{10,5^{\circ}}$ N. $77,1^{\circ} \mathrm{IV} .\left(26^{\circ} \mathrm{C}\right.$. und $\left.6 \mathrm{I}\right)=38$; sonst überwiegt 4 St. $=45$ aufsteigend bis $5 \mathrm{I}$, zweimal nur $4 \mathrm{I}$, dies zwischen K. Aguja und K. de Vela. - I 885 von La Guayra nach Mayaguez, IV IO-I2 zwischen $10^{\circ} 45^{\prime} \mathrm{N} .66^{\circ} 57^{\prime} \mathrm{WV}$. bis $\mathrm{I} \mathrm{S}^{\circ} \mathrm{I}^{\prime} \mathrm{N} .67^{\circ} 32^{\prime} \mathrm{IV}$. (SIV. Pünte Portorico's) ist 4 St. wieder überwiegend $=45$ ( 6 von I I Beobachtungen); da die Wasserwärme nahe gleich ist, so wird es an den beiden Stellen mit geringstem Salzgehalt $=4 \mathrm{I}$ (bei $\mathrm{I}_{3,1^{\circ}} \mathrm{N}$. $67,3^{\circ} \mathrm{WV}$. und $16^{\circ} \mathrm{N} .67,5^{\circ} \mathrm{WV}$.) an den dreien mit größtem $47-49-49$ $\left(I_{5,2}{ }^{\circ} \mathrm{N}\right.$. $16,6^{\circ} \mathrm{N}$. $18^{\circ} \mathrm{N}$. alle $\left.67,5^{\circ} \mathrm{IV}.\right)$ - Von St. Thomas nach Hâvre 1885 IV I 7 -IS beginnen die Beobachtungen bei $20,2^{\circ}$ N. $63,5^{\circ} \mathrm{WV}$. G. dort und bei $23,0^{\circ} \mathrm{N}$. $61^{\circ} \mathrm{WV}$. fand man den größten Salzgehalt daher auch 4 St. $=5 \mathrm{I}$ und 52 , sonst bis $22,1^{\circ} \mathrm{N}$. $6 \mathrm{I}, 3^{\circ} \mathrm{IV}$. G.

45 , bis $24^{\circ} \mathrm{N}$. $60^{\circ} \mathrm{W}$. $=47$, bei $24,4^{\circ} \mathrm{N}$. $59,6^{\circ} \mathrm{WV}$. 49 d. i. wieder bei ziemlich gleicher Wärme dem Salzgehalt entsprechend größeres spez. Gew. -- 1902 IV 23-24-27-30 auf D. D. Croatia hatte Hr. Dr. $G$. Scliott Wasserwärme und Salzgehalt gemessen; aus den 6 Angaben ist abzuleiten : von $20^{\prime \prime} 53^{\circ} \mathrm{N} .60^{\circ} 22^{\prime} \mathrm{IV}$. bis $18^{\circ} 2 \mathrm{I}^{\prime} \mathrm{N}$. $64^{\circ} 26^{\prime} \mathrm{W}$. nimmt $4 \mathrm{St}$. ab von $45 \mathrm{zu}$ 39. Bei der NIVPünte Portorico's ist es $=37$, im Mona Paß und Slich des Hafens von S. Domingo -35. - Diese Angaben und die im Mai sind eine Einheit der letzten Stelle geringer als die von $\mathrm{Hr}$. Dr. Schott veröffentlichten; ob derselbe 4 St. nach der genaueren Tafel von Hr. Kmudscn ableitete, während ich die gebrauchte, die ich für alle anderen Beobachtungen benutzt habe, ist mir nicht bekannt.

Mai. Hr. Dr. Schott beobachtete von San Domingo bis la Guayra 1902 V I, 2 bei I5" I I' N. $69^{\circ} 6^{\prime} \mathrm{WV}$. und II ${ }^{\circ} 23^{\prime} \mathrm{N} .67^{\circ} 29^{\prime} \mathrm{WI} .4^{\prime} \mathrm{St} .=36$ und 34 entsprechend der geringfügigen Zunahme von IVärme und Abnahme des Salzgehaltes; von $L_{a}$ Guaira nach Carúpano und Port of Spain V 11, I2 bei geringer

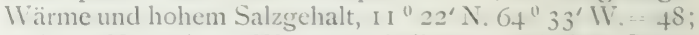
$10^{\prime \prime} 54^{\prime} \mathrm{N} .63^{\prime \prime} 37^{\prime} \mathrm{WV} .=45$; halbwegs zwischen Carúpano und Trinidad 41; V 13 Port of Spain große Wärme, wenig Salz = 12. Von letzterem Hafen nach St. Thomas V 14,15 bei $12^{\prime \prime} 1^{\prime} \mathrm{N}$. $62^{\prime \prime} 26^{\prime} \mathrm{IV}$. 26 , bei $13^{\prime \prime} 53^{\prime} \mathrm{N}$. $63^{\prime \prime} 10^{\prime} \mathrm{WV}=28$, bei $15^{\circ} 5 \mathrm{~S}^{\prime} \mathrm{N}$. 
$63^{\circ} 5^{\prime} \mathrm{W}$. und halbwegs zwischen Santa CruzSt. Thomas $=32$. Von St. Thomas nach Fort Liberté bei $19^{0} 2 \mathrm{I}^{\prime} \mathrm{N}$. $68^{0} \mathrm{I} 4^{\prime} \mathrm{W} .=32,20 \mathrm{Sm}$. NNE. von Monte Christi $=36$, in der Lagune (Ft. Dauphin Bai) =29. Von K. Haïti(Haitien)Hâvre V 22-26 5 Beobachtungen von $20^{\circ} 4 \mathrm{I}^{\prime} \mathrm{N}$. $71^{0} 26^{\prime} \mathrm{W}$. bis $30^{\circ} 22^{\prime} \mathrm{N}$. 6I ${ }^{0} 4^{\prime} \mathrm{W}$., abnehmende Wärme, zunehmender Salzgehalt daher $4 \mathrm{St} .=37-55$. - D. D. Holsatia, Hâvre-St. Thomas 1886 V 9-Io von $2 \mathrm{I}, 2^{\circ} \mathrm{N} .60,6^{\circ} \mathrm{W}$. bis St. Thomas 6 Beobachtungen, die aber ungenau sind, weil die Wasserwärme während der Beobachtung des spez. Gew. nicht angegeben ist; 4 St. ugf. $=49$ abnehmend zu 42 .

Juni. D. D. Hungaria, Hâvre-Vera Cruz I 887 VI I $8-25$ von $30^{\circ} 20^{\prime} \mathrm{N} .64^{\circ} 37^{\prime} \mathrm{W}$. bis $26^{0} 9^{\prime}$ N. $76^{0} 34^{\prime}$ W. G. (vor NE. Providence-Kanal) bei im Ganzen zunehmender Wärme und schwankendem Salzgehalt 4 St. ebenfalls schwankend $=44-46-4 \mathrm{I}, 43$, 42-47-39, 41; in der Florida Straße bis Sand Cay Lt. $\left(25^{\circ} 55^{\prime} \mathrm{N} .79^{\circ} 22^{\prime} \mathrm{W} .-24^{0} 25^{\prime} \mathrm{N}\right.$. 8 I $^{0} 55^{\prime} \mathrm{WV}$.) sehen wir bei hoher aber schwankender Wärme bald mehr bald weniger Salzgehalt daher geringeres $4 \mathrm{St}$, als im Ocean, dabei ungleich: bis Florida. Lt. $=4 \mathrm{I}$ und 32 zunehmend $\mathrm{zu} 36$, abnehmend $\mathrm{zu} 29$, zuletzt 34 . SWlich der Dry Tortugas bei $24^{\circ} 10^{\prime} \mathrm{N} .83^{\circ} 25^{\prime} \mathrm{W}$ wieder 40, dann den Änderungen von Wärme und Salzgehalt entsprechend schwankend, Meistbetrag 40 und 4I, Mindestbetrag 30 und 3I. - Auf diesem Wege im Slichen Teil des Golfs von Mexico war also das spez. Gew. des Meerwassers im Ganzen geringer als wenige Tage vorher im durchfahrenen Teil des Atlantic. D. D. Holsatia von Hâvre nach K. Haiti I885 VI I I-I4 gelangt ebenso nördlich in vorliegendes Gebiet, bei $30,4^{\circ} \mathrm{N}$. $59,8^{\circ} \mathrm{W}$.; wie erwähnt ist die Wasserwärme beobachtet zunehmend bis $25,5^{\circ} \mathrm{N}$. $65,9^{\circ} \mathrm{W}$. dann etwas geringer und der Tageszeit entsprechend, Salzgehalt schwankend, kurz vor und bei der wärmsten Gegend am stärksten; dementsprechend ist $4 \mathrm{St}$. am größten im Nlichsten Teil $=53$ nimmt ab bis $25^{\circ} 57^{\prime} \mathrm{N}$. $65^{\circ} 20^{\prime} \mathrm{W}$. zu 38 , dann $40-38-40$ bis $24,5^{\circ} \mathrm{N}$. $67,1^{\circ} \mathrm{IV}$. G. weiter bis vor Turks I. Paß Meistbetrag 39, Mindest betrag 37, in dessen Slichem Teil und bei $20,3^{\circ} \mathrm{N} .72,3^{\circ} \mathrm{W}$ $=40-38$. - I 886 VI I 5, I6 St. Thomas-Hâvre von $20^{\circ} 55^{\prime} \mathrm{N}$. $62^{\circ} 47^{\prime} \mathrm{W}$. bis $24,1^{\circ} \mathrm{N}$. 59,6, $\mathrm{W}$. sind die Beobachtungen wie die im Mai wieder ungenau wegen Fehlen der Wärme-Angabe während jener, so wic sie sind zeigen sie einige Schwankungen, Meistbetrag $=47$, Mindestbetrag $=44$

Juli. D. D. Hungaria, I $887 \mathrm{~V}$ era Cruz-Tampico, die einzige Beobachtung unweit Vera Cruz VII I giebt wegen der größten damals beobachteten Oberflächenwärme und nicht hohem Salzgchalt $4 \mathrm{St}$. nur $=26$. Von Tampico nach Progreso VII 4-5 bei $2 \mathrm{I}^{\circ} 56^{\prime} \mathrm{N} .95^{\circ} \mathrm{I} 8^{\prime} \mathrm{WV}$. $-2 \mathrm{I}^{\circ} \mathrm{I} 5^{\prime} \mathrm{N} .90^{\circ} \mathrm{I} 9^{\prime} \mathrm{W}$. ziemlich gleiche Wärme aber schwankender Salzgehalt daher 4 St. $=32-30-34-24$. Von Progreso nach Ha iti $21^{\circ} 50^{\prime} \mathrm{N}$. $86^{\circ} 40^{\prime} \mathrm{W}$. bis $19^{\circ} \mathrm{I} 8^{\prime} \mathrm{N}$. $76^{\circ} 38^{\prime} \mathrm{W}$. VII 8-IO ist an ersterem Ort nahe der Ekante der Yucatan Bk. (nicht weit von Land) nur 27 dann zunehmend bis 4I (unweit K. Cruz) darnach 35 und 40. Von Haiti nach St. Thomas Nwärts des Mona Paß
VII 2 I in Folge hohen Salzgehaltes 46. St. ThomasHâvre VII 23,24 bei $21,7^{\circ} \mathrm{N}$. $61,7^{\circ} \mathrm{W}$. bis $23^{\circ} 46^{\prime} \mathrm{N}$. $59^{\circ} 47^{\prime}$ W.: 39-36-35. - D. D. Holsatia von St. Thomas-Hâvre von $21,4^{0} \mathrm{~N}$. $62,5^{\circ} \mathrm{W}$. bis $24,3^{\circ} \mathrm{N}$. $59,6^{\circ} \mathrm{W}$. (7 Angaben) nimmt 4 St. ab: 48-50-49-43-43-36-36.

August. Keine Beobachtungen.

September. D. D. Hungaria; Hâvre-St. Thomas I 887 IX 9 bei $20^{\circ}$ I $^{\prime} \mathrm{N}$. 6 6 I ${ }^{\circ} 5^{\prime} \mathrm{W} .=4 \mathrm{I} ; 19^{0} 5 \mathrm{O}^{\prime} \mathrm{N}$. $62^{\circ} \mathrm{o}^{\prime} \mathrm{W}, \mathrm{G} .=36$.

Oktober. D. D. Hungaria; St. Thomas-Hâvre I 887 X I4 bei $22^{\circ} 27^{\prime}$ N. $59^{\circ} 53^{\prime} \mathrm{W} .=38$

Norember. D. D. Holsatia; Hâvre-St. Thomas. I 885 XI 25,26 bei $22^{0}$ I $3^{\prime} \mathrm{N} .59^{0} 55^{\prime} \mathrm{W}$. - I $9^{0} 9^{\prime} \mathrm{N}$. $62^{\circ} 44^{\prime} \mathrm{W} .7$ Beobachtungen; bei etwas zunehmender Wärme, erst ab- dann zunehmendem Salzgehalt 4 St. = $39-37,+1,39-39$.

Dezember. D. D. Holsatia, St. Thomas--La Guayra, I 884 XII 28,29 bei $15,8^{\circ}$ N. $65,4^{\circ} \mathrm{W}$. bis $10,6^{\circ} \mathrm{N} .66,2^{\circ} \mathrm{W}$. IVie eingangs erwähnt, ist für viele Orte die Wärme der Meeres-Oberfläche nicht angegeben, daher konnte für jene $4 \mathrm{St}$. nicht abgeleitet werden, in diesem Monat nur auf genannter Strecke und für $5 \mathrm{Be}$ obachtungen für Salzgehalt; da weder dieser noch die Wärme erheblich sich ändern, so ist auch $4 \mathrm{St}$. am erstgenannten Orte $=39$ an allen anderen nur 35 .

D. D. Hungaria berichtet folgende Lotungen: I887 VI 24 mttgs. : $23^{\circ} 34^{\prime}$ N. $89^{\circ} 8^{\prime}$ W. I 60 Fd. $=290$ Meter, Korallenschlick. - VII 5 a. $5-8_{\mathrm{h}}: 2 \mathrm{I}, 4^{\circ}$ N. $9{\mathrm{I}, 6^{\circ}}^{\circ} \mathrm{W}$. - 2I ${ }^{\circ} \mathrm{I}^{\prime} \mathrm{N} .9 \mathrm{I}^{\circ} 5^{\prime} \mathrm{IV} .24-22-19-18^{1 / 2} \mathrm{Fd}$. $=44-40$ 35-34 Meter; mttgs.: $2 \mathrm{I}^{0} \mathrm{I}^{\prime} \mathrm{N}$. $90^{0} \mathrm{I}^{\prime} \mathrm{W} .6^{1 / 4} \mathrm{Fd}$. $=\mathrm{II}, 4$ Meter. VII $S$ a. $8^{\mathrm{h}}: 2 \mathrm{I}^{0} 5 \mathrm{O}^{\prime} \mathrm{N}, 86^{\circ} 4 \mathrm{O}^{\prime} \mathrm{W}$. $\mathrm{I} 5^{1 / 2} \mathrm{Fd}$. $-28,3$ Meter rote Korallen.

\section{Tafel 4.}

\section{Wind, Seegang und Schiffsversetzung (Strömung)}

bei den vorhergehenden Beobachtungen.

Die Herren Beobachter waren Alle ersucht, Wind und Seegang rechtweisend anzugeben d. i. ihre Richtung von der Nord- Süd-Linie gerechnet, nicht nach dem Kompaß; die Schiffsversetzung d. h. den Unterschied des Schiffsortes nach der Besteck-Rechnung (Kurs und nach dem Logg zurückgelegte Seemeilen) mit dem nach Beobachtungen, oder nach Land-Peilungen ist man gezwungen anzunehmen als von Strömung verursacht, obwohl es ist die sogen. algebraische Summe von Strömung und unbekannten Fehlern im Kompaß, Steuern und Schätzen des zurïckgelegten Weges. Unwillkürlich hegt man gewisses Mißtrauen gegen diejenigen Angaben, deren Richtung gänzlich oder nahe zusammenfällt mit dem Schiffskurse oder ihm ebenso entgegengesetzt ist, - doch ist auch zu bedenken, daß wenn solche Versetzungen nicht regelmäßig sich zeigen, das Mißtrauen schwinden könnte. 
Januar. D. D. Holsatia. I885 I $2-5$ und II; im Süden, zwischen La Guayra und Colon sind nur wenig vollständige Angaben vorhanden; vor dem Golf v. Triste und S. Juan Bai Wind Elich 3; I 3, 4 Savanilla Pt. und Galera de Zamba B. querab Wd. ENE. 4, 5, zwischen $12^{0} 21^{\prime} \mathrm{N}$. 7 $\mathrm{I}^{0} \mathrm{I} 5^{\prime} \mathrm{W}$. -

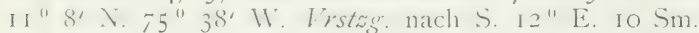
I I I vor dem G. v. Darien NNE, und NE 4, Seegg. NE. 5. Bewölkung cicu, ci, cu, 3-o. - St. Thomas -Hâvre I 29 Wd. E. 3 ; mttgs. $20^{\circ} \mathrm{IO} \mathrm{O}^{\prime} \mathrm{N} .63^{\circ} 36^{\prime} \mathrm{W}$. Versetzung in $16 \mathrm{Std}$. S. $87^{\circ} \mathrm{E}$. I6 Sm. I $30 \mathrm{Wd}$. ENE. 2-3. Vrstgg. N. $42{ }^{0} \mathrm{E} .8 \mathrm{Sm}$. - S. Östr. Ung. M. S. Zrinyi, in Port au Prince, Haiti 1886 I $\mathrm{I}-8$ berichtet von sehr leichtem Land- und Seewind nur ausnahmsweise 3 erreichend, nicht selten Windstille; Landwind zu rechnen aus dem Elichen Halbkreis, Seewind aus dem westlichen, beide nicht regelmäßig, Bewölkung $\mathrm{o}-8 \mathrm{ci} \mathrm{cu}, \mathrm{cu}$ und str., ein paarmal ist Thau bemerkt. - Von Pt. au Prince nach Kingston, Jamaica I 8- IO ist im Gonaive $\mathrm{K}$ anal mgs, anfangs noch Landbrise $=\mathrm{E}$. 3, wird abflauend durch $\mathrm{S}$. drehend nchmttgs., Nlich von K. Dame Marie, still und Seewind W. I, dreht Wlich von diesem Standpunkt nach SE. I, dann unweit $\mathrm{Navassa} \mathrm{I}$. wird er NE. I-2, auf dem weiteren Wege bis Kingston N., auch NzE. 4 und 5. - Seegang unweit Pt. Pr. E. 2, dann O, von K. Dame Marie an mit dem Winde SE. I, NE. I, N. und NE. 4, N. 3-4-2. Bewölkung O-IO ci str, ci cu, cu, str. bei $r$ auch ni. Niederschlag: außerhalb Gonaive Kanal: Horizont m.; in der Nähe von Navassa I. nchmttgs. p. bei Wd. NW. 6. - Im Hafen von Kingston I IO-I 8 ist der Wind fast stets leicht und still, nicht oft 2 nur einmal bis 3, vorwiegend Nlich, aber weniger aus dem NElichen als aus dem NW.Viertel, wenig zwischen W., S., E. Bewölkung: O-IO, anfangs viel stri, zuletzt viel $\mathrm{cu}$, sonst ci str. auch ni. Niederschlag: I IO $=7,2 \mathrm{~mm}$., I I I (p. und $40 \mathrm{~min} . \mathrm{r}$ ) $=23,9 \mathrm{~mm}$. I I5 nchts. leichter $r$, dreimal ist Thau angegeben, einmal sehr leichter Nebel aus $N$., ebenso $m$ im NE Hrzt. - Von Kingston nach Havanna, Cuba; I I8-25. mgs. nach Verlassen des Hafens Wd. W. I, sonst nahe der SKüste Jamaica's: E. auch EzS. 4 und 3; bei der SIVSpitze der Insel ENE. 3, dann ENE. 3, E. 2, einige Stunden NW, und Stille, weiter bis S. vom Rosario Kan. anfgs. NNE. 4, darauf NE. 4, 5 allmählich zu I-2 abnehmend; dort wird Wd. N. 3; dreht durch NE. 3 auf E. 3 und 4, Slich von K. San Antonio NE. 4. Beim Segeln um dieses Vorgebirge ändert der Wind von NE. durch E, auf ESE., wird an der NIVSeite Cuba's still, kommt dann auf SW. ganz flau, dreht, zunehmend, über WNW. bis NW. 7, zuruick nach WNW. bis 8, mit W. 6 gelangt Zrinyi nach Havanna. Seegang wurde erst merklich, nachdem man frei war von Jamaica, er kam dort von NE. I und blieb aus dieser Richtung bis in die Nähe der I. of Pines, anfgs. zunehmend bis ugf. in der Mitte des Weges: 5, dann wieder abnehmend bis 2, rundum K. Antoni o E. I-3, darauf NE-ESENNE I - 3, nach Einsetzen des NWlichen Windes NIV bis Havanna 2-6. Bewölkung o-9, oben ci, cicu, ci str, untere cu und str. Blitzen: abds. bei $22^{\circ} \mathrm{I} 7^{\prime} \mathrm{N} .85^{\circ} 7^{\prime} \mathrm{W}$.: in SW. und $N W^{\prime}$, ferner bei $23^{\prime \prime} 21^{\prime} N$. $84^{\circ} 16^{\prime} \mathrm{WV}$. in
SW-NW-NE. Niederschlag nur einmal, querab der NW. Rundung Cuba's: $1 / 2$ Std. $=3 \mathrm{~mm}$. Im Hafen von $H$ avanna bis zum letzten Januar ist der Wind nur aus dem Wlichen Halbkreis, anfangs 5, dann höchstens 3 bis still; am Abend des 30. vmttgs. und abds. 31. ist angegeben Wind aus dem Elichen Halbkreis, außerdem Stille, NW. und N. 2. - Bewölkung: O-IO, anfgs. hauptsächlich str., dann auch cu, obere: ci-cicu-ci str. manchmal filzig, auch fadenförmig. Niederschlag: nur zweimal leichter Thau, am 30. r. $=29 \mathrm{~mm}$. - Die Herren Beobachter an Bord Zrinyi widmeten große Aufmerksamkeit dem Gewölk, dessen Richtung und Zug; hier diesem im Einzelnen gerecht zu werden bin ich nicht im Stande, - bei hierauf gerichteter Sonderarbeit, sollte dies Journal nicht umgangen werden.

Februar. S. Östr. Ung. M. S. Zrinyi in Havanna II I-IO, überwiegend Wind aus dem Elichen Halbkreis $\mathrm{I}-2$, einigemal bis 5 zunehmend, auch Stille und ein paarmal Wind aus dem Wlichen Halbkreis. Bewölkung: O-IO, wie Ende Januar; am $4 . a .5^{\text {h }}$ ist eingetragen: Sturmartiges Aussehn der Athmosphäre; p. $9^{h}$ auch am 6. a. $\mathrm{I}^{\mathrm{h}}$ in W. geröteter Himmel. Niederschlag: Thau ist dreimal angegeben, $r$. und p. funfmal, zusammen $=8 \mathrm{~mm}$. Blitzen am 8. a. $5^{\mathrm{h}}$ in NW. - N. - E. p. $6^{1 / 2}-7^{1 / 2} \mathrm{~h}$ in SE., p. $9^{\mathrm{h}}$ in NE. - Während der Reise von Havanna nach Nassau, New Providence, II IO-I 3 bis zum Slichen Eingang der Bemin i Straße ist der Wind $\mathrm{N}-\mathrm{ENE} 2-3$ zuletzt $\mathrm{E}-\mathrm{SE}$. I - O d dann Windstille. In der Enge von Bemini kommt NW. I, dreht auf IVSW. 2, wird im Providence Kanal SE. I-2, S. 3 zuletzt W. und NIV. $4-5-3$. - Seegang bis zur Bemini Str. NE. I-2, dann o auch Dünung von SE; in der Enge und dem größten Teil des Prvd. Kan. NE I in dessen Wlichen Teil 2-3- I. Niederschlag am I2. beim Eingang dieses Kanals einmal leichter $\mathrm{r}=4,4 \mathrm{~mm}$. und Hrzt. $\mathrm{m}$. Bewölkung: $\mathrm{I}-\mathrm{IO}$ cu-str-custr-ci str-cicu, obere cistr-cicu. - Im Hafen von Nassau II 13-I5 ändert der Wind bald durch NNW. 3 auf N. I, bleibt dann zwischen NNE. und NEzE. 3-I. Seegang im Hafen NIV., N-NE. 2-I. - Bewölkung: I-IO, str-cu-custr, obere ci-cistr-cicu. Niederschlag: Thau, Nebel, Regen je eimmal leicht. Von Nassau bis $30^{\circ} 43^{\prime} \mathrm{N}$. $64^{\circ} 23^{\prime}$ IV. II $15-26$ im östlichen Teil des Providence Kanal mit dessen NE. Eingang Wind NEzE., N., WNII. I und Stille, dann kommt auf: SE. 4, bleibt zwischen SE-SSIV. 2-I von $26^{\circ} 7^{\prime} \mathrm{N} .76^{\circ} 53^{\prime} \mathrm{WV} .-26^{\circ} 52^{\prime} \mathrm{N} .75^{\circ} 54^{\prime} \mathrm{WV}$. nachdem or kurze Zeit SSW. O-2 gewesen, wird er $\mathrm{NNE}-\mathrm{E}-\mathrm{S} . \quad 3-2-4$ von $27^{\circ} 9^{\prime} \mathrm{N} .75^{\prime \prime} 42^{\prime} \mathrm{W}$. $28^{\circ} 30^{\prime} \mathrm{N} .75^{\circ} 37^{\prime} \mathrm{W}$; ; von hier bis $29^{\prime \prime} 27^{\prime} \mathrm{N}$ -I" 6. II: : IISII 3, II. 3-8, IVNW. 6, NNW. $8-5$. F ïr mehrere Stunden folgt NNE. 5, E. 2, Stille, IV. I, S. 3, darauf zwischen $\mathrm{NIV}-\mathrm{SIV}$. I-3 auch WNIV., 5, N. $6-5$ bis $30^{\circ} \mathrm{II}^{\prime} \mathrm{N}$. $68^{\circ} 24^{\prime} \mathrm{WV}$. Dort dreht IV'd. in das NEviertel 5-I, nach ESE. $\mathrm{I}-2, \mathrm{~S} .4$ bei $30^{\circ} 7^{\prime}$ N. $66^{\circ} 54^{\prime}$ W., zuletzt SSIV $-W N I V .6-S$, d. i. im Ganzen, nahe der Grenze des Passats zu erwartende Wind-Verhältnisse. Seegang und Dünung im allgemeinen dem Wind entsprechend, wenn auch nicht genau mit dessen Richtung ibereinstimmend $1-5$ selbst 6 ! bei geringer Windstärke aus N. 5-2. - Bewölkung: 1-10, 
viel s, cu, ci str, ci cu; obere ci, ci str, ci cu, oft dicht, filzig, auch als Bank u. s. w. Niederschlag: Bei länger anhaltendem Slichen Wind Thau, sehr feucht, im Hrzt. m. ein paarmal auch Regen und Regenschauer zusammen I I,5 mm. - D. D. Paranagua I 886 II I-4 hatte bei $23,1^{\circ} \mathrm{N} . \quad 59.9^{\circ} \mathrm{IV}$. Wind SE. 3, der bis $25^{\circ} \mathrm{N} \cdot 62,5^{\circ} \mathrm{W}$. mit Windstille durch $\mathrm{S}$. bis SW. 2-3-C dreht, dort NE. I-4 aufkommend, aus dieser Richtung bleibt er bis $27^{\circ} 18^{\prime} \mathrm{N}$. $65^{\circ} 35^{\prime} \mathrm{WV}$. G. von wo er, durch $\mathrm{E}-\mathrm{SE}-\mathrm{S} 3-2-4$ ändert bis $30^{\prime \prime}$ I $8^{\prime} \mathrm{N}$. 68 $58^{\prime \prime} \mathrm{W}$ nachher SW. 4-6 wird. - Seegang: anfangs unregelmäßig SE. 2 ; bei $23,8^{\circ} \mathrm{N}$. 60,9 $9^{\circ} \mathrm{W}$. ESE. und NNW. 2 von $24^{\circ} 58^{\prime} \mathrm{N}$. $62^{\circ} 28^{\prime} \mathrm{W}$. bis $26,5^{\circ} \mathrm{N}$. $64,5^{\circ} \mathrm{W}$ NE. 2-4, dort unregelmäßige Nliche Dünung und Seegang 3 , dann N. und NE. 3 , E. 3 bis $28,6^{\circ} \mathrm{N} .67^{\circ} \mathrm{W}$. von hier an wieder SElich und Slich. Wetter fast dic ganze Strecke stark bewölkt und o; oft g. und u. anfgs. 1. in NW., bei $24,2^{\circ} \mathrm{N}$. $6 \mathrm{r}, 4^{\circ} \mathrm{W} .1,4$ Std. $\mathrm{r}$; bei $25^{\circ} \mathrm{N} \cdot 62,5^{\circ} \mathrm{W} .-25,7^{\circ} \mathrm{N} \cdot 63,5^{\circ} \mathrm{W} \cdot \mathrm{p}, 26,9^{\circ} \mathrm{N} \cdot 65^{\circ} \mathrm{W}$ und $28,6^{\circ} \mathrm{N}$. $67^{\circ} \mathrm{W}$. m.; von $29.5^{\circ} \mathrm{N}$. $68^{\circ} \mathrm{W}$. $32^{\circ} \mathrm{N}$. $70,5^{\circ} \mathrm{W}$. häufig anhaltend starker r.; bei $29,5^{\circ} \mathrm{N} .68^{\circ} \mathrm{W}$. starke qSW. - Da wo die IVege S. Ustr. Ung: M. S. Zrinyi und D. D. Paranagua nahe bei einander liegen und sich kreuzen fand ersteres Schiff, ugf. drei Wochen später als letzteres, nicht unähnliches Wetter, nur weniger Regen.

Häiz. I873. I. B. M. S. ,.Challenger" I873. III I2-I5; von $18^{\circ} 56^{\prime} \mathrm{N}$. $59^{\circ} 36^{\prime} \mathrm{IV}$. bis $18,9^{\circ} \mathrm{N}$. 6I, ${ }^{\prime} \mathrm{WV}$ hat Wd. E. 4-7, ESE. 4-5, EzS. meist 4-5, auch 3 selbst 2; dort wird er unbeständiger, dreht durch SE-S. 4--6 nach SzW. 3, zuruick durch SE. bis EzN. nochmals zurück nach $S .2-3-5$ nach $E$., wicder nach SE. 3-I dann bis Wdstk. 5 und 2 ändernd nach NE. (Nähe Sombrero's) bleibt so 1/2 Tag 4-5, dreht dann bis St. Thomas bis EzS. und zuriick nach E. 3--4. Seegang anfgs. 3, dann 2-I-2, die letzten 2 Tage $I$. Bewölkung: ein paarmal Io, nur wenige Mal 4, häufig zwvischen 6 und 9; obere ci, $\mathrm{cu}$, str, $\mathrm{cicu}$, und ci str, die unteren cu, custr, auch ni. Regenböen mehreremal, selbst heftig, zuletzt abds. feuchte Luft. Strömung: S. $76^{\circ} \mathrm{W}, 16, \mathrm{~N} .43^{\circ} \mathrm{W} .10, \mathrm{~N} \cdot 82^{\circ} \mathrm{W} .6$ Seem. III $25-31$. St. Thomas $-28,5^{\circ} \mathrm{N} .65^{\circ} \mathrm{IV}$. Bis $24^{\circ} 39^{\prime} \mathrm{N} .65^{\circ} 25^{\prime} \mathrm{WV}$. IVd. E., EzN., vereinzelt LzS. zuletzt ENE. 3-5, dann bis 2-3; bei letzterem Ort wird Wd. SE. 2-4-3, dreht zurïk nach SEzE., wieder bis $\mathrm{SzW}$. und S. 3-4-3; aus S. einige Stunden bleibend, ändert der Wind dann wieder nach $\mathrm{W}-\mathrm{S}-\mathrm{SzE} .2-5-2$ zuletzt Windstille. - Seegang: 2-3-I; am 30. nchts. $10^{\mathrm{h}}$ bei $27^{\circ} \mathrm{N} .65,2^{\circ} \mathrm{W}$. schwaches Meerleuchten. Bewölkung, obere: cicu-ci-str-ci-cu; untere: cu-custr, mehreremal ni, selbst schwer; Betrag meistens weniger als 5 , anfangs nur vereinzelt 9 , zuletzt häufiger, einmal IO; am 30. p. $4^{\text {h }}$ bei $26,7^{\circ}$ N. $65,2^{\circ} \mathrm{W}$. zog das obere Dunstgewölk von W., p. $10^{\mathrm{h}} 45^{\mathrm{m}}$ bei $27^{\circ} \mathrm{N} .65,2 \mathrm{~W}$. kam dann der Wind von W. Niederschlag: ab und zu p., zuletzt zwei Stunden starke Regenböen. Strömung: III $25-26 \mathrm{~N} .37^{\circ} \mathrm{W}$. ${ }_{14} \mathrm{Sm}$. III $26-27 \mathrm{~N} .55^{\circ} \mathrm{W}$. ${ }_{14} \mathrm{Sm}$., III $27-28 \mathrm{~N} \cdot 44^{\circ} \mathrm{W} .24$, III $28-29 \mathrm{~N} .47^{\circ} \mathrm{W} .20$, III $29-30 \mathrm{~N} \cdot 30^{\circ} \mathrm{W}$. 16, III $30-3$ I N. $55^{\circ} \mathrm{E}$. I4 Sm. D. D. Holsatia I 885 III I $3-$ I 5 von $25,9^{\circ} \mathrm{N}$. $60^{\circ} \mathrm{WV}$ bis Turks I. Paß Wind anfangs väl. E-N $4-5$ mit r. und 1 . in verschiedenen Richtungen auf WSW. $1-3-2$ drehend, schwache Regen- und Gewitterböen aus NWlicher und SWlicher Richtung darauf Stille, Regenbö aus S. Seegang 4-o. Bewölkung $\mathrm{cu}, \mathrm{klcu}$; oben ci unten str. und custr., str. IO-I. Niederschlag bei Wind erwähnt. Strömung: S. $33^{\circ}$ W. 8, S. 19 Sm. - Von Turks I. Paß bis Perle Pt. WVd. SSE-S-ESE-S 5-I. Seegang: Slich 2, SE. 2-3-I. Bewölkung: $\mathrm{cu}, 2-\mathrm{O}$; kein Niederschlag. Strömung o. - Port a u Prince nach Colon III $20-23 \mathrm{Wd}$. im Gonaive Kan. NW. 3; dann NNE-ESE-ENE. zuletzt NE. $4-2-6-5$. Seegang in Richtung und Höhe dem Wind entsprechend 2-5. Bewölkung: $\mathrm{cu}$, zuletzt ci str. 3-I-4; kein Niederschlag. - Strömung: S. $82^{0} \mathrm{~W} .20$, N. $71^{\circ} \mathrm{W} .12 \mathrm{Sm}$.

April. I. B. M. S. Challenger I873 IV I, 2 $28,5^{\circ} \mathrm{N} .65^{\circ} \mathrm{IV}$. bis vielleicht $30^{\circ} \mathrm{N} .65^{\circ} \mathrm{WV}$. Wd. still, SzE.-SE. zuletzt E. und Stille. Seegang O. Bewölkung, obere: ci, cistr.; untere cu, custr., cicu, str. 7-I. IV I abds. Gewölk aus SSW, ziehend, Wind nachher SzE. Kein Niederschlag. Strömung III 3 I IV I. N. $6 I^{\circ}$ E. 4 ; IV I- 2 N. $8{ }^{\circ} \mathrm{IV} .22 \mathrm{Sm}$. D. D. Holsatia Colon-Porto Cabello. I885 IV I-5; $9,7^{\circ} \mathrm{N} .79,3^{\circ} \mathrm{WV}$. Wd. N. 5, NE. 4-6-5, ENE. 4-3-5-4; ESE. 4-3. Seegang, ugf. dem Wind entsprechend; seine Anderungen sind früher angegeben als die des Windes; Höhe zwischen 3 und 6 , ebenso. Bewölkung: c. str., cu, vereinzelt nim. o-9. Niederschlag: nur einmal d, aber unter 23 Angaben: dreizehnmal $\mathrm{m}$. Strömung: N. $31^{\circ} \mathrm{WV}$. 17, N. $64^{\circ} \mathrm{W} .2, \mathrm{~S}, 2,-\mathrm{N} .67^{\circ} \mathrm{W}$. I $3 \mathrm{Sm}$. - Von La Guayra-Mayaguez. IV 10, II. $10^{\circ} 45^{\prime} \mathrm{N}$.

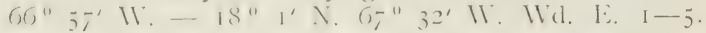
Seegang: E. zw. 5-2. Bewölkung: cu, ci, cistr, cicu 5-2. Niederschlag: eimmal, auf etwas mehr als halbwegs, leichte Regenbö. Strömung: N. $86^{\circ} \mathrm{W}$. I $6 \mathrm{Sm}$.; am zweiten Tagc: keine. - St. Thomas--Hâvre. I 885 IV I7, I8, $20,2^{\circ} \mathrm{N}, 63,5{ }^{\circ} \mathrm{WV} .-24,4^{\circ} \mathrm{N}, 59,6^{\circ} \mathrm{W}$. Wd. E. 3. anhaltend ESE. 3, E. 2, SE-E. I-2. Seegang: E. 3, kurze Zeit ESE. 3, bald wieder E. 2, anfgs. auch $\mathrm{N}$. Dinung 4. Bewölkung: oben ci; unten cicu; cu, str. und cistr. I-5. Niederschlag: im letzten Teil dieses Reise-Abschnittes erst einzelne schwache, dann einzelne stärkere Regenböen. - Strömung: N. $52^{\circ}$ E. 4 . N. $54^{\circ} \mathrm{W} .7 \mathrm{Sm}$. - D. D. Croatia; bei $21,3^{\circ} \mathrm{N} .59,8^{\circ} \mathrm{W}$. - St. Thomas; 1902 IV 23, 24 Wd. Nlich, NE., NNE., NE. 3 zuletzt 4 und 5. Seegang: anfgs. Sliche Dünung, ugf. So Sm. vor Sombrero Nliche Dünung, im Ganzen leicht bewegte See; zwischen Sombrero und St. Thomas mäßige See. Wetter: anfgs, r, dann bewölkt. Strömung: vom 21. bei $25^{\circ} 7^{\prime} \mathrm{N}$. $53^{\circ} 52^{\prime} \mathrm{W}$. bis 24. nahe Sombrero d. i. in 3 Tagen nach N. $47^{\circ} \mathrm{W}$. 20,6 Sm. - St. Thomas-San Juan, Portorico IV 25, 26 Wd. ENE., NE., ENE. 5, bei bewölktem Himmel. San Juan-San Pedro de Macoris IV 27, 28 Wd. E., ENE., Elich 5-3. See: bewegt und mäßig bewegt. Bewöllte Luft. - San Pedro de Macoris-San Domingo IV 29 Wd. Elich und Nlich 2. Seegang: anfgs. bewegte Dünung, dann leicht bewegte See. - San Domingo-La Guayra IV 30 p. $4^{\mathrm{h}}-$ MN. Wd. Elich 3-5. Seegang: mäßig bewegt und bewegt. Leicht bewölkte Luft. 
Mai. D. D. Holsatia; $21,2^{\circ} \mathrm{N} \cdot 60,6^{\circ} \mathrm{IV}$. - St. Thomas I886 V 9, Io Wd. SElich 4-2. Seegang; SElich 3-I. Bewölkung oben ci, unten cu, str. 4-I, - D. D. Croatia. San Domingo-La Guayra; 1902 V I, 2. Wd. E., ENE., E., ENE. 5-6-5 dreht unweit Buen Ayre durch E. nach ESE. 5-3. Seegang: bewegt, von Buen A yre an aus ESE. Bewölkte Luft, nahe der Mitte des Weges r. Strömung: S. $78^{\circ} \mathrm{W}$. $29 \mathrm{Sm}$. in $39^{3 / 4} \mathrm{Std}$. La Guayra-Porto Cabello V 4. Wd. Elich, ENE. 2-3-2. See mäßig bewegt. Bewölkte Luft. - Porto Cabello-Curaçao V 5. Wd. NE.. ENE, 3-5. See leicht bewegt und bewegt. Bewölkte Luft. - Curaçao-Porto Cabello V 7, 8. Wd. NE., 5, ENE. 4-2. See bewegt und mäßig bewegt. Bewölkte Luft. - Porto Cabello-La Guayra V 9, IO. IVd. ENE. 4-3. See mäßig bewegt. Bewölkte Luft. - La Guayra-Carúpano V. IO, II. Wd. E. 5-4. See: bewegt, grob, abnehmend, bewegt. Bewölkte Luft. - Carúpano - Port of Spain V I2, 13. Wd. E. 3. See mäßig und leicht bewegt. Bewolkte Luft. - Port of Spain-St. Thomas V I4-I6. Wd. Nlich 2, E. 3-4-3-2. See: leicht, lebhaft und leicht bewegt. Bewölkte Luft. Strömung: S. $48^{\circ} \mathrm{W} .12 \mathrm{Sm}$. in 12 Stunden. N. $76^{\circ} \mathrm{W} .4 \mathrm{Sm}$. in $24 \mathrm{Std}$. - St. Thomas-K. Haït. Wd. anfgs. Slich 2-3, an der Küste Portorico's umlaufend und unbeständig 3-I; quer über Mona Paß NElich I-2, dann ENE. 2-3 unweit K. Frances Viejo Wd. umlaufend 3, dann Süd 6-8-5, später SElich 4-2. Seeg.: im Ganzen leicht bewegt, Nlich von Portorico ruhig. - Niederschlag: Nlich von Portorico regnerisch, bei dem SWind stark böig mit $r$. sonst bewöllkte Luft. - K. Haïti-Hâvre V $22-26$ $19^{\circ} 49^{\prime} \mathrm{N} .72^{\circ} \mathrm{IO} / \mathrm{W}$. $-30,4^{\circ} \mathrm{N} .6 \mathrm{I}, 1^{\circ} \mathrm{W}$. Wd. bis 25. mgs. ENE. 3-5 dann bis Mittag Elich 3-7; nchmttgs. bis 26. mttgs. durch $E$. bis $S$. und zurück nach SE. drehend, gegen M. N. zu 10 anwachsend, dann bis 4 mindernd, später 5-6-5. Secgang im Ganzen der Windstärke entsprechend, mäßig bewegt bis hoch, auch Nliche und NEliche Dünung, zuweilen hoch. Bewölkung bis 25. mgs. leicht, dann böig bis 26. vmttgs., viel $\mathrm{r}$. auch mit q., wenn nicht regnend gänzlich bezogen, zuletzt bewölkt. - Strömung: Bis 23. mttgs. in 26,7 Std. $=\mathrm{N} .12^{\circ} \mathrm{E} 9 \mathrm{Sm}$.; bis $24 . \mathrm{N} .6 \mathrm{Sm}$. ; $24-27$ von $25^{\circ} 32^{\prime} \mathrm{N}$. $66^{\circ}$ I $7^{\prime} \mathrm{W} .-32^{\circ} 46^{\prime} \mathrm{N} .57^{\circ} 55^{\prime} \mathrm{WV}$. in 3 Tagen = N. $49^{\circ} \mathrm{WW} \cdot 30 \mathrm{Sm}$

Juni. D. D. Hungaria; Hàvre-Vera Cruz. I 887 VI I $8-25$. Von $30^{\circ} 20^{\prime} \mathrm{N} .64^{\circ} 37^{\prime} \mathrm{W}$. - NE. Providence Kanal Wd. SW. 4 am 20. bei $28^{\circ} 6^{\prime} \mathrm{N}$. $71^{\circ} 4^{\prime} \mathrm{W}$. Suid $2-3$ bis $27^{\circ} \mathrm{N}$. $74^{\circ} \mathrm{W}$.; später SSE. In der Florida Str. bis Fl. Lt. IVd. ESE. 4, dann SE. 3, von Sombrero Cay - Dry Tortugas SSE. 2-3. Weiter bis zur Y ucatan 13k. SW. 2-I, und Windstille; Wlich derselben ESE, 4. Seegang im Ganzen nahe mit dem IVind, 2-6-1-2. Bewölkung meist c.; am NRand der Bank cu, bei dem ersten SWwind u mit Gewitter, bei der Windstille am NWrande der Bank o, q. 7 und Gewitterluft. Strömung VI is-19 N. $66^{\circ} \mathrm{W}$. I 4 , -20.S. I -2I. N. $86^{\circ} \mathrm{W}$. 28 . Im Golf von Mexico VI $23-24$ N. $66^{\circ}$ WV. 19, W. 22 Sm. - D. D. Holsatia.

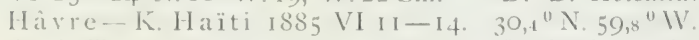
durch ' 'urk's In. Pak - $20,3^{\circ} \mathrm{N} \cdot 72,3^{\circ} \mathrm{W}$. also mahe entgegengesetzt dem WVege für den I 7 Jahre später Ende Mai Hr. Dr. G. Schott und D. D. Croatia Berichte lieferten. IVd. bis $29^{\circ} \mathrm{N} .62^{\circ} \mathrm{WV}$. NE. 4-5 dreht bis $26,5^{\circ} \mathrm{N} .64,8^{\circ} \mathrm{W}$. langsam bis SE. $5-2$ wird dort rasch wieder ENE. und umlaufend $\mathrm{I}-2-\mathrm{I}$ bis $24,3^{\circ} \mathrm{N} .67^{\circ} \mathrm{WV}$. von dort ESE. 4, SE. 5-4 zuletzt wieder ESE 5. Seegang: Richtung nicht angegeben; Höhe $4-\mathrm{I}-3$. Bewölkung bis $27,5^{\circ} \mathrm{N}$. $63,6^{\circ} \mathrm{WV}$. : m. o. dann b. c. 4-2; von $22^{1} / 2^{0} \mathrm{~N} .69^{1 / 4^{0}} \mathrm{IV}$. m. o.r., m.o. und $\mathrm{q}^{2} \mathrm{r}$ zuletzt wieder c. 2; NElich vor Turks In. Paß auch Blitzen in SIV. d. i. in der Richtung der Inseln und Riffe Strömung: VI I0-I I S. $67^{\circ} \mathrm{WV} .28$; I I-I 2 S. $24^{\circ} \mathrm{IV} .5$ $12-13$ S. $27^{\circ} \mathrm{IV}$. S. $13-14$ S. $72^{\prime \prime} \mathrm{WV}$. 10 Sm. St. Thomas - Havre 1886 VI 15-16: $20,90 \mathrm{~N}$ $62,8^{\circ} \mathrm{W} .-24,1^{\circ}$ N. $59,6^{\circ} \mathrm{W}$. IVd. SSE-SE-Sl. $3-2$ - Seegang SElich 2. - Bewölkung: str. $2-7-6$ auch o: viel q. und g. auch u. zweimal r. - Strömung: nötiger Anhalt nicht vorhanden.

Juli. D. D. Hungaria; Vera Cruz-Tampico I 887 VII I. Bei der von diesem Tage mitgeteilten Beobachtung, angestellt Nlich von V. C. war IVd. Nlich 2; Seegang: N. 3. Bewölkung: 5. - T ampico-Progreso. VII 4-5. Wind E. 4-3, zuletzt NE. 4. Secgang: E. 4. Bewölkung: 3-5; kein Niederschlag mitgeteilt. Strömung: VII 4 Tampico- $2 \mathrm{I}^{\circ} 5 \mathrm{O}^{\prime} \mathrm{N}$ $94^{\circ} 36^{\prime} \mathrm{WV}=\mathrm{E} .3$; VII $4-5-2 \mathrm{I}^{\circ} 15^{\prime} \mathrm{N} \cdot 90^{\circ} 19^{\prime} \mathrm{W}$ $=$ E. $5 \mathrm{Sm}$.- Progreso-Haiti VII $8-102 \mathrm{I}^{\circ} 5 \mathrm{O}^{\prime} \mathrm{N}$ $86^{\circ} 40^{\circ} \mathrm{W}$. - I $9^{\circ}$ I $8^{\prime} \mathrm{N} .76^{\circ} 38^{\prime} \mathrm{WV}$. IVd. anfgs. ENE. I, dann E. 2-5, zuletzt ESE 5. Seegang: E. 3 und ESE 4--6, aus letzterer Richtung lange vor Drehen des Windes Bewölkung: 2-3; Slich der Skuiste $\mathrm{C}$ u ba's qp. und q. 6. Strömung: von Progreso $-2 \mathrm{I}^{\circ} 5 \mathrm{O}^{\prime} \mathrm{N}$. $86^{\circ} 4 \mathrm{O}^{\prime} \mathrm{IV}$. $=\mathrm{N} .17^{\circ} \mathrm{W} .5,-20^{\circ} 4 \mathrm{I}^{\prime} \mathrm{N} .8 \mathrm{I}^{\circ} 46^{\prime} \mathrm{W} .=\mathrm{S} .87^{\circ} \mathrm{WV}$. I $8 \mathrm{Sm}$ - Vl. vom Mona Paß VII 21. Wd. E. 6 mit q. 7 Seegang: E. 7. Bewölkung: 5. Strömung: N. 67 11 . 1 $25 \mathrm{Sm}$. St. Thomas - Hatre VII 23, 24. $21,7^{\circ} \mathrm{N}$ $6 \mathrm{I}, 7^{\circ} \mathrm{W} .-23^{\circ} 46^{\prime}$ N. $59^{\circ} 47^{\prime}$ WV. Wd. ESE. 4-3; E. 3. Seegang mit dem IVind 2-5. Bewölkung: $0-4$. Niederschlag nicht mitgeteilt. Strömung: VII 23-24 N. $22^{0}$ E. $5 \mathrm{Sm}$. - D. D. Holsatia; St. Thomas-

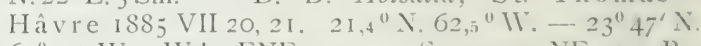
$60^{\circ} 5^{\prime} \mathrm{W}$. Wd. ENE. 4-5. Seegang: NE. 2. Bewölkung: 4-2. Niederschlag nicht mitgeteilt. - Strömung NEzE I $3 \mathrm{Sm}$.

August. Keine Mitteilungen.

September. D. D. Hungaria. Havre-St. Thomas I 887 IX 9. Zwei Beobachtungen: a. $S^{\text {th }}$ bei $20^{\circ}$ I $3^{\prime} \mathrm{N}$. $61^{\circ} 5^{\prime} \mathrm{W}$. und mitgs. $19^{\circ} 50^{\circ} \mathrm{N} .62^{\circ} \mathrm{O}^{\prime} \mathrm{WV}$. IVd. und Seegang: ESE. 4. Bewölkung: 4-3. Niederschlag: Keiner. Strömung: VII 8: $22^{\circ}$ I $5^{\prime} \mathrm{N} .58^{\circ} \mathrm{IV}$. - VII 9. N. $82^{\circ} \mathrm{W}$. $13 \mathrm{Sm}$.

Oktober. D. D. Hungaria. St. Thomas-Hàve $\mathrm{X}$ 14. Eine Beobachtung a. \& h bei $22^{\prime} 27^{\prime} \mathrm{N} .59^{\prime \prime} 53^{\prime} \mathrm{IV}$. IVd. L. 4. Scegang: ENE. 3. Strömung: I 13-I4 mttgs. $22^{\circ} 53^{\prime}$ N. $59^{\circ} 25^{\prime} \mathrm{IV}$. N. $20^{\prime \prime} \mathrm{IV}$. I I Sm.

Yovember. D. D. Holsatio. Havre-St. Thomas. I 885 XI $25,26.22,7^{\circ}$ N. $59,4^{\prime \prime} \mathrm{W},-19^{\circ} 9^{\prime} \mathrm{N}$. $62^{\circ}+4^{\prime} \mathrm{W}$. IVd. SSE. 2--3. Seegang: SSE. I-2. Bewölkung: $2-3$. Niederschlag: liciner. Strömung: nicht bestimmbar. - S. Östr. Ung. M. S. .Zrinyi"; Tenerifa, Santa Cruz-Port of Spain, Trinidad. 
I 885 XI I 2, I3. II ${ }^{\circ} 43^{\prime} \mathrm{N} .58^{\prime \prime} 57^{\circ} \mathrm{W} .-10^{\circ} 44^{\prime} \mathrm{N}$ $6 \mathrm{I}^{0} 4 \mathrm{I}^{\prime} \mathrm{W}$. Wd. E. $2-3$, NE. 5, E. O-I, SE. 2 E. 3-I, SSE. I. Seegang: E. 2-O. Bewölkung 2-5-2 custr., cu, str., obere cistr., cicu. Niederschlag anfgs. r. 4,5 mm.; später: einmal Hrzt. m. Strömung XI II-I2. NzE. ${ }^{3} / 4 \mathrm{E} .5 \mathrm{Sm}$. - In Port of Spain XI I3-I $\mathrm{Wd}$. vorwiegend $\mathrm{NE}-\mathrm{E}$. 3-O; vereinzelt N. und NzW. I-O; SSE.-SE I-O, zuletzt ESE. 2-3 - Bewölkung: $0-4$, vereinzelt 8 - Io viel str., cu, cistr. obere cistr., auch cicu. Niederschlag: p, d, r zusammen I, $9 \mathrm{~mm}$. - Port of Spain, Trinidad-Bridge town, Barbados. XI I8. I9. Wd. NE. I-4. Seegang: E. 3-1. Bewölkung: 3-8. Niederschlag: p. $8,2 \mathrm{~mm}$. Strömung: SW. $\%$. W. I $3 \mathrm{Sm}$. - Im Hafen von Bridgetown XI I9. 20. Wd. NE.-E. I - Bewölkung: I-9 viel cu, str., obere cistr., cicu. Niederschlag: p. 5,3 mm. - Bridgetown, BarbadosKingstown, St. Vincent; $13^{\circ} 4^{\prime} \mathrm{N} .59^{\circ} 46^{\prime} \mathrm{IV}$. $13^{\circ} 7^{\prime} \mathrm{N} .60^{\circ} 59^{\prime} \mathrm{W}$. Wd. E.-SE. 3, einmal 2. Be wölkung: 3-IO, cu,str., obere cistr. Niederschlag: p. $5,7 \mathrm{~mm}$; am $2 \mathrm{I}$ a $4^{\mathrm{h}}$ Mondregenbogen. - Im Hafen von $\mathrm{K}$ ingstown. Wd. ESE. $-\mathrm{NE}$. O-2. Bewölkung: 3-IO meist cu, str., auch ni, obere cistr. Niederschlag p. $10,9 \mathrm{~mm}$. - Kingstown, St. Vincent-Port Castries, St. Lucia. XI 23, 24. I $3^{0} 14^{\prime} \mathrm{N} .6 \mathrm{I}^{0} 17^{\prime} \mathrm{IV}$. - I $4^{\circ} \mathrm{O}^{\prime} \mathrm{N} .6 \mathrm{I}^{\circ} \mathrm{I}^{\prime} \mathrm{II}$. Wind: Stille, N-E. I-4. Bewölkung: 2-9, cu-str. obere: cistr. - Niederschlag p. 4,1 mm. - In Port Castries Wind E.-NE.- LSE 2-o. - Bewölkung: 3-9, cu-str-ni, obere: cistr. cinmal sehr rascher Wolkenzug NE. - Niederschlag: einmal d, p. = II,2 $\mathrm{mm}$. - Port Castries, St. Lucia - Fort de France, Martinique XI 26. I $4^{\prime \prime} 9^{\prime} \mathrm{N}$. $6 I^{\circ} 2^{\prime} \mathrm{W}$. und $14^{\circ} 32^{\prime} \mathrm{N}$. $6 \mathrm{I}^{\circ} 6^{\prime} \mathrm{IV}$. IVind $E$. und NE. 3. Bewölkung: 5 und 4. Niederschlag: P. I,8 mm Im Hafen von Fort de France damn von St. Pierre. Martinique XI 27-30. Wind E.-NE. O-3. Seegang: zuletzt E. $\mathrm{I}-3$. Bewölkung: $\mathrm{O}-\mathrm{IO}$, cu-str. auch ni, obere cistr-cicu. Niederschlag: p. und r. $30,5 \mathrm{~mm}$

Dezember. D. D. Holsatia: Hâvre-St. Thomas. I 884 XII 25, 26: 22, $0^{\circ}$ N. 59,6 ${ }^{\circ} \mathrm{W}$. I $8^{\circ} 49^{\prime} \mathrm{N}$. $63^{\circ} 3^{\prime} \mathrm{IV}$. Wd. NE. 3-2. Seegang: NE. 3-I. Bcwölkung: ci und cu 6-2. Niederschlag: keiner. Ström ung: kein Anhalt. - St. Thomas - La Guayra. XII 28, 29 St. Croix - II,4 ${ }^{0} \mathrm{~N} .66,4{ }^{0} \mathrm{WV}$. anfangs ENE. 3, zuletzt E. 2. Seegang: ENE. und Elich I Bewölkung: custr., ci, cu, ci cu 3-2. Niederschlag: keiner. Strömung: kein Anhalt. - S. Östr. Ung. MI. S. "Zriny i“ St. Pierre, Martinique. I 885 XII I. Wd. SE-XE. 3-I. Bewölkung: 1-5. Niederschlag: keiner. St. Picrre -Roseau road Dominica. XII I, 2. Wd. NNE. I, NE. 5-6, E. 4. Seegang: E. 4-3. Bewölkung: 0-4, cu,str. obere cistr. Niecterschlag: p. $0,5 \mathrm{~mm}$. Roseau road XII 2. Wd. ESE. I-2, E. 2-3, NNW. O-I, NE. I-2, Bewölkung: $7-4, \mathrm{cu}, \mathrm{str}$, obere cistr. Secgang: anfgs. E. I, zuletzt NE. I; zulctzt Hrzt. m. Roseau road.-Pointe à Pitre, Guadeloupe XII 3. Wd.NE.-EzS. 2--4. Seegang: nichtbemerkt. Bewölkung: 6-3. Niederschlag: r. 4,5 mm. - In Pointe à Pitre XII 3-6. Wd. SE.-FNE. I-3 auch Stille. Bewölkung: I-9, str., cu obere cistr. Niederschlag: p. I6,9 $\mathrm{mm}$. Pointe à Pitre, Guadeloupe-St. Johns harbour,
Antigua. XII 6, 7. Wd. E.-ENE.-E. 3-4-2 Seegang: E. und NE. 4-r. Bewölkung: 7-2, cu, str. cicu, obere cistr., cicu. Niederschlag: keiner. - In St. Johns harbour, Antigua. XII 7, S. Wind E.-NEzE. I-4. Seegang: ENE. I-3. Bewölkung 2--6, str, cu obere cistr. Niederschlag: p. 1, $3 \mathrm{~mm}$. Antigua-Basseterre, St. Kitts. XII 8, 9. Wd. E, ENE. 4-5. Scegang: ENE. 2-4. Bewölkung 4-5, cu, str. Niederschlag: keiner. - In Basseterre NII 9-1 . Wd. Ii-NEzl. 2-4. Secyang: 2-3 Bewölkung: I-IO, cu, str., ni obere cistr. Niederschlag : p. I $7,6 \mathrm{~mm}$. - St. Kitts-St. Thomas. XII I I-I2 Wd. ENE.-NE. I--7. Seegang: ENE. I-4 zuletzt ENE und N. 4-5. Bewölkung: 2-9, str., cu obere cistr. Niederschlag: p. $16,2 \mathrm{~mm}$. - In $\mathrm{St}$. Thomas. XII 12-I5. IVd. NE.-ESE, I-4. Seegang: nur anfgs. ENE. 2. Bewölkung: O-IO, cu, str., ni obere cistr. Niederschlag: p. 5,4 mm. - St. ThomasSan Juan, Portoric o. XII I 5, 16. Wd. NE.-ESE. 3--4. Bewölkung: $8-\mathrm{O}-4$, cu, str. obere cistr., cicu. Niederschlag: p. I,3 mm. - In San Juan. XII 16-20. Wind meistens ESE. 3-2, sonst NE.-EzN.-E.-SE.-SW - WVW , und NNW, I -3 und Stille, - Bewölkung: I--IO: str.-cu-ni obere: cistr.-cicu, abds. cinmal 1. Niederschlag: zweimal Thau, sonst p. und $r$. $=9, \mathrm{~s} \mathrm{~mm}$. - San Juan, Portorico-Rhede der Stadt San Domingo. XII $2 \mathrm{I}-23$. Wind NNE.-ENE., vorwiegend NE. 3-8. - Seegang meist mit dem Wind, doch auch ein Paar Strich nördlicher 2-5. Bewölkung: 3-IO, str-cu obere: cistr-cicu; am 22-23. stürmisch aussehende Luft. - Niederschlag: p. und r. 9,2 mm. San Dom ingo. XII 23--25, Wind fünfmal N. 2, sonst NNW.-NNE.-ESE.-SE.-SSE.-S. I-3. Seegang: am häufigsten Dünung aus $S$., sonst NE. 2-4. Bewölkung: S-IO, str-cu-ni obere: cistr.-cicu. Niederschlag: p. $=17,8 \mathrm{~mm}$. hiervon cinmal in $26^{\mathrm{m}} 7,8 \mathrm{~mm}$. - San Domingo-Portau Prince, Haïti, XII 25-3I. IVd. bis zur SPünte der Insel Häti XII 27, fast stets zwischen S. $-\mathrm{SW}$ - - WNW. I-5 nur zweimal E. und ENE. I-3, auch Stille, dann meistens E. auch NE. und N. I -4 bis zur Landspitze IVlich von $V$ ache I., von hier NNIV., NIV., NE., E., SSE. I-3 bis (nordwärts von Gonaive I.) Port a Prince. Seegang: einigermaßen dem Wind entsprechend; so lange dieser Slich und W1. ebenfalls aus S. (teilweise als Dunung) und W, vereinzelt mit SWI. I-3, dann E., vereinzelt ESE. und NW. I-2. Bewölkung: 2-IO, str., cu, ni ob. ci, ci str, cicu; bis zur SPinte dreimal Blitzen in NE, N. und SW., zweimal auch Hrzt. $\mathrm{m}$. Niederschlag: $\mathrm{p}$. und $\mathrm{r}=4 \delta, 4 \mathrm{~mm}$.

Von Anfang an wollte ich hier nur beriicksichtigen, auf einigen in das vorliegende Gebiet fallenden EinzelReisen beobachtete Wasserwärme, spez. Gew. und daraus abgeleiteten Salzgehalt; da nach meiner Ansicht WVind und Wetter darauf Einfluß haben, fügte ich noch bei, einen Überblick iiber diese; doch will ich nicht in Betracht ziehen den Barometerstand und seine während des Tages regelmäßig sich zeigende Anderung. Wenn Jemand diese als Gegenstand einer besonderen Arbeit wählt, so crlaube ich mir ihn auch aufmerksam zu machen auf 
das Journal S. Öster. Ungar. M. S. Zrinyiz, da wie ich bereits erwähnte, die Beobachtungszeiten waren: $\mathrm{I}^{\mathrm{h}}, 5^{\mathrm{h}}, 9^{\mathrm{h}}$ vinttgs. und nchmttgs., von denen $9^{\text {h }}$ dem höchsten Stande näher liegt als $8^{\mathrm{h}}$ : der bei vierstündlichen $\mathrm{Be}$ obachtungen auf Handelsschiffen paßsendsten Zeit; $5^{\text {h }}$ ist nicht soweit von $4^{\text {h }}$ (ungefährer Zeit des niedrigsten Standes) daß es als unpaßisend betrachtet werden kann. Zriny'i's Barometer war ein Aneroid, mehrere Vergleiche wurden aber angestellt. die genuigend übereinstimmten, um dic Angaben der erwähnten Anderung beachtenswert zu machen. Die Thermometer waren auf Z rinji so gut aufgestellt, daß aus dem Unterschiede zwischen trocken und feucht gehaltenem abgeleiteter Dampfdruck und Prozente der Feuchtigkeit ebenfalls als durchaus zuverlässig betrachtet werden müßen. - Auf I. Brt. M. S. .Challenger" ist jede zweite Stunde der Stand des Barometers angeschrieben, das Journal dieses Schiffes gehört also auch zu denen, welche die regelmäßige $\mathrm{Ab}$ und Zunahme des Barometerstandes, sowie sein Verhalten vor WVind- und Wetteränderung deutlich zeigen.

Wic ich bereits erwähnte, ist es wohl möglich, daß Paranagua das einzige Handelsschiff ist, von dem vorliegen vierstiundliche Beobachtungen des spez. Gew. für den Weg: Küste Brasiliens-New York; es wäre sehr lehrreich, wenn dies fortlaufend geschähe, da im Hochsommer die Land-Abwässerung ugf. gleiche Wärme haben mag mit dem sogen. Golfstrom, im IVinter mit dem Labradorstrom, also nur clas Aräometer angeben kann, ob man sich in jener oder in diesen befindet; dieser Teil der Rcise der Paranagua erscheint mir besonders wichtig, deshalb stelle ich ihn hier zu allgemeiner Verfugung.

Auf den Nutzen des Aräometers wies bereits Manury, d. i. vor mehr als 50 Jahren, die Journale von Commodore Folun Rodgers, U. S. N. A. S. ..Vinccune's" und von Kpt. H. Toynbee, Brt. S. .Gloriana", die er erwähnt (letztere, sowie andere von ihm genannte mit den Abbildungen der gefangenen Tierc), vielleicht auch die von Dr. Ruschenberger, Dr. Raymond, Ltnts. Porter und Lee waren vor 3I Jahren noch auf dem Institut, ,Deutsche Seeriarte." Von den Kapitänen die zu Maury's Zeit und für ihn spez. Gew. beobachteten erinnere ich mich an Kpt. Ileyland, der damals möglicherweise den ..Gincral Jakobi" unter hannöverscher lilagge fulır; in sein Journal hatte er das von ihm benutzte Aräometer gezeichnet; er baute I 860 oder 61 in Stcttin eine Schoonerbark mit der er samt Familie und Mannschaft in ostasiatischen Gewässern spurlos verschollen ist. Ehre seinem Andenken! - Ausdehnung des Seewassers, Verhältnis des spez. Gew. zum Salzgehalt waren zu damaligen Zeiten unsicher bekannt Tabellen dafür nicht vorhanden, die Notwencligkeit: bei Beobachtung des spez. Gew, mit ihr zu verbinden diejenige der IVärme des Wassers im Glase nicht hervorgehoben, - immerhin waren die Angaben jener Herren geniigend, die Aufmerksamkeit auch hierauf zu lenken. - Nebenbei: Kpt. Tojnbec fand auf einer seiner Reisen in der Nähe des Aquators im Atlantic die WVindverhältnisse besser in Übereinstimmung mit Maury's P'ilot Chart als mit dessen Anleitung; dies bemerkte or im Journal mit der lolgerung, es sei dort also besser sich nach jener Karte als nach der Anleitung zu ricinten;
Maury scheint dies aber nicht übel aufgenonmen zu haben.

Fiür diese Veröffentlichung des Abschnittes von Paranagua's Journal: Küste Brasiliens bis New Yorkberechnete ich nach felineks Tabellen, 5. Auflage 1903, Dampfdruck und Prozente Feuchtigkeit, denn ich betrachte die Psychrometer-Angaben als zuverläßig. Kpt. Behrmann hatte bereitwilligst auf mein Ersuchen sogleich fertigen lassen ein Psychrometer-Häuschen von Jalousien, weiß angestrichen, ohne Boden, so grof, daß die beiden Thermometer von einander und von der inneren Wandung nach allen Richtungen wenigstens IO $\mathrm{cm}$. entfernt waren; sie wurden nur von dïnnem Messingdraht gehalten; das war angebracht auf der Brïcke, möglichst weit vom Schornstein, Lampen u. s. w., in vollem Luftzuge, sodaf etwa hineingelangte Feuchtigkeit möglichst rasch wieder trocknete. Auf der ersten (früheren) Reise, auf der die Instrumente an Bord waren, hatten die Steurer nicht genügend beachtet, kein Salzwasser in clas kleine IVassergefäß kommen zu lassen, in Folge dessen hatte sich eine leichte Salzkruste an das feuchte Thermometer gesetzt, wodurch es unrichtig angab; dies war ihnen aufgefallen und sie frugen mich deswegen, als ich hier an Bord kam, - sagten mir dann zu, das Gefäß täglich mit frisch IVasser zu fülen, die Thermometer ebenso abzuwischen, das Läppchen wenigstens wöchentlich z.u wechseln und falls doch Spuren von Ansatz an der Kugel sein sollten, diesen vorsichtig durch Abschaben und Abbürsten mit lauem WVasser zu entfernen; wo dicht vor Sandy Hook am feuchten Thermometer Wärme unter $\mathrm{O}^{\circ} \mathrm{C}$. beobachtet war, habe ich den Dampfdruck etc. nicht berechnet, weil ich nicht einsehe wie dann auf Handelsschiffen der Wachthabende Zeit haben kann, das Nötige zu tun um am feuchten Thermometer richtig ablesen zu können. - Der Barometerstand ist übertragen auf $\mathrm{O}^{\circ} \mathrm{C}$., deshalb bezeichnete ich ihn als Luftdruck: den Aufstellungsort erinnere ich nicht mehr, daher ist er nicht übertragen auf die Meeresoberfläche, $0,4 \mathrm{~mm}$. diirfte der Meistbetrag sein, der lierfür noch zuzulegen wäre.

Ein flüchtiger L berblick über diese Reise zeigt:

Von ugf. $12^{\circ} \mathrm{S} .36^{\circ} \mathrm{NI}$. bis $1^{\prime \prime} \mathrm{S}$. $3 \mathrm{~S}^{\circ 1} \mathrm{II}$. ISS6 I $21-23$ wehte der l'assat etwas SI. von E. und ron E. leicht bis flau, bei letzterer Gegend I 24 dreht er nach nördlich von li., wird bei $1^{\prime \prime} \mathrm{N}$. $+0^{\circ} \mathrm{WV}$. NE. und NNE. bald nachher wieder östlicher; bei $21^{0} \mathrm{~N}$. $57^{\circ} \mathrm{VV}$, dreht er südlich von E., bei ugf. $24^{\circ} \mathrm{N}$. $6 \mathrm{r}^{\circ} \mathrm{WV}$. MI.N. II $2-3$ verliert das Schiff den Passat. der im Ganzen nur leichte bis mäßige Stärke hatte. Nach kurzer Stille und SIIlichem Wind wird dieser wieder NE., bleibt aus dem östlichen Halblireis bis $30^{\prime \prime} \mathrm{N} .68^{1} 2^{\circ} 11^{\text {. II }}$ 4, dort dreht er durch SII. auf IVXII., immer mälsig und leicht; im NIVlichen Viertel nimmt die Wincistärke $7 u$ bis leicht stiirmisch doch bald läist sie nach, bei $37^{1 / 4^{0}} \times .73^{1 / 2^{0}} \mathrm{~W}$. II 7 kurze Zeit Stille dann Nlich flaue, NIV. leichte Brise bis Sandy Hook.

Der Secgans entspricht ugf. der Windrichtung und Stärke, zuweilen war er begleitet von Dünung aus anderer Richtung oder höherer als der Seegang selbst; dies ist durchaus nicht selten, manchesmal Vorbote von Wind aus anderer Richtung als der z. Z., manchmal 
von, selbst in großer Entfernung wehendem, weil die Wellenschwingung sich viel weiter fortpflanzt als der Wind reicht.

Die Versetzung (Unterschied zwischen Schiffsort nach Loggerechnung mit dem nach Beobachtung, von jenem z.u diesem gerechnet) erreichte keinen bedeutenden Betrag, höchstens I9 Sm. in 24 Stunden. Bis $10^{0} \mathrm{~S}$. zeigt sich der brasilianische Küstenstrom, von dort bis zum nächsten Mittag bezw. $63 / 4^{0} \mathrm{~S} .34^{3} / 4^{0} \mathrm{~W}$., als Ausnahmefall nahe ostliche, vielleicht Einfluß des $S$. Francisco Flußes. Bis $6^{\circ} \mathrm{N} .44^{\circ} \mathrm{W}$. erkennt man wieder die Passatströmung, weiter bis ugf. $5^{\circ} \mathrm{N} .5 \mathrm{I}^{\mathrm{O}} \mathrm{W}$. den sógen. Gegenstrom. Es folgen die unsicheren Versetzungen in der Nähe der Passatgrenze, dort auch beeinflußt von Abzweigungen des Golfstroms, nur bei Annäherung an die amerikanische Küste zeigt sich deutlich dessen NEliche Richtung.

Der Luftdruck nimmt ab bis der Wind nach nördlich von E. dreht d. i. ugf. $\mathrm{r}^{0} \mathrm{~S}$. $39^{\circ} \mathrm{WV}$., von dort nimmt er wieder zu bis $27^{1 / 4^{\circ}} \mathrm{N} .65^{1 / 2^{\circ}} \mathrm{WW}$. um nahe I0 $\mathrm{mm}$. (758.2-768,0 mm.); weiterhin entspricht seine Ab- und Zunahme der Windrichtung, er ist vor SW. (der bald durch $\mathrm{W}$. dreht) am niedrigsten $=757,8$, vor und bei NW. am höchsten 771,8 , Schiffsort $33^{33} / 4^{0} \mathrm{~N}$. $72^{1} / 4^{0} \mathrm{~W}$., von hier mit Annäherung an Land abnehmend, trotzdem der Wind (von kurzer Stille unterbrochen) im NWlichen Viertel bleibt.

Die Luftu'ärme kann nur richtig angegeben werden von gut und zur Ablesung bequem aufgestellten Thermometern, die geschiitzt sind gegen unmittelbare Sonnenbestrahlung, vom Schiff und Zubehör entstandener Wärme, dagegen dem Einfluß des Windes gut ausgesetzt; dabei sind sic stets rein $z u$ halten, haftet an ihnen Staub, Rufs, Salz, Salzwasser u. a. so zeigen sie unrichtig. Manche Schiffe haben tatsächlich keinen Platz für Beobachtung der Luftwärme, da sollte man Ablesen der Thermometer für allgemeine Zwecke unterlassen, doch ist es nach anderen Richtungen wertvoll und wichtig die IVärme auf und in dem Schiffe selbst genau zu kennen, - dann sind die Instrumente an geeigneten Stellen anzubringen, ihr Stand so zu beobachten, sowie anzuschreiben, daß daraus Meist-, Mindest und Durchschnittsbetrag ableitbar ist. Auf Paranagua waren, wie schon crwähnt, die Thermometer gut aufgestellt und gut gehalten, die Luftwärme also ersichtlich; auf vorliegender Reise war sie an größten (Meistbetrag 29, ${ }^{\circ}$ und $28,1^{\circ}$ C.) zwischen $7^{\circ} \mathrm{S}$. $34^{33} / 4^{0} \mathrm{~W}$. bis $3^{0} \mathrm{~S}$. $36^{1 / 2^{0}} \mathrm{WV}$. I 22 und 23 ; mit gewöhnlichen Schwankungen nimmt sie allmählich $a b$ bis $24^{\circ} \mathrm{N} .61^{\circ} \mathrm{W} .=23^{\circ} \mathrm{C}$, dann rascher bis $30^{1 / 2^{\circ}} \mathrm{N} .69^{\circ} \mathrm{W} .\left(=20^{\circ}-\right.$ wohl Vorbote des NIVI. Windes); weiterhin ist die Abnahme sprungweise, nicht weit von Sandy Hook beobachtet man $-2,3^{\circ}$ bei jener Stelle $+0,9^{0}$ am II 8.

Dampfiruck (Dunstspannung) d. h. Einflul3 des Gehaltes an Wasserdampf auf den Barometerstand, und $\%$ Feuchtigkeitsgehalt der Luft werden berechnet nach dem Unterschied in den Angaben des trocken und feucht gehaltenen Thermometers, wozu, wie bereits ein paarmal erwähnt Reinhaltung derselben durchaus notwendig ist. Bei abnehmender Wärme vermindert sich im allgemeinen der Dampfdruck (die Dunstspannung), dabei erhält derselbe
Unterschied in den Angaben der beiden Thermometer höheren Wert je geringer die Wärme ist; wenn sich das feucht $\mathrm{zu}$ haltende Thermometer mit Eis bedeckt, sind die Verrichtungen für genaue Ablesung (wie ebenfalls bereits erwähnt) zu zeitraubend um -auf dem überwiegend größten Teil der Handelsschiffe vorgenommen zu werden. - Im vorliegenden Fall war der Dampfdruck am höchsten $\left(2 \mathrm{I}-23,5 \mathrm{~mm}\right.$.) zwischen $8^{1} / 2^{0} \mathrm{~S} .35^{\circ} \mathrm{W}$. bis $4^{0} \mathrm{~N} .42^{1 / 2}{ }^{0} \mathrm{~W}$., Meistbetrag bei $\mathrm{r}^{0} \mathrm{~N} .40^{0} \mathrm{~W}$. I 25 ; man erkennt plötzliche Abnahme (2 $1 / 2 \mathrm{~mm}$., von 20,6 zu I $8,1 \mathrm{~mm}$.) bei $8^{1} / 2^{0} \mathrm{~N} .45^{1 / 2^{0}} \mathrm{WV}$. I 28 , dann wieder ( 16,9 zu I $4,0 \mathrm{~mm}$.) bei $30^{1} / 4^{0} \mathrm{~N}$. $69^{\circ} \mathrm{IV}$. II 4 , von wo er mit mehreren zunächst so zu sagen großen Sprüngen, auch ein Paar Rückspringen, abnimmt, so daßs er bei IVärme, die nahe zum und unter den Gefrierpunkt gesunken ist, nur 3 bis $4 \mathrm{~mm}$. beträgt. Der Feuchtigkcits-Gehalt der Luft kann nicht genau übereinstimmen mit dem Dampfdruck; wir sehen ihn hier nur selten unter $70 \%$, am geringsten (weniger als $60^{\circ} \%$ ) zwischen $35^{\circ}$ und $37^{\circ} \mathrm{N} \cdot 73^{\circ}-73^{1 / 2} \mathrm{~W}$. bei böigem NWl. Wind; andauernd hoch $(90-98 \%)$ naturlich bei häufigem Regen II $4-5,30^{\circ}-32^{\circ} \mathrm{N}$. $68^{1 / 2} 2^{0}-70^{1 / 2}{ }^{0} \mathrm{WV}$. - Je mehr Seereisen benutzt werden zur Erholung und zur Stärkung der Gesundheit, um so mehr Wert gewinnen die meteorologischen Beobachtungen auf Schiffen, nicht zum wenigsten auch die Angaben über Luftdruck, Wärme, Dampfdruck und FeuchtigkeitsGehalt der Luft.

Bei den Witter-Angaben sind zu beachten die betr. Regenschauer im Passatgebiet; in seinen Mitteilungen über die Regenverteilung des atlantischen Oceans wies, wenn ich nicht irre, Hr. Prof. Dr. Koeppen schon vor ein Paar Jahrzehnten daraufhin, daßs sie auch auf dem Ocean nicht so selten sind als im allgemeinen angenommen wird. Nördlich des Passats fand Paranagua für Örtlichkeit und Jahreszeit nicht ungünstiges WVetter; im letzten Teil der Reise ist es als guinstig zu betrachten, daß weder Schnee noch Glatteis bemerkbar war.

Die Wasserwärme blieb ugf. $27^{\circ} \mathrm{C}$. von $12^{\circ} \mathrm{S}$. $36^{\circ} \mathrm{IV}$. I 21 bis $7^{\circ} \mathrm{N} .45^{\circ} \mathrm{IV}$. I 27 . Ausnahmestellen waren: bei $8^{\circ} \mathrm{S} .35^{\circ} \mathrm{W},-26,0^{\circ}$, bei $\mathrm{I}^{1 / 2}{ }^{\circ} \mathrm{N} .40^{\circ} / 4^{\circ} \mathrm{WV}$. $28,1^{0}$; bis $12^{1 / 2^{0}} \mathrm{~N}$. $49^{33} / 4^{0} \mathrm{~W}$. bleibt sie dann zwischen $26,4^{\prime \prime}$ und $25,8^{\circ}$, bei $13^{\circ} \mathrm{N}$. $49^{1} / 3^{\circ} \mathrm{W}$. ist $24,8^{\circ}$ wieder eine Ausnahmestelle, die gewissermaßen anzeigt einen breiten Gürtel von höchstens 25,6 ${ }^{\circ}$ mindestens $24,8^{\circ}$ bis $22^{\circ} \mathrm{N} .58^{1} / 2^{\circ} \mathrm{W}$. - jedoch hat die Gegend bei $18^{\circ} \mathrm{N}$. $54^{\circ} \mathrm{WV}$. bis $19^{1 / 2^{\circ}} \mathrm{N}$. $54^{1 / 2^{\circ}} \mathrm{W}$. zwei warme Stellen von $26,4^{\circ}$ und $26,2^{\circ} \mathrm{C}$. Die Wasserwärme nimmt allmählich ab von obiger Grenze der $25^{\circ} \mathrm{C}$. bis $30^{3} / 4^{\circ} \mathrm{N}$. $69^{\circ} \mathrm{IV}=19,0^{\circ}$; gleich darauf zeigt sich nur $17,3^{\circ}$; nun treten ein die Schwankungen, die verglichen sind mit Bändern wärmeren und kälteren Wassers; sic reichen bis $37^{3} / 4^{0} \mathrm{~N}$. $73,15^{0} \mathrm{~W}$. wo II 7 nur $\mathrm{I} 3,3^{0}$ man beobachtete; von dort ist rasche Abnahme bis - $0,5^{\circ}$ bei Sandy hook; eine ausnahmsweise warme Stelle $20,6^{\circ}$ fand sich bei $36^{\circ} \mathrm{N} .73^{\circ} \mathrm{W}$

Der Salzgehalt war am größten zwischen $10^{\prime \prime}-$ I I $^{\circ} \mathrm{N}$. $35^{1} / 2^{0}-35^{\circ} \mathrm{W}=3,7 \times \%$ vorher war er ugf. 3,75 , nahm ab $z$ u 70 bis $5^{1 / 2^{0}}$ N. $35^{1 / 4^{0}} \mathrm{~W}$.; mit Schwankungen (cine Stelle 65 zwischen $7 \mathrm{I}$ und 70 bei $2^{1 / 2^{0}} \mathrm{~S} .37^{0} \mathrm{IV}$.) zeigt sich die Abnahme weiter zu 63 bei $\mathrm{I}^{0} \mathrm{~N} .40^{1 / 2^{0}} \mathrm{~W}$. von hier ist er bald zunehmend zu 68 und 67 , bald 
D. D. „Paranagua“ (H. S. Am. Dsch. Ges.) Kapt. Behrmann, 1886. Januar 21 bis Februar 8.

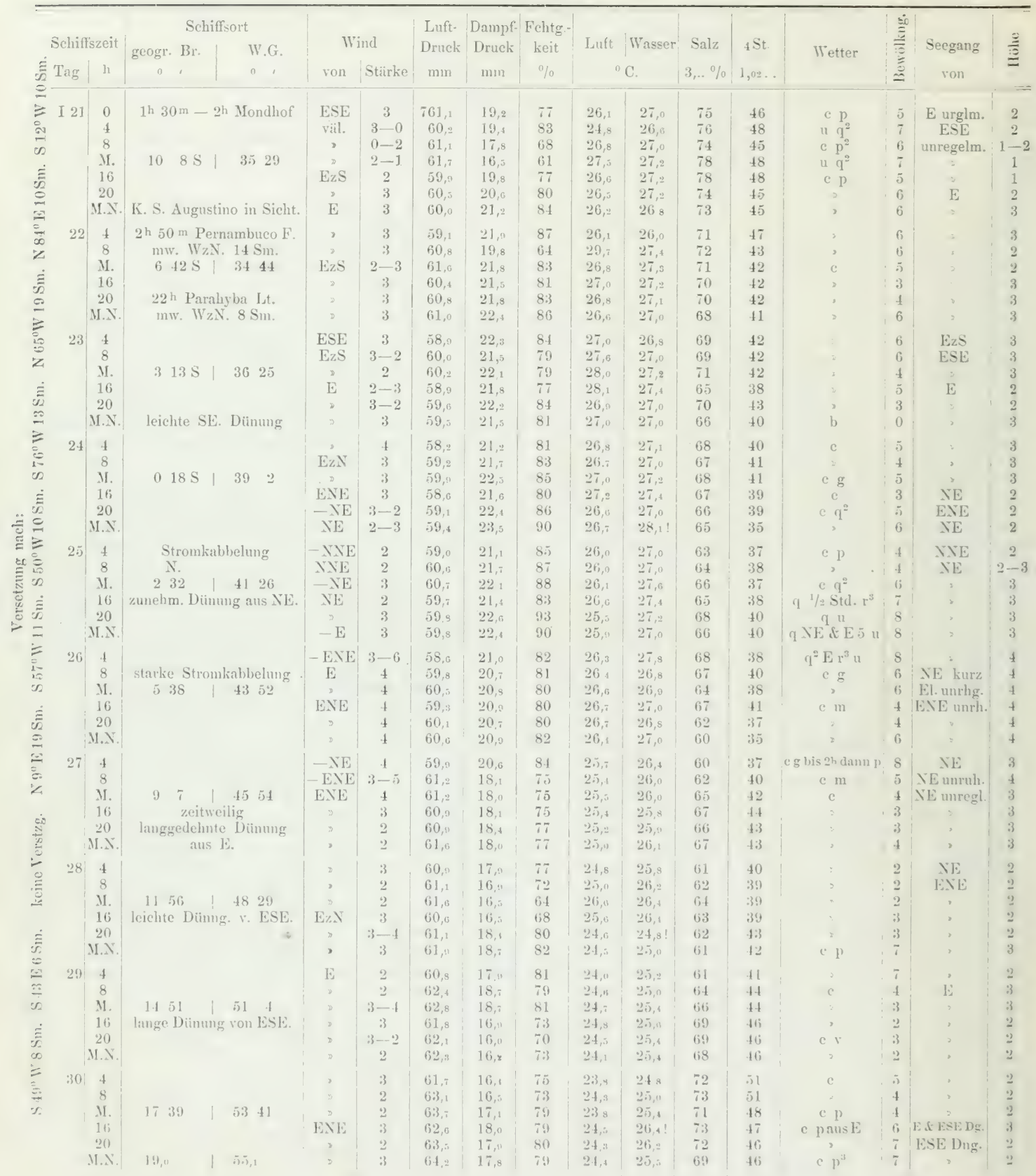


Rio Janeiro - New-York; Journal geführt von Herrn Friedr. Nieschulz.

Jan. 20. M. $13^{\circ} 35^{\prime}$ S. $36^{\circ} 37^{\prime}$ W. G.

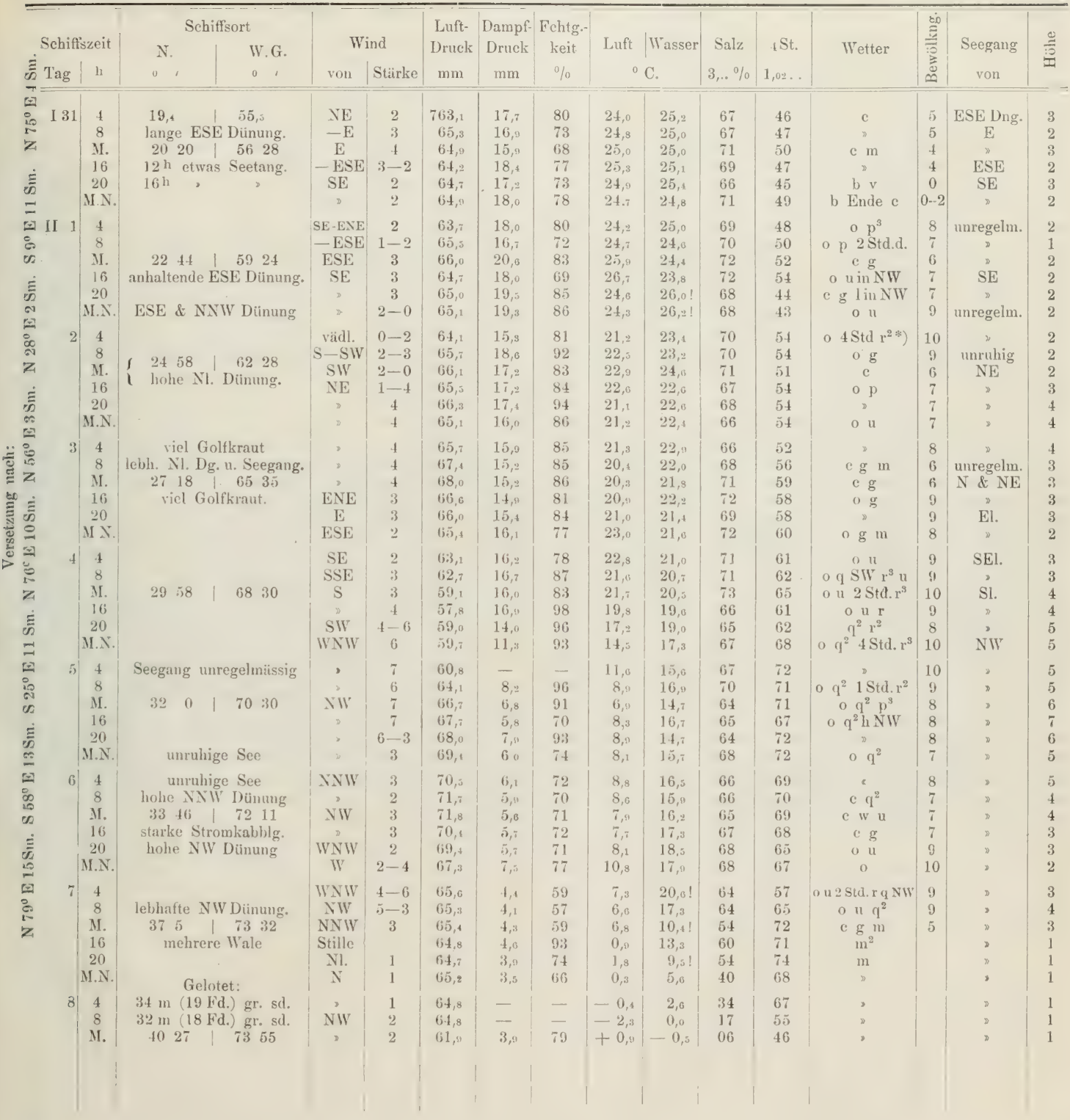

Mittags passierten Sandy Hook. 
abnehmend $z U 60$ und $6 \mathrm{I}$ bei $\mathrm{I}_{4}{ }^{\circ} \mathrm{N}$, $5 \mathrm{O}^{\circ} \mathrm{W}$., letzterer dort gewissermaßen andeutend die Grenze einer Gegend größeren Salzgehaltes der bei $16^{1 / 2^{0}} \mathrm{~N} .52^{3 / 4}{ }^{0} \mathrm{IV} .70$ übersteigt bis $30^{\circ} \mathrm{N}$. $68^{1} / 2^{\circ} \mathrm{W}$., als Meistbetrag 73 als Mindestbetrag 66 aufweist. Bei letzterwähnter Stelle beginnt wieder eine Gegend des Schwankens d. h. bald abnehmenden bald zunehmenden Salzgehaltes, das einigermaßen sich anschlielst an die "Bänder der Wasserwärme, sie reicht bis $36^{\circ} \mathrm{N} .73^{\prime \prime} \mathrm{W}$. wo man zuletzt 64 fand (der Meistbetrag war 70 und 68, eben vorher war jene warme Stelle von $20,6^{\circ}$ C. aber auch nur $3.64 \%$ Salz); man frägt sich, ob nicht an Ausnahmestellen die größere Wasserwäme entstand durch näher an die Oberfläche gelangende Schichten wirklichen (Golfstroms - d. i.) Passat-IVassers. - Mit Annäherung an die Mündung des Hudson, nimmt der Salzgchalt, entsprechend dem Küistenstrom und der Land-Abwàsserung, rasch $a b$, - beträgt bei Sandy hook doch noch etwas melrr als $3 \%$; die eine verhältnismäßig warme Stelle zeigt auch durch ihren größeren Salzgehalt den Einfluß des vergleichsweise nicht fernen Passatwassers. -

Unwillkürlich frage ich mich, ob nicht der östliche Passat, die Aequatorströmung unterstützend, in mehr oder weniger breiten Streifen vor sich hertreibt das, durch den starken Regenfall der sogen. Stillengegend weniger salzhaltig gewordene Wasser; es ist wohl nicht ausgeschlossen, daß in der Nähe Amerikas und seiner vorliegenden Inseln hinzukommt ein Teil des von der LandAbwässerung gebrachten IVassers, dessen Beimischung von Schlamm und Sand schon fruher niedersank. Von kälteren Gegenden stammendes durch Eissclımelze und starke Niederschläge salzärmeres Wasser findet seinen Weg in Streifen auch durch die und unter den »Bändern " des Warmwasserstromes, während zu vereinzelten salzreicheren Stcllen - wie friher erwähnt - stellenweise stärkere Verdunstung beitragen kann.

Das spez. Geri. des Meerwassers an der Oberfläche ist, wie erwähnt, hauptsächlich abhängig von seiner Wärme und Salzgehalt; wo also letzterer bei (jleichbleiben ersterer abnimmt, wird auch das spez. Gew. abnehmen,
— wo er zunimmt, letztere nicht, wird es größer werden; andererseits bleibt der Salzgehalt gleich und die IVärme nimmt zu, so wird spez. Gew. geringer, nimmt sie ab, su wird es größer; ändern jene beiden nach derselben Richtung so hängt es $a b$, von dem Verhältnis indem es geschieht, nach welcher Richtung das spez. Gew. sich ändert; verhältnismäßig größere Wärme verringert es, verhältnismäßig größerer Salzgehalt vermehrt es. - So sehen wir auf dieser Reise der Paranagua in der südlichen breiten Gegend mit nahe gleicher IVasserwärme sobald der Salzgehalt abnimmt das spez. Gew. geringer, - da aber die Gegend mit weniger Salzgehalt weit nach Norden reicht, bis dahin wo das IVasser etwas kälter wird, hebt sich das spez. Gew. entsprechend, nimmt stark zu sobald kälteres VVasser salzreicher ist, — jedoch auch, sobald seine Abnahme der IVärme erheblich größer wird als die des in ihm gelösten Salzes, sodaß am Ende der Reise vor dem Hudson das spez. Gew. des kältesten Wassers, trotzdem es erheblich salzärmer ist, mehr beträgt und gleich ist, dem hier in Betracht gezogenen gleichzeitig wärmsten und salzreichsten unweit der Küste Nord-Brasiliens.

Wellonbervegung, Wïrme, Salzgelualt und spez. Gew. des Meerwassers sind nach verschiedenen Richtungen wichtig fur Benutzung, des Meeres und der Kiisten, hauptsächlich für Leben, Entwicklung, Gedeihen der Meertiere und Meerpflanzen.

Für die an Gebrauch ähnlicher Karten und Tabellen Gewöhnten, mögen hier gegebene Übersichten unnötig sein; soweit meine Kenntnis reicht, sind jedoch letztere dem größten Teil der sie Gebrauchenden nützlich, selbst notwendig, da sie erleichtern das sogen. Lesen der Karten, sich Hineindenken und Hineinfinden.

Die Küstenlinien, Flüße, Untiefen sind durchgebaust von der brit. Admkt. North Atlantic Ocean. II'cstern Portion. No. [1063] 2060 B', und um $1 / 4$ des linearen Maßstabes photographisch verkleinert, in Bezug auf die Vorlage also $1: 3 / 4$. 


\title{
BEITRÄGE ZUR MEERESKUNDE.
}

\author{
III. \\ Zur Kenntnis der Wirbelstürme.
}

(Mit Tafeln und Journalauszügen.)

»Bei den Prüfungen für die Befähigung zum Sec-, Steuermann und-Schiffer, solle größere Kenntnis der Eigenheiten von Wirbelstürmen verlangt werden." - Solcher Antrag stand vor ein Paar Jahren im Deutschen Nautischen Verein zur Verhandlung. - Nach meiner Ansicht kann man es nur, wenn das Allgemeine dieser Natur-Erscheinungen besser bekannt ist als früher, auch leicht zugänglich. Besser bekannt mag Einzelnes sein z. B. in den Zuständen der Atmosphäre unter denen sie entstehen, in den Ursachen ihrer Weiter-Bewegung u. dgl. ; Schiffsführern und denen, die vorkommenden Falls ihre Stelle zu vertreten haben, ist selbstverständlich sehr nützlich, dies zul kennen jedoch kommt vielmehr darauf an zu wissen: welche Eigenheiten werden gefährlich, und was ist zu beachten, um die Gefahr gänzlich, oder wenigstens ihren schwersten Teil zu vermeiden?

In Bezug hierauf ist Zunahme unserer Kenntniße, wenn überhaupt vorhanden, jeclenfalls sehr gering, denn gegenwärtig stetig Hervorgehobenes war schon von den Herren gesagt, die im vorigen Jahrhundert allgemeine Züge und Einzelfälle dieser Stürme veröffentlichten; vor Allem betrifft dies die IVindrichtung nach dem sogen. Zentrum hin. In meiner kleinen Arbeit Die IVirbelstürme oder Cyklonen mit Orkangewalt « (Schulsc'sche Hofbuchhandlung; Oldenburg IS8I) brachte ich letzteres in Erinnerung; Herr Geh. R. Prof. Dr. F. Hann stellte es besonders gut dar in seinem Lehrbuch der Meteorologie.

Zunächst unterblieb s. Z. eine annähernd richtige Darstellung der Windbewegung aus Rücksicht auf die Bequemlichkeit des Kupferstechers, dementsprechend bezeichnete man, der "Einfachheit" wegen unrichtig gegebene als ,,ungefähr" dies wurde jedoch, „,der Einfachheit wegen" nicht beachtet, sondern als Regel angenommen: der Wind wehe senkrecht auf die Verbindungslinie des Beobachters mit dem sogen. Zentrum d. h. jene Richtung mache mit dieser einen Winkel von $90^{\circ}$ oder 8 Kompaßstrichen; leider scheint der Glaube daran noch nicht gänzlich verschwunden.
Man'y's i 859 geschehener Hinweis auf die Unwahrscheinlichkeit der 8 Strich - Bequemlichkeit scheint wenig beachtet geblieben zu sein. Dem unlängst verstorbenen friheren Direktor des Observatorium auf Mauritius Herrn Meldrum gebührt das große Verdienst I 860 zuerst tatkräftig aufgetreten zu sein, gegen solchen Gebrauch von »ungefähr « als »beständig«; er sprach für Fälle im südlichen indischen Ocean'; ihm folgten: I871 Hr. Robt. H. Scott, Direktor der Meteorological Office, London, - $1872 \mathrm{Hr}$. Ililson, Meteorologe in $\mathrm{Kal}$ kutta für die Bai von Bengalen, $1874 \mathrm{Hr}$. Kpt. Toymbec, Marine Superintendent der Meteorological Office, L,ondon, für den nordlichen atlantischen Ocean (von diesem Herm sagte Man'y' I 859: made the Gloriana glorious), trotzdem kam es wieder zu Zehnstrich (aufs Neue Redficld bequem gemacht)- und Zwölfstrich-Regehn.

Von größtem Belang für das tägliche Leben betrachtet man mit Recht Zusammenstellungen und Schlüße, dic von Herren stammen, welche die Erscheinungen an Ort und Stelle kennen lernten, - wo möglich in den Gegenden leben, in denen sie vorkommen, - sonst in so großer Nähe, claß sie leicht von Betroffenen Auskunft erhalten können; Schiffsführer und Steuerleute legen wohl besonderen IVert auf solche Arbeiten, die gefertigt sind von Herren, die früher ihre Verantwortung trugen.

Westindien, das I \$2 I dem Nordamerikaner Redficld, I 849 dem Briten Recid als Ausgang diente für ihre grundlegenden Arbeiten, fand erst I877 in dem Direktor des Observatorium vom Colegio de Belin, Havanna, Hr. Bcnito I Tiñes einen Mann der den Orkanen jener Gewässer eingehendere Aufmerksamkeit widmete; - nach seinem Tode scheint er in Westindien selbst keinen Nachfolger erhalten zu haben, doch veröffentlichte das Hydrograpliisclic Ant der Vercinigten Staaten Nordamerike's manches auf sie Beziigliche in den monatlichen Pilot Charts of the North Atlantic, außerdem das Weather Burcau des U. S. N. A. Department of Agriculture i. F. 19000 als Bulletin H. (W. B. No. 232) 
cine Arbeit des Professors der Meteorologie Herr E. B. Garrot: West Indian Hurricanes $\left(4^{0}, 69\right.$ S. 7 Kt. für den geringen Preis von I 5 cts.), dic außerordentlichen Wert besitzt; in ihr ist wiedergegeben der auf westindische Orkane bezuigliche Teil des an letzteres Amt gesandten Berichtes von Hr. Dr. Linrique del Monte; Mitglied der Universität Havanna's, der auch enthält das Wichtigste aus Hr. Dir. l'iñes allerdings auf wenig Fälle begriundeten Folgerungen. In der Arbeit von $\mathrm{Hr}$. Prof. Garriot findet man ein Verzeichnis der 355 von 1493 bis 1855 und der 95 von $1878-1900$ bekannten westindischen Orkane, letzterc mit Gegend des Entstehens. Umbiegens und Verschwindens, ferner Wiederholung der Liste von 54, die Mai I494 - Olitober I875 über Cuba zogen; diese ist entlehnt aus dem Diario de la Marina, Olitober 9. 1873, in dem sie veröffentlichte Hr. Marcos 7 . Melero. Auf $\mathrm{Cuba}$ beobachtete man den niedrigsten Barometerstand $-687,3 \mathrm{~mm}$. I 846 Oktober 10-II; der nächst-niedrigste war 7 I $2.7 \mathrm{~mm}$. I 837 Oktober 25-26. Die Arbeit enthält auch viele Einzelberichte, meist von Landstationen, und erlittene Schäden. - Uber besondere Teile Westindiens (Porto Rico und St. Kitts - St. Christopher) veröffentlichte dasselbe U. S. N. A. Deftnt. of Agriculure. Heather Burcan als IV. B. No. 268. Bulletin No. 321902 eine Arbeit von $\mathrm{Hr}$. IIm. H. Alcxander: sie erwähnte auf Portorico i. d. Jn. 1515-1 $\$ 99$ 40 Orkanc, - auf St. Kitts i. d. Jn. I623-I899 5 I Orkane; auferdem für ganz Westindien 46 Orkane von 1492-I899. - Barometerstand ist nur angegeben auf St. Kitts durch Hr. George Fames Eaelyn, Basseterre; in einem der letzteren $187 \mathrm{I}$ August $2 \mathrm{I}$. a $8^{\mathrm{h}} 5^{\mathrm{Oll}} \mathrm{zog}$ das Zentrum über die Stadt, schon Io Minuten vorher hattc das Barometer den niedrigsten Stand crreicht $-723,9 \mathrm{~mm}$; in 7 Stunden und 40 Minuten betrug die Abnahme $33 \mathrm{~mm}$., die $\mathrm{Zu}$ nahme in I St. 30 Min. $25,4 \mathrm{~mm}$. ( 1835 Aug. 12. auf Antigua nahm der Barometerstand ab $25,4 \mathrm{~mm}$. in I Std. 27 Min.)

Für den nördlichen und sïdlichen indischen Ocean sowie ostasiatische Gewïsser scheint diese Untersuchung geruht zu haben, bis, wie bereits erwähnt Hr. Dir. Mleldrum is60 für den südlichen indischen Ocean sie wieder aufnahm. - In den I 3 Jahren I $875-88$ (vorher:) erschien nur ein amtlicher Bericht über einen Cyclon der Mrabischen See (Meeresteil von der Osthüste Arabiens bis zur Westküste Vorderindiens), doch sind mir unbekannt die Veröffentlichungen von $\mathrm{Hr}$. Dr. Buist und li. Chambers (einige Cyclone Nemoirs). Sts. des Meteorological Department der Regicrums i'on Indien, Dir. Hr. F. Liliot M. A., ist herausgegreben 1891 : Untersuchung der Eigenart und des Verlaufs der Stuirme der Arabischen See (An inquiry into the Nature and Course of Storms in the Arabian Sea) von $\mathrm{Hr}$. IV. L. Jallas. Assistent in jener Abteilung; in diesem Buche (424 S. 64 Taf.) dessen WVert IH. E. Kunpping mit Recht hervorhebt, sind behandelt 54 Cyclonen der Jahre 1648 Mai bis 1889 Juni; niedrigster Barstd. 1842 X 25

$684, \mathrm{smm}$. in Ryacottah. Dieser Sturm entstand in der Bai von Bengalen, durchepuerte die I Ialbinsel Vorderindiens, die $A$ rabische See, bis Aden soll man ihn gespourt haben; die Beobachtungen (entnommen dem Foum. Asiat. Soc. of Bengal XII S. 339) reichen von Olt. 20. bis Nov. 2 ; sie zeigen eine ausnahmsweise große Anzahl von Barstd. unter $690 \mathrm{~mm}$.

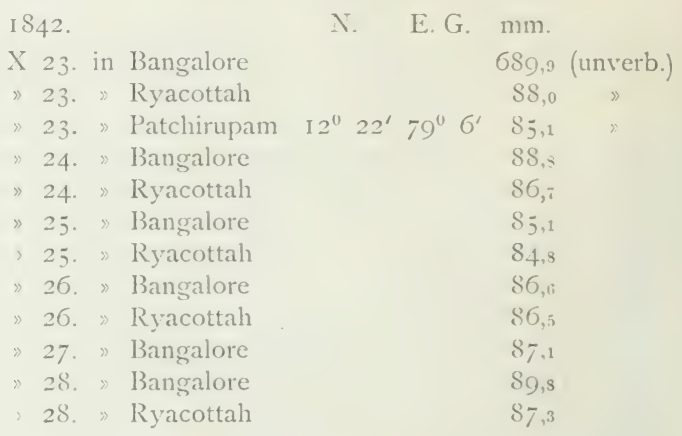

Wie hoch ïber dem Meere diese Orte liegen ist mir nicht bekannt. - Es muß dahingestellt bleiben, ob auch der Barstd. am 24. - 27. unberichtigt ist; wenn die Wärme $=+30^{\circ} \mathrm{C}$. war, so wären noch $3,4 \mathrm{~mm}$. abzuziehen, Standfehler bleibt fraglich; auffallig ist bei solchem Sturm die geringe Änderung im Barometerstande während 5 Tage. - Auf dem Schiffe .,Scaton" war im selben Cyclon der niedrigste Barometerstand $=70 \mathrm{I}, 0 \mathrm{~mm}$, wahrscheinlich nahe am »Zentrum *; sonst finde ich im Werk des Hr. Dallas den niedrigsten Barometerstand in der Arabischen See $=689$, mm. an Bord der ..Inchulva" und im Zentrum 1881 Mai 29; in weniger als einer Stunde nahm er zu bis $7 I_{1,2} \mathrm{~mm}$., d. i. um $2 \mathrm{I}, 3 \mathrm{~mm}$. - Hr. Dallas behandelt auch sehr eingehend den 》Aden Cyclon « I 885 Mai 30.-Juni 3., für uns eine besonders traurige Erinnerung durch den Untergang S. M. S. "Augusta", Ehre dem Andenken der Besatzung! friihere Arbeiten uber ihn erschienen sts. des Instituts Deutsche Secaiarte: Ann. d. Hydr. I886. - Adm. Cloui: Ann. Hydrogr. 1886 und Revue Mar. et Coloniale I 887 , - auch Meteorological Office; London Official No. 30. 1891 .

Für die Bai von Bengalen (Meeresteil zwischen der Ostkuiste Vorder-Indiens und Ceylon bis zur Westküste Hinterindiens, den Andamanen ncbst Nikobaren) arbeitete (nachdem Herr Dir. Meldrum auf Mauritius begonnenl im Meteorologischen Amt Indiens Hr. Wilson. cler die »Regel aufstellte: Sieht man in den WVind, so liegt das Zentrum ro bis II Kompaßstriche nach rechts ", -- doch wies (erst i J. I $\$ 88$ ) $\mathrm{Hr}$. I3lanford von selben. Int darauf hin, dals dies in den verschiedenen Stïrmen verschieden sei. W'enn Hr. Blanford's "Vade mecum * erschien, ist mir nicht bekannt; gewöhnlich wird Bezug genommen auf seine Veröftentlichung in der englischen Zeitschrift Nature XXXVIII., Is\&s Juni 21 , nach welcher der Richtungswinkel in der Bai von Bengalen durehschnittlich I2 Kompalistriche beträgt. - In seiner i 88 g herausgegebenen Arbeit: A practical guide to the climates and weather of India, Ceylon and burmah and the storms of Indian Seas folgert Hr. Blanford S. 234 in cer bai von liengal beträst der Richtungswinkel: 
zwischen $15^{\circ}-22^{0} \mathrm{~N}$. innerhalb $500 \mathrm{Sm}$. Entfernung vom Zentrum nach 132 Beobachtungen durchschnittlich $122^{0}\left(=\mathrm{II}^{3} / 4\right.$ Kompaßstriche),

zwischen $15^{\circ}-22^{\circ} \mathrm{N}$. innerhalb $50 \mathrm{Sm}$. vom Zentrum nach 12 Beobachtungen durchschnittlich $123^{\circ}$ ( = I2 Kompaßstriche),

zwischen $8^{0}-15^{\circ} \mathrm{N}$. innerhalb $500 \mathrm{Sm}$. vom Zentrum nach 68 Beobachtungen durchschnittlich $129^{\circ}\left(-12^{1} / 2\right.$ Kompaßstriche).

Die Grade und Teile von Kompaßstrichen sind natürlich nur gegeben um zu zeigen, daß die Rechnung so durchgeführt ist, um den Rechnungsfehler sehr klein bleiben zu lassen gegen den unvermeidlichen Beobachtungsfehler.

Seite 242 giebt Hr. Blanford für den Richtungswinkel im Mai, Oktober und November im nörd. lichen Teil der Bai von Bengalen 9-I3 Kompal3striche, - in der geographischen Breite von Madras, Ceylon und den Nikobaren IO-I 4 Kompaßstriche; in Anhang IV. S. 359 sagt er kürzer: wenn das Zentrum noch in größerer Entfernung ist beträgt der Richtungswinkel ugf. I2 Kompaßsstriche, sobald es näher kommt ugf. IO Kompaßstriche.

Die Meteorologische Abtcilung der Regicnung Indiens veröffentlichte später für den Gebrauch der Seeleute: Hand-Book of Cyclonic Storms in the Bay of Bengal, dessen neueste Auflage erschien 1900 Bd. I, 1901 Bd. 2; letzterer enthält nur die 47 Tafeln; Verfasser dieser Arbeit ist Hr. Foln Eliot MI. A. In der Bai von Bengalen, seit 1737 bis 1899 , waren bekannt 319 Cyclonen und cyclonenartige Stürme, doch sind für viele Jahre die Listen unvollständig; nach einigen gut untersuchten, giebt $\mathrm{Hr}$. F. Eliot den Richtungswinkel durchschnittlich $=-10^{1} / 2$ Kompaßstriche $\left(=\right.$ I I $\left.8^{\prime \prime}\right)$, oder zwischen IO-I I Kompaßsstriche (I I $2^{0}-$ I $24^{v}$ ), als kleinsten $86^{0}=7^{3} / 4$ Strich, als größ3ten $160^{0}=14^{1 /} *$ Strich. Der niedrigste bis I 899 beobachtete Barometerstand war $=689,2$ mm., im Zentrum der False Pt. Cyklone und auf Fialse P't. Leuchtturm »dies wurde bemerkt, was $\mathrm{zu}$ beachten ist, von einem geschulten Beobachter mit einem, auf einem Land-Observatorium geprüften Barometer, daher kann es als ganz genau angenommen werden.« - Außer, bei Durchnahme der einzelnen Monate, Vorzcichen, Begleiterscheinungen, gegebenen Einzelheiten, sind 8 Cyklone eingehend besprochen.

Die ostasiatischen Gewässer (China See, ostchinesische See, Gelbe See, Golf ron P'echili, westlichster 'Teil des Pacilic) sind seit 1879 bzw. 1883 Wirbelstürme dort Taifune genannt, außerordentlich beachtet. 1875 begann in Fapan die Einrichtung cines regelmäßSigen meteorologischen Dienstes, die allmälich vergrößsert und erweitert wurde; in ihm war mehrere Jahre erster Assistent, ein Deutscher, Hr. E. Knipping, der vorher auf einem Dampfschiff als Obersteuermann die japanische Küste befahren und regelmäßig meteorologische Beobachtungen angestellt hatte. Es ist erklärlich daß dieser Herr den, Japan und die in angrenzenden Gewässern beschäftigten Schiffe so häufig schädigenden Taifunen besondere Aufmerksamkeit zuwandte, - daher erschienen von ihm über diese, 1879 beginnend, mehrere eingehende
Abhandlungen zusammen mit den vollständigen, ihm zugängigen Berichten. Solche Veröffentlichungen hörten dort leider auf, als er Japan verließ (seit einer Reihe von Jahren ist er in $\mathrm{Hamburg}$ Assistent am Institut "Deutsche Secwarte"); Hr. E. Knipping gab dem Winkel von Windrichtung am Beobachtungsorte mit dessen Verbindungslinie nach dem sogen. Zentrum den (auch hier schon melirfach benutzten) Namen „Richtungswinkel“, (Ann. d. Hydr. VIII IS8o. Der Prinz Adalbert Taifun S. 549,) der, weil er kurz, bezeichnend, und allgemein verständlich ist, auch von mir angewendet wird; im Englischen heißt er bearing angle, genau Peilungs-IVinkel, was in dieser Sprache wieder leichter allgemein verständlich ist, als direction angle. Hr. E. Knipping (Ann. d. Hydr. VIII Isso S. 562) sagt ebenfalls: wich kann einer mechanischen Anwendung der Regeln nicht beistimmen — - ebenso wie es auch sicher ist, daß keine Regel die ruhige besonnene Überlegung des Seemannes im Taifun ersetzen kann. " Letzterem Ausspruch stimmt gewiß jeder bei, der auf Schiffen sei es im Hafen, sei es auf See Taifune durchmachte, auch wenn er nicht selbst Seemann war.

Es ist mir nicht bekannt, wenn die chinesische Regierang auf den Leuchttürmen und leuerschiffen der Küsten China's regelmäfige meteorologische Beobachtungen einrichten ließ; seit $186_{3}$ sollen sie in JesuitenMissionen bei Shanghai und Orten am Yang-tse angestellt, I87 I in ' Zi ka wei cine WVetterwarte eingerichtet worden sein. An dieser wurde 1873 Direktor Hr. Marc Decheorens, der den Taifunen besondere Aufmerksamkeit widmete und I 879 begann, eingeheifde Arbeiten über sie zu veröffentlichen. Nach seinen Fortgang von Z. (er ist seit Jahren Direktor des Observatorium St. Louis auf Jersey; brit. Kanal-Insel) setzten seine Nachfolger die Herren Chcialier und L. Froc seine Arbeiten eifrig fort; von letzterem sind am bekanntesten die Abhandlungen über den plltis -Taifun I 896 Juli $22-25$ und über den $\gg$ De IV itte «-Taifun I90 I Angust I-6, auch Taifun Bahnen südlich Formosa (Typhoon highways to the South of Formosa).

In Hongkong ist seit 1883 als Direktor des dortigen Regierungs-Observatorium angestellt $\mathrm{Hr}$. W. Doberck, der anfangs allein, danm mit dem Assistenten $\mathrm{Hr} . F$. G. Figs den Taifunen ebenfalls sehr genau folgt. Von ihm ist am bekanntesten $»$ Law of storms in the Eastern Sea's z zuerst erschienen in den Observations and researches made at the observatory of Hongkong I8S6 als Report on the Typhoons of I884 and 1885 , in denen es auch i. J. IS98 wieder veröffentlicht wurde als Appendix A. zum Jahresbericht für 1897; ein Sonderabdruck ist verausgabt 1898 in $\mathrm{Hongkong}$. Die erste Übersetzung ins Deutsche gab Hr. Prof. Dr. Bergholz, Bremen, in der Meteorol. Ztschrift. I S8S. Bis Schluss d. Js. I 898 hatten genannte Herren die Berichte iiber 275 Taifune durchgearbeitet; das Institut erhielt i. J. Iyo2 regelmäßige Berichte von 40 Landstationen, davon 4 auf den Philippinen, auch von Wei hai wai, von T singtau anscheinend nicht; außerdem die Journale von I64 Schiffen mit im Ganzen Beobachtungen an 9073 Tagen. - Über spätere Taifune als die d. Js. 1896 finde ich dort keine Veröffentlichung; dies wird erklärlich 
durch die geringe $\triangle$ nzahl der Gehilfen und durch den geringen Umfang der Kolonie Hongkong, die dem Observatorium keine große Summe bewilligen wird; es ist ancrkennenswert, daf 3 dort überhaupt ein clerartiges eingerichtet und unterhalten ist.

Herr Direktor W. Doberck, Hongkong, äußert sich in der oben crwähnten Neu-Ausgabe seines law of Storms in the Eastern Seas: Das Einbiegen des Windes in einem Taifun hängt vom Monsun ab. In Mai, Juni, Juli und August ist der Winkel zwischen Wind (cl. h. der Richtung aus der er weht also in den IVind schend) und der Peilung des Zentrum II Strich recht vor dem Zentrum, $10^{1 / 2}$ Strich im rechten Viertel. 12 Strich hinter dem Zentrum und ${ }_{1}{ }^{1} 1 / 2$ Strich im linken Viertel. Während September, Oktober und November ist er II Strich vor, $I_{1}^{1 / 2}$ rechts, I 2 hinter und II Strich links vom Zentrum. Dies zeigt, daf3 der Monfun einwärts auf das Zentrum zuweht und mit dem cyklonischen Wind vereint wirlit. Man bemerkt, daß vorn der IVind quer über die Bahn weht und einem Schiffe behilflich ist, sic zu kreuzen, indem man den Wind an Steuerbord 3 Strich von achtern hält. Hinter dem Zentrum weht der Wind mehr grade nach $\mathrm{ihm}$ hin, auch stärker als vor ihm." "Der Richtungs-] Winkel hängt auch ab von der Entfernung des Zentrums. Iei $25 \mathrm{Sm}$. ist er $10^{1 / 2}$ Strich (sehr unsicher), bei $75 \mathrm{Sm}$. ist er I I Strich, bei $125 \mathrm{Sm}$. ist or ${ }_{1} I^{1} / 2$ Strich, bei $150 \mathrm{Sm}$. I I $3 / 4$ Strich, bei $200 \mathrm{Sm}$. ist er 12 Strich, bei größerer Entfernung als $300 \mathrm{Sm}$. liegt das Zentrum vielleicht 15 Strich von der Windrichtung (sehr unsicher). "Der Winkel hängt auch ab bis zu gervissem Grade von der geogr. Breite, südlich vom nördlichen Formosa ist dies jedoch nicht erkennbar; in $30^{\circ} \mathrm{N}$. ist der Winkel aber durchschnittlich ugf. 10 Strich und jenseits Japan kann man vielleicht 9 Strich annehmen.

»In der Nähe mancher Küste sind diese Annalımen irrig, sobald das Zentrum nicht sehr nahe ist. " Es folgen Beispiele.

Fur die Filipinen hat das Observatoriun in Manile nach der hier in Betracht gezogenen Richtung ebenfalls gearbeitet, für dortige, dem Fremden allerdings " fremdes Verhältnisse vielleicht recht viel. Schon i 874 erschien eine kleine Arbeit von Herm Manucl Villaricencio: Baguios. Redactada par la Comision Hidrografica de Filipinas - welche behandelt die Stiurme bezw. Taifune jenes Archipels. Das Observatorium des Atenco municipal de Manila, Director $\mathrm{Hr}$. R. F. Faura nahm diese Arbeiten spater auf; durch die Übersetzung von Hr. Prof. Dr. Paul Bergholr, Bremen, ist am bekanntesten geworden die I 897 erschienene Arbeit des Direlitors obengenannter Anstalt Hr. Fosć Alguc': Baguios ó Ciclones Filipinos, (im Deutschen gegeben als: Dic Orkane des fernen Ostens), das aber melnr darstellt ein Handbuch iblber Wirbelstürme im Alleemeinen mit Beispielen aus den Filipinen, besonders Manila. laiir Spanien war dies Buch gewils schr wertvoll, in Nittel- und Nord-Europa könnte man derartiges sicherlich unabhängieg ausarbeiten und Beispiele geben aus den verschiedensten Tropengegenden; selbst bei Beschränkung auf den pfernen Osten" brauchte man sich nicht zu beschränken auf einen einzelnen Teil desselben, sondern kann aus jedem, je nach zur Verfügung stehenden Mitteln, nur gewissermaßen durchschnittliche oder in Bezug auf Barometerstand, Bahn oder dgl. die äußersten Grenzen der bekannten Fälle geben. Die Ansichten Hr. Dir. Algués mögen nicht alle geteilt werden, jedoch kann man nur sagen seine Ernennung zum Leiter des meteorologischen Dienstes auf den Filipinen sts. der Regicnung $I$. St. I. Am. war Anerkennung seiner Tätigkeit in dieser Richtung.

IVie aus oben Gesagtem ersichtliclı, blieb in Europa das Streben nach weiterer Erkenntnis der Wirbelstiirme und das Bekanntgeben des Lirreichten durchaus nicht unberüclisichtigt; die staatlichen meteorologischen Anstalten oder einzelne ihrer Angestellten suchten je nach Umständen dem nie aufhörenden Bedürfnis und Verlangen gerecht zu werden; auch Private traten ein mit einzelnen Zusammenstellungen und eigner Erfahrung, so in Deu tschland Kapt. Ruete, in England Hr. Corpenter Capt. R. N., in Frankreich Ltnt. Rerertigat, in Rußland Ltnt. Spindler. - Deutschland konnte erheblich mehr veröffentlichen als andere Länder, sowohl weil in Allge. meinen gute Schulbildung vorhanden ist, als auch weil seit Jahrzehnten durch gute staatliche Navigationsschulen und durchaus nicht unzweckmäßige P'rüfungen für umfaßende Kenntnis des zur Schiffsführung Nötigen gesorgt war, - nicht zum Mindesten, weil Hr. Prof. Dr. Minter (Mitglied der Universitäts P'rüfungs-Kommission in Greifswald) 1877 auf der lagung des Nautischen Vereins in Berlin den deutschen Seeleuten das Zeugnis ausstellen konnte, von allen Berufszweigen, die er kenne. seien die deutschen Seeleute die einzigen, die wenn von mehr lernen und dementsprechend melhr Ansprïchen bei der Prüfung die Rede sei, sich dagegen nicht sträubten, sondern sagten, das könne gerne geschehen, Schaden könnten sie davon nicht haben, nur solle man nicht fordern, sie sollten deswegen weniger praktische Seeleute sein. - Dies muß sich natïlich auch aussprechen in der Anzahl der Beobachter sowie der Guite der Beobachtungen soweit diese von jenen abhängig ist. Schon MIIary nannte deutsche Beobachter, in der "Han sa" wurden Orkan-Beobachtungen mitgeteilt, außerdem ist die, aus den der Kais. Marine bewilligten Mitteln eingerichtete und erhaltene friber $\gg \mathrm{Hydrographische}$ Mitteilungen " dann "Annalen der Hydrographic und Maritimen Meteorologie "genannte Zeitschrift, bald nach Einrichtung des Hydrographischen Amtes und Übernahme des Institutes .. Deutsche Seciurte" durch das Deutsche Reich ein sehr billiges und geeignetes Blatt, sowohl Einzelfälle als Übersicht von Zusammenstellungen und daraus abgeleiteten Schliissen allgemein zugänglich zu machen. - Das Institut ,Deutsche Secwivete" trug dem jeweiligen Stand unserer Kenntnis der Virbelstiirme vollauf Rechnung in den von ihm herausgegebenen ...Sigelhandbuch fiir den atlantischen Oiean

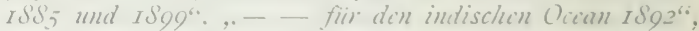
..- - fuir den stillen Gican ISQT". In letzterem ist auch in den Hauptsachen wiederholt eine Arbeit über Wirbolstiilme im sidllichen stillen Ocean zwischen Australien und den Paumotu Inseln, von dem schon genannten Hr. LE. Kuipping. soweit mir bekannt für diese Gegend die einzige vorhandene; sie erschien schon 
früher in "Aus dem Archio der Deutschen Seewurte" Dasselbe Segelhandbuch enthält eine Liste von $36_{3}$ Taifunen zwischen den Jahren I 780 und I $\$ 98$, nebst ihrer Verteilung über die einzelnen Monate und Gegenden. Alle drei Werke geben auch Berichte über Einzelfälle und Bahnen. - Die bekannt gewordenen niedrigsten Barometerstände in Taifunen sind 1880 September 27 . a. $10^{\mathrm{h}} 3 \mathrm{O}^{\mathrm{m}}=686,8$ möglicherweise $683,5 \mathrm{~mm}$. bei $22^{0} \mathrm{O}^{\prime} \mathrm{N}$. I $2 \mathrm{I}^{\circ} 3 \mathrm{O}^{\prime} \mathrm{E}$. G. an Bord der französischen Bark ., Chateaubriand" Kpt. Leroy und I9OI August $22 \mathrm{I}^{\mathrm{h}} \mathrm{I}^{5 \mathrm{~m}}-45^{\mathrm{ml}}$ $=686,3 \mathrm{~mm}$. bei $26^{\circ} 44^{\prime} \mathrm{N}$. I $23^{\circ} 2^{\prime} \mathrm{E}$. G. an Bord des Dampfschiffes Laisang Kpt. Geo. Pay'ne im De Witte Taifun. - Ob und mit welchem Fehler behaftet sind die Beobachtungen: 1869 August 20. a. $\mathrm{I}^{\mathrm{h}}=687,8 \mathrm{~mm}$. bei $32^{\circ} 16^{\prime}$ N. $134^{\circ} 26^{\prime}$ E. G. auf Brit. Bk. Southern Belle, - 1869 September 2I. p. $7^{\mathrm{h}}=701,5 \mathrm{~mm}$. bei $33^{\circ} 20^{\prime}$ N. $137^{\circ}$ IO' E. G. auf dem Transportschiff V. S. N. A. "Idaho" - und $704,3 \mathrm{~mm}$. bei $2 \mathrm{I}^{\circ} \mathrm{I}^{\prime} \mathrm{N}$. I $25^{\circ} 19^{\prime}$ E. G. auf I. B. M. S. Conqueror. Kommandant E. F. Parson - ist mir nicht bestimmbar.

In Bezug auf den Richtungswinkel sagt das 1897 erschienene s Segelhandbuch für den Stillen Ozean S. 250: "Zahlreiche Messungen haben ergeben, daß die Peilung des Zentrum durchschnittlich 6 bis 8 Strich beträgt, aber außerordentlich stark schwanken kann. _ - - Auf offner Śee, bei sehr hoher Windstärke und in mittleren Breiten, ist die Peilung meist größer als das Mittel, nämlich 6 bis 8 Strich, bei geringerer Windstärke gleich oder kleiner 5 bis 4 Strich. " Es folgen Einzelheiten, auf die hier nicht eingegangen werden kann; die Bezeichnung "Richtungswinkel «iehe ich vor.

Nach allen mir bisher bekannt gewordenen $\mathrm{Zu}$ sammenstellungen kann ich nur wiederholen, meine i88 I ausgesprochene Ansicht »Regeln lassen sich nicht geben, weil man nicht bestimmen kann die Ausnahmen von solchen Regeln (Piddington trotz zur Regel gemachter 8 Striche »unbedingte Regeln sind Unsinn «) daher hat man sich auf Ratschläge zu beschränken. "Nach allen seitdem erschienen Arbeiten kann ich, in Bezug auf Windbewegung zum Zentrum hin im Allgemeinen nicht ändern den damals gegebenen Rat: ein Winkel der Windrichtung mit der Verbindungslinie des Beobachtungsortes und dem sogen. Zentrum im Betrage von $135^{\circ}$ oder 12 Kompaßstrichen ist keine übertriebene Annahme, oder "stellt man sich mit dem Gesicht in den Wind", so liegt das Zentrum rechts oder links (je nach nördlicher cder südlicher geogr. Breite) nach hinten, und zwar sind hierfuir 4 Kompaßstriche $=45^{\circ}$ keine übertriebene Annahme, jedoch nicht als eine unzweifelhaft bewiesene Tatsache, oder als Bequemlichkeitsregel zu betrachten. Man findet ihn auch in: $W$. Döring. Der Wetterkundige Navigateur. -- Die Orkane. 2. und 3. Auflage. (F. Schulze'sche Hofbuchhandlung, Oldenburg.) S. I81 und 182. Dort heißst es: Nach Buy's Ballots Gesetz findet man die Lage des Zentrums vom Schiffe aus wie folgt: Kehrt man das Gesicht gegen den Wind, so hat man auf der nördlichen Erdhälfte den geringsten Luftdruck (Zentrum) rechts, (auf cler linken links) meistens nach hinten, und zwar sind hierfür 4 Kompaßstriche $=45^{\circ}$ unter Umständen keine übertriebene
Annahme; - in der Anmerkung: "Diese Annahme ist jedoch nicht als eine unzweifelhaft bewiesene Tatsache zu betrachten. " Die beiclen Figuren S. I 84 und I 85 sind zwei von denen, die ich veröffentlichte auf Tafel V und VI oben erwähnter Arbeit; unter den am Schluße von $\mathrm{Hr}$. Döring genannten In abgekiirzter Form angeführte Werke" findet man meines nicht. Von Buys Ballot erinnere ich mich des Hinweises, daß der Richtungswinkel nicht immer 90" betrage; er sagte: "Geht man mit dem IVind", dies ist gleichbedeutend mit dem gewöhnlich gebrauchten. "Kehrt man den Riicken zum Wind «; der Seemann, der wissen will wo der Wind herkömmt, wird allerdings das Gesicht zum Winde kehren.

Der im Nautischen Verein gestellte Antrag scheint darauf hinzuweisen, daß allgemein giltige Ratschläge als genügend man nicht betrachtet; zu dem, was mehr geboten werden kann gehört Zusammenfassen von Vorhandenem, zahlreichere möglichst vollständige Arbeiten uiber Einzelfalle, hervorragende Einzelberichte u. dgl. Das Vorhandene ist zerstreut in vielen Jahrgängen von schon erwähnten Zeitschriften, dabei ist das Zikazeci Obscratorium in sofern in Vorteil, als die zahlreichen Taifun-Arbeiten seiner Direktoren Jahre lang einzeln erschienen; so niedrig wie der Preis derselben ist, so sind doch die Gesamtkosten nicht gering. Aus dem hauptsächlich I $875-76$ gesammelten Stoffe hatte ich bereits I8,6 eingehende Zusammenstellungen gefertigt, betr. ein Paar Fälle im westlichen Nord-Atlantic, doch konnte ich sie damals nicht gemeinnützlich machen und kann es jetzt nicht, weil die Kosten zu groß" sind (deswegen verlangten damals Verleger Unerfüllbares), als aber die Barometerkurve der Laisang im "De Witte "Taifun veröffentlicht wurde, schien es mir angebracht, zu erinnern, daß bereits von ähnlichen, außergewöhnlich niedrigem Barometerstand in tropischen Wirbelstürmen mehr Fälle veröffentlicht waren als dabei genannt wurden, auch Einzelnes, was mir zu fehlen scheint, zu ergänzen. - Die Königliche Bibliothek in Berlin besaß nicht die mir nötigen Büicher; die Bibliothek des $\mathrm{Kgl}$. preußischen meteorologischen Instituts in Berlin darf laut Ministerial-Verordnung Buicher außerhalb seiner Räume nicht verleihen, - das Kgl. dänische, niederländische, würtembergische meteorologische Institut und das der französischen Republik in Kopenhagen, de Bilt, Stuttgart und Paris konnten sogar wiederholt mir behilflich sein und waren es die Herren Direktoren Professor Dr. Panlsen, Dr. IVind, Sclunidt, Professor Dr. Mascart, sowie die Herren Bibliothekare auf bereitwilligste und freundlichste Weise. Schon früher erwähnte ich, wie ungemein zuvorkommend meine Arbeiten in London und de Bilt gefördert wurden, außerdem haben die genannten Institute in London, Paris und die Hydrograplizsche Abtcilung (Chef S. T. Herr F. Spindler) des Kaiserl. mussischen Marine Ministcrinm, St. Petersburg wieder sehr entgegenkommend, für den Chateaubriand-, Iltis- und de Witte Taifun dort vorhandene Berichte für mich abschreiben lassen, das $\mathrm{Kgl}$. norwegische (Direktor $\mathrm{Hr}$. Prof. Dr. H. Molin) und das $\mathrm{Kgl}$. dänische Institut besaßen keine für diese 3 Fälle. Gegenwärtig biete ich 
auf III Tafel $\mathrm{z}$ eine Übersicht ïber die Häufigkeit tropischer Wirbelstürme in den einzelnen Gegenden, - auf III Tafel 1-8 Bahnen von Taifunen die zum größten Teil erst bekannt wurden, nachdem fertig gestellt waren die betr. Tafeln und das Verzeichnis im Segelhandbucl: für den Stillen Ozean herausgegeben I 897, vom Institut Deutschc Sicziartc - auf III Tafel A-C Darstellung der Windbewegung, hier der Richtungswinkel im Chateanbriand-, Iltis- und de Witte Taifun. - auf III Tafel a-d Wiederholung von mir früher veröffentlichter Barometerkurven in Taifunen mit sehr niedrigem Barometerstande und Zusammenstellung der Barometerkurven in obcn senannten 3 Taifunen.

Dic Bevorzugung ostasiatischer Gewässer wolle man erklärlich finden, da ein Mann nicht Alles leisten kann, ich in jenen Gegenden mehrere Jahre als Matrose, Stenermann und Schiffsfihrer gefahren habe, dort Gehörtes, Geschenes und Erlebtes von Anfang an mich anspornte, diese Eischeinungen Betreffendes z.u sammeln und zusammenzustellen; die ersten bezüglichen Arbeiten gingen leider i. J. 1859 bei einem Schiffbruch verloren, spätere wurden i. J. I864 in Alexandrien entwendet.

\section{T'afel \%.}

\section{Häufigkeit der Wirbelstürme}

\section{innerhalb der Tropen und angrenzenden Gegenden.}

Die Häufigkeit der Wirbelstürme kann auf verschiedene Weise gezählt werden, zunächst sobald feststeht daß dieselben Sturme über gröliere bezw. weite Strecken zogen jeden nur als einen einzigen rechnend, - dann: bestimmte geographische Gebiete abgrenzend, wic oft in jedem von ihnen solcher Sturm beobachtet ist. Tafel $\mathrm{z}$ diufte man betrachten als beide Zählweisen vercint verwendend; für sic sind in folgender Veise benutzt Veröffentlichungen und von mir gesammelte Journal-Auszuige.

Mlit Ausnahme der Bai ron Bengalen und des Südlichen Indischen Ocean ist die geographische Grundlage der früheren /usammenstellungen und Bahnen das Viereck von $5^{\prime \prime}$ geogr. Breite und $5^{\prime \prime}$ geogr. Länge; für ersteren Meeresteil wählte Hr. Eliot solche von 4 "Breite und $4^{0}$ Länge, für den anderen $\mathrm{Hr}$. Mcktrum und das Aliteorolugical ()fficc. London, solche von IO" geogr. Breite und geogr. Länge, - beide änderte ich in die gebräuchlicheren von je 50. Luber "Ostasiatische Gewässer《. "Sidlicher Pacifice und () hat das Institut .. Dentsche Sicrearte" im Segel-Handbuch fuir den Stillen Ozean Kärtchen und eine Tafel veröffentlicht in denen die Anzahl der Wirbelstirme bis \%. J. 1892 in solche Felder eingetragen ist; - fuir diese Mecresteile bildete dies gewissermaßsen den Stamm; auf III Tafel 2.8 sind abgezeichnet alle Taifunbahnen, die auf den zum genannten Segelhandbuch gehörenden Karten noch nicht veröffentlicht sind, aber erschienen in den Arbeiten der Hrr. Direktoren /)oberts.
Figg, Dechcorens, Chevalicr und Froc, sowie in den "Annalen der Hydrograplice" bis Ende 1904 und von mir entworfene. - In sämtlichen " $5^{\circ} \mathrm{V}$ ierecken ist $^{\circ}$ gebildet die Summe der durch sie gezogenen Bahnen und in sie eingetragenen Einzelfälle (im Cyklonen- $\Lambda$ tlas für den Indischen Ozean als stationäre Cyklonen betrachtet); mit ihr sind vereint die anderen Angaben, die sich finden in "West Indian Hurricanes". "Hurricanes especially those of Porto Rico and St. Kitts", "Handbook of Cyclonic Storms in the Bay of Bengals, Piddingtons sailors Hornbook (soweit in der Karte ich sie zu erkennen vermochte) "Annalen der Hydro. graphie bis Ende 1904 und in meinen Journal-Auszuigen.

Alle derartigen Zusammenstellungen können Vollständigkeit nicht beanspruchen, weil Felder leer bleiben, nur weil von dort keine Berichte vorlicgen, andre mit zu geringer Anzahl bedacht sind, weil Einzelfalle nicht bekannt wurden; ferner zeigt die gezeichnete Bahn nur die geschätzte des sogen. Zentrum, während auch in angrenzenden Abteilungen der Wind mit Starke I I und I2 wehte; andererseits mag zuweilen die Windstärke überschätzt sein.

Die größte Anzahl der Nachrichten von tropischen Wirbelstuirmen, dort "Taifune" genannt, scheint vorzuliegen aus ostasiatischen Gew ässern (bis $45^{\circ} \mathrm{N}$.): I992; selbst wenn die nördlich von $35^{\circ} \mathrm{N}$. vorhandenen 333 nicht mitgerechnet werden, sind 1659 noch erheblich mehr als die Anzahl derer aus dem siidlichen Indischen Ocean: 1196. - Hierzu mag beitragen, daß die Küstenfahrt Ostasiens bedeutend größer ist als die an und zwischen den Gestaden Afrikas-Australiens, obwohl Japan erst verhältnismäßig kurze Zeit dem Verkehr europaischer Schiffe geöffnet ist, auch zun indischen Ocean hier noch gerechnet sind, die Gewässer West- und Nordwest-Australiens. Falls die letztgenannten Küsten schon länger von Europäern bewohnt und noch vorhanden wären die Journale der Schiffe die fruher nach der Ostkïste Afrikas mit der IVestkuste Madagaskars, von dort nach Arabien und Indien fuhren: dürften aus jenen Gegenden erheblich mehr Berichte vorliegen; ob die Stampfmühlen für diese Arbeiten das Geringste von ihnen zuriickgaben ist wohl sehr fraglich.

Der Einflus des Verkehrs auf die Anzahl der Berichte zeigt sich in noch höherem Maalie im Siid-und im Östlichen Nord-Pacific (129 bezw. 60), dann im Verhaltnis derer aus der Arabischen see (15t) zu denen aus der Bai ron Bengalen (9r 4 ); obwohl die Fahrt nach II estindien ailter, auch stets stäker betrieben war als die nach der Bai ron Bengalen, ist doch die Menge der Berichte aus jener Gegend (9\$o) nicht erheblich gröticr als aus clieser.

In Bezug auf den Raum zwischen bestimmten Breitengraden, zeigt $\mid 1$ estindien die meisten Mitteilungen iiber Orkanc von $15^{\prime \prime}-20^{\circ} \mathrm{N}$. (315), die Arabische see (5t) zwischen denselben; die Ba i von Bengalen (606) ebenso wic Ostasiatische Gewässer (\$+2) von $15^{11}-25^{11} \mathrm{~N}$. letztere einen 7weiten Neistbetrag (319) von $30^{\circ}-35^{\circ 1} \mathrm{~N}$., Sirdlicher Indischer Ozean (3+4) zwischen 15"-20" S.; Süd-Pacific bei Neu-Kaledonien mit den Neu-Hebriden (31), Samoa (29), 
Fidji In. (28) und Tonga In. (I7); im Östlichen Nord Pacific stammen bis jetzt die meisten Berichte aus Gegenden zwischen $15^{\circ}-20^{\circ} \mathrm{N}$. (26).

Das Institut Deutsche Secwarte hat die Mitteilungen aus den einzelnen Monaten für Ostasiatische Ge. wässer noch gesondert als östlich und westlich von I $30^{\circ}$ E. G., für den Süd-Pacific nach der Küste Australiens und Inselgruppen. Für den Süd-Pacific ist dies hier unverändert beibehalten; betr. Ostasiatische Gewässer bleibt es dahingestellt, ob nicht die Teilung: $100^{\circ}-120^{\circ} \mathrm{E}$., I $20^{\circ}-140^{\circ} \mathrm{E}$., östlich von $140^{\circ} \mathrm{E}$. noch zweckmäßiger wäre, doch ist hier die ursprüngliche geblieben. Die Arabische See ist gesondert in $40^{\circ}-65^{\circ}, 65-80^{\circ} \mathrm{E}$., die $\mathrm{Bai}$ von Bengalen: $75^{\circ}-85^{\circ}, 85^{\circ}-100^{\circ} \mathrm{E}$; der Indische Ocean: $35^{\circ}-65^{\circ}, 65^{\circ}-95^{\circ}, 95^{\circ}-125^{\circ}$ E.; der Östliche Nord-Pacific: $175^{\circ}-\mathrm{I} 35^{\circ}, 135^{\circ}-90^{\circ} \mathrm{W}$.; Westindische Gewässer: $100^{\circ}-80^{\circ}, 80^{\circ}-55^{\circ} \mathrm{W}$ Längenstreifen zwischen je $5^{\circ}$ geogr. Länge sind hier nicht berücksichtigt, dagegen später Einzelfelder.

Am zahlreichsten zeigen sich uberall (wie schon lange bekannt) die Berichte von Wirbelstümen aus den heißesten Monaten sowic aus denen der und nach der Herbst-, Tag- und Nachtgleiche, nur die Arabische See bildet bis jetzt eine Ausnahme; hier sind die Berichte am häufigsten im Mai und Juni (36 bezw. 34), dann in April und November $(24,29)$; ob mit zunehmendem Verkehr nach den Küsten Arabiens nebst Persiens das Verhältnis ein anderes würde, dürfte sich erst zeigen nach langer Reihe von Jahren. - Bai von Bengalen zeigt Meistbetrag im September: I8I, dann Oktober: I 44, Juni: I07, Juli und August jeder: 129; Ostasiatische Gewässer Mcistbetrag im Sep. tember: 605, es folgen August: 388, Juli: 28 I, Oktober: 254, November: 158. - Südlicher Indischer Ocean, Meistbetrag Januar: 318, Februar: 300, März: 236, Dezember: IO5. - Süd-Pacific, Neistbetrag Januar und März, jeder: 37, F ebruar: 23, 1)ezember 16. Östlicher Nord-P'acific, Neistbetrag September: 17 , Oktober: 13. Juli und August: je I1. - Westindien, Meistbetrag August: 303, September: 283, Oktober: 246.

Bei so geringer Anzahl Berichte wie vorliegen vom Pacific, können wenige Jahre herbeifuiluren erhebliche Änderung in den Zahlen einzelner Monate.

Die Wintermonate der Tropen sind, wenn nicht ganz frei, doch am freiesten von Wirbelstürmen, dabei ist auffallend, daß sie dann in mehr nach dem Aequator hin gelegenen Gegenden verhältnismäßig häufiger sind, als in den näher an den Wendekreisen liegenden.

In den einzelnen Vierecken von $5^{\circ}$ geogr. Breite und $5^{\circ}$ geogr. Länge findet man ebenfalls ausgesprochen den Einflur3 der Anzahl durchfahrender Schiffe auf die Anzahl der Berichte, doch scheinen auch Ausnahmen vorhanden. Westindische Gew ässer zeigen die meisten Berichte (1 12 ) im Felde $15^{\circ}-20^{\circ} \mathrm{N}$. $65^{\circ}-60^{\circ} \mathrm{W}$.; dort liegen St. Thomas, die Sombrero-Einfahrt und Guadeloupe, südlich davon Martinique, Trinidad I. mit l'ort of Spain; zwischen $10^{\circ 1}-15^{\circ} \mathrm{N} \cdot 65^{\circ}-60^{\circ} \mathrm{W}$ : 59 Ber.; $15^{\circ}-20^{\circ} \mathrm{N}$. $80^{\circ}-75^{\circ} \mathrm{W} .64$ Ber. ist Jamaica ein Sammelplatz für Schiffe; so kann man annehmen, daß die größere Fahrt nach den Südstaaten der
Union, Havanna und den Nordhäfen Yucatan's zusammen mit geringer Anzahl der Orkane an der Küste Zentral-Amerika's veranlaßte ein Überwiegen der Berichte aus oben genannten Gegenden; ob die Fahrt von Segelschiffen durch den Old Bahama Kanal nach Havana und New Orleans beitrug in jenem Wege die Zahl der Berichte zu vergrößern, mag unsicher sein

In der Arabischen See ist es die Fahrt nach Karachi, Bombay, Goa, Cochin, in der Bai von Bengalen die nach $\mathrm{Ca}$ lcutta, welche die meisten Berichte lieferte; in Ostasiatischen Gewässern, ist die nach Hongkong, Shanghaï, den japanischen Häfen deutlich ausgesprochen, die Vierecke $15^{0}-20^{0} \mathrm{~N}$ I I $5^{\circ}-\mathrm{I} 20^{\circ} \mathrm{E}$, und $30^{\circ}-35^{\circ} \mathrm{N}$. $130^{\circ}-\mathrm{I} 35^{\circ} \mathrm{E}$. (I 28 , 103 Ber.) müßen Gegenden sein, durch die Taifune besonders häufig ziehen, in ersterer auch entstehen. - Im Südlichen Indischen Ocean sind es die Vierecke in der Umgebung von Mauritius, Réunion und Rodriguez wo die meisten Berichterstatter und Cyclonenbahnen zusammentreffen; im Süd-Pacific die Umgegend der Fidji, Samoa und Tonga In.; im Östlichen Nord-Pacific ist es die Fahrt nach dem Golf von Californien und vor ihm liegenden Häfen, welcher wir verdanken die meisten Nachrichten iiber solche Naturereigniße.

Aus Gegenden, aus denen keine oder nur selten Mitteilungen zu uns gelangen, erfahren wir Nichts oder nur Wenig über dort Geschehenes.

\section{Bahnen der Wirbelstürme.}

Hr. E. Knipping beschrieb in seinen Arbeiten über die Taifune Japans sein Verfahren bei Entwurf ihrer Bahnen; in meiner schon erwähnten Arbeit, „Die Wirbelstiirme oder Cyclonen mit Orkangewalt", ging ich ebenfalls ein, auf die unvermeidliche Unsicherheit solcher Entwürfe, wies S. 54 darauf hin, dals die größte Annäherung möglich wird, wenn das Zentrum über mehrere nahe bei einander liegende Orte zog, dieser Fall sehr selten ist. (I 879 VII 31 . bis VIII I. Gelbe See 5 Schiffe. I880 IX 27, 28 Süd-Ende Formosa's und Formosa Kanal 4 Beobachter, $1880 \mathrm{X} 2,3$ südlich von Japan 6 Schiffe); S. 56 . Das Zentrum mag sich in vielfach gewundenen Kurven bewegen, die Tangenten eines solchen Entwurfs " (Tangenten an Kreise deren Halbmesser geschätzte Entfernung z. Z. niedrigsten Barometerstandes) kann man daher nur betrachten als Sehnen (Abscissenlinien) solcher Kurven und die auf ihnen bezeichneten Orte des Zentrum als Durchschnittspunkte der Normalen (Ordinaten), welche vom wirklichen Ort des Zentrum auf die Sehnen gezogen werden; - es wird wohl schwieriger sein, dic Kurven, als die Sehnen zu bestimmen.

Ohne Kenntnis der gegenseitigen Arbeiten sind damals Windungen und Schleifen oder Schlingen in den Bahnen schon nachgewiesen und als am wahrscheinlichsten betrachtet von Hr. E. Knipping und Dir. Dechesrens. Die Tatsache, daß gezeichnete Bahnen nur Schätzung und Annäherungen an die tatsächlichen sein können ist 
unleugbar und zeigt sich.dem Arbeiter bei jedem von ihm betrachteten Falle, - dem Benutzenden, wenn ihm vorliegen von Verschiedenen ausgeführte Behandlungen desselben Falles. Streit über größere oder geringere Wahrscheinlichkeit der einen oder anderen, wäre überflüßig, da bei der Unsicherheit der Anhaltspunkte Abweichung der Ansichten natürlich ist, es auch unvermeidlich bleibt, einer oder anderer Mitteilung verschiedene Beachtung zu widmen.

In Bezug auf allgemeine Richtung der Bahnen von Wirbelstürmen, kann ich ebenfalls nur wiederholen, in meiner mehrfach genannten Arbeit v. J. I88I S. I9 Gesagtes

Die Bahmen der Wirbelstiirme (der Tropen) sind zwar nicht regelmäßig zu nennen, sie liegen aber in folgenden Grenzen:

Auf dem offenen Meere der nördlichen Erdhälfte ziehen die Wirbelstirme $z$ wischen $10^{\circ}$ und $25^{\circ} \mathrm{N}$. gewöhnlich nach Richtungen zwischen West und Nord, in ugf. $20^{\circ}-35^{\circ} \mathrm{N}$. biegen sie auf nach Nord, dann um nach Richtungen zwischen Nord und Ost.

A uf dem offenen Meere der suidlichen Erdhälfte ziehen die Wirbelsturme z.wischen $10^{\circ}$ und $25^{\circ} \mathrm{S}$. gewöhnlich nach Richtungen zwischen IVest und Süd, in $\mathrm{ugf}, 20^{\circ}-35^{\circ} \mathrm{S}$. bicgen sie auf nach Süd, dann um nach Richtungen zwischen Süd und Ost.

Die Fälle, in denen Wirbelstiirme zwischen $10^{\circ}$ und $25^{\circ}$ geogr. Breite auf dem offnen Meere der nördlichen Erdhälfte nach Richtungen zwischen Nord und Ost oder Süd und West, - auf dem offenen Meere der südlichen Erdhälfte nach Richtungen zwischen Süd und Ost oder Nord und West ziehen sind selten.

In Binnenmeeren (wie die Karaibische, Arabische, China See, Bai von Bengalen, der Teil des indischen Oceans $z$ wischen der NW. Küste A ustraliens und dem ostindischen Archipel u. a. m.) ziehen die Wirbelstiirme nach sehr verschiedenen Richtungen, dort sind die Bahnen auf der nordlichen Erdhälfte auch südlich von WVest und Ost, auf cler suidlichen Erdhälfte auch nördlich von WVest und Ost gerichtet. - (Vergl. nachstehende Figuren, bedeutend kleiner als die oben genannter Arbeit, auch ein wenig geändert.)

Es ist nicht nachgewiesen, claß cin Wirbelsturm dessen Bahn anfänglich fast gerade nach West oder Nord bezw. Siid gerichtet ist, später immer nach Ost umbiegt oder die ursprungliche sehr nördliche bezw: suidliche Richtung beibehält, - die Lage der Bahn nach dem Umbiegen scheint von der vor dem Umbiegen nicht abhängig zu scin.

Weil es wohl besser ist, die Bezeichnung: Circlone nur zu benutzen für die Arabische Sec, Bai von Bengalen, Südlichen Indischen Ocean, schreibe ich hier statt Cyclone: Wirbelsturm. - Taifun, bleibe Sondername für Ostasiatische Gew ässer, Orkan fur IV estindische, II ̈rblelsturm für Siid- und ostlichen Nord Pacific, auch für allgemeine
Bezeichnung. - Jeder Sturm ist Teil eines Wirbels, ein Wirbelsturm hat verhältnismäßig kleinen Durchmesser.
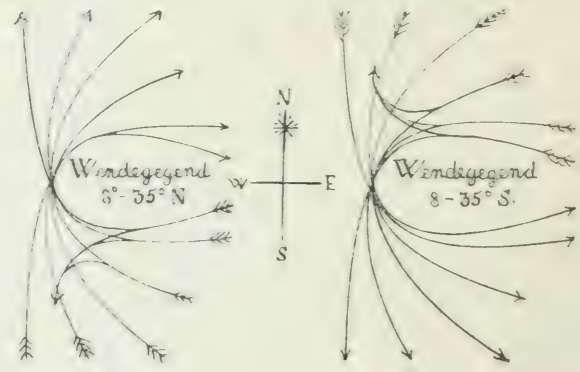

Tafel 1-8.

Taifun-Bahnen.

\section{(Bahnen der Wirbelstürme Ostasiatischer Gewässer.)}

Es ist bereits erwähnt, daß durch die Herren $E$. Knipping, s. Z. Tokio, Dirktn. Decheorens, Chewalier, Froc, Zi ka wei, Doberck und Figg. Hongkong, Kpt. Ruete, unsere Kenntnis der Taifune und ihrer Bahnen erheblich gefördert ist, - auch daß das Institut Dentsche Sceziarte, die Hauptzüge des, bis zum Erscheinen der Segelhandbiicher für den Indischen und Stillen Ocean Bekannten in diesen gegeben, in den Annalen dor Hydro. sraphic ergänzt hat; ferner daß ich in Tafel $2-8$ alle dort noch nicht mitgeteilten nebst von mir entworfenen Bahnen eintrug. Bei letzteren mag Nanchem sonderbar erscheinen die Gradheit der Linien und Kürze der Wendungen; sie zu gebrauchen schien mir am zweckmäßigsten, um zu zeigen, daß diese gezeichneten Bahnen nur Anmäherung, nur Abscissenlinien sind an und für die wirklichen Wege des sogen. Zentrum der Taifune.

Tafel 1 zeigt von $\mathrm{Hr}$. Dir. Doberk. Hongkong, entworfene ungefähre Taifun-Bahnen, die nach Klassen geordnet sind; vielleicht würde Mancher sie nennen Durchschnitte von Gruppen. - Begreiflich ist: wenn man vor sich hat eine grofe Anzahl solcher Bahnen in begrenzter Mecresgegend, crkennt man auch Gruppen und sieht die mehr einzelnen liälle stärker hervortreten, als bei Zusammenstellungen geringeren Unifanges; ebenso begreiflich ist das hieraus entstehende Verlangen, durch Zusammenstellung von Durchschnitts-Linien die Gruppen uibersichtlicher zu machen, - nur darf nicht ïbersehen werden, daß Hr. Dir. Dohirk selbst hinweist, auf die erheblichen Abweichungen der einzelnen Fälle. In seinem ...(icsetz der Stärme in () stasiatischen Geäizssern" sagt genannter Herr betr. dieser Karte und der Klassen: 


\section{„Die verschiedenen Klassen der Taifune und die Zeiten des Jahres in denen sie sich zeigen."}

»Im Jahre I886 äußerte ich die Hoffnung, es könne möglich sein, aufzustellen durchschnittliche Bahnen aller verschiedenen Abarten der Taifune, sobald ein Paar Hundert Pfade verfügbar seien. Dies ist jetzt geschehen auf Grund von 244 Taifunen, die während der letzten 13 Jahre bemerkt sind, - oder durchschnittlich I9 Taifune im Jahre.

Folgendes ist ihre Verteilung über die verschiedenen Monate des Jahres:

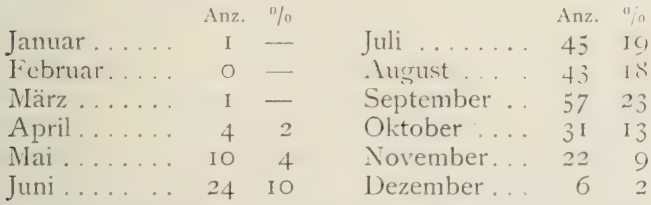

Im J. I 884 schlug ich vor, Einteilung der Taifune in 4 Klassen (Vergl. "Obsrvtns and Researches made at the Hongkong Observatory in 1884"App. M.), doch konnte damals nicht geschehen die endgiltige Einteilung in Unterklassen :

$$
\text { Klasse I. }
$$

"I a $\alpha$ entstehen in der China-See nördlich von $15^{\circ} \mathrm{N}$. am häufigsten nahe $18^{\circ}$ bis $20^{\prime \prime} \mathrm{N}$. $113^{\prime \prime}$ bis I $6^{\circ} \mathrm{E}$.) und gelangen auf das Festland oder nähern sich wenigstens dem Festlande im IV. von Hongkong. $\mathrm{Zu}$ dieser Klasse gehören IO $\%$ aller angemerkten Taifune; sie zeigen sich vorwiegend von Mitte Juni bis Ende September."

I I a, entstehen im Pacific und gelangen in die ChinaSee nördlich von $15^{\circ} \mathrm{N}$; sie erreichen das oder wenigstens nähern sich dem Festland im IV. von Hongkong. $12 \%$ der Taifune gehören in diese Klasse. Vorwiegend ereignen sie sich vom Beginn Juli bis Mitte Oktober."

"I b entstehen im Pacific, gelangen in clie ChinaSce nördlich von $15^{\circ} \mathrm{X}$., ziehen nach $\mathrm{SIV}$. und verschwinden auf See. Nur einer oder zwei Fälle dieser Art sind angeschrieben (spät im Jahre).

„I c entstehen in der China-See und ziehen nach $\mathrm{N}$. aber auf weit abweichenden Bahnen, die liegen in verschiedenen Richtungen zwischen IV., rund durch $\mathrm{N}$. bis ENE. Manchmal biegen sie um sobald sie auf das Festland kommen. Sie zeigen sich von Juni bis Ende September, aber sie sind am häufigsten im Beginn der Taifun-Zeit $(4 \%)$.

"I d entstehen in der China-See, dort biegen sie um, und ziehen manchmal in den Pacific nahe an Süd-Formosa vorbei. Sic erscheinen vom Mai bis September einschl. (2\%).

, Taifune der Klassen I a und I c (26\% aller Taifune) ziehen häufig über Hongkong. «
KI asse II.

II a entstehen im Pacific, gelangen in die ChinaSee nördlich von $15^{\circ} \mathrm{N}$. und auf das Festland von China im E. von Hongkong. Dort ziehen sie nach $\mathrm{N}$. ( $\left(\mathrm{II}_{\mathrm{a}_{1}}\right)$ oder $\mathrm{W}$. (II $\mathrm{a}_{2}$ ). Sie ereignen sich im Juli, August und September $(2 \%)$.

II b entstehen im Pacific und bewegen sich in den Formosa-Kanal. Sie erscheinen von Juni bis September einschl., am häufigsten in August und September $\left(7{ }^{\circ} \%\right)$.

II c entstehen im Pacific, ziehen nördlich von Formosa und nach China hinein. Sie kommen vor von Juni bis September mit deutlichem Méistbetrag im Juli $(3 \%)$.

II d entstehen in hoher Breite im Juli und August, ziehen IVwärts nach China hinein $(4 \%)$.

Mit Ausnahme von II a 1 , die in Hongkong zuweilen schwere SIV. Stürme verursachen, sind Taifune von Klasse II dieser Kolonie nicht gefährlich."

$$
\text { Klassc III. }
$$

Diese Taifune entstehen und wüten hauptsächlich im Pacific.

III a dringen auf die Küste von Luzon doch biegen sie um (gewöhnlich ehe das Zentrum in die China-See gelangt). Sie zeigen sich iiberwiegend in Oktober und November $\left(\mathrm{I}^{1} / 2 \%\right.$ ). *

III b dringen auf dic Küste Formosa's aber biegen um, gewöhnlich in Oktöber (I \%) «

III c ziehen nach $\mathrm{N}$. und erreichen Korea im Juli, August und September $(4 \%)$.

III d biegen im Pacific um und erreichen Japan zwischen Juni und Oktober einschl. Am häufigsten sind sie in August und September (1 $5 \%$ \%).

III e bleiben im l'acific. Sic kommen vor von Mai bis Dezember einschl., die geogr. Breite ihres Erscheinens nimmt in Ganzen ab mit der Höhe der Sonne am Mittag. Zu dieser Klasse gehören IO \% aller angemerkten Taifune, jedoch müßen viele vorhanden sein, die keine Schiffe treffen daher nicht bekannt werden. Ihr Überwiegen kann auf $12 \frac{1}{2} \%$ geschätzt wcrden.

$$
\text { Klasse IV. }
$$

"IVa a entstehen in der China-See Slich von $15^{\circ} \mathrm{N}$., sie ziehen auf Hainan und Annam zu. Sie erscheinen von Mai bis Dezember, doch trifft man sic selten in August $\left(8^{1 / 2} \%\right.$ ). In November entstehen sic öfter in ugf. I I" $\mathrm{N}$. I I 6" li. 《

IVaßentstehen im Pacific und gelangen in die China-See Slich von $15^{\circ} \mathrm{N}$. Sie sind weniger häufig als die in der China-See entstehenden, da der lange Weg über die südlichen Philippinen dienlich ist, sie aufzubrechen. Sic zeigen sich am Beginn und Ende der TaifunZeit (3 " $/ 0)$." 
IV b gelangen in die China-See nachdem sie in niedriger Breite iiber die Philippinen gezogen sind; dann bewegen sie sich nach SIV. und verschwinden auf See. Sie ereignen sich vom Beginn des September bis zum Beginn des Dezember, doch sind sie am häufigsten in November $\left(4^{1} / 2 \%\right)$.

IV c biegen in der China-See um und ziehen zuriick in den Pacific. Ihre Zeit ist am Beginn und Ende der Taifun-Zeit, jedoch meistens im Mai $(4 \%)$.

IV d kommt vor im Golf von Siam in April und Dezember ( $1 \%$ \%).

'Tafel 1 veranschaulicht dic durchschnittichen 11 ege dieser verschiedenen Arten der Taifune. Das durchschnittliche Fortschreiten in 24 Stunden ist auch bezeichnet, doch muß erinnert werden. dafs die einzelnen Taifune sich bewegen in sehr unregelmäßigen Bahnen, deren groljc Abweichungen verschwanden von den durchschnittlichen l'faden; der Betrag ihres Vorrückens ist ebenfalls verschicden. Annchmbarer Weise ist die Kenntnis wo und wenn Taifune vorwiegen, ebenso nutzlich fuir Reisende und Frachtfahrer, als für den WetterToraussager, der in Ermangelung genauer Beobachtungen dic ihn mittelst Drates crreichen, vorhersagen muß nach Pfaden wie in dieser Tafel.

_ _ - Taifune der Klassen IV a, IV b oder I b erscheinen in ungewöhnlich niedriger geogr. Breite in der China-See besonders spät im Jahre, wälırend der NE. Monfun in höchster Entwicklung ist, der in diesen Gewässern viel stäker weht als der SII. Monsun.

Die auf 'Tafel $2-5$ eingetragenen Wege von Taifuncen vor dem Jahre is 77 sind von mir entworfen nach meteorologischen Fournalen oder Abschriftcn aus ihnen, die mir von den betr. Anstalten Gro/3britannicns, der Niederlande, Dentschlands (durch Exc. v. Stosch. damals Chef der Kais. Admiralität), Lorze'gens, Dän'marks. Rußßand. Östreich-Lingarn, Italien, P'ortugal, zum Gebrauch guitigst gestellt wurden, ihnen beigelegten Zeitungsausschnitten, sowie nach Schiffsjonmalen. die Rhedercien und Schiffsfiulher mir gütigst lichen, auch der Kariserl. Marinc (ebenfalls durch Exc. $\tau$. Stosch, mit gütiger Befurwortung des Hr. Chefs des Hydrographischen Amtes, Kpt. z. Sce, später Vice.Admiral Frhr. $\%$. Sclulcinitz. Exc.). - Die Mittel zu betr. Reisen u. s. w. verdankte ich hiesiger libl. Arirhoff Stiftung (I iursprache von $\mathrm{Hr}$. Heinr. Ansinct und Bürgermeister Dr. Pctersen) sowie dem hiesigen I eroin Hamburger Asscuradeure (Dir. Hr. R. Gavideluens)

Die Teile einer Bahn, die in den Vorlasen als unsicher bezeichnet sind, wurden hier durch Fragezeichen kenntlich gemacht

Die angegebene geogr. Lage ist die z. \%. des niedrigsten Barometerstandes.

'lafel 2. März, Mai, Juni. Die Bahnen des Monats $\mathrm{N}$ är (alle zwischen $3 \mathrm{O}^{\circ}-45^{\circ} \mathrm{N}$.) sind entnommen der Arbeit des Hr. Dir. Mecheorns. \%i ka wei I880: ()n the storms of the Chinese Seas and on the storm of the 19. and 20. March I8SO; es fehlt die vom 16-17 III I880; sic faillt ganz auf das Land, beginnt ugf. bei
$5 \mathrm{I}^{\circ} \mathrm{N}$. I I $3^{\circ} \mathrm{E}$., liegt von hier SSEwärts, in ugf. $46^{\circ} \mathrm{X}$. $115^{\circ} \mathrm{E}$. fängt sie an SEl. und Elicher zu werden. IVendegegend ugf. $44^{\prime \prime} \mathrm{N}$. I $20^{\circ} \mathrm{E}$., dann schneidet diese Bahn $125^{\circ} \mathrm{E}$. wenig Nlich von $45^{\circ} \mathrm{N}$, $130^{\circ} \mathrm{E}$. bei ugf. $47^{\circ} \mathrm{N}$., endet nahe $135^{\circ} \mathrm{E}$. bei ugf. $49^{\prime \prime} \mathrm{N}$. Die Bahn von I 880 IlI $28-30$ ist jenseits I $30^{\circ} \mathrm{E}$. von mir aus Versehen vollgezogen d. h. dem Entwerfenden als nahe sicher erscheinend: in genannter Arbeit ist sie von I $30^{\prime \prime} \mathrm{l}$. an nur gestrichelt, also als sehr unsicher betrachtet. - Die Bahn 1857 V $22-27$ ist gezogen nach Berichten vom Brt. S. Mencius, Kpt. IVm. Quirk; I9,s N. I I $6,8^{0}$ E.; Brt. S. Versailles, Kpt. J. H. Carter; $19^{1} / 4^{0} \mathrm{~N}$. I $17^{1} / 2^{\prime \prime} \mathrm{E}$.; Am. S. Ariel, Kpt. F. Cutle; $23^{\circ} \mathrm{N} .128^{1} / 2^{\circ} \mathrm{E}$. - I866 V I-4 Ndld. 3 m Schr. Singapore, Kpt. J. P. Stoop; I $5,6^{\circ}$ N. I I $5^{0}$ E. Brt S. Northflect, Kpt. IV. Symington; $17^{1 / 4^{0}}$ N. I I $7^{1 / 2} 2^{0} \mathrm{E}$. ; D. Bk. Laura, Hmb., Kpt. J. Gerritz; I $8,3^{\prime \prime}$ N. I I6, $2^{\prime \prime} \mathrm{E}-1870 \mathrm{~V} 6-10$ D. Bk. G. F. Händel, Brm., Kpt. H. Sanders; $12,9^{\circ} \mathrm{N}$. I $13,8^{0}$ E.; D. Bk. Eduard, Hmb., Kpt. A. G. Sohst; I $5,2^{\circ} \mathrm{N} . \mathrm{I}_{4} 42^{\prime \prime} \mathrm{E}$. D. Bg. Falke, Hmb., Kpt. R. Göttsche: I $2,7^{\circ} \mathrm{N}$. $112,3^{\circ} \mathrm{E}$. 1). Bk. Condor, Hmb., Kpt. P. Hansen; I I" N. $109,4^{0}$ E; D. BK. Catharina, Hmb., Kpt. A. Fokkes; 8, s" N. I I ${ }^{01}$ E.; D. Bk. Gesine Brons, Emden, Kpt. B. E. Groencwold $9,3^{\circ} \mathrm{N}$. I IO, $4^{\prime \prime} \mathrm{E}$; Arabie $13^{1} / 2^{0} \mathrm{~N}$. $1 \mathrm{I}^{3} / 4^{0} \mathrm{E}$.; Advance; $13^{1} / 2^{0} \mathrm{~N}$. I I $4^{1} 2^{0} \mathrm{E}$; Crimea; $13^{1} 2^{\prime \prime}$ N. I $12^{\prime \prime}$ E. ; Brt. S. Caractacus, Kpt. G. Murray; Paracels Riff. - $1875 \mathrm{~V}$ 31. S. Port. MI. S. Tagus, Macao. D. Bk. A. E. Vidal, Hmb., Kpt. M. Angelbeck. Whampoa. Hongkong. - I $86_{5}$ VI 29, 30 S. Dpf. Orjflamme; $22^{1} / 2^{01}$ N. I $15^{0}$ E. Ndld. Bk. J. M. de Raath. Kpt. J. de Boer. Hongkong. - is I VI I3-16. Brt. S. Dpf. Erlking, Kpt. Ino Steele; I $2,6^{\prime \prime} \mathrm{N}$. I I $1,5^{\circ} \mathrm{E}$. D. Bk. Ino, Hmb, Kpt. J. H. Bannau; I 2,4 X. IO9, $0^{0}$ E. Brt. Bk. Hope, Kpt. H. Henderson? I $3,2^{\circ} \mathrm{N}$. I I $3,0^{\circ} \mathrm{E}$. D. Bk. Herzog Ernst, Brm., Kpt. P. Conrad; I6,s N. I $15,8^{\circ}$ E. D. Bk. Marie; $17,2^{\prime \prime}$ N. I I $2.1^{\circ}$ E. Ndld. Bk. Constance; I $8^{3} / 4^{0} \mathrm{~N}$. I I $4^{1} / 2^{0}$ E. Ndld. 13k. Katerina Maria $20^{\prime \prime} \mathrm{N}$. I I $4^{1} / 4^{\prime \prime} \mathrm{E}$. D). Bk. Batavia, Brm., I $7,3^{\prime \prime} \mathrm{N}$. $114^{\circ}$ E. D. BK. Jan Peter, Altona, Kpt. R. Molsen; $17,7^{\circ} \cdot \mathrm{N}$. I I 4,2 E: Siam. Bk. Bua Cao. $13^{11} \mathrm{~N}$. I I $3^{0} \mathrm{E}$.? Siam. Bk. Siam; $14^{1} / 2^{\prime \prime}$ N. I 1 I $^{\prime \prime} \mathrm{E}$. Siam. S. Hongkong $16^{1} / 2^{\prime \prime}$ N. I $14^{\prime \prime}$ E. D. Bk. Catharina, Hmb., Kpt. A. Fokkes, Hongkong. Am. S. Sooloo; I $5,7^{0}$ N. I I 3,2 E. Firz. S. Jeanne Alice zwischen Macclesfield Bk. und Paracels. Frz. Bk. Humboldt; Hongkong - Hainan. Am. 4 m. Bk. Kattie C. Bessie $2 I^{\prime \prime} \mathrm{N}$. I I I" $\mathrm{E}$.

1872 IV 3-4. beobachtete I. Brt. M. S. Nassau, Kmdt. IVm. Chimmo in Cebu einen schwachen Taifun. der Ergänzung findet durch D. Bk. Minerva, Hmb., Kpt. R. Loose; $12,7^{\circ}$ N. I I $6,1^{\prime \prime} \mathrm{E}$. doch konnte ich darnach keine Bahn entwerfen; viele mir zugegangene bezw. von mir in London und Utrecht gefundene Berichte konnte ich nicht verwenden um Bahnen zu entwerfen. weil sie vereinzelt blieben, Ortsbestimmungen zu unsicher waren u. a. m.

I'atel 3. Juli. Die Bahn des Iltis-Taifun nach Hr. Dir. Froc ist punktiert, dic desselben Taifun nach Hrm. Dir. Doberk und ligers ist gestrichelt, um beide auffalliger zu machen; wie erwähnt sind Abweichungen in Arbeiten iber denselben Taifun sts. mehr als eines Sachkundigen, durchaus nichts Auffallendes, und dem einen 
Entwurf ist im Ganzen durchaus nicht mehr Wahrscheinlichkeit zuzusprechen als dem anderen, weil für den größten Teil solcher Bahnen die Anhaltspunkte zur Genauigkeit fehlen. In Bezug auf den Ausganspunkt im Pacific kommt hier hinzu, daß Hrrn. Dir. Doberck und Figg der Bericht vom Lothair bekannt wurde, den in der Arbeit von Hr. Dir. Froc ich nicht finde.

Schmerzhaft war und bleibt fuir uns Deutsche der Verlust des Iltis mit dem größten Teil seiner Besatzung. Ehre ihrem Andenken! Mit Dank nahmen wir entgegen die ihn betreffende Arbeit von Hr. Dir. Froc, von der ein sehr ausführlicher Auszug gegeben ist in der MarincRundschau. - Hrrn. Dir. Doberch und Figg für ihre Arbeit dankbar, folgt hier der vom Hongkong Observatorium gegebene Bericht uber denselben Taifun (Obsrvtn. u. Res. f. 1896 . Hongkong I 897 S. I 37 u. w:) :

1896 Juli 1\% a. I I $20^{\text {m }}$. Der Barometerstand hat sehr zugenommen in E. Japan, wenig abgenommen an der. Küste China's und bei Bolinao. Ausgenommen auf dieser Station ist der Luftdruck im Allgemeinen uiber dem normalen. $\mathrm{Zu}$ crwarten in Hongkong und $\mathrm{Um}$ gebung: leichter Wind von S. und SSW ; schön.

18. a. I $I^{h} 20^{m}$. Depression im Pacific ENE. von Bolinao. a. I $1^{\mathrm{h}} 3 \mathrm{O}^{\mathrm{m}}$, Baromstd. hat erheblich abgenommen bei Bolinao und an der SEküste China's; im höchsten Norden (China's) ist der Luftdruck ebenfalls geringer geworden, da dem Anschein nach über der Manschurei eine andere Depression liegt. Zu erwarten: leichter W. Wind; schön.

»19. a. I $1^{\text {hl }} 30^{m}$. Der l3aromstd. nahm noch beständig $a b$ auf Luzon und längst der China Kuiste; während der letzten 24 Stunden war die Abnahme besonders rasch auf L,uzon und an der S. nebst SE. Kiiste China's, Die Depression erstreckt sich über ein weites Gebiet, doch berichtet man nur leichten Wind. Das Zentrum der Depression liegt möglicherweise Ewärts von Formosa. Zn erwarten: leichter oder mäßiger IV. IVind; schön. «

》20. a. I I h $30^{m}$. Seit gestern zeigte sich mäßiger Fall des Queckilbers (im Barometer) an der China-Kuste und ein bedeutender in Japan. In dem Gebiet, umfaßst von Luzon, der China-Küste und Japan ist der Luftdrucl: im Allgemeinen gering. Das zentrale Gebiet dieser ausgebreiteten Depression liegt möglicherweise im Pacific Swärts von SIV. Japan. Zu erwarten: mäßiger W. und SW. Wind; meistens schön aber im Ganzen weniger beständig, möglicherweise einige Regenschauer.

21. a. I $1^{\mathrm{h}} 1 \mathrm{O}^{\mathrm{m}}$. Baromstd. wenig verändert, die Verteilung des Luftdrucks ist ziemlich dieselbe wie gestern. Das Gebiet des niedrigsten Baromstd. scheint noch zu scin im Pacific zwischen Formosa und SIV. Japan. Zu erwarten: leichter IV. und SIV. Wind; schion.

22. a. $11^{\mathrm{h}} 30^{\mathrm{m}}$. Scit gestern fand statt weitere Abnahme des Luftdrucks auf Luzon und längs der China-Kiiste. Das zentrale Gebiet der Depression liegt anscheinend noch zwischen Formosa und Japan. Zu erwarten: leichter oder mäßiger IV. WVind; meistens schön aber im Ganzen weniger beständig, vielleicht ein Gewittersturm. Am 22. p. $4^{\mathrm{h}} \mathrm{IO}^{\mathrm{m}}$ Taifun N. von Formosa nähert sich der Küste zwischen Fu tschau und Schanghai.»
23. a. $\mathrm{IO}^{\mathrm{h}} 2 \mathrm{O}^{\mathrm{m}}$. Das Taifun-Zentrum auf seiner Nwärts Bewegung ist eben Nwärts von Schanglıai gezogen. a. I $\mathrm{I}^{\mathrm{h}} 2 \mathrm{O}^{\mathrm{m}}$. Der Baromstd. zeigt eine starke Abnahme in Schanghai und eine geringe zwischen Futschau und Hongkong, während in Bolinao keine Veränderung ist. Der Luftdruck bleibt im Allgemeinen gering, olnne ausgeprägte Neigung im Süden zu steigen, es ist wahrscheinlich daß eine andre Depression sich bildet im N. Teil der Chiua See. Zu erwarten: leichter NW. oder veränderlicher Wind; schön.

Da der Taifun auf den sich obige Angaben beziehen im Beginn weit aufen im Pacific blicb, ist es nur möglich bis zu seiner Annäherung an die Küste seine wahrscheinlichste Bahn als Vermutung anzudeuten. Bcobachtungen an Bord der Bark Lothair, die im Pacific von Callao nach Hongkong segelte, zeigen, daß das \%entrum der Störung möglicherweise lag in I $8^{\circ} \mathrm{N}$. I $32^{\circ} \mathrm{E}$. und von hier in NNIVI. Richtung sich bewegte. Am 21. scheint es in ugf. $25^{\circ}$ N. $129^{\circ}$ E. i. d. Nähe der Liu kiu In. gewesen zu sein; scheinbar nicht im Stande umzubiegen, bewegte es sich wieder NVIwärts, da hoher Luftdruck, vom l'acific westwärts sich ausdehnend, über L. Japan und angrenzende Gewässer südwärts vorriickte. Am 22. mttgs. lag das Zentrum wahrscheinlich in $27^{0} \mathrm{~N}$ $126^{1} / 2^{0} \mathrm{E}$. Folgende Beobachtungen des Barometerstandes am 22, zeigen, wie sehr die Isobaren SWwärts gedehnt waren: Yokohama 762,0, Nagasaki 753,9, Schanghai 75 I,3, Sliarp Peak 747.5, Hongtiong 748,8, Bolinao 75 I,8 mm. Das Dpfsch. , Wuhu geriet in das Zentrum am 22. p. I I I $^{\text {h }} 29^{\circ} 37^{\prime} \times$. $123^{\circ} \cdot 46^{\prime} \mathrm{E}$. das Barometer zeigte damals als niedrigsten Stand 718,3 (unberichtigt) Wind totenstill. Vor Ankunft des Zentrum war der IVind von NE. und nach seinem Überziehen von STV. mit voller Taifun-Stärke, begleitet von sehr schwerem Regen mit hohem, wirrem Seegange; im Gebiet des \%entrum hörte der Regen jedoch auf und der Seegang, obwohl wirr, hatte keine Kraft. Dic Störung zog ungemein rasch NVWärts, da das Zentrum am nächsten Morgen, 23. nahe $6^{\text {h }}$ dicht bei Schanghai vorbeizog, wie sich zeigt aus Beobachtungen an Bord des Dpf. "Chingping ", das in der Nähe des Kiutoan Fsch. am Anker lag. Fs war daher ein glicklicher Umstand, daßs am 22. p. $4^{\text {h }}$ vom Hongkong Observatorium telegraphisch Schanghai gewarnt wurde, als im gefahrlichen Halbkreise liegend, da man hätte annehmen können, das Zentrum würde zwischen China und Japan nordwärts ziehen, Schanghai also in groker Entfernung vom Zentrum im linken Halbkreis bleiben, wo in einigem Abstande von ihm mäßig starker Wind ist. Das Telegramm erwies sich als Warnung wohl begründet, auch scheint es, daß3 keine andre IVarnung gegeben wurde, die auf einen Sturm in jenen Hafen hinwies. (NB. Hr. L. Froc, Direktor des Zi ka wei Observatorium widerspricht der Meinung, nur das Hongkong Obsrvtm. habe Schanghai vor Sturm gewarnt und teilt mit, bezügliche VVarnungen des $/ \mathrm{i}$ ka wei Observatorium).. "Chingping hatte äußerst schweren Sturm von NNE., Baromstd. abnehmend bis 23. a. $5^{\text {h }} 30^{\mathrm{m}} \mathrm{zum}$ niedrigsten $=728,2$, gleichzeitig ward der Wind nahe still und drehte rasch zuriick durch N. und W. a. $7^{\text {th }}$ hatte man abnehmenden Sturm von SSIV. bei zunehmendem Baromstd. Diese Beobachtungen zeigen, daß das 
Zentrum in sehr geringer Entfernung Ewärts vom Schiff vorbeigezogen sein mufs. Am Mittag dieses Tages war die Lage des Zentrum nahe $32^{33} 4^{0}$ N. $120^{33} / 4^{0} \mathrm{E}$. G. In Tschinkiang wehte um a. $9^{\mathrm{h}}$ sturmischer Wind von NIV., Bar. 742,9, riickdrehend auf W. Stk. 6, um p. $3^{\text {b }}$, Bar. 743,2. Auf See hatte S. Dpf. Nangchang mttgs, in ugf. $34^{1} / 2^{0}$ N. $123^{\prime \prime}$ E. Bar. 747,5 mit starkem Sturm aus E, rückdrehend nach SE. Hoher Luftdruck lag auf Japan an diesem und dem folgenden Tage. Die Störung bewegte sich ugf. NNWwärts, zog ein wenig IV. von Hauki L.t. $\left(38^{\prime \prime} 4^{\prime}\right.$ N. $120^{\circ} 39^{\prime}$ E. $)$ früh am Morgen des 24; in Tschi fu und auf den Leuchttiurmen des Schantung Vorgebirges hatte man E-drehende Stirme zwischen dem Abend des 23. und Morgen des 24. ऽ. Dpf. Kalgan litt unter dem Sturm, das \%entrum lag etwas $\mathrm{IV}$. von seinem Schiffsort $\left(39^{\circ} 3^{\prime} \mathrm{N}^{\prime}\right.$. $120^{\circ} 50^{\prime} \mathrm{E}$. $)$; man hatte starken NE. Sturm nach SE. drehend, niedrisster Barstd. 741,4. In Folge des Taifun (die Chinesische Telegraphen Verwaltung hatte keine Warnungen befördert), geriet unglicklicherwcise das deutsche Kanonenboot "Iltis am 23. abds, bei dem Vorgebirge auf Strand und wurde gänzlich wrack. Am Mittag war das Zentrum im Golf von Liao tung. Der Taifun bog um am 24. Es scheint als sei am 25. abds, bei IIladiwostok er vorbeigezogen, von dort über den N. Teil der Japan Sce, möglicherweise Ewärts weiter. Während des Bestehens dieses Taifuns. war an der $\mathbf{S}$. und SE. Küste China's außsergewöhnlich heißes und trocknes Wetter vorherschend.

Diese Ubersicht giebt einige Ergänzungen zu den Berichten, die aufgenommen sind in die Arbeit von $\mathrm{Hr}$. Dir. Froc (die auch enthält Einiges aus dem hier Gegebenen vom I8. und 19. Juli). Zunächst erfährt man, daß das bei Hr. Dir. Froc nur British Steamer bezeichnete Dampfschiff " $\mathrm{W}$ uhu " hieß; der Unterschied in der geogr. Länge am 22. a. $11^{\mathrm{h}} ; 123^{0} 4 \mathrm{O}^{\prime}$ und $123^{\circ} 4^{6}$ kann an einer Stelle ein unbemerkt gebliebener Druckfehler scin, - hier kaum von Belang; Hr. Dir. Froc giebt den Barstd. dieses Schiffes berichtigt, dadurch wird der Unterschied von $3,3 \mathrm{~mm}$. erklärlich; daß im Hongkong Bericht die Windrichtung NE. gegeben ist in dem von Zi ka we i NlzzL. (so lese ich NE/E.) ist nebensächlich, doch ist in letzterem nicht erklärlich, was mit $N^{1 / 2 E}$. gemeint ist, da man auf Schiffen besonders während blendenden Regens die Windrichtung doch nicht auf halbe Kompaß-Striche schätzen kann. In Bezug auf Seegang ist beachtenswert die Ergänzung: im Bereich des sogen. Zentrum war der Seegang obwohl wirr, doch ohne Kraft. Noch beachtenswerter erscheint die Ergänzung zum Bericht des Dpf. Chingping. Hr. Dir. Froc giebt als \%eit des niedrigsten Baromstd. 23. a. $7^{\text {h }}$ Hrrm. Dir. Doberck und Figg $5^{\text {h }} 30^{\mathrm{m}} ;$ um $5^{\text {h }}$ war nach erstercm Barstd. $730,0 \mathrm{~mm}$, um $5^{\text {h }} 3 \mathrm{O}^{\mathrm{m}}$ nach letzteren 728,2, Abnahme in 1/2 Stunde: $1,8 \mathrm{~mm}$., Zunahme in $1^{1 / 2}$ Stcl.: nur $0,5 \mathrm{~mm}$. ( $\left.7^{1 \mathrm{~h}}=2=728, \pi\right)$. In der crsten Arbeit ist nur zu ersehen, daf3 bei diesem Schiffe die $W$ indrichtung $u m 5^{\text {h }}$ NNE, war, um $7^{\text {th }} \mathrm{SSW}$; die später erschienene Übersicht sagt eingehender: " $5^{\text {h }} 3 \mathrm{O}^{\mathrm{m}}$ (niedrigster Barmstd.), gleichzeitig ward der Wind nahe still (when the wind fell almost calm) und drehte rasch zurick durch $\mathrm{N}$. und $\mathbb{W}$., a. $7^{\text {th }}$ hatte man abnehmenden
Sturm von SSIV bei zunehmendem Barometerstand. " Nach den, Hr. Dir. Froc's Arbeit beigegebenen Berichten erreichte das Zentrum am 23. $5^{\mathrm{h}} 15^{\mathrm{m}}$ das S. Dpf. Lienshing Kpt. Buller $30^{\circ} 5^{\prime} 8^{\prime}$ N $122^{\circ} 35^{\prime} \mathrm{E}$. und der Wind der dort vorher NNE. I 2 gewesen, kam $5^{\mathrm{h}} 3 \mathrm{O}^{\mathrm{m}}$ mit starken Stößen aus SIV. Chingping am Anker bei Kiutoan Fisch. $3 I^{\circ} 12^{\prime} N$. I $2 I^{\prime \prime} 44^{\prime} \mathrm{E}$. befand sich also ugf. IVNW ${ }^{1} / 2 \mathrm{~W} .46 \mathrm{Sm}$. ron jenem Ort; daßs das Zentrum in der kurzen Zeit von $1 / 3$ Stunde sich so rasch fortbewegt habe ist kaum denkbar; nun befanden sich aber die beiden S. Dpf. Cho y sang, Kpt. II. E. Sawer und Meefoo Kpt. Klopfer zu jener Zeit am Anker bei Napier I. $30^{\prime \prime} 40^{\prime}$ N. $122^{\prime \prime} 24^{\prime} \mathrm{E}$. also nur SSIV' $1 / 2 \mathrm{WV}$. $20 \mathrm{Sm}$. von der Stelle an der $5^{\mathrm{h}} 15^{-11}$ Lienshing in das Zentrum geriet; jene berichten aber (außer stiundlichen Angaben), der eine, dals um $4^{\text {h }} 20^{\mathrm{m}}$ - der andre, daf um $4^{\mathrm{h}} 3 \mathrm{O}^{\mathrm{m}}$ der niedrigste Barstd. war, dabei bei jenem der IVind von NE. 9 auf $\mathrm{N} .2$ gedreht hatte bis $5^{\text {th }}$ nach $\mathbb{W}_{z S}$. 5, dann nach SWV. 7 , SWzS. \& und weiter Slich drehte, - der andre um $4^{\text {h }}$ W W. NNE. 9, $4^{\text {h }} 30^{\mathrm{m}} \mathrm{NIV}$. IO, $5^{\text {h }}$ WV. 10 und weiter Slich drehte. Wäre der Bericht der Lienshing nicht vorhanden, so würde man annehmen, das Zentrum sei iber C hoy'sang und $\mathrm{Ching}$. ping gezogen; dieses Schiff lag von jenem NW. $48 \mathrm{Sm}$.; - es ist weit eher denkbar, daß ein Taifun-Zentrum in jener Gegend diese Strecke in 1 Std. IO $^{\mathrm{m}}$ zurücklegte, als eine gleiche Strecke in nur is Minuten. Der Bericht vom S. Dpf. Lienshing ist ebenso zurerläßjig wie der von den anderen Schiffen, daher ist der Iltis-Taifun einer von den Fällen, die hinweisen (wenn man nicht "beweisen " sagen will) auf das Vorhandensein von Nebenzentern (Teil-llinima) auch in Taifunen. - Bei Raffles I. d. i. nahe bei Napier I. lag S. Dpf. Singan Kpt. Famicson: nach nur vierstiundlichen Angaben und einer Bemerkung änderte von $4-S^{\text {h }}$ der $1 \mathrm{ind}$, von i I zu 9 abnehmend, von NVE. nordwärts durch $\mathrm{IV}$, nach S., aus dieser Richtung wieder zu I I zunehmend, also ähnlich wie bei Choysang und Meefoo.

Hrrn. Dir. Dobirck und Figg nemen noch ein S. Dpf. Nanshang am 23. mittgs. bei ugf. $34^{1 / 2^{\prime \prime}} \mathrm{N}$. $123^{0} \mathrm{E}$. Barstd. 747,5 mm. Wd. E. schwerer (fierce) Sturm, nach SE. drehend.

Von der Hydrograplizistu'n Abtcilung Linis. Russ. Marine Ministcrium (Chef S. T. Hr. Spindler) sind (wie bereits erwähnt) guitigst mir zugegangen Abschrift aus dem Journal des T a mbow vom 20-25. Juli I \$ 46 , und des Dmitryi Donskoj 23-26. Juli r 896 ; erstere also weiter reichend als in der Arbeit von Hr. Dir. Froc und durch Aufenthalt in Nagasaki der Barometerstand mit dortigen vkfls, unmittelbar vergleichbar; das andre Schiff fuhr von Tschimulpo nach 11 ladiwos tok, giebt also Auskunft sozusagen über die Verhältnisse neben und hinter clem Taifun am 23. nebst folgenden Tagen. Am Bord des T am bow am Nachmittag des 22. und Morgen des 23. ist der Barometerstand nicht nur zweistïndlich sondern stiundlich angeschrieben, der niedrigste nicht angegreben $6^{\mathrm{h}} 3 \mathrm{O}^{\mathrm{m}}$ sondern $7^{\mathrm{h}} 3 \mathrm{O}^{\mathrm{m}}$, auch finden sich andre Abweichungen. - Ferner erhielt ich durch die Guite des Meteorologischen Kentral-buran in Paris (Dir. Hr. Prof. Dr. M/asiart) Abschrift des Journals mit besonderen Bemerkungen des französischen P. Dpf. Y arra, 
1896. Juli. Russ. Frw. Fl. Dpf. "Tambow".

Hongkong - Nagasali - Wladiwostok.

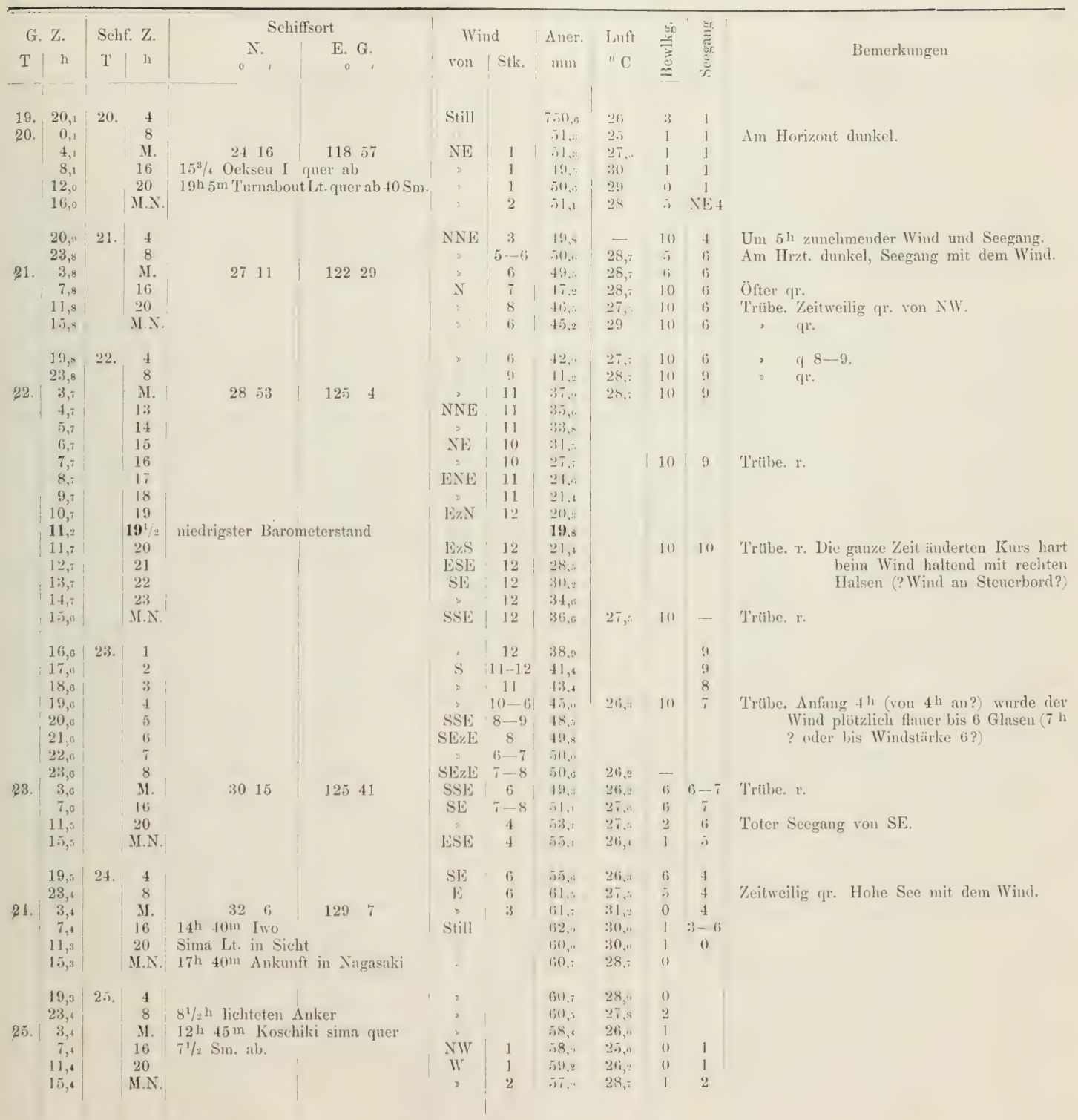


Hongkong' - Observatorium 22 $18^{\prime} 12^{\prime \prime}$ N. $114^{\circ} 12^{\prime}$ E. G. 1896 Juli.

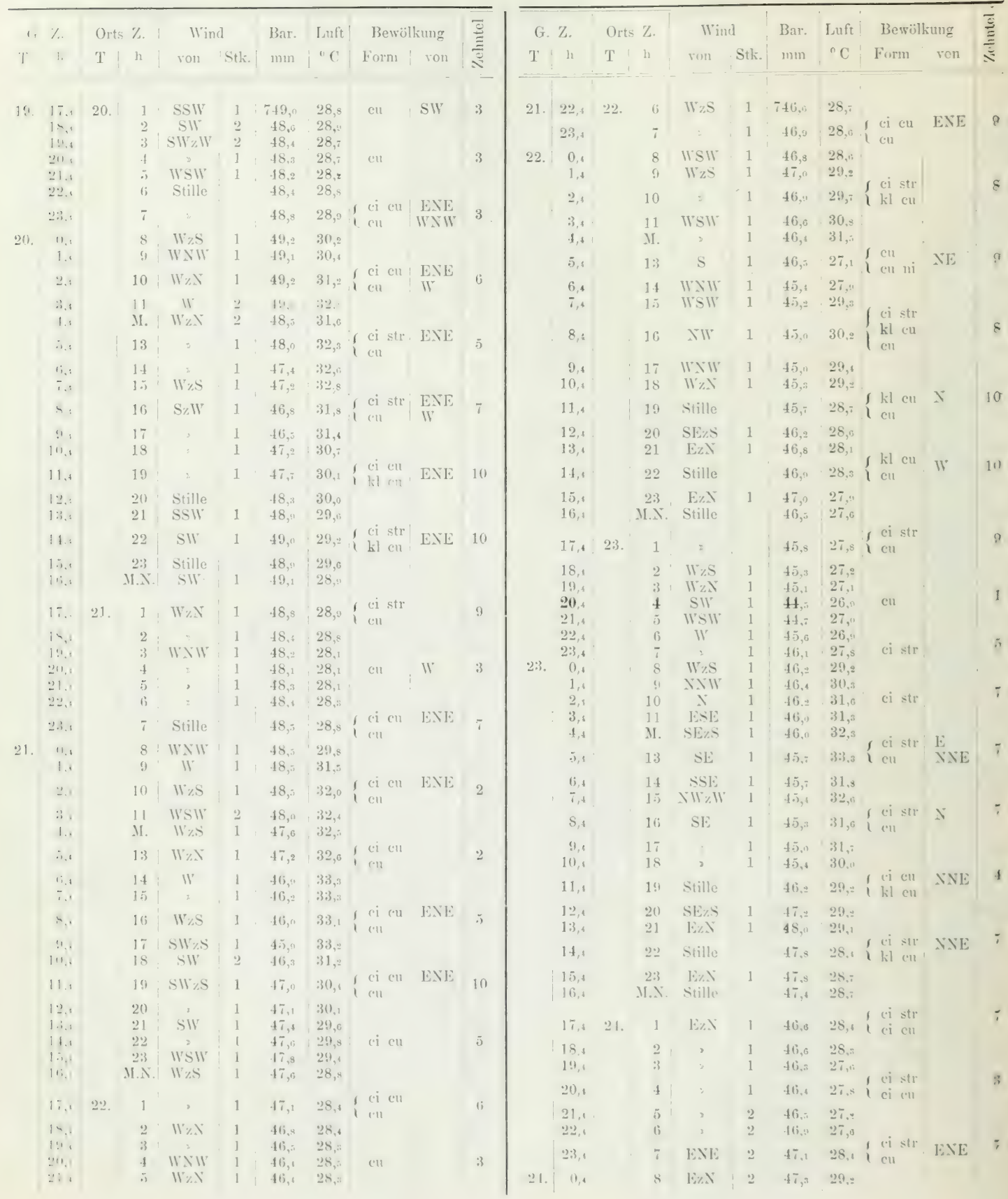




\section{Hongkong - Observatorium $22^{\circ} 18^{\prime} 13^{\prime \prime}$ N. $114^{\circ} 12^{\prime}$ E. G. 1896.}

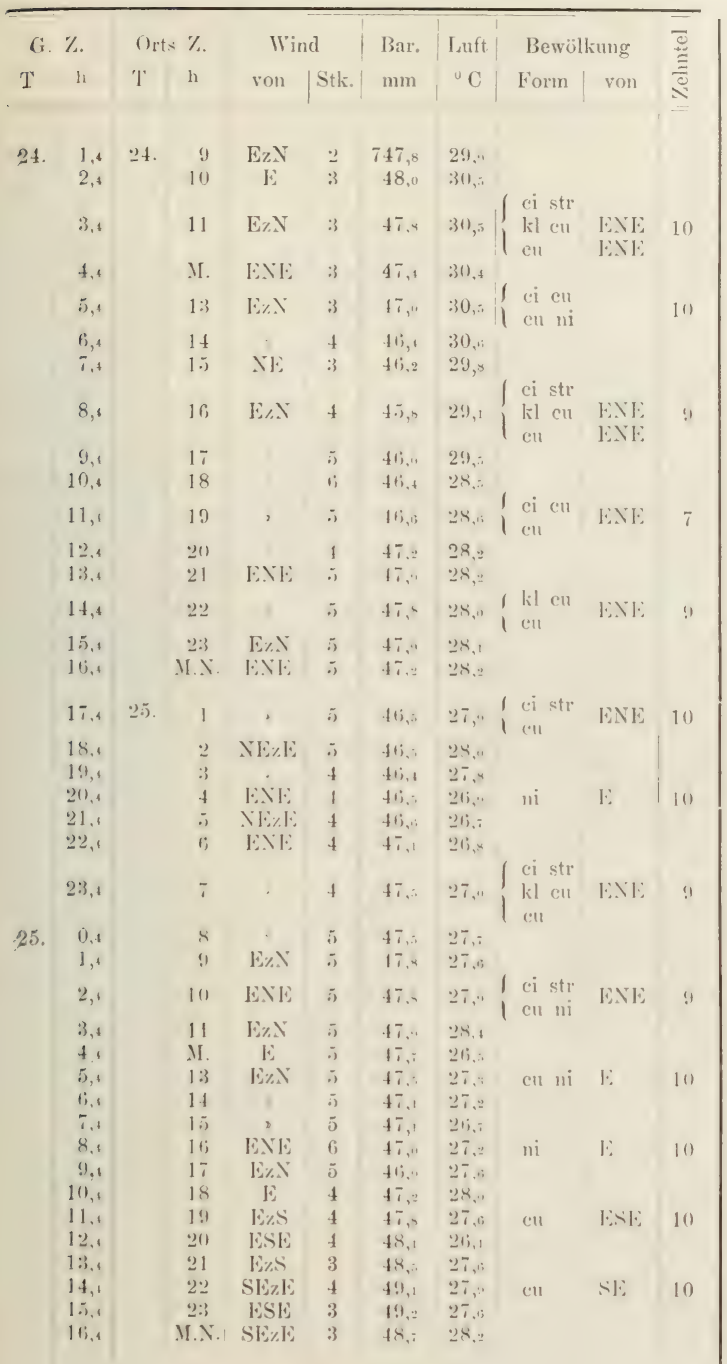

Hier sind nur abgeschrieben die Angaben an den Tagen, die gehören zur später folgenden Zusammenstellung der Barometerkurven. Als Anhaltspunkte fïr die in der Übersicht der Hrrn. Dir. Doberck und Figs erwähnten Ab- und Zunahme im Barometerstande diene beistehende Vereinigung der Nitteilungen von a. $4^{\text {h }}, 10^{\text {h }}$ P. $4^{\text {h }}$, IO ${ }^{\text {h }}$ der vorhergchenden und folgenden Tage.

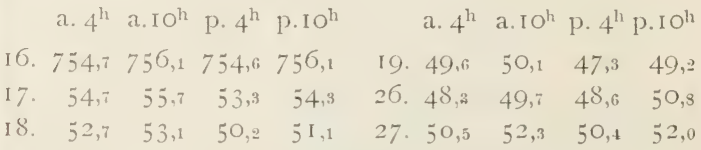

Der Zeit-Unterschied mit Greenwich ist 7,6 Stunden, Hongkong vor Greenwich.

Vom 27. an nahm der Barstd. wieder ab, als ein Vorzeichen des Taifun dessen Zentrum am 28 . $12^{\mathrm{h}} 5^{\mathrm{m}}$ über Apari auf Luzon zog (1 $8^{\circ} 22^{\prime} \mathrm{N}$. $12 \mathrm{I}^{0} 33^{\prime} \mathrm{E}$.), den man auch in Hongkong traf; hier war der niedrigste Barstd, am 29. abds. zwischen $9^{1} / 2^{h}$ und $I^{h}\left(2 I, 5^{h}-22^{h}\right)$ Ortszeit, in der Ubersicht steht $733,3 \quad(28,87$ Zoll $)$ dies scheint ein Druckfehler statt $(28,78) \quad 73 \mathrm{I}, 0$ da in den stiundlichen Angaben steht: $9^{\text {h }}(28,561) 733,1-\mathrm{IO}^{\mathrm{h}}(28,783)$ 731,1 . In Hongkong war die größte Wind-Geschwindigkeit 108 stat. miles $=174 \mathrm{Km}$. i. d. Std. $=48,3$ Meter i. d. sec. -

Der Regenfall betrug:

$$
\begin{aligned}
& \text { am I6. : } 1,0 \mathrm{~mm} \text {. } \\
& \text { 22. : 1 2,4 } \\
& \text { 25. : 19,3 } \\
& \text { 26. : } 34,9 \text { 》 } \\
& \text { 27. : } 58,9
\end{aligned}
$$

Dies (Dunst) am 22. Thau, am 16. 24. und 28 . Regenbogen am 25. Blitzen ohne Donner am 20. 21. 23. Donner olne Blitz am 20. Gewittersturm am 22. $12^{\text {h }} 30^{\mathrm{m}}$ $-14^{\mathrm{h}}$ in $\mathrm{E}-\mathrm{N} \mathrm{W}$. in der Entfernung.

Sonnen-Halo (Ring) am 16. 17. 19. 20.22. 23. 24 .

Sonnen-Krone(Hof) 》 I9.23.

Mond-Halo (Ring) 》16.18.19.20.21.22.23.24.25.27. Mond-Krone (Hof) » I6. I7. I8. 19. 20.2 I. 22. 26.

Nebel am 2 I., Leichter Nebel am 20. 23. 
1896. Juli. Franz. Post-Dampfsch. "Yarra", Kapt. Le Coispellier, Ltnt. Mar. Res، Beobachter Hr. A. Pernot, Kpt. f. gr. F. Ltnt. Hongkong - Wusong - Kobe.

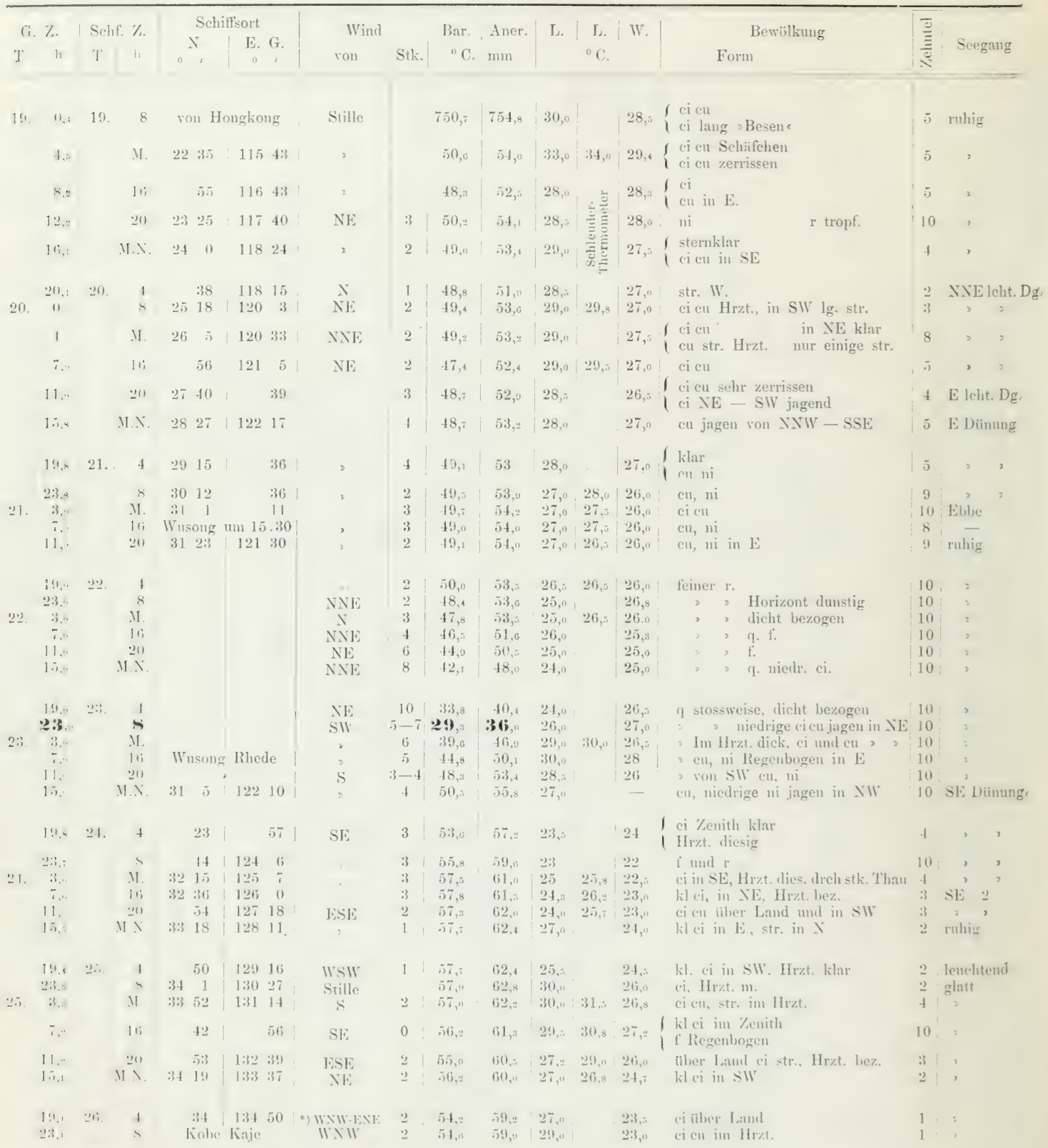




\section{Bemerkungen.}

In der Nacht vom 21. - 22. Juli, $\mathrm{MN}-4^{\text {h }}$ wurde das Wetter regnicht, mit veränderlichem Wind von $\mathrm{N}-\mathrm{NNE}_{3}$. Feiner $\mathrm{r}$.

\begin{tabular}{|c|c|c|c|c|c|c|c|c|c|}
\hline & $\mathrm{h}_{\mathrm{h}}^{\mathrm{G} . \mathrm{Z}}$ & & $\begin{array}{c}\text { Schiffszeit } \\
\mathrm{h} h \mathrm{~h}\end{array}$ & ron & Stïke & Wetter & & Bar. & \\
\hline $\begin{array}{l}21 . \\
22 .\end{array}$ & $\begin{array}{c}19,0-23,0 \\
23,0-3,9 \\
3,9-7,9 \\
7, n-11,9 \\
11, n-15,9\end{array}$ & 22. & $\begin{array}{l}4-8 \\
8-12 \\
12-16 \\
16-20 \\
20-\mathrm{MN}\end{array}$ & $\begin{array}{c}\text { NNE - N } \\
\text { NNE } \\
\text { NE } \\
D\end{array}$ & $\begin{array}{l}\text { zunehmend bis } 4 \\
\begin{array}{c}4-5 \\
7-8\end{array}\end{array}$ & feiner $r$. & MN & $\begin{array}{c}\text { (unbe- } \\
\text { richtigt) } \\
750 \\
48 \\
45,3\end{array}$ & wir sind in einem Taitum \\
\hline 23. & $\begin{array}{r}15,9-19,9 \\
19,0-23,0 \\
3,9-7,9 \\
7,9-11,9 \\
11,9-15,9\end{array}$ & 23. & $\begin{array}{l}0-4 \\
4-8 \\
M-16 \\
16-20 \\
20-\mathrm{MN}\end{array}$ & $\underset{\mathrm{S}}{\mathrm{S}}-\mathrm{S}$ & $\begin{array}{l}\text { Sturm } \\
\text { Sturm bis } 7 \text { h } \\
\text { abnehmend } \\
4-3 \\
4\end{array}$ & r. & \begin{tabular}{|c|}
$23+\mathrm{h}$ \\
$8 \mathrm{~h}$ \\
$\mathrm{M}$ \\
16 \\
20 \\
$\mathrm{MN}$
\end{tabular} & $\begin{array}{l}37 \\
31,5 \\
33 \\
14 \\
49 \\
52 \\
54\end{array}$ & $\begin{array}{l}\text { sehr heftige Stosswinde } \\
\text { Der Wind andert bis } 5 \text { h nach WNW sehr } \\
\text { frisch; von } 6 \text { h bis } 7 \text { h dreht der Wind } \\
\text { nach SW dann bis } 9 \text { h } 30 \mathrm{~m} \text { nach SS W bleibt } \\
\text { so mit Stössen und einigen } q \text {. } \\
\text { Windstösse }\end{array}$ \\
\hline & $15, \Omega-19,0$ & 24. & $0-4$ & S'E (?SzE) & $3-4$ & & $2 \cdot 4+$ & 56 & Ziemlich hoher Seegang \\
\hline
\end{tabular}

Der Taifun ist nach $\mathrm{N}$ von Shanghai gezogen. Nach Beobachtungen entstand der Taifun SEwärts von Gutzlaff, zog NEwärts ein wenig nach NNE einbiegrend; zwischen $6-7^{\text {h }}$ mgs. zog die Erscheinung nach Norden. sein Zentrum $50 \mathrm{Sm}$. E. von Saddle I. - (Es folgen die stündlichen Beobachtungen):

\begin{tabular}{|c|c|c|c|c|c|c|c|c|}
\hline \multicolumn{2}{|c|}{ Gr. \% } & \multicolumn{2}{|c|}{ Schiffszeit } & $\begin{array}{c}\text { Aner. } \\
\text { mm }\end{array}$ & "C. & \multicolumn{2}{|c|}{ Wind } & Bar. $0^{n} \mathrm{C}$ \\
\hline 22 & 15.9 & 23 & 0 & 748,1 & 23 & NNE & 8 & 742,7 \\
\hline Juli & $16, \cdots$ & Juli & 1 & 46, & 28 & $\infty$ & & 40,4 \\
\hline & 17, & & 2 & 44,3 & 27 & & & 38,2 \\
\hline & 18, & & 3 & 42,0 & 28 & & & 35,7 \\
\hline & 19,9 & & $t$ & 40,4 & 30 & NE & 9 Böen & 33,8 \\
\hline & 20,9 & & 5 & 38,0 & 31 & ? (oben WNWW) & & 31,1 \\
\hline & 21,0 & & 6 & 36,1 & 32 & , & & 29,0 \\
\hline & 22: & & $\gamma$ & $\mathbf{3 5}, 1$ & 32 & WNW (SW) & 5 & 28 \\
\hline & 23,9 & & 8 & 36,0 & 31 & SIV & 6 & 29,3 \\
\hline $2: 3$ & 0 & & 9 & 39,0 & 33 & SSW & 6 & 32,0 \\
\hline & 1,9 & & 10 & $+2,0$ & 34 & & & 34,9 \\
\hline & 2,0 & & 11 & 44,0 & 34 & SSIW, Stösse & $5, q$ & 36,9 \\
\hline & 3,0 & & M. & 46,3 & 34,3 & IVSIV & 96 & 39,6 \\
\hline & $4, v$ & & 13 & 47,0 & 34 & & & 40,2 \\
\hline & 5,9 & & 14 & 18,2 & 34 & SSIV & 5 & 42,0 \\
\hline & 6 & & 15 & 49,0 & 34 & & & 43,3 \\
\hline & $7, n$ & & 16 & 50.0 & 34 & & & 44,8 \\
\hline & $8, n$ & & 17 & 51,0 & 34 & S & 4 & 45,8 \\
\hline & 9, & & 18 & 52,0 & 34 & & & 46,8 \\
\hline & 10, & & 19 & 53,0 & 32 & & & 47,4 \\
\hline & 11.3 & & 20 & 53,4 & 31 & & & $48,4$. \\
\hline & 12,0 & & 21 & 54,0 & 31 & & & 19,2 \\
\hline
\end{tabular}

Von Wusong nach Kobe. Bei Verlassen des Yangtse unruhiger (haché) Seegang, der 24 Stunden anhielt; durch starkes Rollen und Stampfen macht das Schiff sehr unregelmäßige (désordonné) Bewegungen.

NB. Für das Aneroid ist angegeben eine Korrektion von $+\mathrm{I} \mathrm{mm}$. Diese ist hier angewandt. Da der unberichtigte Barometerstand und Wärme-Angaben des Auszuges übereinstimmen mit denen des Journal (Bar. à m. und Therm. att.) so ergab sich der im Auszuge mitgeteilte in [] gesetzte berichtigte Barometerstand. 
1896. Juli. S. Russ. M. S. "Dmitrij Donskoj". Tschimulpo - Wladiwostok.

\begin{tabular}{|c|c|c|c|c|c|c|c|c|c|c|c|c|c|c|c|c|}
\hline \multicolumn{2}{|c|}{ G. \%. } & \multicolumn{2}{|c|}{ Schf. \%. } & \multicolumn{4}{|c|}{ Schiffsort } & \multirow{2}{*}{$\begin{array}{l}\text { Wind } \\
\text { von }\end{array}$} & \multirow{2}{*}{$\begin{array}{c}\text { Bar: } 0^{6} \mathrm{C} \\
\mathrm{mm}\end{array}$} & \multirow{2}{*}{$\begin{array}{l}\text { Dampf- } \\
\text { Druck } \\
\text { mm }\end{array}$} & \multirow{2}{*}{$\begin{array}{c}\text { Feligkt. } \\
\%\end{array}$} & \multirow{2}{*}{$\begin{array}{l}\text { Luft } \\
\text { " C. }\end{array}$} & \multirow{2}{*}{$\begin{array}{l}\text { Wetter und } \\
\text { Wolken }\end{array}$} & \multirow{2}{*}{$\frac{0}{1}$} & \multicolumn{2}{|c|}{ Seegang } \\
\hline $\mathrm{T}$ & $\mathrm{h}$ & $\mathrm{T}$ & h & I. & , & & G. & & & & & & & & von & Hühe \\
\hline $\begin{array}{l}22 . \\
23 .\end{array}$ & $\begin{array}{c}23,6 \\
3,6 \\
7,6 \\
11,6 \\
1 \mathbf{5}, 6\end{array}$ & 23. & $\begin{array}{r}8 \\
\text { II. } \\
16 \\
20 \\
\text { I. N. }\end{array}$ & $\begin{array}{rr}37 & 1 \\
36 & 5 \\
& 4 \\
& 5 \\
35 & 5\end{array}$ & $\begin{array}{l}14 \\
56 \\
41 \\
22 \\
57\end{array}$ & $\begin{array}{l}126 \\
125\end{array}$ & $\begin{array}{l}25 \\
50 \\
31 \\
22 \\
22\end{array}$ & $\begin{array}{l}\text { SE: } \\
\text { Still } \\
\text { SSE } \\
2 \\
2\end{array}$ & $\begin{array}{c}756, \\
57,7 \\
57,4 \\
57,2 \\
\mathbf{5 6}\end{array}$ & $\begin{array}{l}19,3 \\
18,1 \\
17,7 \\
20,3 \\
20,3\end{array}$ & $\begin{array}{l}74 \\
76 \\
72 \\
82 \\
88\end{array}$ & $\begin{array}{l}26,8 \\
25,2 \\
26,0 \\
25,8 \\
24,8\end{array}$ & $\begin{array}{l}g \text { cus } \\
\text { be cus } \\
g \text { cu ni } \\
2=3 \\
=23\end{array}$ & $\begin{array}{c}8 \\
4 \\
10 \\
10 \\
10\end{array}$ & $\begin{array}{c}\text { SE } \\
\text { ¿ } \\
\text { SSE } \\
? \\
?\end{array}$ & $\begin{array}{l}3 \\
2 \\
3 \\
4 \\
4\end{array}$ \\
\hline & $\begin{array}{r}19,6 \\
23,6 \\
3,7 \\
7,7 \\
11, \\
15,6\end{array}$ & 24. & $\begin{array}{r}4 \\
8 \\
\text { II. } \\
16 \\
20 \\
\text { MI.N. }\end{array}$ & $\begin{array}{r}3 \\
345 \\
2 \\
335\end{array}$ & $\begin{array}{r}34 \\
5 \\
52 \\
25 \\
4 \\
54\end{array}$ & $\begin{array}{l}124 \\
125\end{array}$ & $\begin{array}{r}22 \\
25 \\
56 \\
0 \\
28 \\
58\end{array}$ & $\begin{array}{l}2 \\
: \\
:\end{array}$ & $\begin{array}{l}60, \overline{7} \\
59,2 \\
60,0 \\
58, \\
59,7 \\
59,7\end{array}$ & $\begin{array}{l}19,5 \\
19,5 \\
20,4 \\
20, \times \\
20,3 \\
18,3\end{array}$ & $\begin{array}{l}90 \\
91 \\
90 \\
88 \\
88 \\
76\end{array}$ & $\begin{array}{l}23, ; \\
23, \\
24,4 \\
25,4 \\
24,8 \\
25,4\end{array}$ & $\begin{array}{l}\text { gw eus ni } \\
\text { gw ens } \\
\text { be ww cus } \\
\text { be m s } \\
\text { be }\end{array}$ & $\begin{array}{l}\vdots \\
8 \\
5 \\
1 \\
2 \\
1\end{array}$ & $\begin{array}{l}2 \\
2 \\
3 \\
3 \\
3\end{array}$ & $\begin{array}{l}6 \\
5 \\
5 \\
5 \\
4 \\
4\end{array}$ \\
\hline 25. & $\begin{array}{r}19,3 \\
23, \\
3, \\
7,4 \\
11,4 \\
15,4\end{array}$ & 25. & $\begin{array}{r}4 \\
8 \\
\mathrm{M} . \\
16 \\
20 \\
\mathrm{MI} . \mathrm{X}\end{array}$ & $\begin{array}{r}5 \\
5 \\
341 \\
3 \\
3 \\
35\end{array}$ & $\begin{array}{l}52 \\
56 \\
11 \\
31 \\
56 \\
29\end{array}$ & $\begin{array}{l}126 \\
127 \\
128 \\
129\end{array}$ & $\begin{array}{r}38 \\
25 \\
5 \\
50 \\
22 \\
51\end{array}$ & $\begin{array}{l}\text { SE } \\
\text { E } \\
\text { ENE } \\
\text { Still } \\
\text { W } \\
,\end{array}$ & $\begin{array}{l}60,2 \\
61,0 \\
60,5 \\
60,7 \\
58,9 \\
56, ?\end{array}$ & $\begin{array}{l}18,3 \\
20, \\
23,1 \\
21,4 \\
21,0 \\
20.6\end{array}$ & $\begin{array}{l}76 \\
88 \\
87 \\
75 \\
81 \\
85\end{array}$ & $\begin{array}{l}25,4 \\
24,8 \\
27,0 \\
28,4 \\
26,6 \\
25,4\end{array}$ & 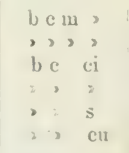 & $\begin{array}{l}2 \\
1 \\
3 \\
2 \\
2 \\
2\end{array}$ & $\begin{array}{c}\stackrel{2}{\mathrm{E}} \\
\text { ENE } \\
\stackrel{+}{W} \\
\overrightarrow{3}\end{array}$ & $\begin{array}{l}4 \\
2 \\
2 \\
1 \\
1 \\
2\end{array}$ \\
\hline 26. & $\begin{array}{r}19,3 \\
2: 3,3 \\
3,3 \\
7,3 \\
11,3 \\
15,3\end{array}$ & 26. & $\begin{array}{c}1 \\
8 \\
11 . \\
16 \\
20 \\
M . N .\end{array}$ & $\begin{array}{l}36 \\
\\
37 \\
38 \\
38 \\
39 \\
39\end{array}$ & $\begin{array}{r}7 \\
51 \\
30 \\
10 \\
53 \\
31\end{array}$ & 131 & $\begin{array}{r}8 \\
28 \\
46 \\
56 \\
10 \\
10\end{array}$ & $\begin{array}{c}3 \\
\text { ENE } \\
\text { XE } \\
\dot{y}\end{array}$ & $\begin{array}{l}5.5, \\
55, \\
56, \\
57,4 \\
58,4 \\
58,\end{array}$ & $\begin{array}{l}19,4 \\
17,9 \\
18,3 \\
17,0 \\
14,1 \\
13,5\end{array}$ & $\begin{array}{l}80 \\
76 \\
73 \\
80 \\
76 \\
74\end{array}$ & $\begin{array}{l}25,4 \\
25,1 \\
26,0 \\
23,4 \\
21,1 \\
21,0\end{array}$ & $\begin{array}{l}\text { b - } \\
\text { be } \text { s } \\
\text {, , cu } \\
\Rightarrow, \text { cus } \\
\text { g cus ni } \\
\text { g cu ni }\end{array}$ & $\begin{array}{c}0 \\
1 \\
1 \\
5 \\
10 \\
10\end{array}$ & $\begin{array}{c}3 \\
\text { ENE } \\
\text { XंE }\end{array}$ & $\begin{array}{l}2 \\
2 \\
3 \\
3 \\
4 \\
3\end{array}$ \\
\hline
\end{tabular}

1896. Juli. Franz. D. "Salazie" Kpt. M. Paul. Beobachter M. Gos (Paulin), Ltnt. Yokohama - Kobe.

\begin{tabular}{|c|c|c|c|c|c|c|c|c|c|c|c|c|c|c|c|}
\hline & \multicolumn{2}{|c|}{ Sche. \% } & \multicolumn{3}{|c|}{ Schiffsort } & \multicolumn{2}{|c|}{ Wind } & \multirow{2}{*}{$\begin{array}{r}\text { Bar. } 0^{\circ} \mathrm{C} \\
\text { เมm }\end{array}$} & \multirow{2}{*}{ Aner. } & \multirow{2}{*}{\multicolumn{2}{|c|}{$\begin{array}{l}\text { I.uft IIs. } \\
\text { "C. }\end{array}$}} & \multirow{2}{*}{$\begin{array}{l}\text { Bewölkung } \\
\text { Form }\end{array}$} & \multirow{2}{*}{$\frac{0}{1}$} & \multirow[b]{2}{*}{ Seegang } \\
\hline $\mathrm{T}$ & h & 'T & h & N. & E. & G. & von & Stk. & & & & & & & \\
\hline 20. & $\begin{array}{r}2, i \\
11,7\end{array}$ & 20. & II.X. & $\begin{array}{l}\text { Kaje } \\
3527\end{array}$ & $\begin{array}{c}\text { Yokoham: } \\
1394\end{array}$ & & $\begin{array}{l}S \\
D\end{array}$ & i & $\begin{array}{r}756.8 \\
57,4\end{array}$ & $\begin{array}{r}755 \\
56\end{array}$ & $\begin{array}{l}25 \\
24\end{array}$ & $\begin{array}{l}24 \\
24\end{array}$ & cul ni & $\frac{6}{7}$ & bewegt \\
\hline 21. & $\begin{array}{r}2,7 \\
14,7\end{array}$ & 21. & M. & & & & $\mathrm{N}$ & $\begin{array}{l}3 \\
2\end{array}$ & $\begin{array}{l}56, \\
58, \times\end{array}$ & $\begin{array}{l}60 \\
61\end{array}$ & $\begin{array}{l}24 \\
26\end{array}$ & $\begin{array}{l}24 \\
24\end{array}$ & ${ }_{n i}{ }_{n i}$ & $\frac{6}{7}$ & ruhigg \\
\hline 22. & $\begin{array}{r}2,7 \\
14,7\end{array}$ & 22. & M. & & & & $\mathrm{SW}_{\mathrm{W}}^{\mathrm{WW}}$ & $\begin{array}{l}2 \\
1\end{array}$ & $\begin{array}{l}62,3 \\
633,7\end{array}$ & $6 ; 3$ & $\begin{array}{l}29 \\
27\end{array}$ & $\begin{array}{l}26 \\
25\end{array}$ & $\stackrel{4 i c+11}{2}$ & $\begin{array}{l}4 \\
3\end{array}$ & \\
\hline 23. 1 & $\begin{array}{r}2,7 \\
14,7\end{array}$ & $2: 3$. & $\begin{array}{l}\text { M. } \\
\text { M.N. }\end{array}$ & & & & $\begin{array}{l}\text { SII } \\
\text { Stille }\end{array}$ & 2 & $\begin{array}{l}63, ; \\
62,7\end{array}$ & $\begin{array}{l}6 i 3 \\
62\end{array}$ & $\begin{array}{l}29 \\
24\end{array}$ & $\begin{array}{l}2.5,5 \\
25,5\end{array}$ & cu & $\frac{2}{3}$ & \\
\hline 24.1 & $\begin{array}{r}2,7 \\
14,7\end{array}$ & 21. & $\begin{array}{l}\text { M. } \\
\text { M.X. }\end{array}$ & & & & 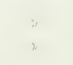 & & $\begin{array}{l}622_{, 4} \\
60,8\end{array}$ & $\begin{array}{l}61 \\
59\end{array}$ & $\begin{array}{l}28 \\
25\end{array}$ & $\begin{array}{l}28 \\
2.5\end{array}$ & ci & $\frac{2}{2}$ & \\
\hline 25. & $\begin{array}{r}2,7 \\
14,7\end{array}$ & 25.5. & M. & & & & 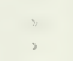 & & $\begin{array}{l}60, \overline{7} \\
59,6\end{array}$ & $\begin{array}{l}.78 \\
55\end{array}$ & $\begin{array}{l}28 \\
28\end{array}$ & $\begin{array}{l}26 \\
26\end{array}$ & , & $: 3$ & \\
\hline 26. & $\begin{array}{r}2,7 \\
6,7 \\
10,9 \\
14,9\end{array}$ & 26. & $\begin{array}{c}\text { II. } \\
16 \\
20 \\
M .1 .\end{array}$ & $\begin{array}{rr}34 & 3.4 \\
& 16 \\
33 & 50\end{array}$ & $\begin{array}{ll}1339 & 4 \\
137 & 4 \\
136 & 4\end{array}$ & & $\begin{array}{c}\text { SW } \\
\text { II } \\
x \\
x\end{array}$ & $\begin{array}{l}2 \\
5 \\
4 \\
3\end{array}$ & $\begin{array}{l}54,0 \\
55,5 \\
55 ., 5 \\
56,5\end{array}$ & $\begin{array}{l}53 \\
51,5 \\
51 \\
5.5\end{array}$ & $\begin{array}{l}27 \\
27,5 \\
26,2 \\
27\end{array}$ & $\begin{array}{l}28 \\
26 \\
26 \\
27\end{array}$ & cul ni & $\begin{array}{l}4 \\
5 \\
4 \\
5\end{array}$ & $\begin{array}{l}\text { loch } \\
\text { stark bewegt }\end{array}$ \\
\hline 27. & $\begin{array}{r}18,3 \\
23,11 \\
3,11\end{array}$ & 27. & $\begin{array}{r}1 \\
8 \\
11 .\end{array}$ & $\begin{array}{r}25 \\
58 \\
3.4 \quad 41\end{array}$ & $\begin{array}{r}1355 \\
1\end{array}$ & $\begin{array}{r}55 \\
22 \\
11\end{array}$ & $\begin{array}{l}\text { Stille } \\
\text { Kiaje: }\end{array}$ & & $\begin{array}{l}56,4 \\
58,8 \\
58,8\end{array}$ & $\begin{array}{l}55 \\
58 \\
57\end{array}$ & $\begin{array}{l}26 ; \\
2.5 \\
23\end{array}$ & $\begin{array}{l}27 \\
25 \\
21\end{array}$ & ; : & $\begin{array}{l}6 \\
1 \\
1\end{array}$ & $\begin{array}{l}\text { bewegt } \\
\text { ruhig }\end{array}$ \\
\hline
\end{tabular}


1896. Juli. Frz. Dpf. "Melbourne" Kpt. MI. Rogliano. Beob. MI. Peroneille, Ltnt. Shanghai -- Hongkong - Congio.

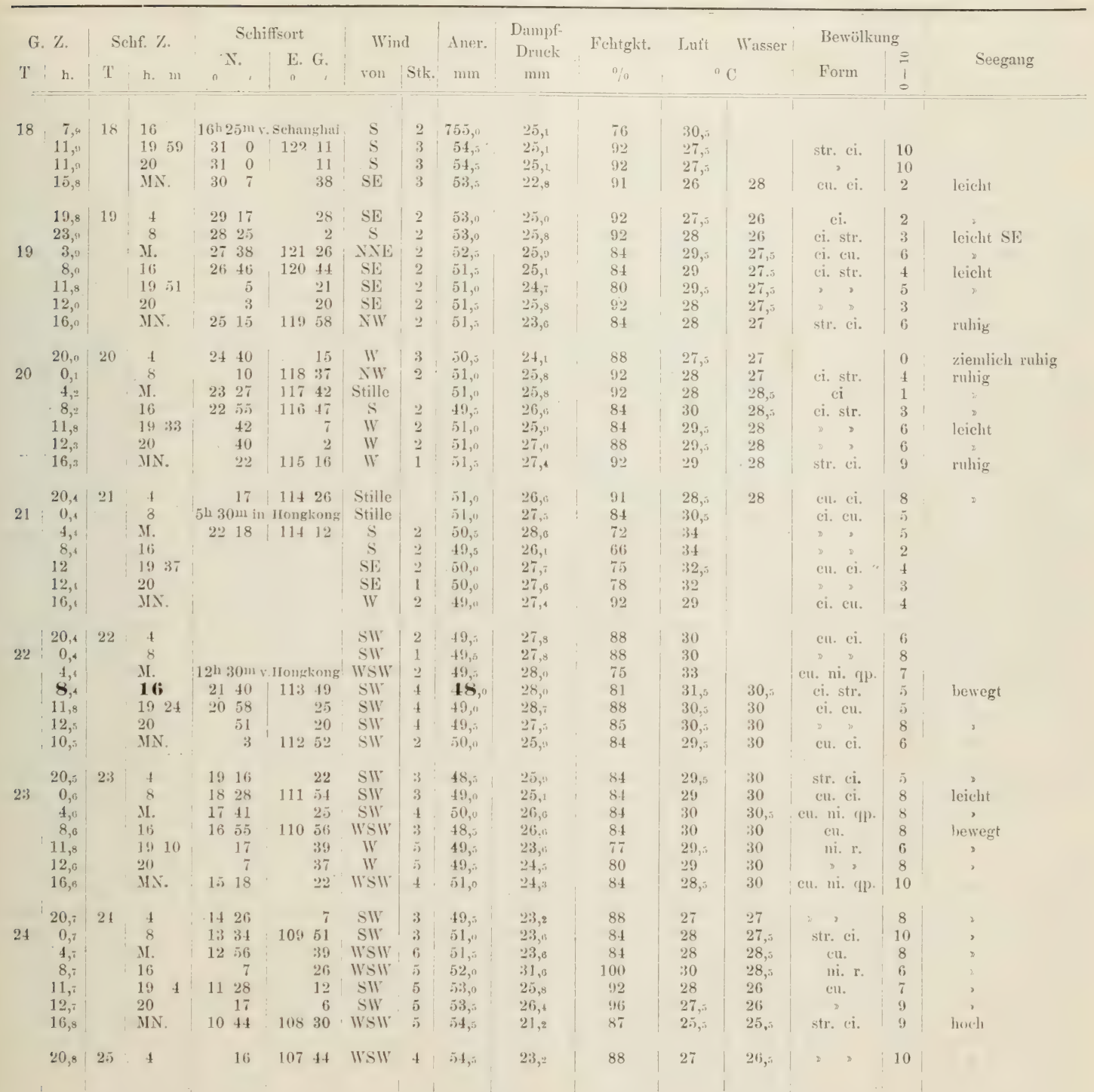

$7^{\text {hi }} 2 \mathrm{O}^{\mathrm{m}}$ ankerten vor Congio. Von $22 \mathrm{mttgs}$ - $23 \mathrm{mttgs}$. Versetzung nach SSI io Sm. 
Juli 19-25., die abgesehen von längerer Zeit und Bericht an der Ruickseite des Taifun) auch Abweichungen von bisher Bekanntem enthalten, - Bericht des franz. S. Dpf. Melbourne Juli 18-2I. Schanghai-Hongkong, Juli 22-25. Hong kong-Cong io also ChinaSee während und nach dem Taifun, - Bericht des frz. S. Dpf. Salazie Juli 20-26. Yokohama, 26-27. Yokohama-Kobe, also aus größerer Entfernung, japanische Nitteilungen ergänzend. Sämtliche gütigst mir mitgeteilte Abschriften lasse ich in Übersetzung folgen. In London, de Bilt, Kopenhagen, Kristiania befinden sich leider keine Ergänzungen des bisher Bekannten. Die entsprechenden Angaben aus Obsrvtns, und Res., Hongkong (Hrrn. Dir. Doberck und firgg) schliefie ich ebenfalls an.

Tafel 3 enthält nur 3 von mir entworfene Bahnen: I 862 VII 26, 27. Nacao. Whampoa. Canton. - I 873 VII 9-I3. D. Bk. Laura, Hmb., Kpt. G. H. C. Horn;

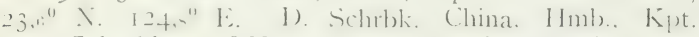
J. P. Schmidt $27,6^{\circ}$ N. $122^{0}$ E. S. M. S. Nymphe, Kpt. z. See v. Blanc; $28,7^{\circ}$ N. I $23,2^{\circ}$ E. S. I. M. S. Governolo, Kmmdt. Enrico Accini, $31,4^{\circ}$ \. $124,4^{\circ}$ E. D. Pink Gustav und Marie, Kiel, Kpt. P. Doose, Yangtse Fsch.

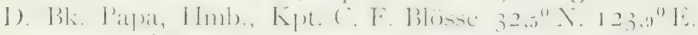
Nagasaki. (Diese Bahn ist auch vorhanden als No. 38 im Juli Kärtchen des Segelhandbuchs für den Stillen Ocean). I874 VII 17-I8. I. Brt. M. S. Kestrel, Kmdt. Charles B. Theobald; Kilung. D. Schrbk. China, Hmb., Kpt. Schmidt; 26,8" N. I2 I, $6^{\prime \prime}$ E. D. Bk. Papa, Kpt. Blösse; $26,9^{0}$ N. I $121, i^{0}$ E. Nagasaki.

T'ufel 4. A ugust. Hier fällt auf, die in dem Nebenkärtchen eingetragene Bahn I882 VIII I-IO., sic ist entworfen von Hr. Dir. IFare Jecherrens und zeigt im Großen, einen ähnlichen Weg, wie ihn wohl jede derartige Naturerscheinung im Kleinen nimmt, (außer mehr oder weniger kurzen, auch tiefen Biegungen und Abweichungen) andere derartige zeichnete ich nicht nach, in erwähnten Segelhandbuichern des Instituts ,.Deutsche Sccuarte" sind ebenfalls ein l'aar eingetragen; aus schon genanntem Grunde kommt nicht in Betracht, daß nach denselben Nitteilungen Bahnen sich auch auf andre Weise darstellen lassen.

I859 VIII I6. 1). Bk. General Jacobi, Brm., Kpt. Weylandt; Macao; Brt. S. Acrolite, Kpt. R. E. Alleyne, Whampoa. - VIII 28, 29. Ndld. $3 \mathrm{~m}$. Schr. Maria Elisabeth, Kpt. IV. v. d. Valk; Amoy; Brt. S. Aërolite, Kpt. R. L. Alleyne; Whampoa; D. Bk. General Jacobi, Brm. Kpt. Weylandt. - 1860 VIII 7-8. Brt. S. Flying Cloud (NEl, von Kilung), Brt. S. Gazehound, Sl. von Amoy. - 1868 VIII I-6. Ndld. Bk. Admiraal de Ruyter, Kpt. W'. Witting $8,8^{\circ}$ N. 122,3" E.; I. Brt. M. S. Rifleman, Kmdt. John W. Reed; Balabac Str.; D. Bk. Batavia, Hmb., Kpt. J. B. F. Grell, 9,2 ${ }^{\circ}$ N. IO2,6" E. D. BK. Condor, Hmbg., Kpt. P'. Hansen; I $4,3^{\prime \prime} \mathrm{N}$. I $3,6^{0}$ L. D. I3k. Norma, Hmb., Kpt. C. A. Pöhl; $12,2^{\prime \prime}$ N. $112,4^{\circ}$ L. Ndld. S. Graham, Kpt. F. J. Staverinus, 13,2" N. $114^{0}$ E. Brt. Bk. New York, Kpt. F. Monnich; $21,2^{0}$ N. $113,, 0$ l:. Ndld. S. IVyk aan Zee, Kpt. G. Mamoning; $21,4^{\circ}$ N. $114^{\circ}$ L. D. Bk. Linst \& Naria, Brm., Kipt. J. Gennerich i $8^{\circ}$ N. $125^{\circ}$ E. D. Bk. Rob. Rickmers, 13rm; 12,20 N. 111" Ii. - I871 VIII 17-2I.
Brt. S. Eliza Shaw, Kpt. G. Gaye; $27,4^{\circ} \mathrm{N} .125,6^{\circ} \mathrm{E}$. D. Bk. Esmeralda, Hmb., Kpt. P. Koppelmann; $29,6^{\circ} \mathrm{N}$. $124^{\circ}$ E. D. Schrbk. Formosa, Hmb., Kpt. Paulsen; $33,8^{\circ}$ N. 122,7 E. D. Bk. Johann Carl, Brm., Kpt. L. Haesloop; $35^{\circ}$ N. I $23.2^{\circ}$ E. D. Schr. Julie; Kpt. J. Christensen; G. v. Pechili. I87 I VIII 31. - IX 2. Ndld. S. Aërolit, Kpt. M. J. v. d. Eb; Bashee Kan. Hongkong und Macao. Schwed. Bk. Siam; $2{\mathrm{I}, 5^{\circ}}^{\circ}$ X. I I $5,2^{\circ} \mathrm{E}$. Dpf. Kinshan, Kpt. Cary, Hgkg.-Canton. D. Bk. Mikado, Hmb., Kpt. Lempfert; 20,7 $7^{0}$. I I $5,1^{\circ} \mathrm{E}$. Brt. Bk. Onward, Kpt. Whyte; $21,6^{0}$ N. I I 5.2 ${ }^{\circ}$ E. D. Schrbk. Fiormosa, Hmb., Kpt. J. Paulsen; $22,9^{\circ}$ N. II $7,2^{\circ} \mathrm{E}$.

'Tafel 5. September a. 1857 IX 30. -X I. I. Brt. ML S. Actaeon, Kmdt. Wm. Thornton $22,1^{\circ} \mathrm{N}$. I $3,6^{\circ}$ E. I. Brt. MI. S. Highflyer, Kmdt. C. F. A Shadwell, C. B. und I. Brt. II. S. Dore, Kmdt. Chs. J. Bullock, Canton Fluß. - I870 IX 28. - X 3. Brt. Bk. Violette; $24,3^{\circ}$ N. I $29,6^{\circ}$ E. D. Bk. Ino; Hmbg. Kpt. J. H. Bannau; Nagasali; D. Bkschr. China; Hmb., Kpt. J. P. Sclimidt; Kobć. I. Brt. MI. S. Sylvia, Ltnt. H. C. St. John; $34,4^{\circ}$ N. $133,9^{\circ}$ E. In Yohohama: S. Östr. Ung. MI. S. Friedrich; S. MI. S. Hertha, Kpt. z. S. Köhler und Medusa, Korv. Kpt. Struben. D. Bk. Palma. Hmb., Kpt. Jäger. D. Bg. Falke; Hmb., Kpt. Göttsche. - I87I IX $30-X$ I. D. Bk. Gesine Brons; Emd. Kpt. B. E. Groenewold; $21,{ }^{0}$ N. $120,8^{\circ}$ E. Brt. S. Beemah; I $5,1^{\circ}$ N. II 6,4 E. D. Bk. Palma; Hmb., Kpt. Jäger; $16,5^{\circ} \mathrm{N}$. I $16,1^{\circ}$ E. D. Bk. Mikado; Hmb., Kpt. Lempfert; $21,4^{\circ}$ N. I I $5,9^{\circ}$ E. D. Bk. Juno; $15^{\prime \prime} \mathrm{N}$. $115^{\circ}$ E. Brt. Dpf. Hindostan; $13^{0} \mathrm{~N}$. $112^{1} / 2^{0}$ E. S. Östr. Ung. M. S. Fasana; i $2,8^{\circ}$ N. I I $1,9{ }^{\circ}$ E. D. Schrbk. Formosa, Hmb., Kpt. J. Paulsen; 2 I, ${ }^{\circ}$ X. $115,2^{\circ} \mathrm{E}$. Brt. Bk. Kelso, Kpt. M. Vowel; S,4" N. Iog.s" E. I87I IX 14, 15. D. S. Etha Rickmers, Brm., Kpt. H. Friedrichs; $22,6^{\circ}$ N. I21,9" E. Brt. Schr. Hongkong; Kpt. W. Symington; $25,4^{\circ}$ N. I I $9,4^{\circ}$ E. Brt. S. Dpf. Acantha, Kpt. J. Grange; $27,2^{\circ}$ ․ $121,0^{\circ}$ E. - 1872 IX I2.-I4. D. Bk. Fidelio; Hmb.. Kpt. H. Schuldt; $24,4^{\prime \prime}$ N. I 19,9" E. D. 13k. Ino; Hmb., Kipt. J. H. Bannau; $17,8^{\prime \prime}$ X. I $19^{\circ}$ E. D. Bk. Mikado, Hmb., Kpt. E. Lempfert; 13,200 N. $117,5^{\prime \prime}$ E. D. Bk. Paradies: Hmb., Kpt. E. Popp; 22,3" I. I I 3,6 " E.; Hongliong. Gun Powder Depot. - IS72 IX $29-\mathrm{N} 2$ 2. D. Bg. Hermann Friedrich; Rstk, Kipt. F. Nicjahr; I6.2 "N. I $18,2^{\circ} \mathrm{E}$. Brt. Bk. Velocity; Kpt. G. E. Adams; $15,9 \mathrm{X}$. I 8,3 " E. D. Bk. Ellen Rickmers; Brm., Kipt. C. F. Rehm; $22,1^{\circ}$ N. I I $6,5^{\circ}$ E. D. Bk. Tek Li; Hmb., Kpt. Petersen; $15^{\prime \prime}$ N. II $5,8^{\circ}$ E. D. Bk. Batavia; Hmb., Kpt. G. H. Hertzer; $18,4^{\circ}$ N. I $6, s^{\circ}$ E. D. 13k. Felix Mendelssohn; Brm., Kipt. J. Barber; I $7 . \mathrm{s}^{\prime \prime} \mathrm{N}$. II $3,1^{\circ} \mathrm{E}$. - IS7+ IX 22.-23. Am. S. Highlander; Kipt. Willcomb; 20,7 " N. I 16.2 "L. D. Schrbk. China; Hmb., Kipt. J. P. Schmidt; Swatow. Brt. 13k. Gesyma; Kpt. J. Romney; 22,3" N. I $6,7^{\circ}$ E. Span. Dpf. Formosa; 20,8" N. I I $5,3 \mathrm{E}$. In Hongkong: I. B. M. S. P'rincess Charlotte; Zentrale Polizei-llache; Hafemmeisters Amt; G. Falconer; Brt. 13k. Albueru; 1). Bk. A. E. Vidal, HImb., Kipt. Angelbeck. S. Port. MI. S. Tagus; Macao. Canton. D. Bk. Papa; IImb., Kpt. Blösse; 10,s" N. III, i ${ }^{0}$ E.

T'itel 6. September b. Alle hier eingetragenen Bahmen sind entnommen den Veröfientlichungen des 
Regierungs Observatorium in Hongkong (Hrrn. Dir. W. Doberck und I. Assistent F. G. Figg) über die September Taifune der Jahre $1890-96$.

Tafel 7. 1859 X I4-20. Am. S. Tsar; Kpt. J. M. Jenkins; $12,9^{\circ} \mathrm{N}$. I $21,8^{\circ} \mathrm{E}$. Ndld. Bk. Juno, Kpt. W. J. Chevalier; $19^{0} \mathrm{~N}$. I I $6^{0} \mathrm{E}$. Ndld. Bk. Hendrina, Kpt. C. M. Pompe; $14,8^{\circ}$ N. I I $6^{\circ}$ E. Frz. S. Taffarette Kpt. Dereix; I $7,3^{\circ}$ N. I I $4,3^{\circ}$ E. Am. S. Derby, Kpt. Samuel Hutchinson; II $5^{\circ}$ N. II $3{ }^{\circ}$ E. D. Bk. General Jacobi, Brm., Kpt. R. H. Weylandt $21,8^{\circ}$ N. I I $4,6^{\circ}$ E. Dieser Taifun traf auch das D. S. Der Ost, Stettin, Kpt. Crépin; er veranlaßte, daß das Schiff am Abend X 19. auf Scarborough Shoal trieb und zerschellte. Mit anerkennenswertem Iut, Umsicht und Fleiß, besserte die Besatzung während der dunklen Nacht, und während das Schiff, immer schräger fallend in Stücke brach, von der (wie leicht begreiflich, außerordentlich hohend, wütend zu nennenden) Brandung bald im Ganzen, bald nur in der Nitte oder an einem bezw. beiden Enden höher auf das Riff geschoben wurde - das großse Boot aus, das von den überbrechenden Seeen und den argen Stößen losgerissen, gegen das Leeschanzkleid geworfen war, dem Wrackgut die Steuerbordseite am Hinterende bis unter den Wasserspiegel eingeschlagen hatte. Nan fischte ein Paar Bretter, nagelte sie dort an, die von cler yroßen Luke geschnittenen Persennings daruber, bei Tagesanbruch war man fertig. Mit grolier Anstrengung konnte das Boot auf die Leereeling gehoben aber nicht gestuitzt werden, daher schlug es sofort um, alles hinein gelegte Proviant und dgl. fiel hinaus, doch hielt die Fangleine, so dal3 es nicht wegtrieb. Lin geborgenes Unterleesegel machte man dienlich als Bootssegel, ein Stïck Spiere als Bootsmast, Riemen waren an die Duchten gebunden; die Gig mit Zubehör konnte man ebenfalls bergen, ihr Sonnensegel in zwei Teile geschnitten wurde Bootssegel, ihr Bootshaken Fockmast, zwei ineinander geschobene Bambusstöcke Großmast. Aus dem unversehrt gebliebenen Proviantraum holte man am nächsten Tage Lebensmittel, aus am Roof nicht weggeschlagenen Fifiern IVasser; am zweiten Morgen gliickte es mit vieler Muihe das Großboot über die Nordostseite des Korallenriffs durch die dort schwache Brandung zu bringen; nach 4 Tagen Segeln und Rudern erreichte man die gegenüberliegende Küste Luzons. Der Kapitän war schwer verletzt worden, Obersteuermann und Zimmermann weniger. Am Nord-Ende der Untiefe glaubte man das Wrack einer Dschunk zu sehen; es erwies sich als der Boden des Vorderteils vom eignen Schiff, das vom Zwischendeck bis zur halben Spur des Fockmastes abgebrochen, unter dem Wrack herausgerissen, von den Wellen dorthin getragen war; man kann daraus sich vorstellen, wie hoch und gewaltig Seegang nebst Brandung gewesen, wie das Wrack fortwährend gestoßjen; - wie schwierig, dabei in Regen, überbrechenden Seen u. s. w. stehen zu bleiben und am Boot zu arbeiten. Die Mannschaft tat es unverdrossen. - 1870 X 9-14. Frz. Bk. Eve, Kpt. Mercerin; $16,7^{0} \mathrm{~N}$. $115,8^{\circ} \mathrm{E}$. Brt. Bk. Lizzie Iredale, Kpt. Wilding; $14^{0} \mathrm{~N}$. $111^{\circ} \mathrm{E} .-1870 \times 10-13$. D. Bk. Alexander II., Hamb., Kpt. F. C. Decker; $34^{1} / 2^{0}$ N. $130^{0}$ E. S. Östr. Ung. II. S. Friedrich; $25,7^{\circ} \mathrm{N} .128^{\circ}, 0^{\circ} \mathrm{E}$. Brt. 13k. Belted Will; $30^{1 / 20}$ N. $133^{1 / 20}$ li. 1). I3k. Ino, IImb.,
Kpt. J. H. Bannau; Nagasaki. I. B. M. S. Sylvia, Ltnt.

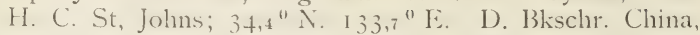
Hmb., Kpt. J. P. Schmidt; Hiogo. Brt. S. Dpf. Sunda, Kpt. G. F. Cates; $34^{0}$ N. I $38^{\circ}$ E. Brt. Bk. Lorton; $20 \mathrm{Sm}$. S. von Omaï Saki. In Yokokama: S. M. S. Hertha, Kpt. z. See Köhler; S. M. S. Medusa, Korv. Kpt. Struben; D. Bg. Falke, Hmb., Kpt. R. Göttsche. Russ. Dpf. Courier, Beob. Hr. E. Knipping, $38,1^{\circ}$ N. $142,2^{0}$ E. - $1871 \times 5-8$. D. Bk. Gesine Brons, Emden, Kpt. B. E. Groenewold; $21,7^{\circ}$ N. I $21,4^{\circ}$ E. D. Bk. Jan Peter, Alt., Kpt. Mohlsen; $2 \mathrm{I}^{1 / 2^{0}}$ N. $12 \mathrm{O}^{\prime \prime} \mathrm{E}$. Brt. S. Star of the North, Kpt. Chs. Rowle; $24^{\circ} \mathrm{N}$. I 19,4 ${ }^{\circ}$ E. S. Östr. Ung. M. S. Fasana; $18,7^{\circ}$ N. I $16,5^{\circ}$ E. D. Bk. Mikado, Hmb., Kpt. Lempfert; 20,6 ${ }^{\circ}$ N. I I $6,5{ }^{\circ}$ E. D. Bk. Johann Karl, Brm., Kpt. L. Haesloop; 20,1 ${ }^{\circ}$ N. I I $5,4^{\circ}$ E. In Hongkong: D. Bk. Ino, Hmb., Kpt. J. H. Bannau und Falconer. D. Schrbk. Formosa, Hmb, $2 \mathrm{I}, 7^{\circ} \mathrm{N}$. I I $4^{0} \mathrm{E}$. -- 1873 X 27 - XI I. D. S. C. R. Bishop, Brm., Kpt. J. (iennerich; $I G, 1 "$ N. I $3 I_{,}, "$ E. Schrbl: General Martinez, Tacloban. Schrbg. Colon. Babatnon. Schrbgs, Paz, Legaspi, Navarro; Viri In. Schrbgs. Matilde Encarnacion, Librada, Caridad, Dalumpiri. Bg. Rodrigo; Cartaignan. Schrbg. Maria Dolores; Arroroy. Schrbg. Vida; Bocana de Sorsogan. Schrbg. Comercio; $12,9^{\circ} \mathrm{N}$. $122,7^{\circ}$ L. Bondo. Romblon In. Calapan. Batangas. Schr. Sennor del Hucrto; Tilig. S. Span. M. S. Cer-

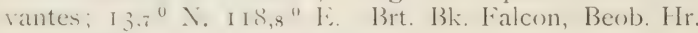
John Catnack; $15^{\circ} \mathrm{N}$. I $10^{1 / 4^{0}} \mathrm{E}$.

Tafel 8. November, Dezember. I87I XII 4-6. Ndld. Bk. Johanna Antonia, Kpt. E. Wessels;

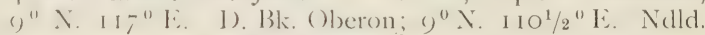
13k. Constance; $10,1^{0}$ N. $109,2^{6} \mathrm{E}$.

Manche, wenn nicht viele Beobachter, die eingehend berichtet haben, ohne ihre Mitteilungen besonders berücksichtigt zu finden, ersehen wohl aus hier Gegebenem, daß diese doch zu einer oder anderer Zeit dankbar benutzt werden; hoffentlich kann ich später noch mehr zur Verfügung stellen.

\section{Windrichtung in Wirbelstürmen. Richtungswinkel.}

Tafel a, A-C.

Die geringe Zunahme unserer Kenntnis über die Luftbewegung oder Windrichtung in Wirbelstirmen ist bereits erwähnt; es ist nicht möglich, letztere im Ganzen anders zu betrachten, wie IVirbel eines Gases, unter, sich beständig änderndem Einfluß der Umgebung. Der kleinste dieser Wirbel ist viel zu groß, als daß er sich im Versuchsraume im Kleinen herstellen -ließe; ebenso wenig kann man dies mit den Verhältnissen unter denen sie entstehen, sich verschieben und auflösen. Ein Vorwärtskommen ist es dagegen, daß man bei Zusammenstellungen, bei der Wetter-Voraussage, kurz gesagt bei allgemeiner Betrachtung, die Lage des sogen. Zentrum, weniger einflußreich ansieht, als die Verteilung des Luftdrucks, gleichgiltig ob man dies bezeichnet: Lage der Isobaren, - oder: Richtung des Gradienten; das sind 
gedachte Linien und Maaße, die, wenn in Zeichnungen sowie Zahlen dargestellt, die Verteilung des Luftdrucks übersichtlich, auch nach Zahlenwert mefbar machen.

Dic Zusammenstellung, die der Wetter-Voraussage zu Grunde liegt, bezweckt fuir diesen Fall WVarnung vor drohender Gefahr, damit jeder, die ihm zur Verfuigung stchenden Nlittel ergreifen kann, um sich zu schiitzen gegen Schaden durch Naturgewalt. Der außcrhalb des Bereichs der Warnung befindliche Schiffsführer hat im cignen Barometer, trotz dessen unberechenbaren Wertes, streng genommen, geringen Anhalt betr. Verteilung des Luftdrucks, weil ihm fehlt die Verbindung mit anderen Orten. Selbst auf ein großes, mit starker Dampfkraft ausgerüstetes Schiff bleibt der Wind nicht olne Einfluß, $\mathrm{cr}$ ist es, der den noch gefährlicheren Seegang hervorruft, - da aber nie vorauszusehen ist, der Umfang der Gefahr, die geraten in das sogen. Zentrum mit sich bringt, - selbst Annäherung daran, durch rasche WindÄnderung, von ihr veranlaßte Änderung der Lage des Schiffes zum Seegang, äußerst gefährlich werden kann: so wird der Schiffsfuhrer stets wünschen, der Zusammensteller möge ihm Anhalt geben, - ähnlich wie aus der Abnahme im Barometerstande er einen Anhalt sucht für die Annäherung an das sogen. Zentrum, - auch aus der Windrichtung die Richtung zu bestimmen, in welcher das Zentrum liegt, - bezw. er möge Beweise liefern, daß bisher Bekanntes noch giltig ist oder ob anderungen in ihm sicher begrindet sind.

Im Vorhergehenden ist gezeigt worden. wie für die einzelnen Gegenden gesucht ist und gesucht wird, diesem IVunsch zu entsprechen, wobei sich herausgestellt hat, daß fur sie genauerer Anlalt nicht unwahrscheinlich, im großen Ganzen der ursprünglich in Worten gegebene noch heute giltig ist.

Meine Ansicht ging und geht dahin, daß außer den aus Wetterkarten abzuleitenden Schluissen, fur Schiffsführung es nötig ist, die Fälle hervorzuheben, - in Wort, Zahl und Zeichnung zu zeigen, in denen Orte besonders Schiffe in das sogen. Zentrum gerieten und wie gleichzeitig war: Richtung nebst Stärke des IVindes auch wie grof der Winkel der Windrichtung mit der Verbindungslinie des Beobachters außerhalb und innerhalb des \%entrum. - Dieses zieht über Orte und Schiffe häufiger als Viele glauben, doch ist es nicht leicht, cine größere Anzahl Beobachter zu finden, deren Angaben gleichzeitig sind; immerhin konnte ich solche fälle sammeln, hoffe noch mehr zu erhalten, doch biete vorläufig eine Wiederholung von 2 Fällen aus dem südlichen Indischen Ocean, dann, wie schon erwähnt, dic aus dem "Itis « - und De Witte -Taifun mit ausnahmsweise reichlichen Mitteilungen, ferner aus dem Chàteaubriand Taifun, da in ihm der Barometerstand ebenfalls ausnahmsweise niedrig war und das Zentrum an mehreren Stellen nachweisbar ist (5, an zweien gleichzeitig).

'I'afel a, unten: Richtungswinkel im Indischen Ocean. Die Ursache der Wiederholung aus Hansa XXI. S. 77 ist die häufige Unvollstaindigkeit von und Unbekanntschaft mit älteren Jahrgängen von Zcitschriften bei seltener Mitteilung solcher Fälle aus jenem Meerestcile. Der Maasstab ist hier ein wenig vergrölsert, auch sind Entfernungskreise eingefugt, wie es Hr. L. Knipping tat bei Arbeiten über Taifune Japans, - ferner ordne ich hier die Angaben nach linker (gefährlicher) und rechter (günstiger) Hälfte von der Bahn gerechnet, nebst Vierteln, sowie Entfernung vom Zentrum.

Entsprechend der Annahme, die wahrscheinlichste Lage der Bahn sei die Verbindungslinie zweier Orte, über dic nacheinander das Zentruni zog, so lag sie hier von Gabrielle Alice nach Bylgia. Es ist dies einer der selten nachweisbaren Fälle, in denen auf der südlichen lìrdhälfte die Bahnrichtung war nach nordlich von E. der Ort der Gabrielle Alice ist allerdings nicht so gut bestimmbar wie der von Bylgia.

1859 Mai 6. $2 \mathrm{I}, 3^{\text {h }}$ G. Z. Frz. Gabrielle Alice $27,7^{\circ} \mathrm{S} .55,9^{\circ} \mathrm{E}$. Mai 7. $20,1^{\text {h }} \geqslant \geqslant$ D. By-lgia $26,7^{\circ} \geqslant 58,4^{\circ}$ Beide Schiffe im Zentrum; Bahnrichtung nach N. $66^{\circ} \mathrm{E}$. $146 \mathrm{Sm}$. in 22,8 Stunden $=6,4 \mathrm{Sm}$. i. d. Std.

Linke Hälfte: worderes Viertil

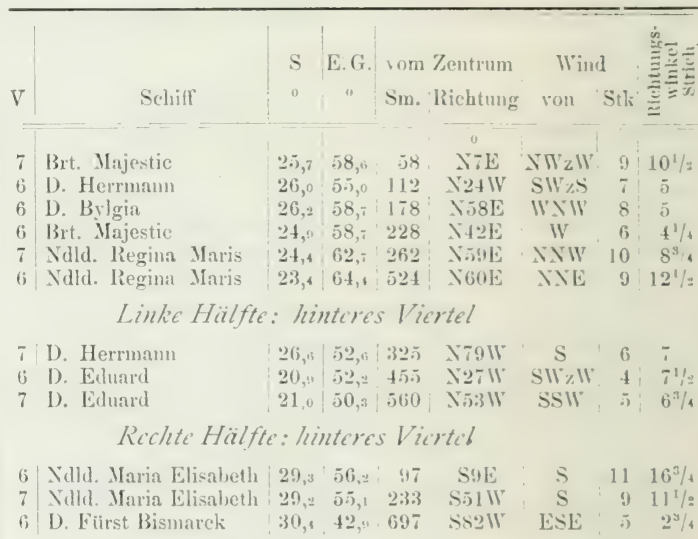

Betrachtet man wegen Schwankungen in der Richtung und wegen der Möglichkeit plötzlicher Zunahme des Vorruickens vom Zentrum als gefahrliches Viertel das zwischen 4 Strich je rechts und links von der bahn, so waren in ihm V 6 Regina Maris, Majestic, Bylgia; 17 nur Regina Maris; zu erinnern ist, daß die gefïhrlichste Lage auch abhängt von Eintfernung, Kurs und Geschwindigkeit des Schiffes.

Bei letrachtung des Richtungswinkels in Bezug auf Richtung und Entfernung von Zentrum ist hier z.u beriicksichtigen, dak es sich um einen selten erscheinenden Fall handelt, auch nur wenig Berichte vorliegen; innerhalb $100 \mathrm{Sm}$. befand sich kein Beobachter im gefalhrlichsten Viertel, nur einer im linken vorderen, dort war der Richtungswinkel 10 $\frac{1}{2}$ Strich d. h. mäligiges Eimbiegen der Windrichtung nach dem Zentrum hin; bei einem anderen Schiff in diesem . Dsstand wehte der W'ind ugf. recht auf das Zentrum zu $16^{3 /} /$ Str., das Eimbiegen war also sehr stark; bei $100-200 \mathrm{Sm}$. sind beide Schiffe in der linken (gefährlichen) Hälfte, das nähere im hinteren Viertel, das entferntere im vorderen, - bei beiden ist der Richtungswinkel abbiegend; bei 200-300 Sm., sind das näichste und das entfernteste im vorderen linken 
(gefährlichsten) Viertel, das erstere hat den Wind stark abbiegend $\left(4^{1 / 4}\right)$, das letztere wenig einbiegend $\left(8^{3} / 4\right)$, das dritte im hinteren rechten Viertel stark einbiegend (I I $1 / 2$ ); bei mehr als $300 \mathrm{Sm}$. Abstand zeigt sich hier nur einmal erhebliche Einbiegung (1 $\left.2^{1 / 2}\right)$, sonst stetig zunehmendes Abbiegen.

Die Windstärke betrug I I nur bei einem Schiff in $97 \mathrm{Sm}$. Entfernung vom Zentrum. Unwillkïrlich frägt man, ob hier nicht mehrere - und an der Grenze der Passate sowie Monsune, häufig viele - sogen. Zentren neben einander zogen oder lagen? Die Möglichkeit clavon scheint sehr nahe liegend, es ist nur schwer, Beweise zu erhalten; daran schließt sich die Frage, ob nicht Bylgia in einem anderen Zentrum gewesen sei als Gabrielle Alice? möglich ist dies auch, der Zusammensteller kann aber nur nach den erreichbaren Berichten urteilen.

\section{'T'afel A-C.}

Nach Erscheinen meiner friheren Arbeit $\gg$ Dic Wirbelstürme oder Cyklonen mit Orkangewalt « äußerten einige Herren, es wäre wünschenswert, wenn beregtes Vorkommen auf oder bei Land stattgefunden, dieses und die Bahn angedeutet zu sehen; gegenwärtig erfülle ich den ersten Teil des Wunsches, - teilweise um zu zeigen, sowohl wie trotz des verhältnismäßig großen Maaßstabes es schwierig ist, ein Paar lälle im selben Rahmen darzustellen, - wie viel undeutlicher das Bild würde, wenn die verschiedenen Orte des Zentrum noch verbunden wären durch einen starken, die Bahn bezcichnenden Strich, - wie kostspielig es käme, für jeden Fall cin besondres Kärtchen zu bringen - wie wenig kenntlich das Land jedoch bleibt, wenn der Maßstab verkleinert wird.

Bei diesen drei Darstellungen (von denen für die beiden letzten verhältnismäßig viel Berichte vorliegen) fällt sogleich auf, dic ungleichmälßige Vertcilung der 13erichterstatter; einerseits ist sie Folge der Lage jener Küste und Inseln, welche gering bleiben läßst den Verkehr nach SE. (von Formosa aus auch nach E.), andererseits jedoch ist zu gering, das \%usammen-Arbeiten der verschiedenen meteorologischen Anstalten.

Schon I88 I sagte ich (a. o. O. S. 124)

der 'Zusammensteller von Berichten, kann, trotz besten IVillens, nur Unvollständiges und Fehlerhaftes geben, wenn die Mitteilungen der Beobachter nur in geringer Anzahl vorliegen, auch in ihnen selbst Lücken vorhanden sind. - - Ausdrücklich sei wiederholt, daß dadurch dem Werte der Berichte selbst kein Abbruch getan ist, sie werden von jedem gewissenhaften Sammler und Zusammensteller stets mit dem größten Dank entgegengenommen. - - - Alles auf diesem Gebiet Erreichbare wird nur dann erreicht werden, wenn sämtliche meteorologische Anstalten sich nicht allein nach gewissen Richtungen hin zu gemeinsamer Arbeit vereinen und sich gegenseitig das vorhandene Material ergänzen, sondern auch Privatforscher olne Weiterungen und ohne persönliche Animosität das vorhandene Material benutzen und verwerten können. Die Schwierigkeiten, welche sich solchem gemeinsamen Arbeiten in den IVeg stellen, sind nicht uniberwindbar, - _ _ . "

Der I874 gewählte Weg war allerdings ungeeignet, warum sollte es aber nicht möglich sein, zunächst in Schanghai eine Wetterwarte zu errichten, die von allen dort an Handel und Seefahrt beteiligten Staaten, im Verhältnis ihrer Beteiligung unterhalten, zu deren Stellen dementsprechend auch die Beamten berufen, deren Leitung abwechselnd einem Angehörigen der betreffenden Nationen anvertraut wird. - Dann hätten die verschiedenen Anstalten ihr Gebiet abzugrenzen und aus jedem anderen stammende Berichte, den betreffenden Ämtern zu übermitteln. Unumgänglich notwendig ist es unter allen Umständen, nicht auf das freiwillig Zugebrachte zu warten, - nicht irgend einen moralischen Zwang anzuwenden, - nicht irgend wie persönlichen Vorteil in Aussicht zu stellen, noch den Glauben möglich zu machen, durch Ausfüllen von Beobachtungsh:eften sei es erreichbar, - sondern durch Berufstreue, guten WVillen und die Höfligkeit die Mann dem Manne schuldet, durch Freigebigkeit in Bezug auf eigne Veröffentlichungen: Vertrauen zu gewinnen, - die Bereitwilligkeit zu erzeugen, in einer guten Sache mitzuwirken, - auch in Bezug auf Journal-Führung, Beobachten, Beschaffen von Instrumenten melr zu leisten, als man ohne solche Anstalten leisten wïrde.

Tafel A auf 'I'afel b. Richtungswinkel im Chateaubriand Taifun. Man könnte auch sagen: Châte a ubriand-Faugh Ballaugh Taifun, da letzteres Schiff gleichzeitig mit ersterem im Zentrum desselben Wirbelsturmes war (ebenfalls seltenes Zusammentreffen); der Kürze halber und weil der ausnahmsweise niedrige Barometerstand auf Chàteaubriand Ursache ist, diesen Fall hier abgesondert zu crwähnen, beschränke jch mich auf jenen Namen. Journal-Ausziige von I. Brt. M. S. Magpie, Brt. Dpf. Gaëlic und Oceanic, die im Metcorological Office, London ich genommen, hatte ich verloren, durch Guite der Hrrn. Dir. Dr. Shaaw, MarineSuperintendent Kpt. Campbell Hepreorth, Assstn. Gebr. Harding und beteiligte Beamte, sind mir die Abschriften sehr rasch wieder gefertigt.

Nach den von Hr. Dir. Decherens mitgeteilten Berichten, den weiterhin folgenden eben genannten und dem (von mir genommenen nicht verlorenen) des Bellerophon, herrschte im Formosa Kanal sowie Ost$\mathrm{Ch}$ in a See starker und bis zu heftigem Sturm zunehmender NE. Wind (fraglich, ob schon als Monsun anzusehen), im SE, - S. von S. Formosa, auch bei Swatau und Sl, davon NW. Wind, in Hongkong veränderlicher, flauer. Dies war cyklonisch, den Zug des Taifun in den Formosa $\mathrm{K}$ anal begünstigend, - dort ihn hindernd, nordwärts sich zu richten, - wohl auch beitragend $z u$ seiner Aufösung bei Annäherung an und Gelangen auf das Festland.

Von Châteaubriand, Faugh Ballaugh, Kvik, E mma, Sindh, waren nur die Schiffsorte mitgeteilt, an denen jene Schiffe im Zentrum sich befanden; die betr. Zeiten für Ch., F. B. und $\mathrm{K}$. liegen so nahe aneinander, daß man annehmen kann, sie alle, auch Emma aber nicht Sindh, hätten während dieses Zcitraumes, 
ihren Ort zu wenig geändert, um dies in Betracht zu ziehen; später, als Takao und Sindh im Zentrum waren, ist diese Annahme nicht mehr zuläßig, darum sind von den beiden Orten aus keine Richtungslinien nach den 4 Segelschiffen hin gezogen. Weil die Ortsänderung von Sindh überhaupt nicht schätzbar, so ist dies Dampfschiff nur zu seiner eignen Zentrums-Zeit verbunden mit den anderen Beobachtungsorten.

Wenn kein Bericht von Châutea ubriand vorläge, würde man, als im Zentrum Faugh Ballaugh allein in Betracht ziehen, deshalb geschah es hier in soweit, daß in 'Tafel $\boldsymbol{A}$ auch von ihm aus Richtungslinien gezogen und in nachstehender Tabelle Entfernung erreichbarer Beobachter, ihre Richtung von F. B., IVind und Richtungswinkel mit eingetragen sind: $I a$ ). Nach dem zur Kenntnis Gekommenen ist nicht $\mathrm{zu}$ entscheiden, ob das sogen. Zentrum sich ausdehnte bis F. B, oder ob dies Schiff in einem Neben-Zentrum sich befand. Lehrreich ist der Fall, weil er zeigt wie leicht ein sehr zweifelhafter als sicherer, wenn auch sehr seltener betrachtet werden kann. Die Bahnrichtung von F. B. nach $\mathrm{Kvik}$ hin $=\mathrm{S} .35^{\circ} \mathrm{W}$. möchte man betrachten, als hier durch das nahe, ablenkende hohe Formosa erklärlich, die Geschwindigkeit des Vorrückens von $49 \mathrm{Sm}$. in 0,8 Stunden $=6$ I Sm. $=$ I I $3 \mathrm{Km}$. i. d. Std, wäre in viel höherer geogr. Breite schon auffällig, würde aber in $23^{\circ}-2 \mathrm{I}^{1 / 2}{ }^{0}$ geogr. Br. als besonders beachtenswert aufzufassen sein.

Von Faugh Ballaugh aus sind die Richtungslinien (linearen Gradienten vom Zentrum bis Beobachter, ohne Beriicksichtigung von Zwischenorten) voll gezogen, von $\mathrm{Ch}$ ateaubriand aus gestrichelt, von $\mathrm{Kvik}$ aus punktiert, von Takao aus voll mit Querstrichen, von Sindh aus sind sic mit Kreuzen bezeichnet.

Die Bahn des Zentrum, gewöhnlich betrachtet als die des Taifun, lag also wahrscheinlich von Châteaubriand nach $\mathrm{Kvik} z u=\mathrm{S} .70^{0} \mathrm{~W}$. oder WSIV1/4 IV., die Geschwindigkeit von $30 \mathrm{Sm}$. in $0,8 \mathrm{Std}=37^{1 / 2} \mathrm{Sm}$. i. d. Std. ist für die geogr. Breite jener Gegend $\left(22^{0} \mathrm{~N}\right.$.) noch recht groß. Von Kvik zog das Unwetter nördlich von Emma über die Sspitze Formosa's oder auf See un diese herum nach N. $42^{0} \mathrm{~W}$. oder NIV1/4N auf Takao zu; auch auf dieser Strecke ist das Vorriicken $62 \mathrm{Sm}$. in 3,3 Std. $=18,8 \mathrm{Sm}$. i. d. Std. ziemlich rasch; von Takao aus bis Sindh ist die Bahnrichtung nach N. $80^{\circ} \mathrm{WV}$. oder $\mathrm{WzN}$, Weg in $10,3 \mathrm{Std}$. $=169 \mathrm{Sm}$.

I $5,5 \mathrm{Sm}$. i. d. Std., dort wohl nicht selten; von Sindh an fehlen unmittelbare Anhaltspunlite für den Zug des Zentrum, wahrscheinlich erreichte es sudlich von aber nahe an Swatau das Festland von China.

Bei Betrachtung nebenstehender Tabelle und der folgenden zum Iltis und zum De IVitte Taifun, ist zu beachten, daß die Nähe der Küsten, — von Kalt- und von Warmwasscr-Strömung, — von den Mündungen grofser Fluisse nicht olme Einfluts bleiben wird auf die WVindrichtung in solchem Unwetter, - ferner das bei Entfernung des Zentrum von weniger als $100 \mathrm{Sm}$. dic unvermeidliche Unsicherheit des Schiffsortes bei Berechnung der Richtung vom Zentrum folglich auch des
Richtungswinkels darin eine nicht unbedeutende Unsicherheit veranlaßt. - Die Möglichkeit ist nicht ausgeschlossen, durch zahlreiche Zusammenstellungen solcher Zentrums. gruppen bestimmen zu können ersterwähnte Einflïsse auf die Richtungswinkel; das Unvermeidliche der Unsicherheit im Schiffsort auf möglichst geringes Mafs zuruickzuführen ist Pflicht der Schiffsfiulhrer und ihrer Gehilfen; man wird mir wohl zutrauen die Erkenntnis und Erfahrung in der Schwierigkeit, die oft vorhanden sein kann, diese Pflicht zu erfüllen, ihr Bestehen ist und bleibt zweifellos.

Trotzdem nicht anzunehmen ist, das Zentrum zog von Faugh Ballaugh zu Kvik, so weichen ab in I a die Richtungswinkel nicht mehr als höchstens $2^{3 / 4}$ Strich von denen bei I), weil $30 \mathrm{Sm}$. Unterschied im Schiffsort nicht mehr beträgt als die mögliche Unsicherheit in je zwei Schiffsorten unter solchen Umständen zu veranschlagen ist.

Windstärke I I - I 2 sehen wir in diesen 4 Fällen [I)-4), I a) nicht] nur bis 50 Sm. Entfernung vom Zentrum, Wdstk. Io bis ugf. I00, 9 bis ugf. 300, doch ist in mehr als $200 \mathrm{Sm}$. Abstand von ihm, die IVindstärke auch nur 5 .

Die Richtungswinkel in $\mathrm{I}-4$ sind im vorderen rechten (gefährlichen) Viertel $S^{1 / 2}-\mathrm{I}^{3} / 4$ Strich d. h. wenig bis sehr stark auf das Zentrum zugeneigt, in einem Fall (2) Kvik im Zentrum) ist der IVinkel bei Faugh Ballaugh nur 2 Strich, jedoch Vermutung eines Nebenzentrum nahe liegend, - bei Oceanic I $6^{3 / 4}$ Strich d. h. nahe auf das Zentrum zuwehend, doch ist dies Schiff mehr als $350 \mathrm{Sm}$. von diesem entfernt. In dem rechten hinteren Viertel (gewöhnlich noch als gefährlich betrachtet) sehen wir nur in weniger als $50 \mathrm{Sm}$. Entfernung vom Zentrum bei 2) Chàteaubriand den Richtungswinkel nahe \& Strich, sonst $13-16^{3} / 4$ Strich d. h. stark einwärts bis recht auf das Zentrum zu, selbst etwas auswärts weisend. - Im linken hinteren Viertel ist hier nur ein Ort: Takao bei 4) Sindh i. Z.; dort betrug der Richtungswinkel nur 7 Strich, dies kann Einflufs des Landes sein: - im linken vorderen Viertel zeigt sich der Winkel $\mathrm{IO}^{3} / 4-\mathrm{I}_{4}{ }^{3}, 4$ Strich d. h. die Windrichtung ist stets stark nach dem Zentrum hin. -

Wegen der Unsicherheit in, auch mögliches Schwankens der Bahnrichtung und Geschwindigkeit des Vorrüickens liegt es nahe als gefälulichstes Viertel zu betrachten das 4 Strich rechts und links von der Bahn; dann waren in diesem Viertel die Schiffe die sich in folgenden Richtungen vom Zentrum befanden: bei I) zwischen S. $25^{\circ} \mathrm{WV}$. durch IV. bis $N$. $65^{\prime \prime} 11 \%$; bei 2 ) zwischen $\mathrm{N} .87^{\circ} 1 \mathrm{~V}$. durch $\mathrm{N}$. bis N. $3^{\prime \prime} \mathrm{E}$.; bei 3) zwischen S. $55^{\circ} \mathrm{WV}$. durch IV. bis N. $35^{\prime \prime} \mathrm{IV}$; bei f) ebenso. In diesen Fällen betrug der Richtungswinkel bei I) unter 50 Sm. Entfernung $9^{3 / 4}$ und $14^{3} \simeq$ Strich, in $400 \mathrm{Sm}$. Entfernung $10^{1 / 4}$ Strich; bei 2) $60 \mathrm{Sm}$. ab $10^{1 / 4}, 200-3 \mathrm{SO} \mathrm{Sm}$. ab $10^{3 / 4}$ bis $1+\frac{1}{4}$ Strich; bei 3) und 4 ) to Sm. vom Zentrum $14^{3 / 4}$ Strich, $130-3$ to Sm. ab $10^{1 / 4}$ bis $13^{1} / 4$ Strich d. h. in weniger als $50 \mathrm{sm}$. war das Einbiegen des Windes mäbig und sehr stark, in gröfserer Entfernung stark und sehr stark 
Richtungswinkel, geordnet nach Lage zur angenommenen Bahn (Hälften und Vierteln) und Entfernung vom Zentrum.

Im Châteaubriand-Taifun I a) Zentrum SEwärts von Formosa I. D. 3 m. Schr. Faugh Ballaugh im Zentrum, $22^{0} 30^{\prime} \mathrm{N}$. $121^{0} 30^{\prime} \mathrm{E}$. Bahnrichtung nach Norw. Bk. Kvik $2 \mathrm{I}^{0} 5 \mathrm{O}^{\prime} \mathrm{N}$. $\mathrm{I} 2 \mathrm{I}^{0} \mathrm{O}^{\prime} \mathrm{E} .=\mathrm{S} .35^{\circ} \mathrm{W}$. $49 \mathrm{Sm}$. in 0,8 Stunden $=6 \mathrm{I} \mathrm{Sm}$. i. d. Std.

Rechte Hälfte: vorderes Viertel

\begin{tabular}{|c|c|c|c|c|}
\hline Schiff & $\mathrm{N}^{\mathrm{N}}$ & E. G. & $\begin{array}{l}\text { vom Zentrum } \\
\text { Sm. Richtung }\end{array}$ & 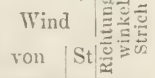 \\
\hline
\end{tabular}

Norw. Bk. Krik $\quad|21 \quad 50| 121 \quad 0|49|$ S35W $\mid$ NW $|12| 7$

\begin{tabular}{l|ll|ll|l|l|l|l|} 
D. S. Emma & 21 & 45 & 120 & 40 & 64 & S $46 \mathrm{WV}$ & IV & $10 \mid$
\end{tabular}

\begin{tabular}{l|ll|ll|l|l|l|l|l|} 
Takao, Formosa I. & 22 & 36 & 120 & 16 & 69 & $\mathrm{~N} 85 \mathrm{~W}$ & $\mathrm{NNE}$ & 10 & $7^{1 / 3}$
\end{tabular}

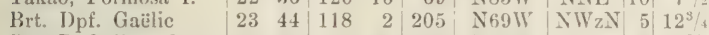

\begin{tabular}{ll|ll|ll|l|l|l|l|l} 
Brt. Dpf. Crusader & 23 & 47 & 118 & 37 & 228 & $\mathrm{~N} 70 \mathrm{~W}$ & $\mathrm{~N}$ & 8 & $9^{3} / 4$
\end{tabular}

\begin{tabular}{|l|l|l|ll|l|l|l|l|l} 
Swatau, China Küiste & 23 & 20 & 116 & 43 & 269 & $\mathrm{~N} 79 \mathrm{~W}$ & $\mathrm{~N} \mathrm{~W}_{\mathrm{ZN}}$ & ? & 12
\end{tabular}

\begin{tabular}{l|ll|ll|l|l|l|l|l} 
1) I. Brt. M. S. Magpie & 22 & 18 & 114 & 12 & 406 & $\mathrm{~S} 88 \mathrm{II}$ & $\mathrm{NNW}$ & 2 & $9^{3} / 4$
\end{tabular}

\section{Rechte Hälfte: hintcres Iiertel}

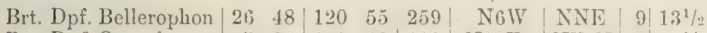
\begin{tabular}{l|lll|ll|l|l|l|l|l|l|l|} 
Bit. Dpf. Oceanic & 27 & 35 & 122 & 48 & 313 & N13E & NEzN & 6 & $14^{1 / 4}$
\end{tabular}

Im Châteaubriand-Taifun. I) Frz. 13k. Chàteaubriand im Zentrum $22^{\circ} \mathrm{O}^{\prime} \mathrm{N}$. $\mathrm{I}_{2} \mathrm{I}^{\circ} 3 \mathrm{O}^{\prime} \mathrm{E}$. Bahnrichtung nach Norw. BK. Krik $2 \mathrm{I}^{0} 5 \mathrm{O}^{\prime} \mathrm{N}$. I $2 \mathrm{I}^{\circ} \mathrm{O}^{\prime} \mathrm{E} .=\mathrm{S} .7 \mathrm{O}^{\circ} \mathrm{IV}$. $30 \mathrm{Sm}$. in 0,8 Stunden $=37^{1 / 2} \mathrm{Sm}$. i. d. Std.

\section{Rechte Hälfte: vorderes Viertel}

Norw. Bk. Krik

D. S. Emma

Takao, Formosa 1.

Brt. Dpf. Gaëlic

Brt. Dpf. Crusader

$\mid$\begin{tabular}{lll|l|l|l|l|}
21 & $50 \mid 121$ & 0 & 30 & $\mathrm{~S} 70 \mathrm{~W}$
\end{tabular} \begin{tabular}{llll|l|l|l}
21 & 45 & 120 & 40 & 49 & $\mathrm{~S} 72 \mathrm{~W}$
\end{tabular} \begin{tabular}{llll|l|l|l}
22 & 36 & 120 & 16 & 77 & $\mathrm{~N} 62 \mathrm{~W}$
\end{tabular} $\begin{array}{lllllll}23 & 44 & 118 & 2 & 22: 3 & \text { N } 62 \mathrm{IV}\end{array}$ $\begin{array}{lllllll}23 & 47 & 118 & 37 & 240 & \mathrm{~N} 64 \mathrm{~W}\end{array}$ $\begin{array}{llllllll}23 & 20 & 116 & 43 & 285 & \text { N } 600 \mathrm{~V}\end{array}$

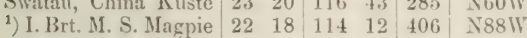

\section{Rechte Hialfte: hinteres Vicrtel}

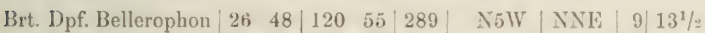
\begin{tabular}{l|llll|l|l|l|l|l} 
Brt. Dpf. Oceanic & 27 & $35 i$ & 122 & 48 & 342 & N12E & NEzN & 6 & 14
\end{tabular}

Im Châteaubriand-Taifun. 2) Zentrum Swärts von Formosa I. I880 September 27. 3,2 G. Z. Norw. Bk. Kvik im Zentrum $2 \mathrm{I}^{0} 5 \mathrm{O}^{\prime} \mathrm{N}$. $\mathrm{I}_{2} \mathrm{I}^{\circ} \mathrm{O}^{\prime} \mathrm{E}$. Bahnrichtung nach Takao, Formosa $I .=N \cdot 42^{0} \mathrm{~W}$. 62 Sm. in 3,3 Std. $==18,8$ Sm. i. d. Std.

\section{Rechte Hälfte: worderes Vicrtel}

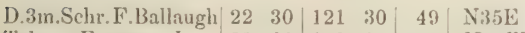
\begin{tabular}{l|ll|lll|l|l|l|} 
Takno, Formosa I. & 22 & 36 & 120 & 16 & 62 & $\mathrm{~N}+2 \mathrm{~W}$ \\
\hline
\end{tabular}

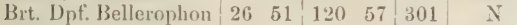
\begin{tabular}{|l|ll|l|l|l|l|} 
Brt. Dpf. Oceanic & 27 & 32 & 122 & 38 & 354 & N15E
\end{tabular} SzII $|11| 2$ NNE $1010^{1 / 4}$ XNE 911 Rechte Hälfte: hinteres Viertel

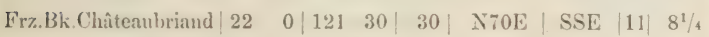

$$
\text { Linke Hälfte: vorderes Vicrtel }
$$

D. S. Emma

Brt. Dpf. Gä̈lic

Brt. Dpf. Crusader

$\begin{array}{llllll}23 & 47 & 117 & 37 & 220\end{array}$

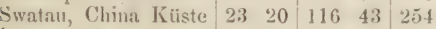

\begin{tabular}{ll|llll|l} 
I) I. Brt. M. S. Magpie & 22 & 18 & 114 & 12 & 379
\end{tabular}
S75IV NNE $|10| 13^{3 / 4}$ \begin{tabular}{l|l|ll}
$\mathrm{N} 54 \mathrm{WV}$ & $\mathrm{N} \mathrm{WZN}_{\mathrm{ZN}} 6$ & $14^{1} / 4$
\end{tabular} $\begin{array}{llll}\mathrm{X} 58 \mathrm{IV} & \mathrm{N} & 9 & 10^{3} / 4\end{array}$ \begin{tabular}{l|l|lll}
$\mathrm{N} 69 \mathrm{~W}$ & $\mathrm{NW}$ & $?$ & $13^{3} / 4$ \\
$\mathrm{~N} 86 \mathrm{~W}$ & $\mathrm{NW}$ & 3 & $10^{3} / 4$
\end{tabular}
Im Clâteaubriand-Taifun. 3) Zentrum SW. Küste von Formosa I. I 880 September $27,6,7^{\mathrm{h}} \mathrm{G}, \mathrm{Z}$. T a ka o im Zentrum $22^{0} 36^{\prime} \mathrm{N}$. $120^{\circ} 16^{\prime} \mathrm{E}$. Bahnrichtung nach Frz. Dpf. Sindh $23^{\circ} 5^{\prime} \mathrm{N}$. I I $7^{\circ} 25^{\prime} \mathrm{E}$. $=\mathrm{N}$. $80^{\circ} \mathrm{W}$. I69 Sm. in 10,3 Stunden $=15,5 \mathrm{Sm}$. i. d. Std.

Rechte Hälfte: vorderes Viertel

\begin{tabular}{|c|c|c|c|c|c|c|c|}
\hline Schiff & ${ }_{0}^{\mathrm{N}}$ & E. G. & \multicolumn{2}{|c|}{ vom Zentrum } & \multicolumn{2}{|c|}{ Wind } & 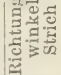 \\
\hline $\begin{array}{l}\text { Brt. Dpf. Gaëlic } \\
\text { Brt. 1)pf. Crusader } \\
\text { Swatau, China Küste }\end{array}$ & $\begin{array}{ll}23 & 59 \\
23 & 47 \\
23 & 20\end{array}$ & \begin{tabular}{|ll}
118 & 28 \\
117 & 37 \\
116 & 43
\end{tabular} & \begin{tabular}{|l|}
130 \\
163 \\
201
\end{tabular} & $\begin{array}{c}0 \\
\text { N50W } \\
\text { N64 IV } \\
\text { N77 W }\end{array}$ & $\left|\begin{array}{c}\mathrm{NzW} \\
\mathrm{N} \\
\mathrm{NW}\end{array}\right|$ & $\begin{array}{l}8 \\
9 \\
?\end{array}$ & $\begin{array}{l}12^{1 / 2} \\
10^{1} / 4 \\
13^{1 / 4}\end{array}$ \\
\hline \multicolumn{8}{|c|}{ Rechte Hälfte: linteres Viertel } \\
\hline $\begin{array}{l}\text { Brt. Dpf. Bellerophon } \\
\text { Brt. Dpf. Oceanic }\end{array}$ & $\begin{array}{ll}27 & 5 \\
27 & 8\end{array}$ & $\mid \begin{array}{ll}121 & 6 \\
122 & 2\end{array}$ & $\begin{array}{l}273 \\
288\end{array}$ & $\begin{array}{l}\text { N10E } \\
\text { N19E }\end{array}$ & $\left|\begin{array}{c}\mathrm{NNE} \\
\mathrm{NEzN}\end{array}\right|$ & & $\begin{array}{l}15 \\
14^{3} / 4\end{array}$ \\
\hline
\end{tabular}

$\left.{ }^{1}\right)$ I. Brt. M. S. Magpie | $22 \quad 18|114 \quad 12| 337|\mathrm{~S} 87 \mathrm{~W}| \mathrm{NW}|3| 11^{3 / 4}$

Im Châteaubriand-Taifun. 4) Formosa Kanal, südlicher Teil. I 880 September 27. I $7^{\text {h }}$ G. Z. Frz. Dpf. Sindh im Zentrum $23^{\circ} 5^{\prime}$ N. I I $7^{0} 25^{\prime}$ E. Bahnrichtung von Takao nach N. $80^{\circ} \mathrm{W}$. $=169 \mathrm{Sm}$. in IO,3 Stunden $=$ I 5,5 Sm. i. d. Std.

\section{Reclite Hälfte: worderes Vicrtel}

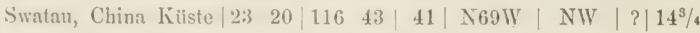

\section{Linkc Hälfte: linteres"Tiertel}

\begin{tabular}{l|ll|ll|l|l|l|l|l} 
Brt. Dpf. Gaëlic & 24 & 17 & 119 & 13 & 122 & N5 54 E & NE & 9 & $16 \%$
\end{tabular}

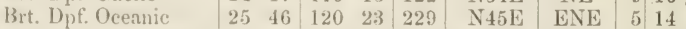
\begin{tabular}{|l|ll|ll|l|l|l|l|l} 
Brt. Dpf. Bellerophion & 27 & 49 & 121 & 35 & 366 & N38E & NE & 6 & $15^{1} / 2$
\end{tabular} Linke Hïlfte: linteres Viertel

'Takao, Formosa I. $\quad 2236|120 \quad 16| 160 \mid$ S80E | SSE | $8 \mid 7$ Linke Hälfte: vorderes Viertel

$\left.{ }^{1}\right)$ I. Brt. M. S. Mngpie | $22 \quad 18|114 \quad 12| 184 \mid$ S75W | NW | $3 \mid 10^{3} / 4$

$\left.{ }^{1}\right)$ In Hongkong IIafen; Boje No. 3.

'Tafel B. Richtungswinkel im Iltis-Taifun. Von der, im allgemeinen eine lange Strecke kenntlichen Bahn, kommt hier nur in Betracht der Teil 1896 VII 22 . I $4, \mathrm{~s}^{\text {h }} \mathrm{G}$. Z. von Brt. Dpf. Wuhu $29,6^{\circ} \mathrm{N}$. I $23,7^{\circ} \mathrm{E}$. NWzNwärts bis Brt. Dpf. Lienshing $31^{\circ} \mathrm{N}$. I $22,6^{\circ} \mathrm{E}$. I 896 VII 22. 2I, ${ }^{\text {h }}$ G. Z. (Richtungslinien von jenem aus voll gezogen, von diesem aus gestrichelt); genau genommen ist wahrscheinlich, die Bahn eines Nebenzentrum von der Nähe der Raffles und Napier In. 30,7 N. I $22,4^{\circ} \mathrm{E}$. NWwärts zu Brit. Dpf. Ching ping am Anker bei Kiutoan Fschf, in der Mündung des Yangtse $3 I_{2} 2^{\circ} \mathrm{N}$. I $21,7^{0}$ E.; - da aber, wenn der Bericht von Brt. Dpf. Lienshing nicht vorläge, man annehmen würde, das Zentrum sei von Brt. Dpf. Wuhu nach Chingping und zunächst in derselben Richtung weiter gezogen, so sind auch die Richtungswinkel auf Chingping zu berechnet (Richtungslinien punktiert). - Da zu unsicher ist die 
Bestimmung der Schiffsorte des Brt. Dpf. Wuhu nach der Zeit zu der das Zentrum über dies Schiff zog, so ist nachher es nicht mehr in Betracht genommen. (Die schon gegebenen, ergänzenden Mitteilungen des Dmitryi Donskoj und des Tambow sind von St. Petersburg, - Yarra, Melbourne, Salazie von Paris, - Hongkong (Obsrvtns. and Res.) von de Bilt gütigst mir übermittelt.

Richtuugswinkel; geordnet nach Lage zur angenommenen Bahn (Hälften und Vierteln) und Entfernung vom Zentrum

Im Iltis-Taifun. I) Zentrum Ewärts vom Chusan A rchipel. I896 Juli 22. I4, ${ }^{\text {h }}$ G. Z. Brt. Dpf. Wuhu im Zentrum $29^{\circ} 37^{\prime} \mathrm{N}$. $123^{\circ} 40^{\prime} \mathrm{E}$. Bahnrichtung nach Brt. Dpf. Lienshing $30^{\circ} 58^{\prime} \mathrm{N}$. $122^{\circ} 35^{\prime} \mathrm{E}=\mathrm{N} \cdot 35^{\circ} \mathrm{W}$ $99 \mathrm{Sm}$. in $6,3 \mathrm{Std} .=15,7 \mathrm{Sm}$. i. d. Std.

Rechte Hälfte: vorderes Viertel

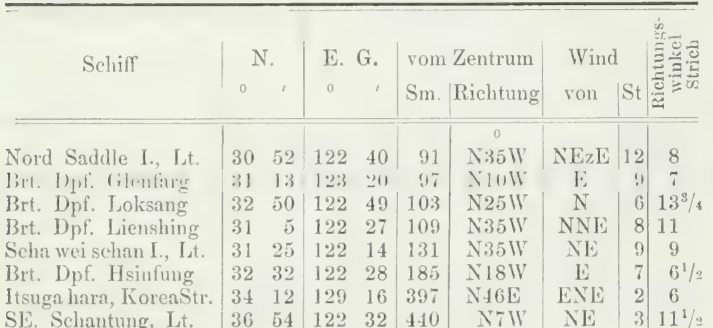

\section{Rechte Hälfte: hinteres Viertel}

\begin{tabular}{l|ll|ll|l|l|l|l|l} 
Russ. Dpf. Tambow & 29 & 30 & 125 & 21 & 89 & $\mathrm{~S} 85 \mathrm{E}$ & $\mathrm{SEzS}$ & 12 & $12 \%$
\end{tabular} \begin{tabular}{|l|rr|rrr|r|r|r|r|} 
Am. Bk. St. Katherine & 31 & 0 & 127 & 0 & 192 & $\mathrm{~N} 64 \mathrm{E}$ & $\mathrm{SE}$ & 12 & $9^{3} \%$
\end{tabular} \begin{tabular}{ll|l|l|l|l|l|l|l|l} 
Nafa, S. Liu kiu In. & 26 & 13 & 127 & 41 & 296 & S $46 E$ & S & 4 & 12
\end{tabular}

\section{Linke Hälfte: hinteres Vicrtel}

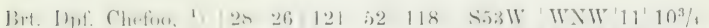

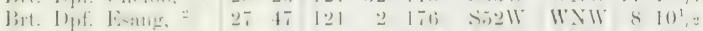

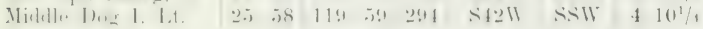
\begin{tabular}{l|ll|lll|l|l|l|l|l|l|l|l|} 
Hongkong Obsrvtr. & 22 & 18 & 114 & 12 & 672 & S49W & Stille $|-|$
\end{tabular}

\section{Linke Hälfte: arderes Viertel}

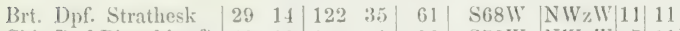
\begin{tabular}{l|lllllll|l|l|l} 
Chin.Dpf. Pingching $\left.{ }^{3}\right)$ & 29 & 10 & 122 & 1 & 90 & S $73 \mathrm{~W}$ & $\mathrm{NW} \% \mathrm{~W}$ & 7 & $11^{1} / 2$
\end{tabular} \begin{tabular}{l|ll|lllll|l|l} 
Brt. Dpf: Choysang, $\left.{ }^{4}\right)$ & 30 & 40 & 122 & 24 & 91 & N $46 \mathrm{~W}$ & NNE & 9 & 10
\end{tabular}

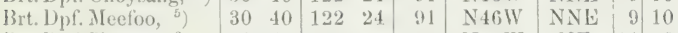

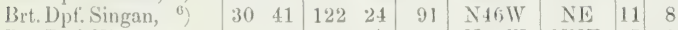
\begin{tabular}{l|rr|rr|r|r|r|r|r} 
Brt. Dpf. Kiangteen & 30 & 31 & 121 & 57 & 104 & N59W & NNE & 7 & $8^{3 / 4}$
\end{tabular} \begin{tabular}{l|ll|ll|l|l|l|l|l} 
Gutzlaff I. Lt. & 30 & 49 & 122 & 10 & 105 & $\mathrm{~N} 47 \mathrm{~V}$ & $\mathrm{NE}$ & 8 & $7^{3} / 4$
\end{tabular} \begin{tabular}{|l|ll|ll|l|l|l|l|l|} 
Brt. Dpf. Chingping, $\left.{ }^{7}\right)$ & 31 & 12 & 121 & 44 & 139 & N47W & NNE & 10 & $9^{3} / 4$
\end{tabular} \begin{tabular}{l|ll|lll|l|l|l|l} 
Zi ka wei Obsrvtr. & 31 & 14 & 121 & 29 & 149 & N49W & NNE & 4 & $9^{3} /$
\end{tabular}

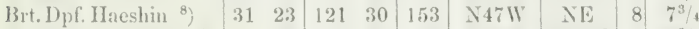
\begin{tabular}{l|ll|lll|l|l|l|l} 
F. Dpf. Ernest Simon ${ }^{8}$ ) & 31 & 23 & 121 & 30 & 153 & N $47 \mathrm{~W}$ & NEzN & 7 & $8^{3} / 4$
\end{tabular}

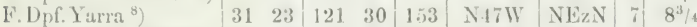
\begin{tabular}{|l|llll|l|l|l|l|l}
\hline 'T'schin liang, Yaugtse & 32 & 13 & 119 & 30 & 265 & N54W & $\mathrm{NE}$ & 2 & $7 \%$
\end{tabular} \begin{tabular}{ll|llllllllll} 
Wuhu, Zollamt," & 31 & 20 & 118 & 17 & 296 & N70W & NEzN & 1 & $6 \%$
\end{tabular}

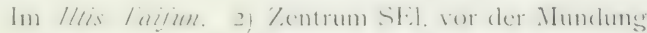
de's Yangtse. I 806 Iuli 22. 2I, h G. Z. Brt. Dpf. Lienshing im Lentrum $30^{\prime \prime} 58^{\prime} \mathrm{N}$. I $22^{\circ} 35^{\prime} \mathrm{E}$. Bahnrichtung wie von Wuhu aus $\cdots$ N. $35^{\prime \prime} \mathrm{WV} .15,7.5 \mathrm{Sm}$. i. d. Std.

Rechte Hälftc: vorderes Tiertel

\begin{tabular}{|c|c|c|c|c|c|c|c|c|c|}
\hline Schiff & & & E. & & $\begin{array}{l}\text { rom } \\
\text { Sm. }\end{array}$ & $\begin{array}{l}\text { Zentrum } \\
\text { Richtung }\end{array}$ & $\begin{array}{l}\text { Wind } \\
\text { ron }\end{array}$ & & \\
\hline rt. Dp,f. & & 26 & 123 & 13 & 4.3 & $\mathrm{~N}+9 \mathrm{E}$ & $\mathrm{s}$ & 10 & $4^{1 / 4}$ \\
\hline Brt. Dpf. Hsi & 31 & 57 & 122 & 28 & 59 & & $\mathrm{E} z \mathrm{~S}$ & 9 & $6^{1}$ \\
\hline Brt. Dpf. Loks & 32 & 50 & 122 & 45 & 112 & $\mathrm{~N} t$ & $\mathrm{NE} z \mathrm{E}$ & 10 & $11^{1 / 4}+$ \\
\hline I. $\quad 1$. & 37 & 24 & 122 & 42 & 381 & & $\therefore E$ & 3 & 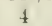 \\
\hline usan, Ko & 35 & 8 & $\mid 129$ & 2 & 412 & $\mathrm{~N} 5$ & NEzY & 5 & $17^{1}$ \\
\hline auki I & & & 120 & 39 & 437 & & $\mathrm{E} z \mathrm{~N}$ & 3 & 8 \\
\hline Zollamt & & & 126 & 43 & 444 & $\mathrm{~N}$ & $\mathrm{NE}$ & 3 & $14^{1} /=$ \\
\hline & & 43 & 121 & 8 & 47 & $\mathrm{~N}$ & ESE & 1 & $6^{3} \%$ \\
\hline D) & & & 118 & 25 & 51 & $\mathrm{x}$ & $\mathrm{SE}$ & 4 & 0 \\
\hline aliu, Fsch & 38 & 55 & 117 & 52 & 530 & $\mathrm{X} 26 \mathrm{~W}^{r}$ & SEzE & 3 & $2^{3} /$ \\
\hline Fiutschwäng, Fschf. & 40 & 35 & 122 & 0 & 576 & $\mathrm{~N}: 3 \mathrm{~W}$ & ESE & & \\
\hline
\end{tabular}

\section{Rechte llälfte: hinteres Viertel}

\begin{tabular}{l|ll|ll|l|l|l|l|l} 
Russ. Dpf. Tambow & 29 & 52 & 125 & 31 & 166 & S 66 E & SE & 9 & $14^{1 / 4}$
\end{tabular} \begin{tabular}{l|ll|ll|l|l|l|l|l|} 
Istugahara, Korea Str. & 34 & 12 & 129 & 16 & 390 & $\mathrm{~N} 60 \mathrm{E}$ & $\mathrm{ENL}$ & $\mathbf{2}$ & $13^{3} / \mathrm{A}$
\end{tabular}

\section{Linke Hälfte: linteres Viertel}

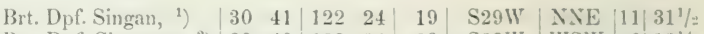
\begin{tabular}{l|lllllll|l|l|l} 
Brt. Dpf. Choysang, $\left.{ }^{2}\right)$ & 30 & 40 & 122 & 24 & 20 & S28IV WSIV & 6 & $12 \%$
\end{tabular}

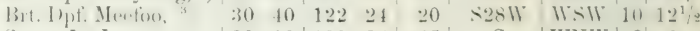
\begin{tabular}{l|ll|ll|l|l|l|l|l|} 
Steep I., Lt. & 30 & 13 & 122 & 35 & 45 & S & WNIY & 8 & 6
\end{tabular}

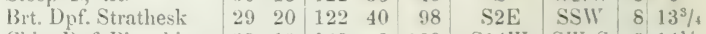

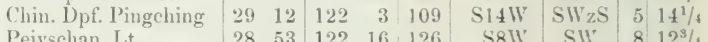

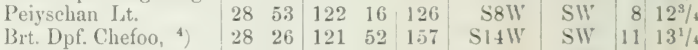
\begin{tabular}{l|ll|lll|l|l|l|l|l|l} 
Brt. Dpf. Esang & 27 & 49 & 121 & 4 & 205 & S $23 \pi$ & SW & 7 & 14
\end{tabular} \begin{tabular}{l|llll|l|l|ll|l} 
Middle Dog I., Lt. & 25 & 58 & 119 & 59 & 294 & S 28 W & SSII & 3 & $11 \%$
\end{tabular} \begin{tabular}{l|ll|ll|l|l|l|l|l|l|} 
Hongkong Obsrrtr. & 22 & 18 & 114 & 12 & 688 & S 41 II & WSII & 1 & $6 \%$
\end{tabular}

\section{Linke Hälftc: vorderes Viertel}

\begin{tabular}{|l|ll|ll|l|l|l|l|l} 
Brt. Dpf. Kiangteen & 30 & 57 & 122 & 6 & 25 & S88IW & NNE & 9 & $6 \%$
\end{tabular}

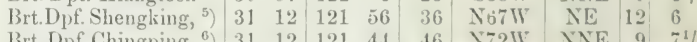

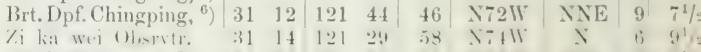

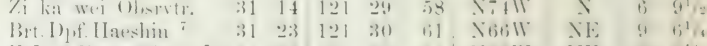

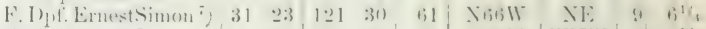
\begin{tabular}{l|ll|ll|l|l|l|l|l|} 
F. Dpf. Yarra ${ }^{7}$ ) & 31 & 23 & 121 & 30 & 61 & No6II & WNW & 5 & $16 \%$
\end{tabular} \begin{tabular}{l|ll|ll|l|l|l|l|l} 
Wuhu, Mission & 31 & 20 & 118 & 22 & 222 & $\mathrm{~N} 84 \mathrm{~W}$ & $\mathrm{XNW}$ & 9 & $10^{1} / 2$
\end{tabular} \begin{tabular}{l|ll|ll|l|l|l|l|l} 
Wuhu, Zollamt & 31 & 20 & 118 & 22 & 222 & $\mathbf{N} 84 \mathrm{~W}$ & $\mathrm{~N}_{\mathrm{Z}} \mathrm{W}$ & 3 & $9 \%$
\end{tabular}

Im Iltis-Taifun. 3) Zentrum bei Kiutoan Fschf,; Sl. Teil der äußeren Y a ng ts e Mündung I $\$ 96$ Juli 22 . 2 I, $4^{\text {h }}$. Brt. Dpf. Chingping im Zentrum $3 \mathrm{I}^{0} \mathrm{I} 2^{\prime} \mathrm{N}$. $121^{\circ} 44^{\prime} \mathrm{E}$. Bahnrichtung von Brt. Dpf. IV uh u her, = ugf. N. $44^{\circ} \mathrm{WV}$ $139 \mathrm{Sm}$. in 6,6 Std. = 2 I Sm, i. d. Std.

\section{Rechte Hiilfte: vorderes liertil}

Brt. Dpf. Issinfung

Brt. 1)pf. Lolising

NE. Schantung L.t. Hauki l. Lt.

Lian ti schan It.

'T'sehi mul po, W' Korea But The H: Hean

Takn Fschf.

Yiu tsehwing Fschf.

\begin{tabular}{|c|c|c|c|c|c|}
\hline 31 & 58 & 122 & 28 & 59 & N391: \\
\hline 32 & 50 & 122 & 45 & 111 & N28E: \\
\hline & 24 & 122 & 42 & 375 & NIE \\
\hline & + & 120 & 39 & 415 & $x=\mathbb{W}$ \\
\hline & 43 & 121 & 8 & 1.52 & Nill \\
\hline 37 & 30 & 126 & 43 & 453 & $\sqrt{2} 33 \mathrm{E}$ \\
\hline is & 41 & 118 & 30 & 178 & 191 \\
\hline 38 & 55 & 117 & 52 & 199 & $\mathrm{~N} 22 \mathrm{~W}$ \\
\hline & 35 & 122 & 0 & 503 & 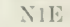 \\
\hline
\end{tabular}

\begin{tabular}{|ll|ll|l|l|}
31 & 58 & 122 & 28 & 59 & N39k
\end{tabular} \begin{tabular}{rr|rr|r|r|}
32 & 50 & 122 & 45 & 111 & N28E \\
37 & 24 & 122 & 42 & 375 & N7E
\end{tabular} $38+120 \quad 39+15 \quad \mathrm{~N} / \mathrm{II}$ \begin{tabular}{ll|l|l|l|l}
37 & 30 & 126 & 43 & 453 & $\mathbf{2} 33 \mathrm{E}$
\end{tabular} \begin{tabular}{|ll|ll|l|l|}
38 & 55 & 117 & 52 & 499 & $\mathrm{~N} 22 \mathrm{~W}$
\end{tabular} 1) Rafiles In. 2) Napier I. 3) Napier 1. Yangtse Mdg. o) Kintoan Fohf. i) Wusong.
ExS $910 \%$ NEzli 10 8\% SL $24 \%$ Eza 3 . $8 \%$ ESE $25^{3 /}$ SE 37 SEl: 4 : 31 \begin{tabular}{l|ll} 
SEzE & 3 & 3
\end{tabular} ISE : 35
1) T'ai techan In. 2) Bullock Hfn. "3) Montagu I. ") Napjier I. 5) Napier 1. ") Raffles I. ${ }^{7}$ ) Kintoan Fschf. 8) Wiusong.
Tai tschan In. 
Rechte Hälfte: linteres Viertel

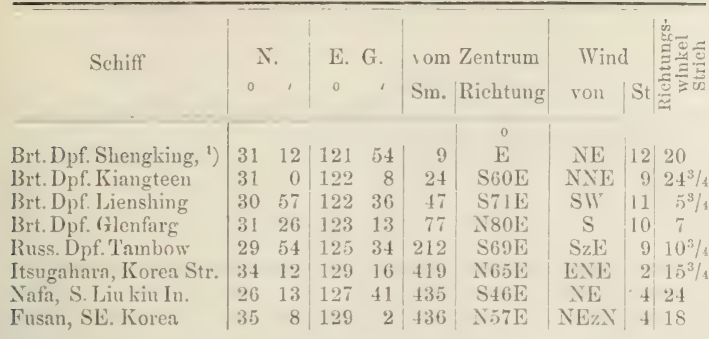

Linke Hälfte: hinteres Viertel

\begin{tabular}{|c|c|c|c|c|c|c|c|c|c|}
\hline Brt. Dpf. Singan, ${ }^{2}$ ) & 30 & & 122 & 24 & 46 & $\mathrm{~S} 42 \mathrm{E}$ & NNE & |11 & $26^{1} \mu$ \\
\hline Brt. Dpf. Choysang, ${ }^{3}$ ) & 30 & 40 & 122 & 24 & 47 & S43E & SIVzWV & 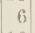 & \\
\hline Brt. Dpf. Meefoo, ${ }^{3}$ & 30 & 40 & 122 & 24 & 47 & $\mathrm{~S} 43 \mathrm{E}$ & IVSW & 10 & \\
\hline Chin. Dpf. Pingching & 29 & 15 & 122 & 5) & 118 & $\mathrm{~S} 9 \mathrm{E}$ & SSW & $\theta$ & \\
\hline Brt. Dpf. Strathesk & 29 & 25 & 122 & 45 & 119 & $\mathrm{~S} 26 \mathrm{E}$ & $2 \mathrm{~W}$ & 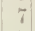 & \\
\hline Pei yu schan I & 28 & 53 & 122 & 16 & 148 & S11E & SW & $\tau$ & \\
\hline Brt. Dpf. Chefoo, ${ }^{5}$ ) & 28 & 26 & 121 & 52 & 166 & S2E & $\mathrm{SW} z \mathrm{~S}$ & 10 & \\
\hline Inf Fenner & 27 & 51 & 121 & 6 & 204 & $\mathrm{~S} 9 \mathrm{~W}$ & SII & $\tau$ & \\
\hline g I. Lt. & 25 & 58 & 119 & 59 & $32 \tau$ & $\mathrm{S} 16 \mathrm{~W}$ & SSIY & 3 & \\
\hline Hongkong Obsrvtr. & 22 & 18 & 114 & 12 & 672 & $\mathrm{~S}: 37 \mathrm{~W}$ & WSW & 1 & \\
\hline
\end{tabular}

\section{Linke Hälfte: vorderes Viertel}

\begin{tabular}{|c|c|c|c|c|c|c|c|}
\hline Zi ka wei, Obsrvtr. & $31 \quad 14$ & $|12|$ & 29 & 13 & N81 W & $\mathrm{N}_{\mathrm{z}} \mathrm{W}$ & 5. $9^{9} / 4$ \\
\hline Brt. Dpf. Haeshin ${ }^{6}$ ) & $31 \quad 23$ & 121 & 30 & 16 & $\mathrm{~N} 18 \mathrm{~W}$ & NE & $7^{3} / 4$ \\
\hline F.Dpf. Ernest Simon ${ }^{\circ}$ ) & $31 \quad 23$ & 121 & 30 & 16 & $\mathrm{~N}+8 \mathrm{~W}$ & 10 & $7^{3} \%$ \\
\hline F.Dpt. Yarra ${ }^{6}$ ) & 3123 & 121 & 30 & 16 & N4SW & WNW & 5. $17^{3} / \mathrm{s}$ \\
\hline Brt. Dpf. Peiyang, "7) & $32 \quad 1: 3$ & 119 & 30 & $12 ?$ & $\mathrm{~N} 62 \mathrm{~W}$ & Eli: & $66^{1} \%$ \\
\hline Wuhu, Mission & 3120 & 118 & 17 & 167 & $\mathrm{~N} 87 \mathrm{~W}$ & NNII & $10 \quad 10^{1} / 4$ \\
\hline Wuhu, Zollant & $31 \quad 20$ & 118 & 17 & 167 & $\mathrm{~N} 87 \mathrm{~W}$ & $\mathrm{~N} \% \mathrm{~W}$ & $3 \quad 9 \%$ \\
\hline
\end{tabular}

1) Yaugtse Mdg. 2) Raffles ln. 3) Napier I. 4) Napier 1. 5) Tai tschan In. ${ }^{6}$ ) W $W^{7}$ song. ${ }^{7}$ ) unterhalb Tschinkiang.

Windstärke I I-I 2 zeigt sich sowohl in geringer Entfernung vom Zentrum, als auch bis $200 \mathrm{Sm}$. von ihm, doch ist selbst in weniger als $50 \mathrm{Sm}$. Abstand auf See nur Wdstk. 8 angegeben. - in ugf. I00 Sm. abwärts bis 5. Wer immer Neigung hatte, solche Verhältnisse zu beachten, der weiß auch, dak am Land bezw. in Häfen an nahe bei einander gelegenen Stellen WVindrichtung und Windstärke sehr verschicden sein können; an der einen gewährt eine Erhöhnung des Landes Schutz, unweit von ihr kommt der IVind um die Höhe herum ein Paar Kompaßstriche verändert und erheblich stärker; allerdings müssen andre Gründe vorhanden sein, wenn nahe entgegengesetzter angegeben wird. In meiner fruiheren Arbeit S. 33 wies ich schon darauf hin, - auch auf die Ursache abweichender Berichte von Schiffen. Bei geringen Unterschicden in Höhe ïber dem Erdboden oder dem Meere kann ebenfalls erheblicher Unterschied in Windstärke und WVindrichtung sein, das wissen wir von dem Dienst auf Segelschiffen und sehen es an Gegenständen, die der WVind weiter trägt.

I) und 2) betrachtend sieht man im worderen rechten (gefährlichen) Vicrtel bis $60 \mathrm{Sm}$. Abstand vom Zentrum sehr kleine Richtungswinkel ( $4^{1 / 2}$ und $61 / 2$ Strich), wobei zu erinnern ist an den Einfluß des möglichen Fehlers der Ortsbestimmung; bei $\pm 100 \mathrm{Sm}$. Entfernung ist der
Winkel $7-13^{3} / 4$ Strich, bis $200 \mathrm{Sm}$. ist er $\mathrm{I}^{1} 1 / 4-61 / 2$ Str.; die nächsten Angaben sind aus nahe 400 bis nahe $600 \mathrm{Sm}$. wobei die zwischen $2-14^{1} / 2$ Strich betragenden Winkel oder die Windrichtungen es annehmbar machen, alle jene Orte befanden sich unter dem Einfluß eines anderen Zentrum.

Im hinteren (gewöhnlich noch als gefährlich bezeichneten) Vicrtel der rechten Hälfte befanden sich nur wenige Beobachter; bei nahe $90 \mathrm{Sm}$. Zentrums-Abstand war der Richtungswinkel I $2^{1} / 2$ Strich, das Einbiegen also schon stark, bis $200 \mathrm{Sm} .=9^{3 / 4}$ und $\mathrm{I} 4^{1} / 4$, bis nahe $400 \mathrm{Sm} .=12$ und $\mathrm{I} 3^{3 / 4}$ Strich.

In der linken Hälfte hinterem Tiertel sieht man nur bei 2) Steep I. einen kleinen Winkel von 6 Strich in weniger als $50 \mathrm{Sm}$. Entfernung vom Zentrum, wenn bei Raffles I. in kaum $20 \mathrm{Sm}$. Abstand der Wind fast grade vom Zentrum weg zu wehen scheint, so mag die Ursache sein, daß die Windrichtung ist die $\mathrm{I}, 3$ Stunden früher angeschriebene; so wie die Angaben sind ist die Zeit der Winddrehung durch $\mathrm{N}$. und $\mathrm{W}$. bis S. nicht ersichtlich. In 20-130 Sm. Abstand sind die Richtungswinkel $10^{3 / 4}$ bis $14^{1 / 4}$ Strich, weiter bis $300 \mathrm{Sm}$. $10^{1 / 4}$ bis 14 Strich, also stets starkes und sehr starkes Einbiegen des Windes erkennbar. - In dem fast $700 \mathrm{Sm}$. entfernten Hongkong war z. Zt, von I) und 2) Windstille oder bei sehr flawem Wind ein kleiner Richtungswinkel

In der linken Hälfte vordercm Viertel sind bei 2) und 25-46 Sm. Entfernung vom Zentrum die Richtungswinkel kleiner als 8 Strich $=6-7^{1 / 2}$, doch ist hier, auch vorher bei den unter Napier I. ankernden Schiffen zu beachten das Vorhandersein eines Nebenzentrum (wenn nicht von Nebenzentren) das an der Westseite der äußeren Yangtse Mündung sich zeigte. In 60 bis etwas melir als I00 Sm. Abstand sind bei $I$ ) die Winkel 8-II Strich, bei 2) in dem von Nebenzentren nicht beeinflußten $\mathrm{Li}$ ka wei $9^{1 / 2}$, bei den anderen hingegen $61 / 4$ und $16^{1 / 4}$ Strich; in rund $140-150 \mathrm{Sm}$. Abstand sincl $7^{3 / 4}-9^{3 / 4}$ Strich; $260-300 \mathrm{Sm}$. I) bei flauem Wind am Yangtse $6^{3 / 4}$ und $7^{1 / 4}$; 2) bei bis $220 \mathrm{Sm}$. näher gekommenem Zentrum und an etwas höher über dem Schiff gelegener Stelle - sogar bis zum starken Sturm zugenommener Windstärke - $9^{1 / 2}$ und Io Strich. Sehen wir wieder auf das Viertel: $45^{\circ}=4$ Kompaßstriche rechts und links vor, d. i. N. $80^{\circ} \mathrm{W} .-\mathrm{N}$. $\mathrm{IO}^{\circ} \mathrm{E}$. von dem Zentrum, so befand sich in ihm der größte Teil der Schiffe und Orte, die vorhin angegeben sind in den vorderen Vierteln der rechten und linken Hälfte; um nicht weitschweifig zu werden genügt, hinzuweisen auf die Grenzen der Richtungswinkel von $2-17^{1} / 2$ Str. und die Tatsache, daß die sehr kleinen und sehr großen verursacht sein mögen durch Nebenzentren und, bei bedeutender Entfernung, durch damalige Abhängigkeit von andren Hauptzentren mit deren Einfluß derjenige des hier in Betracht gezogenen, später sich vereint haben mag.

Tabelle 3) ist beachtenswert, weil die Abweichungen der Richtungswinkel ebenfalls hinweisen auf Nebenzentren; die Verbindungslinie $W u h u-C h i n g p i n g$ geht so nahe vorbei an Napier I., daß ich, außer schon angeführtem Grunde, der Einfachheit wegen, diese Linie als Bahnrichtung annahm. 


\section{Richtungswinkel im „De Witte“-Taifun,}

geordnet nach Lage zur angenommenen Bahn (Hälften, Vierteln) und Entfernung vom Zentrum.

Im De Witte-Taifun. I) Zentrum in der Ost China See NEl. von Formosa I., NNIV. von Meiaco Sima In. Igol August 2. I $3^{\text {h }}$ G. Z. Brt. Dpf. Laisang im Zentrum $26^{\circ} 44^{\prime}$ N. $123^{\circ} 2^{\prime} \mathrm{E}$. Bahnrichtung nach D. Dpf. Shantung, Ost China, Little Paß $26^{\circ} 55^{\prime} \mathrm{N}$. $120^{\circ} \mathrm{I} 4^{\prime} \mathrm{E} .=\mathrm{N}$. $86^{\circ} \mathrm{W}$. $150 \mathrm{Sm}$. in $10 \mathrm{Std}$. $=15 \mathrm{Sm}$. i. d. Std.

Rechte Hälfte: vorderes Tiertel

\begin{tabular}{|c|c|c|c|c|c|c|c|c|c|}
\hline Schiff & & & E. & & $\begin{array}{l}\text { rom } \\
\text { Sm. }\end{array}$ & Zentrum & $\begin{array}{l}\text { Win } \\
\text { von }\end{array}$ & & $\Xi$ \\
\hline & & & & & & & & & \\
\hline Brt 1 & 28 & 26 & 121 & 52 & 119 & IV & $\mathrm{NE}$ & 11 & $9^{2} /$ \\
\hline int. Dp & 27 & 51 & 121 & 6 & & & NNE & 9 & 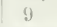 \\
\hline 4 & $20 ;$ & itti & 1211 & 211 & $11 \%$ & i) & III & ; & 12 \\
\hline f. Shantu & 26 & & 120 & 14 & 150 & $\mathrm{~N} 86 \mathrm{WI}$ & $\mathrm{NzE}$ & 10 & \\
\hline (4) & & & 120 & 35 & 15 & & $\mathrm{SE}$ & 3 & $23^{3} \%$ \\
\hline 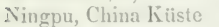 & 29 & 55 & 121 & 39 & 28 & & $\mathrm{XE}$ & 9 & $10^{1}$ \\
\hline & 30 & 33 & 122 & 27 & 23 & & $\mathrm{NE}$ & 9 & $11^{1} / \mathrm{s}$ \\
\hline$\left.{ }^{6}\right)$ & 31 & & 121 & 28 & 282 & $\mathrm{Ni}$ & ENE & 10 & $8^{1}$ \\
\hline $\left.\operatorname{tch}^{7}\right)$ & 31 & 14 & 121 & 28 & 282 & Y 1 & $\mathrm{E}$ & 6 & $6^{1}$ \\
\hline & 31 & 14 & 121 & 29 & 2 & & E & $i$ & iti \\
\hline 8) & 31 & 18 & 121 & 44 & 282 & $\mathrm{~N}]$ & E & is & $\therefore$ \\
\hline 9 & 31 & 23 & 121 & 30 & 290 & $N 1$ & $\mathrm{EzS}$ & in & it \\
\hline & 32 & 0 & 122 & 23 & 31 & & $\mathrm{E} z \mathrm{~S}$ & & is: \\
\hline bi 0 & 31 & 55 & 12 & 17 & 34 & $y$ & $\mathrm{E}$ & $\therefore$ & $\dot{0}$ \\
\hline & 31 & 20 & 118 & 17 & 37 & & $\mathrm{SE}$ & & \\
\hline Iadras & 31 & 20 & 118 & 17 & 372 & & $\mathrm{SE}$ & & \\
\hline & 31 & 20 & 118 & 17 & 37 & & $\mathrm{EzN}$ & & $\therefore$ \\
\hline & 32 & 9 & 1 & 25 & 37 & 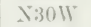 & $\therefore$ \&l: & 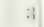 & $1:$ \\
\hline & 29 & 43 & 116 & 8 & 405 & $N_{6}$ & $x$ & (1) & it \\
\hline & 30 & 34 & & 20 & 51 & & SE & & $\therefore 31^{2}$ \\
\hline & 36 & 4 & 120 & 16 & 5S2 & $\mathrm{N} 16 \mathrm{~W}$ & ESE & 2 & \\
\hline
\end{tabular}

\section{Reclite Hälfte: linteres I'iertel}

Oschima, $\begin{array}{llll:ll:l}28 & 0 & 129 & 13 & 340 \mid & \mathbf{1} 75 \mathrm{E}\end{array}$ $\mathrm{SE} \quad \mid 810^{3} \%$

\section{Linke Hälfte: hinteres Vicrtel}

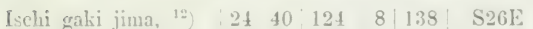

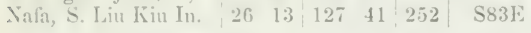

Linke Hälfte: vorderes Vicrtcl

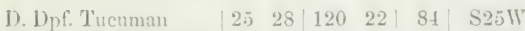

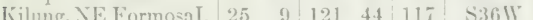
Taibolin, X. FormosaI. 25 t 121 2S 131 StoW \begin{tabular}{ll|ll|lll|l|l|l|l} 
Turnabout I., L.t. & 25 & 26 & 119 & 56 & 137 & S56W & S & 8 & 21
\end{tabular}

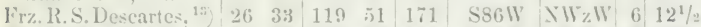

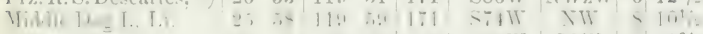

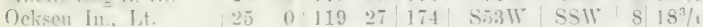

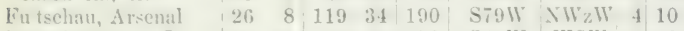
\begin{tabular}{l|ll|lllllll} 
Pescadores ln., Lt. & 23 & 33 & 119 & 31 & 270 & Still & WS IV & 5 & 10
\end{tabular}

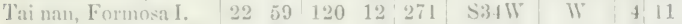

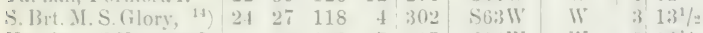

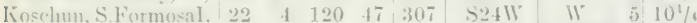

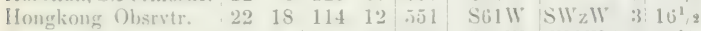

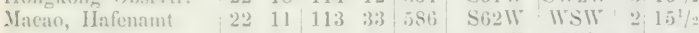
Fr\%. Bk. Brizeux 183611350708 S4ll $511+16$

Im De Wïte-Taifun. 2) Zentrum an der Ost China Küste, Little Paß. Igor August 2. $23^{\text {b }}$ G. Z. D. Dpf. Shantung im Zentrum $26^{\circ} 55^{\prime} \mathrm{N}$. $120^{\circ} 14^{\prime} \mathrm{E}$. Bahnrichtung ron Brt. Dpf. Laisang $=$ N. $86^{\circ} \mathrm{W}$.

\section{Reclite Hälfte: worderes Vicrtel}

\begin{tabular}{|c|c|c|c|c|c|c|c|c|c|}
\hline Sehiff & & & E. G & & $\begin{array}{l}\text { rom } \\
\text { Sm. }\end{array}$ & $\begin{array}{l}\text { Zentrum } \\
\text { Pichtung }\end{array}$ & $\begin{array}{l}\text { Wind } \\
\text { ron }\end{array}$ & $\mathrm{St}$ & \\
\hline $\begin{array}{l}\text { Wuhu, Chin. Dpt. Co. } \\
\text { Wuhu, Madras, 1, } \\
\text { Wuhu, Mission } \\
\text { S.Chin. MI. S. Haichi, } 2 \text { ) } \\
\text { Tschin kiang, Yangtse } \\
\text { Hamkin. Yangic. } \\
\text { S. M. S. Hertha, s) } \\
\text { Hauki I., Lt. }\end{array}$ & $\begin{array}{ll}31 & 2 \\
31 & 2 \\
31 & 2 \\
31 & 5 \\
32 & \\
30 & 3 \\
36 & \\
38 & \end{array}$ & $\begin{array}{r}20 \\
20 \\
20 \\
55 \\
5 \\
34 \\
4 \\
4 \\
4\end{array}$ & $\begin{array}{l}118 \\
118 \\
118 \\
120 \\
119 \\
114 \\
120 \\
120\end{array}$ & $\begin{array}{l}17 \\
17 \\
17 \\
17 \\
25 \\
20 \\
16 \\
39\end{array}$ & \begin{tabular}{l|}
284 \\
284 \\
284 \\
300 \\
317 \\
37 \\
549 \\
669
\end{tabular} & 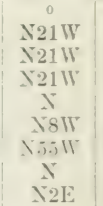 & $\begin{array}{l}\text { SEzE } \\
\text { ESE } \\
\text { EzN } \\
\text { E } \\
\text { ESE } \\
\text { XNE } \\
\text { SE } \\
\text { SWzS }\end{array}$ & $\begin{array}{l}7 \\
8 \\
8 \\
2 \\
5 \\
2 \\
2 \\
2 \\
3\end{array}$ & $\begin{array}{l}4 \\
5\end{array}$ \\
\hline
\end{tabular}

\section{Rechte Hälfte: hinteres I'iertel}

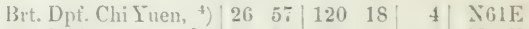
\begin{tabular}{|l|ll|ll|l|l|} 
Brt. Dpf. Bombay, ${ }^{5}$ ) & 27 & 47 & 121 & 2 & 67 & Х39E \\
\hline
\end{tabular} \begin{tabular}{ll|llllll} 
S.Brt.II.S.Phoenix, $\left.{ }^{6}\right)$ & 28 & 26 & 121 & 52 & 126 & $\times 44 \mathrm{E}$
\end{tabular}

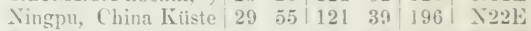
\begin{tabular}{l|lllllll} 
Brt. Dpf. Chungking & 30 & 0 & 121 & 39 & 199 & $\mathrm{~N} 22 \mathrm{E}$
\end{tabular}

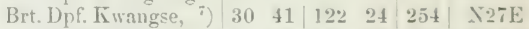
\begin{tabular}{ll|llll|l|l|l} 
D. Dpf. Stuttgart, & s) & 31 & 14 & 121 & 28 & 267 & N14E
\end{tabular} \begin{tabular}{l|lllllll} 
S.B.M.S. Waterwitch & ) & 31 & 14 & 121 & 28 & 267 & XitE
\end{tabular} \begin{tabular}{ll|llllll|l} 
Zi ka wei, Obsrrtr. & 31 & 14 & 121 & 29 & 267 & Nite
\end{tabular} Kiukiang, langtse $\quad 29 \quad 43 \quad 116 \quad 8 \quad 275 \quad$ \52E $\begin{array}{llllllll}\text { Brt. Dpf. Naeduff, o, } & 31 & 18 & 121 & 49 & 275 & \text { N17E }\end{array}$ \begin{tabular}{|l|llll|l|l|l|l} 
Wusong, Yangtse & 31 & 23 & 121 & 30 & 276 & $\times 14 \mathrm{E}$
\end{tabular} $\begin{array}{llllllll}\text { Br1. Dpf. Lee Yuen } & 31 & 25 & 121 & 56 & 284 & \text { YisE }\end{array}$

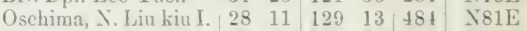
SE. Sehantung, Lt. $\quad 36 \quad 54 \quad 122 \quad 32 \quad 610 \quad$ N11E \begin{tabular}{llllll|l|l|l|l} 
NE. Sehantung, Lt. & 37 & 24 & 122 & 42 & 640 & NilE
\end{tabular} $\begin{array}{llllllll}\text { Tschifu, Zollamt } & 37 & 34 & 121 & 32 & 612 & \text { N } 6 \mathrm{E}\end{array}$ $\operatorname{SSE}|11| 7^{1}=$ SE $10 \quad \pi \%$ ESE $11 \mid 11$ \begin{tabular}{l|l|l} 
ENE & 9 & 12
\end{tabular} SE $\quad 9 \quad 6$ E $\quad 9 \quad 10^{1} \%$ E $11 \quad 9 \%$ E $79 \%$ ESE $8 \quad 7^{1 / 4}$ XNE $6 \quad 9 \frac{1}{1}$ ESE $10 \quad 7^{1} / 2$ ESE $907 \%$ EzN $: 910 \%$ $\mathrm{SE} \quad 8,11 \%$ $\mathrm{SSE} \quad 2 \quad 3$ $\begin{array}{l:lll}S & 2 & 1\end{array}$ $\begin{array}{llll}\text { SSE } & 3 & 3\end{array}$

\section{Linke Hälfte: hinteres Vicrtel}

D. Dpf. Tucuman Brt. Upt. Laisang

Ischi gaki jima, io $\begin{array}{llllll}\text { Nafa, S. Liu kiu In. } 26 & 13 & 127 & 41 & 402\end{array}$

\section{Linke Hälfte: iorderes I"̈ertel}

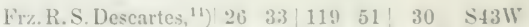

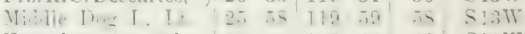
Fu tschau, Arsenal $\quad 26 \quad+119$ 34 60 S36W \begin{tabular}{|l|llllll|l} 
Turnabout I. I.t. & 25 & 26 & 119 & 56 & 90 & sioll \\
\hline
\end{tabular} \begin{tabular}{llllll|l|l|l} 
()ekseu 1., I.t. & 25 & 0 & 119 & 27 & 123 & S20W
\end{tabular} S. Brt. Y.S. Filory; 12) 24 2S 118 33 189

\begin{tabular}{lllll|l} 
Pescadores In., Lt. $\left.{ }^{13}\right)$ & 23 & 33 & 119 & 34 & 205
\end{tabular} \begin{tabular}{llll|llll} 
Tainan, Formosa & I. & 22 & 59 & 120 & 12 & 236
\end{tabular} Honghong. Obsrrtr. 22 is 114 12 430 \begin{tabular}{llllll|l|l|l} 
Ifacao, Hafenamt & 22 & 11 & 113 & 33 & 463
\end{tabular} Fr\%. Bk. Brizenx : 20 1 11140,540
$\mathrm{S} 25 \mathrm{E} ; \mathrm{SI}_{\mathrm{Z}} \mathrm{S}: 11 ; 10^{3} \%$ SOSE SSE o $10^{2} \%$ $\mathrm{S} 5 \mathrm{HE} \quad \mathrm{S} \quad 10.12^{3 / 4}$ SE $\quad$ 6. $12^{1} \%$
Tai tschau In. \#) Bullock Hfu. s) Euyan I. 4) Little Pant. ('hin Kiiste. ") Schanghai. i) Schanghai. \&) Kintoan Fschit. II 12) Meiaco sima In. ia) Samsahi Bai. 16) Anov:
1) Lagersehift: ") Kiang Yug. 3) Tsingtau. "T Fuyan I. 3) Bullock Hfin. (i) Tai tschau I. if Rattles I. o) Schanghai. y) Schang. hai. Kintoan Fschf. Iw Jeiaen sima In. "Somsah Bai. is Amoy. 14) Formosa K:unil. 
Tafel C. Richtungswinkel im De Witte Taifun. I.) Die Bahn kann als Abscissen linie nur gezogen werden vom Brt. Dpf. La isang $26,7^{\circ}$ N. $123,0^{\circ}$ E. I90I VIII 2. I $3^{\text {hl }}$ G. Z. zu D. Dpf. Shantung und Brt. Dpf. Chi yuen, beide nicht weit von einander am Anker vor der China Küste im Little Pali und bei F u yan I. $26,9^{\circ}$ X. IO2, ". I: I90 I VIII 2. $23^{\mathrm{h}}$ G. Z. - Die Richtungslinien sind voll gezogen von Laisang aus, von Shantung aus gestrichelt.

Die später folgenden, hier schon benutzten Auszüge aus den Journalen S. Brt. M. S. Waterwitch (Schanghai) und Lagerschiff Madras (bei $\mathrm{W}$ uhu, Yangtse), Frz. Bk. Brizeux, Hongkong Observatorium (Obsrvtns. and Res.) erhielt ich, wie erwähnt gütigst zugesandt von London, Paris und de Bilt.

Die Bahnrichtung, die, bei Mangel anderer Mitteilungen, auch hier von D. Dpf. Shantung aus angenommen wird als dieselbe wic die ron $L$ a isang bis zu ihm, lag nach N. $86^{\circ} \mathrm{IV}$; ; die Strecke von diesem Schiff bis zu jenem beträgt I $50 \mathrm{Sm}$., Zeitunterschied zwischen Ziehen des Zentrum über jene $=$ Io Stunden, durchschnittliche Geschwindigkeit also I $_{5} \mathrm{Sm} .=27^{3} 4$ km. i. d. Std.

Im rechten vorderen (gefährlichen) Viertel wären alle Schiffe und Orte in N. $86^{\circ} \mathrm{VV}$. durch N. bis N. $4^{\prime \prime} \mathrm{E}$. Richtung vom Zentrum, im rechten hinteren (gewöhnlich zur gefährlichen Hälfte gerechneten) Viertel alle Schiffe N. $4^{\circ} \mathrm{E}$. durch E. bis S. $86^{\circ} \mathrm{E}$. 1 . Ztrm.; im linken hinteren alle S. $86^{\prime \prime} \mathrm{E}$. durch S. bis S. $4^{\circ} \mathrm{IV}$. v. Ztrm., im linken vorderen diejenigen S. 4" $\mathrm{W}$. durch $\mathrm{W}$. bis N. $86^{\circ}$ W. v. Ztrm. befindlichen. Das, wegen Schwanken von Bahn und Vorrücken, gefährlichste Viertel läge zwischen N. $4 \mathrm{I}^{\circ} \mathrm{W}$. durch $\mathrm{W}$. bis S. $49^{\circ} \mathrm{IV}$. vom Zentrum.

Windstärke I I und 12 ist angegeben bis $140 \mathrm{Sm}$. vom Zentrum, in einem Fall sogar in ugf. $270 \mathrm{Sm}$. (Schanghai) da zwei andere Beobachter, die nicht weit von jenem entfernt waren nur Wdstk. 7 und $S$ berichten so liegt die Vermutung nahe, jener lag an einer besonders ausgesetzten Stelle, vielleicht unweit einer engen Straße, durch die die IVindlsraft wie in einem engen Rohr, verstärkt auftrat; dieselbe 1 dstk. I I ist dort zu 7 auf einander folgenden Zeiten mitgeteilt, das wären 29 Stunden! WVdstk. 9 und 10 ist angegeben bis $285 \mathrm{Sm}$. vom Zentrum; selbstverständlich liegen vor Berichte auch von geringer Kraft des Windes bis in $60 \mathrm{Sm}$. vom Zentrum.

Die Richtungswinkel bei $I$ ) im rechten, a'orderen (scführlichen) Vicrtel mit zwei Ausnahmen (Kwangse $230 \mathrm{Sm}$. Lee Yuen $318 \mathrm{Sm}$.) stammen von Ankerplätzen oder Hafenorten; bei I20-145 Sm. Abstand vom Zentrum waren 9-12 $\frac{1}{2}$ Strich; in $150 \mathrm{Sm}$. Abstd. an einem Ort $7^{1 / 2}$ an einem anderen $29^{3 / 4}$ Strich; daher liegt nahe die Vermutung, die Windrichtung sei durch die Umgebung stark abgelenkt worden. Zwischen 200-290 Sm. beträgt der Rchtgswkl. I I $1 / 4-5^{1 / 2}$ Strich, mit zunehmender Entfernung kleiner werdend. Von rund $320-580 \mathrm{Sm}$. sind nur kleine Winkel $(1 / 4-61 / 2)$, ausgenommen bei Kiu kiang $=9^{3 / 3}$ Str. und Hankau doch ist bei Wdstk. I an letzterem Ort die Wind richtung sehr häufig veränderlich.

Im rechten, hinteren (gewü̈hnlich noch als gefährlich botraclutetcn) Viertel lieferte einen Bericht nur Oschima von den nördlichen Liu kiu Inseln, $340 \mathrm{Sm}$. entfernt: $\mathrm{IO}^{3 / 4}$ Strich also schon stark werdendes Einbiegen des Windes nach dem \%entrum hin.

Im linken linteren Fiertel, befanden sich nur zwei Beobachter: einer auf den El. Meyaco sima In. ugf. $140 \mathrm{Sm}$. ab, der andre auf den S. Liu kiu In. rund $250 \mathrm{Sm}$. ab, die Richtungswinkel waren $9^{3} / 4$ und $12^{1 / 2}$ Str. also ziemliches bis starkes Einbiegen der Windrichtung.

Im linken, vordoren Vicrtel fallen auf, die beiden großen Winkel bei Turnabout I. und Okseu I. I.t.: 2 I bezw. I $8^{3} / 4$ Str., beide Orte sind zu betrachten als verhältnismäßsig frei liegend. Mit Ausnahme von Tucuman $8 \frac{1}{4}$ Str. $84 \mathrm{Sm}$. ab und weit im SW. Brizeux I $6 \mathrm{Str} .708 \mathrm{Sm}$. ab, befanden sich wieder alle Beobachter am Lankle oder an Ankerplatzen, folglich mus Einwirkung der Umgebung als möglich erachtet werden. Nur bei Tucuman war geringes (wenn überhaupt) Einbiegen des WVindes, da dic anderen Berichte Richtungswinkel von Io und mehr Strich geben so kann man nicht zurickhalten, die Vermutung, auch hier bestand IVI. von Ockseu In. und Turnabout I. ein Neben-Zentrum, Hongkong, Macao, Brizeux waren jedoch unter vollem Einfluß des SIV. Monsun, bei dem man annimmt im Allgemeinen lagert der niedrigste Luftdruck über dem Festlande Asiens.

Richtungswinkel (De Witte Taifun) 2.) Da das Zentrum erheblich $(150 \mathrm{Sm}$.) nach nahe $\mathrm{W}$. geriickt ist, so befindet sich fast nur noch $1 / 3$ der vorigen Berichterstatter im vorderen rechten, gefährlichen Viertel, alle an Land oder in Hafenorten bezw. im Yangtse; nur in IV uhu ist der Wind stiimisch. In Hankau zeigt sich mäßiges Einbiegen des Windes, sonst sind bei leichtem bis frischem Wind dic Richtungswinkel klein, die Windrichtung also allein abhängig von der allgemeinen Verteilung des Luftdrucks; alle Beobachter waren 280-670 Sm. vom Zentrum.

Im rechten, hinteren auch noch geführlich batrachteten Viertel, sind wieder alle Beobachter an Land oder in Hafen- bezw. Ankerplätzen, denn selbst Chung king und Lee Yuen befanden sich vor der Mündung des Ningpu Reviers und bei den Banken der Yangtse Mündung. Die Richtungswinkel sind sehr verschieden, in $4-200 \mathrm{Sm}$. Entfernung zwischen 6 und 12 Strich d. i. bei mäßigem Abbiegen bis starkem Einbiegen des Windes. In 250-290 Sm. Abstand liegen die Winkel zwischen $7^{1 / 4}$ und $10^{1 / 2}$ Strich, also findet statt geringes Abbiegen und mäßiges Einbiegen des IVindes; $484 \mathrm{Sm}$.

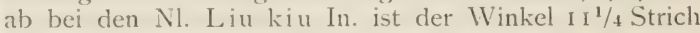
d. i. starkes Einbiegen; 610-642 Sm. ab, im Norden, wie bei den letzten beiden Berichterstattern des vorigen Vicrtels sind sehr kleine Richtungswinkel, verstärkend die Ansicht dortigen Einflußes der allgemeinen Luftverteilung oder anderer Zentren.

Im linken hinteren Viertel, 86 und I $_{5} 2 \mathrm{Sm}$. vom Zentrum ist bei Taifun und steifer Brise, der Richtungswinkel $10^{3} / 4$ und $10^{1} / 4$ Str., d. h. das Einbiegen des Windes beginnt stark zu werden; auf einer der El. 
Meiaco sima In. und einer der Sl. Liu kiu In. bei sehr starkem Sturm bezw. steifer Brise sind die Winkel $12^{*}, 4$ und $12^{1} / 2$ Str. also starkes Einbiersen des Windes.

Im linken vorderen Viertel sind mit Ausnahme von $540 \mathrm{Sm}$. SIV1. befindlichem Brizeux alle Beobachter an Land oder im Hafen und am Ankerplatz. In 30-90 Sm. Entfernung rom Zentrum, bei mäßiger Brise bis sehr starkem Sturm Richtungswinkel $9^{3 / 4}-13^{1 / 4}$ Strich also mäßiges bis sehr starkes Eimbiegen. I 20 - I $40 \mathrm{Sm}$. ab. starke 13rise bis stürmisch I I $-14^{\prime}$. Strich also starkes und sehr starkes Einbiegren; in 430-540 Sm. Entfernung WVinkel von $I_{1} 1 / 2$ und $14^{1 / 2}$ Str. - gegen 10 Stunden vorher also wahrscheinliches /usammenschliefien des SIV. Jonsuns mit dem Einfluß eines Taifun Zentrum.

liur das Bahn- he zw. Gefährlichste Vicrtel (vor dem Zentrum $45^{\circ}$ rechts und links von der wahrscheinlichen Bahnrichtung) kommt hier in Betracht nur I) denn bei 2) liegen in ihm nur Hangkau, Hongkong und Macao; bei ihnen ist der Wind flau, bei ersterem der Richtungswinkel 9 Str., bei letzteren beiden $14^{1} \_$Strich. Das betr. Viertel schliefst ein, wie erwähnt, die Richtungen S. $49^{\prime \prime} \mathrm{IV} .-\mathrm{IV} . \mathrm{N} .4 \mathrm{I}^{\circ} \mathrm{IV}$; $120-100 \mathrm{Sm}$. vom Zentrum sind die Richtungswinkel $7^{1 / 2}-\mathrm{I}^{1 / 2} / 2$ Strich also. wahrscheinlich von der Umgebung veranlaßstes Abbiegren und bis starkes Einbiegen des Windes; außerdem sind bei $135-175 \mathrm{Sm}$. Abstand 3 ausnahmsweise große Richtungswinkel 29\% 3 , I, und $18^{3 / 4}$ Strich, die wie schon erwähnt, ein Nebenzentrum vermuten lassen. Die Windstärke war 3-10 also leichte Brise bis sehr starker Sturm.

Diese Einzelfälle, bestärken mich darin, anzuraten, im Allgemeinen Richtungswinkel von 12 Strich oder ein Einbiegen des IVindes von 4 Strich als sehr wohl möglich zu betrachten. Dies schliefst nicht aus, daß, durch vermehrte Zusammenstellungen fuir bestimmte Gegenden und Monate, genamerer Anhalt gegeben wird.

\section{Barometerkurven in Taifunen.}

\section{I'afel a- d.}

Leider wird das Barometer von manchem Beobachter, auch von manchem Seefahrer, als WVahrsager betrachtet, es ist aber kein Wahrsager, sondern ein sehr guter Waruer, - cin um so besserer, je häufiger sein Stand angeschrieben wird und je mehr man sich in Witterungskunde oder Wetterkenntnis geubt hat. \& Dies veröffentlichte ich i. J. I8SI in meiner hier mehrfach erwähnten Arbeit Die $1 V$ irbelstürme u. S. W. ; es ist noch jetzt giltig. - Hr. $\mathcal{F}$. Jiliot. M. A. in seinem schon fribher senannten Hand-hook of Crolonic Storms in the bay of Bonsal, 2. Aufl. 1000. S. 33-30 giebt eine genaue Beschreibung des Schiffs-Barometers und scines Gebrauchs nebst mehreren /eichnungen; in ersteren wurde ich eingehend unterrichtet auf einer Kol. preufischen Navigationsschule vor 50 Jahren, es kinn also kein \%weifel sein, daf sic jetzt auf allen deutschen cingeburerert sind; - von $\mathrm{Hr}$. I: s Abbildungen entlehne

ich hier drei. "Aus Sparsamkeit" werden (abgesehen ron den wbequemen * aber unzuverlässigen Aneroids) manchmal beschafft Barometer in Holzfaßung mit minderwertigen Verniers; die 3 Zeichnungen zeigen deutlich die Notwendigkeit, diesen, nur scheinbar unbedeutenden Teil des Instruments doch so zweckmäßig als möglich einzurichten, damit das Auge regelmäßig gebracht wird in wagerechte Linie mit dem obersten Teil der Kuppe des Queckilbers im Barometer. - Denkt man sich als

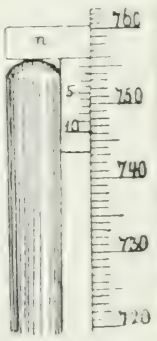

Fin. 1

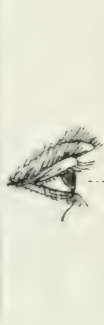

Fig. 2

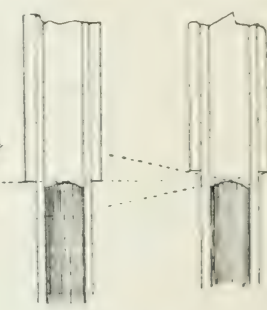

Fis. 3 .

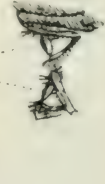

nicht vorhanden den in Fig. I mit $\mathrm{n}$ bezeichneten Teil des Vernier, so sieht man letzteren wie er bei vielen mit Holzfassung versehenen Barometern vorhanden ist: daß es dabei sehr schwierig, die Null-Linie mit dem obersten Teil der Kuppe in wagerechter Linie zu halten, ist leicht zu erkennen; auch wenn $\approx n *$ nur an der Vorderseite des Barometer-Rohres angebracht wird, kann man sich nach Fig. 3 vorstellen, wie unsicher wird dic Einstellung des Vernier. IVie sie sein soll und wie notwendig es ist zum Vernier zu verwenden ein kleines unten wagerecht abgeschnittenes Metallrohr, welches umschließt das Glasrohr des Barometers: zeigt Fig. 2; Fig. 3 führt deutlich vor Augen die Notwendigkeit, das Barometer so anzubringen, um das Auge muihelos halten zu können wagerecht mit der gen. Kuppe des Ouecksilbers; in gezwungenen Stellungen ist man dessen nie sicher, - besonders nicht auf einem stets mehr oder weniger bewegten Schiffe. - Von Hr. Kpt. Rabe, auf der Brigg "Schwan sah ich vor ugf. 30 Jahren den Beweis geliefert, daßs man auch in einer hleinen Kajuite auf einem kleinen Schiffe ein Barometer zweckentsprechend anbringen kann. Er lutte in der freiesten Ecke des sehr beschränkten Raumes den Träger befestigt, - auf genügender Höhe und gehöriger Entfernung vor dem Instrument ein hinreichend starkes Messingrohr gezogen, an dem man sich vorkommendenfalls beim Ablesen halten konnte.

Trotzdem schon 1853 der Konfirenz in brïssil durchaus zweckentsprechende Herstellung des SchiffsBarometers vorgezeigt und von jener als Muster angenommen wurde, - die sich auch durchaus bewährt hat. - sind doch in neucrer \%eit Instrumente in Gebrauch gekommen, deren Verengung zu kurz oder ungenigend ist, sodali sic bei Schiffsbewegungen pumpen. -- Das haitte nie geschehen dürfen, denn an solchem Barometer läfst sich nichts Sicheres beobachten; wer sagt, man nimmt nach ein Paar lieobachtungen des höchsten und 
niedrigsten Standes das Mittel, der zeigt Unkenntnis der Hauptbedingung des 》Mittels «: daß die Einrichtungen und Beobachtungsweise derart sind, um die Ergebnisse zweifellos möglichst nahe auf entgegengesetzter Seite, in möglichst gleicher und möglichst geringer Entfernung vom richtigen Ergebnis liegend $\mathrm{zu}$ machen. Bei einem "pumpenden "Barometer ist nicht die geringste Sicherheit der Erfullung dieser Hauptbedingung; aus der Sachlage ist leicht zu. ersehen, daßj sie es nicht sein kann, - folglich kann ein pumpendes Barometer eine richtige Ablesung nicht gestatten, es kann nur zeigen, ob seit der letzten, der Barometerstand »ungefähr " um ein Paar Nillimeter sich geändert hat. "Pumpende Barometer mögen Veranlassung gewesen sein, auf Schiffen einzuführen zusammengesetzte Aneroide mit Schreibvorrichtung; dies sind nicht zu unterschätzende Hilfsmittel zur Ergänzung von, aber kein Ersatz. für gute Quecksilber-Barometer; abgesehen davon, daß ihre Herstellungsweise mehr Fehlerquellen enthält als die der letzteren, ist nicht zu erkennen, in welchem Betrage die Bewegungen des Schiffes sie beeinflussen. Je näher ein Instrument am Bewegungsmittelpunkt aufgestellt werden kann, um so geringer wird es naturgemäli von der Bewegung beeinflußt; solche Anbringung ist auf Schiffen selten möglich, besonders in diesem Fille, da das Barometer und/oder sein Ersatz stets leicht zugänglich sein müssen. So lange bei genügender Beleuchtung Füße und Hände hinreichenden Halt haben; auch das Barometer nicht am Ringe anliegt, wird man seinen Stand noch $1 / 4 \mathrm{~mm}$. genau ablesen können, der Schreibstift eines Schreib-Aneroid, auch wenn ein Dutzend Luftdruckkästchen es richtiger angeben machen soll, kann dann nicht allein mehrere Millimeter hin und her sschleudern sondern auch zurick- oder vorausbleiben, Anhalt dafür könnte wieder nur ein gutes Schiffs-Barometer geben.

Schon vor 50 Jahren wurde in der Navigationsschule mir gelehrt, daß in den sogen. Tropen auch in Subtropen das Barometer eine tägliche Periode des Luftdrucks zeige d. h. dal jenes Stand morgens und abends $10^{\text {h }}$ am höchsten, mgs, und nchmttgs. $4^{\text {h }}$ am niedrigsten sei, Unregelmäßigkeit darin auch aufmerksam mache auf Unregelmäßigkeit im Zustand der Atmosphäre; später und noch vor 15 Jahren traf ich gepruifte Schiffsführer und Steuerleute, die einige Jahre in den Tropen gefahren hatten, davon aber nichts wußten »dort drohte kein schlechtes Wetter, also achteten wir nicht auf das Aneroid.« - In meiner mehrerwähnten Veröffentlichung S. 6 wies ich auf die betr. Periode hin, S. 15 sagte ich eingehender: "Schon in größerer Entfernung von dem Sturm, manchmal schon Tage vor seinem Eintreffen, giebt das Barometer leise Warnung durch Unregelmäßigkeit in der täglichen Periode, die Abnahme in seinem Stande ist stärker als dic Zunahme." - Aus den früher mitgeteilten Ergänzungen $z u$ den Berichten uiber den Iltis-Taifun und aus den bald folgenden über den Chàteaubriand und De Witte Taifun wird dies wohl einigermaßen kenntlich. Außer Acht darf allerdings nicht gelassen werden, daß3 in Passaten und Monsunen (wenn nicht überall) mehr oder weniger mit dem Wind fahrende Schiffe aus Gegenden mit höherem Luftdruck gelangen in Gegenden mit niedrigerem Luftdruck,
- gegen den Wind fahrende Schiffe gelangen aus Gegenden mit niedrigerem Luftdruck in Gegenden mit höherem: aber ein geübter Beobachter wird bald lernen den Unterschied zu erkennen, zwischen der Änderung im Barometerstande, die abhängt von der Ortsveränderung und derjenigen die abhängt von der Annäherung einer Störung im gewöhnlichen Zustand der Atmosphäre.

Sehr wiinschenswert ist es, daß alle meteorologischen Anstalten und alle an sicherer Reise der Seeschiffe beteiligte Personen hinwirkcn auf zweistündliche regelmäßige Beobachtungen und Anschreiben des Barometerstandes, der Luft- unid Wasserwärme, Wolkengestalt, Niederschlag und Seeganges, wenigstens von mgs. $6^{\mathrm{h}}$ bis abds. $8^{\mathrm{h}}$ beide eingeschlossen; Beachten des spec. Gew. des Meerwassers ist auch sehr nuitzlich, wie bereits gesagt (Beiträge zur Meereskunde II. S. I4 S. 22 Sp. I), zeigt der aus ihm (olıne große Mühe) abgeleitete Salzgehalt zu gewissen Zeiten richtiger als das Thermometer ob in Land-Abwässerung oder im Meerwasser man sich befindet. "Warum wird das nicht allgemeiner bekannt " frug man mich, als auf mein Ersuchen, man es fortlaufend getan und zutreffend gefunden - man war sehr crstaunt als ich nachwies, es sei damals schon mehr als 30 Jahre veröffentlicht. - Wie ich bereits an andren Stellen erwähnte, hatte ich Gelegenheit vor 15 Jahren in 2 Sommern 3 mal den Nutzen solcher Beobachtungen auf Schiffen deutlich zu zeigen. - In Bezug auf Barometer-Beobachtungen sind die zweistündlichen durchaus wichtig zur Beurteilung der täglichen Periode, dies hoffe ich an einem Beispiel später eingehend zeigen zu können, doch läfit es sich auch erkennen aus den vorher und im I'olgenden gegebenen Ergänzungsberichten, sowie den Tafeln $\mathrm{a}-\mathrm{d}$, nur ist bei diesen $\mathrm{zu}$ beachten, daß sie nach Greenwich Zeit entworfen, also mit Hilfe der beigeschriebenen geogr. Länge die einzelnen Angaben $71 / 2$ bis 9 Stunden später anzusetzen sind. Die Übertragung auf eine bestimmte Zeit ist notwendig, um das Gleichzeitige deutlich zu kennzeichnen.

Vereinigung von Barometerkurven macht nicht uiberflüßig die Darstellung der Wetterlage, wie die täglichen Wetterkarten sie zeigen, sondern jene ergänzen diese für bestimmte Fälle. Von den schon ein paarmal erwähnten drei Taifunen gab nur Hr. Dir. Decheorens für den Chateaubriand-T a ifun eine Zusammenstellung der Barometerstände nach den ihm mitgeteilten Berichten wenigstens von vier der Beobachter, die damals im Zentrum waren, sie ist wiederholt von $\mathrm{Hr}$. Dir. Froc in Typhoon Highways in the far Last, No. I. Across the South End of Formosa Strait S. 19. - Hr. Dir. Dechearcns gab derartige Zusammenstellungen auch fuir andere Taifune. - In den Arbeiten über den Ilt is - und den De Witte-Taifun ist keine Vereinigung solcher Kurven.

Tafel a. Der Inhalt dieser Tafel ist, wie auf ihr bemerkt, bereits vor Jahren veröffentlicht in den Verhandlungen des Vereins für naturwissenschaftliche Unterhaltung in Hamburg, Bd. V, VI, VII; er ist hicr wiederholt wegen des ungewöhnlich niedrigen Barometerstandes in den betr. 3 Fällen.

Die eigenartige Kurve nach den Beobachtungen I. Brt. M. S. Conqueror 1865 September $3-5$ ist 
veranlaft durch das gewiß sehr seltene Vorkommen, dafi dies Schiff zweimal in das Zentrum desselben Taifun geriet, indem es beigedreht liegend rascher trieb als das Zentrum vorrückte, also um das Zentrum herum trieb. In Bezug auf die Kurve nach dem Barstd. an Bord 13rt. Bk. Southern Belle I869 VIIl I9 sei hier nochmals crwähnt (vgl. Vhdlg. V. f. Naturw. Uthltg. $\mathrm{H} \mathrm{mbg} . \mathrm{V}$. S. I 59) daß in dem ursprunglichen Zeitungsbericht der vor mir benutzt wurde von Hrrn. Marine Stabsarzt Dr. Nammann (Beiheft zum MarineVerordnungsblatt) und Baron i'. Hordt (Reizen door de Chinesche Zee u. S. w. I. 2d. Druk iS79) offenbar enthalten ist ein leicht crklärlicher Fehler des Zcitungs-Berichterstatters, der den ihm als niedrigst genannten Barstd.: Sicben und zwanzig sicben (Koll englisch) schrieb 27,7 statt 27,07 , denn da man mit Hilfe des Vernier ablesen konnte $27,3 \mathrm{Z}$., so luäte man $27, ; \mathrm{Z}$. gewiß ablesen können; deshalb ist hicr angenommen, so wie fruher, $687,6 \mathrm{~mm} .=27,07 \mathrm{Z}$. engl. als niedrigster Barstd. Soweit Zunahme im Betrage des niedrigsten Barometerstandes auf verschiedenen Schiffen die im "Zentrum " waren. betrachtet werden kann als "Auffuillen des Zentrum ", fand es hier statt von Southern Belle zu Brt. Bk. Ocean Queen und D. Bk. Condor.

Letztere Bemerkung gilt auch für den Taifun vom 2I-22. IX I 869 , von $V$. S. N. Am. S. Id a ho, zu D. Bk. Condor und D. Bk. Joachim Christian. - Wenn vorliegen Berichte, auf nach einander im " Kentrum « befindlichen Schiffen habe der Barometerstand stetig abgenommen, so könnte man sprechen von zunehmender "Luft-Entleerung « oder "Vertiefung « des Zentrum.

Bei diesen vier Zusammenstellungen erkennt man (wie bei allen derartigen) aus den Kreuzungsstellen der cinzelnen Kurven, welche Gegenden - unter Voraussetzung der Berichtigung aller Angaben für Standfehler, Wärme u. s. w. - in einer Karte zu bezeichnen wären als unter gleichem Luftdruck liegend (durch Isobarein verbunden werden könnten). Nicht selten dürfte dadurch hingewiesen werden auf die Notwendigkeit zahlreicher freiwilliger Mitarbeiter, die auch die wenigen nötigen Instrumente selbst beschaffen oder von Privaten erhalten, da aus den Steuerkassen d. h. von den Regierungen immer nur ein bestimmter Teil für bestimmte Zwecke bewilligt werden kann.

'Iafel b. Barometerkuren im Châteaubriand'Taifun. Hr. Dir. Decharens sagt in The Typhoons of the Chinese Seas in the year 1880 beziglich des auf Frz. Bk. Châteaubriand benutzten Aneroid. "Nach Vergleich mit dem Quecksilber Baronieter des Hafenmeisters von A moy soll der Stand dieses Aneroid 3,3 mm. zu hoch gewesen sei; « unter der Voraussetzung, clal3 der betr. Stand sich nicht geändert, hätte man die Kurve um diesen Betrag zu ernicdrigen. Da kein Anhalt ist, ob diese Voraussetzung zutrifft, benutzte ich die Angaben wie sie gegeben sind. - Dieser Taifun und cliese Kurve sind, wie erwähnt, auch angewandt von

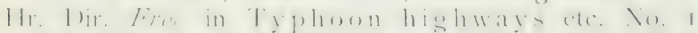
als Beispiel und Darstellung vom "Auffiillen « des Zentrum, Da nicht bestimmbar ist, ob dic Barometer vergleichbar waren und die Schiffsorte nur fur eine \%eit gegeben sind, blieben im Folgenden unberticksichtigt die Barometerkurven und Angaben ron Chàtea ubriand. Faugh Ballaugh, Kvik, Emma, Crusader.

Die Barometer-Kurven geben den Überblick, die Berichte die Zahlen des Barometerstandes, jene leiten auf den Vergleich, diese gestatten ihn in Bezug auf Örtichkeit und Entfernung. So sehen wir am Morgen des 25. IX G. Z. oder ugf. Mittag Ortszeit an der SEKüste Chinas (teilweise mit Hinzuziehen von Tafel B. Magpie-Bellerophon) in der Richtung N. $63^{\prime \prime} \mathrm{E}$. Entfrng. $=257 \mathrm{Sm}$. nur $0,5 \mathrm{~mm}$. Utschd. Barstd.; vor der ESeite der SMündung des Boungo Kanals in ugf. cler vierfachen Entfernung (Bellerophon -Oceanic) einen Utschd. von ugf. $2 \mathrm{~mm}$. also nahe gleichmäßig zunehmend. Der IVind ist E\%N-NE-N. mäßig bis stark. Während bis M. N. G. Z. in Hongkong der Luftdruck nahe gleich bleibt (nur $0,3 \mathrm{~mm}$. niedriger), nimmt er bei den in fast entgegengesetzter Richtung einander sich nähernden Schiffen langsam ab, beträgt bei ihnen (Abstd. N. $57^{0}$ E. 5 i $5 \mathrm{Sm}$.) nur I,5 mm., aber in umgekchrtem Verhältnis, denn während er I2 Std. fruiher im W1. Pacific am höchsten war, in der Mitte des Formosa Kanals nahe China Kiiste der niedrigste, ist er jetzt im El. Teil der EChina See (Oceanic) am niedrigsten, in Hongkong am höchsten. Bald nachher kommt zu den bisherigen Beobachtern ein vierter auf Gaëlic, der als in Swatau die von Hr. Dir. Decharens mitgeteilten Beobachtungen beginnen nur S. $77^{\circ} \mathrm{E} .4^{1} \mathrm{Sm}$. von diesem Ort ist, 26. $20,2^{\text {h }}$ G. Z. doch schon erheblicher niedrigeren Barstd. hat (vgl. Kurve und Bericht) 752,0 gegen 754,9. Von beiden Beobachtern kann man annehmen, sie befanden sich damals ugf. recht vor der Bahn des, im westlichen l'acific nach dem Slichsten Teil Formosa's ziehenden Taifun, daher (als Grundmaß fuir Entfernung benutzend den Grad geogr. Breite

60 Sm.) kann man bestimmen die Böschungszahl (den numerischen Gradienten) Swatau-Gä̈lic 26. IX 20, 2 G. Z. (4I:60 = 2,9: $x, x=$ 4, $x$. Von Takao sind die Beobachtungen damals leider noch nicht begonnen. Eigentiimlicherweise ist damals bei Hongkong (Magpic) der Barometerstand 756, 2 nahe gleich dem bei Oceanic 756,1 , bei Bellerophon (zwischen $\mathrm{S} w$ at a u bezw. Gaëlic und Oceanic) wenig höher 756,7; die Orte dieser 3 lieobachter sind: H. $22,3^{\circ} \mathrm{N}$. I $14,2^{\circ}$ E. B. $26,5^{\circ} \mathrm{N}$. $120,7^{\circ} \mathrm{E}$. O. $28,1^{\circ} \mathrm{N}$. $124^{\circ} \mathrm{E}$. oder S EChina K ̈̈ste, - nahe der EChina. Kiiste ugf. Nitte zwischen Fu tschau- IVen tschau und etwas WV. von der Mitte der EChina See. Als Takao im Zentrum war, befanden sich die funf hier in Betracht gezogenen Beobachter in solchen Stellungen, um den Barstd. bei ilnen nur vergleichen zu können mit Takao selbst $726,4 \mathrm{~mm}$; d dies ergiebt die Böschungszahlen (wieder nach Entfernung geordnet) T.-G. N. $50^{\circ} 11$. I 30 Sm., 7+3, - 7,s; T. - S. 201, $749,5 \quad 6,9 ;$ T.-B. N. $10^{0}$ E. $273,754,6 \cdots 6,2 ;$ T. -0 . N. $19^{\circ 1}$ E. $288,755,4=6,0 ;$ T. $-11 . \quad S .87^{\circ} \mathrm{IV} \cdot 337$, 752,9 4 4, Betrachten wir die Kurven in Tafel b, so sehen wir dieselben um diese Zeit in 2 Gruppen geteilt, in denen jene nahe parallel sind, jedoch dabei himweisend auf die größsere Annäherung des \%entrum. Zur suidlichen 
1880. IX. Brt. Dpf. "Bellerophon", Kpt. F. W. Freeman. Hongkong -- Schanghai.

(Meteorological Office, London. Mit gütiger Erlaubnis des Meteorol. Council, Dir. Dr. Shaw und Kpt. Campbell Hepworth, Commdr. Brt. R. N. R., Marine Superintendent, von mir abgeschrieben.)

\begin{tabular}{|c|c|c|c|c|c|c|c|c|c|c|c|c|c|}
\hline \multicolumn{2}{|c|}{ G. Z. } & \multicolumn{2}{|c|}{ Schf. Z. } & \multicolumn{2}{|c|}{ Schiffsort } & \multicolumn{2}{|c|}{ Wind } & \multirow{2}{*}{$\begin{array}{l}\text { Luft- } \\
\text { Druck } \\
\text { mm }\end{array}$} & \multirow{2}{*}{\multicolumn{2}{|c|}{$\begin{array}{l}\text { Luft } \\
\quad{ }_{0}\end{array}$}} & \multirow{2}{*}{ Wetter } & \multicolumn{2}{|l|}{ Seegang } \\
\hline $\mathrm{T}$ & h. & $\mathrm{T}$ & h. $\mathrm{m}$ & N. & E. G. & von & Stk. & & & & & von & Höhe \\
\hline 25 & $\begin{array}{r}4,1 \\
8,1 \\
12,1 \\
16\end{array}$ & 25 & $\begin{array}{c}\text { M. } \\
16 \\
20 \\
\text { M.N. }\end{array}$ & T'sing se & quer & $\begin{array}{l}\mathrm{NE} \\
\mathrm{NE} \\
\mathrm{NE} \\
\mathrm{NE}\end{array}$ & $\begin{array}{l}5 \\
5 \\
5 \\
5\end{array}$ & $\begin{array}{r}760,3 \\
59,6 \\
59,6 \\
59, \pi\end{array}$ & $\begin{array}{l}26,4 \\
25,5 \\
25,5 \\
25,1\end{array}$ & $\begin{array}{l}26,5 \\
26,2 \\
24,9 \\
25,1\end{array}$ & $\begin{array}{c}\text { c. b. } \\
\text { c. } \\
\text { b. }\end{array}$ & $\begin{array}{l}\mathrm{NE} \\
\mathrm{NE} \\
\mathrm{NE} \\
\mathrm{NE}\end{array}$ & $\begin{array}{l}4 \\
4 \\
4 \\
4\end{array}$ \\
\hline 26 & $\begin{array}{r}20 \\
0 \\
4 \\
8 \\
12 \\
16\end{array}$ & 26 & $\begin{array}{r}4 \\
8 \\
\text { M. } \\
16 \\
20 \\
\text { II.N. }\end{array}$ & $\begin{array}{ll}25 & 23 \\
25 & 36\end{array}$ & $\begin{array}{ll}119 & 57 \\
120 & 16\end{array}$ & $\begin{array}{l}\text { NE } \\
\text { NNE } \\
\text { NNE } \\
\text { NNE } \\
\text { NNE } \\
\text { NNE }\end{array}$ & $\begin{array}{l}5 \\
5 \\
6 \\
6 \\
7 \\
7\end{array}$ & $\begin{array}{l}59,4 \\
60,0 \\
59,8 \\
57,2 \\
56,6 \\
57,3\end{array}$ & $\begin{array}{l}24,9 \\
25,5 \\
24,8 \\
25,4 \\
24,9 \\
23,9\end{array}$ & $\begin{array}{l}25, \\
24,9 \\
25,6 \\
26,1 \\
25,3 \\
25,2\end{array}$ & $\begin{array}{l}\text { b. c. } \\
\text { " } \\
\text { b. } \\
\text { b. c. }\end{array}$ & $\begin{array}{c}\text { NE } \\
\text { NNE } \\
\text { NNE } \\
\text { NE } \\
\text { NE } \\
\text { NEzN }\end{array}$ & $\begin{array}{l}4 \\
4 \\
5 \\
6 \\
6 \\
7\end{array}$ \\
\hline 27 & $\begin{array}{c}20 \\
0 \\
3,9 \\
\boldsymbol{\gamma}, 9 \\
11,9 \\
15,9\end{array}$ & 27 & $\begin{array}{c}4 \\
8 \\
\text { M. } \\
\mathbf{1 6} \\
20 \\
\text { M.N. }\end{array}$ & $\begin{array}{l}\text { Gelegentlich sch } \\
\qquad \begin{array}{rr}26 & 53 \\
27 & 10\end{array} \\
\text { Von MI. bis } \\
\text { WVind von }\end{array}$ & $\begin{array}{l}\text { were Windstüfe } \\
\qquad \begin{array}{l}12058 \\
1219\end{array} \\
4^{\text {hi }} \text { dreht der } \\
\text { l.- - NNE. }\end{array}$ & $\begin{array}{c}\text { NyE } \\
\text { NNE } \\
\text { NNE } \\
\text { NNE } \\
\text { NNE } \\
\text { NE }\end{array}$ & $\begin{array}{l}7 \\
8 \\
9 \\
9 \\
9 \\
6\end{array}$ & $\begin{array}{r}56,8 \\
55,8 \\
55,3 \\
\mathbf{5} \mathbf{t}, 3 \\
58,0 \\
56,\end{array}$ & $\begin{array}{l}23,8 \\
23,7 \\
23,8 \\
24,4 \\
23,8 \\
24,2\end{array}$ & $\begin{array}{l}24,9 \\
24,8 \\
25,5 \\
25,5 \\
25,4 \\
25,5\end{array}$ & $\begin{array}{l}\text { c. } \\
\text { o. } \\
\text { o. } \\
\text { o. c. } \\
\text { o. r. }{ }^{2} \\
\text { p }\end{array}$ & $\begin{array}{l}\text { NNE } \\
\text { NNE } \\
\text { NNE } \\
\text { NNE } \\
\text { NNE } \\
\text { NEzE }\end{array}$ & $\begin{array}{l}7 \\
8 \\
8 \\
8 \\
5 \\
5\end{array}$ \\
\hline 28 & $\begin{array}{r}19,9 \\
23,9 \\
3,9 \\
7,9 \\
11,9 \\
15,9\end{array}$ & 28 & $\begin{array}{r}4 \\
8 \\
\text { II. } \\
16 \\
20 \\
\text { MI.X. }\end{array}$ & 2835 & $122 \quad 6$ & $\begin{array}{c}\text { NEzE } \\
\text { E } \\
\text { ESE } \\
\text { NNE } \\
\text { NNE } \\
\text { NE } \% \text { L }\end{array}$ & $\begin{array}{l}5 \\
3 \\
3 \\
4 \\
1 \\
5\end{array}$ & $\begin{array}{l}57, \pm \\
59,4 \\
59,11 \\
59,7 \\
60,5 \\
61,0\end{array}$ & $\begin{array}{l}24, \\
25,5 \\
26,1 \\
25,1 \\
24,4 \\
23,8\end{array}$ & $\begin{array}{l}25,3 \\
24,9 \\
25,2 \\
24,9 \\
25,2 \\
24,4\end{array}$ & $\begin{array}{c}\text { c. } \\
\text { c. } \\
\text { c. } \\
\text { o. } \text { r. }^{2} \\
\text { c. } \\
\text { c. }\end{array}$ & $\begin{array}{l}\text { NEzE } \\
\text { SE } \\
\text { Slich } \\
\text { Slich } \\
\text { Slich } \\
\text { Slich }\end{array}$ & $\begin{array}{l}4 \\
4 \\
4 \\
4 \\
4 \\
4\end{array}$ \\
\hline 29 & $\begin{array}{r}19,9 \\
23,9 \\
5,1\end{array}$ & 29 & $\begin{array}{rr}4 & \\
8 & \\
13 & 15\end{array}$ & ankerten b. d. rot & en Boje Wusong & $\begin{array}{l}\mathrm{NE} \\
\mathrm{NE}\end{array}$ & $\begin{array}{l}4 \\
3\end{array}$ & $\begin{array}{l}61,2 \\
62,8\end{array}$ & $\begin{array}{l}22,7 \\
22,2\end{array}$ & $\begin{array}{l}23,3 \\
23,0\end{array}$ & o. c. & $\begin{array}{l}\text { unregelmäßig } \\
\text { unregelmäßjig }\end{array}$ & $\begin{array}{l}2 \\
2\end{array}$ \\
\hline
\end{tabular}

Gruppe gehören die in Tafel b mit 5, I0, 8 und 12 bezeichneten: Takao, Gaëlic, Swataund Magpie, - zur nördlichen die 9 und I bezeichneten: Bellero. phon und Oceanic. Auffallend ist, daß nach IX 26. $20^{h}$ G. Z. bei Gaëlic, Swatau, Bellerophon die tägliche Periode unterbrochen ist; während sie bei G. und B. es bleibt bis zum niedrigsten Barometerstande, wird sie bei $S$. am IX 27 . von $7,2^{\mathrm{h}}-12,2^{\mathrm{h}} \mathrm{G}$. $\mathrm{Z}$. oder I $5^{\mathrm{h}}-2 \mathrm{O}^{\mathrm{h}} \mathrm{O} . \mathrm{Z}$. nochmals kenntlich. Diese Unterbrechung und die Bemerkung bei B. zeigen dies Schiff tatsächlich im Bereich des Taifun.

Nur ugf. $\mathrm{I}^{1 / 2}$ Stunder nach Taka o berichten gleichzeitig Ga c̈lic und Belleroph on den geringsten Barstd. ob er es wirklich war bleibt fraglich, weil, besonders bei 13. die Zwischenzeit zwischen je zwei Angaben fü genaue Bestimmung noch zu groß3 ist; ob Schreibbarometer in solchen Fällen helfend eintreten, hängt sicherlich ab von der Lage und den Erschiitterungen des Schiffes; sorric von unberechenbaren Zufälligheiten in der Herstellung des Instrumentes und voribergehenden, unbemerkt bleibenden. - Ob z. \%t. des niedrigsten berichteten Barstds. beide Schiffe sich in solcher Stellung zum Zentrum befanden, um aus dem Unterschied jenes das BöschungsVerhältnis als sicher bestimmbar zu betrachten: erscheint fraglich; leitet man es gebrauchsmäßig ab (Bellerophon von Gaëlic N. $35^{\circ}$ E. $237 \mathrm{Sm}$.) so erhält man $-3,4$.
Der von Gaëlic angebene geringste Barstd. ist noch $2,1 \mathrm{~mm}$. niedriger als der bei $\mathrm{S} w a t a \mathrm{u}$, demnach ist man geneigt zu glauben, das Zentrum sei diesem Beobachter näher gewesen als jenem; neben dem Bericht von Sindh, könnte man also auch den von Gä̈lic ansehn als Hinweis auf "Auffullung des Zentrum "

I 889 IX 27 . I $7^{\text {h }}$ befand sich Frz. P. Dpf. Sindh im Zentrum, die Beobachter um ihn derart verteilt, daß3 der Barstd. bei Hongkong (Magpie), Swatau und Gaëlic mit dem auf ihm selbst vergleichbar ist; die Richtung nach Oceanic und Bellerophon ist derart, um es wohl zuläßig zu erachten, die Böschungszahlen Sindh: Gaëlic, Gaëlic: Oceanic, Oceanic: Bellerophon als für diese Richtung im Taifun geltend anzunehmen. Die Tabelle S. 25 wieder benutzend erhält man: Sindh: $738,1 \mathrm{~mm}$ - Swatau N. $69^{0}$ IV. 4I Sm. $7+5,1$ It,i: Sindh Gälic: N. 54" li. 122 . Sm. $747,2=4,5 . \quad\left[\right.$ Gaëlic - Oceanic N. 35 $5^{\circ}$ E. Iog Sm. $754,2=3,9$; Oceanic-Bellerophon: N. $27^{\circ}$ W. $139 \mathrm{Sm} .757,0=1,2]$. Da Takao um genannte Zeit den Barometerstand nicht berichtet, so kann die betr. Böschungszahl nicht abgeleitet werden. Sindh-Magpie: S. $75^{\circ} \mathrm{IV} .{ }_{1} 84 \mathrm{Sm} .753,3=5,0$.

Als Swatau den niedrigsten Barstd. berichtet, weisen die Kurven darauf hin, und die Zahlen der Berichte beweisen es, daß bei Gaëlic der Einfluß der täglichen 


\section{September. Brt. Dpf. "Gaëlic", Kapt. W. H. Kidley. Hongkong - Yokohama.}

\begin{tabular}{|c|c|c|c|c|c|c|c|c|c|c|c|c|c|c|c|c|c|c|}
\hline \multicolumn{3}{|c|}{$\begin{array}{c:c}\text { G. } \mathrm{Z} . \\
\mathrm{T} & \mathrm{h}\end{array}$} & \multicolumn{2}{|c|}{$\begin{array}{l}\text { Schf. } / \mathrm{s} \text {. } \\
\text { T' h }\end{array}$} & ${ }_{0}^{N}$ & Schiffsort & $\begin{array}{l}\text { iffsort } \\
\begin{array}{|c}\text { E. } \\
0\end{array}\end{array}$ & G. & \multicolumn{2}{|l|}{ Wind } & $\begin{array}{l}\text { Bar: } \\
\mathrm{inm}\end{array}$ & \multicolumn{2}{|c|}{$\begin{array}{l}\text { Is. } \\
{ }^{0} \mathrm{C} .\end{array}$} & $\begin{array}{c}\text { Bewölkung } \\
\text { Form }\end{array}$ & $\frac{0}{1}$ & Wetter & $\begin{array}{l}\text { Seegang } \\
\text { ron }\end{array}$ & $\begin{array}{c}\text { co } \\
\text { Höhe }\end{array}$ \\
\hline \multirow{2}{*}{\multicolumn{2}{|c|}{26.}} & 4,3 & 26. & M. & 22 & 21 & 115 & 16 & Viidl. & 2 & 756,5 & 26,8 & 26,9 & ci & 2 & b c & \multirow{2}{*}{$\begin{array}{l}\text { NE Dünung } \\
\text { wirre Dünung }\end{array}$} & $\left.3^{2}\right)$ \\
\hline & & 8,3 & & 16 & & 34 & & 51 & Viidl. & 2 & 54,2 & 26,3 & 26,9 & $\frac{\text { ci cu }}{\text { eu str }}$ & 5 & $=5$ & & 2 \\
\hline \multirow{2}{*}{\multicolumn{2}{|c|}{$\begin{array}{l}\dot{\bar{\Xi}} \\
\text { } \\
20 \\
\text { si }\end{array}$}} & 12,2 & & 20 & & 47 & 116 & 23 & Vïill. & 2 & 54,7 & 26,3 & 26,3 & & 6 & o $\mathrm{c}$ & , & $\left.4^{2}\right)$ \\
\hline & & 16,2 & & II. N. & & 59 & & 54 & Väidl. & 2 & $53, \overline{7}$ & 26,3 & 26,3 & diesig & 9 & $g$ & sehr wirre Dünung & $\left.4^{3}\right)$ \\
\hline \multirow{2}{*}{\multicolumn{2}{|c|}{$\begin{array}{l}= \\
= \\
0 \\
0\end{array}$}} & 20,2 & 27. & 4 & 23 & 11 & 117 & 27 & $y$ & 3 & 52,0 & 24,0 & 25,2 & $\frac{\mathrm{cu}}{\mathrm{cu}-\mathrm{sir}}$ & 5 & o $\mathrm{e}$ & sehwere wirre Dünung & $\left.4^{4}\right)$ \\
\hline & & 22,1 & & 6 & & 22 & & 40 & SW & + & 50,7 & & & & & & & 5) \\
\hline \multirow[t]{8}{*}{$\dot{s}$} & 27. & 0,1 & & 8 & & 34 & & 52 & $\mathrm{NIV}$ & i) & 50,0 & 25,2 & 24,1 & $\frac{\mathrm{cu}}{\mathrm{cu} \text { str }}$ & 7 & u c & ' & 5 \\
\hline & & 2,1 & & 10 & & 43 & 118 & 1 & NW & 5 & $49, \overline{7}$ & & & & & & & \\
\hline & & 4,1 & & M. & & 52 & & 10 & NIV & 6 & 47,6 & 27,9 & $2 \tilde{5}, 8$ & $\frac{\text { custr }}{\text { cu ni }}$ & 9 & $u g$ & , & 59 \\
\hline & & 6,1 & & 14 & & 59 & & 23 & XXII & 8 & 44,6 & & & & & & & 7) \\
\hline & & 8,1 & & 16 & & 59 & & 39 & $\mathrm{~N}_{2} \mathrm{WV}$ & - & 10,8 & 24,6 & 24,7 & $\frac{\mathrm{cu}}{\mathrm{cu}}$ & 10 & $>\quad$ & hoher u. sehr wirrer Seeg. & $\left(9^{8}\right)$ \\
\hline & & 10,1 & & 18 & & 59 & & 54 & $\mathrm{~N}$ & 9 & 41,0 & & & & & & & \\
\hline & & 12,1 & & 20 & 24 & 0 & 119 & 10 & $x$ & - & 42,0 & 25,2 & $24, \overline{7}$ & $\frac{\mathrm{cu}}{\mathrm{eu}}$ & 10 & d u & & 9 \\
\hline & & 14,1 & & 22 & & 6 & & 11 & NNE & 10 & 45,8 & & & & & & & \\
\hline \multirow{11}{*}{ 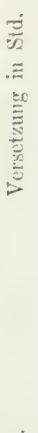 } & & 16,1 & & II. Y. & & 14 & & 13 & NE & 10 & 47,1 & $25, ;$ & 24,7 & $\begin{array}{l}\text { cu } \\
\text { eu } n i\end{array}$ & $|10|$ & $\mathrm{ur}$ &,, 2, & 99 \\
\hline & & 18,1 & 28. & 2 & & 21 & & 14 & NEzE & 9 & $4 \pi, 4$ & & & & & & & \\
\hline & & 20,1 & & 4 & & 28 & & 16 & $\mathrm{E}$ & 8 & 47,9 & 25,2 & 25,2 & $\frac{\text { str }}{\mathrm{cut}}$ & $i$ & $\mathrm{~g} r$ & hohe Sce u. wirre Dünung & 9 \\
\hline & & 22,1 & & 6 & & 35 & & 17 & & & 49,7 & & & & & · & & 10) \\
\hline & 28. & 0 & & 8 & & 42 & & 33 & SE & 5 & 53,2 & 25,7 & 25,2 & $\begin{array}{l}\text { sir } \\
\text { ni }\end{array}$ & 10 & o g & & 8 \\
\hline & & 2 & & 10 & & 49 & & 49 & & & 53,7 & & & & & & & \\
\hline & & 4 & & M. & & 57 & 120 & 0 & Viidl. & 2 & 54,2 & 26,8 & 26,3 & $\frac{\mathrm{str}}{\mathrm{ni}}$ & 5 | & g c & wirre Dïnung & $\left.5^{11}\right)$ \\
\hline & & 8 & & 16 & 25 & 16 & & 34 & & & 55,2 & 26,8 & 26,3 & $\frac{\mathrm{ell}}{\mathrm{cu}}$ & $\tau$ & o g & , & 4 \\
\hline & & 11,9 & & 20 & & 34 & 121 & 9 & ESE & 3 & 56,5 & 24,0 & 25,2 & $\frac{\mathrm{ei}}{\mathrm{str}}$ & 5 & b e & YE Diinung & $\left.3^{12}\right)$ \\
\hline & & 15,9 & & II. N. & & 53 & & 44 & El. & 3 & 56,0 & 25,2 & 25,2 & $\begin{array}{l}\mathrm{ci} \\
\mathrm{eu}\end{array}$ & 5 & 20 & , & $\left.3^{13}\right)$ \\
\hline & & 19,8 & 29. & 4 & 26 & 21 & 122 & 18 & El. & 2 & 57,3 & 26,8 & 26,3 & $\frac{\mathrm{ci}}{\mathrm{str}}$ & 5 & $=3$ & NE - E Dünung & 2 \\
\hline \multirow{5}{*}{ 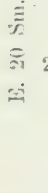 } & & $2: 3,8$ & & 8 & & 30 & & 52 & viil.ra.u.d. Kompass & 2 & 57,3 & 26,8 & 26,3 & $\frac{\mathrm{ci}}{\text { str ni }}$ & 6 & $\mathrm{rc}$ & , - , & $\left.2^{14}\right)$ \\
\hline & 29. & 3,8 & & M. & & 49 & 123 & 30 & $\mathrm{XNE}$ & 3 & 57,3 & 27,4 & 25,8 & $\frac{\mathrm{cu}}{\mathrm{cu} \mathrm{ni}}$ & 8 & q $\mathrm{c}$ & $=-$ & $\left.2^{13}\right)$ \\
\hline & & $7, \bar{i}$ & & 16 & 27 & 2 & 124 & 6 & $\mathrm{NE}$ & 2 & 55,2 & 26,8 & 26,3 & $\frac{\text { cuvกnNE }}{\text { cu ni }}$ & 5 & , & NEl. Diinung & $\left.3^{16}\right)$ \\
\hline & & 11,7 & & 20 & & 14 & & 41 & NE & 3 & 56,8 & 26,3 & 26,8 & $\frac{\text { cuvon NE: }}{\text { ní str }}$ & 6 & , & , & 4 \\
\hline & & 15,6 & & II. N. & & 28 & 12.) & 17 & $\mathrm{NE}$ & 5 & 56,8 & 263 & 25,8 & cti & 6 & $=2$ & , & $\left.4^{17}\right)$ \\
\hline
\end{tabular}

Standiehler des Barometer unbekaunt.

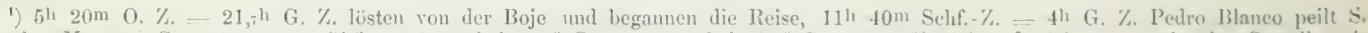

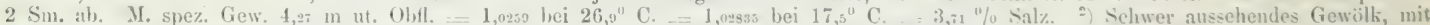
geringer oder keiner Bewegung. ") Bezogen mit schwïlem (drïckendem, sultry) fefïhl, und sehr wirre I) hinung aber kein Brechen der Wellen. \$) Der II ind ist nördlich, aber holt nach NW und seine Stïke nimmt zu. oj ( Um fih) häbliches, drohentes Aussehen und stürmisches Wetter

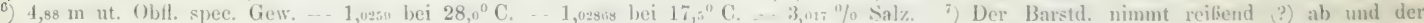
Wind holt nordwiirts, das Schift ist im (vorderen) rechten Viertel des Taifun; stenerten nach Norden, lis wir dicht unter Lamd waren, dann

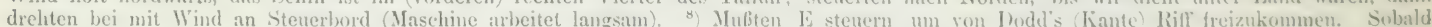
wir von ihm klar waren drehten wir wieder bei. In den Bien betrug die Windstïrke 12. Das Sehiff lag gut auf der See, uahm aber viel Wasser iiber. 5) Um M. N. Wind NE. und hesser aussehender Himmel; der Barometerstand nahm raseh zu. 1u) Iher Wind hat etwas sl.

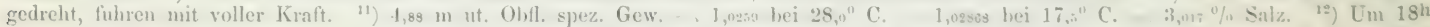

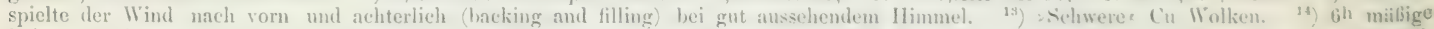

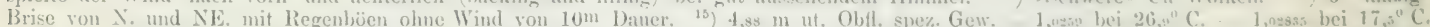

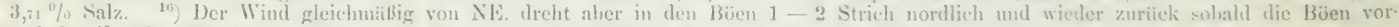
iiber sind. ${ }^{17}$ ) Die Bïen halten nicht lange an, sind aher zahlreich, mil sehr schweren seen.

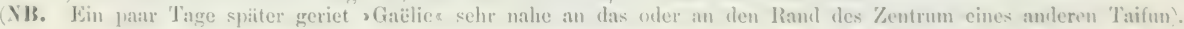


1880. September. Brt. Dpf. "Oceanic", Kpt. John Metcalfe. Yolrohama - Hongkong.

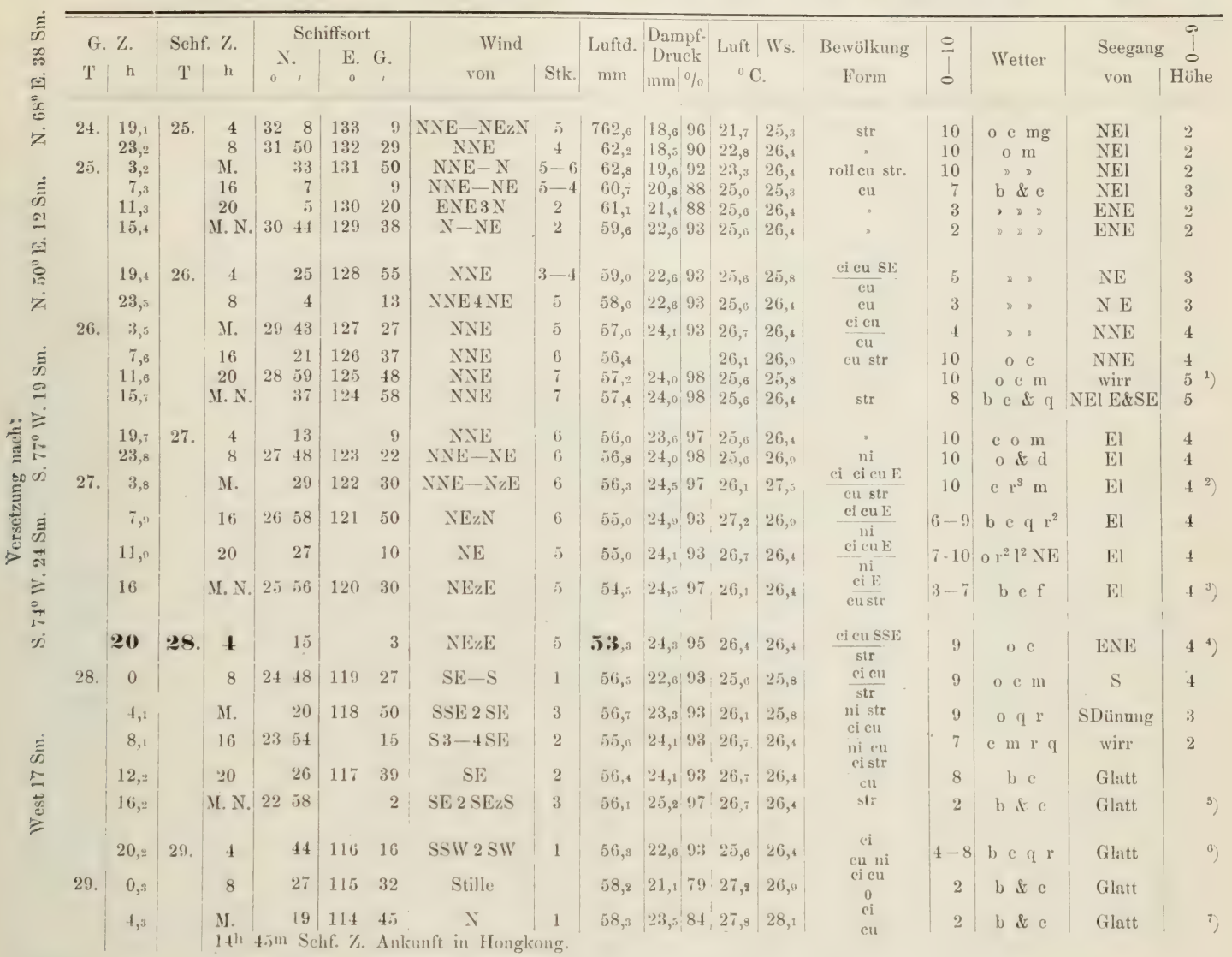

1) Die Seen banen sich zuweilen hoch nuf. 2, Die unteren Wolken ziehen mit dem Wind (d. i. ugf. quer zu den oberen). Mttgs. starker Regen; der Wind sprang nach ESE, nach dem Regen sprang er zuriick. ${ }^{3}$ ) Der Himmel ist zuweilen wolkenlos aber mit Dunst uiberzogen; der Wind weht stolweise. ${ }^{4}$ Um $2 \mathrm{~h}$ starker. Wind und hohe See; 3 h sahen Tumabout Lt. $4^{\mathrm{h}}$ IVind und See erheblich mïßiger;

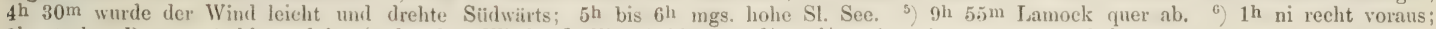
$2^{\mathrm{h}}$ starker Regen mit hin und her ïnderndem Wind. ${ }^{7}$ ) Eine Schlange, $1^{3 / 4}-2^{1 / 2} \mathrm{~m}$ lang $\mathrm{kam}$ an uns vorbei.

Periode bereits wieder bemerklich wird, indem die $\mathrm{Zu}$ nahme im Barstd. auffallend geringer ist, - andererseits Magpie, Oceanic, Bellerophon noch unter dem Einfluß des Zentrum sind, da bei den ersteren beiden kurz vorher der niedrigste Luftdruck angegeben ist, bei letzterem statt weiterer Abnahme noch geringe Zunalime beobachtet war. Swatau und Hongkong lagen in entgegengesetzten Hälften des Taifun, also kann der Unterschied im Barstd. nicht benutzt werden zur Ableitung der Böschungszahl; sucht man dagegen den damaligen Schiffsort von Gaëlic, Oceanic und Bellerophon, denkt man ihn eingetragen in Tafel A (hier nicht geschehen, um die Richtungslinien von angegebenen
Zentrumorten klarer bleiben zu lassen) so wird man wohl die Böschungszahlen Swatau - Gaëlic, Gaëlic Oceanic, Oceanic-Bellerophon, gelten lassen als Annäherung an die entsprechenden gegen Ende des Taifun. Demnach wäre (vgl. Tafel A und Berichte) zunächst der Standort der Beobachter S wa t a u: $23^{\circ} 20^{\prime} \mathrm{N}$. I $16^{\prime \prime} 43^{\prime}$ E. $742,9 \mathrm{~mm}$; Gä̈lic $24^{0} 29^{\prime} \mathrm{N}$. I $19^{\circ} \mathrm{I}^{\prime} \mathrm{E}$. 748,2 ; Occanic $25^{\circ}$ IO $^{\prime}$ N. I I $9^{\circ} 57^{\prime}$ E. 753,9 ; Bellerophon $28^{\circ} 4^{\prime} \mathrm{N}$. $121^{0} \quad 46^{\prime}$ E. 757,6 ; darnach S. -G.: N. $64^{0}$ E. $156 \mathrm{Sm} .=2,0 ;$ G. -O.: N. $42^{0}$ E. $55 \mathrm{Sm} .=6,2 ;$ O.-B.: N. $29^{\circ}$ E. $200=\mathrm{I}, 1$.

Es ist 7 u beachten, daß ugf. 7 Std. ehe Sindh ins Zentrum geriet, auf Magpie in Hongkong bei 
18s0. September. I. Brt. M. Vrmsg. S. "Magpie", Kpt. R. H. Napier R. N. Hongkong Hafen. Boje No. 3. $22^{\circ} 18^{\prime}$ N. $114^{\circ} 12^{\prime}$ E. G.

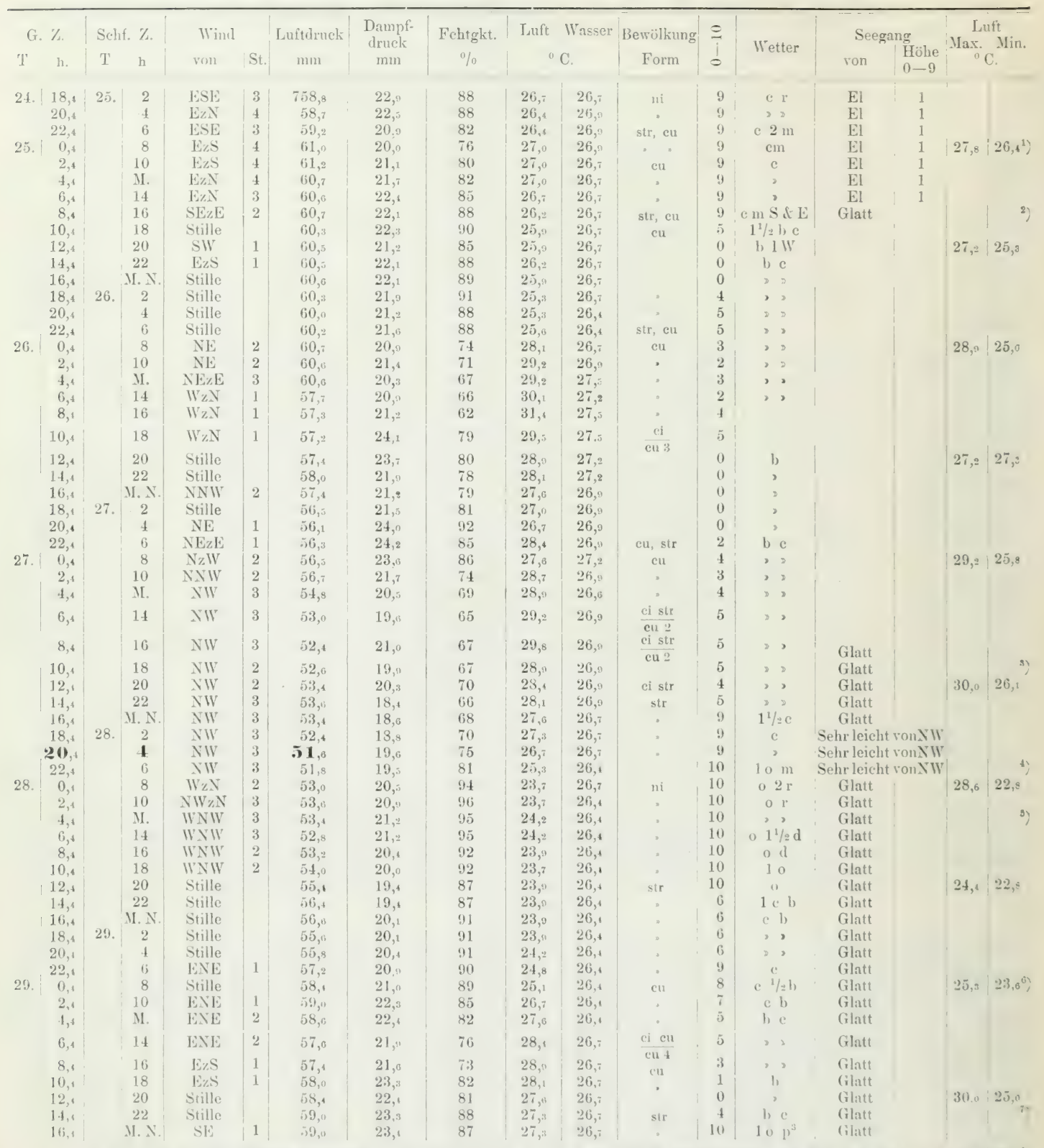

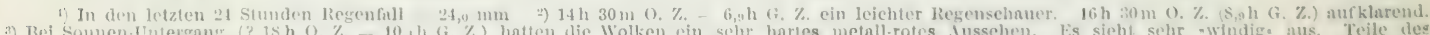

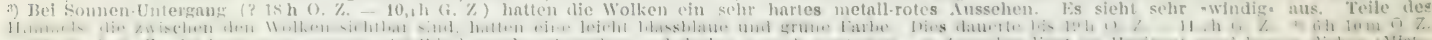

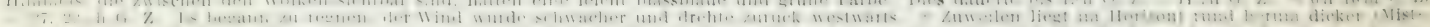

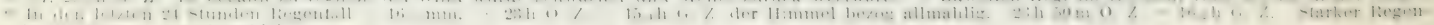
schater der wat: 1/, stal, anhielt. 
Sonnenuntergang beobachtet ist »windiges A Aussehen und eigenartige Färbung des Gewölks, also Anzeichen des in der Nähe befindlichen Unwetters, von dem die Kolonie damals verschont blieb. - Am Ende des Taifuns zeigen die Barometerkurven der vier (neuen) Beobachter wieder einiges Gleichartige und den erheblich höheren Luftdruck an dem Teil der E. China Küste zwischen ugf. vor Wen tschau und der Mündung des Y angtse nach Aufhören des Unwetters sehen wir nahe gleichen Luftdruck an der SE. - und dem Slichsten Teil der E. Küste China's; genauere Einzelheiten liefern die Berichte.

Aus den Mitteilungen von Oceanic und Bellerophon kann man schließen, daß über die ganze E. Chin a See der Taifun einen gewissen Einfluß hatte auf Gewölk, Wetter und Seegang. Da Ga èlic später noch von einem Taifun befallen wurde und nach den, von $\mathrm{Hr}$. Dir. Decheorens veröffentlichten Berichten, als G. den Hafen von Hongkong verließ das Unwetter bereits heranzog: so kann man sagen, der bald nach Gelangen in See sich zeigende wirre und schwere Seegang war an der S. und SE. China Kuiste das erste Anzeichen des Taifuns, das bald nachher unterstiitzt wurde durch Unterbrechung der täglichen Periode im Barstd.; indes würde ich doch cist noch auf andere Erscheinung im Seegang warten, ehe ich gewölnnlich aus "wirre Dünung» auf Annäherung eines Wirbelsturmes schlöß̉e. In der Nähe einer Küste kann Dünung und Seegang viel leichter hoch und wirr werden als auf offenem Meere, indem der Rücklauf der den Grund und die Kuiste berührenden Wogen die anlaufenden durchbricht, nirgend ausgleicht, sondern sogar, bald seltener bald öfter »aufbäumen " oder hoch und spitz auflaufen macht. Kpt. Kidley war ebenfalls uiberzeugt vom Zweifelhaften des nur wirren Seegangs, denn an 26.-27. M. N. Schf. $Z$. schreibt er ausdriicklich: kein Brechen der Wellen; das schwüle oder drückende Gefüll, vereint mit jenem mußte mehr Aufmerksamkeit erregen, das Verhalten des Barometerstandes gab Gewißheit der Annäherung des Taifun.

T'afel c. Barometerkurven im, ,Iltis"'Taifun. Die hierzu gehörenden Berichte von S. R. 11. S. Dmitrij Donskoj. Russ. Frw. IFl. S. Tambow, Frz. P. Dpf. Yarra, Melbourne, Salazie und vom Hongkong Observatorium sind bereits mitgeteilt bei Übersetzung der Übersicht iiber die betr. Tage sts. Hrrn. Dir. Doberck und Figg III. S. I 3-19. Neu hinzugekommen zu den von Hrr. Dir. Froc gegebenen sind nur solche, die zeigen Begleiterscheinungen an den Grenzen des eigentlichen Taifun-Gebiets; die anderen beiden: Tambow und Yarra geben willkommene Ėrgänzungen, wie es bei guitiger Zusendung mehr eingehender Berichte erklärlich ist. Erneuter Dank dafuir den genannten geehrten Anstalten und Herren. Die große Anzahl der Beobachter zwang zur Sonderung in Schiffsberichte (Tafel c oben) und in Landberichte (Tafel c unten); jene haben den Vorteil der größtenteils kiurzeren Zwischen. zeit der Beobachtungen, dagegen den Nachteil des bewegten Standpunktes und nur zul oft unvermeidlich ungünstiger Beleuchtung; diese haben den Vorteil untadelhafter, fester Aufstellung des Instrumentes, den Nachteil meistens längerer Zwischenzeiten der Beobachtungen.
Dic bei den »Richtungswinkeln « erwähnte ungleichmäßige Verteilung der Beobachter zeigt sich auch deutlich bei diesen Kurven. Bei den Schiffsberichten erkennt man zwei Hauptgruppen, Tafel B mit hinzuziehend sieht man die eine am großen E.Horn der China-Küste und ugf. in der Mitte der E. China See, wo am 22.-23. Juli der niedrigste Barstd. berichtet ist, die andre im Nl. Teil der Gelben See, an der Schantung Küste im Golf von Petschili und Liaotong mit dem geringsten Luftdruck am Abend des 23. und am 24. Juli; eine dritte Gruppe in der Japan See und Japan am 26. Juli Schf. Z. ist weniger auffallig. - Die Landberichte lassen 4 Gruppen erkennen; die erste ist nur vertreten durch Nafa d. i. S.Liukiu In., die zweite umfaßt den Tschu san Archipel, Mundung des Yangtse einschl. Schanghai, die dritte Schantung und die Küsten obengenannter Golfe; die vierte, hauptsächlich durch Wladiwostok kenntlich, zeigt auch Korea und wird ergänzt durch die dritte der Schiffsberichte.

Vergleicht man die Kurven des Tambow mit denen von Dpf. Whutu und Lienshing so würde man auch ohne Kenntnis von Tafel 3 und B. schließen, das Zentrum müsse nahe bei Tambow vorbeigezogen sein; da jene Tafeln dieser Tafel c vorangegangen, so wird augenfällig die gegenseitige lirgänzung. Es ist nicht möglich, ein bestimmtes Urteil zu fällen, ob bei Dpf. IV uhu tatsächlich der nicdrigste Barometerstand des Zentrum war; nimmt man an, der berichtete sei es gewesen, so weist dic Kurve auf "Vertiefung " des Zentrum bis es $6^{1 / 2}$ Std. später über Lienshing zog. Verhältnismäßig nahe, wie die Beobachter im Tschu san Archipel und in der Niindung des $Y$ angtse sich waren, ist bei den Kurven unvermeidlich nahes, an einander und teilweises in cinander liegen; ich versuchte, die von Chingping No. 26 durch geschlängelte Linie etwas kenntlicher zu machen. Vergleicht man die Kurve von Dmitrij Donskoj mit der von Tschimulpo (Landberichte No. 39) so fält auf, daf3 bei jenem obgleich or S.rärts fuhr, der Barstel. länger geringer blieb als bei diesem, der niedrigste dort angegeben ist nahe IO. Std. später als am nördlicher gelegenen Ort. - Da Melbourne während der liahrt von Schanghai nach Hongkong an den Orten der anderen Beobachter vorbeifährt, so liegt die Kurve seines Aneroids, ungefähr parallel bezw. in der ihrigen, ehe das Zentrum sich der Küste näherte; so zeigt sic auch, daß die Zeit des niedrigsten Barstds. auf dem Schiffe das sich ugf. $40 \mathrm{Sm}$. SSWI. von Hongkong befand, ugf. zusammenfällt mit dem hier (Landbericlite A). Dic weitere Lage von M's. Kurve ebenfalls im Vercin mit der H.s deutet an -wie weit S.wärts kenntlich war der Einfluß des Taifuns bis er den Golf von Petschili erreichte. - Bei den Landbeobachtungen sicht man an den Kurven recht deutlich den Nachteil der langen Zwischenzeiten der Berichte; man vergleiche z. B. Hongkong A, Nafa 29, Zi ka wei 33 mit Tschin kiang 34 , Tamsui 30 , Fusan 40, an denen es besonders auffällig wird; man frägt unwillkürlich ob bei den weniger auffalligen wie Steep I. 45, Gutzlaff I. 46, N. Saddle 1. 47 , Schaweischan I. 48 u. a. nicht recht wünschenswerte Angaben verloren sind, und $o b$ an derartigen Küsten und Inseln nicht

$$
\text { Fortsetzung S. } 40 \text {. }
$$




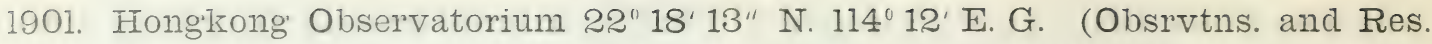
of the Hongkong Obsrvtr., Dir. W. Doberck, for the year 1901. Hongkong 1902).

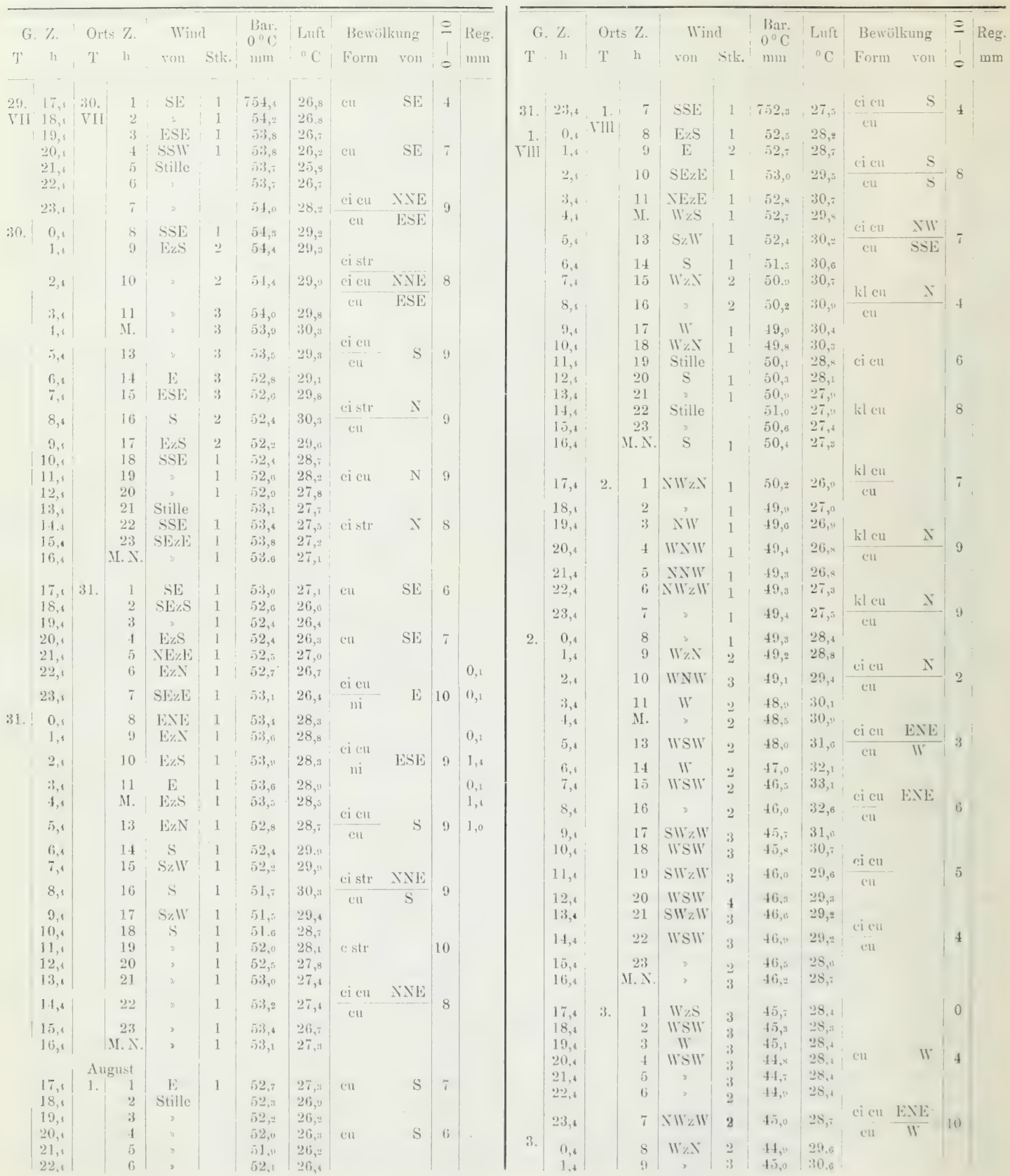




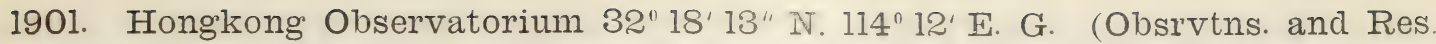
of the Hongkong Obsrvtr., Dir. W. Doberck, for the year 1901. Hongkong 1902).

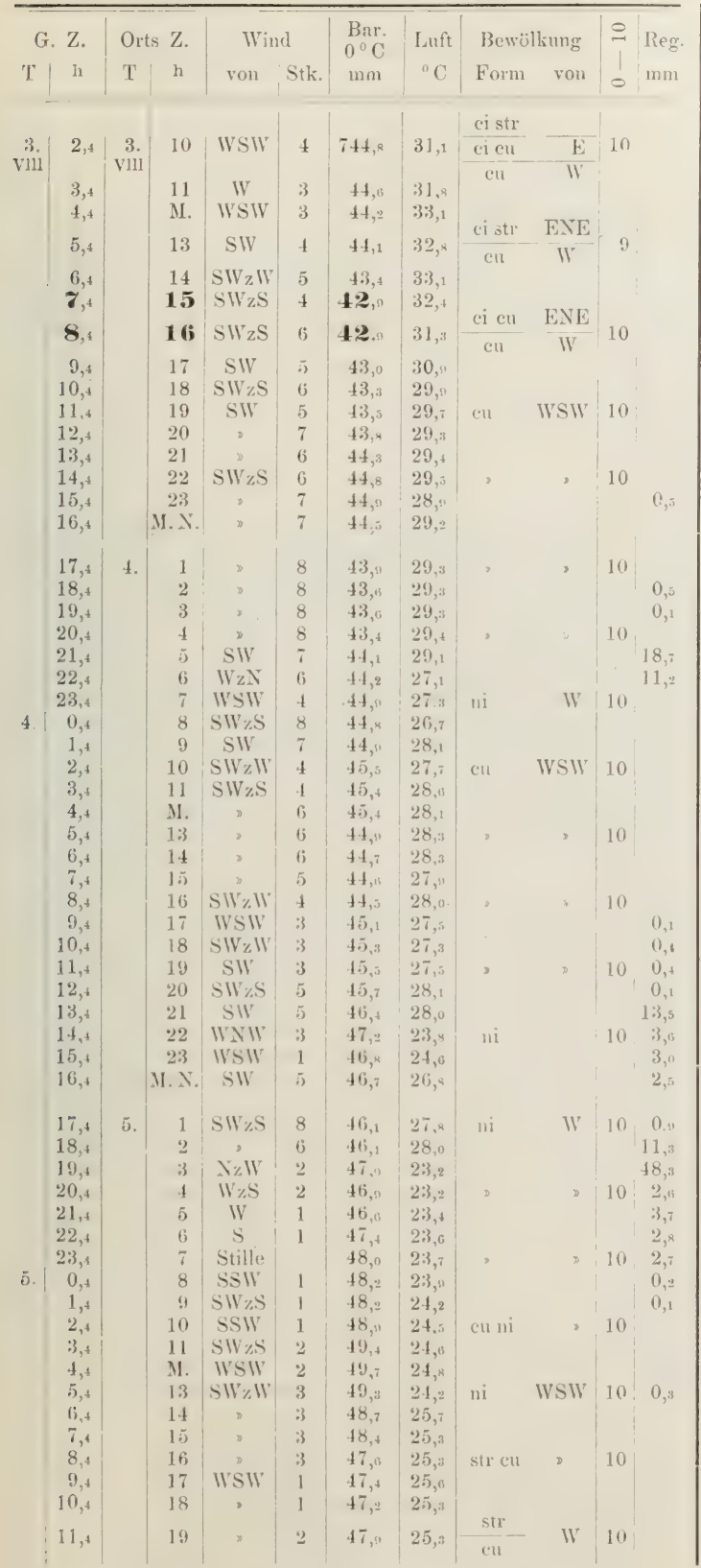

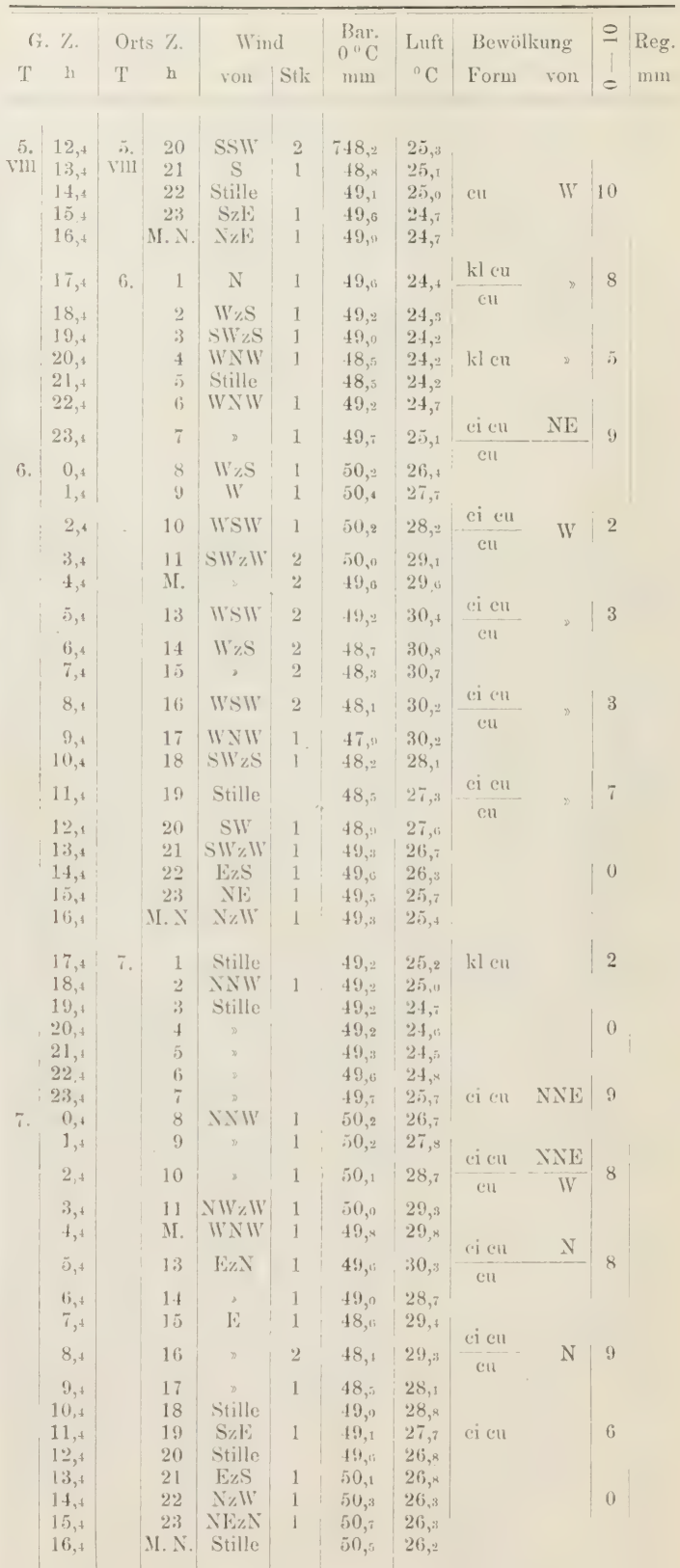


Da dic von Hr. Dir. Froc veröffentlichten Beobachtungen am 7. August aufhören, sind sie auch hier nur bis zum Ende des 7. mitgeteilt; der Barometerstand nahm noch zu bis zum 10. wie folgende Zusammenstellung zeigt:

\begin{tabular}{|c|c|c|c|c|c|c|c|c|c|}
\hline & \multicolumn{2}{|c|}{$4^{\mathrm{h}}$} & \multicolumn{2}{|c|}{$10 \mathrm{~h}$} & \multicolumn{2}{|c|}{$16^{\mathrm{h}}$} & \multicolumn{2}{|c|}{$2^{l 1}$} & \multirow[b]{2}{*}{$\begin{array}{c}\text { liegen } \\
\text { mm }\end{array}$} \\
\hline & $\begin{array}{l}\text { Bar. } \\
\mathrm{mm}\end{array}$ & $\begin{array}{l}\text { Luft } \\
{ }^{\circ} \mathrm{C} \text {. }\end{array}$ & $\begin{array}{l}\text { Bar. } \\
\text { mm }\end{array}$ & $\begin{array}{l}\text { Luft } \\
\text { "C. }\end{array}$ & $\begin{array}{l}\text { Bar. } \\
\text { mum }\end{array}$ & $\begin{array}{l}\text { Juft } \\
\text { "C. }\end{array}$ & $\begin{array}{l}\text { Bar } \\
\text { mm }\end{array}$ & $\begin{array}{l}{ }^{\text {L unft }} \\
{ }^{\circ} \mathrm{C} \text {. }\end{array}$ & \\
\hline 29 & $75.4,0$ & $2 \pi, 0$ & 755 & 29,8 & 754,1 & 29 & 754,7 & 27 & 0) \\
\hline VIII 8. & 49,8 & 24,8 & 51,5 & $2 \overline{7}, 4$ & 49,8 & 26 & 51,3 & 26,2 & 0 \\
\hline YIII 9. & $.51,1$ & $25,2=$ & $5: 3,0$ & 27,3 & 5) 1 , & 27 & 53, & $26,+$ & 0 \\
\hline VIII 10. & 51, & 25,1 & 53,1 & 28,1 & 51,4 & 27,0 & 52, & 25,4 & 1,1 \\
\hline
\end{tabular}

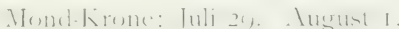
Ungewölnliche Sichtbarkeit: August 8., I0. luli il. Blitz ohne Donner (Wetterleuchten): Gewittersturm. August $4^{\text {h }}$ h $^{\mathrm{h}} \mathrm{im} \mathrm{NE}$, entferis

Quccksilber-Schreibbarometer zur Ergänzung der gewöhnlichen Quecksilberbarometer wohl angebracht wären? Man vergleiche (von den sogen. schönen Künsten ganz abgeschen), welche Beiträge von Privaten bewilligt werden zu den staatlichen Ausgaben für Zoologie, Astronomie, Geographie u. a. m., wic selten dagegen für Meteorologie besonders den maritimen Teil; um so dankbarer bin ich, für die mir vergönnte Ermöglichung meiner Arbeiten. Die Kurven WV ladiwostok's 42, und der Nlichen Landstationen der vierten Gruppe machen ebenfalls aufrällig den Nachteil langer Zwischenzeiten; die durch erstere besonders deutliche starke Abnahme in Luftdruck findet Ergänzung sowohl durch die Kurven der Beobachter an Landstationen Koreas als der Schiffsberichte aus der Korea Straße und dem suidlichen Zugang zu Kobe; Genaueres geben die Berichte.

Die Abschriften aus den Wetterbiichern von Tambow und Yarra zeigen folgende Abweichungen von der in Hr. Dir. Froc's Arbeit S. 17 gegebenen Zusammenstellung des Zeitraums zwischen Beginn der Abnahme im und dem niedrigsten Barometerstande. Bei von $\mathrm{Hr}$. Dir. Froc vorangestelltem Yarra begann die Abnahme genau genommen bei Verlassen von Hon gkong VII I9., da aber erst VII 2I. mgs., noch melir VII 22. mgs. die tägliche Periode im Barstd. unregelmäßjig ist, so wird die Mehrzahl der sich mit solchen Arbeiten Beschäftigenden den Beginn der Abnahme wohl erst VII 22. $4^{\text {h }}$ ansetzen, Gesamt-Abnahme also 27 Stunden; dic rasche Abnahme mag von Einigen angenommen werden von VIf 22, $20^{\text {h }}$ von Anderen VII 23. $0^{\text {ht }}$ also II -7 Stunden, Gesamt-Abnahme $=2$ - 2 ,, $0 \mathrm{~mm}$., soweit Unterschied mit Hr. Dir. Froc angenommen werden soll (23 Std. II Std. $21,0 \mathrm{~mm}$.) ist er äulerst gering. Genau so, betrachte ich die Sachlage bei Tambow; auch in den hier vorliegenden Mitteilungen beginnt eine allgemeine $\mathrm{Abnahme}$ in weiterem Sinne bereits V11 20. deutlicher ausgesprochen erst VII 2I. mittgs. oder $16^{\mathrm{h}}$, Gesamt-Abnahme also $31^{1} \frac{1}{2}$ oder $271 /$. Stcl, rasche Abnahme von VII 22. $4^{\text {hn }}$ an $15^{1} /$. Stcl., Gesamt-Abnahme von VII 2I. mttgs. gerechnet 29,7 mm., bei Hr. Dir. Froc 31 Std., 14 Std. 29,5 mm. Derartige Abweichungen ergeben sich sehr leicht bei Benutzung derselben Vorlage wieviel mehr noch bei verschiedener; daß stündliche Mitteilungen einen großen Vorzug haben vor zweistündlichen ist unbestreitbar.

Tafel d. Barometerkurren im De Witte Taifun. Die verhältnismäßig große Anzahl der Beobachter machte hier ebenfalls notwendig eine Sonderung in Schiffsberichte und Landberichte. Durch die, den Ann. d. Hydr. entnommenen sts. des Instituts "Deutsche Sccairte" veröffentlichten Mitteilungen der drei deutschen Dampfschiffe, Tucuman, Stuttgart, Shantung, — der im Meteorolog. Off., London, von mir abgeschriebenen des Brt. Dpf. Macduff, der verlorenen aber durch Güte letzterer Anstalt ergänzten S. Brt. M. S. Waterwitch und Lagerschiff Madras, - dem Bureau Cintral Mitiorol., Paris sowie vom Kol. Nald. Meteorol. Inst., de Bilt guitigst übermittelten der Frz. Bk. Brizeux bezw. des Obsrvtm. Hongkong: sind sehrwertvolle Ėrgänzungen geliefert zu den von Hr. Dir. Froc s. Zt. gesammelten und sehr rasch der gemeinsamen Benutzung zugänglich gemachten Berichten; - dies ist auch gut kenntlich aus den Kurven. Bei Allen, die nicht kannten oder sich nicht erinnerten an die früher mitgeteilten ugf. gleich niedrigen Barometerstände in der Arabischen See, der Bai von Bengalen, im Châteaubriand Tai. fun. waren erklärlich Zweifel an dem Bericht über den niedrigsten Barstd. an Bord des Dpf. Laysang, sicht man jedoch neben ihm die Kurve von Shantung und erimnert sich des "Auffillen s des Zentrum bei Annahlerung an Land, so liegt es sehr nahe letztere Kurve /4 betrachten als Bestätigung ersterer. Die Kurven der nicht weit von cinander am Anker liegenden Dpf. Shantung und Chi luen zeigen wieder wie ungemein steil ist die Abstufung oder Böschung des Luftdrucks in unmittelbarer Nähe des sogen. Zentrum.

So wie beim slltisa-Taifun bezw, aus Tafel B, und c. so erkennt man auch beim De Wittes-Taifun aus den 
Kurven der Tafel d, die Teilung der Beobachter in drei Hauptgruppen: E. China See mit Formosa und dem S1. Teil der E.Küste China's, - der untere Yangts e, einschließlich seiner Münd ung und Schanghai, - Schantung, mit den Binnenmeeren und deren Küsten nördlich von ihm.

Die Angaben von Middle Dog Lt., verglichen mit denen von $\mathrm{Nafa}$, Ischigakijima, Kilung, Fu tschau u. a. (von Hongkong's stïndlichen ganz abgesehen) lassen wieder die langen Zwischenzeiten sehr bedauern; beachtet man dabei die kurze Aufeinanderfolge der Schiffsbeobachtungen und hat nur einiges Verständnis für die Schwierigkeit, sobald die geringste Möglichkeit vorhanden ist, in die Kajuite oder das Kartenhaus zu gelangen um dort - trotz aller Unbequemlichkeit den Barometerstand so genau wie möglich abzulesen und anzuschreiben, - oder aber bei der unvermeidlicherweise geringen Anzahl der Deckbesatzung doch noch einen Steuermann zum Barometer zu stellen, um sowohl häufiger regelmäßßig anzuschreiben als auch auf Ausnahmen in dessen Stand zu achten, - wie dieser wieder Stunden ausharren soll in der Stickluft eines kleinen geschlossenen, nur durch die beim Barometer aufgehangene, dunstende Lampe erleuchteten Raumes, alles um ihn schwankend, knarrend, wenn nicht ächzend, dabei das Schiefliegen und Arbeiten des Schiffes, als Stuitze höchstens ein für diesen Zweck »irgendwie" angebrachtes, dünnes Tau, sonst vielleicht nur die 》lackierte" Deckstiitze oder die eignen "Seefüße : dann wird man wohl dem, der dies s. Zt. kennen lernte, nicht verargen, wenn er auf diese Nebenumstände hinweist, und wie sehr die Schiffsfuihrer sowie die Steuerleute, die noch dann ihr Möglichstes tun, etwas Gutes zu leisten, Achtung, Anerkennung, Dankbarkeit verdienen.

Vergleicht man die Orte der Beobachter auf Tafel C mit den Kurven der ersten Gruppe, besonders der Schiffsberichte in dieser Tafel d, hauptsächlich die kaum 6 Stunden auseinanderliegenden tiefsten Punkte von B, I6, 17, A, I0 14, 19, so erkennt man ohne Schwierigkeit: wenn auch keine für alle Fälle geltende Regeln vorhanden sind, um aus der Abnahme im Barometerstancle Schluße zu ziehen wieviel Seemeilen man entfernt ist vom Zentrum eines Taifun, so ist doch für den einzelnen Fall, die Abnahme im Barometerstande in steigendem Verhältnis größer, je näher das Zentrum an einem Orte vorbeizieht. - Selbst der Laie kann einigermaßen erkennen, warum dann dem Barometer fortwährende Aufmerksamkeit gewidmet wird, und warum es die Entscheidung giebt, ob bisheriges Verfahren beibehalten wird, oder ob, vielleicht mit letzter Anstrengung des Schiffes, seiner Fortbewegungsmittel, seiner Anker und Ketten, seiner Besatzung, die entgegengesetzte Handlungsweise man versucht. Das Zentrum kann spielend glatt vorüberziehen, - nachdem kann das Schiff besser liegen als bisher, - aber ebensogut kann in ihm der Seegang toben und aus dem größten und stärksten Schiff in kurzer Zeit ein Wrack machen, oder wenn ihm dies nur teilweise gelingt, kann es der aus entgegengesetzter Richtung kommende Wind mit Hilfe des bisherigen und des neu auflaufenden hohen Seeganges vollenden.
Der bekannten Gefahr, sucht man durch Maßregeln zu begegnen, wenigstens sie zu mindern, dem Ungewiß gegenüber muß man leider nur zu oft nach dem Strohhalm greifen! -

Die Korrektion des Aneroid auf Madras war in Lond on nicht bekannt; die im Wetterbuch des Schiffes enthaltenen Beobachtungen weisen darauf hin, daß $\mathrm{Hr}$. Kpt. Tamplin hier nur eintrug, die von ihm persönlich angestellten; ob zur Zusendung an $\mathrm{Hr}$. Dir. Froc er selbst sie vereint hat mit am Land im Hause der Chin. Dpf. Co. angestellten, ob dies in der Mission oder von Hr. Dir. Froc geschehen, kann hier nicht entschieden werden

Die dauernden, stiindlichen Barometer-Angaben von Brt. Dpf. Macduff, beweisen großes, sachliches Verständnis für ihren IVert sts. der Herren Stcucrleute; so sehr die Kurve von anderen eingeschlossen ist, erkennt man doch leicht, wie unregelmäßig ist bei solcher Gelegenheit die $\mathrm{Ab}$ - und Zunahme im Luftdruck. - Die Unterschiede in den hier betrachteten Mitteilungen von S. Brt. M. S. IV aterwitch und D. P. Dpf. Stuttgart haben wohl teilweise Grund in einem beständigen Unterschied im Stand der Barometer, teilweise können es sein kleine nach entgegengesetzten Seiten fallende Fehler in der Ablesung, möglicherweise war eines der Instrumente nicht genügend eingerichtet fur Schiffsbewegung; es ist nicht annehmbar, daß bei derartigem IVetter ein Schiff - sei es am Anker, sei es an der Kaje - ganz ruhig liegt. - Eigenartig ist clas Verhalten des Barometer auf Frz. Bk. Brizeux gegen das des Observatorium in Hongkong; jenes erreicht den niedrigsten Stand noch ugf. $250 \mathrm{Sm}$. Swärts von diesem und selbst der Gewittersturm, der Brizeux befällt als dies Schiff nahe an Hongkong ist, hält nicht auf, die Zunahme des Standes, die bei ihm ugf. 23 Stunden fruher begann als beim Festlande.

Nach den Barometerkurven zu urteilen, muß das Unwetter näher an Kiu Kiang, Hankau, Wuhu, Hauki, Tschan kia tschoang bezw. dem Golf von Petschili, gezogen sein, als Schanghai bezw. der Mündung des Yangtse, Tsingtau, Tschifu und östlicher gelegenen Orten.

So wie beim "Iltis -Taifun vermißt man ungern auch hier Schiffsberichte aus der E.China- und Gelben See.

Jedem in dieser Richtung Arbeitenden ist gewiß sehr willkommen der S. 47 folgende Bericht von Hr. Kpt. Gourio, Frz. Bk. Brizeux betr. einen SElich von Formosa bestandenen Taifun; ergänzende Angaben sind möglicherweise enthalten in den regelmäßigen WetterBerichten von den Liu kiu In., S. Kap Lt. Formosa I., K. Bolinao und in den Wetterbuichern von Schiffen eingesandt an die verschiedenen meteorologischen Anstalten. Falls der Bericht vereinzelt bleibt, so wäre es einer der Taifune gewesen, deren Kraft auf einem beschränkten Raum zur Geltung kam, die nur zu oft gänzlich unbemerkt bleiben, wenn nicht etwa ein anderes Schiff bemerkt: In - - Richtung lagert (oder zeigt sich) drohend aussehendes Gewölk. 
1901. Juli-August. Frz. Bk. "Brizeux", Nantes, Kpt. Gourio. Barry Dock - Hongkong.

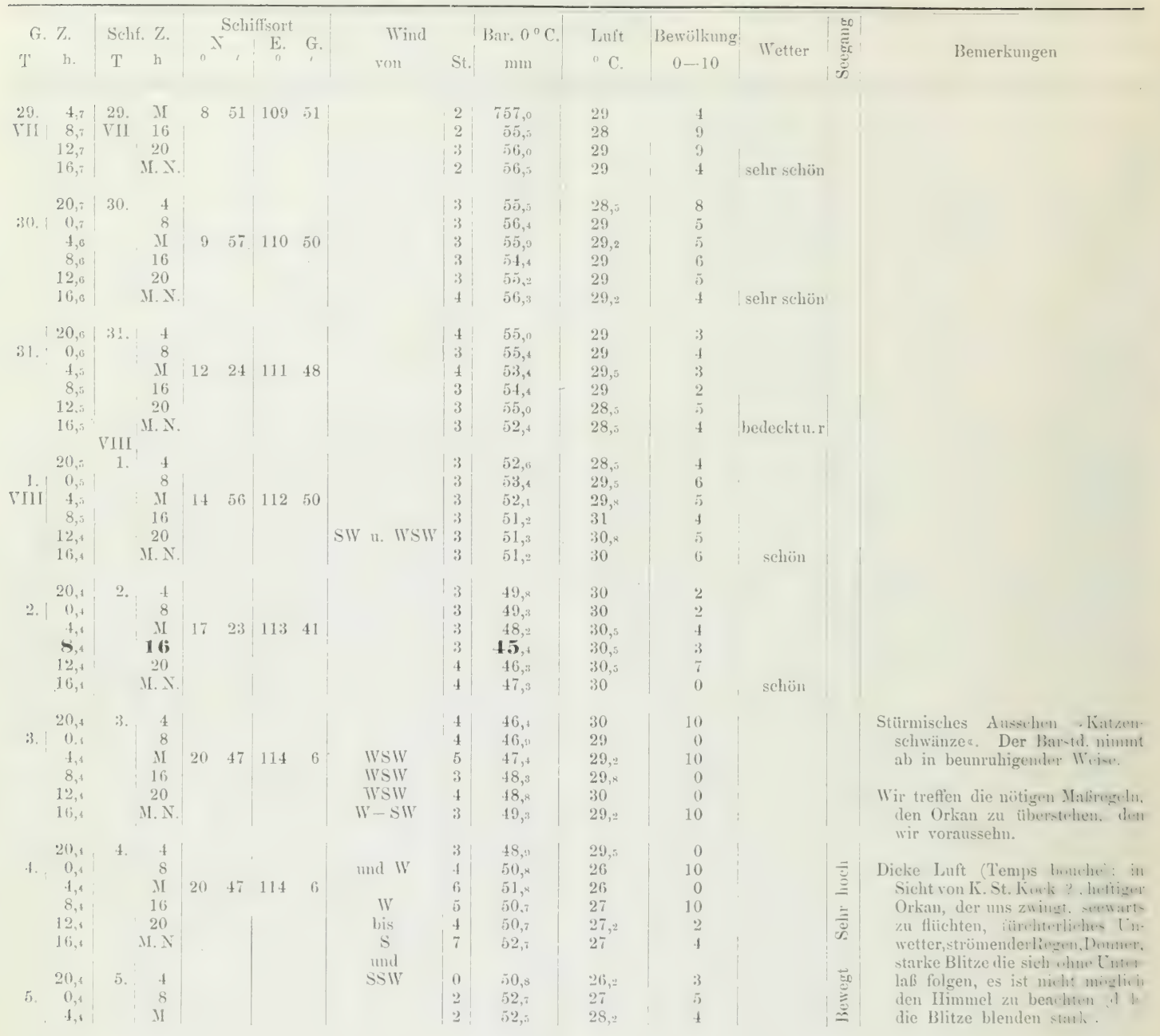


1901. August. Brt. Lagerschiff "Madras", Kapt. L. H. Tamplin, F. R. Met. Soc. am Anker in Wuhu (Yangtse) $31^{\circ} 20^{\prime}$ N. $118^{\circ} 1^{\prime} \gamma^{\prime}$ W. G.

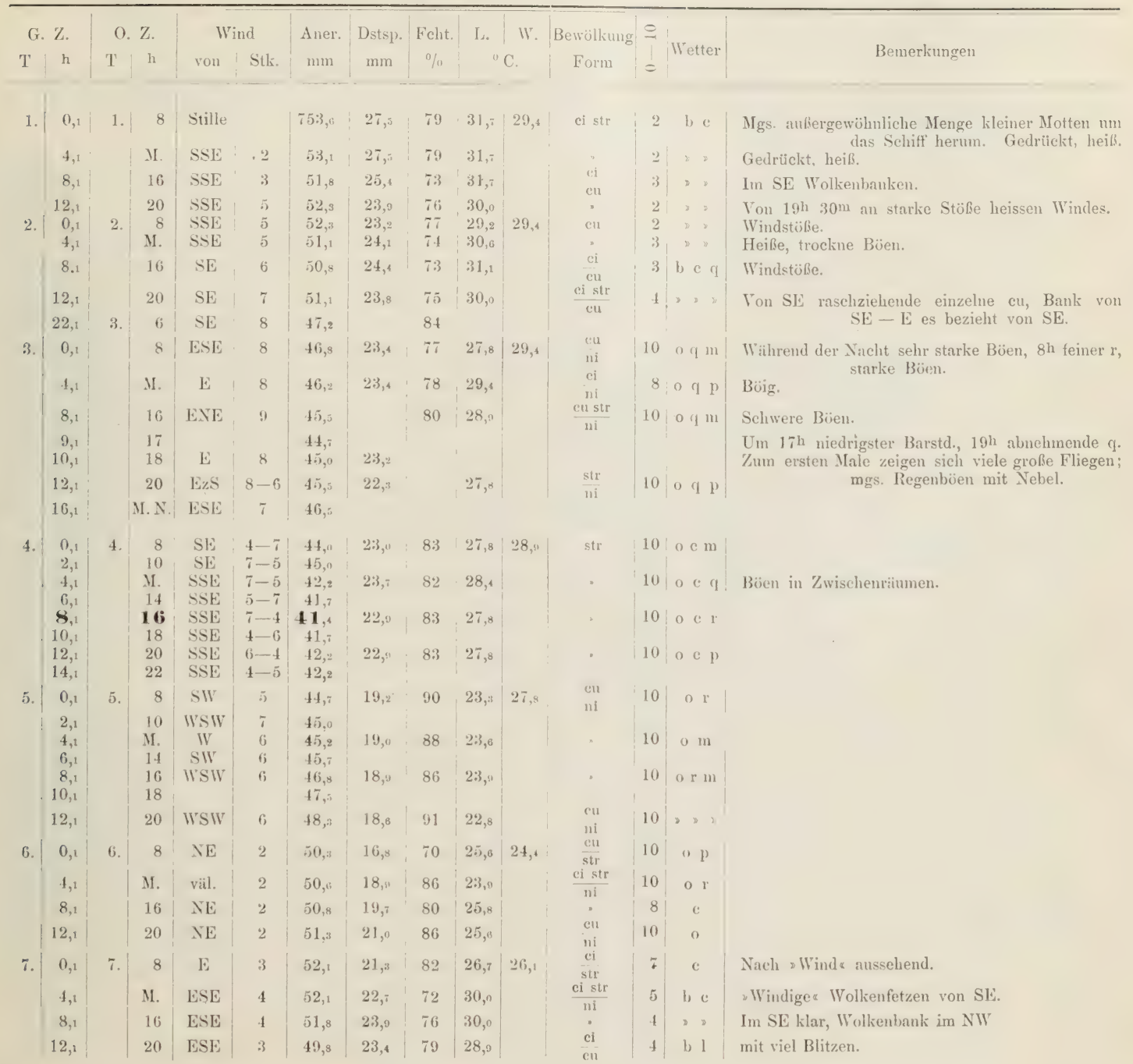


1901. September. Brt. Dpf. "Macduff", Kapt. R. Glegg. Schi Wiu Yan-Moji.

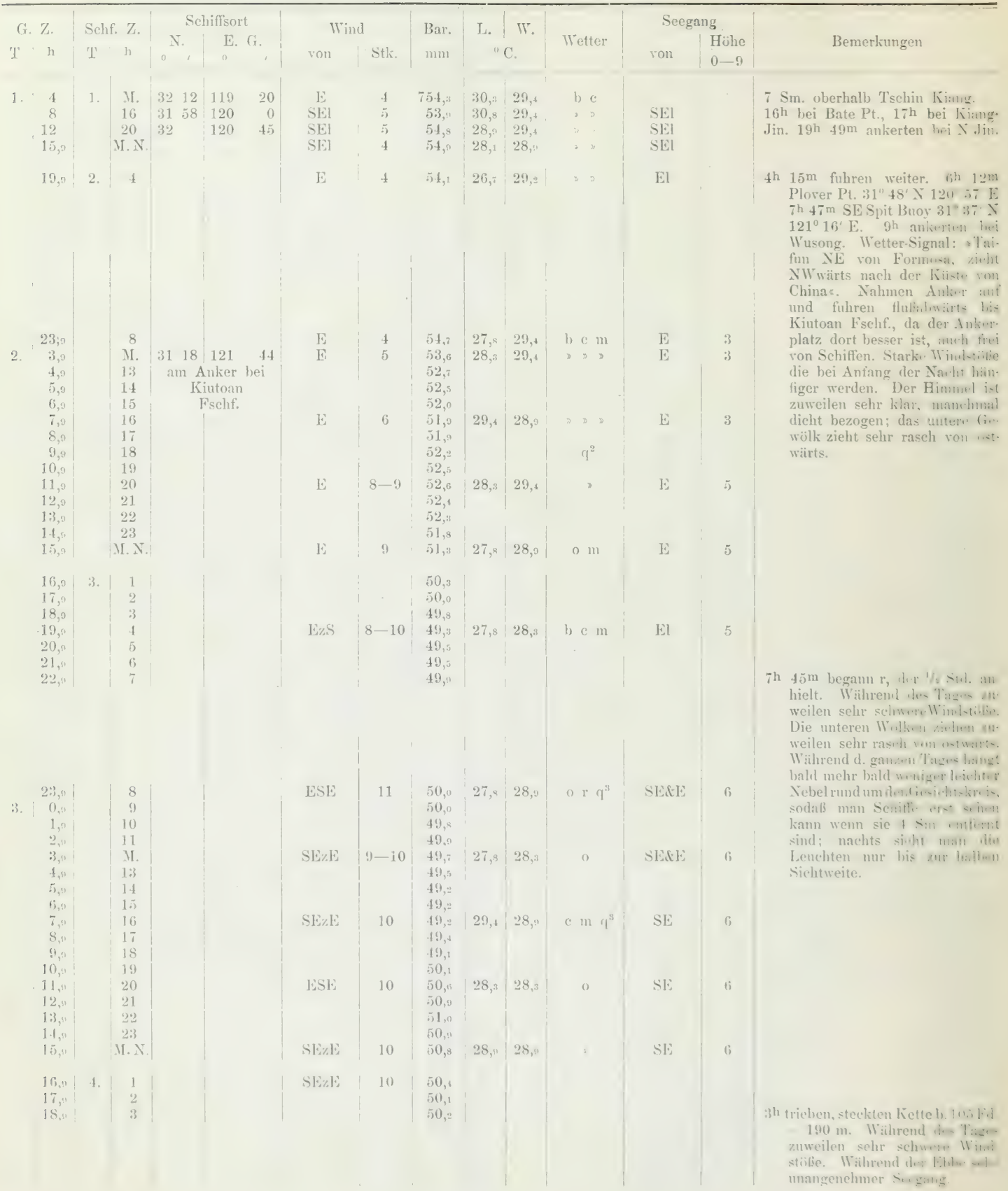


1901. September. Brt. Dpf. "Macduff", Kapt. R. Glegg. Schi Wiu Yan - Moji.

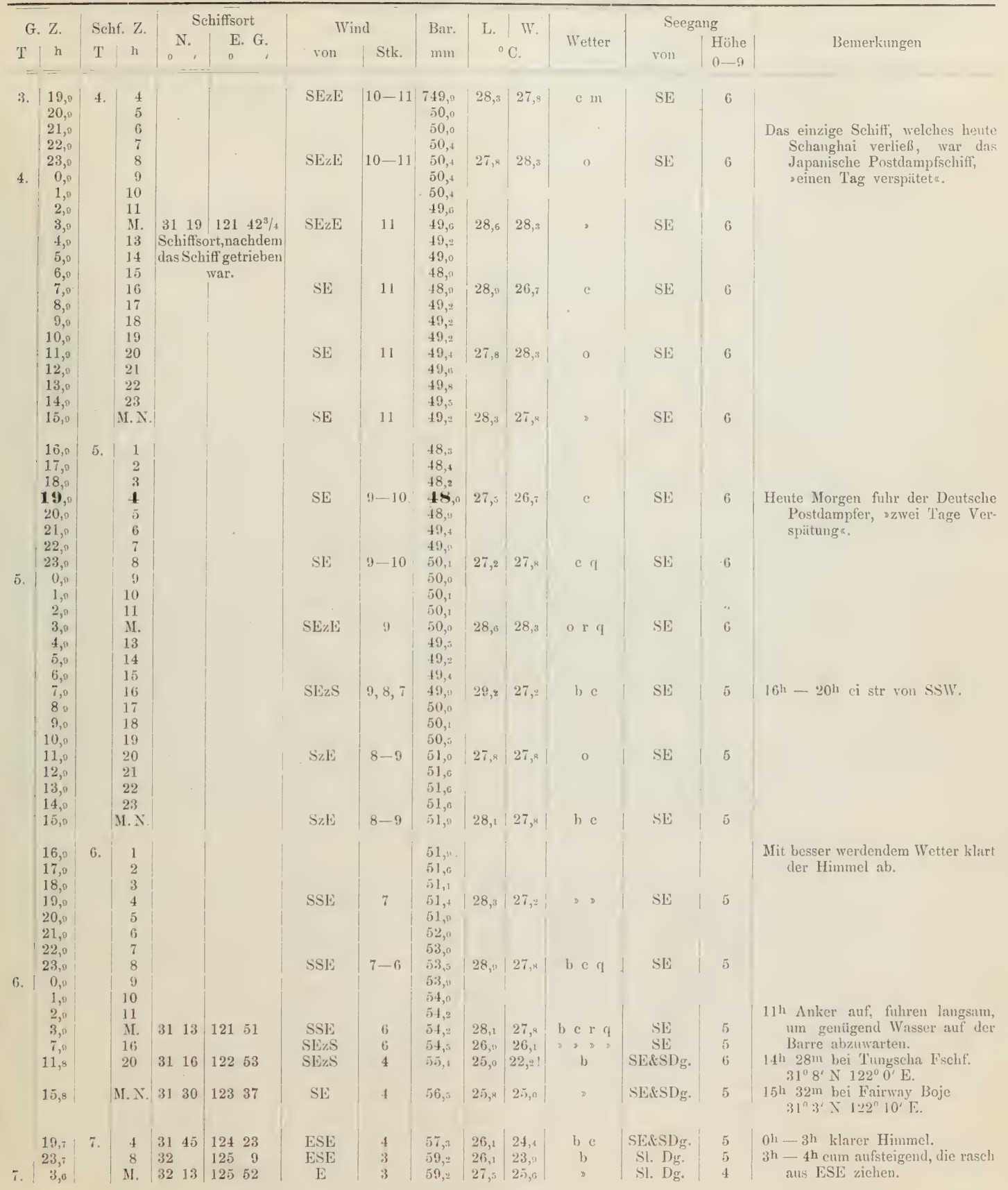


1901. August. S. Brt. MI. S. "Waterwitch", Kapt. W. O. Lyne, R. N. Hongkong - Schanghai.

Bis I. $1^{\text {h }}$ am Anker im Yangtsekiang, dann nach Schanghai fahrend, von $19^{\mathrm{h}} 3 \mathrm{O}^{\mathrm{m}}$ in Schanghai am Anker liegend: $3 \mathrm{I}^{0} \mathrm{I} 4^{\prime}$ N. $12 \mathrm{I}^{0} 29^{\prime}$ E. G.

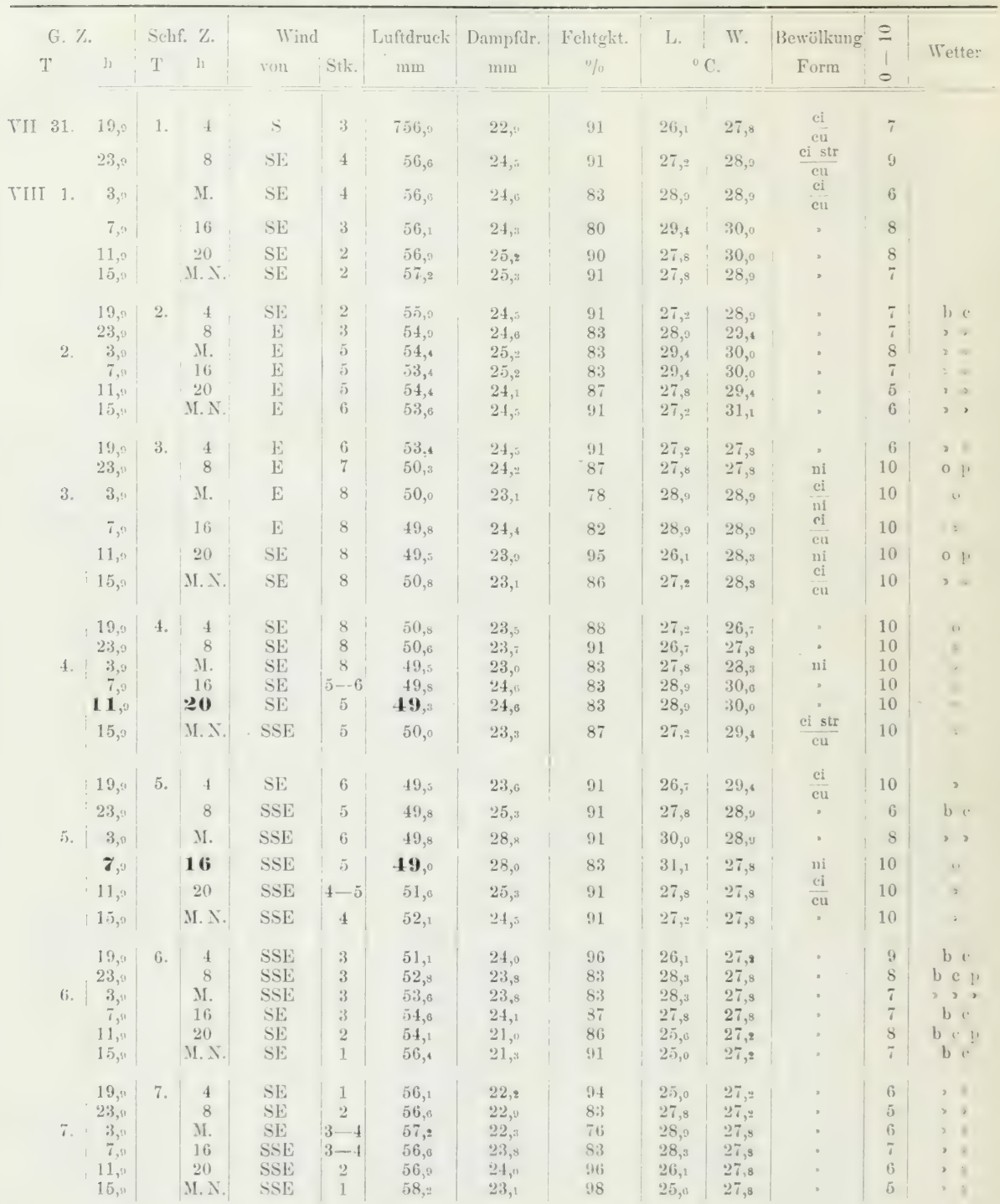




\section{September. Frz. Bk. "Brizeux", Nantes, Kapt. Gourio. Hongkong - San Francisco.}

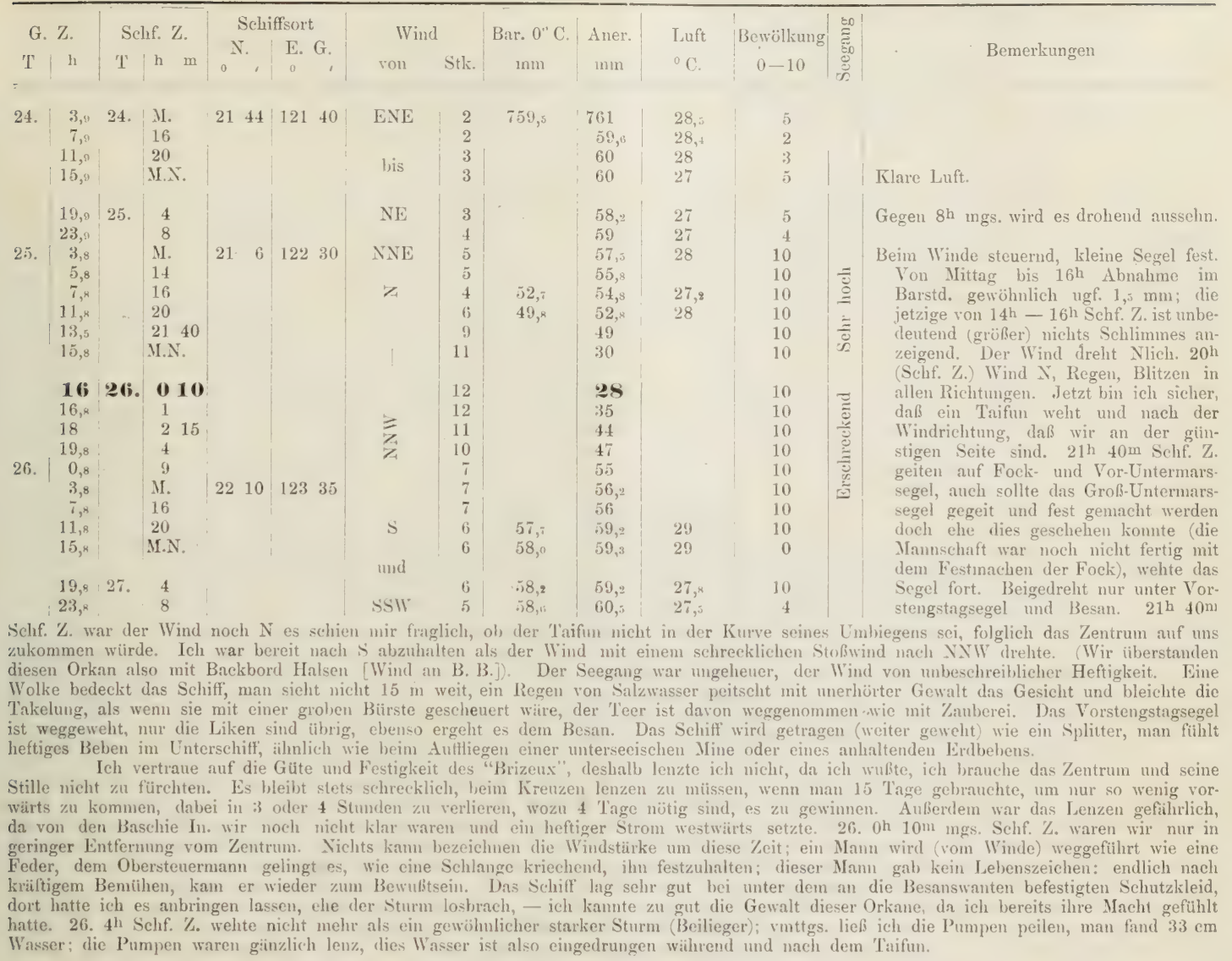

In Hongkong begann eine, nicht bedeutende Abnahme im Barstd. IX. 22., sie hielt an bis 25 . $16^{\mathrm{H}}$ O. $Z$. $=8 ., 4^{\text {h }}$ G. Z. erst am 30. war der Barstd. vom 22. nahe wieder erreicht vergl. folgende Zusammenstellung (nach Obsrvtns. and Res. f. 1901).

\begin{tabular}{|c|c|c|c|c|c|c|c|c|c|}
\hline $\begin{array}{c}\text { 0. Z. } \\
\text { IX }\end{array}$ & ${ }^{4 \mathrm{~h}}$ & $\begin{array}{l}\text { Luft } \\
{ }^{\circ} \mathrm{C} .\end{array}$ & $\begin{array}{l}10^{\mathrm{h}} \\
\mathrm{mm}\end{array}$ & $\begin{array}{l}\text { Luff } \\
\text { "C. }\end{array}$ & $\begin{array}{l}166^{\mathrm{h}} \\
\mathrm{mm}\end{array}$ & $\begin{array}{l}\text { Luft } \\
{ }^{\circ} \mathrm{C} \text {. }\end{array}$ & $\begin{array}{l}22^{h} \\
m u\end{array}$ & $\begin{array}{l}\text { Luft } \\
{ }^{\circ} \mathrm{C} .\end{array}$ & $\begin{array}{c}\text { Regen } \\
\text { mm }\end{array}$ \\
\hline 22. & 758,4 & 23,6 & 760,2 & 25, & 758,6 & 27,3 & 759,4 & 26,4 & 50,1 \\
\hline & 58,5 & 25,0 & 60 & 28,2 & 5 & $2 \pi, 3$ & 58 & 26,4 & \\
\hline & 57,6 & 25,2 & 58 & 28, & 55, & 28 & 57, & 26,3 & \\
\hline & 55, & 25,2 & 57,6 & $28, *$ & 54, & 29 & $b$ & 27,3 & \\
\hline & $5 \tilde{0}, \%$ & 26,3 & 58,4 & 28,2 & 56,2 & 27 & 58,0 & 26,2 & 16,0 \\
\hline & 57 & 24 & 58 & 27,1 & 50 & 28 & 56 & 26,3 & 11,4 \\
\hline & 56 & 25, & 58 & 28,3 & 55 & 28, & 57 & 26,8 & 0,3 \\
\hline & 56 & 25,4 & 59, & $26, t$ & 58 & 26,6 & 59 & 24,8 & 2,5 \\
\hline & :8, & 24,7 & 59,7 & 26,3 & 58,1 & 26,15 & 59,4 & 26,2 & \\
\hline
\end{tabular}

Die Windstärke war in dieser 'Zeit größtenteils $\mathbf{I}-2$, wenigemal $O$, nur ausnahmsweise bis 5 zunehmend, die Windrichtung sowohl aus dem Elichen als Wlichen Halbkreis, - am 25. von $\mathrm{O}^{\mathrm{h}}-7^{\mathrm{h}}$ Stille, dann NNW. durch IV. bis S. ändernd I -2 , in der letzten Stunde SEzE. 2. Von IX. 22.-30. ist in Hongkong ferner beobachtet: Sonnen-Krone (-Hof) am 25., 26. Leichter Nebel am 25., 26., 27. Dies (Dunst) am 24., 27., 28. Thau am 23., 24., 25., 26., 27., 28. Blitzen ohne Donner (Wetterleuchten) am 25., 27. Blitzen und Donner am 22. Gewittersturm am 28. $19^{\mathrm{h}} 30^{\mathrm{m}}-29.3^{\mathrm{h}} \mathrm{N}-\mathrm{S}$. in der Entfernung. 
Jeder, der die volle Kraft eines Taifun, Cyklon, Orkan gefuhlt hat, weiß, daß die. Beschreibung von Kpt. Gourio keine Ubertreibung ist; er hat eine Skizze beigelegt, wie die Bahn des Unwetters er sich vorstellt. Jeder Schiffsfuhrer ist gewissermaßen gezwungen, der Entwicklung der Ercignisse entsprechend, solche Vorstellung sich zu machen, um nach besten Kräften das Schiff mit Allem an, auf und in ihm zu sichern; der Zusammensteller soll wissen, daß nach einem
Einzelbericht keine Bahn zu entwerfen ist, man katnn \%. li. nur sagen: in diesem Fall zog das Unwetter von irgend einer Richtung im Osten, nach einer im Westen, wahr. scheinlich, da der Wind $\mathrm{I}$., NITY., später $S$. war, erst wenig Slich rom Schiff, dann NIVwärts. $33 \mathrm{~cm}$. Wasser im Schiff in 10-12 Stunden bei derartigem Wetter ist noch glimpflich abgekommen; früher waren nicht wenig Segelschiffe in jenen Gewässern, in die bei solchem Unwetter gleiche Menge WVasser in einer Stunde eindrans.

Hoffentlich bin ich auch ferner im Stande Berichte \%u erhalten und mit bisher sesammelten, suwie Zusammenstellung zerstreuten nützlichen Stoffes gemeinnuitzlich zu machen.

Hamburg, don 30. Wärs 1905.

\section{A. Schück.}

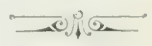

\section{Berichtigungen.}

Zwei magnetische Beobachtungen vor der Westküste Norwegens.

Seite 4. Spalte r., Zeile 11 v. u., statt Kutter verkanfen lies: Kutter zu verkaufen.

Beiträge zur Meereskunde. I.

Seite 10. Spalte r., Zeile 13 v. o., statt Faden lies: Fladen.

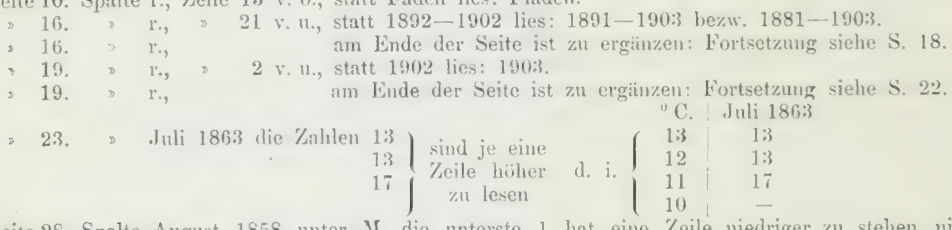

Seite 28. Spalte August 1858 unter If. die unterste 1 hat eine Zeile niedriger zu stehen, nicht bei $12{ }^{\circ} \mathrm{C}$. sondern bei $11^{\circ} \mathrm{C}$.

Beiträge zur Meereskunde. II.

Scite 23. Spalte r, Zeile 22 v. u., (3 Absatz \%. 3) statt $40^{\circ} / 4$ lies: $40^{1 / 4} \mathrm{~W}$.

Beiträge zur Meereskunde. III.

Seite 4. Spalte 1., Zeile 17 v. o., statt Monfun lies: Monsum.

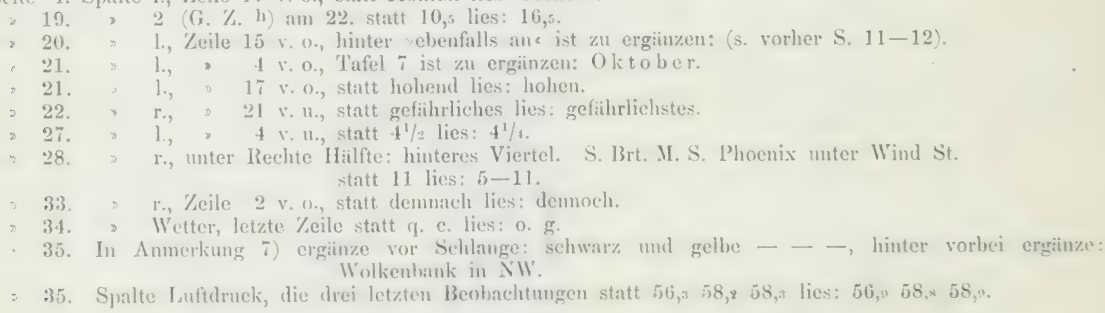




Heereskunde I.

Fischereikarten.

Fig. 2.

'I'af. 1. Hering.

e Noordzee. Haax lem 1895.

rländische Fischer

VGfahren.

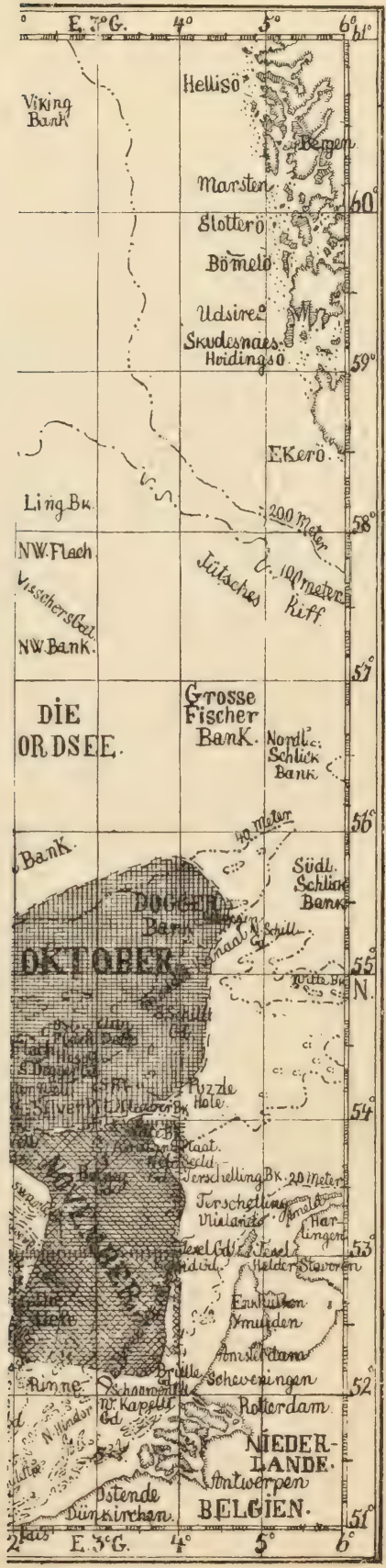


A schücћ. BEITRÄGE zur MEERESKUNDE. I. Jafel1.

KELNDLD. METEOROLOGISCHES I NSTITUT:K.FI Andeutung der Gegenden m denen 185b-18b1 niederlä den besten HERIN GSFANG hatlen

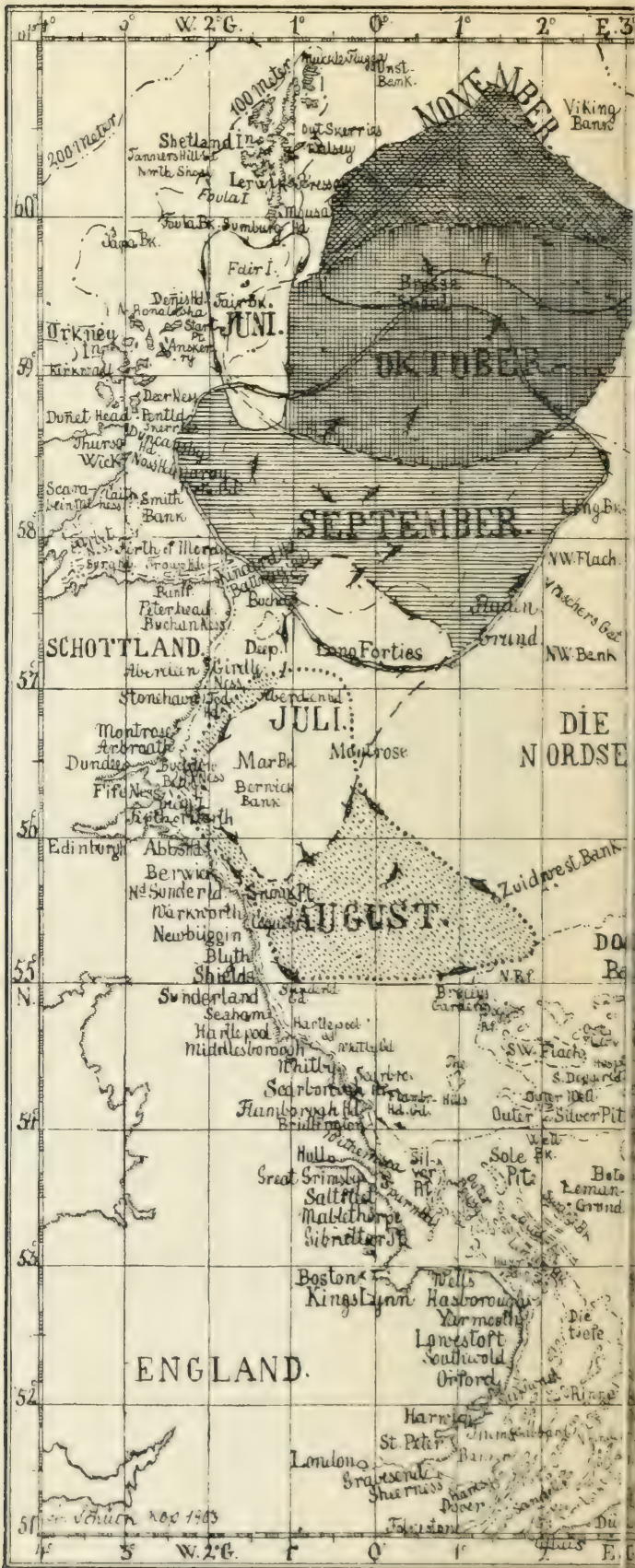


Fig. 1.

DRAU:' Itrecht. 1862 sidieFischer
A H0OGENDIJK Jz De Grootvisscherij op de Noordzee. Haax lem 1895.

Skizzeder Gegenden nach denen niederlän dische Fischer geroöhnlich zum HERINGSFANG fähren.

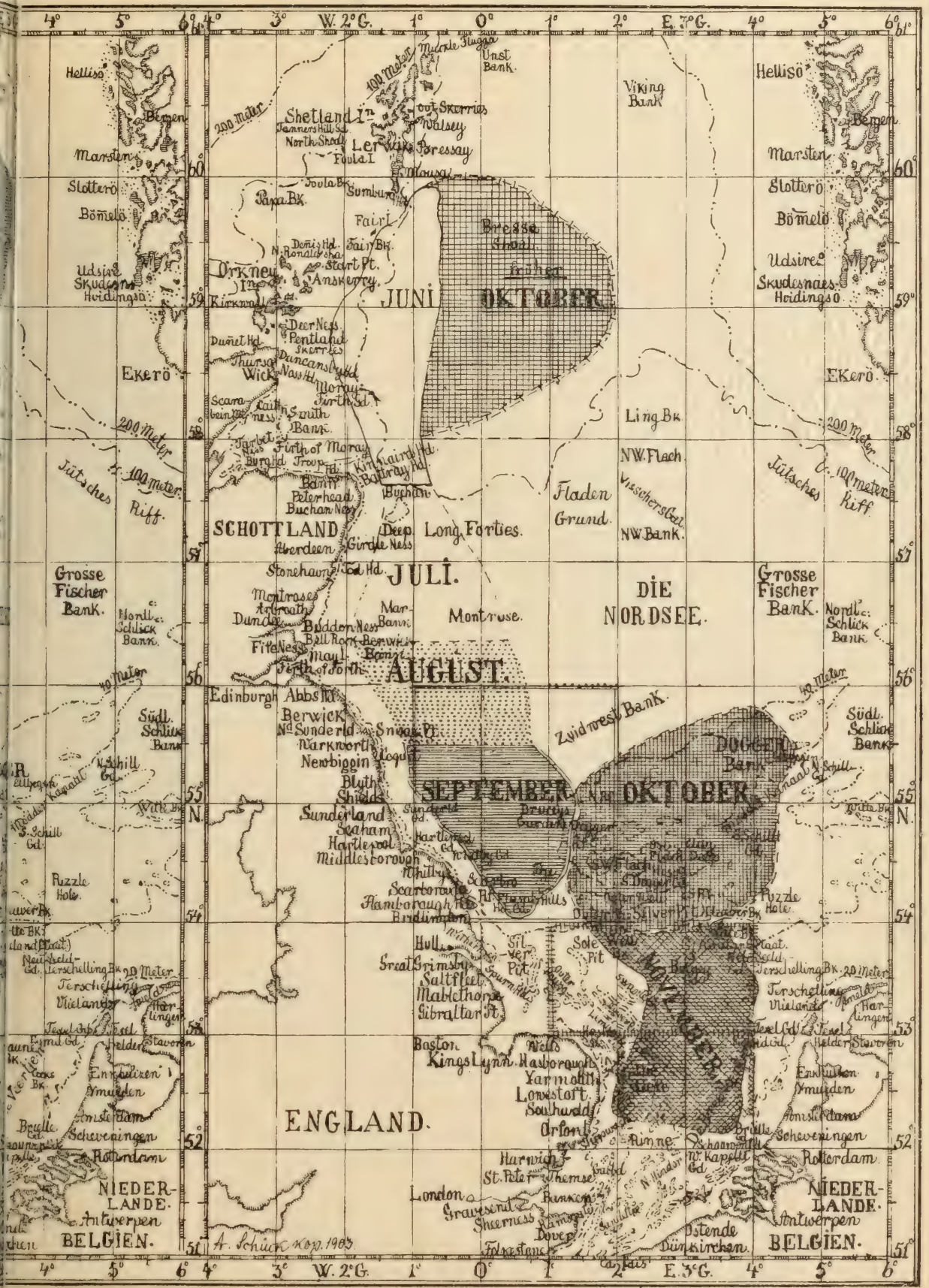


Heereskunde I.

Fischereiliarten.

'Taf'. 1. Hering. 


\section{Meereskunde I.}

Fischereikarten.

Taf. 2. 


\section{DieFANGGRÜNDE der DEUTSCHEN FISCHDAMPFER. \\ Nach DUGE's Statislik \\ ouf $5 / 12$ verkluinert cus:}

MITTEILUNGEN des DEUTS CHEN SEEFISCHEREI VEREINS BD XVI1901.

Fig.

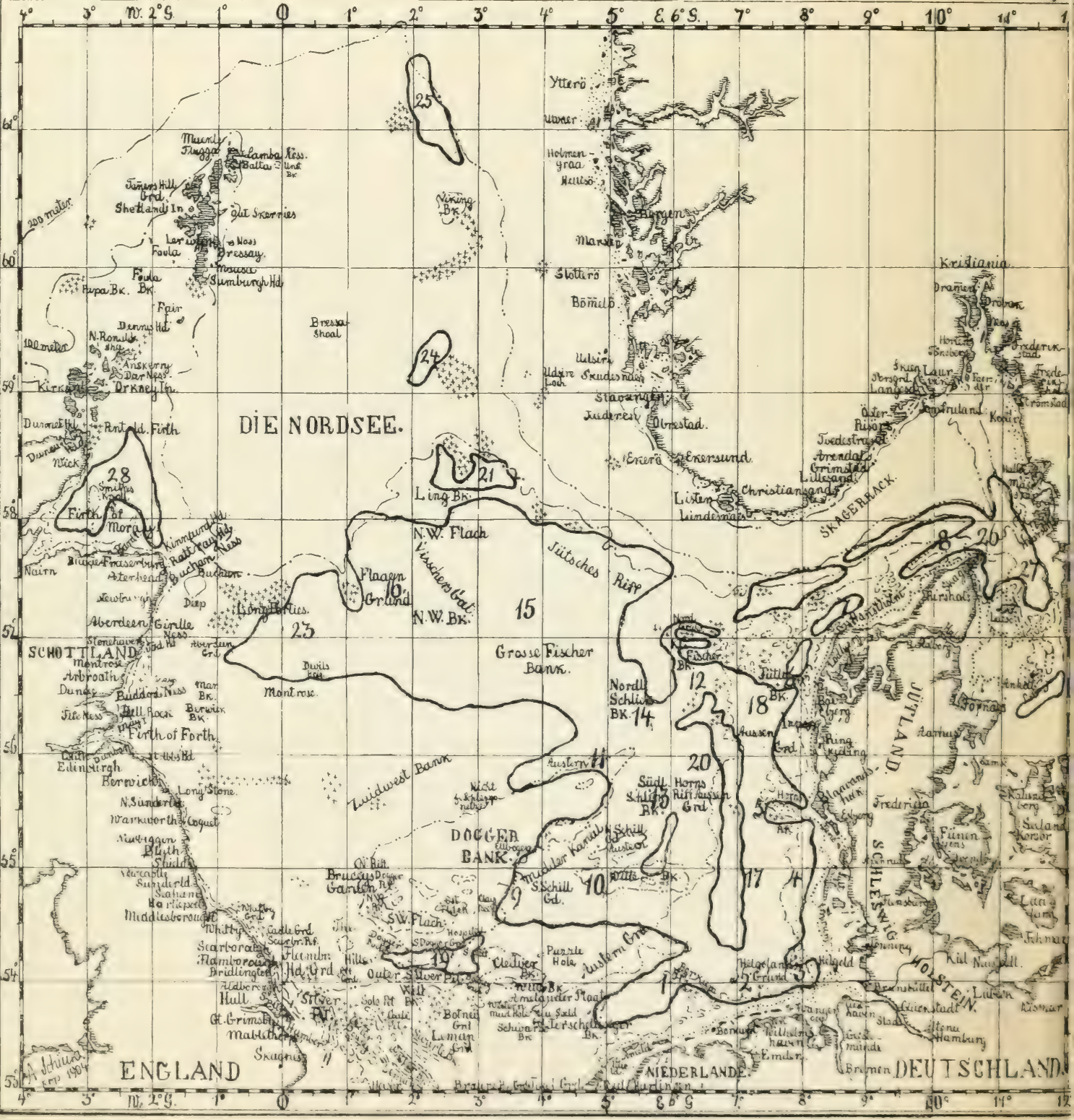


Meereskunde I.

Fischereikarten.

Taf. 2.

A. Schiuer. BEITRÄ GE zur MEERESKUND

DieFANGGRÜNDI

MITTEILUNGEN des DE

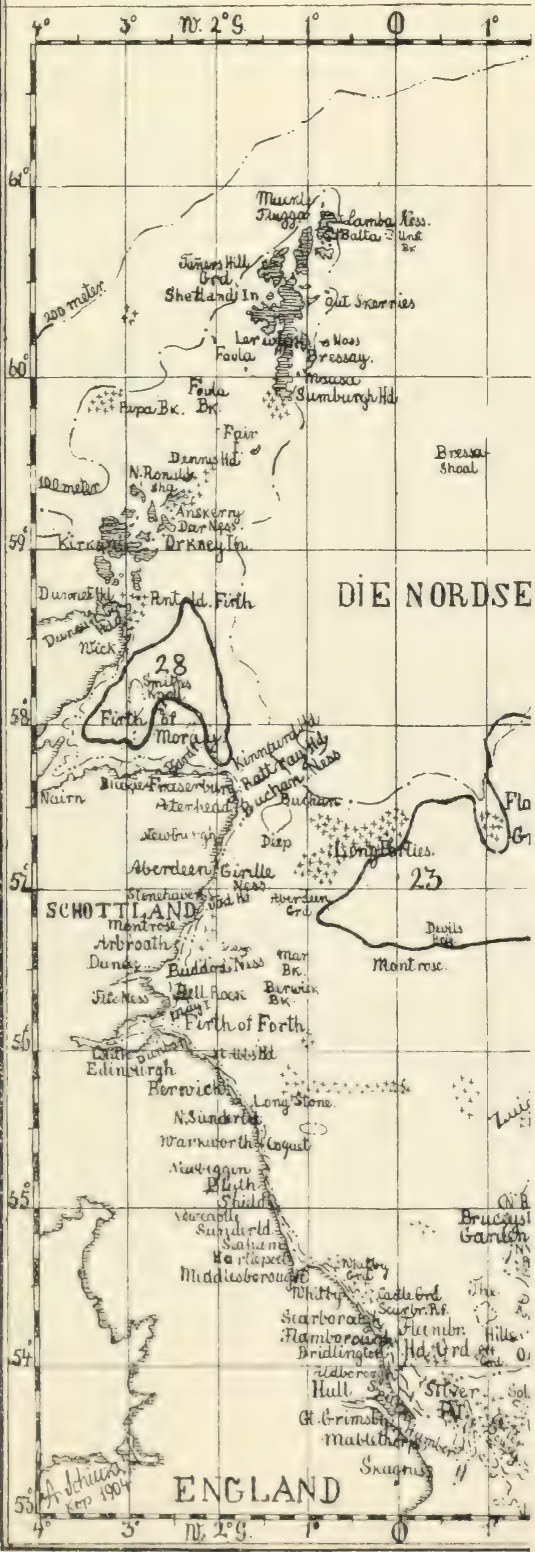




I.

I.

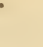


A. fchün. BEITRÄGE zur VEERESKUNDEII. Jatel 1 .

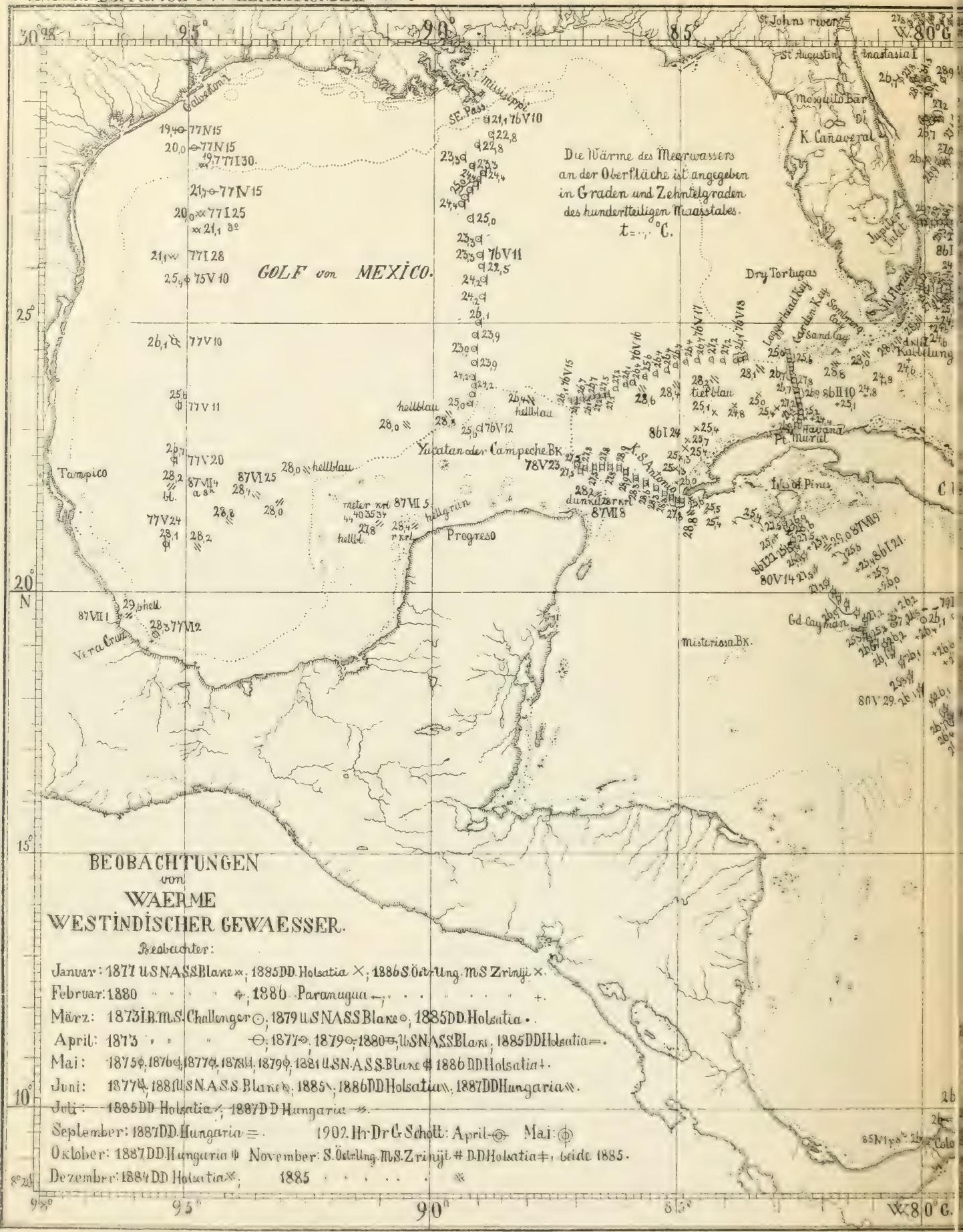


Meereskunde II.

Wrutindin.

'Taf. 1. Wairme. 
Meereskunde II.

Westindien.

'T'at'. 2. Salzgehalt. 


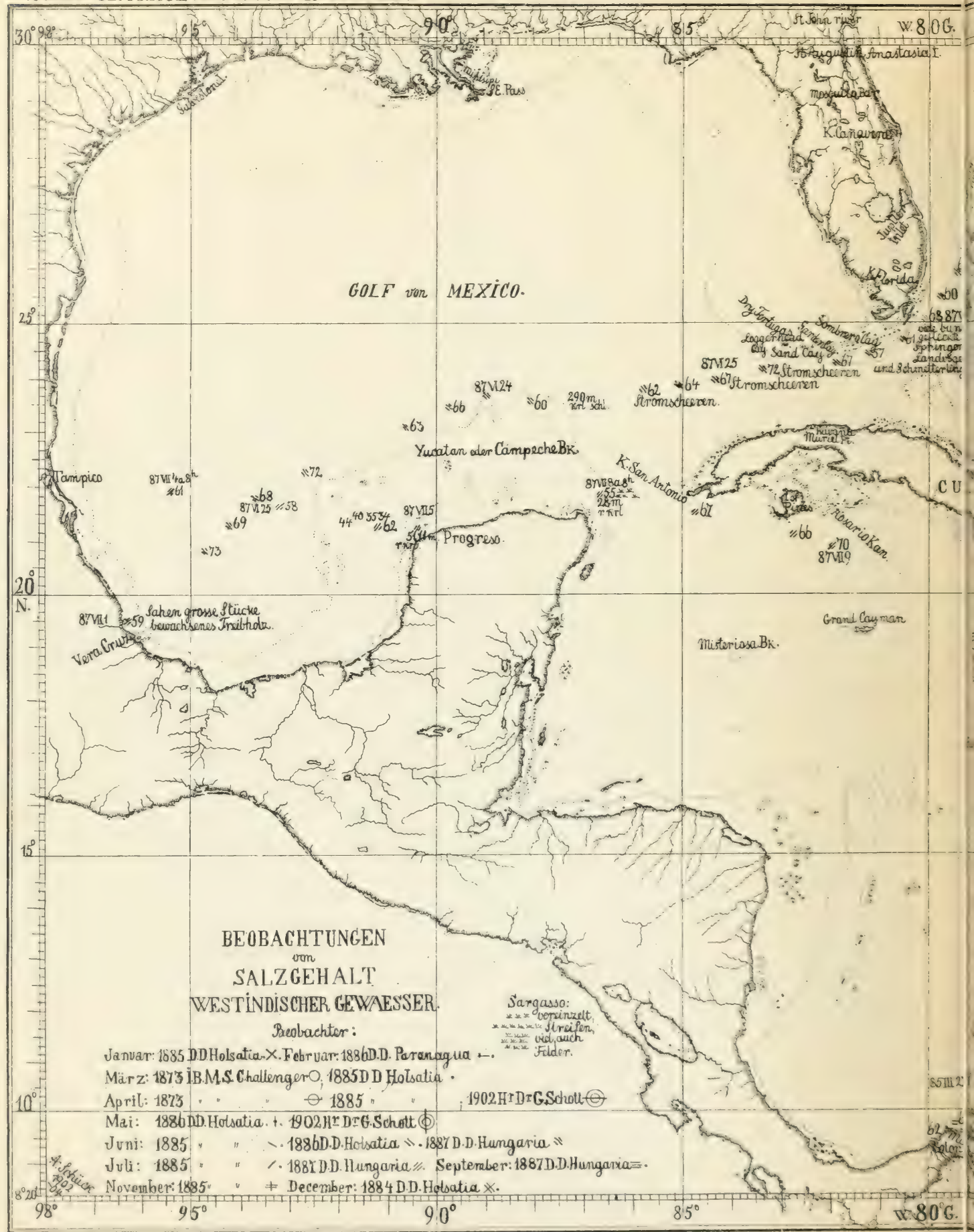




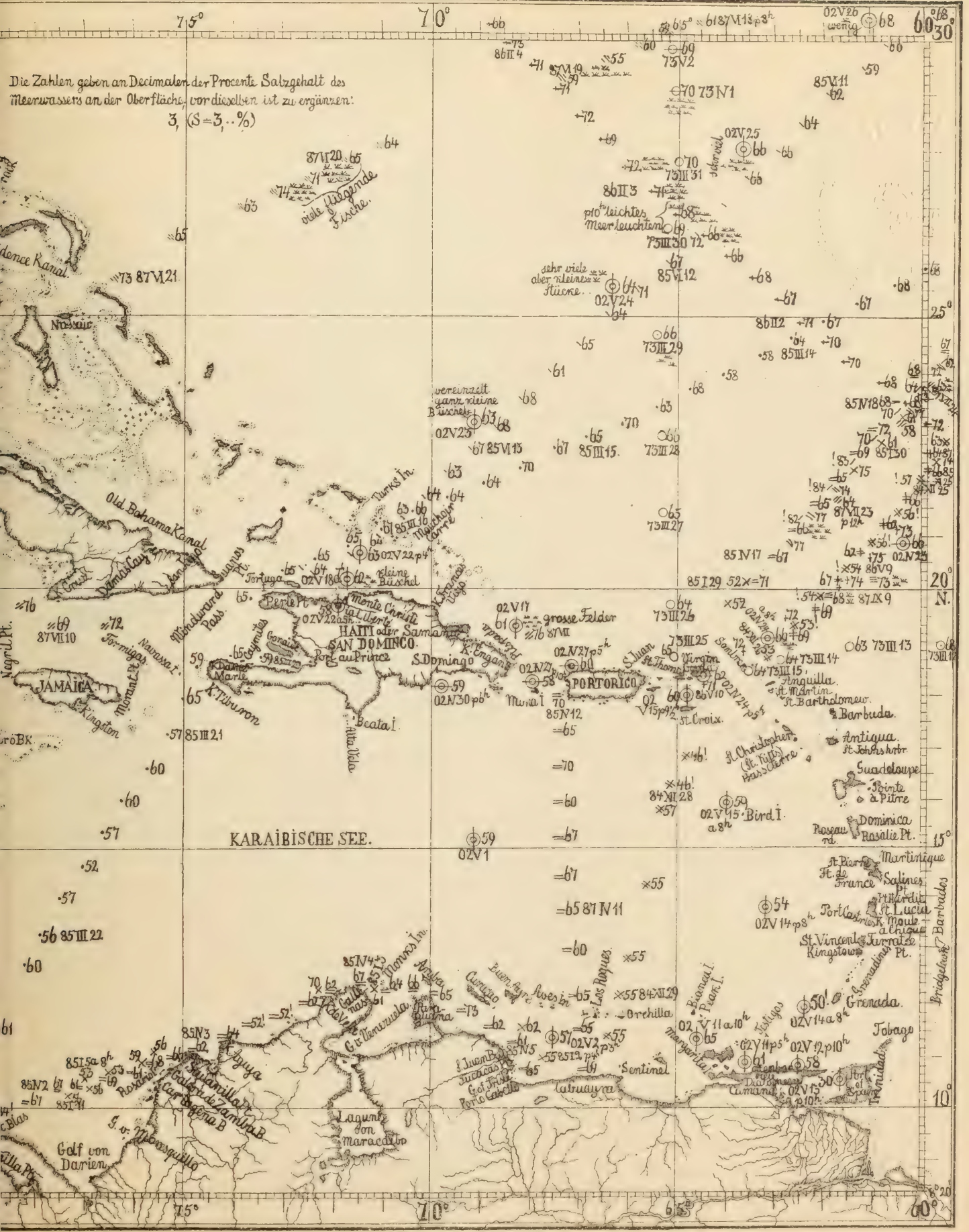


Meereskunde II.

Wustiudirn.

T'aí. 2. Salygehalt. 
Ieereskumde II.

Westindiell.

'Taf: 3. Spez. Gew. 


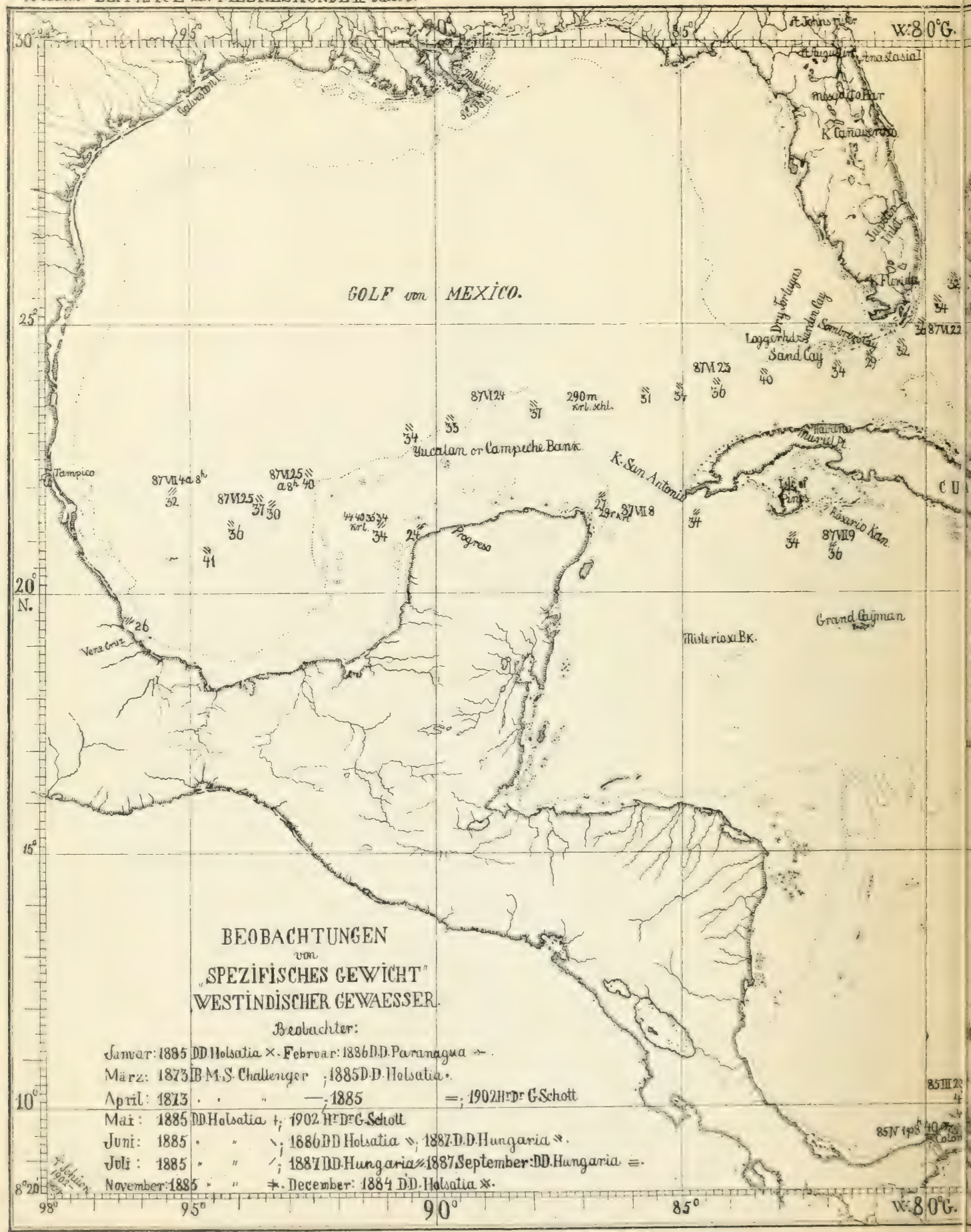




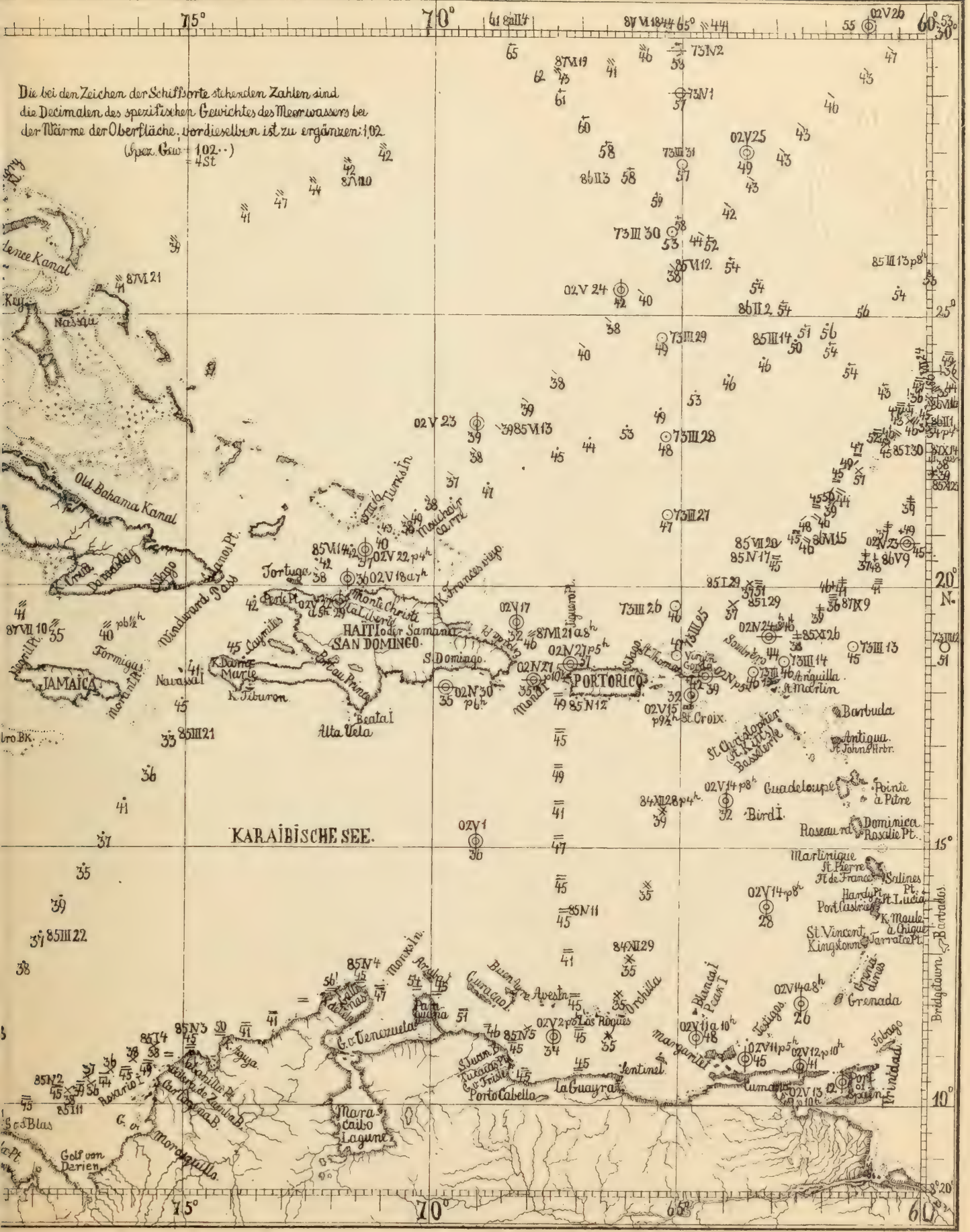


Heresliumde II.

Winstindien.

Taf: 3. Spez. Gew. 
Meereskmude II.

Westindien.

Taft. 4. Wind 11. Strom. 


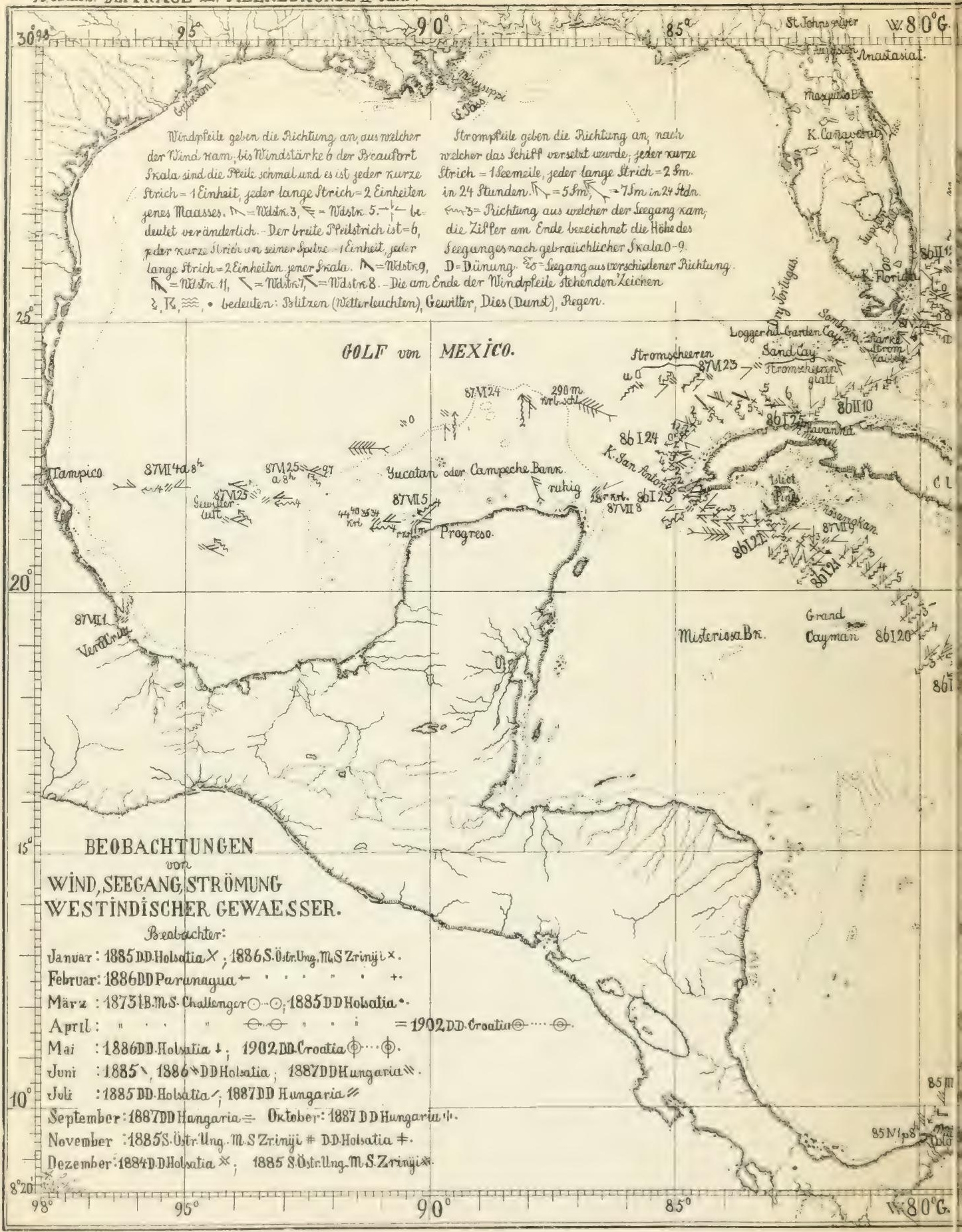




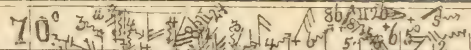

$92 \mathrm{2} 26 \mathrm{qf}, 60^{1 / 4}$ Hit

$$
\begin{aligned}
& \text { 1) } \\
& D^{2} \leqslant
\end{aligned}
$$

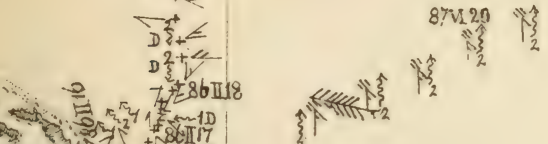

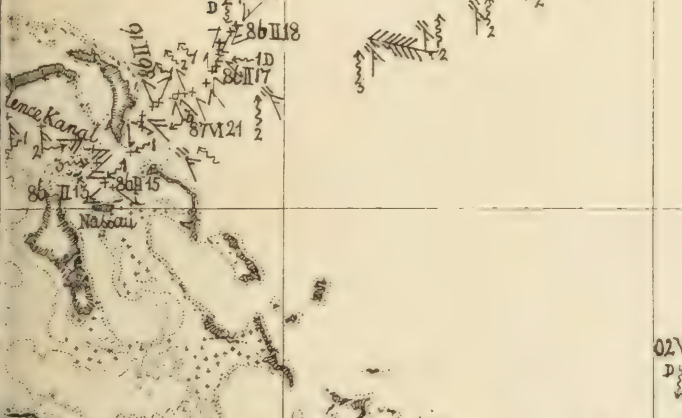

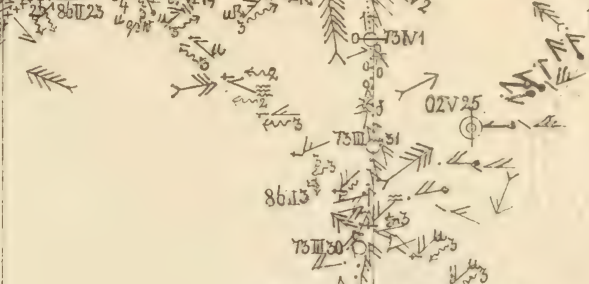

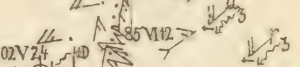

सQ

$\rightarrow \frac{\mu^{2}}{y^{2}} 1$ :

PP.

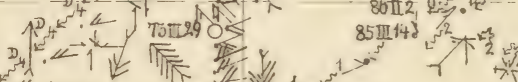

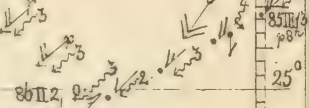

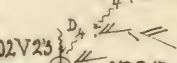

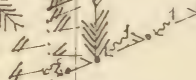

ज.

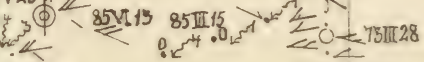

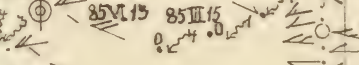

स: 2

《i:

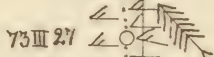

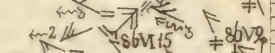

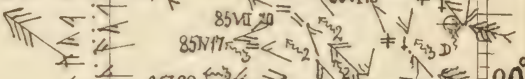

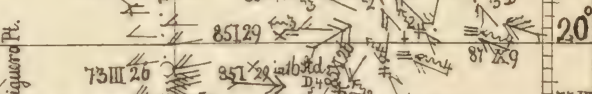

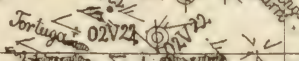
(1)

$1+2016$ एक $n^{2}=x^{85130}=3 x^{34}$

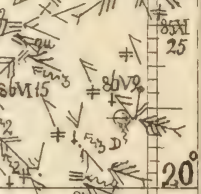

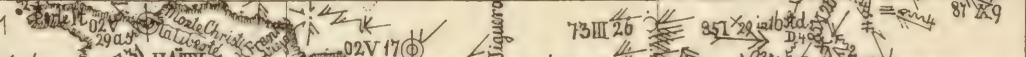

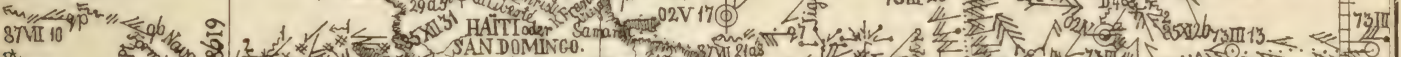

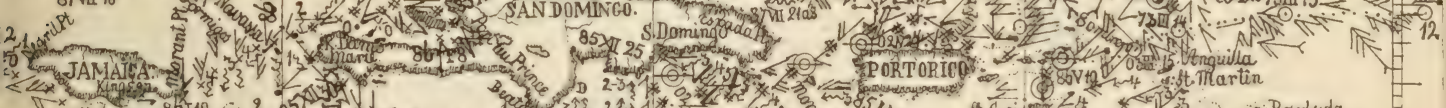

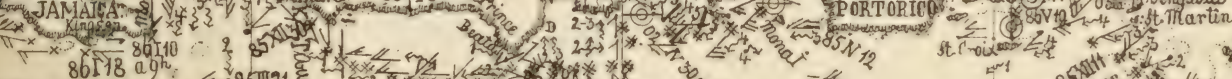

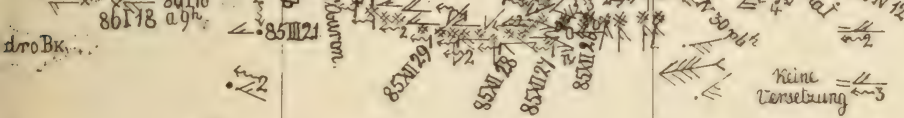

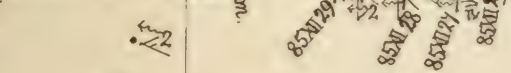
:

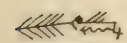

KARAIBISCHE SEE.

: $4 \pi$ in

22. . $\frac{14-5}{4-5}$

पtw 5

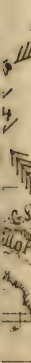
सK $\leqslant \quad=\frac{4}{4-3}$ (n) (क) $02 \mathrm{~V} 1=\frac{\mathbb{m}}{\mathrm{m}}$

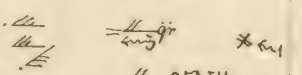

sctarito

(n) 
Meereskinmde II.

Westindien.

I'at. to Wind II. Strom. 
Meereskunde III.

Taifune.

Taf. 1. Bahnen. 
At. Serucco. BEITRÄ̈GE zur MEERESKUNDE. III. WIRBELSTÜRME, BAHNEN. Jafel t.

W. DOBERCK.

Direktor des Hongkong 0 0 servatorium,

DAS GESETZ DERSTÜRME

in

OSTASIATISCHEN GEWAESSERN.

Hongkong 1898.

UNGEFAEHRE

TAIFUN - BAHNEN.

Die römischen Ziffern nebst Puteinischen und griechischun Buchstaben bedeuten

Hr. Dir.:Doberck's Taifun-Klassen.

Diekura en sesuracehten Striche bedeuten

${ }_{10}^{\circ} 0^{\circ}$
$140^{\circ}$

$x 0^{\circ}$

In Deutschland feroffentlicht in.

Meteorologische Zeitschrift 1897.
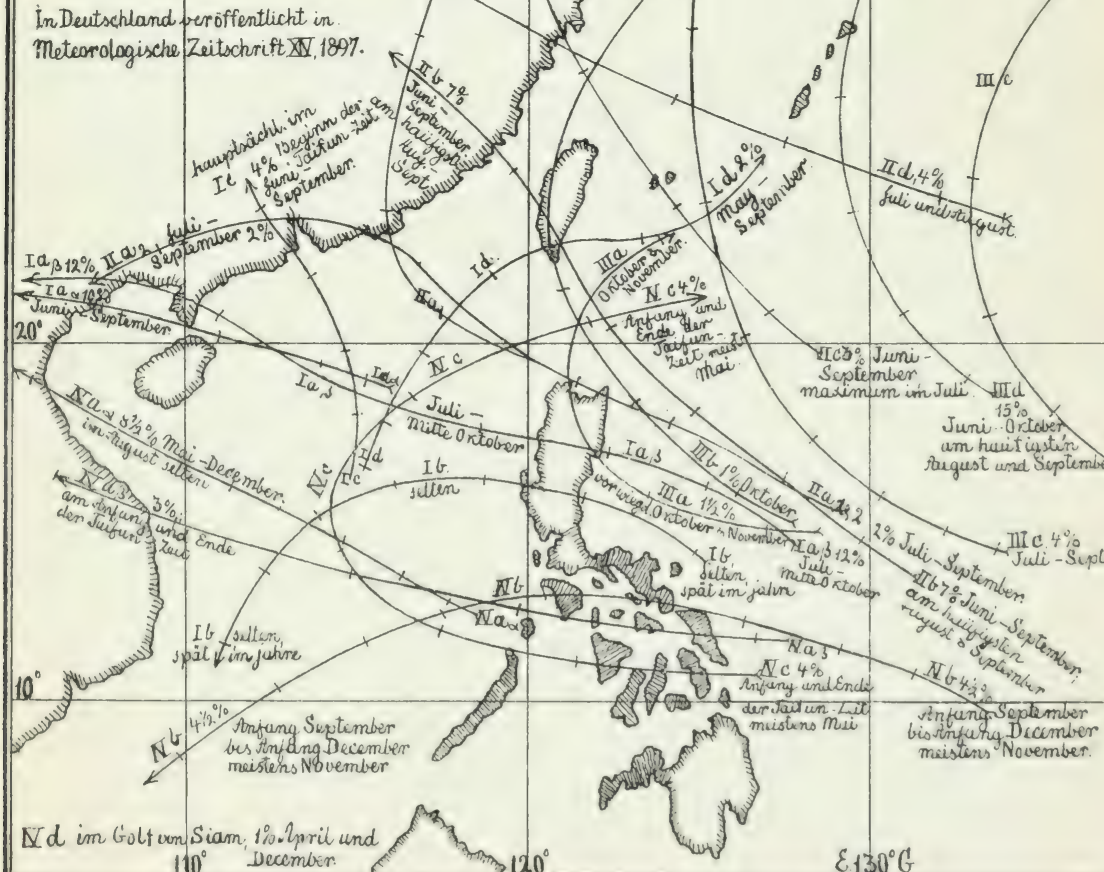
Meereskumle III.

'Taifune. III, V, VI.

Taf. :. Bahnen. 
A. Schüon. BEITRRÄGE sur MEERESKUNDE. II. WIRBELSTÜRME, BAHNEN. Japel2

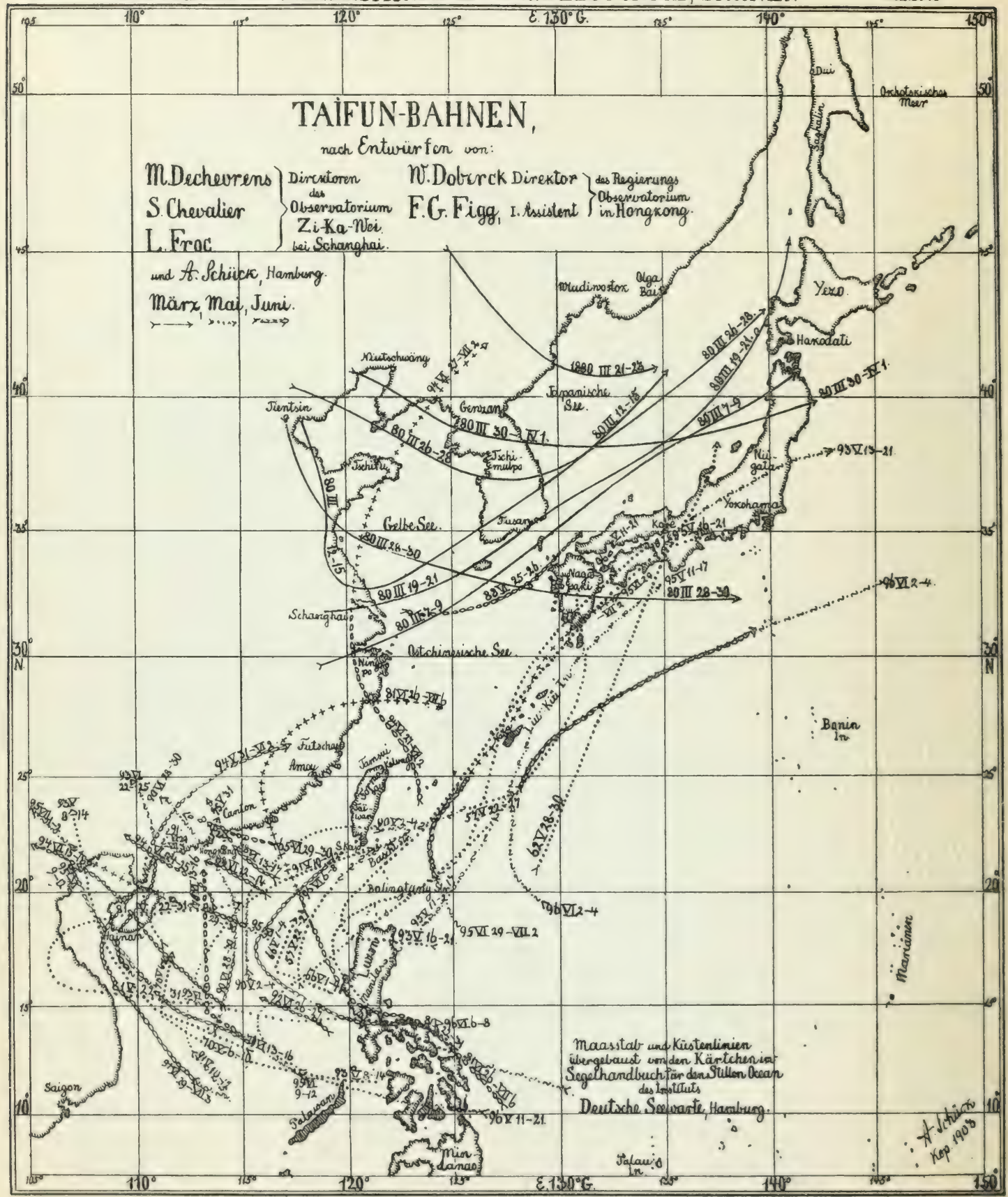


Meereskunde III.

Taifune. VII.

Taf. 3. Bahnen. 
A. Schück. BEITRÄGE zur MEERESKUNDE.III. WIRBELSTÜRME BAHNEN.

Tafel 3.

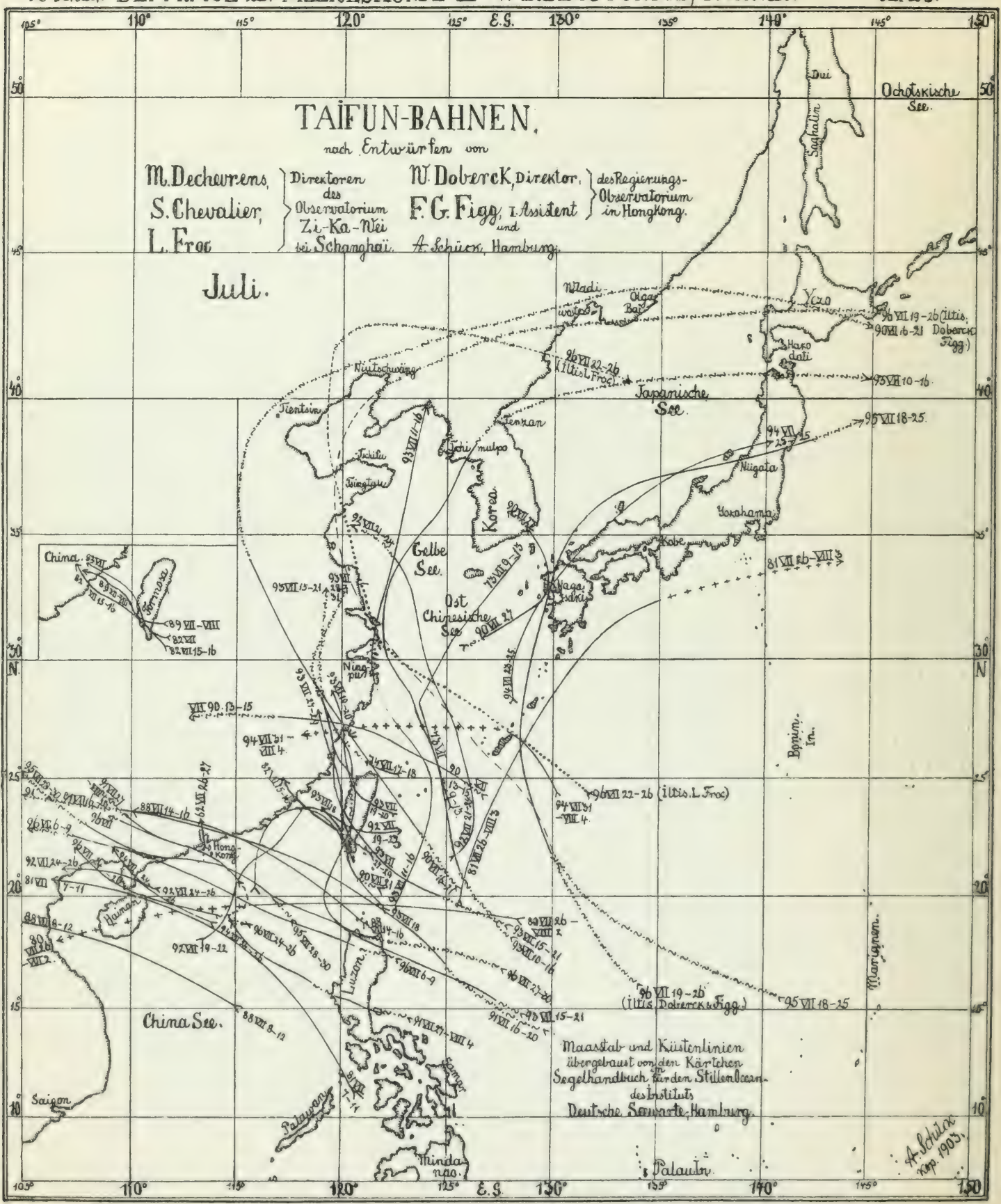


Meereskunde III.
Taifune. VIII.
Taf. 4. Bahnen.

Meereskunde I
Taifune. VIII.
Taf. 4. Bahnen.

Meereskunde III.
Taifune. VIII.
Taf. 4. Bahnen.

\author{
Taf. 4. Bahnen.
}

\begin{abstract}
1.
\end{abstract}


A. Schück. BEITRÄGE zur MEERESKUNDE. III. WIRBELSTÜRME, BAHNEN.

Jafel 4.

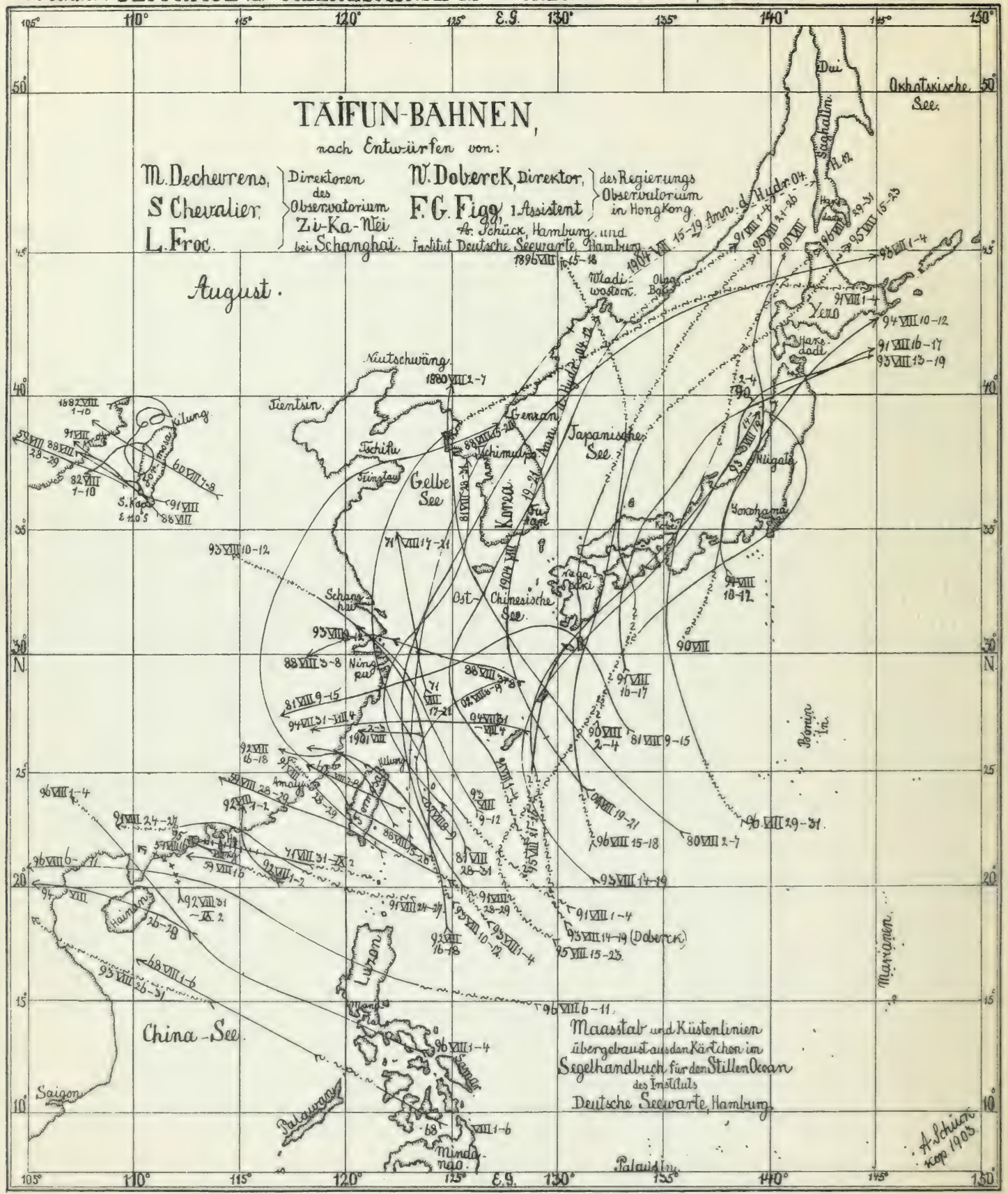


Meereskunde III.
Taifune. IX a.
Taf. 5. Bahnen.

Meereskunde III.
Taifune. IX a.
Taf. 5. Bahnen.

Meereskunde III.
Taifune. IX a.
Taf. 5. Bahnen.

af. 5. Bahnen.

Meereskunde III.
Taifune. IX a.
Taf. 5. Bahnen.

.

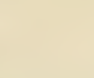

(n)

(n)

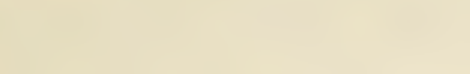

$\sqrt{2}$ 
A.Schücn.BEITRÄGE zur MEERESKUNDE. III. WIRBELSTÜRME BAHNEN.

Jufel 5

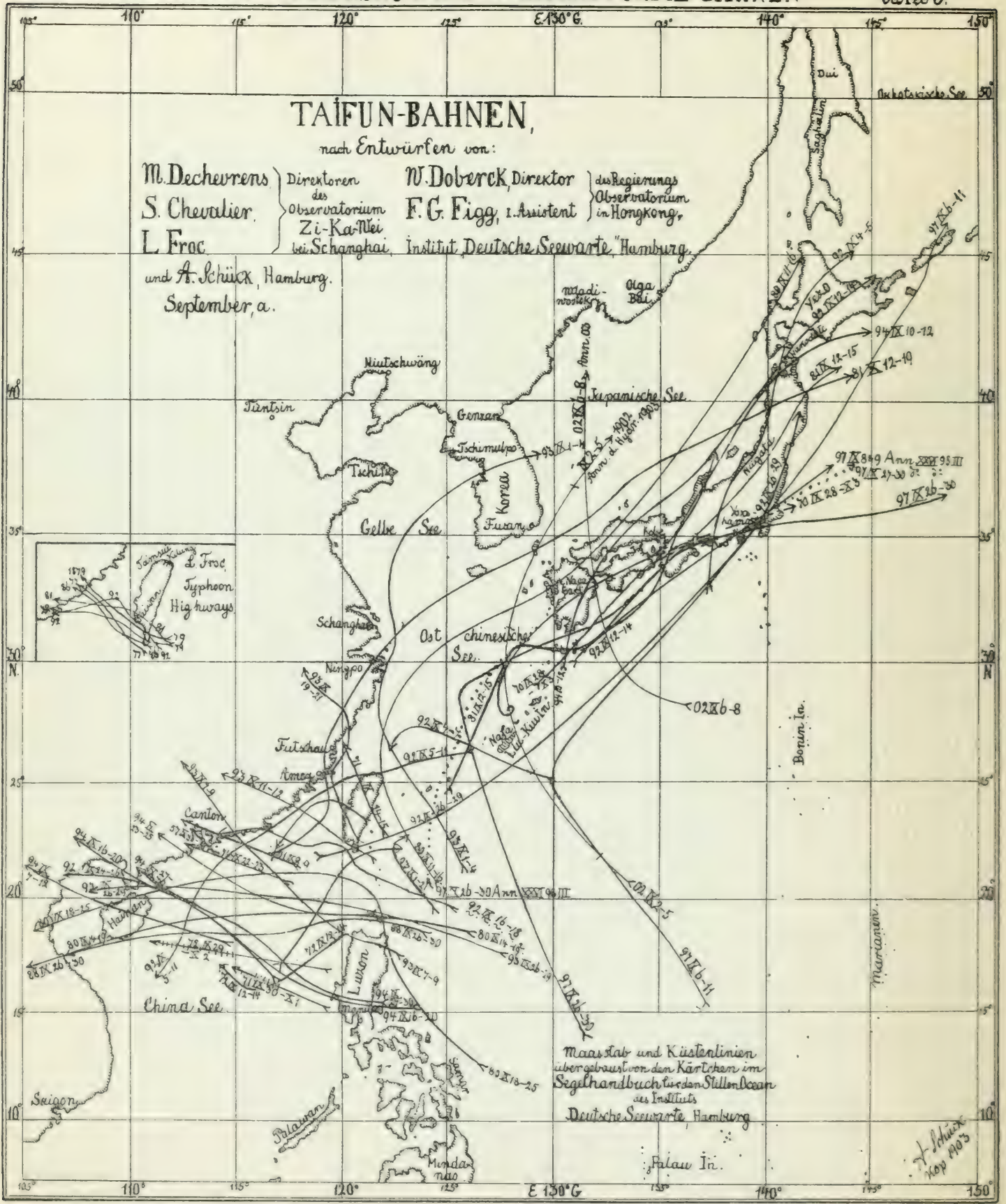


Meereskiunde III.

Taifune. IX b.

Taf. 6. Bahnen. 
A. Schüc BEITRÄGE zur MEER ESKUNDE. III. WIRBELSTÜRME, BAHNEN.

Tapel 6

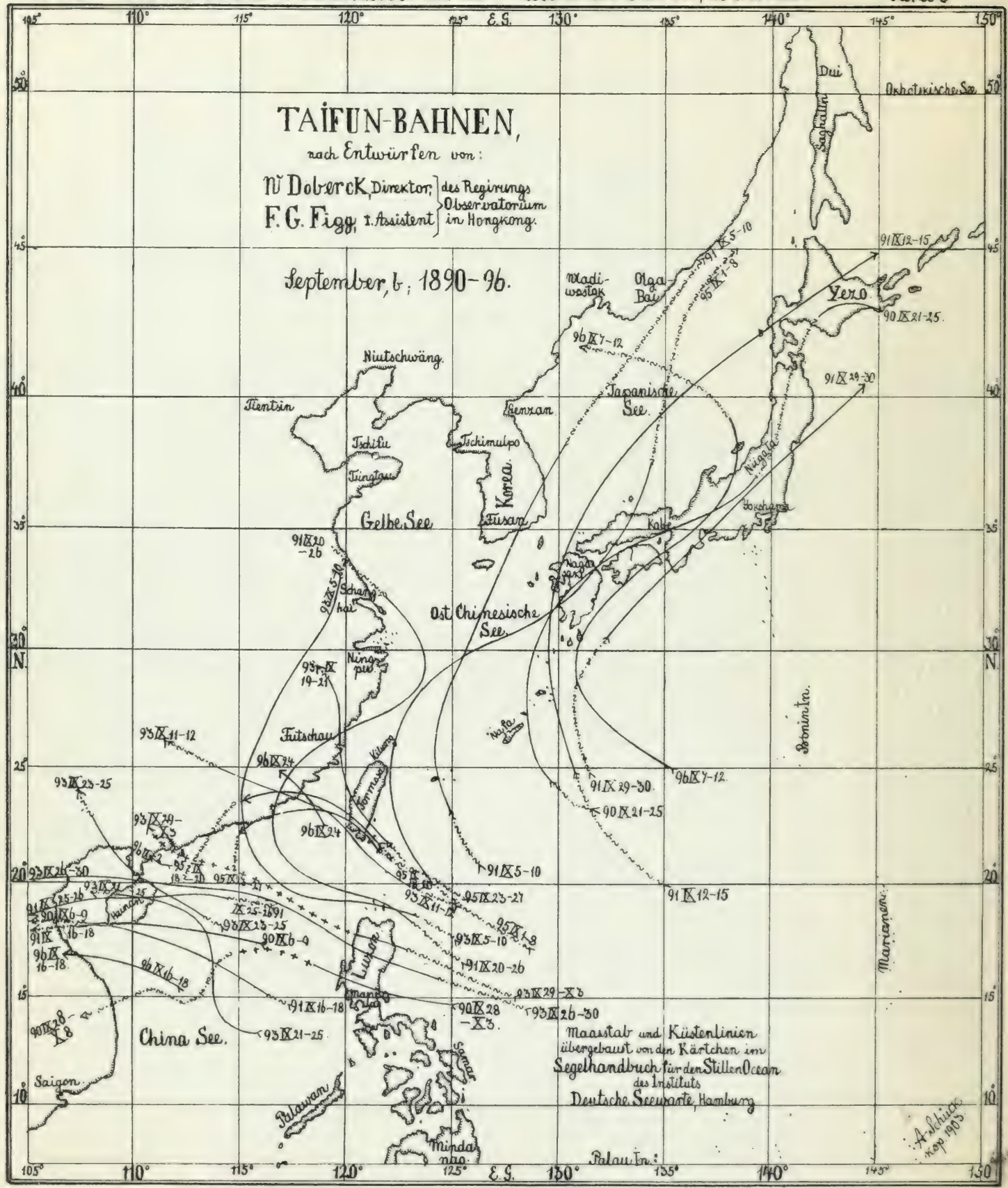


Meereskunde III.

'Taifune. X.

Taf. 7. Bahnen. 
A.Schilon. BEITRÄGE zur MEER ESKUNDE.II. WIBBBELSTÜRME, BAHNEN. Jafd\%.

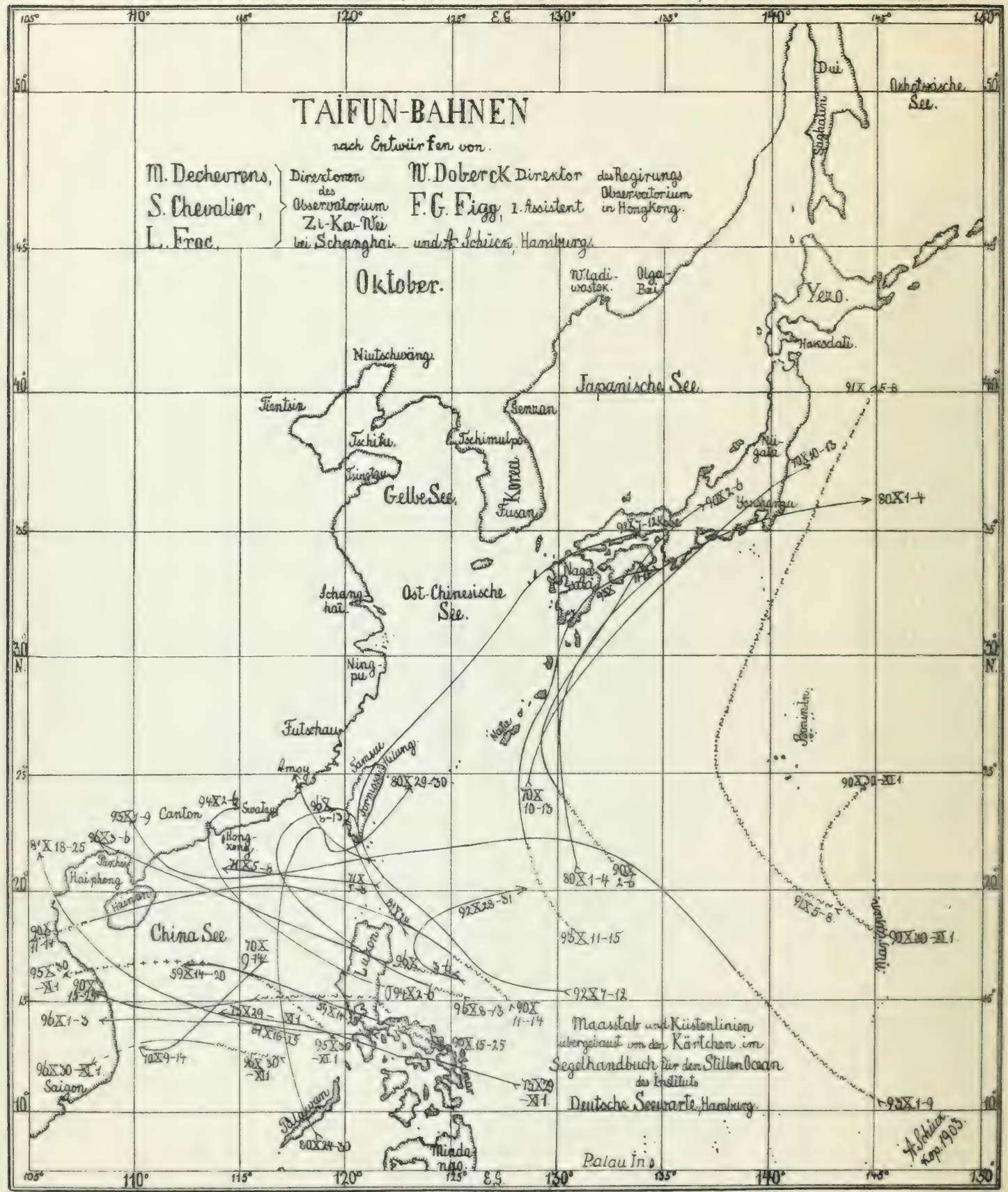


Meereskumde III.
T'aifune. Chateaubriand.
Taf. A. Taf. b. Barlirvu.

Meereskumde III.
T'aifune. Chateaubriand.
Taf. A. Taf. b. Barlirvu.

Meereskumde III.
T'aifune. Chateaubriand.
Taf. A. Taf. b. Barlirvu.

Intons

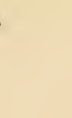

(20

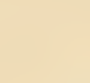




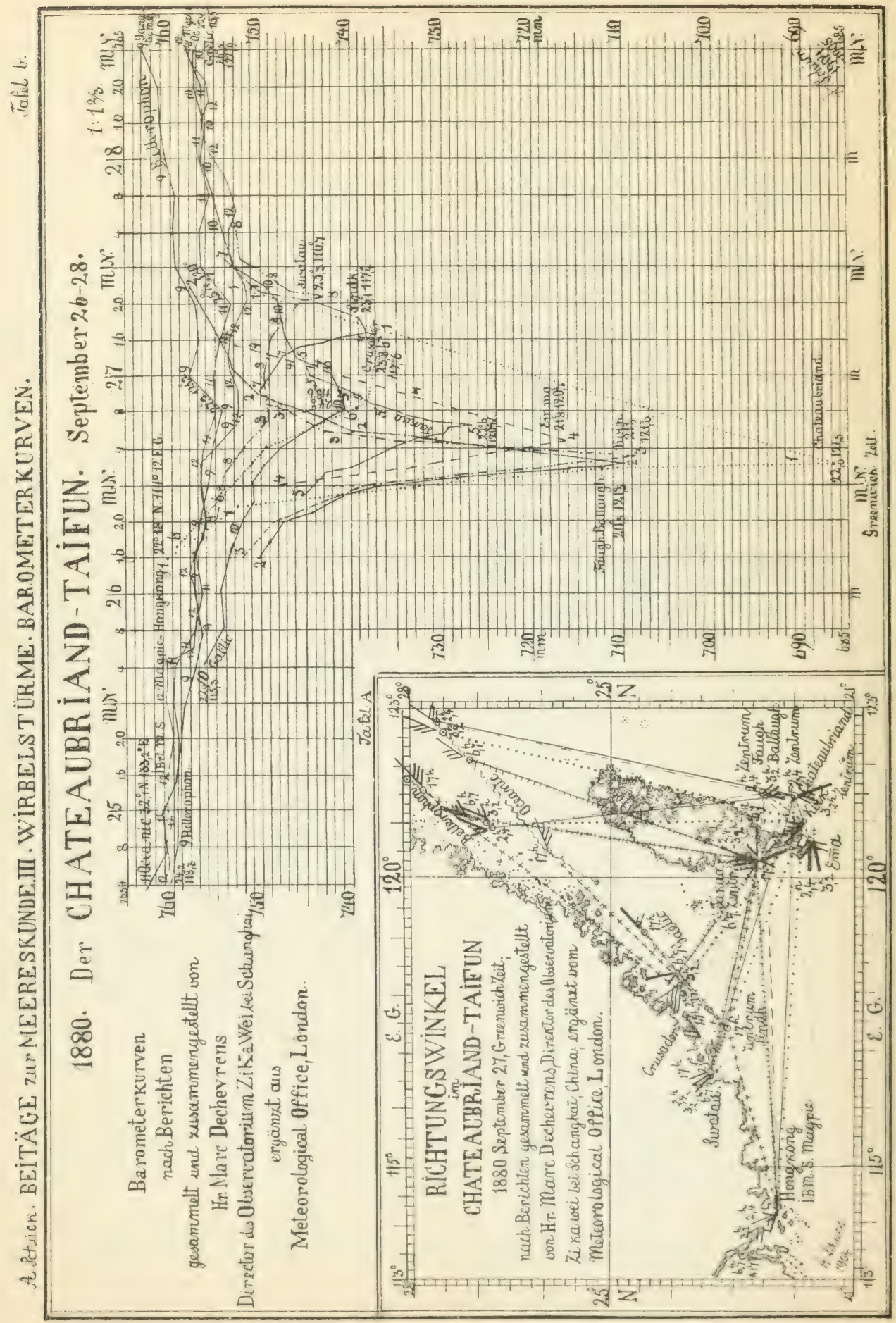


Meereskuude III.

Taifune. Iltis.

'Taf. c. Barkiru. 
Meereskunde III.

Taifune.

Taf. a. Barkrru. 
A Schüm. BEITRÄGE zvr MEERESKUNDE. BAR OMETERKIIRVEN in TAIFUNEN. Jafela.

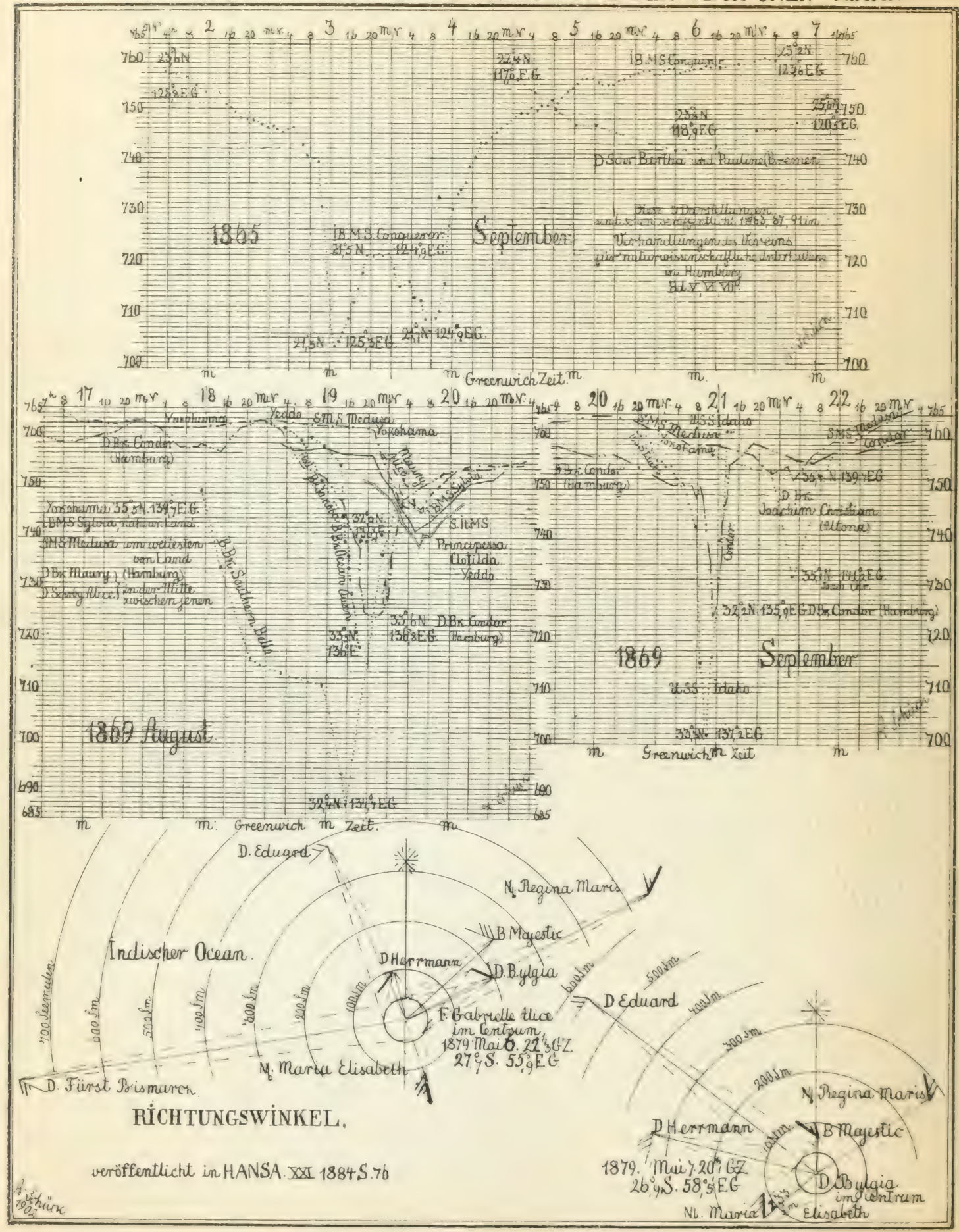


Meereskunde III.

Taifune. Ie Witte.

'Taf. d. Barkrvn. 


1901. Der DE WITTE-'

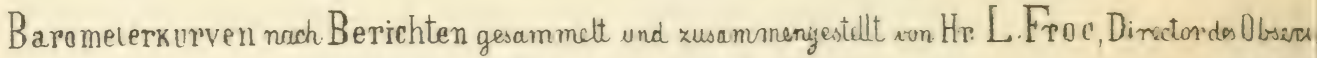
und Bureau Central Meteorologique Paris.

Schiffsbi

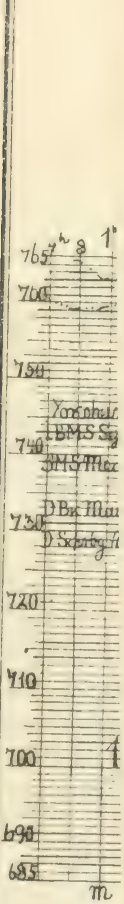

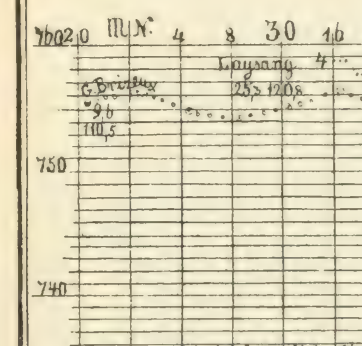

mir 31 to mor

$21620 \mathrm{~m} / \mathrm{V}$

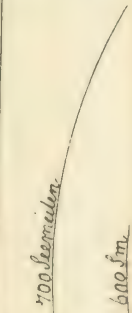

$\sqrt{1}$ D. Fiurs

we

730

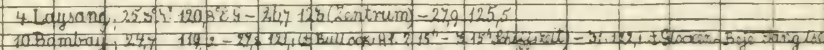

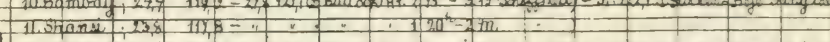

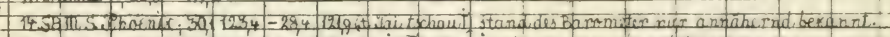

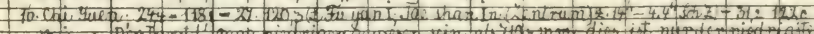

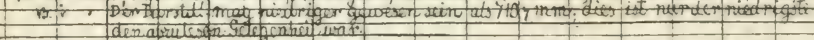

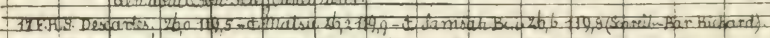

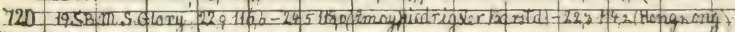

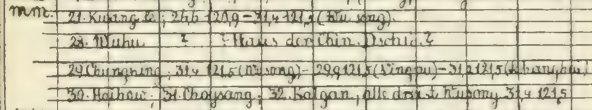

710

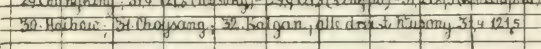
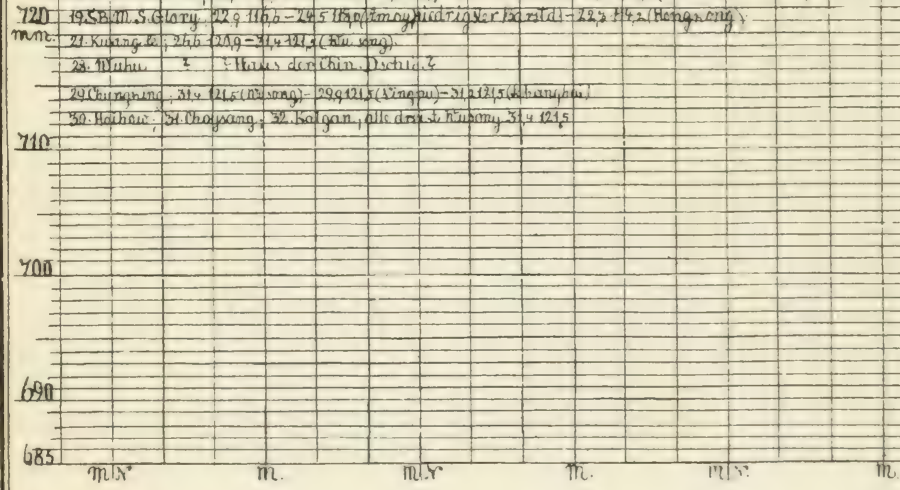

layinang $\frac{4}{4 \cdot 3 b_{3}}$ it

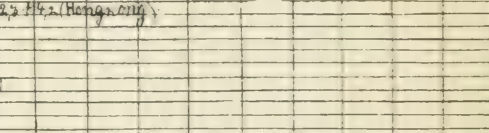

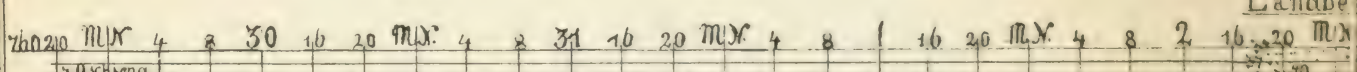
3oschanal

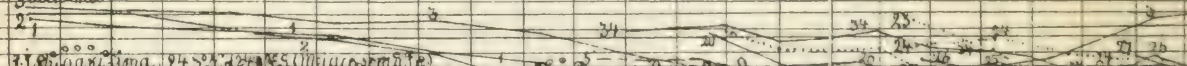

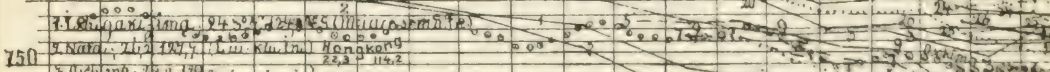

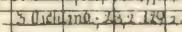

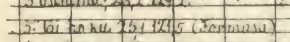

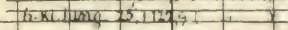

मrankan 25 गयर? ?

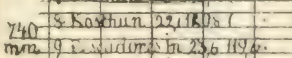

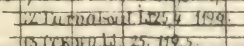

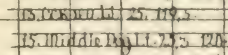

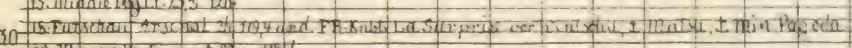

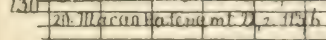

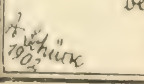
725

mon $+\frac{1}{2}+\frac{1}{n}$
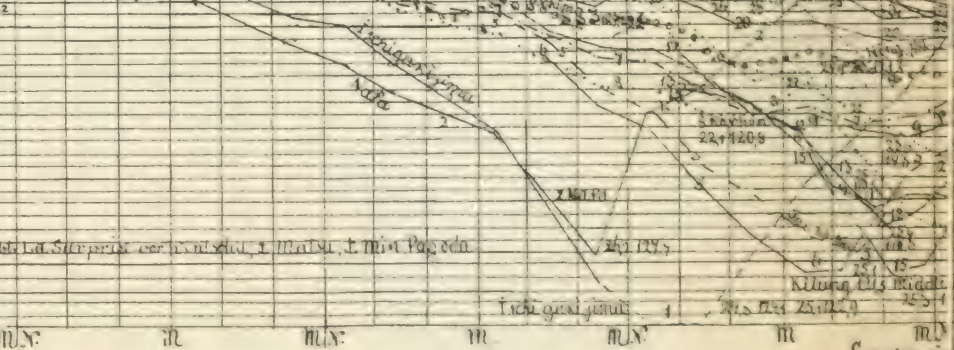

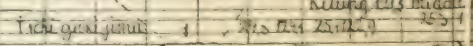

in + mit:

nu?

m

Gresinut 


\section{AİFUN. Julis1 - Avgust 6 .}

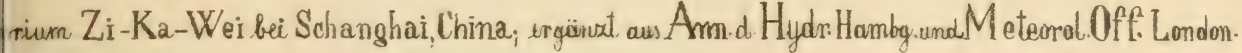

hte.

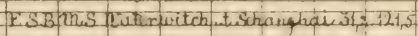

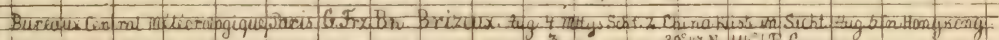

Bas

\begin{tabular}{|c|c|c|c|c|c|c|c|c|c|c|c|c|c|c|c|c|c|c|c|c|c|c|c|}
\hline \multirow{2}{*}{\multicolumn{3}{|c|}{07}} & & & & & & & & & & & & & $\log _{3}+1$ & & & $9^{\circ}+4 \mathrm{~N}$ & & & & & \\
\hline & & & chan & {$[$ [i. } & & & & & & & $\pi$ & 1. & 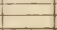 & -1 & 0 & 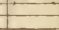 & & & & & 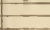 & & 700 \\
\hline & 600122 & & & & 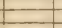 & & & & & & & & & & & & & 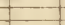 & & & 7 & $\div$ & \\
\hline & & & & & & & & & & & & & & & & & & & & - & & & \\
\hline & & & & E & & $E$ & $=$ & & & & & & & & & & & - & $=$ & $1=$ & & & \\
\hline & & & & & & $E$ & & & & & & & & & & & & & & & & & \\
\hline & $E$ & & & & $=$ & & - & & - & & & & & & & & & & & - & 11 & & שs \\
\hline & 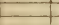 & & & - & & . & & & & & & & & & & & & & & & - & 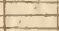 & $\square$ \\
\hline & & & & & & 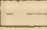 & & & $\therefore$ & & & & & & & & & $E$ & & & & & \\
\hline
\end{tabular}

ile:

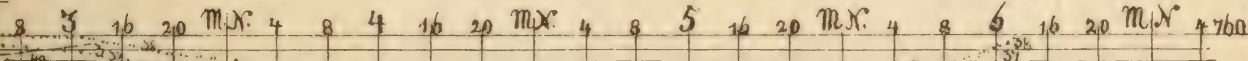

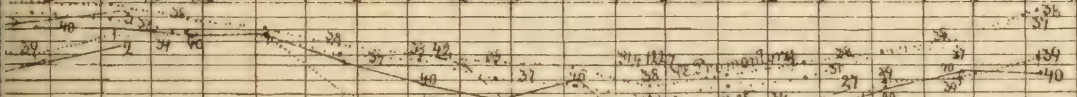

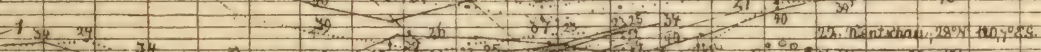

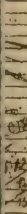

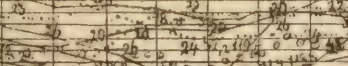

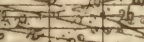

$\sqrt{13}$

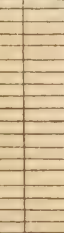

inse:

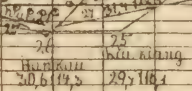

$m$.

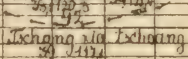

chang la techoang

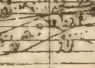

$\frac{2023}{21}$

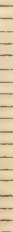

$-$

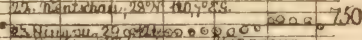

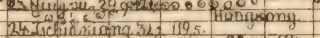

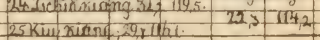

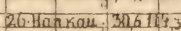

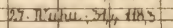

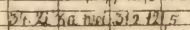
22. Se tramantary skig, 12,5

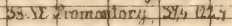

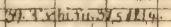
40- Houxi:321 12004_- $\quad 730$

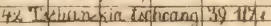


Iteereskunde III.

'Taifune. De Witte.

'I'af. d. Barkrvn. 



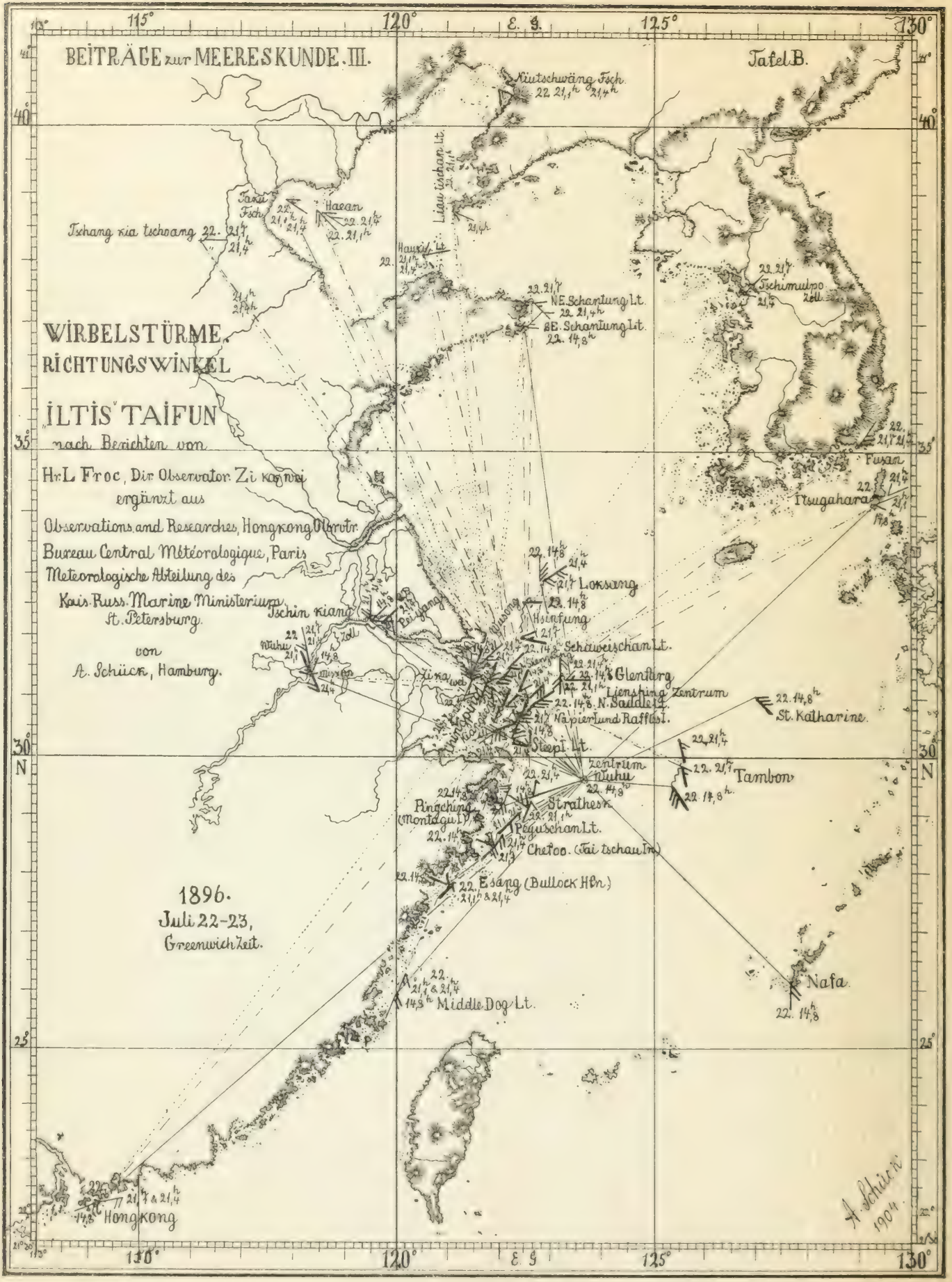




\author{
Meereskunde III.
Taifune. De Witte.
Taf. C. Rehtgswkl. \\ Meereskunde III.
Taifune. De Witte.
Taf. C. Rehtgswkl. \\ Meereskunde III.
Taifune. De Witte.
Taf. C. Rehtgswkl. \\ Meereskunde III.
Taifune. De Witte.
Taf. C. Relitgswkl.
}

.

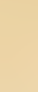

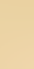

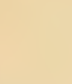

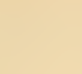

(n)

$\sqrt{2}+x^{2}$

$\sqrt{2}+x^{2}$

$\sqrt{2}+x^{2}$

$\sqrt{2}+x^{2}$

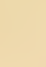

$\sqrt{2}+x^{2}$

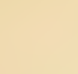

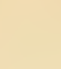

.

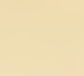




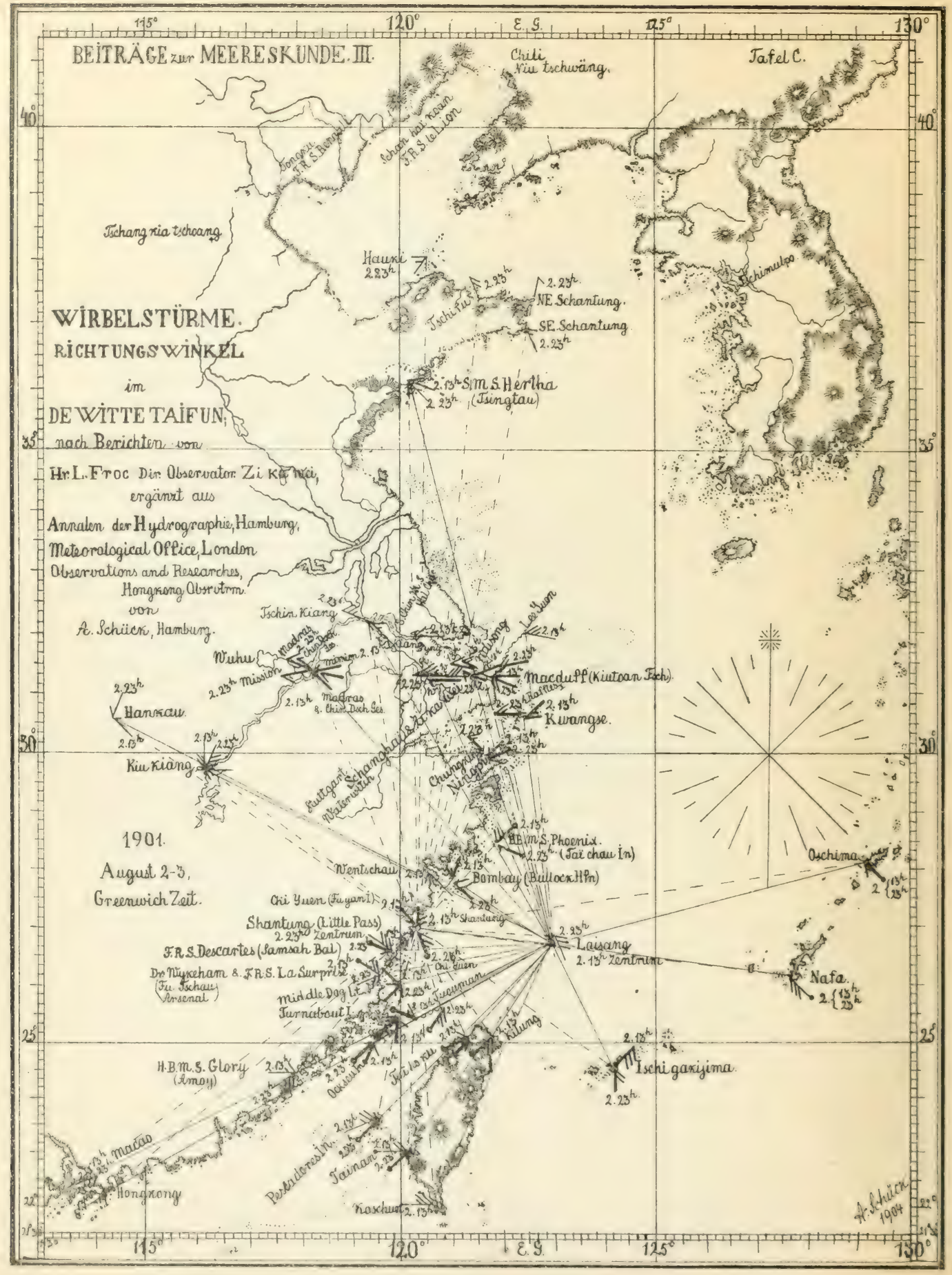


Meereskmude III.

Taifune. XI, XII.

Taf. 8. Bahnen. 
A.Schür. BEITRÄGE yur MEERESKUNDE. II. WIRBELSTÜRME, BAHNEN.

Tatel 8.

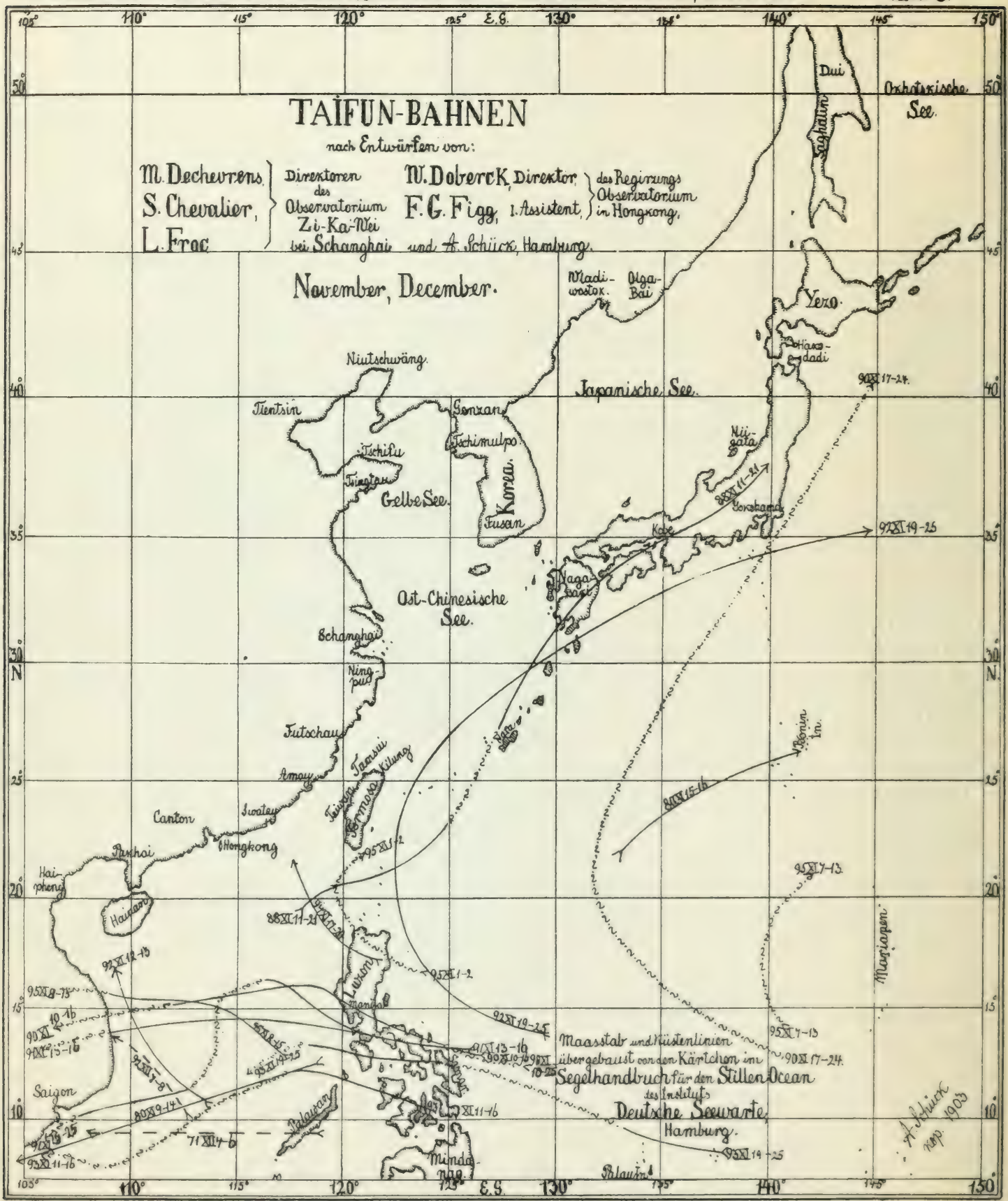


Meereskunde III.

Wirbelstiirme.

Taf. z. Häufigkeit. 
WESTINDISCHE GEWAESSER.1494-1900.

|Jan.Febr|tärz|Apriil Mai|Juni Juli | Aug. | Sept.| Okt. | Nov. Dez.| Zusammen:

BEITRÄGE zUN MEERESKUNDE.

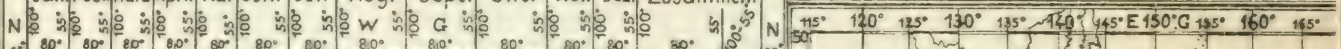

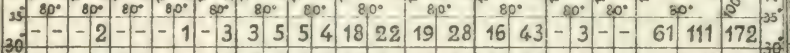

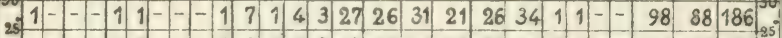

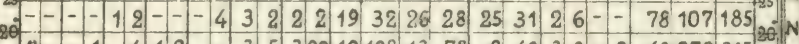

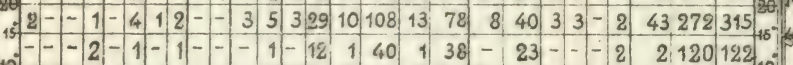

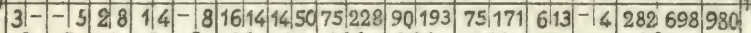 \\ \begin{tabular}{l|l|l|l|l|l|l|l|l|l|l|l|l|}
3 & 5 & 10 & 5 & 8 & 30 & 64 & 303 & 283 & 246 & 19 & 4 & 980 \\
\hline
\end{tabular}}

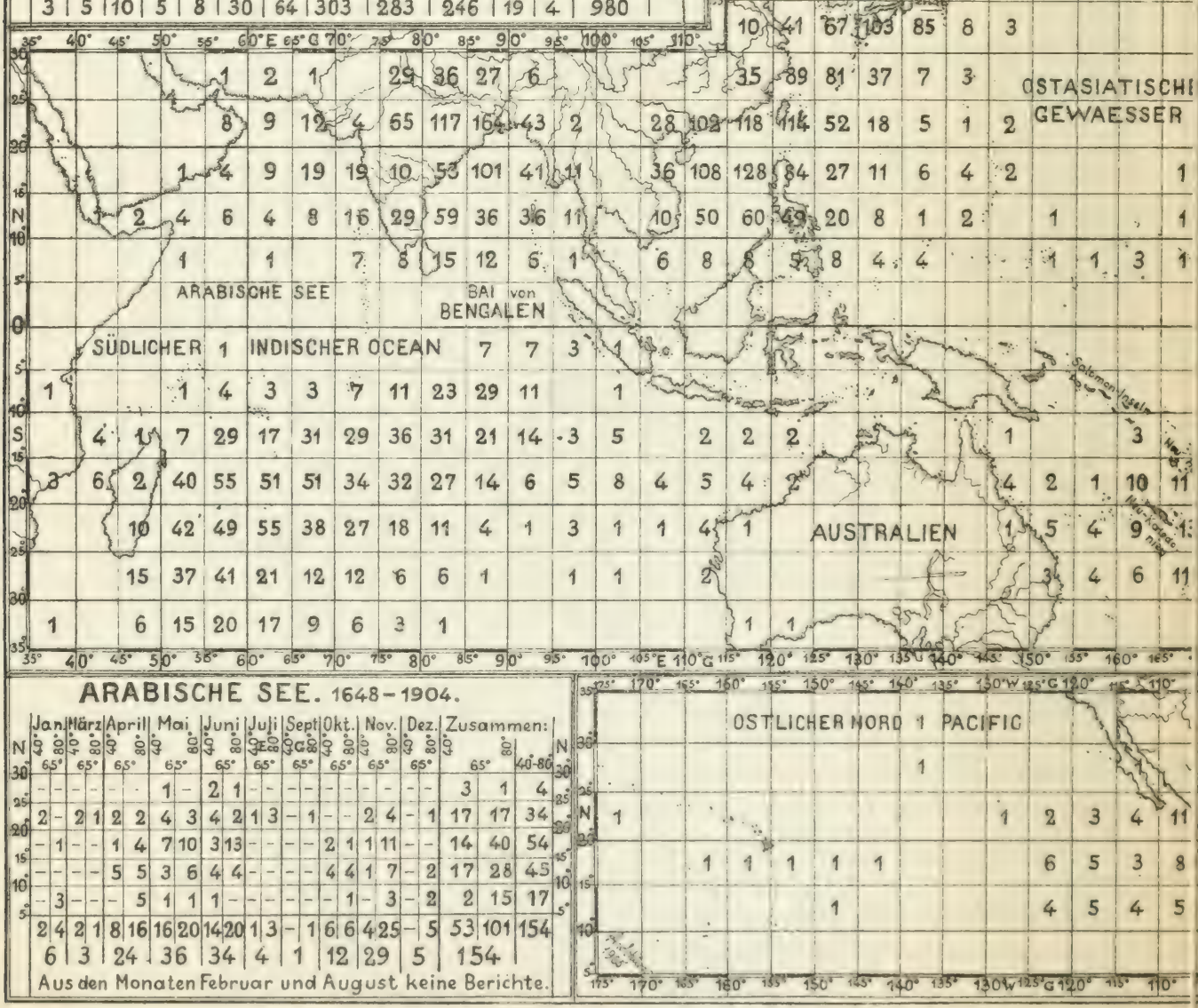


Meereskunde III.

Wirbelstïrme.

Taf. z. Häufigkeit. 
$y=174$

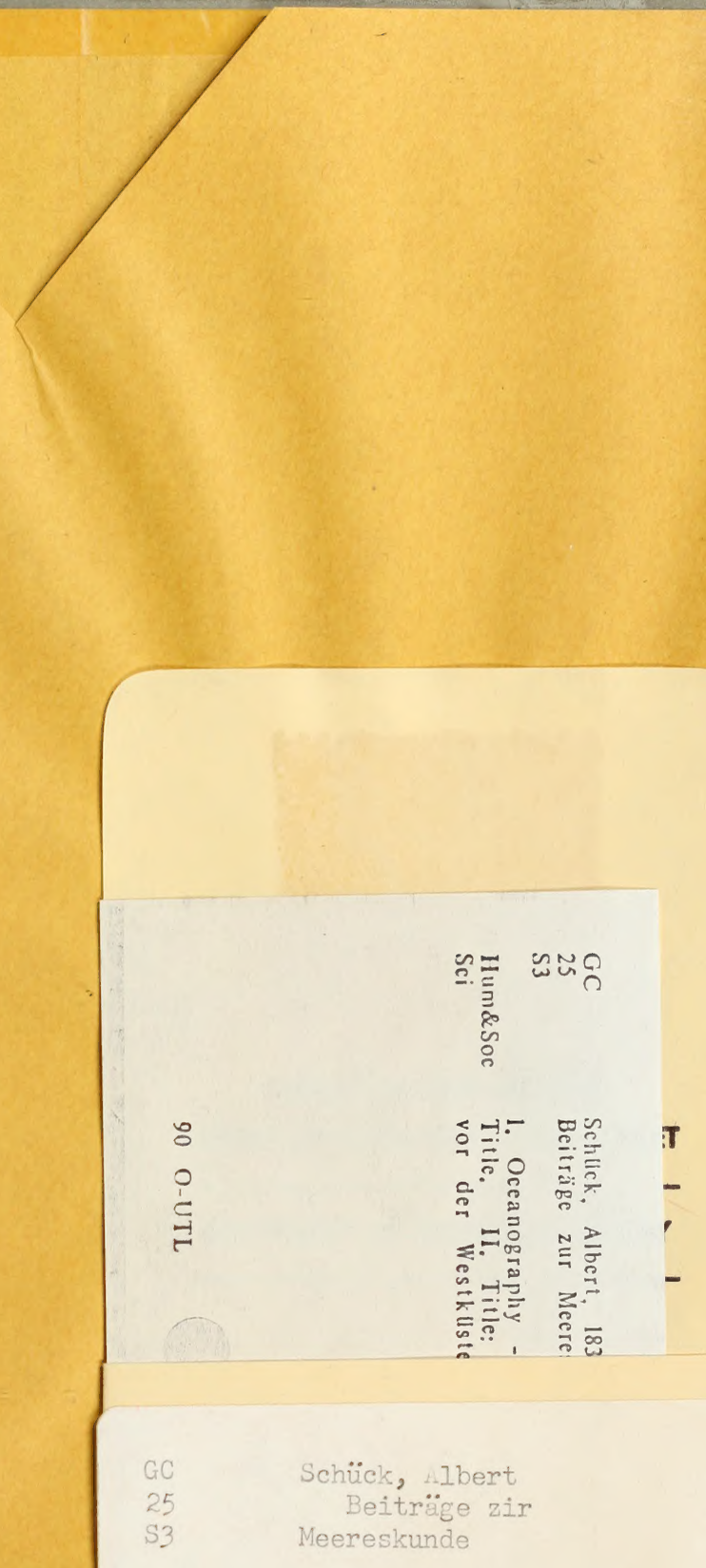


